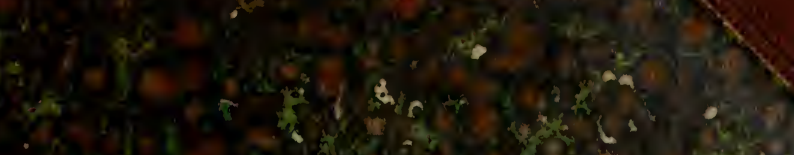

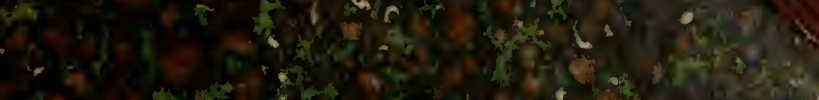

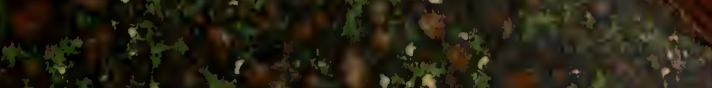

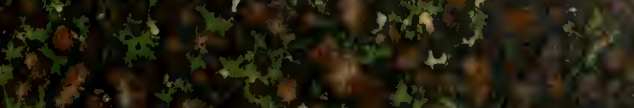

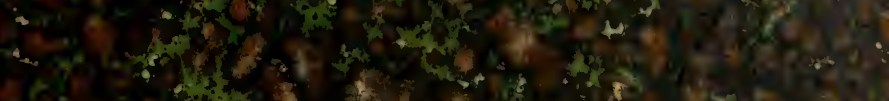

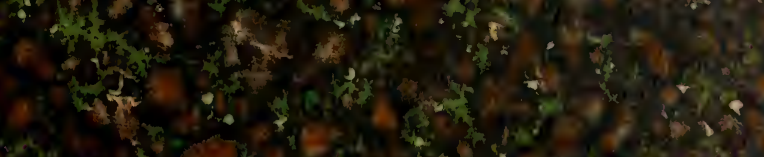

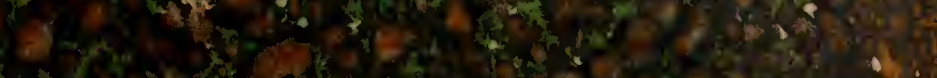

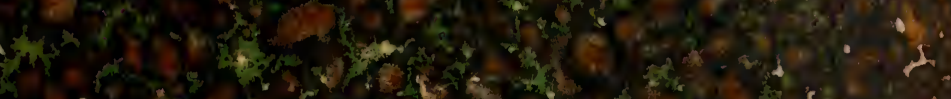

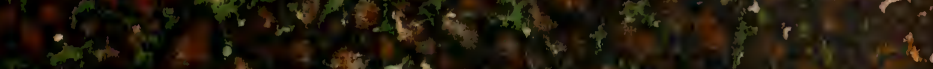

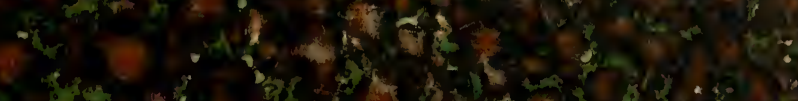

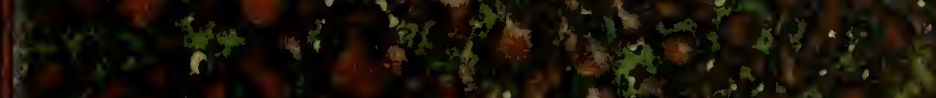

is

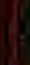

(1)

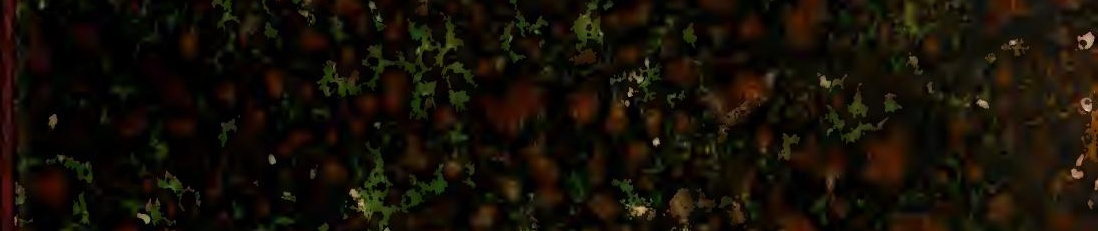

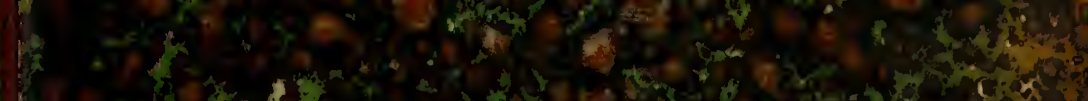

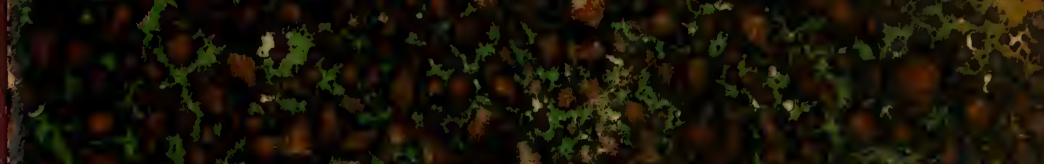

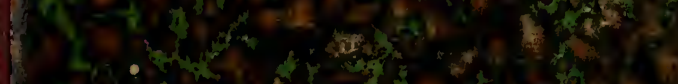

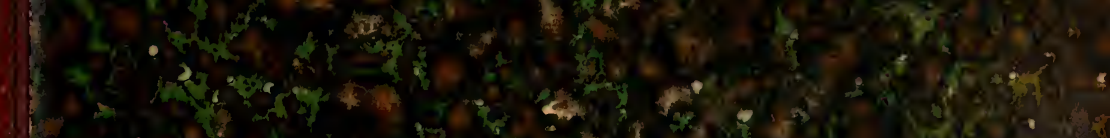

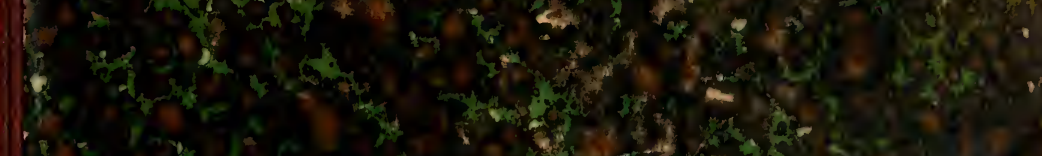

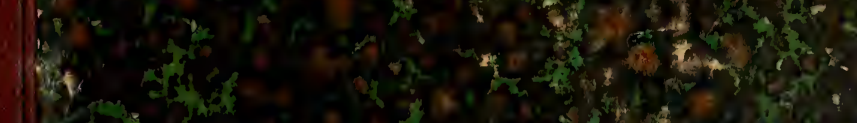

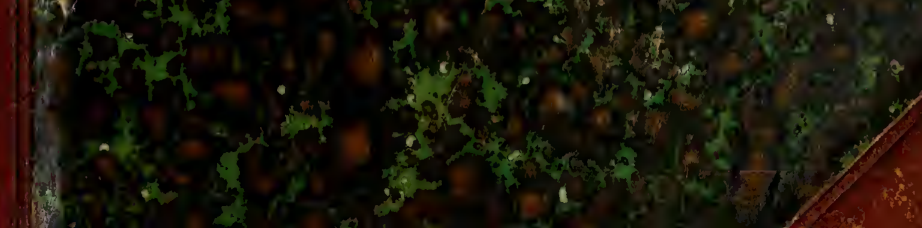




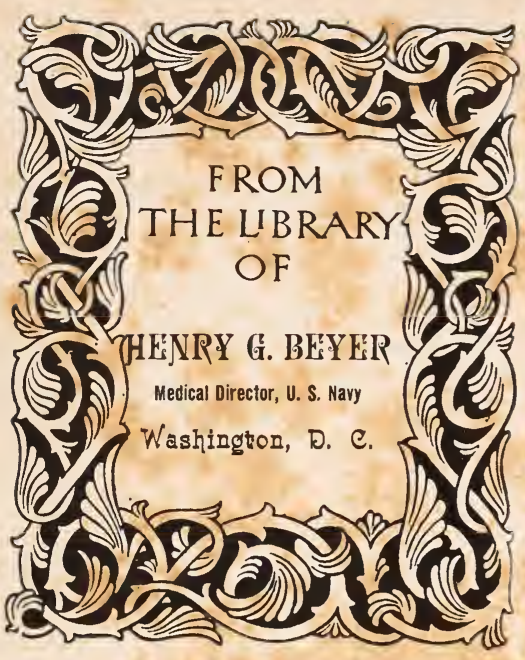




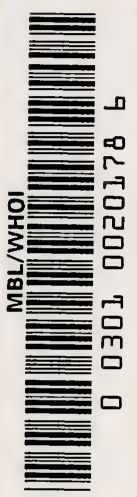





LUDWIG EDINGER.

\section{NERVÖSE CENTRALORGANE.}

5. AUFLAGE. 



\section{VORLESUNGEN}

ÜBER DEN BAU DER

\section{NERVÖSEN CENTRALORGANE}

DES MENSCHEN UND DER THIERE.

FÜR ÄRZTE UND STUDIRENDE

VON

Pror. Dr. LUDWIG EDINGER, ARZT IN FRANKFURT AMI MAIN.

FÜNFTE, STARK VERMEHRTE AUFLAGE.

MIT 258 ABBILDUNGEN.

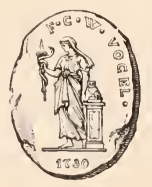

LEIPZIG,

VERLAG VON F.C.W. VOGEL.

1596. 
Das Uebersetzungsrecht ist vorbehalten.

Der Nachdruck der Abbildungen ist nur nach Verständigung mit dem Verleger gestattet.

Englische Uebersetzung ist erschienen.

776 
SEINEM LEHRER

\section{HERRN GEH. MEDICINALRATH PROF. DR. W. WALDEYER}

WIDMET

DIESEN ERSTEN VERSUCH

EINER VERGLEICHENDEN ANATOMIE DES GEHIRNES

IN VEREHRUNG UND DANKBARKEIT

DER VERFASSER. 



\section{Aus dem Vorworte zur ersten Auflage.}

Die folgenden Vorlesungen wurden im Winter 18s3/84 vor einem Auditorium von praktischen Aerzten gehalten. Es war die Aufgabe des Vortragenden, Zuhörer, die im Allgemeinen mit den gröberen Formverhältnissen des Gehirnes vertraut waren, mit dem Wichtigsten bekannt zu machen, was über die feineren Verhältnisse ermittelt war. Es galt vor Allem, diese Verhältnisse so darzustellen, dass sie, soweit dies bislang möglich, als ein Ganzes erschienen. Vieles Controverse konnte nur angedeutet werden, da und dort konnte bei zweifelhaften Punkten oft nur eine Auffassung Erwähnung finden, diejenige, welche mir nach eigenen Untersuchungen oder nach der Ansicht guter Autoren als die richtigste erschien.

Hier läge ein wuıder Punkt der folgenden Darstellung, wenn sie irgendwie die Prätension hätte, mehr sein zu wollen, als eine Einführnng in die Lehre vom Bau des Centralnervensystemes.

Der Verfasser ist sich, wie Alle, die selbst auf dem schwierigen Gebiete der Hirnanatomie mit Hand angelegt haben, vollauf bewusst, dass es nur recht wenige Facta sind, die ganz fest stelıen, dass kein Gebiet der Anatomie mehr dem Wechsel unterworfen sein wird, als das hier Vorgetragene. Er will desshalb schon jetzt, vor der Lektüre des Büchleins, den Leser daranf aufmerksam machen, dass möglicher Weise die eine oder andere Linie etwas allzu sicher und fest eingezeichnet wurde. Mit Absicht, nur im Interesse didaktischer Klarheit, ist das nirgends gescliehen.

Frankfurt a. M., im Mai $15 \$ 5$.

\section{Der Verfasser.}

\section{Vorwort zurr fünften Auflage.}

Nicht ohne ein gewisses Bedenken tritt der Verfasser mit dieser Auflage vor seinen Leserkreis. Ist das kleine Buch doch nun zu einem grösseren algewachsen und bringt es doch einen Stoff, der bisher noch nicht übersichtlich dargestellt worden ist, die vergleichende Anatomie des Centralnervensystemes, zum erstenmale zusammengefasst. Es sind drei Abschnitte aus dem ursprünglich einheitlichen Werkchen hervorgegangen, Abschnitte, die von einander so weit unabhängig sind, dass Diejenigen, welche etwa weiteren Gesichtspunkten und vergleichend anatomischen Dingen weniger Interesse entgegenbringen, die beiden ersten Theile überschlagend im dritten das alte Buch in etwas 
vermehrter und reicher illustrirter Auflage wiederfinden. Dankbar des Interesses gedenkend, das gerade ärztliche Kreise den "Vorlesungen" bisher entgegengebracht, habe ich den dritten Abschnitt, welcher ausschliesslich das Sängergehirn, vorwiegend das menschliche, beschreibt, sorgfältig neu durchgearbeitet und durch Beigabe von zahlreichen, nach Photographieen gearbeiteten Abbildungen von Schnitten erweitert. Namentlich wurde - zur Erleichterung des Studiums bei Sectionen - eine vollständige Serie von Frontalschnitten durch ein ganzes Gehirn beigefiïgt.

Der erste Abschnitt soll in den heutigen Stand der Grundanschauungen einführen. Er berücksichtigt auch, was früher nicht der Fall war, das Functionelle.

Der zweite Theil des Buches verwirklicht endlich einen Plan, den ich seit dem Beginn meiner hirnanatomischen Studien nie aus dem Ange gelassen habe. Fast durchweg auf eigenen Untersuchungen beruhend, giebt er eine Uebersicht über das. was sich hente mit einiger Sicherheit vom Aufbau und Entwicklungsgang des Centralnervensystemes in der Thierreihe aussagen lässt. Diejenigen. welche auf diesem noch so wenig bebanten Gebiete gearbeitet haben, werden die Schwierigkeiten, die sich überall aufthïrmen, beriicksichtigend das Gebotene mild beurtheilen. Ein erster Versuch zu ïbersichtlicher Darstellung trägt das Buch ïberall die Mängel an sich, die ein solcher bieten muss. Niemand weiss das besser als der Terfasser selbst. Wemn, wie hier, die Anlage des Ganzen ein Eingehen in Details verbietet, so wird es nicht möglich sein, ïberall die ausreichende Begründung für das Vorgetragene zu geben*). So viel das immer möglich war, ist es in den zahlreichen Abbildungen geschehen, deren Beigabe des Herrn Verlegers Liberalität ermöglicht hat. Diese neue 5. Auflage hat 113 Abbildungen melır als die 4. und von den neuen Abbildungen sind 99 der vergleichenden Anatomie gewidmet. Das Centralnervensystem ist frïher vorwiegend von Aerzten studirt worden. Diesen lag natïrlich als nächste Aufgabe vor, das menschliche Gehirn besser verstehen zu lernen. Vergleichend sind fast nur die Säuger herangezogen worden. Immerhin besitzen wir auch von niederen Vertebratentypen mehrere vortreffliche Schilderungen.

Hier ist nun der Versuch gemacht, weit hinab in der Thierreihe zu steigen. zu ermitteln, wo bestimmte Formen auftreten, wie sie variiren, welche Functionen sie auf einzelnen Zuständen der Ausbildung erfïllen

*) Für eingehendere Studien auf dem Gebiete der vergleichenden Anatomie des Centralnervensystemes verweise ich auf die Arbeiten, welche in den „Jahresberichten der Hirnan atomie " eitirt sind, die ich seit 10 Jahren in Schmidt's Jahrbüchern gebe für die Begründung vieler eigenen Dinge auf die Studien, welche ich im gleichen Zeitraume im Anat. Anzeiger veröffentlicht habe, vor Allem aber auf die "Beiträge zur vergleichenden Anatomie des Centralnervensystemes ", von denen bisher drei Hefte - Diesterwegs Verlag, Frankfurt a. M. - erschienen sind. 
können. Es ist auch versucht worden, zu ermitteln, was jedem einzelnen Theile des Nervensystemes als Principielles zukommt. Ein Tersuch ist es, zu dem sich der Verfasser berechtigt glaubte, weil ihn Studien auf dem Gebiete der vergleichenden Anatomie seit nun 10 Jahren beschäftigen. Möge er nur als solcher beurtheilt werden.

Die Vorrede der zweiten Auflage dieses Buches schloss mit den Worten:

„Es muss eine Auzahl auatomischer Anordnungen geben, die bei allen Wirbelthieren in gleicher Weise vorhanden sind, diejenigen, welche die einfachsten Aeusserungen der Thätigkeit des C'entralorgans ermöglichen. Es gilt nur immer dasjenige Thier oder diejenige Entwicklungsstufe irgend eines Thieres ausfindig zu machen, bei der dieser oder jener Nechanismus so einfach zu Tage tritt, dass er voll verstanden werden kann. Hat man das Verhalten einer solchen Einrichtung, eines Faserzuges, einer Zellanordnung, nur einmal irgendwo ganz sichergestellt, so findet man sie gewöhnlich leicht auch da wieder, wo sie durch neu Hinzugekommenes mehr oder weniger undeutlich gemacht wird.

Das Auffinden solcher Grundlinien des Hirnbaues aber scheint die nächstliegende und wichtigste Aufgabe der Hirnanatomie. Kennen wir nur erst einmal sie, so wird es leichter sein, die complicirten Einrichtungen zu verstehen, mit denen das höher organisirte Gehirn arbeitet."

Dies war gewissermassen ein Programm und einen Theil der Ausführung dieses Programmes bringt die neue Auflage.

Frankfurt am Main, im Juni 1596.

Edinger. 



\section{INHALTSVERZEICHNISS.}

\section{Theil.}

Einführung in die Anatomie der nervösen Centralorgane.

ERSTE VORLESUNG.

Ueberblick über die Geschichte nnd die Methoden der Erforschung der nervösen Centralorgane.

ZWEITE TORLESUNG.

Grundbegriffe. Ganglienzelle und Nerv

DRITTE VORLESUNG.

Centralorgan und periphere Nerven. Physiologisches

\section{Theil.}

Uebersicht ïber die Entwicklung nnd die vergleichende Anatomie des Vertebratengehirnes.

VIERTE VORLESUNG.

Die Entwicklung des Gehirnes und der Ganglien.

FÜNFTE VORLESUNG.

Der Aufbau des Rïckenmarkes

SECHSTE VORLESUNG.

Die Oblongata und die Kerne der Hirnnerven . . . . . . . . . . . . . . 70

SIEBENTE VORLESUNG.

Die Oblongata. Fortsetzung

ACHTE VORLESUNG.

Das Kleinhirn

NEUNTE VORLESUNG.

Das Mittelhirn

ZEHNTE VORLESUNG.

Das Zwischenhirn

ELFTE VORLESUNG.

Das Endhirn, Telencephalon, Vorderhim im engeren Sinne, Grosshirn. (1. Riechapparat und Stammlappen)

ZTVOLFTE VORLESUNG.

Das Vorderhirn. (2. Der Hirnmantel) . 


\section{Theil.}

Specielle Anatomie des säugergehirnes mit besonderer Berïcksichtigung des Gehirnes des Meuschen.

DREIZEHNTE VORLESUNG.

Die Formverhältnisse des Gehirnes beim Menschen

\section{VIERZEHNTE VORLESUNG.}

Vom Gehirne der Säugethiere und vom Riechapparate.

\section{FÜNFZEHNTE VORLESUNG.}

Die Rinde des Vorderhirnes und das Markweiss der Hemisphären, die Commissuren und der Stabkranz

SECHZEHNTE VORLESUNG.

Die Capsula interna, das Corpus striatum und die Ganglien des Zwischenhirnes

\section{SIEBZEHNTE VORLESUNG.}

Metathalamus und Hypothalamus. Die Regio subthalamica und die Gebilde an der Hirnbasis .

\section{ACHTZEHNTE VORLESUNG.}

Die Basis des frehimes. Der Sehmerv und sein Ursprung. Die Vierhügel . . . 263 NEUNZEHNTE VORLESUNG.

Haube und Fuss des Mittelhirnes

ZIVANZIGSTE VORLESUNG.

Die Brïcke und das Kleiuhirn

EINUNDZWANZIGSTE VORLESUNG.

Die Wurzeln der peripheren Nerven, die Spinalganglien und das Rückenmark • . 310 ZWEIUNDZWANZIGSTE VORLESUNG.

Der Faserverlauf im Rückeumarke 326

DREIUNDZWANZIGSTE YORLESUNG.

Das verlängerte Mark

\section{VIERUNDZWANZIGSTE VORLESUNG.}

Die Medulla oblongata und die Haube der Brücke

FÜNFUNDZWANZIGSTE VORLESUNG.

Die Brücke. - Schlussübersicht 


\section{THEIL.}

\section{EINFÜHRUNG IN DIE ANATOMIE}

DER

NERVÖSEN CENTRALORGANE. 



\section{Erste Vorlesung.}

\section{Ueberblick iiber die Geschichte und die Methoden der Erforschung der nerrösen Centralorgane.}

Meine Herren! Die Anatomie des Centralnervensystems, mit deren Grundzïgen Sie diese Torlesungen bekannt machen sollen, hat seit der Renaissance der anatomischen Wissenschaft das Interesse zahlreicher Forscher lebhaft in Anspruch genommen. Tesalius, Eustachio, Aranzio, Variolo, Fallopia haben die Grundlagen geschaffen, auf denen in späteren Jahrhunderten weiter gebaut werden komnte. Im 17. Jahrhundert erschienen schon grössere Monographien, welche mit Rücksicht auf die damalige Untersuchungstechnik fast als erschöpfend $\mathrm{zu}$ bezeichnen sind: so die Bücher von Th. Willis und von Raim. Vieussens. Immerhin. konnte Willis noch Gebilde wie die Streifenhügel, die vordere Commissur, die Pyramiden und die Oliven als neu beschreiben. Wichtige Beiträge zur Hirnanatomie gaben damals noch F. D. Sylvius, J. J. IT epfer und van Leuwenhoeck, welcher Letztere zuerst mikroskopische Untersuchungen des Gehirns anstellte. V. II a l a c a l' n e in Italien, S. Th. v. Sömmering in Dentschland, Vicq d'Azyr und Rolando in Frankreich trugen gegen Ende des vorigen Jahrhunderts wesentlich zur Tertiefung unseres Wrissens vom Gehirn bei.

Als unser Jahrhundert anbrach, war der allgemeinen Formbeschreibung der Organe des Centralnervensystems kaum noch etwas Wesentliches zuzufügen. Trotzdem war man in dem, was wir heute als den wichtigsten Theil der Lehre vom Bau des Centralnervensystems bezeichnen müssen, in der Kenntniss vom feineren Zusammenhang der Theile, vom Faserverlauf, kaum vorwärts gekommen. Auch die vergleichend anatomischen Untersuchungen, die man gerade in den ersten Jahrzehnten des 19. Jahrhunderts aufnahm, brachten diese Lehre nicht vorwärts. Was noch auf wesentlich makroskopischem Wege zu erreichen war, haben Reil, Gall und Spurzheim, F. Arnold, C. B. Reichert, Foville, Burdach u. A. geleistet.

Namentlich Reil, der zuerst die künstliche Härtung des Gehirns als vorbereitendes Mittel allgemein geltend machte, hat bereits eine grosse Anzahl anatomischer Facta, die nicht gerade auf der Oberfläche liegen, richtig gesehen. Als seine wichtigsten Entdeckungen muss man die Ab- 
grenzung des Stabkranzes und des Hirnschenkelsystems bezeichnen, deren Beziehungen zu der sie durchquerenden Balkenfaserung er zuerst erkannte; die Schleife und ihr Ursprung aus den Vierhügeln, der Linsenkern, die Insel und vieles Andere haben erst seit seinen Untersuchungen Aufnahme in die Anatomie gefunden.

So recht wie ein Markstein steht am Ausgangspunkt dieser älteren Periode Burdach's Buch "Nom Bau und Leben des Gehirnes“, das, 1 s19 erschienen, alles bis dahin Geleistete treu zusammenfasst und vieles Neue klärend hinzufügt.

Man bediente sich, bis zur Mitte unseres Jahrhunderts etwa, ganz vorwiegend der anatomischen Zergliederung mit dem Messer und der Abfaserung gehärteter Gehirnstücke mit der Pincette. Gall, Burdach, Reil, F. Arnold, Foville haben unter Benutzung der letzteren Methode viel Neues entdeckt. Tiedemann's und Reichert's Verdienst ist es wesentlich, dass man auf dem Wege der Ent wi cklungsgeschich te die allgemein morphologischen Terhältnisse besser verstehen lernte.

Seit aber Ehrenberg (1S33) dargethan hatte, dass das „Seelenorgan“ aus zahllosen allerfeinsten „Röhrchen" zusammengesetzt sei, seit Rema k die Ganglienzellen genauer beschrieben (1535) und Hannover (1S40) deren Zusammenhang mit den Nervenfasem nachgewiesen hatte, war es offenbar. dass die einfache Zerfaserung nicht im Stande sein könne, die erstrebte Einsicht in den Bau und Zusammenhang der Centralorgane zu verschaffen. Es ist das grosse Terdienst von B. Stilling, eine neue Nethode eingeführt und geübt zu haben: die Anfertigung von dümnen Schnitten oder vielmehr ganzen Schnittserien, die in verschiedenen, aber bestimmten Richtungen durch das Organ gelegt werden. ${ }^{1)}$ Die so erhaltenen Präparate wurden genau durchforscht, ihre Bilder combinirt und so die Anordnung und der Aufbau des centralen Nervensystems reconstruirt. Durch diese Methode und durch die Studien, die er unter ihrer Benutzung anstellte, hat Stilling die Grundlage für die moderne Anatomie des Rückenmarks, der Oblongata, des Pons und des Cerebellum geschaffen. Am 25. Januar 1542 liess Stilling bei einer Kälte von $-13^{\circ} R$. ein Stück Rückenmark frieren und machte dann mit dem Scalpell einen mässig. feinen Querschnitt durch dasselbe. „Als ich diesen“, schreibt er, „unter das Mikroskop brachte und bei 15 facher Linearvergrösserung die prächtigen Querfaserstrahlungen (centralen Nervenbahnen) sah, da hatte ich einen Schlüssel gefunden, der die Gemächer zu dem wunderbaren Bau des Rückenmarks öffnete. Nicht froher hatte Archimedes sein zï@ıx gerufen, als ich bei jenem Anblick ausrief."

Die Stilling'sche Methode ist die auch jetzt noch am meisten rerwendete zur Untersuchung des Centralnervensystems. Sehr erleichtert wird ihre Anwendung durch die vorzügliche Härtung, welche nach den Angaben

1) Schon vor Stilling fertigte man dïme Schnitte des Centralnervenssstems an (z. B. Rolando 1524), aber die Reconstruction der Organe mittelst der Combination ausgedehnter Schnittserien rersucht zu haben, ist wesentlich Stilling's Terdienst. 
von Hannover und von Eckhardt die verdünnte Chromsäure und die Lösungen von chromsauren Salzen an den nervösen Centralorganen hervorbringen. Die Schnitte werden meist mit Mikrotomen gemacht, welche ein exactes Schneiden und grosse gleichmässige Schnitte ermöglichen. Um die Construction von hierzu geeigneten Mikrotomen haben sich Welcker, Rivet, Weigert, Gudden, Strasser u. A. verdient gemacht. Man kann jetzt ein ganzes menschliches Gehirn in eine Serie lückenloser Querschnitte von weniger als $1 / 20 \mathrm{~mm}$ Dicke zerlegen.

Die erhaltenen Abschnitte können ungefärbt untersucht werden. Alles, was Stilling gefunden, wurde an solchen ungefärbten Präparaten gesehen.

Zweckmässiger aber ist es, sie zu färben. Es ist Gerlach's Verdienst, zuerst (1555) auf die Vortheile aufmerksam gemacht zu haben, welche man durch Tränken der Präparate mit Carmin erhält. Die spätere Zeit hat noch manche Färbemethoden hervorgebracht, namentlich wurden Anilinfarben (Nigrosin u. A.) benutzt. Aber wir haben erst in neuester Zeit durch Golgi (15s3) eine Methode erhalten, welche mehr leistet, als die alte Gerlach'sche. Dieselbe beruht auf Schwärzung der Zellen und ihrer Ausläufer durch Chromsilber. Dieser Methode verdanken wir ganz neue und ungeahnte Einblicke in den feineren Aufbau des C'entralnervensystems.

Sorgfältige Härtung und Nachbehandlung mit Anilinfarben haben es zuerst Nissl ermöglicht, Präparate herzustellen, welche einen Einblick in das Structurbild der Ganglienzelle gewähren. Der Faserverlauf wird durch Carminfärbung nicht sehr viel deutlicher. Dagegen gelingt es durch eine ausgezeichnete, von Weigert (ISS4) herrührende Methode der Hämatoxylinfärbung, auch die feinsten Fäserchen tief blauschwarz zu färben und so, der Stilling'schen Methode folgend, ihren Verlauf leichter zu erforschen, als es früher möglich war. Schöne Bilder kann man auch durch die Osmiumsäurebehandlung (Exner, Bellonci) erhalten.

Die gefärbten Schnitte werden seit den diesbezüglichen Angaben ron Clarke (1551) in Alkohol entwässert und damn durch ein ätherisches Oel oder Xylol durchsichtig gemacht.

$1 \$ \$ 6$ hat P. Ehrlich gezeigt, dass es gelingt, am lebenden Thiere Axencylinder und Ganglienzelle durch Methylenblau zu färben. Dieses Verfahren ist in den Händen von Retzius u. A. für die Erforschung des feineren Aufbaues der Theile im Centralnervensystem von der grössten Wichtigkeit geworden.

Der Stilling'schen Methode sind die meisten Forscher gefolgt, welche in der zweiten Hälfte dieses Jahrhunderts das Centrahnervensystem untersuchten. Ich werde am Schlusse jeder Yorlesung Ihnen die Namen derer mittheilen, welchen wir das Wichtigste in der Erkemntniss des dort behandelten Hirntlıeiles verdanken. Aber heute schon müssen Sie sich merken, dass wir zwei Männern, Stilling und Meynert, das Allermeiste rerdanken, was wir vom feineren Bau des Gehirnes und Rückenmarkes wissen, dass alle neueren Arbeiter von dem ausgegangen sind, was jene schufen. 
Benedict Stilling hat die ganze Grundlage unseres Wissens von der Brücke, dem Kleinhirn, dem rerlängerten Marke und dem Rückenmarke geschaffen durch eine Reihe grossartig angelegter und ron nicht wieder erreichtem Fleisse zengender Werke, die sicher ein monumentum aere perennius des grossen Casseler Arztes bleiben werden.

Neynert aber hat nicht nur alle Gebiete des Hirnes und Rückenmarkes systematisch auf Schnitten und abfasernd durchgearbeitet und dabei mehr Thatsachen neu entdeckt, als, Stilling ausgenommen. irgend ein früherer Forscher, sondern er lat auch in wahrhaft genialer Conception auf Grund der feineren Anatomie eine Theorie des Hirnbaues aufgestellt, welche auf die Anatomie und auf die Psychologie in gleichem Maasse bis hente fruchtbringend und zu Neuem anregend fortwirkt.

Es liegt im Tesen der Stilling schen Methode begründet, dass die Terfolgung einer Nervenbahn auf lange Strecken hin nur sicher und möglich ist. so lange die sie zusammensetzenden Züge nicht durch Ganglienzellen unterbrochen werden oder aus der Schnittebene abbiegen, so lange sie nicht in ein Fasergewirr eingehen oder sich aus einem Bündel in zahlreiche sich zerstreuende Fäserchen spalten. Auch im Rückenmark der kleinsten Thiere kommt kaum eine Faser vor, deren ganzer Terlauf in einer Schnittebene zu übersehen wäre.

Man hat sich daher, nachdem man namentlich durch stilling's Arbeiten angefangen hatte, sich etwas auf dem schwierigen Gebiete zu orientiren, nach weiteren Methoden umgesehen, welche ein Auffinden und Terfolgen der Faserbahnen gestatten. Bekanntlich hat Waller 1552 gezeigt, dass durchschnittene Nerven in ganz bestimmten Richtungen degeneriren. Nun fand Türk schon vorher (1550), dass auch die Unterbrechung: der Leitung im Rückemmark zu Degenerationen führte, die nach aufwärts sich in anderen Fasersträngen fortpflanzten, als nach abwärts. Es gelang durch seine Arbeiten, sowie die von Bouchard, von Flechsig, Charcot und vielen Anderen nachzuweisen, dass im Rückenmark und im Gehirn ganz bestimmte Fasergebiete an immer den gleichen Stellen liegen, Fasern, welche, wenn sie degenerirt sind, auf die ganze Länge ihres Verlaufes hin sich rom gesund gebliebenen Gewebe abheben und so leicht ihrer Richtung entlang verfolgt werden können. Das studium dieser secundären Degenerationen ist seitdem wichtig für den Fortschritt der uns beschäftigenden Lehre geworden. Deshalb wollen wir noch einen Augenblick auf das Waller'sche Gesetz etwas näher eingehen. Man formulirt es jetzt so, dass man sagt: Der Axencylinder einer Nervenfaser hat nur Bestand, so lange er noch mit seiner Ursprungszelle zusammenhängt. Er degenerirt sammt seiner Narkscheide in dem Gebiete, welches nicht mehr unter dem Einfluss der Ursprungszelle steht. Nun hat aber Forel gezeigt, dass bei Neugeborenen nach einfacher Nerrendurchschneidung und bei Erwachsenen, wenn der Nerv sehr nahe am Kern durchtrennt wird, Degenerationen auch in dem noch mit der Zelle zusammenhängenden Stücke entstehen kömnen, und Bregman hat bei besonders darauf gerichteten Untersuchungen den 
Zerfall des centralen Stumpfes bestätigt. Dieser scheinbare Widerspruch gegen das Waller'sche Gesetz ist durch die Arbeiten ron Nissl gelöst worden. Nissl hat nämlich gezeigt, dass eine schädigende Einwirkung von der Durchschneidungsstelle auf die centrale Zelle ausgeübt wird, dass diese vorübergehend sehr in ihrer Structur geschädigt werden kann. In solchen Fällen kommt es dann zu Zerfall auch des centralen Axencylinders, weil er eben nicht mehr mit einer normalen Ursprungszelle zusammenhängt. Bei der Beurtheilung secundärer Degenerationen muss man in Zukunft auf diese Thatsachen, die ja für die Pathologie besonders wichtig sind, gebührende Rücksicht nehmen.

Das Fasergebiet, in dem eine solche Degeneration sich constant fortzupflanzen pflegt, nennt man auch ein Fasersystem. Eine Anzahl von Rückenmarkskrankheiten befallen, im Anfange ihres Auftretens oder immer, nur bestimmte Systeme, z. B. nur die Hinterstränge des Rückenmarks. Man nemnt sie Systemerkrankungen. Auch die Untersuchung solcher Systemerkrankungen kann zur Erkenntniss des Faserverlaufes benutzt werden (Flechsig, Westphal, Strümpell). Durch genaues Studium pathologischer Veränderungen haben ferner noch Charcot und seine Schüler, besonders Pitres, Féré, Ballet, Brissaud u. A., befruchtend auf die Hirnanatomie gewirkt.

Zuweilen gewähren Missbildungen die Möglichkeit, die eine oder die andere Bahn leichter zu erkennen, als dies im normalen Gehirn möglich ist. So konnten $\mathrm{Onufrowics} \mathrm{Kanfmann} \mathrm{u.} \mathrm{A.} \mathrm{Fälle} \mathrm{von} \mathrm{Balkenmangel}$ untersuchen, in denen, eben durch den Ausfall der Balkenfasern, andere Züge im Gehirn mit bisher nicht bekannter Deutlichkeit hervortreten.

Es lag nahe, absichtlich ganz bestimmte Theile der Wurzeln oder des Rückenmarkes z. B. zu durchschneiden und so durch die willkürlich erzeugte secundäre Degeneration weiter in den Bau einzudringen. Solche Tersuche wurden viele gemacht, und manches Wichtige verdanken wir den Experimentatoren, welche so vorgingen. So wurden beispielsweise durch die Durchschneidungsversuche von Singer und von Schiefferdecker, denen sich später Löwenthal, Sherrington, Mott u. v. A. beigesellten, unsere Kenntnisse vom Verlauf der Nervenwurzeln im Rückenmark sehr bereichert.

Technisch kömnen solche Degenerationen auf zwei Weisen studirt werden. Man kann entweder den völligen Untergang der Fasern abwarten und dann den Verlauf der verödeten Strecke verfolgen, oder man kann durch Einlegen des Präparates wenige Wochen nach der Operation in eine osmiumsäurehaltige 'Lösung' die Zerfallproducte schwärzen ( I a r c h i). Namentlich die letztere Methode giebt sehr klare Bilder, Linien ron schwarzen Pünktchen der degenerirten Fasern auf hellem Grunde.

Wenn man bei neugeborenen Thieren periphere oder centrale Nerrensubstanz operativ entfernt, so entwickeln sich mit den rerletzten Stellen im Zusammenhang stehende Fasern nicht weiter, gehen allmählich sogar ganz zu Grunde. Diese Erfahrung hat Gudden (1570) benutzt, um uns 
mit einer neuen und fruchtbaren Untersuchungsmethode $\mathrm{zu}$ beschenken. Er hat beispielsweise die nach Exstirpation eines Auges im Gehirn entstehenden Atrophien auf Schnitten u. s. w. verfolgt und so die nächsten centralen Endigungen des betreffenden Sehnerven aufgefunden. Wo immer sonst noch am Gehirn er experimentirt und nachträglich untersucht hat, überall hat er Neues und Wichtiges zu Tage gebracht. Ausser Gudden rerdanken wir namentlich Mayser, Ganser. Forel, Monakow und Löw entha l wichtige, mit dieser Methode gewonnene Kenntnisse über den Faserverlauf im Rückenmark, die Ursprungsart verschiedener Hirnnerven, den Terlauf der Schleife im Gehirn u. v. A.

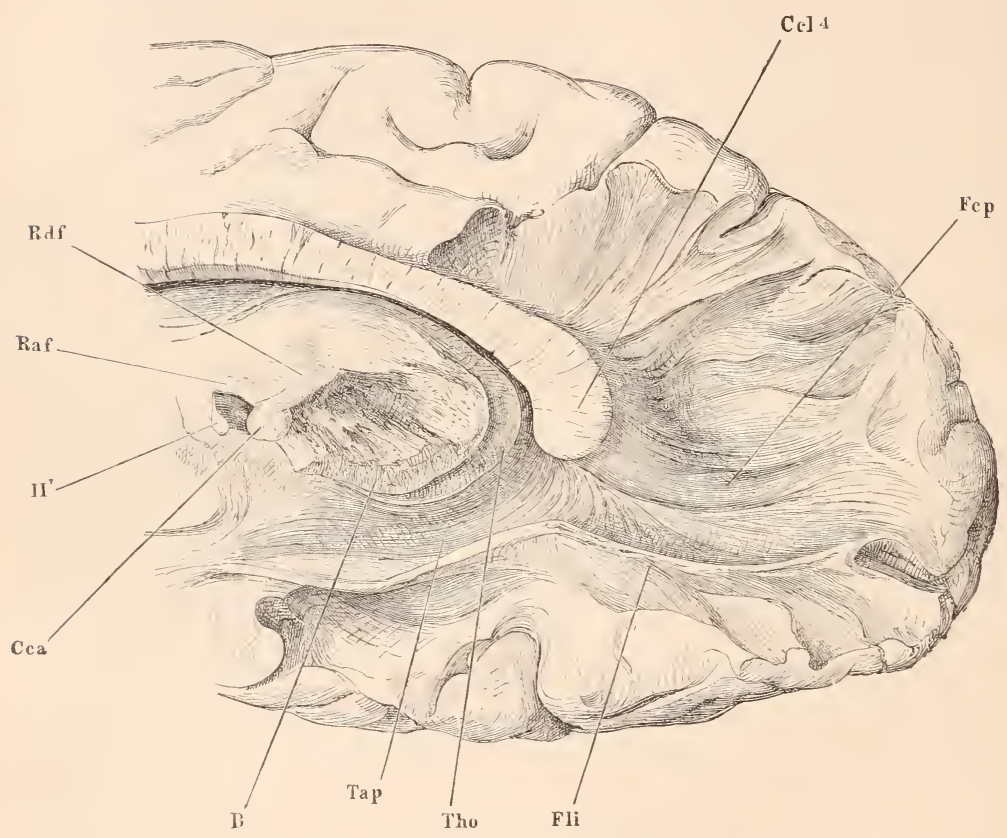

Fig. 1.

Die Faserung des Balkens, durch Abbrechen des erhärteten Präparates mit der Pincette dargestellt, nach Henle.

Zuweilen bieten sich Fälle, wo die Natur gleichsam selbst ein Gud d en sches Experiment am Menschen angestellt hat. so konnte ich einmal die atrophischen Nervenbahmen, welche nach intranteriner Amputation eines Armes zurückgeblieben waren, bis hoch hinauf in das Rückenmark verfolgen; ein andermal hatte ich Gelegenheit, das Nervensystem eines Kindes zu untersuchen, das vor oder doch bald nach der Geburt eine ausgedehnte 
Erweichung der Scheitellappenrinde bekommen hatte. Im Rückenmark fehlte die gekreuzte Pyramide ganz.

Die Lehre vom Faserverlauf hat durch die Methode der secundären Degenerationen und Atrophien einen guten Schritt vorwärts gethan. Noch förderlicher aber wurde ihr eine neue Methode, welche sich auf die Untersuchung der Markscheidenentwicklıng gründete.

Es gebührt das Verdienst, diese Methode in die Forschung eingeführt und mustergültig ausgenutzt zu haben, P. Flechsig. In einer Reihe von Mittheilungen (1572-1S51), dann in einem grösseren Werk über die Leitungsbahnen im Gehirn und Rückenmark (1576) hat er gezeigt, dass die verschiedenen Faserzüge, welche auf dem Schnitt durch das Centralorgan des Erwachsenen so gleichartig aussehen, in der Embryonalzeit sich sehr wesentlich dadurch unterscheiden, dass sie zu verschiedener Zeit ihr Nervenmark bekommen. Ganze „Systeme“ auf dem Rïckenmarksquerschnitt sind noch durchsichtig zu einer Zeit, wo andere bereits weiss, markhaltig geworden sind. Die Verfolgung der weissen Partien auf Quer- und Längsschnitten ist sehr viel leichter, giebt sehr viel sicherere Resultate, als die Verfolgung von Nervenfasersträngen am völlig ausgebildeten Organ.

Um Ihnen einen Begriff von den Eigenheiten der einzelnen bislang erwähnten Methoden zu geben, demonstrire ich

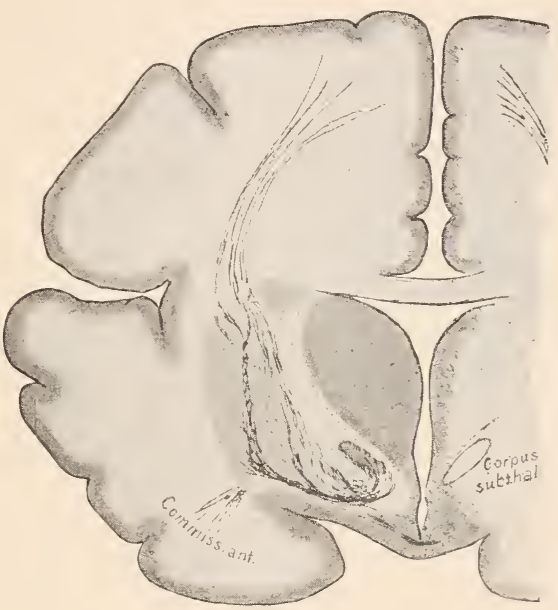

Fig. 2.

Frontalschnitt durch das hintoro Ende der Fossa Sylvii am Gehirn einer neunmonatlichen todtgeborenen Frucht angelegt. Die markhaltigen Fasern schwarz gezeichnet. In Wahrheit heben sie sich weiss von grauem Untergrunde $a b$.

Ihnen zunächst hier ein

Präparat, das durch Abfaserung hergestellt wurde und den Verlauf der Balkenfasern im Grosshirn zeigen soll (Fig. 1).

Die folgende Zeichnung ist nach einem Frontalschnitt gefertigt, der durch das Grosshirn einer neummonatlichen todtgeborenen Frucht gelegt wurde. Das ganze hier abgebildete Gebiet ist beim Erwachsenen von Nervenfasern erfüllt, die, in mannigfacher Richtung verlaufend und sich durchkreuzend, schwer zu verfolgen sind. Bei unserer Frucht aber ist von all den vielen Fasern des Grosshirns nur der eine als Haubenbahn bezeichnete Strang markhaltig. Nirgends im Grosshirn als an dieser 
Stelle finden sich markhaltige Nervenfasern. Deshalb ist es Flechsig zuerst gelungen, unter den rielen Bahnen des Grosshirns, die uns zum Teil noch recht wenig bekannt sind, die Haubenbahn als distinctes Bündel zu entdecken und ihren Terlauf zum Theil klar zu stellen.

Die dritte Abbildung stellt einen Schnitt durch den Halstheil eines Rückenmarkes dar, das einem Manne entstammt, der vor der Geburt den linken Torderarm verlor. Sie sehen, dass die grane und die weisse Substanz, namentlich aber die erstere, links stark atrophisch sind. Die genauere Feststellung dieser Ausdehnung der Atrophie gestattete einen Schluss auf die Lage der centralen Enden der durchtrennten Nerven.

Das Terständniss fïr die allgemeine Morphologie des Centralnerrensystems ist durch nichts mehr gefördert worden, als durch die vergleichende Anatomie und durch die Entwicklungsgeschichte.

Was wir von der Entwicklungsgeschichte der uns hier interessirenden Organe wissen, rerdankell wir wesentlich Kölliker, His. Tiedemann, Reichert, v. Mihalkovics. Götte. Kupffer.

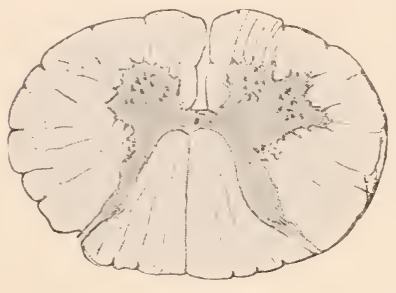

Fig. 3.

Schnitt durch das Halsmark eines 45 jährigen Mannes, der mit einem kurzen Amputationsstumpf des linken Vorderarms zur Welt kam.

Noch in das 17. Jahrhundert ragen die ersten Tersuche, dem Gehirne auf vergleichendem Tege näher zu treten, hinein und die Literatur der ersten Hälfte unseres Jahrhunderts zählt schon eine ganze Anzahl von schriften, die sich mit dem Gehirne niederer Wirbelthiere beschäftigen. Namentlich war es das Fischgehirn, das immer wieder zu nenen Studien anregte. Die zahlreichen Arbeiten dieser Zeit fanden einen gewissen Abschluss durch das Werk ron Leuret und Gratiolet iiber das Gehirn der Wirbelthiere und ausserdem durch wirklich gross angelegte Monographien, ron denen ich namentlich diejenige des Wolmarer Arztes Dr. Girgensohn über das Gehirn der Fische erwähne, weil sie im Jahre 1546 veröffentlicht. eine der, wie mir scheint, seltenen Arbeiten ist, die ron grossen, zum Theil heute noch gïltigen und lehrreichen Gesichtspunkten ausgehen. Natürlich beschäftigen sich alle diese Arbeiten nur mit der äusseren Form des Gehirnes. Das gilt auch für einige spätere, die ron allgemein morphologischen Gesichtspunkten aus unternommen, uns gerade über die äussere Form genau belehrt haben. Hier wären die Terke ron Gottsche. Tiault, Talentin, Miclucho-Maklay, Baudelot u. A. zu nemnen, die das Gehirn, speciell der Selachier und der Teleostier genauer durchgearbeitet haben. Das Gehirn der Amphibien und der Reptilien ist vielfach ron den vergleichenden Anatomen untersucht worden, doch giebt es fïr das allgemein morphologische wenig brauchbare ältere Literatur. ausser den Werken von Treviranus und ron Carus. 
Hier aber setzte damn die nenere Technik der successiven Querschnitte ein. Reissner zunächst, später in ausgezeichneter Weise Stieda haben zuerst versucht, in dem wirklich schwierigen Gebiete sich an Schnitten zurecht zu finden und wir verdanken ganz besonders dem letztgenamnten Autor die grundlegenden Studien über den imneren Bau des Gehirnes der niederen Wirbelthiere. Rasch folgten, nachdem stieda einmal Vertreter der Fische, Amphibien und Tögel geschnitten und abgebildet hatte, weitere Arbeiten in gleichen Sinne. Fast alle Thierklassen wurden von Mehreren untersucht. Den Fischen widmete Fritsclı eine prachtvolle Monographie, deren Angaben dann später durch eine Arbeit ron Mayser, die ich zu den klassischen der Himliteratur rechnen möchte, erweitert und zum Theil sehr modificirt wurden. Neben der Ma yser'schen Monographie steht als ebenbürtig noch ein W'erk, dessen Lectüre ich Ihmen auch besonders empfehlen möchte, die Beschreibung des Petromyzongehirnes ron A hlborn. Diese Arbeiten haben den Grnnd zu unserer heutigen Kenntniss vom Gehirne der niedersten Vertebraten gelegt. Noch haben sie, mangels guter technischer Methoden, rom feineren Aufbau relativ wenig nur berichten können. Erst die Untersnchungen des Italieners $(\mathrm{H}$ is e p pe Bellon ci, der mit ausserordentlicher Klarheit die Anfgaben erfasste, die sich bei derlei Untersuchungen bieten und mit grosser Präcision das Gewonnene darznstellen wusste, zeigten, welche Probleme hier noch der Lösung harrten. Bellonci ist noch jung gestorben, aber die wenigen kleinen Aufsätze, die er hinterlassen hat, gehören zum allerbesten, was wir auf diesem Gebiete besitzen. Einen wesentlichen Forschritt erfulm unsere Kenntniss des Gehirnes der niederen Vertebraten durch die entwicklungsgeschichtlichen und vergleichend anatomischen Studien Rabl R ückhardt's, dem wir nächst Stieda überhaupt erst die Möglichkeit verdanken, die einzelnen Gehirntheile mit den entsprechenden Theilen der längst schon besser gekannten Säuger zu homologisiren. Nun erst konnte ein frisches Toranarbeiten beginnen und bald zeitigten demn auch wichtige Arbeiten; überall wurden die gestellten und nun lösbar gewordenen Aufgaben in Angriff genommen. Drüben in Amerika, wo bereits Mason ein grosses rergleichend anatomisches Tafelwerk veröffentlicht hatte, arbeiteten spitzka mit seinen Schülern, dann Osborn, dem wir wichtige Studien über die Commissuren und auch uiber das Amphibiengehirn rerdauken, C. L. Herrick, der mit grossem Fleisse Tertreter aller niederen Kilassen untersncht hat; in England erschienen die Studien ron Sanders, bei uns waren Tiedersheim, Köppen, Meyer, der Terfasser u. A. thätig. Doch ist zumeist noch mit völlig ungenügender Methodik gearbeitet worden, so dass trotz vieler Arbeit wenig zuverlässliches Material bisher vorliegt. Terhältnissmässig am besten sind die Amphibien und Reptilien bearbeitet; auch ron den Fischen sind einzelne Hirntheile wenigstens etwas bekannt. Am schlechtesten steht es noch um die Kenntniss des Togelgehirnes. Seine Hemisphären haben noch gar keine ausreichende Bearbeitung erfahren, während für das 
Mittelhirn und die Nervenursprünge wenigstens durch S. R. y Cajal, v. Gehuchten und Brandis Einiges bekannt geworden ist.

Die wichtigste Studie über das Vogelgehirn ist diejenige von $B \varkappa \mathrm{mm}$.

Die Homologisirung wurde namentlich auch durch B u r k h a r d t's vergleichend anatomische und $K u p f f e r s$ und $H$ is rergleichend entwicklungsgeschichtliche Studien mehr und mehr erleichtert, die erst die Wichtigkeit der Ein- und Ausstülpungen, welche wir an den läutigen Gebilden des Gehirnes beobachteten, für derlei Tergleiche kemnen lehrten.

Die Ansbente, welche die vergleichende Anatomie für die Lehre rom Faserverlauf ergeben hat, ist bisher nicht so gross, als man erwarten dürfte. Gegenüber der Feststellung und Beschreibung der äusseren Form ist vielfach das Interesse am feineren Bau gering gewesen, obgleich ja eigentlich dieser Kern und jene nur die äussere Schale ist. Dazu kam die Unzulänglichkeit der Methoden, mit denen man sich lange behelfen musste. Nur Tenige vermochten in dem Gewirre der Bahnen, das auch bei den niedersten Wirbelthieren bereits vorhanden ist, einzelne Züge klar zu erkemnen, einzelne Ganglien und Nervenursprünge zu unterscheiden. Denn so einfach und 'durchsichtig auch die äusseren Terhältnisse oft bei niederen Wirbelthieren sind, so ist doch der innere Ban, besonders in den hinter dem Zwischenhirn liegenden Hirngebieten, oft kanm minder complicirt, als bei den Säugethieren selbst. Die Zellen und Faserzïge, welche den einfachsten motorischen. sensorischen und psychischen Verrichtungen dienen, müssen ja wohl iiberall dieselben sein, und sie sind schon bei den Larven der Cyclostomen nicht mehr ganz einfach, durchsichtig.

Ich habe daher versucht, dadurch der Lösung unserer Aufgaben etwas näher zu kommen, dass die rergleichend anatomische Methode mit derjenigen der Markscheidenentwicklung combinirt wurde. Wir können ja jetzt jede einzelne Markscheide färben und verfolgen. In der That gelang es der vergleichend entwicklungsgeschichtlichen Methode, bei den Embryonell der niederen Wirbelthiere endlich die gesuchten ganz einfachen Terhältnisse aufzufinden und eine Anzahl Nervenbahnen sicher als allen Wirbelthieren zukommend zu ermitteln.

Ton allergrösster Wichtigkeit für unsere Gesammtauffassung des Nervensystems waren aber die Entdeckungen, welche sich an die oben erwähnte Golgi'sche Imprägnationstechnik der Nervenzellen und an die vitale Methylenblaufärbung Ehrlichs anschlossen. An anderer Stelle wird über sie berichtet werden. Hier aber sei schon hervorgehoben, dass wir durch diese Erweiterung der Technik endlich in die Lage gekommen sind, über die Beziehungen der Zellen zu einander, ïber den feineren Aufbau mehr Klarheit zn erlangen. Diesen Methoden verdanken wir die wichtigsten Entdeckungen, welche in den letzten Jahren auf dem Gebiete. des Centrahnervensystems gemacht worden sind, ihnen allein verdanken wir den Einblick in das bisher so gut wie ganz unbekannte Nervensystem der Wirbellosen und die Retzius dort geglückte Entdeckung, 
dass ein einzelnes Nervensystem unter Umständen in seinen sämmtlichen Beziehungen bei einem Wirbellosen zu übersehen ist. Durch die vortrefflichen Arbeiten dieses Forschers sind uns dem auch in rascher Folge das periphere und centrale Nervensystem von Vertretern zahlreicher Klassen der Wirbellosen bekannt geworden. Die vitale Metlylenblaufärbung, die vor Anderem dies ermöglicht hat, ist sehr vergänglich und das Arbeiten mit ihr schwierig, genanes Abpassen des richtigen Zeitpunktes u. s. w. erfordernd. So war es mit besonderer Freude zu begrüssen, als Bethe vor Kurzem ein Verfahren lehrte, das ein so vollständiges Fixiren der Nethylenblaustïcke ermöglicht, dass diese nachher weiter erhärtet, geschnitten u. s. w. werden können. Es ist zu erwarten, dass die Methode in ihrer heutigen Vervollkommunng uns ein besonders erfreuliches Fortschreiten der Erkenntniss ermöglichen wird.

Sie sehen, meine Herren, der Wege zum Ziele sind viele. Für jede einzelne Aufgabe wird man sich immer nen die Frage vorlegen müssen, welche Methode anzuwenden ist, vor Allem, wo man erwarten darf, den einfachsten Verhältnissen zu begegnen. Selten nur wird die Lntersuchung von Organen des erwachsenen Menschen zu sicherem Ziel führen, meist wird es nöthig werden, a uf irgend einem Wege sich künstlich grössere Einfach heit zu schaffen.

Von Zeit zu Zeit hat man versucht, das, was über die feinere Anatomie des Centralnervensystems bekannt war, in eine schematische Zeichnung zu fassen. Die ältesten schematischen Darstellungen der Hirnfaserung, welche mir bekannt wurden, finden sich bei Descartes in dem Tractatus de homine, der 1662 erschien.

Von älteren hierher gehörigen Arbeiten sind namentlich die Rückenmarksschemata ron Kölliker, Ludwig. Bidder und Leydig, dam das berühmte Schema von B. Stilling zu nennen. Grössere Gebiete noch umfassen Zeichnungen von Meynert (vom Rückenmark bis zu den Vierhïgeln), von A eby, von Flechsig und von Jelgersma (das ganze Centralnervensystem).

In den folgenden Vorlesungen, meine Herren, wollen sie an vielen Stellen Wort und Bild auch nur als eine Art Schema betrachten. Sie verfolgen nur den Zweck, Ihnen die wichtigsten Thatsachen aus der Lehre vom Faserverlauf im Centralnervensystem möglichst ïbersichtlich vorzuführen. Dabei ist vieles Controverse, das sich noch nicht in den Gesammtplan einfügen lässt, nur kurz gestreift, gar manches Detail nicht erwähnt. Ueberall, wo es anging, sind nicht nur die auf rein anatomischem Trege gewonnenen Linien gezeichnet worden. sondern anch die Bahnen, welche aus gut beobachteten pathologischen Facten erschlossen werden konnten. Ein Schema ist nicht immer und überall ein Bild vom Faserverlauf; es ist oft genug nur die graphische Darstellung der Schlüsse, welche aus zahlreichen Beobachtungen gezogen werden konnten.

Ein Schema ist ein schwankendes Gebände; es muss bald da, bald dort ausgebessert werden; es wird oft genug des Niederreissens und des Wieder- 
aufbauens einzelner Theile bedürfen. Man hat die Berechtigung bestritten, Schemata aufzustellen auf einem Gebiete, das noch so viele Lücken aufweist, wie unser Wissen rom Bau des Centralnervensystems. Lassen Sie es uns aber mit dem alten Burdach halten, der da 1 s19 schrieb: „Das Sammeln einzelner Baustoffe ist es doch nicht allein, was noth thut. In jedem Zeitraume, wo eine neue Masse derselben gewonnen worden ist, mögen wir von Neuem darangehen, sie zum Gebäude zu fügen. Durch solche Gestaltgebung wird das Fortschreiten des Forschungsgeistes zu nenen Entdeckungen keineswegs gehemmt; vielmehr erfahren wir gerade erst, wemn wir das Ganze überschauen, die Lücken unserer Kemntnisse und lernen einselıen, welche Richtungen die Forschnng künftig nehmen muss. Möge der Versuch eines solchen Baues sich immer wiederholen. Keiner geht vorüber, ohne dem Wissen förderlich gewesen zu sein."

Von alteren Gesammtdarstellungen des Centralnerrensystems seien die folgenden erwähnt: Köllìker, Handbuch d. mikroskop. Anat. Leipzig 1554. - Neynert, Vom Gehirne der Säugethiere: Stricker's Handb. d. Lehre ron den Geweben. 1870. - Meynert, Psrchiatrie I. Wien 1ss4. - Henle, Handbuch d. Anatomie d. Nerrensystems. Braunschweig 1579. - L n ys, Recherches sur le Système nervenx cérébrospinal. Paris 1565. IV. Kranse, Handb. d. menschl. Anatomie. I. Bd. Hamover 1si6. - Wernicke, Lehrb. d. Gehirnkrankh. I. Cassel 1s\$1. - Schwalbe, Lehrb. d. Neurologie. Erlangen 1sbl. (Enthält die meiste Literatur bis 1ss1.) - Hug nen in, Allg. Pathol. d. Krankh, d. Nerrensystems. I. Zürich 1573. - Kahle r, Nerrensystem in Told's Gewehslehre. 2. Aufl. 16ss. Von neueren Werken nenne ich: r. Lenhosseck, Der feinere Bau des Nervensystems. 2. Aufl. Berlin 1\$95. - S. Ra mon y Cajal: Neue Darstellung rom histol. Ban des Nervensystemes. Arch. f. Anat. u. Phys. Anat. Abth. 1s93, in allen Weltsprachen erschienen. V. Horsley, The structure and functions of the brain and spinal cord. London 1592. Obersteiner, Anleitung beim studium des Baues der nervösen Centralorgane. 3. Anfl. Wien 1596. - It endel, Artikel ., Gehirn“" in Eulenburg's Realencyklopädie. 3. Aufl. WTien 1695. - Féré, Traité élémentaire d’Anatomie médicale du svstème nervenx. 2. Aufl. Paris 1591. - Brissaud, Anatomie du cerveau de l'homme. Atlas und Text. Paris 1593. Van Geluuchten, Le srstème nerveux de l'homme. Lierre 1s93. - Charpy, Système nervenx in: Poirier's Traitè d'Anatomie humaine. Paris 1s94 - Kölliker, Handbuch d. Gewebelehre. Bd. II. - Bechterew, Die Leitungsbahnen n. s. w. Leipzig 1594. J. Déjèrine u. Iad. Déjèrine-Kln mpke, Anatomie des centres nervenx. Paris 1595.

Die ausführlichste Beschreibung des feineren Aufhanes giebt Köllikers Buch, die genaneste Topographie dasjenige von Déjèrin e.

Ziemlich vollständige Referate ïber alle Einzelarbeiten im Bereiche der Hirnanatomie bringen meine seit 1555 erscheinenden Jahresberichte in Schmidt's Jahrbïchern der gesammten Medicin. Von dem regen wissenschaftlichen Arbeiten auf diesem Geliete zeugt die Angabe, dass ron 15>5-1594 nicht weniger als 1255 Studien zur Anatomie des Centralnerrensystemes in diesen Berichten erwähnt sind.

\section{Zweite Vorlesung.}

\section{Grundbegriffe. Ganglienzelle und Nerv.}

Die Bedeutung und Stellung des Centralnervensystems der Wirbelthiere kann nur voll verstanden werden, wenn man seine Abstammung und seine Beziehungen zum peripheren Nervenapparat, auch zu den Sinnesorganen, einer Würdigung unterzieht.

Der Centralapparat steht nämlich keineswegs so absolut isolirt, so durch morphologische oder physiologische Unterschiede vom peripheren 
Apparat getrennt da, wie man es noch bis in die jüngste Zeit linein vermuthet liat.

Beiden gemeinsam ist bei Tirbellosen und Wirbelthieren die Abstammung von der Zellschicht, welche die Embryonalanlage überzieht, dem äusseren Keimblatt. Ein Theil dieser dümnen Lamelle senkt sich in länglicher Rinne in die Tiefe, um, allmählich sich abschliessend, zu der röhrenförmigen Anlage des Centralnervensystems zu werden, ein anderer dicht neben jener Rinne beiderseits liegender bildet die An lage der Spinal-und Kopfganglien. Tiele zerstreut liegende Stellen weisen Zellen auf, welche, auch beim ausgebildeten Thiere in den äusseren Bedeckungen liegen bleibend, Hautsinnesapparate bilden oder, sich melir oder weniger in die Tiefe senkend, die Anlage anderer Sinnesorgane, des Gleichgewichtsapparates, des Riech- und Hörapparates bilden. Dieses relativ einfache Bild wird nun dadurch um ein weniges complicirter, dass manche Anlagen, welche bei den Wirbellosen völlig in der Peripherie bleiben, bei Wirbelthieren dicht an den Centralapparat sich legen und mit diesem verschmelzen; auch dadurch, dass, wenn eimmal die Nervenrimne geschlossen ist, von ihr aus Zellcomplexe wieder hinaus in die Peripherie wandern, um da später als selbständige, zerstreute Nervenknoten weiter zu leben.

Die längliche Platte geschichteten Epitheles, welche zur Rinne eingebogen, die Anlage des Centralnervensystemes darstellt, heisst II a $\mathrm{r}$ k platte. Schon sehr frïh treten in ihr, wie jetzt für Vertreter aller Wirbelthierklassen nachgewiesen ist, Teränderungen auf, welche zur Bildung von verschiedenen Zellarten führen. Zwischen den Epithelien entstehen, aus ihnen selbst, die Keimzellen, grosse runde protoplasmareiche Gebilde, die Anlagen der zukïnftigen Ganglienzellen. Aus ihmen wächst später der Axencylinderfortsatz aus, und noch später treten zahlreiche Nebenfortsätze am Zellkürper auf, die Zelle so zu einem multipolaren Gebilde stempelnd.

Die Epithelzellen bleiben zum Theil als Umgrenzung des centralen Hohlraumes des Nervensystems bestehen. Dam senden sie, bei allen niederen Wirbelthieren dauernd bis in das reife Leben, peripherwärts einen Ausläufer, der sich zumeist etwas verzweigt und erst an der Peripherie dicht unter der Pia sein Ende erreicht. Dort trifft man oft eigenthïmliche Anschwellungen der Zellenden, aus denen, ganz wie bei den Epithelien der Simnesorgane, ein dümner Stift herausragt. Beim Menschen und den höheren Säuger'n scheinen in der postembryonalen Periode die Endausläufer der Epithelien nicht mehr überall bis an die Peripherie zu reichen. Das Epithel des Centralnervenrohres trägt Flimmern.

Aber lange nicht alle Epithelien werden zur Umkleidung des Hohlraumes verbraucht. Es entstehen durch Zelltheilung sehr viel mehr neue Gebilde, und man kann erkennen, dass diese dann weiter und weiter vom Hohlraum abrïcken, mit dessen WTand sie oft noch durch einen dünnen Faden zusammenhängen. Die Endausläufer dieser Zellen bilden, sich rer- 
zweigend, ein Netzwerk. welches beim Erwachsenen vielleicht die ganze Substanz des Centralnervensystems durchizieht, sich auch in bestimnten Zonen mehr als in anderen rerdichtet. Diese Zellen, welche einen Theil des Gerïstwerkes herstellen, nennt His, ihr Entdecker, Spongioblasten, die unfertigen Ganglienzellen hat er als Neuroblasten bezeichnet.

Dass aus der Markplatte so zweierlei Zellen werden, das ist nur für die Wirbelthiere, hier allerdings für Vertreter aller Ordnungen nachgewiesen, bei den Wirbellosen entstehen jedenfalls die Ganglienzellen auch aus der Ectodermschicht; ob und wie weit bei jenen echte Stützsubstanz vorlanden ist, das ist noch nicht entschieden.

Ist das Centralnervensystem einmal über die ersten

Entwicklungspunkte hinaus, so zeigen sich histologisch schon im Wesentlichen die Terhältnisse, denen man im ausgebildeten Zustande begegnet.

Diesen wollen Sie nun für kurze Zeit Thre Aufmerksamkeit schenken.

Das ganze C'elltralorgan wird aufgebaut von der Gerüstsubstanz und der Nervensubstanz. Die erstere wird zunäclıst repräsen-

Fig. 1.

Nach Ranvier. Aus einem Rückenmarkstückchen. $A$ u. $B$ Ganglienzellen, bei $D$ Axencylinder, $p$ Protoplasmafortsätze, $C$ Neurogliazellen. tirt durch die scheiden der zahlreichen Gefässe. welche als stärkeres Gerüst das Organ überall durchziehen, dann aber durch die Neuroglia.

Die Neuroglia besteht aus einer ungeheuren Nasse feiner Fädchen von recht verschiedenem Kaliber, welche das ganze Centralorgan durchziehen und, indem sie unendlich viele Ueberkreuzungen liaben, ganz das Bild eines feinen Flechtwerkes darstellen. An manchen dieser Ceberkreuzungsstellen liegen dünne Zellplättchen den Faserı an. So entsteht der Anschein. dass die Gliafasern aus diesen Zellen - .. Deiters'sche Zellen" entspringen (c der Figur 4). 
Das Netz der Neuroglia verhält sich an rerschiedenen Stellen des Centrahnervensystems etwas verschieden und bildet hier und da dichte, zum Theil von Nervensubstanz ganz freie Anhäufungen; so überzieht namentlich eine breite Zone fast reiner Gerüstsubstanz die ganze Oberfläche von Gehirn und Rïckenmark, erstreckt sich auch zapfenförmig in die einzelnen Wurzeln noch ein stiick hinein. Ebenso begegnet man an der inneren Oberfläche des Centrahnervensystems, dicht unter dem Epi-

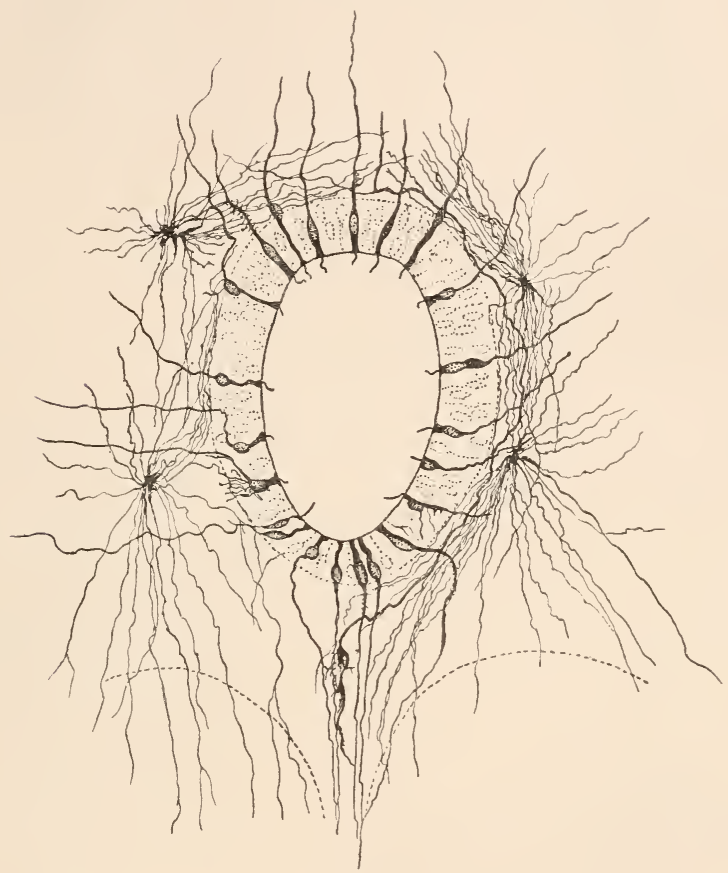

Fig. 5.

Epithelzellen and Neurogliazellen in der Umgebung des Centralkanals. Schnitt durch das Rückenmark eines menschlichen Embryo von $23 \mathrm{Cm}$. Länge. Nach Lenhosseck. Behandlung mit der Go!giCajal'schen Yethode. Man beachte, dass nur ein Theil der Zellen den Silberniederschlag angenommen hat. Das ist ein Vortheil des in der Einleitung erwähnten Verfahrens, weil es nur dadurch bei dem grossen Faserreichthum möglich wird, das, was zu einzelnen Zellen gehört, richtig zu erkennen.

thel, das diese auskleidet, einer besonders reichen Entwicklung von Neuroglia. In der grauen Substanz ist das Flechtwerk theils dichter als in der weissen, theils weniger dicht. Grössere Nervenzellen werden häufig so umsponnen, dass sie in einem engmaschigen Korbe zu liegen scheinen.

Die Neuroglia ist ein ganz eigenartiges Gewebe, das nur im centralen Nervensysteme bis jetzt gefunden worden ist - nur der Sehnerv besitzt 
noch Glia -, das sich durch seine Färbungsverhältnisse absolut von anderen Gewebsarten abgrenzen lässt. welches sich auch bei pathologischen Processen in besonderer Weise verhält. Tenn irgendwo im Centralnervensysteme Nervensubstanz durch Erkrankung ausfällt, so wuchert immer Glia in die leer werdenden Stellen. Nur wo auch ihre Elemente, wie das bei Substanzdefecten ja vorkommt, mit zerstört worden sind, und wo ihre Trachsthumsenergie allein nicht zur Ausfüllung grosser Defecte genügt, hat die Ausfüllung mit Glia ihre Grenze (Weigert).

Es ist schon erwähnt worden, dass die Epithelien des Centralcanales und der Ventrikel lange Ausläufer in die Nervensubstanz hineinsenden. Beim Menschen gehen diese nur an wenigen Stellen bis hinaus zur Oberfläche. Diese Fasern, von denen ich hier eine lehrreiche Abbildung vorlegen kann, gehören natürlich auch zum Stuitzgewebe.

Ob die ganze Neuroglia von den ausgewanderten Epithelzellen des centralen Hohlraumes stammt, oder ob sich ihr, was nicht sehr wahrscheinlich, später in der Entwicklungszeit noch bindegewebige Elemente beimischen, das ist noch nicht sicher entschieden. Die Frage also, ob es nicht etwa zweierlei Stïtzgewebe, ein bindegewebiges und ein epitheliales, giebt, ist noch offen. So weit wir bisher diese Dinge kennen, ist eine einheitliche Abstammung vom Epithel des centralen Hohlraumes wahrscheinlicher.

Auf der Abbildung Figur 6 finden sie einen Schnitt durch das Nellroglianetz der grauen Substanz beim erwachsenen Menschen, wie es sich durch die Weigert'sche Färbung darstellen lässt.

Das eigentliche Nervengewebe, welches die Hohlräume des geschilderten Netzwerkes erfüllt, besteht aus Gangli enzellen und Nervenfasern. Die Gestalt der Ganglienzellen ist eine ausserordentlich verschiedene. Rundliche, fast kugelförmige Gebilde von geringer Grösse mit spärlichen Fortsätzen, multipolare Organismen mit zahlreichen Ausläufern von der zwanzigfachen Grösse jener kleinsten Zellen kommen vor. Im Lobus nervi vagi von Torpedo und im verlängerten Mark der Neunaugen liegen so enorme Ganglienzellen, dass man sie leicht mit blossem Auge sieht; ja wir kennen im Rückenmark des elektrischen Aals, des Malapterurus, zwei isolirt liegende Ganglienzellen von solcher Grösse, dass die mächtige einzige Nervenfaser, welche jede aussendet, genügt, um das ganze, sehr grosse elektrische Organ zu innerviren. Auch je nach der technischen Behandlung des Präparates erhält man sehr verschieden aussehende Bilder von Ganglienzellen. In Figur 4 sind zwei Ganglienzellen abgebildet, wie sie sich nach Behandlung mit Carmin und Picrocarmin darstellen. Figur 6 zeigt dann in der Mitte eine nach Golgi behandelte Zelle, an welcher der Silberniederschlag in einer früher unerreicht schönen Teise die Ausläufer erkennen lässt. Ton der Structur der Zelle ist aber nichts zu erblicken. Structurbilder, wie sie namentlich bei Untersuchungen im Bereich der Pathologie wichtig sind, bekommt man nur auf anderen Wegen. Die zwei stark vergrösserten Zellen oben an Figur 6 zeigen, was bisher hier die mikroskopische Technik leistet. Viele Ganglienzellen 


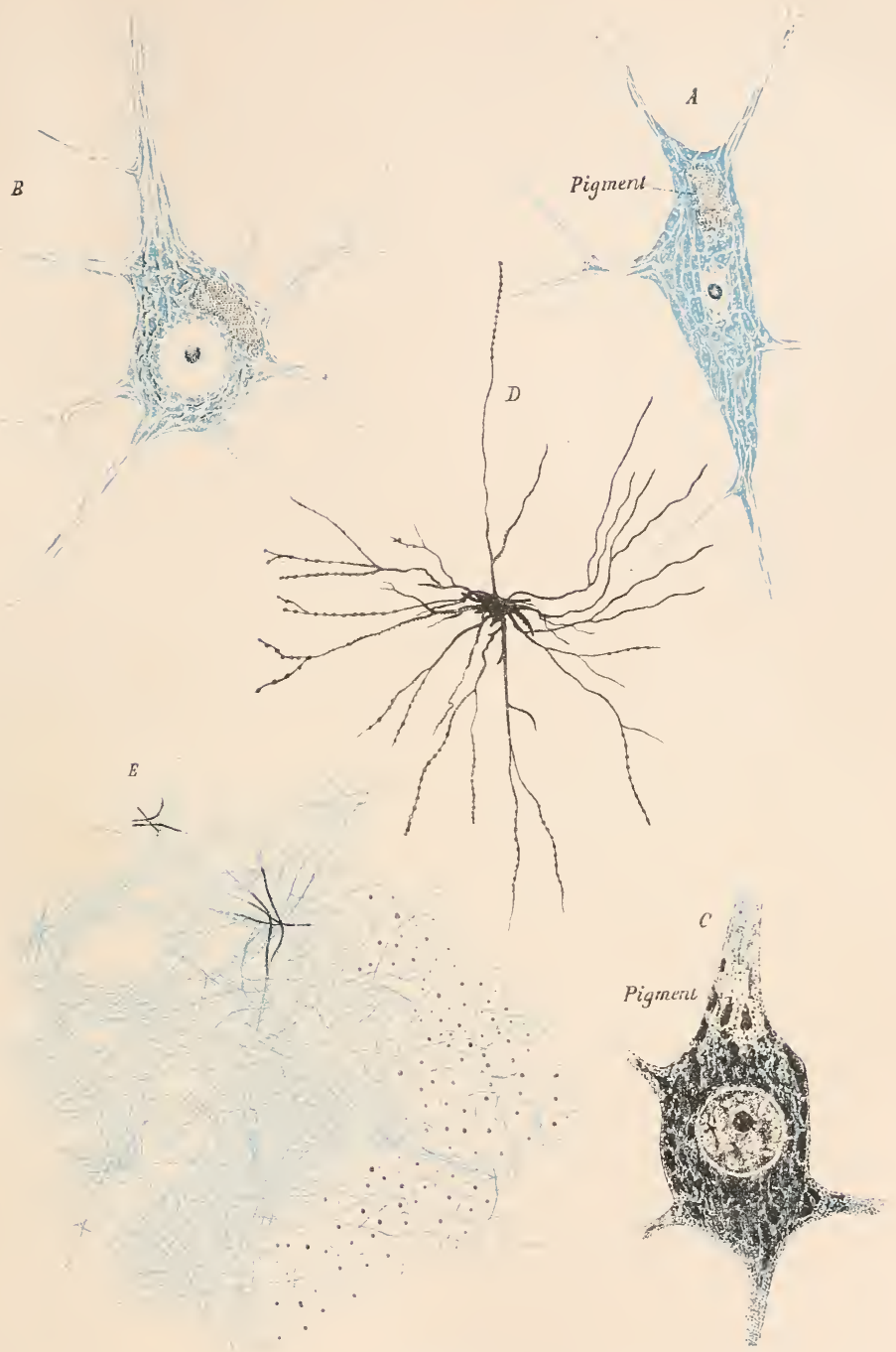

Fig. 6 .

$A$ und $B$ Zellen des Vorderhornes aus dem menschlichen Rückenmarke nach Originalpräparaten von Nissl. Fixirung in Alkohol, Färbung der Zellgranula durch Methylenblau. $C$ Gleiche Fixirung, Färbung mit Hämatoxylin zur Demonstration der Kernstructur. $D$ Ganglienzelle aus dem Vorderhorn von fötalen Hunde. Nach einem Originalpräparat von $\mathrm{Ram}$ on y Cajal gezeichnet. Silberniederschlag auf und in "der mit Chromosmiumsäure fixirten Zelle und ihren Ausläufern. Von den letzteren ist ein grosser Theil abgeschnitten, nur die Stümpfe sind in der Figur noch sichtbar. Der Reichthum an Ausläufern ist also grösser. $E$ Neuroglia an der Grenze von weisser und grauer Substanz. Nach einem Originalpräparat von C. W eig er t. Neurogliafasern blau, Axencylinder schwarz. 
führen Pigment von braungelber Farbe. In den beiden erwähnten Zellen ist seine Lage durch die schwarze Schraffirung angedeutet.

Aus den Ganglienzellen stammen die Nervenfasern. R. Wagner hat zuerst gezeigt, dass aus vielen dieser Zellen nur ein Fortsatz direct bis in den Nerv hinein verfolgt werden kann. und andere Forscher haben das bestätigt. Diesen Fortsatz bezeichnet man als "Ne u $\mathrm{rit}$ " auch als .Axencylinderfortsatz", oder als ,stammfortsatz". Was aus den Axencylindern wird, welche nicht in Nerven gehen. welche Rolle die anderen Fortsätze der Zelle, die „Protoplasmafortsätze“ oder „Dendriten" spielen, das blieb ganz dunkel, bis Gerlach $1 \varsigma 70$ angab. alle jene Fortsätze bildeten unter einander ein Netz, und diesem entstammten damn wieder Nervenfasern.

Im Laufe der letzten Jahre haben unsere Kenntnisse hier eine ganz ungeahnt grosse Erweiterung erfahren. Ermöglicht wurden diese durch die Fortschritte der listologischen und der farbenphysiologischen Technik. Es ist zuerst Bellonci durch Osmiumfärbungen, damn in noch überzeugenderer Weise Golgi durch Behandlung der Zellen mit Sublimatoder auch mit Silberniederschlägen gelungen, nachzuweisen, dass aus einigen Zellen die Axencylinder direct in Nervenfasern übergehen, dass aus anderen Zellen aber Axencylinder stammen, welche sich zu einem Netz verzweigen. An der Bildung dieses Netzes sollen auch Seitenzweige der Axencylinder theilnehmen, welche von den Zellen des erst geschilderten Typus stammen. Aus dem Nervennetz gingen dann, meinte Golgi, wieder Nervenfasern hervor. Es gäbe also eine doppelte Ursprungsart von Nervenfasern: eine directe, und eine erst durch ein Netz vermittelte. Die Dendritenfortsätze der Zellen sollten mit der Bildung von Nerrenfasern nichts $\mathrm{zu}$ thun haben. Ihnen falle vielmehr vielleicht eine ernährende Rolle zu.

Was Golgi aus zahlreichen, zum Theil sehr complicirten Bildern ron der Hirmrinde und dem Rückenmarke des Nenschen und der Säuger geschlossen hatte, das hat B. Haller, welcher an den Ganglien von Mollusken und Türmern arbeitete, wo die listologischen Verhältnisse sehr ïbersichtlich sind, direct zu sehen vermocht. Nach seiner Ansicht stammt aber jenes Netz aus den unter sich wesentlich gleichwerthigen Zellfortsätzen. Durch diese Arbeiten, ebenso durch Studien ron Nansen u. A. schien der Nachweis erbracht, dass es eine doppelte Ursprungsart von Nervenfaserm, eine directe und eine durch jenes Netz vermittelte, gebe.

Aber es hat sich bald gezeigt, dass diese schönen Funde nur den Weg zu anderen, viel weiter tragenden eröffnet hatten, dass sie nur einen Theil der Wahrheit enthielten. Ein spanischer Gelehrter. S. Ramon y Cajal, der mit der Golgi'schen Silbermethode arbeitete, hat in rascher Folge eine Anzahl von Arbeiten veröffentlicht, deren Resultate, durch Kölliker, Gehuchten, Waldeyer. Lenhosseck l. A. controlirt und erweitert, uns zu neuen Anschauungen hier führen. Noch stehen wir im Flusse der wechselnden Meinungen, täglich werden neue Beiträge zu der 
hier interessirenden Frage gebracht. Aber schon kömmen wir uns ein Bild machen, wie es um den feineren Zusammenhang der Elemente im Centralnervensysteme bestellt ist. Dies Bild, dass ich Ihnen gleich entwickeln werde, ist aber nicht allein gegründet auf die Resultate rein anatomischtechnischer Forschung. Nein, in der gleichen Zeit, wo uns histologische Präparate zu den nenen Anschauungen brachten, kam aus Gründen, welche die Entwicklungsgeschichte bot, $\mathrm{His}$, kamen nach Studien im Bereich der Pathologie Forel, dann auch Monakow zu einer Auffassung vom Lrsprung und Ende der Nervenbahnen, die sich fast deckt mit dem, was auf anatomischem Wege gefunden ist. Ja es ist schliesslich Retzius gelungen, an lebenden Nervenzellen bei vielen niederen Thierordnungen durch die vitale Methylenblaureaction Tieles zu demonstrieren, was sich dem aus Präparaten Erschlossenen g'ut eimreiht.

Im Laufe der Vorlesungen wird sich öfter Gelegenheit finden, Kenntniss von den Einzelfacten zu geben, auf welche sich die neue Erkenntniss aufbaut. Heute will ich Ihnen nur mittheilen, wie wir uns, gestiitzt auf von so verschiedenen Seiten zusammengebrachte Beweise, augenblicklich den histologischen Aufbau des Nervensystemes vorstellen dürfen.

Die Ganglienzellen entsenden gemeinhin zweierlei Fortsätze ron ihrem Körper: einen gleichmässig feineren Fortsatz, den Neurit oder Axencylinderfortsatz, welcher der Zelle zuerst entsprosst, und die dickeren, sich immer verzweigenden Dendriten oder Protoplasmafortsätze, welche entwicklungsgeschichtlich etwas später auftreten. Der Stammfortsatz endet, wie es scheint, immer in einer Verästelung. Man kann nun zweierlei Zellen unterscheiden: solche, bei denen der Fortsatz so kurz ist, dass jene Verästelung dicht an der Zelle liegt (s. Fig. $152 g$ ) und solche mit langhin verlaufendem Stammfortsatze (ebenda $d$ und $f$ ). Auf seinem zuweilen viele Centimeter langen Wege giebt ein solcher Fortsatz reichlichere oder spärlichere Seitenästchen, ,Collateralen", ab. Auch diese enden, wie der Fortsatz selbst. mit feiner Aufsplitterung. Wir wissen schon lange, dass der Axencylinder der Nervenfasern aus zahlreichen Einzelfäserchen gebildet ist. So hat es nichts Auffallendes, wenn wir jetzt erfahren, dass sich einzelne dieser Fäserchen während des Verlaufes abtrennen. Man hat natürlich nur sehr selten Gelegenheit, einen Axencylinder mit Sicherheit von seinem Ursprung bis zu seinem Ende zu verfolgen. Was aber bisher über die Endigung dieses wichtigen Zellfortsatzes bekannt geworden ist, was man gesehen und was man aus experimentell vorbereiteten Präparaten erschlossen hat, All das weist darauf hin, dass er wirklich frei an seinem Ende aufzweigt. Zieht er aus dem Centralorgan in die Peripherie, wie etwa in den W'uzehn der Rïckenmarksnerven, so verzweigt er sich im Muskel oder zwischen Epithelien (Motorische Endplatte und Plexus der Sinneskörper und der Oberhant). Aber die wenigsten Axencylinder gelangen zu peripheren Endorganen. Die allermeisten legen sich nach kurzem oder längerem Terlaufe an eine andere Nerrenzelle an, umfassen, umspinnen sie mit ihrer Endpinselung: Ist der 
Zellkörper nicht sehr gross, so hat er durch seine massenhaften Dendriten doch immer sehr reichliche Berührungsflächen, ist er aber sehr ausgedehnt, wie etwa in den Zellen der Spinalganglien, so bedarf der Dendriten weniger.

Die Dendritenfortsätze verzweigen sich nämlich zu mehr oder weniger reichlichem Astwerk, an dem noch durch Aufsitzen von kleinen gestielten Knö̈tchen - s. bei 1. Fig. 152 - eine Oberflächenvergrösserung eintreten kann. Ein Uebergehen von Dendritenfasern in periphere Nervenbahnen ist nicht nachgewiesen.

Ueber die physiologische Bedeutung dieser Fortsätze herrscht vielerlei Meinungsverschiedenheit. Nach eigenen Untersuchungen und nach Kenntnissnahme der von Anderen mitgetheilten Bilder scheint es mir am wahrscheinlichsten, dass sie diejenige Oberflächenvergrösserung der Ganglienzelle darstellen, welche durchaus erforderlich ist, um einen innigen Comnex mit den umspinnenden Fasern des aufgezweigten Stammfortsatzes zu sichern. Auf Fig. $152 a$ und 152 sehen Sie die Endausläufer der Simnesepithelien aus der Riechschleimhant, die Riechnerven, sich nach Durchwanderung der Siebplatte im Riechabschnitt des Gehirns auffasern. Thre Endbüschel umgreifen imnig die dicken Dendritenfasern aus dort liegenden Ganglienzellen. Hier haben sie den Zusammenhang zwischen Olfactoriusbahn erster Ordnung und den Zellen ror sich, aus denen sich die imnerhalb des Riechlappens verlaufende Riechbahn zweiter Ordnung entwickelt. Die Verbindung wird nur hergestellt durch die Beziehungen, in welche der Axencylinder einer Zelle zu den Dendriten einer anderen tritt.

Dendriten und Axencylinder gehen nicht immer an rerschiedenen Stellen vom Zellleib ab. Bei den Wirbelthieren kann man oft genug beobachten, dass die Zelle einen ganz wie ein Dendritenfortsatz aussehenden Zweig aussendet, dem nahe der Abgangsstelle der Axencylinder entsprosst. Bei vielen Tirbellosen ist dies Terhältniss geradezu die Regel. Beim Flusskrebs z. B. entsendet (Retzius) die birnförmig aussehende Zelle zumeist überhaupt nur einen dicken Stammfortsatz, aus dem sich lateral die Dendriten und weiter vorn der Axencylinder entwickeln (Fig. S). Hier scheint ein Terhältniss vorzuliegen, welches darauf hinweist, dass beide Ausläufer einer Ganglienzelle gar nicht etwas absolut und principiell Terschiedenes sind.

Die entwicklungsgeschichtliche Einheit: Ganglienzelle, Axencylinder, Aufsplitterung bezeichnet man als Neuron. Aus zahlreichen über einander gebauten Neuronen ist wahrscheinlich das ganze Nervensystem aufgebaut. - Die Mehrzahl dieser Neurone scheint isolirt dazustehen, mit benachbarten nur durch innigen Contact zusammenzuhängen, ein Contact, der die Uebertragung ron physiologischen Torgängen sehr wohl ermöglichen kamn. Rein morphologische Studien gestatten hier allerdings keine Entscheidung, das enorme Gewirr ron Fasern, welches an den meisten Stellen des Nervensystemes herrscht, die Unsicherheit unserer hentigen 
Methoden, lassen Trugschlüsse allzuleicht entstehen. aber die Erfahrungen der experimentellen Pathologie und der pathologischen Anatomie lehren überall, dass, wenn eine Ganglienzelle erkrankt oder verletzt wird, die Veränderungen sich zunächst nicht weiter fortpflanzen, als die Fortsätze eben jener Zelle reichen. Namentlich liess sich das an den Axencylindern der peripheren Nerven nachweisen, deren oft viele Centimeter langer Terlauf sehr wohl studirt werden kann. Sie sind in ihrem Bestande durchaus von dem normalen Bestand der Zellen abhängig, aus denen sie entspringen.

Diese Umstände sprechen also sehr dafür. dass jede einzelne Ganglienzelle ganz isolirt dasteht, sich nicht direct mit einer anderen verbindet. Es darf aber nicht unerwähnt bleiben, dass von gewissenhaften Beobachtern wiederholt Terbindungszüge zwischen einzelnen Zellen beschrieben worden sind.

Das sind die Grundthatsachen. Sie werden mit ihnen am besten bekannt, wenn Sie erfahren, was wir über den Ursprung und Terlauf einer einzelnen, besonders gut studirten Bahn. bereits wissen:

Viele motorische Nerven entstammen aus grossen Ganglienzellen, welche im Torderhorne des Rückenmarkes liegen. Aus diesen Zellen entspringt je ein Axencylinder. Der tritt aus dem Rückenmarke heraus als Wurzelfaser und dam in einen Nervenstamm ein. Da verläuft er weiter, bis er sich im Muskel zur .Endplatte" aufzweigt (Fig. 7).

Man bezeiclnet das Stïck der Innervationsbaln, welches von der Peripherie bis zur ersten Endigung im Centralorgan reicht, als B a hn e rster Ordnung. Diese Bahnen erster Ordnung, hier also der Abschnitt Vorderhorn, Nerv, Nuskelendigung, sind durch ihr eigenthümliches Verhalten bei Erkrankungen schon seit .Jahren von der Pathologie erschlossen und von den Bahnen höherer Ordnung getremnt worden.

Die Weiterleitung der nervösen Vorgänge erfolgt bei den Säugern in der Teise, dass sich an die Bahn erster Ordnung eine oder mehrere Bahnen zweiter, dritter u. s. w. Ordnung anschliessen. Alle bestehen aus dem Stück: Ganglienzelle, Axencylinder, Aufsplitterung. Kehren wir zum gewählten Beispiele zurück, so finden wir, dass sich um die reichen Dendriten, welche die Vorderhornzelle aussendet, eine Menge feiner Fäserchen verzweigen, Fäserchen, welche sie umfassen, ohne, so weit man bis jetzt weiss, sich direct mit ihnen zu verbinden. Diese Fasern sind zum Theil Collateralen aus einer Bahn, von der wir nach in der Pathologie gemachten Erfahrungen wissen, dass sie aus grossen Zellen in der Hirnrinde (Fig. 152f) abwärts durch das Gelirn und das Riickenmark verläuft. Diese Baln, welche also wieder bestelit aus den Abschnitten: Hirnzelle, absteigender Nerv, Collaterale, Aufsplitterung, ist geeignet die Terbindung zwischen der Endigung im Muskel und der Hirnrinde herzustellen; sie ist das centrale Stück des motorischen Innervationsweges, oder doch ein Theil dieses Weges. Dies nun ist die motorische Bahn zweiter Ordnung. Wie viele Bahnstücke zur Unterlage des ganzen motorischen Vorganges nothwendig sind, wissen wir noch nicht. Auf Fig. 152 
erkennen Sie. dass um die Dendriten der grossen Rindenzellen, aus denen die secundäre motorische Bahn stammt, sich verzweigte Axencylinder aus anderen Rindenzellen herumlegen. Das wäre z. B. eine Bahn höherer Ordnung. Tersuche mit künstlich gesetzten Entartungen werden uns hier weiter bringen können.

Die Arbeiten über die innere Structur der Ganglienzellen, deren Neubelebung wir wesentlich den Studien Nissl's rerdanken, haben noch nicht zu abschliessenden Resultaten geführt. Torwiegend weil die Bedeutung der feinen Zeichnungen noch nicht klar ist, welche in dem Inneren der Zellen nach Torbehandlung mit Sublimat, mit Alcohol etc. mond nachfolgender Färbung in basischen Anilinfarben auftreten; auch weil noch nicht absolut überall sicher gestellt ist wie weit

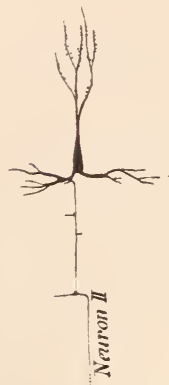
Einzelnes von diesen Zeichnungen auf dem Einfluss der Reagentien selbst beruht. Immerhin haben gerade Nissl's Studien, der den Nervenzellenkörper ganz besonders mit Alcohol zu fixiren räth, zu sehr wichtigen und bereits verwerthbaren Resultaten geführt. Im Zellleib aller Nervenzellen trifft man nach Fixirung in Alcohol eine Substanz. die sich mit Farbbasen tingirt und eine solche, die damit nicht färbbar ist. Die erstere tritt in verschiedenen Zellen, ja wahrscheinlich in verschiedenen Zuständen der gleichen Zelle, in verschiedenen Anordnungen auf. Man begegnet da Körnchen, Fäden und Spindeln, sowie noch mancherlei anderen

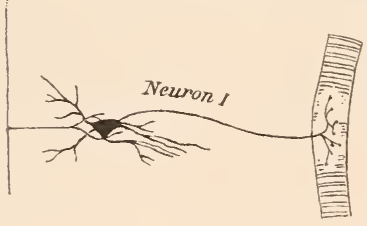

Fig. 7.

Schematische Darstellung des Verhaltens von Ganglienzelle und Nerv in einen Theile des motorischen Innervationsweges. regelmässigen und unregelmässigen gefärbten Gebilden, von denen nur einige durch Lage und Form heute schon besser charakterisirt sind (Kernkappen, Terzweigungskegel u. s. w.) Diese Anordnungen kömnen so verschieden sein, dass $\mathrm{N}$ is s 1 imnerhalb des Begriffes „Ganglienzelle" eine ganze Anzahl verschiedener Zellarten abscheiden komnte. Auch innerhalb des Kernes sollen nach diesem Autor bestimmte Differenzen rorkommen, die er denn auch bei der Zellunterscheidung mitbenutzt. Trifft irgend eine Schädigung die Ganglienzelle, sei es dass ein Gift eingreift, oder dass die Function eine ïbermässige ist, oder dass der Axencylinder abgetrennt wird, immer entstehen imnerhalb der färbbaren Substanz Veränderungen, die bei intensiver Schädigung zu fast völligem Verschwinden derselben führen können. Aber es ist, bleibt nur der Kern ungeschädigt, Restitutio in integrum wieder möglich.

Das Stadium dieser Zellveränderungen ist, wie Sie leicht einsehen, von der allergrössten Wichtigkeit. Eröffnet es uns doch endlich einen 
Einblick in die feineren Vorgänge während der Function selbst. Hier sind wir num ausser durch den vorgenannten Forscher, namentlich durch eine Reilıe schöner Arbeiten ron C. F. Hodge. über Genaueres unterrichtet worden. Hodge hat Nervenzellen verschiedener Art theils direct gereizt, theils von ihrem Axencylinder aus ermüdet, auch Zellen im Stadium der Ermiidung - Bienen nach der Tagesarbeit - untersucht und mit den ausgeruhten Zellen verglichen. Er fand, dass immer die färbbaren Körner u. s. w. abnahmen, dass die ermüdete Zelle sich lichtete, dass sich sogar Tacuolen in ihr bildeten. Dabei nimmt das Gesammtvolum ab. Ueber den letzteren Punkt besteht jedoch keine Uebereinstimmung. II ann, der unter Anderem anch die durch den Lichtreiz ermüdeten Zellen der Sehsphäre des Gehirnes mit ausgeruhten Zellen verglichen hat, fand, wie auch andere Autoren, die müden Zellen etwas angeschwollen. Diese Differenzen sind wohl in dem heutigen Stande der Technik noch bedingt. Töllige Uebereinstimmung herrscht jetzt schon über das Terhalten des Kernes bei der Ermüdung. Dieser nimmt immer an Grösse ab, wird zackig und färbt sich dunkler als ausgeruhter Kern.

Innerhalb der ungefärbten Substanz haben erst Untersuchungen der allerletzten Zeit (Becker, Flemming, Dogiel u. A.) eine feinfaserige Anordnung erkennen lassen. Danach sieht es aus, als würde jede der grösseren bis jezt untersuchten Zellen nach allen Richtungen von langen dünnen Fäden durchzogen, die mit den Fortsätzen ein- und austreten. Solche Fäden durchziehen ïbrigens nicht immer die ganze Zelle, sie gelangen zum Theil schon durch den Fortsatz wieder nach aussen, welcher ihrem Eintritt der nächstliegende ist. Becker hat das an den Zellen des Torderhornes demonstrirt. Erst die rerbesserte Methodik hat diese Fibrillen sicher gestellt, die vielleicht einmal bernfen sind. Unterlagen für die Erkenntniss der Function in den Ganglienzellen abzugeben. Schon vor langen Jahren aber hat Max Schultze auf sie aufmerksam gemacht.

Man sieht die Ganglienzellen und ihre Ausläufer als die Elemente an, welche die Function des Nervensystemes tragen. Schon bei sehr niedrig stehenden Thieren treten sie auf. isolirt und auch schon zu einzelnen Haufen - Ganglienknoten - angeordnet. Je nachdem diese Haufen vereinzelt peripher liegen oder in grösserer Menge und bestimmter Anordnung durch Nervenzüge unter einander verknïpft getroffen werden, spricht man von peripheren Ganglienknoten oder von einem Centralnervensystem. Im Allgemeinen erkennt man, dass in der Thierreihe eine Tendenz zum Zusammenfassen vieler Knoten in ein einziges Nervensystem besteht. Je höher man aufsteigt, um so mächtiger ist dieses, aber es erhalten sich bis hinauf zu den Tertebraten noch immer Theile des Nervensystems mehr oder weniger vom Centralorgan getrennt und von ihm functionell und anatomisch mehr oder weniger unabhängig. Ich werde Thnen bald am Beispiel der Sinnesepithelzellen darlegen. wie sich solche Gebilde allmählich nach dem Centralorgan hin verschieben können. Die Physiologie zeigt, wie nicht nur die in den Eingeweiden 
liegenden Einzelganglien noch relatir selbständig functioniren, sondern wie sogar Gebilde, die, wie die Spinalganglien, schon dem Centralorgan vielfach zugerechnet werden, sich noch einer relativen functionellen Unabhängigkeit von diesem erfrenen.

Ja, es drängt das, was wir rom anatomischen Aufbau und ron den Functionen des Centralnervensystems der Wirbelthiere wissen, mehr und mehr zu der Annahme, dass auch die einzelnen Theile des Centralorganes selbst im Stande sind, in gewissem Maasse noch selbständig zu functioniren, dass anch Gehirn und Rïckenmark der Wirbelthiere nur bestehen aus einer Reihe einzelner Centren. Das Maass, wie ron diesen das eine oder andere höher entwickelt ist, wie es mit den tieferen rerknüpft, und wie diese unter einander und mit höheren Centren functionell und anatomisch verbunden sind, macht die höhere oder niederere Ausbildung eines Centralorganes aus. Wir werden nachher sehen, dass sich im Verlaufe der Stammesentwicklnng einzelne der zum Centralorgan verbundenen Centren hoch entwickelt haben, während andere, auf einem gewissen Typus angelangt, stehen geblieben sind und sich durch die ganze Reihe hindurch ïberall gleichen.

Im Tesentlichen kamn man sich rorstellen, dass jedes Nervensystem aufgebaut ist aus zuleitenden und ableitenden Bahnen und aus solchen, welche Terbindungen der Einzelelemente unter einander herzustellen geeignet sind.

Einen guten Einblick in den Gesammtaufbau eines einzelnen Nervenknotens können Sie gewimnen. wenn Sie eimmal die folgende Abbildung. durchstudiren wollen. Sie stellt das ganze erste abdominale Ganglion des Bauchstranges rom Flusskrebse dar und gestattet bei der relativen Einfachheit aller Terhältnisse ein gutes Eindringen in alle Einzelheiten. Hier haben wir eine Art schema eines nerrösen Centralorganes und überblicken jedenfalls auf eimmal einen Mechanismus ganz, der zur Ausübung der Functionen eines Centralapparates geeignet ist.

Das Nerrensystem des Krebses besteht, wie das aller Gliederthiere, bekanntlich aus einer grossen Zahl einzehner Ganglienknoten, die durch längere und kïrzere Terbindungen zumeist unter sich geeint sind. Aus den rerschieden grossen Nervenzellen $d, e, f$ entspringt immer ein einziger mächtiger Stammfortsatz, der nach kurzem Terlaufe sich auftheilt in eine Faser, die in die Peripherie aus dem Ganglion heraustritt - Axencylinder - und eine solche, die, sich rasch aufzweigend, im Ganglion selbst bleibt. Der Axencylinder geht entweder - aus den Zellen $e$ - direct in einen Nerven hinein. - er ist hier wahrscheinlich motorischer Natur oder er tritt in den Strang, welcher das Ganglion mit den weiter rorn oder weiter rückwärts gelegenen anderen Ganglien verbindet, - so alle Fortsätze aus den ganz grossen Zellen. Die Verbindung kann gleichseitig und gekreuzt sein. So ist der Auslänfer der oberen Zelle $f$ gleichseitig. derjenige der unteren gekrenzt im Verlaufe. Ton dem Stammfortsatz gehen die Dendriten ab, hinein in die Substanz des Ganglions. Sie sind in ihrer 


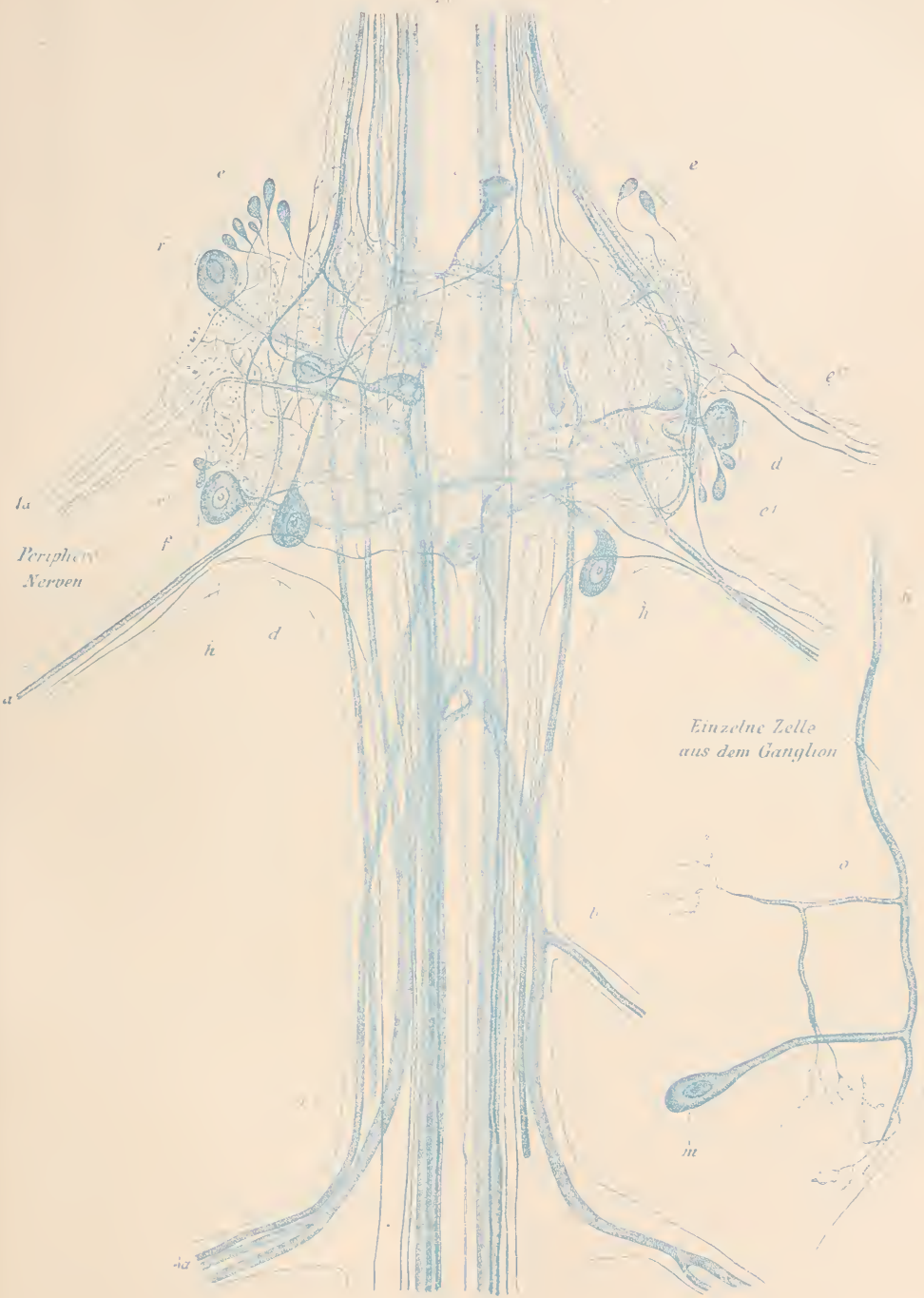

Fig. $S$.

Das erste abdominale Ganglion des Bauchstranges von Astacus fluriatilis. Färbung des lebenden Gewebes durch Methylenblau. Nur die nervösen Bestandtheile färben sich. Erklärung im Texte. Die dicken medialen Fasern $R f$ sind ihrer näheren Bedeutung nach noch nicht erkannt. Nach Retzius. 
feinen Aufzweigung wohl geeignet, die Einzelelemente des ganzen Ganglions unter einander zu verknüpfen. In das feine knotige Flechtwerk, welches sie bilden, tauchen Nervenfasem ein, die entweder von der Peripherie kommen - sensible Nerven? $2 a$ - oder aus anderen Ganglien stammen, $l, i$, oben. Wenn Sie nun einmal den abgehenden Nerven, etwa den mit $2 a$ bezeichneten, betrachten wollen, so sehen Sie, dass er Fasern enthält, die in das Ganglion münden und solche, die von anderen Ganglien der gleichen und der gekreuzten Seite stammen. Wie riele Möglichkeiten der Association sind schon in diesem einfachen Knoten gegeben!

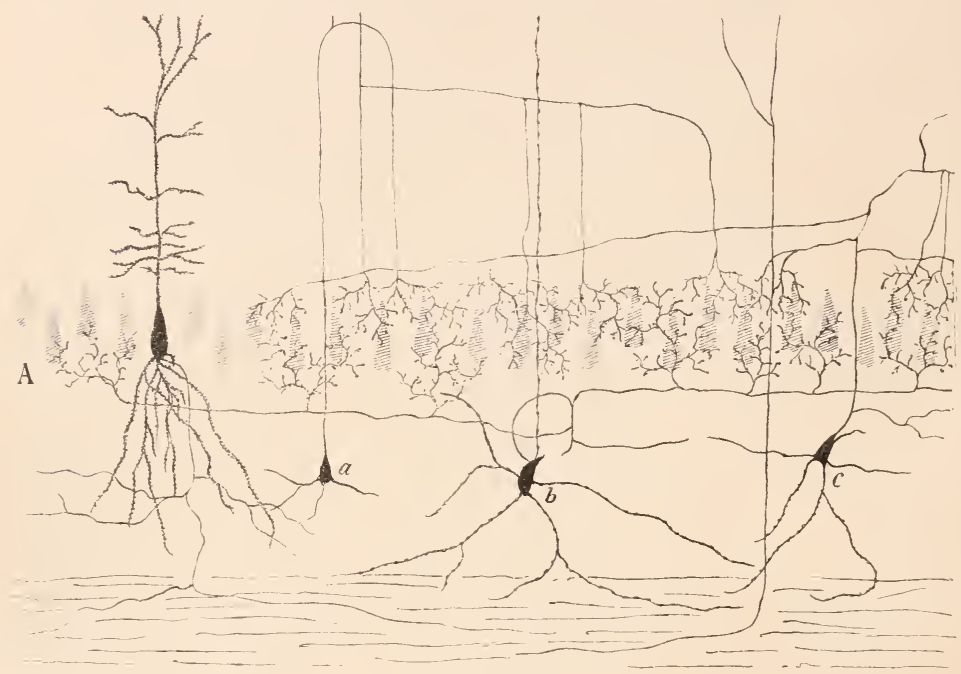

Fig. 9.

Aus der Ammonsrinde des Kaninchens, combinirt nach Präparaten von S. R. y Cajal. $a b c$ Associationszellen. Ihr langer Axencylinderfortsatz spaltet sich zu moosförmigen Reisern auf, welche in die Schicht der Pyramidenzellen $A$ eindringen. Links aussen eine einzelne vollgezeichnete Pyramidenzelle. Sie tritt durch ihren nach unten abgehenden Axencylinder mit dem Nark des Gehirnes und durch ihre nach oben strebenden Dendriten wieder mit anderen Faser - und Zellensystemen nicht abgebildet - in Beziehung. Zu diesen mannigfachen Verbindungen kommt dann noch dio

durch die moosförmigen Fortsätze gegebene Association vieler PyramidenzeIlen unter einandor.

Jede Zelle und jede Faser kamn durch die reiche Endverzweigung zu unzählig vielen anderen Zellen und Fasern in irgend eine Beziehung treten. Ausserdem stehen die meisten in Contactzusammenhang mit Zügen aus entfernter liegenden Centren und viele auch mit der Peripherie.

Es giebt übrigens anch - wenigstens ist das für die Wirbelthiere aller Klassen bereits nachgewiesen - Zellen, welche in gar keiner directen Beziehung zur Aussenwelt stehen und nur geeignet sind, das Territorium einer centralen Zelle mit dem einer anderen in inniger Weise zu verknüpfen, Associationszellen. Solche Zellen sind ungemein weit ver- 
breitet. Nirgend aber wird ihre Bedeutung rascher klar als im Ammonshorne, einer Abtheilung der Riechrinde. Ich lege Thnen hier in Fig. 9 einen Schnitt durch diesen Rindenantheil vor.

Unter der Schicht grosser pyramidenartiger Zellen, welche die Hauptzellage dieses Gebietes bilden, erblicken Sie kleinere Zellen, welche ihren Axencylinder nahe an die Pyramiden oder auch durch sie hindurch senden. Dann aber löst er sich in feine Queräste auf und aus diesen dringen von unten und von oben mächtige Endbüschel zwischen die grossen Zellen hinein. Diese Endbäumchen sind also wohl geeignet, die Elemente der Schicht, wo sie enden, unter einander zu verknïpfen.

Die Nervenfasern im Gehirn und Rückenmark sind von sehr wechselnder Breite und bei reifen Säugeru wahrscheinlich alle mit Markscheiden umgeben.

A

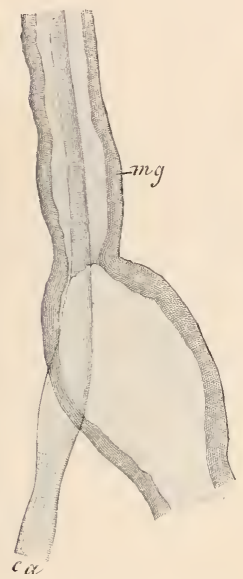

B

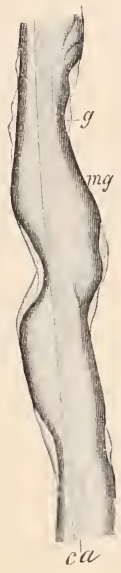

C

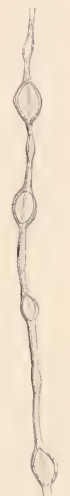

Fig. 10.

Nach Ranvier. Verschiedene Nervenfasern isolirt aus dem Rückenmarke des Hundes; ca Axencylinder, $m g$ Markscheide, $g$ peripherische Hülle, $c$ Kern und Protoplasma an der Oberfläche einiger weniger Fasern zu sehen.

Jede Nervenfaser verliert da, wo sie in das Centralorgan eintritt, ihre Schwa nn'sche Scheide. Nur eine dünne, zuerst von Ranvier gesehene, schon im peripheren Nerven vorhandene Schicht bedeckt innerhalb des Gehirns und Rückenmarkes das Nervenmark.

Das also sind die Elemente, aus denen sich das Centralnervensystem aufbaut.

Im Allgemeinen erscheinen die Theile, welche wesentlich nur aus markhaltigen Nervenfasern bestehen, weiss (weisse Substanz), diejenigen, in welchen die Neuroglia, die Ganglienzellen und Axencylinder vorherrschen, grau (graue Substanz). Die graue Substanz ist gefässreicher als die weisse. 
Die ersten genaneren Kemntnisse ron der Gewebelehre des Centrahnerrensystems verdanken wir, wie schon in der ersten Torlesung erwähnt wurde, Eh renber $g$, Remak und Hannorer. Tach Hannover hat dam Helmholtz 1542 zuerst bei Tirirbellosen die Beziehungen ron Nervenfaser und Ganglienzelle zn einander richtig gesehen, 1544 entdeckte $\mathrm{K}$ öll iker, dass ans einer Zelle eine doppeltcontourirte Faser stammen könne. Dass aus den Ganglienzellen zweierlei Fortsätze entspringen, von denen nur einer, der Axencylinderfortsatz, in den Nerven gelangt, hat $1550 \mathrm{R}$ udolf $\mathrm{IV}$ a $\mathrm{g}$ e e am elektrischen Organ des Zitterrochens gefunden, und $\mathrm{R}$ e ma k hat es 15.54 für die grossen Ganglienzellen des Rückenmarkes bestätigt. Dass hier ein allgemein für die Ganglienzellen gültiges Verhalten vorliegt, das hat dann 1565 Deiters bewiesen. Durch die Arbeiten ron Gerlach, I ax Schultze, Traldeyer, Jolly, A. Key und G. Retzius, Betz, Beran Lewis, Obersteiner, Frend nnd rielen Anderen wurde das gewonnene Wissen rertieft. Im Texte ist bereits derer gedacht, denen wir die wichtigsten Fortschritte in nenester Zeit verdanken. So Tiele haben diesem schwierigsten Kapitel der Histologie ihr Interesse und ihre Arbeitskraft gewidmet, dass ein Anfang 1s57 erschienenes Terzeichniss (Nansen) bereits 341 Arbeiten ïber Nerrenfasern und Ganglienzellen anfzählen kann. Nenere grumdlegende Arbeiten über das Stiitzgewebe stammen ron Boll, Ranvier, Gierke, Vignal, His, Lenhosseck und TV eigert. Der Letztere hat eine Färbemethode erfunden, welche gestattet, diese Gewebsart isolirt zu fürben. So war es ihm zuerst möglich, die bereits bekannten Funde ganz sicher zu stellen und durch nene wichtige zu rermehren.

\section{Dritte Vorlesung.}

\section{Centralorgan und periphere Nerven. Physiologisches.}

I. H.! Tachdem Sie in der vorigen Stunde die Ganglienzelle und die Art, wie sie sich mit anderen Ganglienzellen zu kleinen oder grösseren Complexen verbindet, kennen gelernt haben, erscheint die Frage zunächst als wichtigste, was über die Bedeutung dieser Zellen in physiologischer Beziehung bekannt ist.

Wir wissen zunächst, dass ein motorischer Nerv functionsuntähig wird, wenn er von seiner Ursprungszelle getrennt ist, und wissen auch, dass Zerstörung des Graues, in dem sensible Fasern enden, deren Function völlig aufhebt. Wir wissen ferner, dass wir durch Reizung der Zellen, in denen ein Nerv endet, alle Erscheinungen erzeugen können, welche gewöhnlich bei der Function des Nerven sichtbar werden. Das allein hat zu dem Schlusse geführt, dass in den Ganglienzellen und den Terbindungen, Welche sie unter einander eingehen, die Unterlage für die Nerventhätigkeit gegeben ist. Zahlreiche Versuche haben dann gezeigt, dass ein sensibler Eindruck, der, von der Peripherie herkommend, in das Centralorgan eintritt, dort liegende Ursprungszellen von motorischen Fasern anregen, ihre Endpunkte, die Muskeln, zur Thätigkeit bringen kann. Nan bezeichnet bekanntlich diesen Torgang als Reflex. Die Untersuchung solcher Reflexe hat dann zu dem weiteren sehr interessanten Resultate geführt, dass der: sensible Reiz nicht unmittelbar den motorischen Torgang auslösen muss, dass vielmehr eine gewisse Intensität des ersten Reizes nöthig ist. aber dass auch ein schwacher Reiz, wemn er eine Zeit lang anhält, schliesslich den motorischen Apparat beeinflussen kann. Man nimmt an, dass die Ganglienzellen geeignet sind, Reize, die ihnen zukommen, eine Zeit lang aufzuspeichern, zurückzuhalten, bis dann zu grosse Reizhöhe oder ein ron anderer stelle 
her neu eintretender Reiz sie zu plötzlicher Entladung bringen kann.

Der kleine Nerrenknoten rom Kirebse, den ich Ihnen in der letzten Vorlesung gezeigt habe, empfängt reichlich Fasern aus der Peripherie und entsendet aus den grossen Zellen, welche in ihm liegen, mächtige

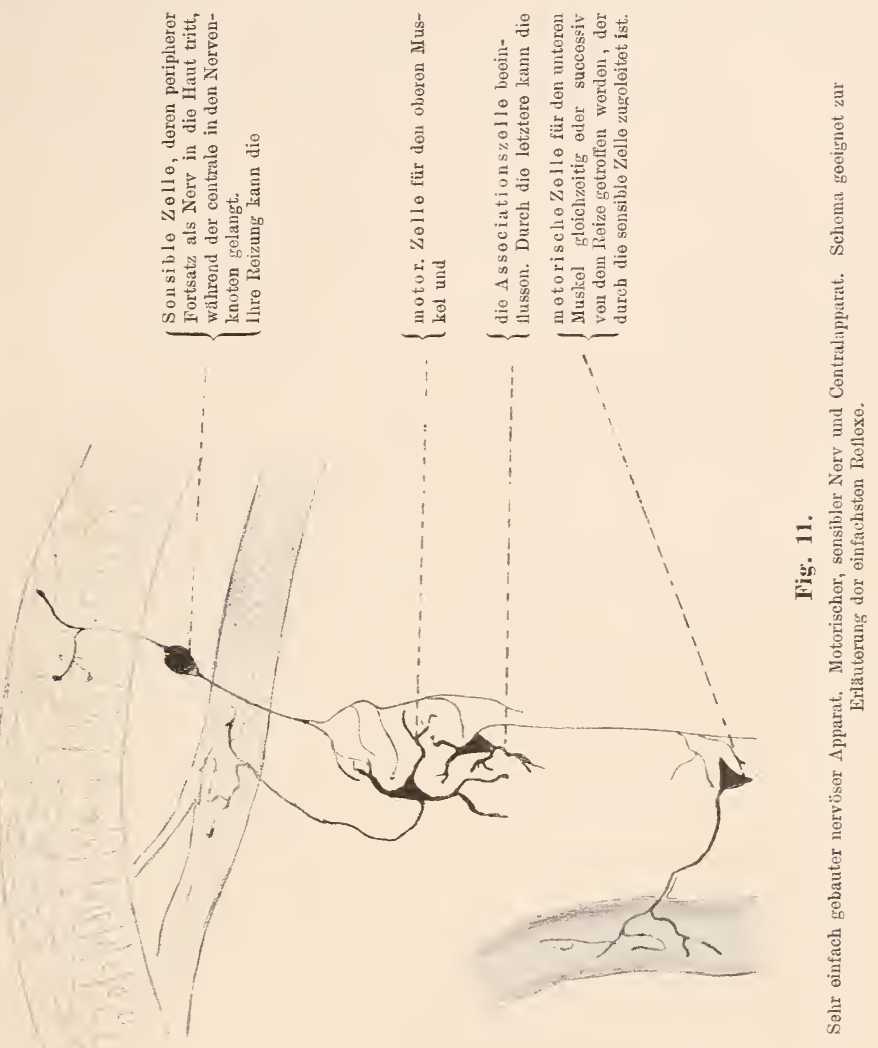

Bahnen in die Muskeln. Ein Blick auf ihn und auch auf obige Figur 1, zeigt Thnen nun schon, dass ein etwa anlangender Reiz keineswegs nur eine einzige Zelle trifft, dass vielmehr ein Eindruck, welcher nur von einer Stelle der Peripherie durch eine einzige Faser dem Centralorgan zugeführt wird, dorten einen ganzen Complex von motorischen Zellen zu "laden" vermag. Die Entladung wird desshalb auch zumeist nicht etwa 
nur eine motorische Faser erregen, sondern je nach der anatomischen Terknüpfung der motorischen Zellen immer gleich einen ganzen Complex ron MIuskelfasern zur Contraction bringen. So erklärt es sich - Exnerwie ein einziger sensibler Reiz zu einer complicirten Bewegung, an der viele Muskeln sich betheiligen können, führt. Was für ein motorischer Erfolg auf einen sensiblen Reiz eintritt, das hängt ab von der Categorie ron Gefühlsnerven, welche erregt sind und ganz besonders von der Terknüpfung der Zellen, welche an der Eintrittsstelle den motorischen Apparat bilden. Sehr Tieles spricht dafür, dass solche Verknüpfungen im Laufe der Stammesentwicklung einmal erworben, weiter vererbt werden, dass also der Bau eines einzelnen Nervenknotens im Tresentlichen der Gleiche für jedes Individuum ist. und dass durch diese angeborene Anlage zahlreiche uns complicirt erscheinende Actionen ein für allemal begründet sind. Aber es giebt Erfahrungen, welche lehren, dass in bestimmten Theilen des Nervenaparates immer neue Terknüpungen durch die Einübung hergestellt werden können. Das Centralnerrensystem zerfiele danach in einen Theil, der angeboren wohl ältester Einübung entstammt und in andere Theile, die erst durch Uebung während des Einzellebens ihre Terbindungen bekommen.

Angeborene Mechanismen sind wohl in allen Theilen des Nervensystemes zu finden, doch zeigt die Beobachtung der Bewegungen ron Embryonen und Neugeborenen, dass mindestens im Bereiche des regetativen Functionen dienenden Apparates, im Sympathicus also und im grossen Gebiete des Rückenmarkes und der Oblongata solche die vorherrschenden sind. Wahrscheinlich kommt hierzu noch ein guter Theil des Mittelhirnes und des Kleinhirnes. Die rergleichende Anatomie lehrt, dass bis hinauf zu den Primaten die vor diesen Hirntheilen liegenden Apparate noch ständig grosser Variationen fähig sind und es zeigt speciell die Beobachtung der Hirmrinde in ihrem individuellen Ausbau, dass hier noch für das Einzelindividum durch Einübung nene Bahnen ständig geschaffen werden.

Soweit rein motorische Effecte als Resultat der Reizungen in Betracht kommen, bezeichnet man den hierzu nöthigen Apparat als Bewegungscombination. Das Wort ist ron Exner gemünt, dem wir eine treffliche Durcharbeitung vieler hierher gehörigen Momente rerdanken. Sie dürfen sich nun aber solche Combinationen ron Ganglienzellen zu gemeinsamer Action nicht als gar zu einfach vorstellen. Die allermeisten Bewregungen bedürfen zu ihrem Ablauf eine längere Zeit, während welcher mehrfach andere Muskeln als die Anfangs in Action getretenen eingreifen können. Es muss desshalb Bahnen geben, die ron einer Combination ron Zellen zu einer zweiten führen, und die erst dann vom Reize beschritten werden, wenn die erste Action vollendet ist.

solche Torgänge wird man mit Exner zweckmässig als successive Bewegungscombinationen bezeichnen. E. hat sie aus physio- 
logischen Beobachtungen geistvoll erschlossen, man kann aber, wenn man das Nervensystem der Evertebraten durchmustert, leicht anatomische Anordnungen finden, die, einmal von einem Reize getroffen, successive Bewegungen in völlig geordneter Weise anslösen können.

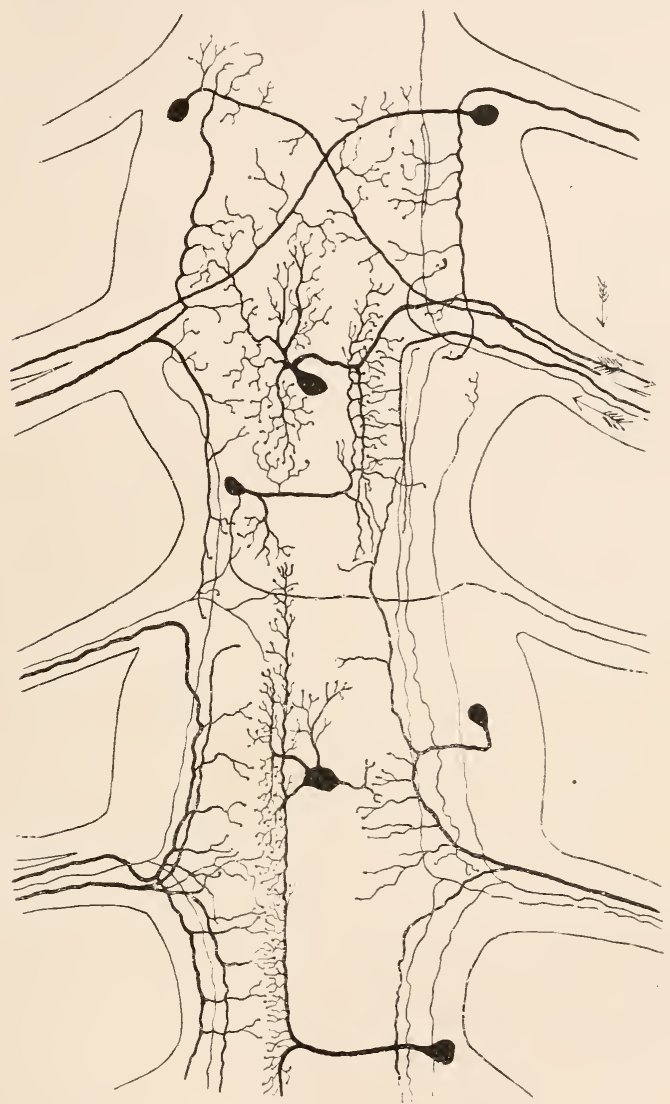

Fig. 12.

Einige Ganglien aus dem Bauchstrange des Regenwurmes, Lumbricus terestris, nach Retzi us - zur Demonstration der Grundlagen von successiven Bewegungscombinationen.

Speciell das Nervensystem der Ringelwürmer, des Regenwurmes z. B., das wir durch die schönen Untersuchungen von Retzius gut kemnen, zeigt, wie durch eintretende sensible Fasern zunächst ein einzelner motorischer Knoten in Thätigkeit versetzt werdeu, und wie dann durch Fortsätze 
grosser Associationszellen die Reizung sich auf das nächste Ganglion übertragen kann. Ausserdem enthält jedes Ganglion noch motorische Zellen, deren Axencylinder nicht zu den Nerven des betreffenden Metameres zieht. sondern erst in Muskeln endet, die weiter vorn und in solchen, die weiter rückwärts liegen. so vermag ein Eindruck, welcher an irgend einem Theile der Körperoberfläche das Thier trifft, zunächst die Muskeln dieses Theiles, dam aber auch diejenigen von weiter rorn oder weiter hinten liegenden Metameren in Thätigkeit zu bringen. Tem eine solche successive Bewegung einmal eingetreten ist, dann wird sie noch durch ein anderes MIoment unterhalten und regulirt. Es ändern sich nämlich mit der veränderten Stellung der Muskeln und Glieder auch die sensiblen Eindrïcke, die sie empfangen. Bleiben wir bei dem einmal gewählten Beispiele rom Regenwurme. Die Muskeln des ersten Metameres ziehen sich bei der Berührung der Tastapparate zusammen, vielleicht auch die des nächsten. Nun aber kommen eben durch diese Contraction wieder andere Theile der Haut in Berührumg mit der Unterfläche, neue Reize werden in anderen Ganglien ausgelöst, es kann sich die Contraction so successiv auf weitere ILtamere ausdehnen, kurz es kann ein Reiz, der an einer einzigen stelle eingreift, passende Coordination der Bewegungen rorausgesetzt, das ganze Thier auf rein reflectorischem Trege zur Bewegung, zum Kriechen bringen. Ja dies Fortkriechen kann den Eindruck der äussersten Zweckmässigkeit im Verhältniss zum Reize machen. Legt man einen Seeigel auf den Rïcken, so fasst er sofort mit den langen Saugfüssen, die seinen ganzen Körper bedecken, an der Unterlage Fuss. Jedes Fiisschen aber contrahirt sich in dem Augenblicke, wo es mit dem Boden in Berïhrung kommt. Das etwa einem Ei gleichende Thier wird dadurch zunächst kräftig an die Unterlage angezogen. Nun aber beginnt ein merkwürdiges Spiel, das Romanes und Ew art uns schön beschrieben haben. An einer Stelle contrahiren sich die Fïsschen etwas fester, vielleicht ist's Zufall an welcher. Sofort verlieren die entgegengesetzten ihren Halt, lassen los, das Thier neigt sich nach der Seite, wo die stärkere Contraction stattfand. Natürlich kommen dadurch neue Saugfüsse eben dort mit der Unterlage in Berïhrung, die contrahiren sich wieder und das geht so fort, bis der Seeigel ganz aufrecht auf der Kante steht; auch nun hört die Bewegung nicht auf, denn immer neue Pedicillen fassen ja Fuss und das geht so fort, bis das ganze Thier mongedreht wieder in normaler Lage ist. Hier haben wir eine sehr zweckmässige, anscheinend nur durch besonders feine Ueberlegung ausführbare Bewegung gesehen, die sich auf ganz einfache Reflexvorgänge zurückführen lässt, auf die Contraction, die in den Muskeln der Pedicillen eintritt, wenn ihre sensiblen Nerven erregt werden. Dass die Bewegung aber eine wohlgeordnete ist, dazu bedarf es doch einer Verbindung der Pedicillarnerven unter einander. Aber bei diesem einfachen Versuche tritt schon ein neves Moment auf, das bisher noch nicht als Eigenschaft des Centralapparates hier erwähnt wurde, das ist das Auf- 
hören der Bewegung, wenn einmal die Ruhelage des Thieres erreicht ist. Hier muss rom Centrum aus eine "Hemmung" eintreten, denn es wäre sonst nicht abzusehen, warum der Seeigel sich nicht weiter bis zur Erschöpfung drehen sollte, da ja immer neue Saugfüsse auch bei der Normallage in Berührung mit der Unterfläche gerathen. In der That ist es als eine Eigenschaft der Nervenknoten überall erkannt, dass sie im Stande sind, nicht nur Bewegungen hervorzurufen, sondern auch solche zu hemmen. Der Mechanismus ist noch nicht klar. Zweifellos können solche Hemmungen ganz ebenso wie die Bewegungen sich weithin von dem zuerst irritirten Ganglion anf andere erstrecken.

Es wäre sehr verlockend, von diesen Grundbegriffen aus nun weiter die Torgänge in einem bestimmten Theile des Nervensystemes, oder Dasjenige zu verfolgen, was etwa bei einer bestimmten complicirteren Action sich in Inneren des Gesammtapparates abspielt. Ich muss aber hier, wo es mir nur darauf ankommt, zu zeigen, wie einfach sich die primitivsten Nervenverrichtungen auf die anatomischen Verhältnisse zurückführen lassen, darauf verzichten, diesen vielfach in ganz Unsicheres noch führenden Weg mit Ihnen zu gehen.

Als einfachsten Centralapparat können wir denjenigen ansehen, welcher sich aufbaut aus zuführenden sensiblen und abführenden motorischen Fasern, wobei angenommen wird, dass die Enden des sensiblen Terven sich irgendwie direct oder auch durch Vermittlung einer zweiten Zelle, an die Ursprungszelle des motorischen Nerven anlegen. Solche einfachen Complexe finden wir weit verbreitet bei den wirbellosen Thieren und auch im Körper der Wirbelthiere. Sie liegen theils in den sympathischen Knoten, theils sind sie als directe Reflexbahnen in den Gesammtapparat des Centralnervensystems einbezogen. Absolut isolirte einfache Reflexcentren sind noch nicht bekannt, immer hängen auch die kleinsten wieder mit anderen ähnlichen zusammen. Einen solchen Knnoten stellt z. B. Fig. 11 dar. Aber alle sind doch nur bis zu gewissem Grade von einander abhängig und für einen grossen Theil ihrer Function völlig selbständig. Um ein Beispiel für solche isolirte Reflexthätigkeit zu geben, erinnere ich an die Bewegungen, welche die Muskulatur eines ausgeschnittenen Darmstückes in völliger Regelmässigkeit ausführt, wenn ihr von der Darmschleimhaut her sensible Reize zugeführt werden. Der Einfluss, den auf diesen kurzen Reflexbogen weiter gespannte Bogen, solche die durch die Sympathicusganglien gehen und solche, welche die Rückenmarkswurzeln passiren, nehmen können, ist bekannt; das sind eben neue Nemrone, die sich an die intestinalen anlagern, sie beeinflussen, instigiren und hemmen können.

\section{Die peripheren Nerven.}

Es war nun so viel von der sensiblen Zuleitung, von dem Abgehen von motorischen Bahnen die Rede, dass wir diesen peripheren Theilen 
des Nerrensystemes nun unsere Anfmerksamkeit schenken müssen. Alle Untersuchungen an Wirbelthieren haben gezeigt, dass die motorischen Nerren grossen Ganglienzellen entstammen, welche ihren Axencylinder in einen Muskel hinein senden, wo er aufsplitternd endet. Alles, was bisher an Wirbellosen beobachtet ist, weist daraur hin, dass dort das gleiche Verhältniss verliegt. Andererseits hat man bei Wirbellosen ganz direct beobachten können. wie aus Zellen in der Hant stammende Nerrenfasern, also sensible Bahnen hinein in das Centralorgan zogen, wo sie frei endeten. Wir rerdanken für die Tertebraten speciell His sehr schöne Untersuchungen über diese Dinge. Bei den Wirbelthierembryonen bildet das Centralnervensystem bekanntlich in früher Entwicklungszeit

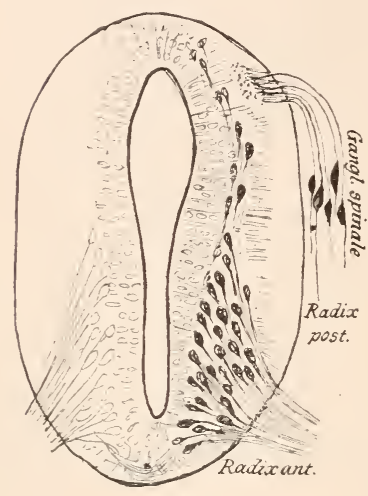

Fig. 13.

Rückenmarkdurchschnitt einer menschlichen Frucht aus der 4. Woche. Man sieht ventral die motorische Wurzel sich aus Zellen des Markes entwickeln. Dorsal wächst - nach einer Frucht von $4 \frac{1}{2}$ Wochen - die sensible Wurzel aus Zellen des Spinalganglions ein. Combinirt aus Abbildungen von $\mathrm{H}$ is. eine hohle Röhre. His komnte nun nachweisen, dass die in den peripheren Nerren enthaltenen Fasern zwei ganz verschiedene Ursprungsarten haben. Alle motorischen Wrureln entstehen als Axencylinderfortsätze ron im ventralen Theil des Nervenrohres liegenden Zellen. Jede Zelle sendet ein Fäserchen aus, das an die Oberfläche tritt und dort sich mit den Nachbarfasern zur Bildung eines ventralen Wurzelbündels vereint. Die sensorischen Wrurzelfasern. die zumeist dorsal abgehen, haben eine ganz andere Herkunft. Sie entstehen nämlich nicht im Centralorgan, sondern ausserhalb desselben, in den Ganglien, welche, neben diesem liegend, es auf seiner ganzen Länge begleiten. Die Zellen dieser Ganglien (Spinalganglien und Ganglien der Hirnnerven) wachsen nach zwei Seiten zu Fasern aus. Eine dieser

Fasern tritt in das Centralorgan ein, die andere wächst als sensorischer Nerv nach der Peripherie.

Bei den Wirbelthieren liegen die Trsprungszellen der meisten motorischen Nerven, namentlich aller derjenigen, welche quergestreifte Muskulatur imnerviren, im Centralorgan. Wir haben ihrer schon in der rorigen Torlesung gedacht, weil sie uns da ein gutes Beispiel abgaben für die Superposition rerschiedener Neurone.

Aber nicht alle motorischen Nerven entstammen der gleichen Stätte. Es giebt überall im Körper zerstreut liegende Ganglienzellen, deren Neuriten in glatten Muskelfasern der Gefässe, des Darmes, des Herzens und anderer Eingeweide enden. Diese gewöhnlich dem Sympathicus zugerech- 
neten Zellen müssen, weil an ihre normale Existenz die Fähigkeit zu Eigenbewegungen der betreffenden Organe geknüpft ist, auch als motorische Ganglienzellen angesehen werden. Sie liegen an vielen Stellen - in der Darmwand z. B. und im Herzen in relativ innigem Contacte mit anderen Neuriten, die von anderen Stellen, aus dem Grenzstrange etwa, aus dem Rückenmark u. s. w. stammen. Auch hier also, im sympathicus, giebt es motorische Bahnen verschiedener Ordnung. Wir haben vorhin erfahren, dass bei den säugern ein guter Theil der secundären motorischen Bahnen bis zum Organe des Bewusstseins irgendwie vordringt. Das ist nun nicht für alle diese Bahnen der Fall. Man stellt sich viel zweckmässiger zunächst die motorischen Centren, die centralen und natürlich erst recht die peripheren sympathischen als selbständig wirkungsfähige vor und untersucht für jeden einzelnen Fall, wie weit höhere Nervenbahnen sich zllgesellen, wie weit höhere Nervencentren eine Einwirkung ausüben können. Bei den Säugern sind ja alle quergestreiften Muskeln rom Centralorgane her innervirt, und nur die glatten, sowie die Herzmusknlatur erfreuen sich einer gewissen Unabhängigkeit von demselben; bei den niederen Thieren aber liegen vielfach auch Ganglienzellen für willkürlich bewegte Muskeln in der Peripherie.

Die sensiblen Nerven der Tertebraten sind zum grössten Theile Ausläufer von Zellen der spinalganglien. Auch sie splittern sich, an der Peripherie angekommen, auf, entweder frei im Epithel, oder zwischen modificirten, meist epithelialen Gebilden, Endapparaten. Für die sensiblen Nerven ist aber ausser der Ontogenie auch einiges von grossem Interesse aus der Phylogenie bekanut gerorden.

Bekanntlich weist die äussere Bedeckung schon sehr wenig entwickelter Thiere, der Cölentheraten z. B., mitten unter den gewöhnlichen Epithelzellen solche auf, welche durch ihre Anordnung zu bestimmten Gruppen und durch den Besitz eines längeren Endfadens, der sich in das Nervensystem einsenkt, sich auszeichnen. Es ist nun in der ganzen Reihe der niederen Thiere ein sehr häufiges Torkommniss, dass im Ectoderm liegende Zellen durch solche Fasern mit dem benachbarten Nervenknoten verbunden sind. Spricht ihre Lage in der Epidermis schon dafür, dass es sich um Antheile des sensorischen Apparates hier handelt, so wird die Termuthung zur Sicherheit, wenn man erkennt, wie vielfach diese Zellen zu Gebilden in Beziehung stehen, welche besondere Reize aufzunehmen geeignet sind. Lange starre Haare, schwingende Borsten, aufgesetzte sitifte scheinen Tasteindrïcke leicht ïbermitteln zu können, während wir ganz analoge Zellen zur Hohlkngelwand da geordnet sehen, wo ein Steinchen, ein Otholith im Inneren der Kugel schwingend, den sinnesapparat für das Gleichgewicht darstellt. Linsenförmige Theile des Ectoderm liegen an anderen Stellen vor ebensolchen Zellen, wohl geeigntet Licht oder Wärmestrahlen diesen in besonderer Weise zu übermitteln. Es ist hier ja nicht möglich eine Schilderung all der mannigfachen Eimrichtungen zu geben, welche bei den Wirbellosen als Simnesapparate fungiren, nur 
das soll hervorgehoben werden, dass ron der einfachen Epithelzelle des Ectodermes bis zu hoch differencirten Apparaten alle Uebergangsformen gefunden werden und dass auch bei den höchsten der gleiche Typus, die

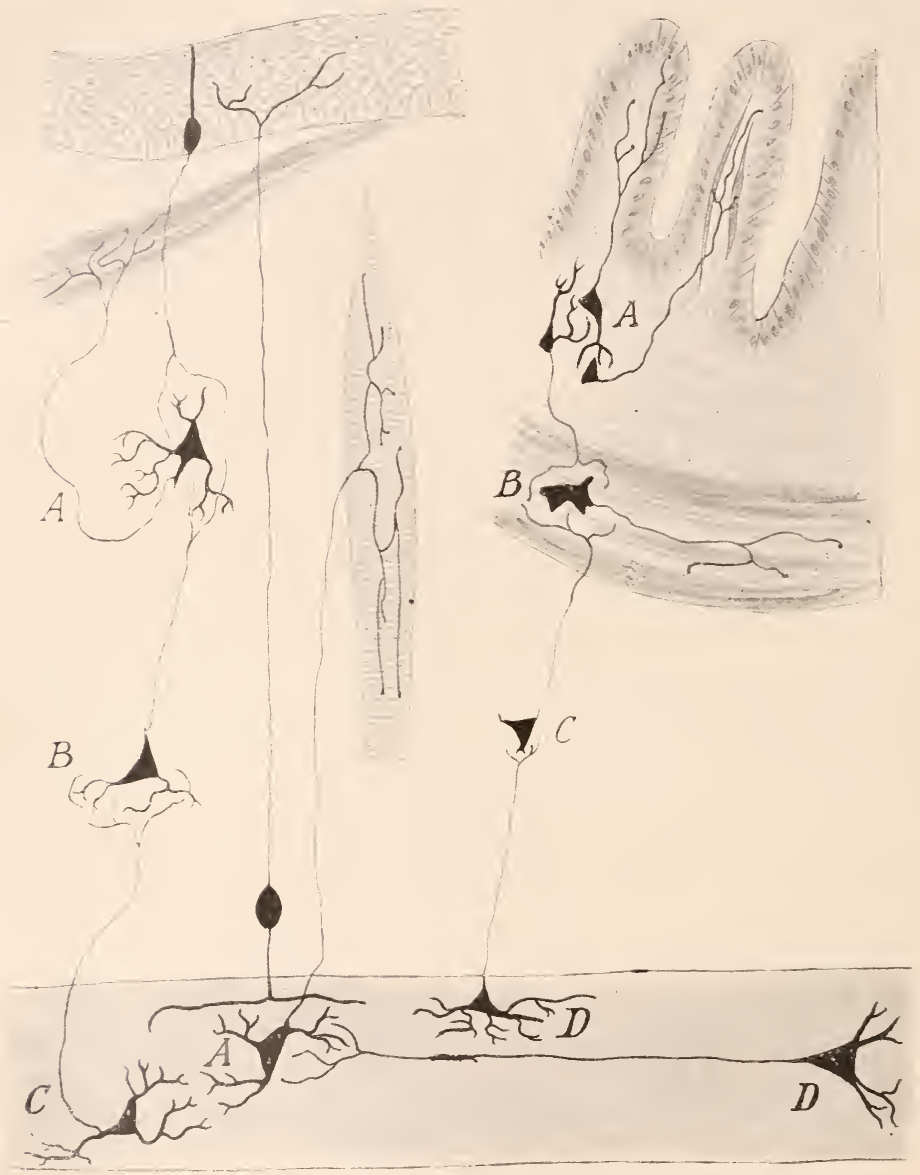

Fig. 14.

Uebersicht über das periphere und centrale Norvensystom.

Drei völlig schematische Abbildungen, die sich nicht an wirkliche Verhältnisse irgend eines speciellen Thieres anlehnen, sondern nur zur Klarmachung der im Texte dargelegten principiellen Dinge bestimmt sind. Nan erkennt Nerven motorischer und sensibler Natur, peripher und centraler lie rende Centren und kann bei Verfolgung der einzelnen Linien sehen, wie solche Centren in sich geschlossen wirken, wie aber auch Einflüsse ron weiter her auf sie wirken können.

$A, B, C, D$ deutet an, dass die Leitangen erster, zweiter u. s. w. Ordnung sich über einander schalten.

Unten Centralorgan, oben drei Beispiele aus der periph. Innervation. 
Epithelzelle, welche einen Fadeu in das Nervensystem hineinschickt, wiederkehrt. Es giebt einen Ort, an dem man auf beschränktem Raume eine ganze Anzahl ron Uebergängen erblickt, die ron der einfachen mit dem Nerven verbundenen Epithelzelle bis zu complicirteren Sinneshïgeln führen. Das ist die Haut einer glasklar durchsichtigen Schneckenart, der Pterotrachea. Der Zusammenhang ron Epithelzellen mit Nerren, die dem Centralorgan zuziehen, ist in den letzten Jahren sehr schön von Lenhosseck für die Epidermis des Regenwurmes geschildert worden. Eigene Untersuchungen und solche ron Retzi us haben mich ron der Richtigkeit seiner Angaben völlig überzeugt. Aus zahlreichen Zellen des Integumentes sieht man feine Fäden entspringen. welche den Nervenknoten zuziehen und dort, zumeist unter Theilung enden. Lenhosseck hat nun eine Hypothese ausgesprochen. welche sich bisher ron grossem heuristischem Werthe erwiesen hat und geeignet ist unsere Anschaung rom sensiblen Theile des peripheren Nervensystems einfacher und folgerichtiger zu gestalten. Alle sensiblen Nerven bei den Wirbellosen und bei den Wirbelthieren stammten, meint L., ron solchen ursprünglich im Integument gelegenen Zellen. Es rückten die Zellen nur vielfach in die Tiefe, einen langen, oft aufgezweigten Faden in der Haut zuriicklassend; bei den Wirbelthieren geriethen sie bis in die Wirbelsäule als Spinalganglienzellen. Ob die Zellen num aber direct im Oberflächenepithel liegen, oder ob sie mit diesem nur durch den Ausläufer. den sensiblen Nerren, verbunden sind, immer senden sie rïckwärts einen Faden in das Yervensystem hinein. Retzius hat bei Mollusken solche Uebergangszellformen mit peripherem Faden von sehr verschiedener Länge beschrieben, wo die einer Epithelzelle gleichwerthige Ganglienzelle nicht mehr in der Haut, sondern in verschiedener Tiefe unter derselben liegt. In Figur 15 lege ich nach Zeichnungen des letzteren Autors eine kleine Reihe ror, welche leicht zeigt. wie man sich nach dem eben Torgetragenen die Entwicklung des sensiblen Nervensystems denken kann.

Es handelt sich übrigens in den Fällen, wo die sensible Endzelle noch ganz in der Peripherie liegt, keineswegs immer um niedere Thiere, vielmehr findet man noch bei den Wirbelthieren dergleichen und zudem die mannigfachsten Uebergangsbilder, wenn man die Nerrenendigung in den simnesorganen studirt. Die Epithelien der Riechschleimhaut senden, wie die der Regenwurmhaut, einfach eineu Fortsatz hinein in das Gehirn, im Ohre aber giebt es keine Endzellen in diesem Sinne mehr, es liegt da die betreffende Zelle im Ganglion spirale der Schnecke, während ihr peripherer Fortsatz die Stiftzellen der Crista acustica aufgezweigt umfasst, ganz wie der sensible Nerr die Epidermiszellen, Fig. 16. Auch für die Geschmacksfasern ist eine derartige Aufzweigung um Zellen nachgewiesen. Ton der Retina wissen wir, dass sie Nervenbahnen enthält, die aus dem Centralorgan kommend, sich um ihre Elemente aufzweigen, daneben aber auch Ganglienzellen führt, die ihren Axencylinder rückwärts dem Centralorgan zusenden. 
Sensible Nerven sind weithin über den ganzen Körper rerbreitet. Nicht nur an den Orten, die man gewöhnlich als empfindend bezeichnet, sondern auch in allen-anderen Geweben und Organen des Organismus finden sie sich. Ob man die Leber oder die Niere, die Lunge oder die Wand eines Blutgefässes untersucht, immer findet man da, in früher ungeahnt grosser Nenge, dünne Nervenästchen aufgezweigt. Ein guter Theil derselben endet wahrscheinlich schon in peripher liegenden sensiblen Endzellen, die dem Reflexbogen des sympathicus angehören, ein anderer aber
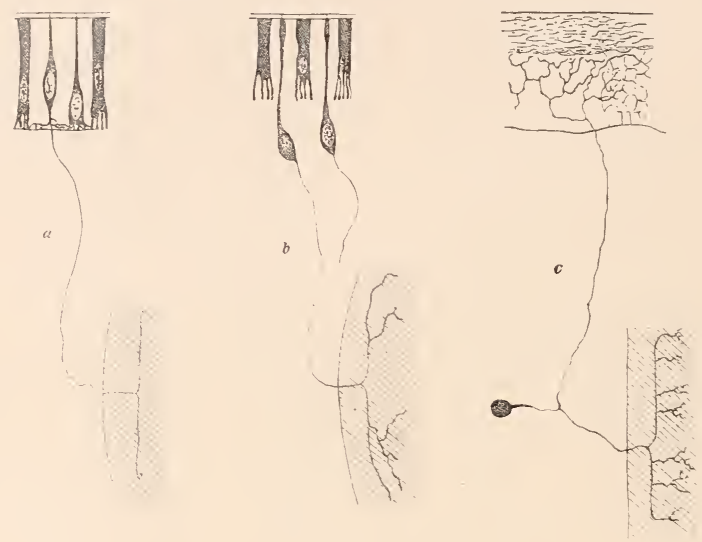

Fig. 15.

Nach Retzius, a Sinnesepithelion des Regenwurmes. "Ebensoleho von einer Schnecko. c Spinalganglienzelle eines Wirbelthieres - ein Fortsatz, der sensible Norv, goht zur Haut, ein zwoiter als Wurzel in das Centralorgan hinein. - In allen drei Zeichnungen ist das Centralorgan schraffirt.

ist höchst wahrscheinlich bis in die spinalganglien zu rerfolgen und bis in das Rïckenmark selbst. Gerade die Untersuchungen der letzten Jahre, die sich der silber- und der Methylenblaumethode bedienen konnten, haben nicht nur den Reichthum an Organnerven entdecken lassen, sondern auch gezeigt, dass wir uns die sensible Innervation der empfindenden Flächen, der Haut z. B. oder der Geschmackapparate, viel zu arm vorgestellt haben. Es liegen da enorme Plexus von Nervenfäden unter und zwischen den Epithelzellen und diese senden zu jeder einzelnen Zelle Aestchen. oft viele zu einer einzelnen. Ich lege, mm nur einige Beispiele zu geben, hier Ihnen Abbildungen vor. welche zeigen wie um jedes Haar herum sich eine wahre Krone ron Nervenfaden legt, wie im Gaumen des Frosches zu den Epithelzellen Endfäden ziehen und wie die Pigmentzellen in der Haut der Firche ron einem förmlichen Netze dicht umsponnen sind. Aus der Leber, der Blase und von vielen anderen Orten her könnte ich Ihnen noch zahlreiche Beweise für die überreiche periphere Innervation 
vorlegen. Wir haben früher viel zu viel Werth auf die einzelnen Endapparate gelegt und meist iibersehen, dass eigentlich der allergrösste Theil der Körpergewebe zellweise schon mit Nerven versorgt ist. Ton dem Reichthum an Nervenfasern in den echten Endapparaten, in den Tastund den Geschmackpapillen z. B. kann man sich kaum eine zu grosse Torstellung machen. Gute Imprägnationen lassen da ungeahnt dichte Plexus erkemnen.

Für welche Leistnngen mag eine so reiche sensible Imervation angelegt sein? Es giebt, das leuchtet sofort ein, eine sehr grosse Anzahl ron Reflexen, die für die Erhaltung des Individuum dringend nothwendig sind, olne dass sie gerade dem Träger bekamnt werden. Die Regulirung der secretionen, der Blutversorgung in der Haut im Verhältniss zur Gesammtwärmeökonomie des Organismus, die Anpassung an verschiedene Belichtung, diespannumg der Muskeln und Sehmen durch die diesen eigenthümlichen Sehnemrefiexe, die rerschiedene Einstellung solcher spammungen, je nachdem die willkürliche Innervation verschieden eingreift, und sehr vieles Andere könnte hier genamnt werden. Zu all dem bedarf es ausser dem motorischen
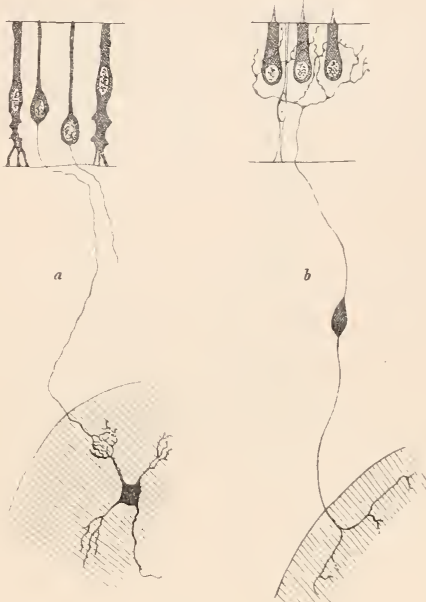

Fig. 16.

Nach Retzius. a Sinnesepithelien der Nase, senden ihren Axencylinder als Riechnerv, Fila olfactoria, rückwärts zum Gehiın, wo er sich aufzweigt. $b$ Eine Ganglienzello aus dem Ganglion spirale oder Schnecke. lhr peripherer Fortsatz verzweigt sich um dio Stiftzellen der Nacula, ihr centraler geht als Ramus cochlearis N. acustici in das Gohirn.

Theile des Reflexbogens eines sensiblen Antheiles. Ja Exner, dem wir besonders die Hinweise auf die Wichtigkeit dieser kurzen Reflexbogen und ilıre Rolle im Organismus verdanken, hat sehr schön erläutert, wie überhaupt zum Zustandekommen wohl jeglicher Bewegung die Intactheit der sensiblen Innervation erforderlich ist. Der Schluckact z. B. zerfällt in einen willkürlich anslösbaren Theil und einen reflectorischen. Anästhesirt man durch Cocain den Rachen, so bleibt zwar die Fähigkeit zum ersten erhalten, der Bissen wird aber vom Oesophagus, dem nun keine sensiblen Eindrücke rom ihm zugeführt werden können, nicht weiter befördert, es bleibt die Reflexaction aus. Nun wird erst klar warum die Schleimlant der Speiseröhre so mächtige sensible Innervation besitzt, warum unter. und in ihrem Epithel solche grossen Plexus von Nervenfasern liegen. Ein anderes, wie mir scheint, gutes Beispiel für die Wichtigkeit sensibler Regulirung rein motorischer Vorgänge bietet die Be- 
wegung unserer Finger. Bekanntlich ist diese recht gestört, die ..Finger sind steif", wenn nur sensible Störungen in der Hand vorhanden sind. Das kann man künstlich erzengen. Durchkältet man die Hand stark, so wird sie steif, unbeweglich, auch für Actionen, die durch Muskeln ausge-
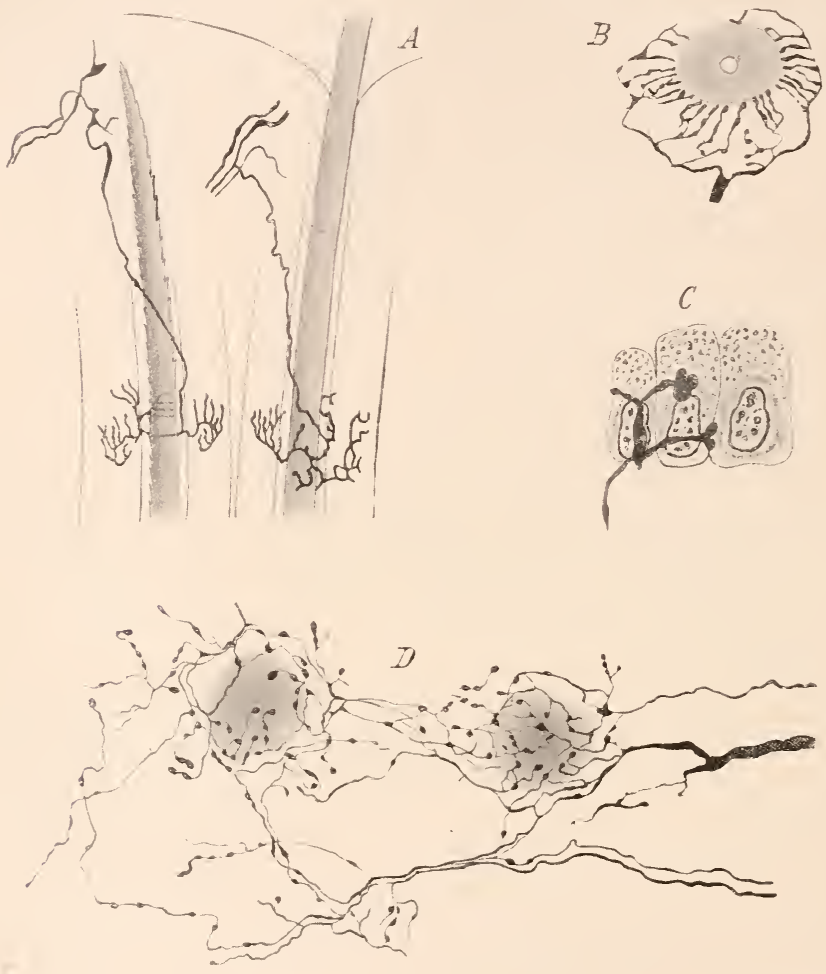

Fig. 17.

$A$. Haare ron der Maus, Nerren mit Silber geschwärzt. B. Ebensolche in Querschnitt. Nach v. Gehuchten. C. Nerren zu Epithelzellen des Froschgaumens. Methylenblaumethode, nach Bethe. D. Pigmentzellen aus der Haut von Alburnus mit dem Nervennetz nach Eberth und Bunge.

führt werden, welche am Vorderarme wärmegeschützt liegen. Diese Muskehn können sich offenbar nicht normal contrahiren, wem sie von den Sehnenund Gelenkenden her nicht regulirende Empfindungen erlangen kömnen. Die steifen Finger, die wir von einem Winterspaziergange nach Hause bringen kömen. beruhen auf dem Torhandensein der Sensomobilität. 
Wahrscheinlich gehören viele Bewegungsstörungen der Hysterischen eben hier'her.

Eine überreiche sensible Innervation ist also erforderlich, nicht nur für zahllose Reflexvorgänge, sondern auch zur Regulirung vieler anscheinend nur dem Nillen unterworfener Bewegungen.

Unter "sensibler Innervation" darf man sich aber nicht 1 " Torgänge denken, welche bewusst in die Empfindung treten. Hier werden alle die Vorgänge darmuter verstanden, bei welchen ron irgend einer Stelle des Körpers her dem nächsten Ganglion oder dem Centralapparat Eindrücke zugefülnrt werden. Ob sie weiter geleitet werden, ob sie ron dem Träger wahrgenommen werden, das kommt für die Begriffbestinmung nicht in Betracht. Empfinden und Wahrnehmen sind nicht das Gleiche.

Die allermannigfachsten Bahnen und Centren dienen der Sensibilität und wir haben bei den Vertebraten. speciell bei dem Menschen, der über die Wahrnehmung einzelner Empfindungen ja Anskunft geben kanı, schon eine ganze Anzahl verschiedener Gefühlsarten kennen gelernt.

Die sensible Controle, deren einzehne anscheinend gleichartige Bewegungen bedürfen, ist nicht überall die gleiche. Namentlich kommen, wie es scheint. bei den höheren Thieren viel mehr regulirende DIomente in Betracht als bei niederen. Aber auch die Sänger kömnen gelegentlich durch Einübung n. s. w. auf die eine oder andere Art der Controle verzichten lernen, können anskommen mit dem, was auf tieferen Stadien der Entwicklung allein regulirt.

Sehr gut wird die Wichtigkeit der einzelnen Arten solcher sensiblen Regulirung von noch ganz elementaren motorischen Vorrichtungen illustrirt durch einen geistvollen Versuch, den J. R i c ha r d E w a l d angestellt hat. Nimmt man einem Hunde beiderseits die Labyrinthe weg, so erleidet der Gesammtmuskeltonus und damit das Termögen das Gleichgewicht anfrecht zu erhalten zunächst eine so enorme störung, dass Gehen und Stehen ganz ummöglich wird. Aber das gleicht sich nach einiger Zeit wieder aus, die Bahnen für den Tastsinn n. s. w. ersetzen zunächst mehr und mehr das Fehlende. Trägt man nun beiderseits dem gleichen Thiere die motorischen Rindenfelder für die Beine ab, so erscheinen jene schweren motorischen Störungen erneut, das Thier ist mfähig zu geordneten, ja zunächst überhampt zu irgend welchen ordentlichen Bewegungen. Anch hier tritt langsam ein Ausgleich ein. Aber der Hund ist jetzt in trauriger Lage, denn er ist für die Controle seiner Bewegungen ganz allein auf seine Angen angewiesen. Hülflos stürzt er zusammen, wenn man das Zimmer rerdunkelt oder ihm die Angen rerbindet.

Niedere Tertebraten - Frösche z. B. - kömen den Defect. welcher durch Labyrinthentferumg entsteht, nicht decken, weil bei ihnen die Möglichkeit von der Hirminde ans nit anderen Formen des Gefühles 
ausgleichend zu arbeiten ganz gering ist. Die bleiben nach Entfermung des Labyrinthes dauernd unfähig zum springen.

Die kurze Uebersicht, welche diese einleitenden Vorlesungen Ihnen, meine Herren, gegeben haben, lässt erkennen, wie complicirt schon bei alltäglichen Verrichtungen der Mechanismus ist, auf dem sie sich abspielen. Wir wollen num in den folgenden Torlesungen das Centralorgan selbst studiren und versuchen, ob es gelingt in ihm wenigstens einen Theil dieses Mechanismus so zu erkemnen, dass er zur Erklärung physiologischer und psychologischer Torgänge benutzbar wird. 


\section{THEIL.}

ÜBERSICHT ÜBER DIE ENTWICKLUNG UND DIE VERGLEICHENDE ANATOMIE DES VERTEBRATENGEHIRNES. 



\section{Vierte Vorlesung.}

\section{Die Entwicklung des Gehirnes und der Ganglien.}

Die letzten Vorlesungen haben gelehrt, dass es zerstreute Nervenknoten mit motorischen und sensiblen Antheilen giebt, dass aber der grössere Theil des centralen Nervensystemes sich bei den höheren Thieren auf einen bestimmten Raum mehr oder weniger concentrirt. Es unfasst dies concentrirte Nervensystem bei den Vertebraten zunächst immer einen länglichen Strang, die Medulla spinalis, in welchen von aussen her die sensiblen Nerven einmünden, während aus Zellen, die im Marke selbst liegen, die motorischen Nerven entspringen. 'Wo viele Nerven eintreten oder entspringen, ist der Centralapparat dicker, ebenso da, wo auf engem Raume besonders mächtige Nerven abgehen. Namentlich im Kopftheile des Thieres ist das der Fall. Alle Cranioten besitzen desshalb da eine besondere Anschwellung, die Medulla oblongata. Ihr entstammen die Nerven für die Kiemenbogen, resp. für das Gebiet, welches aus jenen ableitbar ist.

Eine weitere Vergrösserung liegt weiter vorn, wo die bei fast allen Thieren mächtigen Sehnerven eintreten (Mittelhirndach) und schliesslich findet man regelmässig ganz vorn am Ende des Centralnervensystemes eine meist mächtige Auftreibung, die Stätte, wo zunächst der Riechnerv sein Ende findet.

Im Rïckenmark sowohl als weiter oben, bestehen aber noch Verbindungen einzelner Höhen unter einander. Dadurch kommen neue Vergrösserungen des Centralapparates zu Stande. Schliesslich gesellen sich zu dem ganzen bisher geschilderten Abschnitte immer noch andere Theile, welche nicht in directer Beziehung zu den eintretenden Nerven stehen, wohl aber für einzelne Functionen der Thiere ungemein wichtig werden kömnen. So findet man zunächst dorsal vom verlängerten Marke bei allen Cranioten mehr oder weniger stark entwickelt das Kleinhirn, dann liegt ventral von der Endstätte des Opticus, und auch vor ihr, noch ein mächtiger Apparat, die Mittelhirnbasis und die Mittelhirnganglien, welcher Bahnen aufnimmt, die von unten her und ron ror'n her kommen und auch ebensolche aussendet. Schliesslich entwickelt sich immer vor dem Zwischenhirn und dorsal von der Endstätte des Riech- 
nerven das Stammganglion des Vorderhirnes. dem sich ein Hirn mantel zugesellen kann.

Bekanntlich reicht die Existenz des Rückenmarkes ganz allein ans, niedere Thiere zu relativ complicirten Leistungen zu befähigen. Nan kamn nun anatomisch und auch durch das Experiment verfolgen, wie sich an Werthigkeit verschieden und mannigfach wechselnde Stufen der Ausbildung erreichend die rerschiedenen Hirntheile in der Thierreihe zum Rückenmarke zuladdiren. die Leistungsfähigkeit des Organismus so wesentlich steigernd. Amphioxus besitzt im Wesentlichen nur den metamer angelegten Strang zur Aufnahme und Abgabe der Nerven; was er ron Hirntheilen hat. ist so gering. dass es nach jahrzehntelangen Untersuchungen. an denen unsere besten Iänner sich betheiligt hatten, doch erst in letzter Zeit - durch $\mathrm{Kupffer}$ - aufgefunden werden konnte. Dem physiologischen Tersuche gegenüber ist der Hirnabschnitt ïberhaupt noch refractär geblieben. Geköpfte Amphioxen verhalten sich ganz ebenso, wie solche, welche das spitze vordere Körperende noch besitzen, Steiner. Aber alle cranioten Wirbelthiere besitzen frontal rom Rückenmarke zum mindesten noch die vorhin erwähnten Hirntheile. Aber welche Mannigfaltigkeit der Ausbildung weisen die einzelnen Zellen auf! Trahrlich kaum etwas lehrreicheres und interessanteres auf morphologischem Gebiete lässt sich finden als ein Blick auf das Werden des Gehirnes, auf das Vortreten oder Zurücktreten einzelner Theile, auf die Entwicklung ungeheurer Massen aus Theilen, die bei anderen Thieren noch rein epitheliale Häıte darstellen. Sie werden mit mir diese Dinge num durcharbeitend erkemnen, wie sich allmählich das Ganze auflout, wie es wurde und wie es noch ständig in Aenderung, im Abnehmen da und im Zumehmen dort begriffen ist.

Physiologisch und hoffentlich dereinst auch in psychologischer Beziehung bieten diese Dinge noch ein besonderes Interesse. Es ist gewiss zu beklagen, dass sie hier noch ganz ungeniigend gewürdigt sind.

Am zweckmässigsten betrachten wir zunächst die entwicklungsgeschichtlichen Vorgänge. Sie sind gerade in den letzten Jahren wieder besonders genau studirt worden und diese Studien haben uns so viel Material gebracht, dass man wohl wagen darf, das für alle Klassen Gemeinsame zusammenzufassen.

Dass die ganze Anlage des Nervensystemes aus dem äusseren Keimblatte geliefert wird, dass diese Anlage zu einem Streifen, der bald zur Rimne sich einsenkt, gebildet wird, das wissen Sie aus einer früheren Torlesung. Schon sehr frïh schliesst sich die Medullarrinne zum Medullarrohre. Aber schon ehe dieser Schluss vollendet ist, erkennt man bei allen Wirbelthieren an der Stelle, wo das Gehirn sich entwickelt, drei bläschenförmige Ansbuchtungen: das Vorderhirn (Proencephalon), das Mittelhirn (Mesencephalon) und das Hinterhirn (Rhombencephalon). Die Wand, welche vorn frontal das Vorderhirn abschliesst. wird embryonale Schlussplatte amina terminalis, genannt, weil 
hier der Schluss der ursprünglich flächenförmig ausgebreiteten Hirnanlage in einer Naht erfolgt ist.

Eine kleine Ausstülpung, welehe bei den niederen Vertebraten dauernd, bei den Embryonen der höheren Vertebrateı vorïbergehend in der Schlussplatte nachweisbar ist, zeigt nach $\mathrm{H}$ is den frontalsten, zuletzt geschlossenen Theil der Hiruhöhle an - Angulus terminalis. Kupffer hat sie Lobus olfactorus impar genannt, weil sie, ähnlich wie die Anlage eines Sinnesapparates, sich einer kleinen Epithelansammlung der Haut innig anlegt. Vielleicht haben wir den Rest eines uralten Simnesorganes vor uns.

Der Schnitt durch die Larve des Störes, den ich hier vorlege, enthält, wie die weitere Darlegung zeigen wird, Anlagen der allermannig-

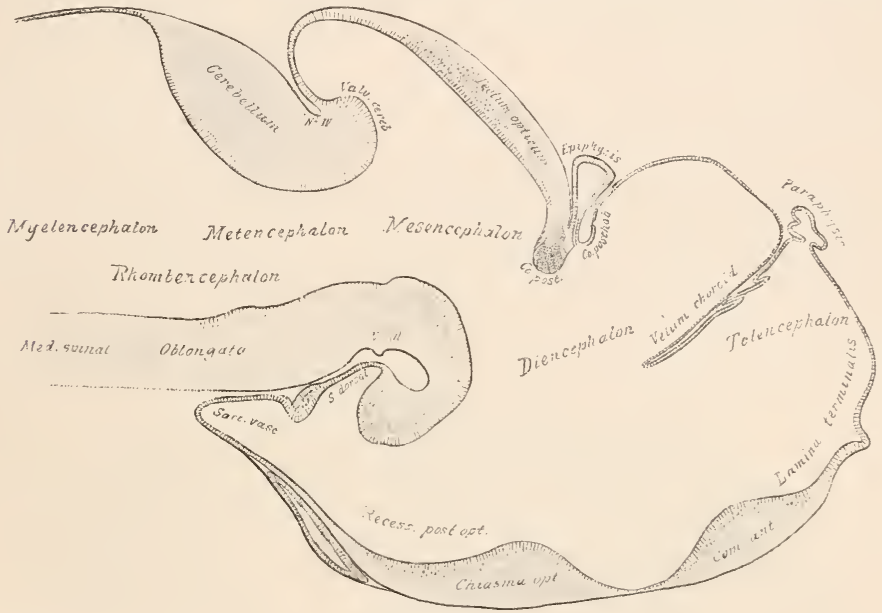

Fig. 18.

Hedianschnitt durch den Kopf einer 4 Jon. alten Larve des Störs, Accipenser sturio, nach C. v. Kupffer.

fachsten Art für die Weiterentwicklıng der einzelnen Hirntheile. Nicht alle kommen zur Ausbildung, viele bleiben auf der Stufe stehen, die hier abgebildet ist; aber bei den höheren Wirbelthieren verwandeln sich die einzelnen kleinen Abschnitte des Hirnrohres in wichtige Gebilde, deren Entwicklung dann für die einzelnen Klassen eine sehr verschiedene sein kann.

Zunächst soll unsere Anfmerksamkeit die kleine Epithelplatte am dorsalen Ende der Schlussplatte fesseln. Hier entsteht nämlich bei den meisten Tertebraten ans demjenigen Theile des Torderhirnes. welcher dorsal und lateral von der Schlnssplatte liegt, ein nenes mächtiges Gebilde, das Endhirn - Telencephalon, eine ganz vorn und dorsal sitzende grosse Blase, die bald durch eine von oben her eindringende Einfaltung in eine rechte und eine linke Hemisphäre zerlegt wird. Alff Fig. 19 
ist das desshalb nicht sichtbar, weil der Schnitt genau median fällt, die die Hemisphären auch beim Stör nicht ausgebildet sind.

Die Hemisphären, welche anfangs sehr unscheinbare kleine Gebilde

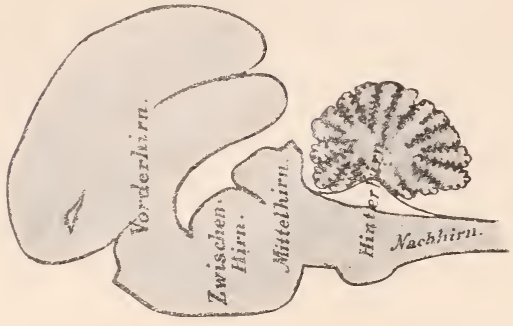

Fig. 19.

Längsschnitt durch das ganze Gehirn einer neugeborenen Katze; das Zwischen- und Mittelhirn vom Vorderhirn bedeckt. Vergr. $1: 2$. sind, wachsen bei den säıgern als Grosshirn bald enorm aus, krümmen sich nach rückwärts und überdecken so allmählich die meisten anderen Blasen. Sie sitzen schliesslich einer Kappe gleich über dem Zwischenhirn (Tha la mus), dem Mittelhirn (Corpora quadrigemina) und dem Hinterhirn (Cerebellum und Pons).

Natïrlich communiciren die Hohlräume der verschiedenen Gehirnblasen, welche später Ventrikel des Gehirns heissen, trotz dieser Rückwärtsbengung der vordersten Blase weiter mit einander.

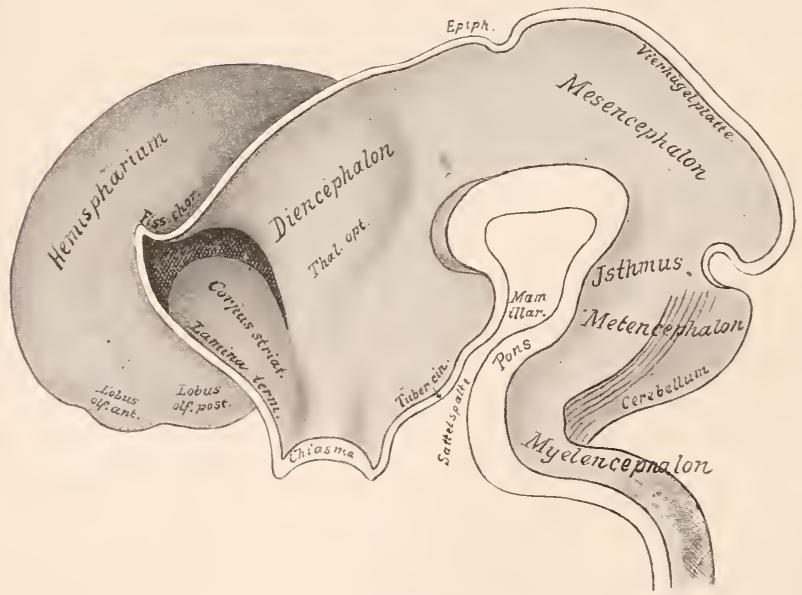

Fig. 20.

Medianschnitt durch das Gehirn eines menschlichen Embryo aus der 5. Woche nach His.

Aus dem ursprünglichen Torderhirn haben sich also zwei Gebilde entwickelt. Gewöhnlich nennt man von nun ab das Telencephalon Vorderhirn, während demjenigen Theil der ursprünglich vordersten 
Hirnblase, welcher nicht in die Hemisphären aufgegangen ist, der Name $\mathrm{Z}$ wischenhirn Diencephalon gegeben wird.

Bei allen Säıgern verdicken sich nun allmählich die Wände der Hemisphären. Nan erkennt aber bald, dass das keineswegs gleichmässig erfolgt. Nahe der Basis legen sich die L obi olfactorii als dickwandige Nassen an und hinter ihnen entwickelt sich ein mächtiger Körper, das Striatum, ebenfalls auf dem Hirnboden. Diese Massen sind damn durch eine Furche von einem mehr dorsalen Abschnitt geschieden, dem Mantel oder Pallium, dessen Wände relativ spät erst dick werden. Nun ist es Ihmen gewiss interessant. wenn ich jetzt schon mittheile, dass hier uralte Verhältnisse sich kundgeben. Bei allen Tertebraten entwickelt sich nämlich der basale Abschnitt, das Stammganglion und die Riechlappen, aber nu bei den höheren erreicht das Pallium nemmenswerthe Ausbildung. Bei Petromyzon und den Fischen bleibt der Mantel zeitlebens ïberhaupt nur eine einfache Epithelwand. Das Pallium aber ist derjenige Abschnitt des Gehimes, welcher später die Rinde tragen und dadurch das Organ sein wird, an dessen Aufbau sich alles höhere seelenleben knüpft. Das Pallium des Störes z. B. bleilst zeitlebens so dïnn wie es Fig. 1s vom Embryo abgebildet ist.

Die Hemisphären sind bei den säugem am höchsten ansgebildet und hier auch am besten studirt. Ihre Entwicklung soll

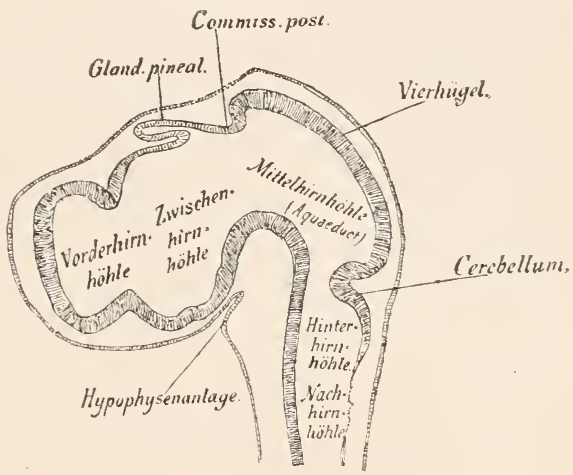

Fig. 21.

Längsschnitt durch den Kopf eines Hühnerembryos von $4 \frac{1}{2}$ Tagen. Die 5 Hirnblasen meist deutlich von einander abgegrenzt. Am Dache des Zwischenhirns eine Ausstülpung, welche später zur Glandula pinealis wird. Das Epithel des Gaumens stülpt sich nach der Hirnbasis zu ein und bildet so die erste Anlage eines Theiles der Hypophysis. Nach v. Mihalkovies.

deshalb auch hier speciell für die säuger geschildert werden, während eine Darstellung dessen, was aus den Hirntheilen wird, welche caudal von dem Hemisphärengehirn liegen, besser sich später geben lässt, wemn wir die Gehirne niederer Thiere kemnen lernen, wo gerade das Zwischenhirn, das Mittelhirn und auch das Hinterhirn besondere Ausbildungsformen zeigen, die bei den Säugeru theils wenig sichtbar, theils ganz verloren sind.

Das Dach des Zwischenhirns bleibt zeitlebens fast in seiner ganzen Länge eine einfache Epithelschicht. Da wo es in das Hemisphärenhirn ïbergeht, wachsen ans der Schädelhöhle reichliche Gefässe herunter, welche diese Epithelplatte vor sich hertreiben. Der so in die Hirnhöhle hineinragende epithelbedeckte Gefässzapfen heisst Velum chorioideum. 
Da die Hemisphären ans dem Zwischenhirn herausgewachsen sind, so muss ihr imnerer Rand in jenes Telum übergehen. Anf dem Fig. 22 abgebil-

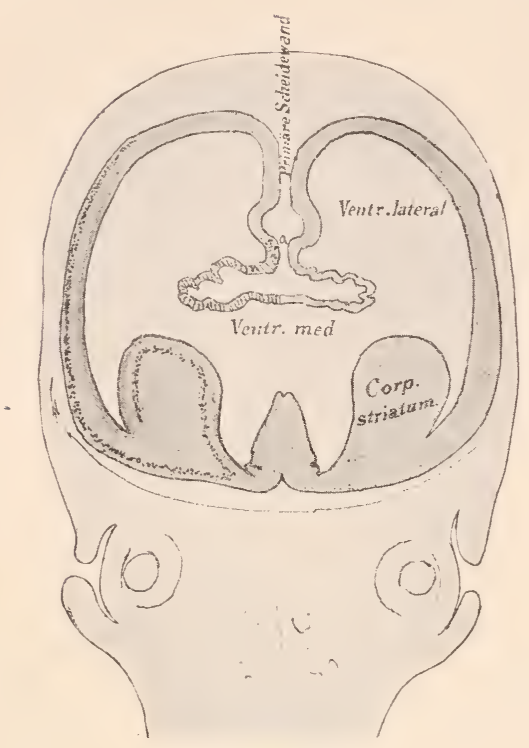

Fig. 22.

Frontalschnitt durch den Kopf eines menschlichen Embryo von $21_{2}$ Monaten, zeigt die Einstülpung der Vorderhirnblase (etwas schematisirt) und die Anlage des Corpus striatum. deten Frontalschnitt durch das Vorderhirn eines frühen menschlichen Embryos wird das deutlich. Auf diesem sehen Sie auch, dass die Höhle des mparen Torderhirns als Tentriculus medius, die der Hemisphären als Ventriculus lateralis bezeichnet wird. Das Velum choroideum sendet in die Seitenventrikel Ausläufer. Plexus chorioidei laterales. Die Stelle. wo die Hemisphärenwand in die einfache Epithelschicht übergeht, wird als Rand der H e $\mathrm{m} \mathrm{is} \mathrm{ph} \mathrm{ä} \mathrm{re} \mathrm{bezeichnet.}$ Dieser Rand ist in seiner ganzen Länge später durch ein weisses Faserbündel, den Fornix, markirt.

Wenn die wichtigsten Theile des menschlichen Vorderhirnes sich einmal gesondert haben, dann hat es die

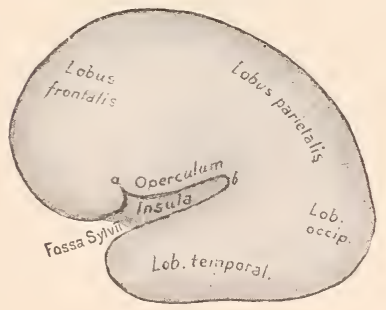

Fig. 23.

Das Gehirn einer menschlichen Frucht aus dem vierten Schwangerschaftsmonate.

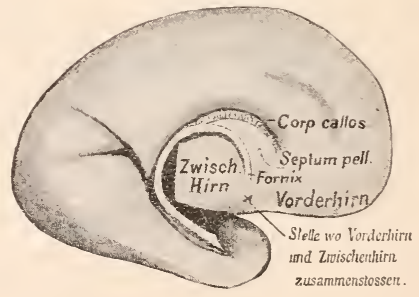

Fig. 24.

Innenansicht der auf Fig. 23 abgobildeten embryonalen Hemisphăre; zeigt den inneren unteren Rand der Hemisphare, welcher zum weissen Markstreif des Fornix verdickt ist. Derselbe wird aber orst nach der Geburt markweiss.

in Fig. 23 wiedergegebene Gestalt. Es ist nach hinten ansgewachsen und auch nach unten hat es sich gekrümmt. Da wo innen in den hohlen Ramm 
der Hemisphären das Corpus striatum himeimagt, hat sich die Anssenwand nicht so ausgedehnt, wie an den anderen Vorderhirntheilen. so ist im Verhältniss zur Umgebung dort eine Vertiefung aufgetreten, resp. zurückgeblieben, die Fossa Sylvii. Leicht kann nun an den Hemisphären auch schon ein vorderer oder Frontallappen, ein hinterer oder Occipitallappen, zwischen beiden ein Parietallappen unterschieden werden. Der nach unten ron der Fossa Sylvii liegende Theil der Hemisphärenwand heisst Temporallappen. Imnen sind die Hemisphären hohl, und folgt die Tentrikelhöhle natürlich der allgemeinen Hirnform. Man lat den Ventrikeltheil, welcher im stimlappen liegt, als Vorderhorn, den im Hinterhamptlappen als Hinterhorn und den im schläfenlappen als Unterhorn bezeichnet. In diesem Entwicklungsstadium verlangt unser besonderes Interesse noch die mediale Hemisphärenwand. Dass dieselbe an ihrem ventralen Rande überall in das Epithel des Plexus chorioides übergeht, haben sie vorhin erfahren. Das ändert sich auch nicht, wenn sie sich mit dem schläfenlappen nach unten krümmt. Von der Basis der embryonalen Schlussplatte bis in die Spitze des Schläfenlappens zieht im Bogen diesen Rand bezeichnend der Fornix daher. Im vorderen Theil des Gehirnes entwickeln sich etwas dorsal rom Fornix die Balkenfasern. sie ziehen zwischen beiden Hemisphären in einer Linie dahin, welche zum Fornix in spitzem Winkel steht. Das Stück, das zwischen Balken und Fornix übrig bleibt, das also aus zwei dünnen Blättern der primären Hemisphärenscheidewand besteht, ist das Septnm pellucidum. Das sind wichtige Verhältnisse, die ich Sie genau an den gegebenen Abbildungen zu studiren bitte.

An dem Fig. 22 abgebildeten schnitte erkennen Sie ein anatomisches Terhältniss, dessen bislang noch nicht näher gedacht wurde. — Am Boden des Torderhirns liegt eine Verdickung der Wand, welche frei in den Tentrikel hinemagt, das Stammganglion. Corpus striatum. Aus dem Corpus striatum entspringen. wie ans der Hirnrinde, Nervenfasern.

Viele Fasern, welche im Vorderhirn entspringen und zu tiefer gelegenen Theilen des Centralnervensystems ziehen, müssen, um dahin zu gelangen. mitten durch das Corpus striatum hindurch. Es wird von den durchpassirenden Fasermassen in zwei Theile gespalten, in einen äusseren und einen inneren. Man hat den ersteren Nucleus lentiformis, den letzteren Nucleus caudatus benannt. Die Fasermasse zwischen beiden hat den Namen Capsula interna empfangen. Beim Embryo von 4 Monaten ist die Theilung des Corpus striatum bereits deutlich, Nucleus lentiformis und Nucleus caudatus erscheinen als selbständige grane Massen.

Das Corpus striatum liegt der ganzen Länge des Hemisphärenbodens an. Hinten ist es jedoch sehr schmal, und es bleibt eigentlich nur der mediale Theil überall nachweisbar, der als Sch wanz des Nucleus caudatus anf allen Qnerschnitten durch das Grosshirn getroffen wird. Der laterale Theil, der Nucleus lentiformis, ist bedeutend kïrzer. Der Nucleus 
caudatus ragt frei in den Tentrikel hinein. Anch der Nucleus lentiformis thut es anfangs. Im späteren Embryonalleben aber wird die schmale S pralte zwischen ihm und der Hemisphärenwand so eng, dass sie nicht mehr nachweisbar bleibt. Immer aber kamn man die Hemisphärenwant. anch beim Erwachsenen noch, ohne Zerreissung von Fasern rom äusseren Rande des Nuclens lentiformis abziehen. Beim ansewachsenen Gehirn hommt die stelle des einstigen syaltes sogar zuweilen zu wichtiger Geltung: Dort erfolgen nämlich ganz besonders leicht die Hirnblutmngen, mud die anstretende Blutmasse erfüllt, wenn sie noch nicht zu gross ist, den Raum zwischen Hemisphärenwand und Aussenglied des Linsenkel'ns.

Der Anblick der kleinen Gehirne, die ich Ihnen eben rorgelegt habe, hat vielleicht schon die Frage bei Thnen erweckt, wie wächst das Gehirn? und der Tergleich mit dem reich gefurchten erwachsenen Organ. die nächste. Wann etwa hat das Gehirn die Form und Grösse erreicht, die es für die grössere Zeit des Lebens, also bis dahin. wo das Alter schwundprocesse hervorruft, behält?

Trenn das Gehirn das Organ ist, an dessen fehlerloses Functioniren der normale Ablauf der seelischen Processe gekniipft ist, damn lohnt es sich sehr wohl zu wissen, wie lange sich noch etwa neue Gewebselemente bilden können und auf Zunahme welcher Theile das Wachsthum des Ganzen beruht. Nun sind leider die Cntersuchungen, welche uns diese wichtigen Dinge beantworten könuten, noch sehr wenig weit gediehen. Es fehlen noch völlig Cntersuchmoen über die Anzahl der Theilungsvorgänge an Ganglienzellen in verschiedenen Hirntheilen in postembryonaler Zeit. Bis jetzt hat man solche Theilungsvorgänge au den Kerneu der centralen Zellen nur sehr selten gefunden, so dass es scheinen möchte, als habe das Gehiru, das etwa im 7 . Lebensjahre amnähernd Form und Gewicht des erwachsenen Organes erlangt hat, bis dahin seine Ganglienzellen alle angelegt. Anch der von schiller gebrachte Nachweis, dass der dïnme Oculomotorius neugeborener Katzen kaum weniger Fasern enthält, als der starke Nerr erwachsener 'Thiere, spricht für die Annahme eines frühen Beendens der Zellbildung. Toch giebt es auch entgegenstehende Angaben. so fand Kayser in der Halsanschwellung des Rückemmarkes Nengeborener nur etwa halb so viele fanglienzellen als am gleichen Platze bei einem 15jährigen Knaben. Der bei dem letzteren erhobene Befund unterschied sich allerdings dann kamm noch von demjenigen, welchen eine Kählıng am Halsmarke eines reifen Mamnes ergeben hatte. Auch Zählungen, die Birge u. A. am Froschrïckenmarke vorgenommen haben. sprechen durchaus dafür, dass bei diesem Thiere noch lauge im reifeu Leben die Ganglienzellen sich vermehren.

Wahrscheinlich kommt das Allermeiste, was postembryonal beim Menschen Hirnvergrösserung elzeugt, auf Auswachsen von Nervenfasern und Collateralen aus vorhandenen Ganglienzellen und vor Allem auf die wohl während des ganzen Lebens weitergehende Markscheidenbildung. Auch 
Tonaldson, dem wir ein vortreffliches Buch ïber das Wachsthum des Gelirnes rerdanken, kommt zu diesen Schlusse.

Das Torderhirn des Menschen und seine Kenntniss liegt Ihren bisherigen Studien so nahe, dass es sich schon rerlohnte, seine Entwicklung: etwas näher zu beschreiben. Da uns in diesen Torlesungen aber nicht der Mensch allein interessirt, so lassen sie uns nun untersuchen, wie sich, nachdem die ersten Entwicklungsvorgänge, welche allen Thieren gemeinsam sind, einmal abgelaufen sind, das Gehirn eines anderen Tirbelthieres gestaltet. Iclı wähle dazu das Gehirn eines Reptiles, unserer Eideclise, das wenig seitlich ron seiner Mittellinie durchschnitten ist. Man kann an ihm sehr gut die einzelnen Theile eines Wirbelthiergehirnes erkennen, weil auch bei den ausgewachsenen Reptilien die Terhältnisse sehr viel einfacher liegen als bei den säugern.

Die Mitte der Abbildung nimmt der Hohlraum des Zwischenhirnes ein. Seine Ahgrenzung dorsal ist fast ansschliesslich aus Epitlelplatten gebildet, die in mannigfachen Ausbuchtungen verlaufend uns später nälıer beschäftigen werden. Auch ventral ist die nach hinten zu einem

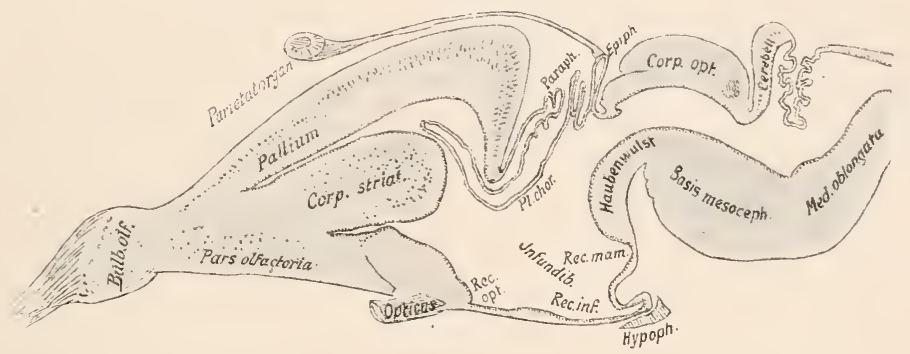

Fig. 25.

Reptiliengehirn. Schema eines Sagittalschnittes.

Sacke, dem Recessus infundibularis, ausgestülpte Wand nur dünn. Die Hypophysis liegt ihr dicht an. Die Seitenwände sind nicht abgebildet, sie enthalten die Thalammsganglien. Die dorsale Zwischenhirnwand setzt sich direct in den Hirnma n te l, das Pallimm fort, welcher die Wand des He m is phärengehirnes ist. Die Basis dieses schon bei den Eidechsen mächtigen Hirntheiles wird rom Stammganglion und rom Riechapparate eingenommen. Caudal schliesst sich den Zwischenhirn das Mittelhirn an, dessen dorsaler Abschnitt als Corpus opticum bezeichnet ist, reil hier die erste Endstätte des Sehnerven liegt, während der rentrale als Haubenwulst und als Basis mesencephali bezeichnete Abschnitt fast ausschliesslich Faserziige und nur wenige kleine Kerne enthält. Nit einer starken Einknickung* geht das Corpus opticum in das Cerebellum über. In diesem Winkel liegen bei allen Wirbelthieren zwei mächtige Faserkreuzungen, von denen die vordere dem Nervus trochlearis angehört. Das Kleinhirn bedeckt 
schon einen Theil der Oblongata. Der grössere aber liegt, bei den Eidechsen wenigstens, frei und nur ron einem dümnen Plexus choroides, dem Plexus ventriculi quarti bedeckt. Damn verengert sich der Hohlraum des Centralorganes mehr und mehr und ein feiner Canal geworden, durchzieht er schliesslich die ganze Länge des letzten Abschnittes des Centralnervensystemes, des Rückenmarkes.

Ueber die Entwicklung der peripheren Nerven habe ich Ihnen schon in der vorigen Vorlesung Nittheilung machen können. Ist das Centralnervensystem in seiner Ausbildung einmal soweit gediehen, dass die Haupttheile sich wohl abgrenzen lassen, so erkennt man, dass rom Zwischenhirn an bis hinab an das Ende des Rückenmarkes der centrale Hohlraum (Tentrikel, Centralcanal) von grauen ganglienzellenreichen Gewebsmassen umschlossen ist. Vom Mittehirn ab sehen wir aus diesen die peripheren Nerven abtreten. Die motorischen Nerven stammen aus Zellgruppen im Grau und treten fast alle an der ventralen Seite vom Centralorgan ab. Die sensorischen Nerven entspringen mit dem grössten Theil ihrer Fasern aus dem Centralorgan dicht anliegenden Ganglien. Aus den Ganglien senkt sich für jeden sensiblen Nerven eine Anzahl „. Wurzelfasern“ dorsal in das centrale Nervensystem ein. Die meisten sensorischen Wurzelfasern gerathen nicht weit rom Ganglion schon in die grane Substanz, einige ihrer Antheile aber laufen erst eine Strecke weit in oberflächlichen Schichten vor- oder rückwärts, ehe sie dort enden. Man bezeichnet diese Antheile als auf- und als absteigende Wurzeln.

Abstammung und Anordnung der Ganglien bieten sehr viel Interessantes und Lehrreiches.

Zunächst zeigt die früheste Entwicklumgsgeschichte, dass es sich in diesen peripheren Gebilden um echte Abkömmlinge des Centralnervensystemes handelt, um Theile, die sich nur schon sehr früh von jenem abgelöst haben. Die Ganglien gehen hervor aus dem Randstreifen der Medullarplatte. Wenn diese Platte sich beiderseits erhebt, um schliesslich mit ihren Randlippen zur Medullarröhre zu verwachsen, gerathen natïrlich die beiderseitigen Randstreifen an einander und bilden einen unpaaren Zellenstrang, der zunächst, keilförmig zugeschärft, in die dorsale Nahtlinie des Rolires mehr oder weniger eingelassen erscheint. Bald verlässt er infolge von Termehrung und Verschiebung seiner Zellen diese Lagerung, tritt aus der Decke des Melullarrohres vollständig aus und theilt sich durch mediane sonderung wieder in einen rechten und linken Strang. Durch segmentale Verdickung gliedert sich diese parige Ganglienleiste in die einzelnen Ganglien ab, die dann seitlich neben dem Medullarrohr mehr und mehr herabrücken. Hat sich diese Abgliederung vollzogen, so ist das ..Primärganglion“. d. h. das Ganglion, soweit es durch Aussonderung von Elementen des Centralorganes constituirt wird, fertig.

Während num die simalganglien bei dieser Konstitution verharren, d. h. rein centrogene Ganglien bleiben. treten die Ganglien der Hirn- 
nerven mit dem Ectoderm oder, richtiger gesagt. mmmehr mit der embryonalen Epidermis für die Daner einer gewissen Entwicklungsperiode ron nenem in contact mol bilden mit dieser zusammen Anlagen primärer sinnesorgane. Jeder Hirmerr gewinnt zwei solcher Contacte oler simnesanlagen an typisch lokalisirten, zu zwei Längsreihen geordneten stellen: eine mehr dorsal gelegene, die „la ter a le" oder "Kupfersche". und eine mehr ventral gelegene, die "epibranchiale" oder "Froriep'sche Anlage".

Alle Kupffer"schen Anlagen finden sich in einer Längslinie. die vorn in der Riechgrube begimnt, durch die Gehörgrube verlänft und bei niederen Irirbelthieren als ..seitenlinie. sich anf den Rumpf fortsetzt. Alle F r oriep schen Anlagen liegen in einer Längslinie, die vorne in der Linsengrube beginnt und sodann genan am dorsalen Rande aller Kiemenspalten entlang läuft. Ton den Knpffer schen Anlagen persistiren zwei und entfalten sich zu bleibenden sinnesorganen: die Riechgrmbe und die Gehörgrube. Die Froriepschen Anlagen dagegen haben durchweg nur embryonale Existenz und wurden desshalb rom ilnem Entdecker als ontogenetisch erhaltene Rudimente verloren gegangener, ancestraler simnesorgane gedentet und .. Kiemenspaltenorgane" benamnt. Deutliche spmen dieser embryonalen Epidermisverbindungen zeigen beim Erwachsenen nur Acustico-Facialis, (ilossopharyngews mnd Tagus : der Kupffer'schen Contact-

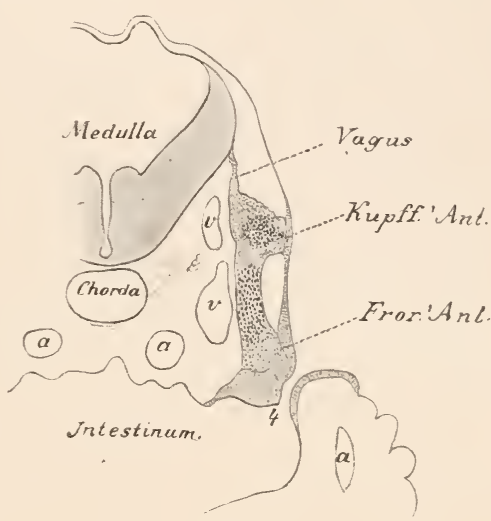

Fig. 26 .

Nach Froriep. Querschnitt durch den Hinterkopf eines Selachierembryos von $12 \mathrm{~mm}$,, in der Höhe der 4 . Visceralspalte; zeigt das Vagusganglion mit seinen zwei Epidermisverbindungen, der latoralen od. $\mathrm{K}$ u p f fer'schen, und der opibranchialen od. Frori op'schen Anlage. $a, a$ Arterien, $v$ Vena jugularis, 4 Kiemenspalte. reihe entsprechen der Komplex der Acusticusganglien, das Ggl. jugulare des IX. nnd das Ggl. jngulare des X.; der Froriep'schen Reihe entstammen das Ganglion geniculi (VII.), petrosum (IX.) mnd nodosum (X.).

Eine Sonderstellung nimmt der Olfactorins ein. Eimmal scheint ihm das Primärganglion ganz zu fehlen; das Riechganglion (His) entsteht selbständig von der Epidermisverdickung der Riechgrube (= K u p ffe r'sche Anlage) als ein rein laterales (ranglion, trennt sich von derselben ab, rïckt an das Gehirn heran mnd verschmilzt hier vollkommen mit dem Bulbus olfactorins. Anch die Riechgrube rerhält sich eigenartig, insofer'n sie von den persistirenden Anlagen die einzige ist, die den Charakter des primären simnesorganes definitiv beibehält. Thre Zellen bleiben in 
situ liegen als peripherische Nervenzellen, die ihren Nerrenfortsatz in den Bulbus olfactorius entsenden. In anderen Simnesorganen, wie in der Gehörgrube, erfolgt eine sonderung: die ursprünglich peripherischen Nervenzellen rücken in die Tiefe und werden zu bipolaren oder psendounipolaren Ganglienzellen, während die an der Oberfläche bleibenden Zellen der Anlage sich zu ..secundären Simneszellen" (G. R e tzius) differenziren. Froriep.

\section{Fünfte Vorlesung.}

\section{Der I uf'bau des Riickenmarkes.}

M. H. Durch die einleitenden Vorlesungen wurden Ihnen num die Grundelemente bekannt, welche das Nervensystem zusammensetzen; auch ihre Anordnung zu grösseren und kileineren Complexen, die Entwicklıng, die jene erfahren, und die Hauptabtheilungen des Centralapparates habe ich Thnen vorgeführt. Die nächsten Torlesungen sollen Sie mit dem Wichtigsten bekannt machen, was wir über den Bau dieser Hauptabtheilungen wissen und ihnen erst soll sich die Schilderung des bestgekannten Centralapparates. desjenigen der Säıger und des Menschen, anreihen.

Ich beabsichtige nun nicht, Thnen genau die äusseren Formen zu schildern, welche jeder einzelne Theil des Centralorganes bei den rerschiedenen Thieren hat; vielmehr will ich versuchen, ob es gelingt. das für den Aufbau principiell Wichtige so darzustellen, dass sie sich synthetisirend ein Gesammtbild schaffen kïnnen.

Auf das Gesammtbild allein kommt es mir an. Denn bald werden Sie erkennen, welch grosses Interesse eine Formentwicklung bietet, die als Träger hochwichtiger Functionen auf diese selbst einen Schluss gestattet. Sie werden erkennen, wie einzelne Theile des Centralapparates, das Rückenmark z. B., zu dessen festem Bestand gehören und in relatir gleicher Weise überall auftreten. dann aber, auch wie andere Gebiete die allergrössten Verschiedenheiten anfweisen. wie ein gowisser Grundmechanismus ïberall wiederkehrt. und wie zu diesem nene. andere Theile sich zugesellen, wachsen. wieder bei anderen Arten verschwinden u. s. w. So wird Ihnen gerade durch eine Lebersicht, die nur in grossen Zügen ein Bild zu zeichnen strebt, die Werthigkeit der einzelnen Theile des Centralnervensystems im Gesammtplane klarer werden nnd es wird nicht die später zu gebende genauere Schilderung des säugergehirnes Ihnen röllig Unbekanntes bringen, das allein stehend sich in keinen Rahmen fügt. Das sängergehirn kann roll nur rerstanden werden. wenn man berïcksichtigt, wie es in der Thierreihe geworden ist.

Den niedersten Centralapparat. denjenigen, der, überall vorhanden, die erste Aufnahme und Crisprungsstätte der Nerren bildet, das R ï cken mark. müssen wir zuerst betrachten. 
Beiderseits ron ihm liegen die spinalganglien, ans deren Zellen die sensiblen Nerven stammen. Bei Wirbelthieren aller Klassen sind sie bisher nachgewiesen. Sie bauen sich auf aus Zellen, deren grosser meist ganz dendritenfreier Körper bei den Fischen an jeder Seite eine Nerrenfaser aussendet. So ist es auch bei den Embryonen der anderen Tertebraten, aber bei diesen rücken später die Fortsätze soweit zusammen, dass sie zunächst gemeinsam in einem einzigen stile rerlaufen, um erst ein weniges abseits der Lrsprungszelle sich zu tremnen. Fig. 27 zeigt mehrere solcher Zelltypen aus Spinalganglien. Wo immer man nun untersucht hat, immer fand sich, dass einer der Fortsätze hinaus in die Peripherie als sensibler Nerr lief, während der andere dem Centralorgan zuzog. Man bezeichnet die Summe dieser centralen Fortsätze als Dorsalwurzel.

Die Zahl der Dorsalwurzeln ist bei den verschiedenen Thieren sehr rerschieden, ja bei Individuen der gleichen Art wechselt sie oft um kleine Zahlen. Das hängt von der Länge der Thiere und von der Anzahl der Metamere ab, welche bei den einzelnen zur Ausbildung kommen. In langer Reihe hinter einander treten diese sensiblen Wryeln an der dorsalen Seite in das Rückenmark ein und wenn sie eingetreten sind, theilen sie sich in auf- und absteigende Aeste, geben auch Collateralen in Menge ab, die sich dam im Grau aufzweigen. Dies Auf- und Absteigen erfolgt in der dorsalsten Rückenmarkzone und wo recht viele derartige Bahnen vorhanden sind, erkennt man daselbst ganze Stränge längsgerichteter Bahnen, die Hinterstränge.

Irgend ein Schnitt durch das Rückemmark eines Thieres lehrt sofort, dass es von einem Einige Formen von Spinalganglienzellen. centralen, epithelumkränzten Hohlraume durchzogen wird, dem Canalis centralis. und dass um diesen herum sich sehr fein organisirte Gewebsmassen anlegen, die graue Substanz. Diese ist peripher umgeben ron zumeist längsgerichteten Nerrenfasern, den strängen.

In diese graue substanz nmm münden nach einem längerem oder kürzerem Verlaufe. welcher zumeist in den Hintersträngen, bei Fischen aber auch in mehr lateral liegenden Bahnen erfolgt, die Hinterwurzelfasern ein. Man kann erkemen, dass sie da zu feinen Endpinseln auseinander fahren und sich so an ein enges Faserwerk anschliessen. welches den ganzen dorsalen Abschnitt der grauen Substanz erfüllt. Wahrscheinlich treten sie da in Contact mit den Ausläufern kleiner Zellen. Nan hat die grane Substanz zerlegt in Hinter- und Torderhörner. Besser aber wäre der 
Ausdruck Dorsal- und Ventralsänlen. Denn mm wirkliche Sänlen, welche sich durch die ganze Längsrichtung des Rïckenmarkes erstrecken, handelt es sich hier. sie entstehen dorsal durch das Faserwerk, welches die eintretenden Hinterwurzeln erzengen, rentral durch Ansammlungen ron Ganglienzellen, welche den Torderwurzeln Ursprung geben.

Die Entwicklung der Dorsal- und der Tentralsänlen hängt natïrlich nur ab von der Menge der Nerrenfasern. welche zu ihnen in Beziehung treten. Einige gute Beispiele hierfïr geben die Fische ab.

Bei diesen wird ein grosser Theil

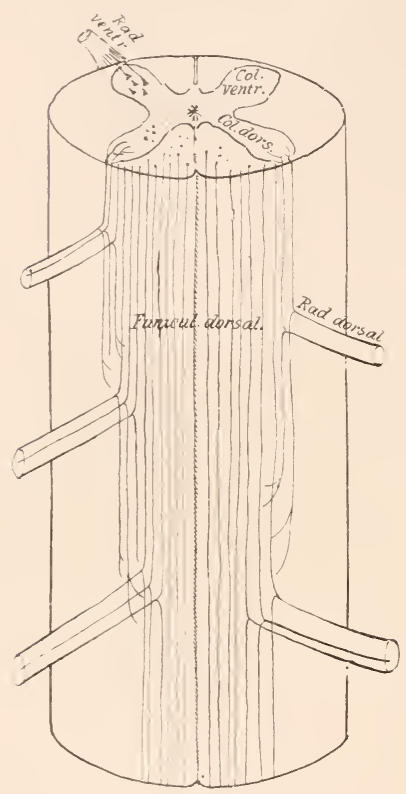

Fig. 28.

Rückenmar' ron hinten gesehen. Schema zur Erläuterung der Begriffe: Dorsal- und Ventralsäulen und zur Illnstration des über dio Hinterstränge Gesagten. der Körperoberfläche nicht von spinalen Terren, sondern ron einem Aste aus der Tagusgruppe rersorot; die spinalen sensorischen Terven sind desshalb relativ dïmn und desshalb ist auch das Hinterhorn, wie Figur 29 A zeigt ziemlich klein. Tenn aber, wie etwa bei Trigla, doch viele sensorische Nerren an einer bestimmten Stelle in das Rückemmark treten. so schwellen die Hinterhörner an der betreffenden Höhe sehr an. Ich lege hier neben einem schnitt durch das Triglahalsmark noch zwei andere sehr lehrreiche Schnitte vor. Der erste entstammt unserem Treissfische, dem Leuciscus rutilus. Hier erkennen sie die kleinen Dorsalsäulen. welche relativ dümnen Trurzeln Aufnahme gewähren, leicht in den zwei schmächtigen hell gebliebenen stellen oben jederseits ron der Mittellinie. Sie sehen gleichzeitig, dass zwischen ihnen die Dorsalstränge nur wenige Fasern entlialten.

Die Tentralsäulen, aus welchen die Yerven für die Muskeln stammen, sind in der bei Trigla abgebildeten Schnitthöhe verhältnissmässig schwach entwickelt, beim Weissfisch sind sie schon sehr viel stärker, aber eine ganz ungewöhnliche Ansdehnung haben sie in dem Rückemmarke des elektrischen tales, des Gymmotus gewomnen. Hier enthalten sie neben den kleinen für die Muskelnerven bestimmten Zellanlıäufungen — zufällig: ist an dem abgebildeten Schnitte keine gnt getroffen - noch einen ungehemren aus mächtigen rundlichen Ganglienzellen bestehenden Kern, den Tucleus nervorum electricorum. Es sind diese Zellen sicher einer Gruppe derjenigen gleichwerthig, welche bei den anderen Thieren die 
Muskulatur versorgen, aber Sie wissen ja anch, dass das elektrische Organ des Gymnotus sich in der Anlage und Differenzirung anf umgewandelte Muskelsubstanz zurückfühıren lässt.

Zumeist also gelangen die Hinterwurzelfasern bald nach ihrem Eintritt in das Rückemmark in dessen graue Substanz, zum Theil erreichen sie diese erst nach längerem oder kürzerem Verlaufe in den Hintersträngen. Es hat sich herausgestellt, dass ein kleiner Theil der Wurzeln die grane Substanz zwar durchläuft, aber dann hinüberkrenzt um in dem anderseitigen Hinterhorn gleich zu enden oder erst eine Strecke durch die anderseitigen Hinterstränge hindurchzuziehen, ehe er endet. Diese gekreuzten sensiblen Bahnen treten in der Commissura dorsalis medullae spinalis auf die andere Seite. Sie sind bei den verschiedenen Thieren sehr ungleich entwickelt und sogar bei nahestehenden Arten in der Stärke sehr wechselnd. Ausserdem ist die Commissura dorsalis in einzelnen Höhen ungleich stark entwickelt. Ihr Faserreichthum hängt von der Stärke der eintretenden Wurzeln und ron deren Nähe zur Schnittstelle ab.

Ein gewisser Antheil der Hinterwurzeln verliert sich nicht bald aufsplitternd nm die Zellen im Gran, er g'elangt vielmehr weiter rentral bis in die Gegend der Tordersäulen. Wir werden ihn später zu besprechen haben.
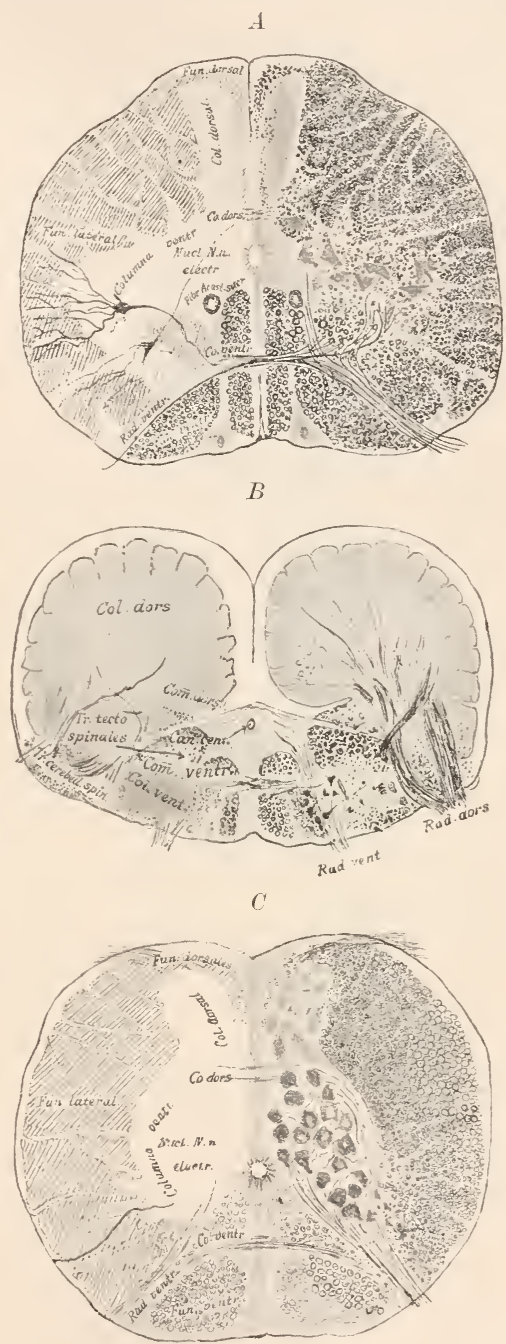

Fig. 29-31.

Die verschieden starke Entwicklung der grauen Substanz. $A$. Rückenmark von Leuciscus. B. von Trigla. C. von Gymnotus, letzteres nach einem Präparate von v. Frits ch. 
Schliesslich muss erwähnt werden, dass ein Theil der sensiblen Bahn bei den Sängern in Zellen gelangt. welche durch ihre Axencylinderfortsätze direct mit dem Kleinhirn in Beziehung stehen. Diese zu langer säule — stilling-Clarkésche Säule - geordneten Zellen sind bisher nur für die säuger fest nachgewiesen, doch ist ihr Torhandensein bei Fischen, Reptilien und Tögeln wenigstens wahrscheinlich. Die sichere Identification ist noch nicht gelungen.

Behalten sie also zunächst, dass die Hinterhörner ihre Existenz den eintretenden Wurzeln rerdanken und dass die Hinterstränge eigentlich

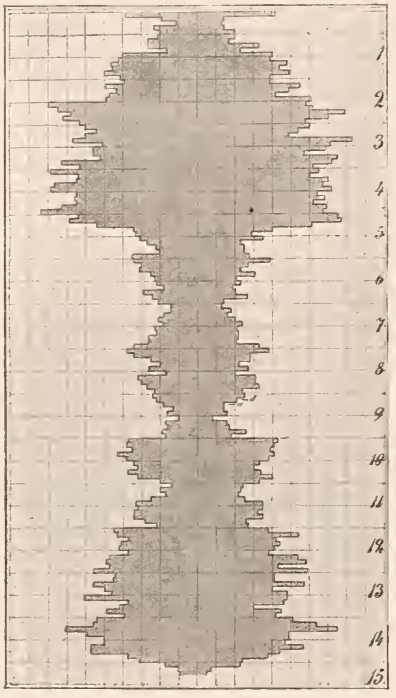

Fig. 32.

Projection in eine Ebene der im Rückenmarke des Frosches gezălten Ganglienzellen. Rechts die Höhenzahl des abgehenden Nerven angegeben. Man erkennt, wie für Armund Beinnerven enorme Zunahme der Zellzahl erfolgt. Nach Birge. wenig mehr sind als Fortsetzungen von T'urzelfasern. Das Gleiche gilt für einen nach Thierordnungen wechselnden Antheil der Seitenstränge.

So also ist der Apparat beschaffen, durch den die sensiblen Eindrücke von der Aussenwelt dem Centralorgan zugeführt werden. Ehe wir die Beziehumgen verfolgen, die er dort eingeht, sollen die Ursprungsverlältnisse der motorischen Nerven geschildert werden. Das kamn kurz geschehen, da es im Wesentlichen schon früher dargestellt wurde. Wollen Sie nur festhalten, dass in dem ventraler liegenden Rüickenmarksgran lange säulen von Ganglienzellen liegen, deren Axencylinder zum grösseren Theil in die Trurzeln der gleichen, zum geringeren in diejenigen der gekreuzten Seite hinaus gelangen. Als motorische Nerven ziehen sie ron da ans weiter. Ziemlich regelmässig bilden diese säulen rentral herabragende Torragungen am Rückenmarksgrau, die Vorderhörner. Auch sie erfahren wie die Hinterhörner Tergrösserung an Stellen, wo viele TVurzelfasern abgehen. So kommt z. B. bei den Thieren mit Beinen je für die Torder1nnd Hinterextremität eine Anschwellung des Rückenmarkes, die Intumescentia cervicalis und lumbalis zu Stande. Schön ist der Unterschied bei Eidechsen und Blindschleichen sichtbar, im Tesentlichen gleiche Thiere, welche sich nur durch das Fehlen resp. Torhandensein der Extremitäten unterscheiden. Besonders deutlich aber sind die Unterschiede im Rückenmarksquerschnitt bei den Schildkröten, weil bei diesen panzerbedeckten Thieren zwar mächtige Extremitätennerven, aber nur ganz dümne Thoracal-Nerven abgehen. 
Die Säulen grosser Ganglienzellen enthalten also die Nervenkerne für die einzelnen Mnskeln. Diese sind zu Gruppen geordnet. Für das Säugerrückenmark kennt man auch schon die Bedeutung einiger dieser Gruppen. Nan weiss z. B.. dass die medialst gelegenen Kerne die langen Rückennuskeln, dass gewisse weiter lateral liegende Zellgruppen im Halsmarke die Daumenmuskulatur mit Yerven versorgen. Das wurde gefunden, indem man sorgfältig die Rüickenmarke solcher Individuen untersuchte, denen durch Experiment oder Erkrankung die einzelnen Muskeln gelähmt waren. und dann die Veränderungen, welche man im Gran fand, mit anderen rerghich, welche ähnliche Entstehmng hatten. Wie weit man für den natïrlich am besten untersuchten Menschen hier schon gekommen ist, das werde ich Ihnen später mitzutheilen haben. Die Zellgruppen bei den niederen Vertebraten sehen in ihrer Anordnung denen bei den gut studirten Säugern so weit gleich, dass man annehmen darf, dass auch hier zusammengehörige Kerne vorliegen.

Die grauen Torderhörner senden ïbrigens nicht alle ihre Fasern in die rentralen ITurzeln. Es ist vielmehr nun für Vertreter der meisten Vertebraten nachgewiesen, dass ein ganz mächtiges Bündel aus ihnen dorsalwärts zieht und mit den Hinterwurzeln das Mark verlässt (s. Fig. 34). Da mit diesen Wurzeln

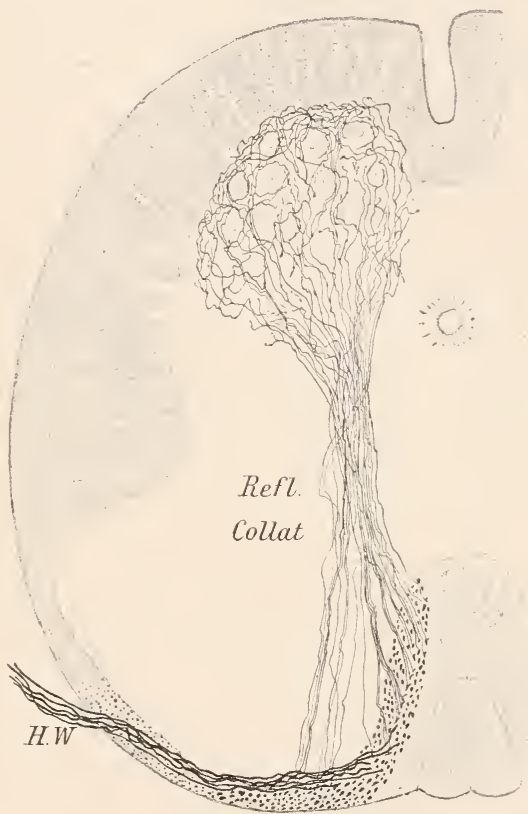

Fig. 33.

Vom Rückenmarke der neugeborenen Maus; nach Lenhosseck. motorische Elemente in den Sympathicus gelangen, welche die Muskulatur der Eingeweide beeinflussen, so dürfen wir wohl in den erwälnten Fasern aus den Torderhörnern diese motorischen Eingeweidenerren erblicken.

Die zwei ventralen wesentlich dem motorischen System angehörigen Zellsäulen und die zwei dorsalen Vergrösserungen der grauen Substanz, welche die sensiblen Wurzeln aufnehmen, zusammen bewirken es, dass auf dem Querschnitte das Rückenmark der meisten Wirbelthiere eine graue Figur von dem Querschnitte eines X enthält. 
Die centrale grane Substanz enthält nicht nur die wenigen Elemente. welche bisher aufgezählt sind. Zunächst birgt sie zahllose Dendriten und anch Axencylindercollateralen aus den Wrurzelzellen, so viele, dass ein schier mentwirrbares Flechtwerk in ihr liegt. In dies Faserwerk treten nmn noch von den Hinterwmzeln kommend mächtige Bahnen ein, welche sich um die Vorderhornwurzelzellen herum verzweigen. Diese sensiblen Elemente, welche so dicht sich an den Ursprung der motorischen Fasern anlegen. wären wohl geeignet, viele kurze Reflexe direct zu rermitteln (Fig. 33). Nicht alle Zellen im Rückenmark und anch nicht alle Fasern stehen in directer Beziehung zu Nervenwurzeln. Es giebt vielmehr eine grosse Menge ron Zellen. Welche ihren Neurit aus der granen Substanz hinaus senden, sei es auf die gleiche. sei es auf die gekreuzte Seite. Meist theilt er sich-dann in einen auf- und einen absteigenden Ast. Beide

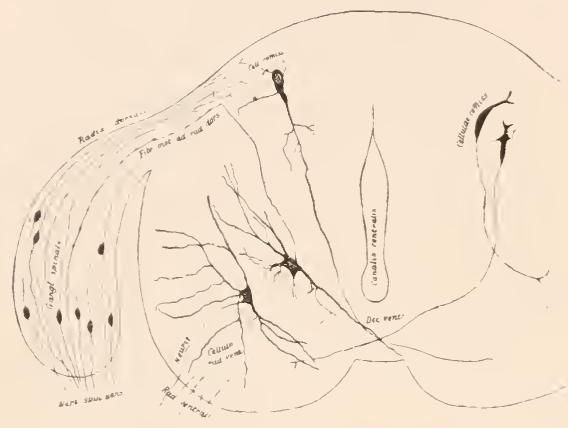

Fig. 34.

Schnitt durch das Rückenmark eines Hühnerembryo. Combinirt nach mehreren Präparaten ron Retzius. Zur Demonstration einiger Zellarten. enden dann, nach längerem oder kürzerem Verlaufe wieder einwärts biegend. in der granen Substanz. Unterwegs schon haben sie zahlreiche Collateralen in jene hinein gesendet. Solche Zellen sind geeignet, rerschiedene Höhen des Rückenmarkes unter einander zı verknüpfen. Маи nemnt sie Cellulae c o $\mathrm{mm}$ is s u ra les. Viele Neurite ans solchen Commissurzellen

kreuzen ganz ventral von der grauen Substanz. mitten zwischen den Vorderhörnern. Nan nennt diese Krenzung Decussatio rentralis des Rückenmarkes. An eben der gleichen stelle liegen übrigens noch andere Kreuzungsfasern, z. B. solche zu Torderwurzeln aus Zellen gekrenzt liegender Vorderhörner, bei Säugern anch noch centralere Bahnen. Bei den Knochenfischen und zum Theil anch bei den Selachiern, sind die einzelnen Elemente der Commissura rentralis soweit getrennt, dass man oft ganz dentlich zwei über einander liegende Commissuren erkennt.

Nitten in der granen Substanz ziehen auch noch überall lange Bahnen markhaltiger Nerven auf- und abwärts, zum Theil verlängerte Wurzelbahnen. zum Theil Abhömmlinge von Commissurzellen, zum Theil auch Fasern anderer Herkunft. Bei den Cyclostomen und bei einigen Knochenfischen sind ihrer relativ so viele, dass es gar nicht zu einer ganz scharfen $\mathrm{Ab}$ scheidung der grauen Substanz von einer peripheren weissen kommt. 
Bei den meisten Vertebraten aber finden wir das centrale Rückenmarksgrau umgeben ron weissen Fasersträngen. Wenn Sie sich eimmal die Hohlräume in dem $\mathrm{X}$ des Querschnittes ausfüllen wollen, so unterscheiden sie sofort Dorsal- oder Hinterstränge, Ventral- oder Vorderstränge und Lateral- oder Seitenstränge. Dass die Hinterstränge zumeist, oder ganz, aus auf- und absteigenden Hinterwurzeln bestehen, habe ich Ihnen vorhin schon mitgetheilt. In den Seiten- und Vordersträngen müssen die Bahnen gesucht werden, welche, aus den Commissurzellen stammend, die Einzelhöhen verknüpfen. Man nennt sie gewöhnlich kurze Bahnen des Narkes. In den Vordersträngen liegen aber, schon von den Fischen an. auch ganz lange Bahnen. So findet man namentlich dicht an der grauen Substanz bei diesen und bei den Larven der Amphibien jederseits eine. manchmal auch mehrere sehr dicke Fasern, die M a u th n e r'schen Fasern. Im Schädel, nahe dem Lrsprung des statischen Nervus VIII aus riesigen Ganglienzellen entspringend, können ihre dicken von enormer Markscheide umhüllten Axencylinder bis hinein in die Schwanzwirbelsäule verfolgt werden. wo sie mit den letzten Sacralnerven austreten (Fritsch). Wer die Wichtigkeit der Schwanzmuskulatur für die Aufrechterhaltung des Gleichgewichtes schwimmender Thiere kennt. der wird wohl erklärlich finden. dass sie speciell mit der Gegend der Ampullennerven verbunden ist. Tenn bei vielen Fischen von Aalform diese Fasern bisher vermisst werden. B. Haller, so kann das sehr wohl auf der bei solcher Körperform wesentlich andersartigen Statik beruhen. In der Fig. 2s sind diese Fasern als Filrae acustico-sacrales bezeichnet.

Soweit wäre das Rückenmark als selbständiges Centrum geschildert. Als solches rermag es bekanntlich in sehr vielen Beziehungen zu fungiren. Alle die Versuche an enthirnten Thieren zeigen das. Sie lehren, dass im Rückenmarke nicht nur die Bahnen für ganz einfache Reflexe vorgebildet sind, sondern, dass auch recht complicirte Bewegungscombinationen von da aus allein innervirt werden kömen. Wenn die geköpfte schlange sich, wie die ungeköpfte. um die gebotene Stïtze windet. wenn die enthirnte Ente davon schwimmt oder das geköpfte Kaninchen einige regelrechte Galoppsprünge ausfülıren kann, so ist das gar nicht anders erklärbar, als dass für diese im Leben unendlich oft ausgeführten Bewegungen im Rückenmark fertige Mechanismen vorhanden sind, die einmal angeregt in genau gesetzmässiger Weise einfache oder successive Bewegungscombinationen erzeugen.

Die Reize. welche das Rückenmark von aussen treffen. also diejenigen, welche ihm auf dem Wege der sensiblen spinalnerven zugeführt werden, sind allein schon im Stand. Tieles von dem zu erzeugen. was man früher für nur durch höhere seelische Processe erreichbar hielt.

Es ist wesentlich das Verdienst von Pflüger und Goltz, wemn wir heute erkennen, dass das Rückenmark ein selbständiges Organ ist, das für sichzu bestehen und infrüher ungeahntweitgehender Treise $\mathrm{zu}$ fungiren vermag. S. Exner hat es unternommen, fiur einige der oben

Edinger, Norvöse Centralorgane. 5. Auflage. 
erwähnten Bewegungscombinationen anatomische Grundlagen zu construiren, die sich an keiner Stelle von dem factisch Nachweisbaren entfernen und nur mit vorhandenen Verbindungsmöglichkeiten rechnen sollten. Längst schon hatte man das einfache Schema des Reflexbogens, die Verbindung der eintretenden sensiblen Bahn mit motorischen Elementen gleicher Höhenlage. Fig. 33 zeigt Ihnen dafür die anatomische Unterlage. Mit dem Nachweis, dass die Dendriten der Einzelzellen sehr vielerlei Zellen unter einander, und dass die Axencylinder der Commissurzellen mannigfache Höhen unter einander verknüpfen können, ergab sich erst die Möglichkeit weitergehende Constructionen auszuführen. Man konnte sehr wohl einen Reiz, der von einer sensiblen Wurzel eingeleitet wurde, auf mehrere motorische Kerne in verschiedenen Höhen sich ausbreiten lassen, auch sich Bahnen ausdenken, welche wegen grösserer Breite u. s. w. leichter als andere oder intensiver von gleichem Reize betreten werden. Nahm man dazu die durch Versuche sehr wahrscheinlich gemachte Eigenschaft der Ganglienzellen, ankommende Reize bis zu gewisser Höhe aufzuspeichern und damn mit einemmale abzugeben, so waren Grundelemente gegeben, an deren Hand man nun bestimmte Bewegungen prüfen konnte. In der That ist es Exner gelungen nachzuweisen, dass Vorgänge, die ganz ungewöhnlich complicirt scheinen, recht wohl heute schon derart analysirt werden können. Natïrlich liess sich für keine einzige Bewegung die Unterlage sicher construiren, aber es muss doch befriedigen, dass unsere heutigen Kenntnisse vom Rückenmarke schon ausreichen zu zeigen, wie die Dinge verlaufen kömnten.

Die Thätigkeit des Rückenmarkes kann von anderen Theilen des Centralorganes aus beeinflusst. regulirt, gehemmt, erregt werden. Sehen wir uns um. was ïber die Bahnen bekannt ist, welche hierzu geeignet wären.

Wesentlich auf Grund eigener Untersuchungen kann ich Ihnen mittheilen, dass von den Selachiern und Knochenfischen bis zu den Säugern einige wenige Bahnen coustant rorkommen. Zunächst ist das Rückenmark immer mit dem Cerebellum rerbunden. Die Bahn - Tractus cerebello-spinalis - liegt bei den Säugern und wahrscheinlich auch bei den Vögeln und Reptilien in der Peripherie der Seitenstränge, bei den Fischen habe ich sie zwar spinalwärts verfolgt, kam aber auf den betreffenden Längsschnitten über die Lage in den Strängen nicht in`s K'lare. Doch habe ich Grund zu der Annahme, dass sie auch hier in den Seitensträngen liegt und in den dicken Fasern wiedererkannt wird, welche Sie z. B. in der Abbildung des Gymnotusrüickenmarkes, Fig. 31, im Seitenstrange sich abheben sehen.

Damn giebt es überall eine Bahn aus der Tiefe des Zwischenhirnes nach den Tordersträngen, die von Alters her bei den Säugern bekannt. dort den Namen Fasciculus longitudinalis dorsalis oder posterior empfangen hat. Fig. 14.

Schliesslich kam mit sehr grosser Wahrscheinlichkeit angenommen werden, dass ein mächtiges Markfasersystem, welches im Mittelhirndache. Tectum opticum, entspringt, überall bis in die Vorderseitenstränge hineingelangt. Es handelt sich bei diesen Fasern, die bei Fischen und Tögeln in der Ursprungsgegend besonders reich vorhanden sind, wahrscheinlich um eine centrale sensorische Bahn. Tiefes Nittelhirmmark heisst sie bei ihrem 
Ursprung; weiter im Hinabziehen heisst das Bündel Schleife. Im rerlängerten Marke kann man mit aller Sicherheit erkennen, dass Fasern aus dieser schleife da entspringen, wo sensible Nerven iln Ende finden. Sie entstammen den Zellen, un welche sich die aus den Ganglien konmende Nervenwurzel aufzweigt. Auch für das Rïckenmark gelang es nachzuweisen, dass aus den Zellen der grauen Substanz, um welche sich die dorsalen Wurzehn aufzweigen, Axencylinder stammen, welche nach Kreuzung in der ventralen Commissur in den Torder- und Seitensträngen lirnwärts ziehen. Diese Fasern sind von den aus Commissurzellen stammenden aber heute noch nicht sicher zu unterscheiden. So ist zwar aus klinischen und experimentellen Gründen wahrscheinlich, dass es eine gekreuzte sensorische Bahm in den Seitensträngen giebt, aber anatomisch steht der Nachweis noch aus. Es handelt sich um einen Schluss nur. Die secundäre sensorische Bahn, welche aus den Zellen des Rückenmarkgranes stammend in den Vorderseitensträngen hirnwärts zieht, ist höchst walırscheinlich ein Theil der Schleifenbahn. endet also im Mittelhirndache. Das ganze System soll in Zukunft als Tractus tectospinales, resp. da, wo es zu Bulbärkernen geht, als Tr. tecto-bulbares bezeichnet werden.

Bei Reptilien und Vögehn erkemne ich noch ein Fasersystem aus den Thalamusganglien zum Rückenmark. Seine Existenz bei Säugern ist wahrscheinlich, über die Fische fehlen mir Erfahrungen. Tractus thalamospinales.

Bei den Säugern gesellen sich nun zu den erwähnten noch einige andere Bahnen. Vor Allem solche aus der Rinde des Hemisphäriums, die Tractus cortico-spinales. Diese bisher nur bei den Säugern nachgewiesenen Züge nehmen bei verschiedenen Arten wechselnde Lage im Rïckemmarke ein. Am längsten sind sie vom Menschen als Pyramidenbahn der Seitenstränge bekannt, bei der JTaus und dem Meerschwein liegen sie in den Hintersträngen ganz nahe der Commissura dorsalis, bei dem Hunde und bei allen Affen sind sie in den dorsalen Abschnitten der Seitenstränge gelegen. Beim Menschen verläuft übrigens ein Theil auch in den Ventralsträngen. Sie sind beim Menschen am meisten entwickelt und bei vielen nieder stehenden Säugern nur in wenigen Fasern repräsentirt.

Messungen von Lenhosseck liaben ergeben, dass sie, welche beim Menschen fast 12 Procent des ganzen Rückenmarkquerschnittes ausmachen, bei der Katze nur 7,76, beim Kaninchen nur 5,3 und bei der Maus gar nur 1,14 Procent des Gesammtquerschuittes einnehmen.

Man hat den Eindruck, dass diese Züge etwa in dem Naasse ausgebildet sind, wie die Grosshirnrinde für die erlernbaren Functionen der Extremitäten in Anspruch genommen wird. Ich bilde hier ein menschliches Rückenmark ab, in dem jene Tractus durch Erkrankung entartet sind und zeichne daneben ein Hunderiickenmark, welches durch Wegnahme der Hemisphären den gleichen Faserausfall erlitten hat, um Thnen 
den Unterschied in der Ausdehnung des Areals der Rindenrückenmarkbahn zu zeigen.

$A$

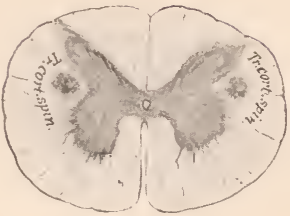

$B$

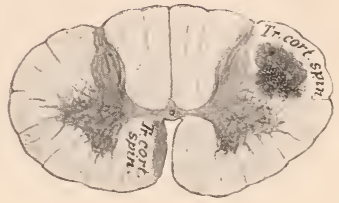

Fig. 35.

$A$ Hunderückenmark, in welchem durch Wegnahmo des ganzen Grosshirnes (Goltz) die Tractus cortico-spinales beiderseits entartet sind. $B$ Menschl. Rückenmark, in welchem, bedingt durch einen starken Bluterguss in die linke Hemisphäre der Tractus cortico-spinalis anterior et lateralis degenerirt ist.

Natürlich gesellen sich alle diese Züge aus frontaler liegenden Hirntheilen zur granen Substanz des Rückenmarkes denjenigen Nervenfasern zu, welche in der Ungebung jener Substanz als weisse Narkstränge liegen und oben schon erwähnt wurden. Der we is s e M a r k m a n t e l des Rückenmarkes ist schon bei den Fischen ein recht breiter. Dort sind es wesentlich die Torder- und die Seitenstränge, welche gut entwickelt sind, die Hinterstränge sind immer sehr riel dïmner als bei den anderen Tertebraten, zum Theil weil in den Seitensträngen Elemente liegen. welche anderswo nur in den Dorsalsträngen verlaufen, zum Theil auch weil, wie schon oben mitgetheilt wurde, die Tersorgung der Körperoberfläche bei den Fischen nicht so ausschliesslich durch spinale Wurzeln geschieht. wie bei anderen Vertebraten.

Dass aus dem Markmantel Fasern in das Grau eintreten, dass aus Zellen im Grau Fasern sich zum Narkmantel gesellen, das ist dargelegt. Bei den Amphibien und den Fischen aber liegen hier noch andere bisher nicht erwähnte Elemente. Es gehen nämlich, wie Sie z. B. an Fig. 29 gut sehen, zahlreiche Dendriten von Ganglienzellen heraus in den Markmantel und zweigen dort auf. Ganz ebenso ist es bei den Embryonen der Vögel und säuger, aber bei den erwachsenen Thieren findet man solche Dendriten im Markmantel nur noch seltèn.

Schliesslich sei erwähnt, dass bei manchen niederen Vertebraten mitten im Markmantel auch echte Ganglienzellen gefunden werden. So giebt es eine Gruppe mächtiger derartiger Zellen an der Peripherie der Dorsalstränge bei den Cyclostomen und bei einigen Fischen "Dorsalzellen" und damn ganz regelmässig grosse Ganglienzellen neben einigen motorischen TVurzeln, welche wohl ihre Neurite in diese hinein senden. Eines merkwürdigen Verhältnisses, welches bei den Vögeln existirt, ist noch zu gedenken. Dort schiebt sich nämlich im Lendenmarke eine Gewebsmasse so zwischen die Dorsalstränge ein, dass diese auseinander gedrängt wer- 
den, so weit, dass man früher eine wirkliche lumbale spaltbildung bei den Vögeln glaubte ammehmen zu dïfeu. Sinus rhomboidalis.

Sie haben mu wohl schon erkannt, dass die Elemente. welche die Rïckenmarkstränge zusammensetzen, sehr verschiedener Provenienz sind. Der blosse Anblick des Querschnittes lässt das freilich nicht vermuthen. Es bedarf zumeist längerer entwicklungsgeschichtlicher und anderer Untersuchungsmethoden, um völlige Klarheit zu gewinnen, zum Mindesten aber ist in allen Fällen sorgfältige Vergleichung vieler Quer- und auch
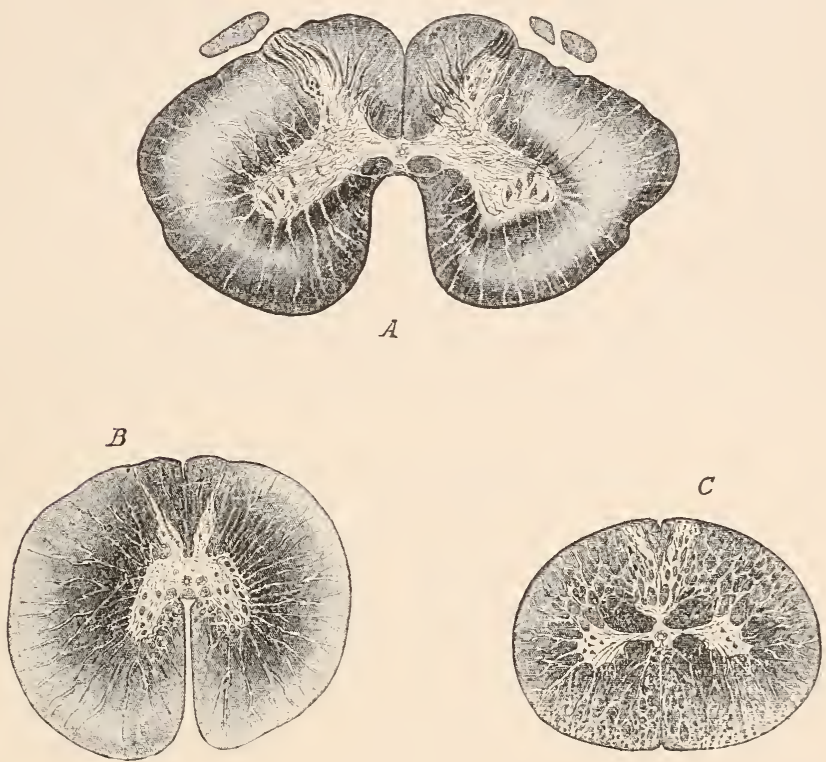

Fig. 36.

Drei Rückenmarksschnitte von grossen Individuen verschiedener klassen. A rom Krokodile, Crocodilus africanus. $B$ vom Strauss, Struthio camelus. $C$ von einem Hai, Mustelus.

Längsschuitte erforderlich, wemu man auch nur über das Gröbste Klarheit haben will.

Ueberraschend wirkt auf denjenigen, welcher nur das menschliche Orgau kemut, die oft sehr beträchtliche Grösse des Rückenmarkes sehr niedrig stehender Thiere. Das Rückenmark ist eben ein ganz selbständiges Organ, dessen Grösse weseutlich von dem mit Spinalnerven zu versorgenden Areal und nur in ganz geringem Maasse von der Entwicklung der auderen Theile des Centralnervensystems abhängt. Es bezieht bei den niederen Vertebraten nur wenig Fasern und auch nicht sehr viele 
bei den höheren ron weiter rorn gelegenen Hirntheilen. Wollen Sie sich einmal leicht hiervon ïberzengen, so nehmen Sie den ja iiberall leicht zu erhaltenden Kopf eines Schellfisches, Gadus aeglefinus, oder sonst einen grossen Fischkopf, öfnen Sie ihn und rergleichen sie das minimale Gehirn mit dem enor'm dicken Rückenmarke. Dieser Fisch besitzt eben ein Rückenmark, das fast ausschliesslich echt spinale Elemente und nur ganz wenige cerebrale enthält. Die spinalen aber sind mächtig, weil die enorme Rumpfmuskulatur und die grosse Körperoberfläche einer reichen Innervation bedürfen.

Dies zunächst bei den hergebrachten Ansichten auffallende Verhältniss kann leicht bis in die hohen Säuger hinein verfolgt werden. Das Gehirn des Pferdes oder des Ochsen ist wesentlich kleiner als dasjenige des Menschen, ihr Rückenmark aber übertrifft das menschliche um mehr als das Doppelte an Dicke.

So will ich Thnen zum Schlusse noch die-Rückenmarke dreier niedrig stehenden Tertebraten vorlegen. die alle bei der gleichen Vergrösserung: gezeichnet sind, die Sie auch wohl mit dem Hunderüickenmarke der Fig. 35 vergleichen mögen. Das Hairüickenmark, das etwas kleiner als die anderen erscheint, kann bei grösseren Exemplaren ganz die Dicke des Krokodilrïickenmarkes erreichen und dieses hat ganz die Grösse und Dicke wie das gleiche Organ ron einem 1 jährigen Kinde.

\section{Sechste Vorlesing.}

\section{Die Oblongata und die Kerne der Hirnnerven.}

II. H. Wir wollen heute den Theil des Centralnerrensystemes betrachten, welcher die Kopfgegend mit Nerven versorgt. Dabei erimnern wir uns, dass der Rumpttheil. das Rückenmark, wie in der vorigen Stunde gezeigt worden ist, ein im Wesentlichen selbständiges Nerrencentrum darstellt, das nur durch einige, für rerschiedene Klassen etwas wechselnde Bahnen mit dem dicht an ihn grenzenden Marke rerbunden ist, dass ein Thier leben und sich in modificirter Weise bewegen kann, wenn der Rumpftheil des Centrahnervensystemes röllig ron dem Kopftheile getrennt ist. ja, dass, bleibt nur der Kopftheil erhalten, welcher wichtige Nerren für Athmung und Kreislauf enthält, die Existenz des Thieres durch den völligen Terlust des Rumpftheiles nicht vernichtet wird; vorausgesetzt natürlich, dass es von den damn einsetzenden äusseren Schädigungen bewahrt werden kam. Das gilt noch für die Säuger, Goltz; für niedere Tertebraten ist es sogar sehr wahrscheinlich, dass auch der Kopfabschnitt für einige Zeit ausser Function bleiben kann, olne dass sofort der Tod einträte.

Wir haben also heute einen Complex ron Nerrencentren zu betrachten, der sich den bisher beschriebenen zugesellt. von ilm pliysio- 
logisch nicht abhängig ist. wohl aber von ihm beeinflusst werden kamn, resp. ihn beeinflussen kamn.

Am Kopfende des Rückenmarkes erkennt man sowohl in der äusseren Form als auf dem Querschnittsbilde sehr wesentliche Teränderungen. es geht in das verlängerte Mark, die Medulla oblongata, iiber. Diese Verändermngen sind mit nur geringen Nodificationen überall die gleichen, aber sie treten bei niederen Tertebraten, wo das Kiemengebiet ron besonders mächtigen Nerven zu versorgen ist. vielfach klarer in Erscheinung als bei den säugern.

Immer erkennt man, dass die Dorsalstränge auseinander weichen, dass an ihrem Grunde die Commissura dorsalis und die dicht unter ihr liegende graue Substanz um den centralkanal offen zu Tage treten. Der dorsale Abschluss der Rückenmarkshöhle wird also nur noch durch eine dünne Membran gebildet. Weiter nach vorn verbreitert sich mit dem Beiseitetreten der stränge dieses membranöse Dach immer meln, es bedeckt damn als Tela chorioidea posterior den zum Tentriculus quartus erweiterten Hohlram des Centrahnervensystemes und geht schliesslich noch weiter frontal direct in die Formatio cerebelli über.

Die Tela choroidea posterior ist ïbrigens kaum je ein einfach glatt ausgebreitetes Deckblatt über dem Ventrikel. Sie ist sehr viel grösser als zu diesem Decken nothwendig wäre und hängt in langen Windungen und Faltungen so-

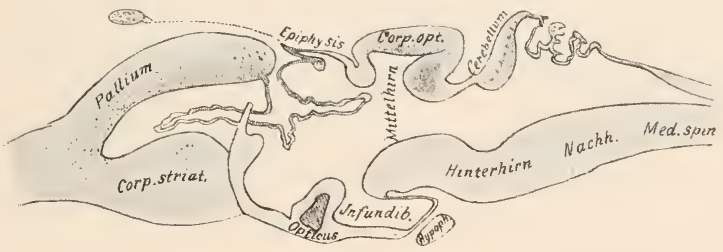

Fig. 37.

Sagittaler Schnitt durch ein Amphibiengehirn, ein wenig Jateral von der Jedianlinie. Zur Demonstration des Uebergangs dor Tela chorioidea posterior nnd ihrer Faltungen. Schema.

wohl in den Ventrikel selbst, als an den Seiten der Oblongata herab. Es hängt von der Thierart ab, und ganz vornehmlich von der Ausdehnung, welche das Kleinhirn erlangt, wie reich jene Faltungen sind. Wenn, wie z. B. bei den Cyclostomen oder auch bei den Amphibien, das Cerebellum sehr klein ist, dam erblickt man bei der Untersuchung des Gehirnes von oben über dem verlängerten Marke eine ganz breite, vielgefaltete, ziemlich ovale, röthliche Platte, eben die Flächenansicht der Tela chor. post. Bei den Vögeln und den Säugethieren ist die dorsale Ausdehnung gering, aber beiderseits vom verlängerten Marke sieht man doch die Zotten in den Ventrikel ragen und neben ihm herabhängen. Siehe Fig. 242. Alle diese Falten sind durchweg von einer einfachen Lage cylindrisclien Epithels gebildet, welches dicht auf einem reichlichen Blutgefässplexus liegt, der rom Schädel her in alle Falten eindringt. Fortgesetzte Untersuchungen über die eigenthümlich wechselnden Körnungen in diesen Zellen, lassen es mir 
als wahrscheinlich erscheinen, dass es sich um active, wahrscheinlich den secernirenden Zellen nahe stehende Gebilde handelt. Beim Frosche erinnern z. B. die einzelnen ron der Decke herabhängenden Adergeflechtknoten auf dem Schnitte lebhaft an die einfach gebauten Glomeruli in der Niere des Thieres. Indigcarmin, welches im Blute kreist, wird in den Epithelien der Tela chorioidea körnig abgelagert.

Ausserdem verdickt sich das Nervensystem sehr wesentlich im Bereiche der oblongata.

Dazu tragen rorwiegend zwei Umstände bei. Erstens das Anftreten der Formatio reticularis. eines Associationssystemes ron Fasern kurzen Terlaufes. welches überall zwischen Rïckemmark und Zwischenhirmbasis angetroffen wird. aber hier unten besonders stark entwickelt ist. und zweitens die Nervenkerne. In Bereiche des schädels treten nämlich auf ganz kurzer Strecke drei sehr mächtige Nerven in das Centralorgan, der Tagus, der Acusticus und der Trigeminus. Da, wo sie ihre Endkerne haben. schwillt jenes natiirlich enorm an. Natirlich trägt auch die

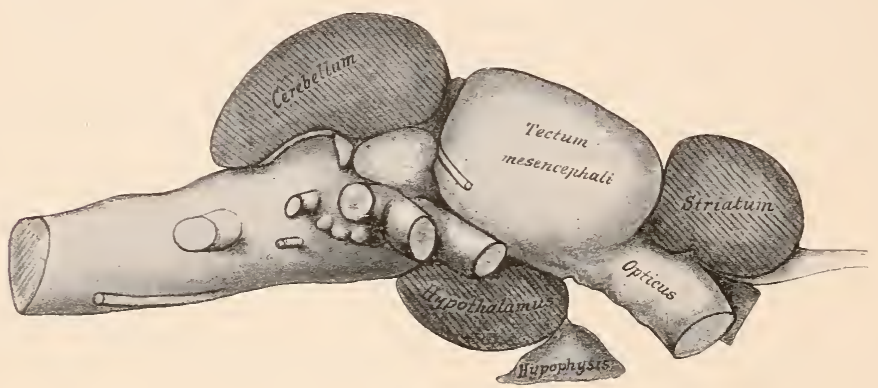

Fig. 38.

Gehirn des Schellifsches, Gadus aoglefinus. Dio Theile, welche nicht direct Hirnnerven zugehören, schattirt.

mächtige rom Hirn her zu solchen Kernen ziehende Faserung nicht wenig zum Tolum bei.

Ton welcher Mächtigkeit bei niederen Tertebraten die Faserung der Hirnnerven ist, daron macht man sich gewöhnlich keine richtige Torstellung. Bei dem Siluroiden. dessen Hirn Fig. 35 bringt, sind die Nervenwurzeln allein zusammen viel grösser als das ganze übrige Hirngebiet, welches nicht zu ihrer Endigung in Beziehung steht. Auf Schnitten durch die Oblongata der Fische erkennt man, dass sie ganz rorwiegend nur Endstätte der mächtigen Trurzeln ist. Alle ïbrige Faserung tritt gegenïber dieser ïbermächtigen ganz in den Hinterorund.

Schliesslich existieren innerhalb des verlängerten Markes noclı einige specielle Centren. welche zum Kleinhirn und zum Acusticus in Beziehung stehen und als viertes Ioment wäre zu erwähnen. dass diese Hirnstrecke natürlich ron den Bahnen durchzogen wird. welche ron frontaleren Hirn- 
theilen dem Rückenmark zuwachsen, ebenso wie sie die ron daher kommenden, ihr allein bestimmten Faserzüge noch aufnehmen muss.

Ein Blick auf die von oben her geöffnete Oblongata des störes — die Tela ist links zur Seite geschlagen - lehrt, wie sich zunächst makroskopisch diese Dinge gestalten. Ich habe absichtlich den Ganoiden gewählt weil er einerseits die allgemeinen Verhältnisse gut erkemnen lässt und auch gleichwie alle Fische sehr grosse deutlich sichtbare Nervenkerne hat, aber doch nicht solche unförmlichen Hervortreibungen da aufweist, wie sie etwa die Cyprinoiden an gleicher stelle oder einige Selachier haben, wo bestimmte Kerne, besonders die Taguskerne sozusagen das ganze Bild beherrschen. Umgekehrt haben die Reptilien. Tögel und Sänger zwar ganz die gleichen Anordnungen; diese sind aber wegen der verhältnissmässigen Kleinlıeit der Hirnnerven, nicht so gut erkemubar.

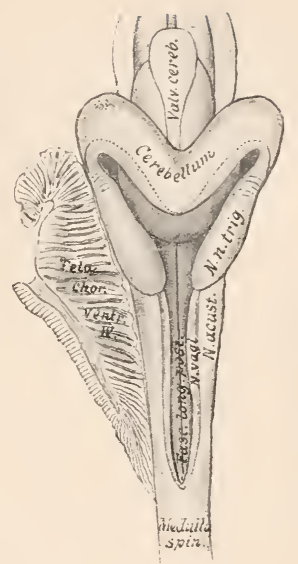

Fig. 39.

Die Oblongata and das Kleinhirn des Störes. Accipenser ruthenus, nach Goronowitsch.
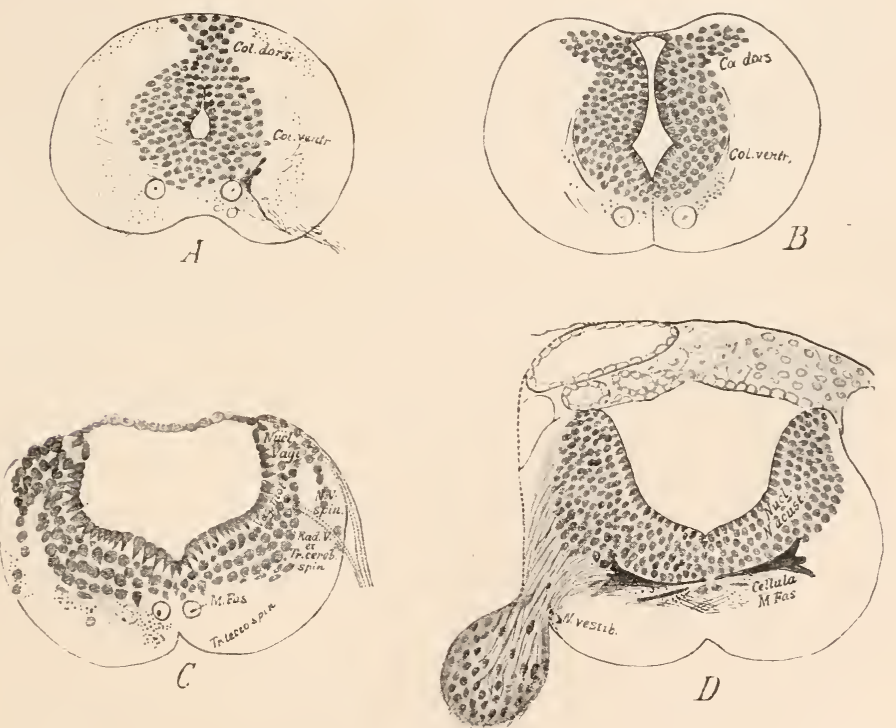

Fig. 40.

Vier Schnitte durch das Ifark einer $4 \mathrm{Cm}$. langen Larve von Salamandra maculata. 
Tenn so grosse Teränderungen am Kopfende des Rückenmarkes auftreten, so macht sich dies noch mehr als bei der äusseren Aufsicht dam geltend, wenn man Querschnitte anlegt.

Vielleicht gehen wir am besten ron der nun einmal für das Rückenmark Thnen bekannten Anordnung aus und wählen, um ganz einfache Terhältnisse zunächst eimmal vor uns zu haben, zum ersten Objekte das Gehirn ron Amplibienlarven. Fig. 40.

Hier wird die graue Substanz noch fast ganz durch jene Anhäufung ron Neuroblasten gebildet, ron denen in der Entwicklungsgeschichte die Rede war; zwar begimnen einzelne in ihrer Umgebung liegende Faserzüge sich mit Mark zu umhïllen, aber noch verwirrt nicht, wie bei älteren Thieren, ein mächtiges Fasersystem die Verhältnisse, auf deren Demonstration es zunächst hier ankommt. Auf $A$ der Figur erkemnen sie die Torder- und die Hintersäulen des Rückenmarkes, aber da der Schnitt aus dem Halsmarke stammt, fällt zunächst auf, dass die letzteren der Peripherie viel breiter anliegen als weiter caudal. Auf $B$ weichen diese Hinterhörner aus einander. das dorsale Epithel des Centralkanales wird zur Bildung der Tela chorioidea rerwendet. Nun liegen beiderseits rom Ventrikel graue Massen, bestimmt, wie die Hinterhörner bisher, sensible Nerren aufzunehmen. Auf Fig. $C$ ist ein solcher Nerv, der Vagus, der hier mündet, eingezeichnet. nur punctirt, weil er auf einem einzigen Schnitte nicht so vollständig zu sehen war, wie es die Abbildung wiedergiebt. Bemerken Sie gleichzeitig die Zunahme der grauen Hintersäule an der Vaguseinmiindung. Noch weiter oben bei $D$ mündet der mächtige Acusticus mit einer seiner Turzeln und nun sehen Sie zwar das Rückenmarksbild völlig rerwischt, aber ein einziger Blick rückwärts über die Figuren lässt Sie erkennen, welchem Gebiete die graue Substanz an der lateralen Kante unseres Präparates entspricht.

Die Torderhörner des Rïckenmarkes sind schon auf $B$ nicht mehr deutlich, aber hier, und besser noch auf $C$. sehen sie, dass ihnen noch Fasern entstammen. Auf Fig. $A$ haben sie den als Hypoglossus fungirenden linken Cerricalnerven abgegeben, auf $C$ entsenden sie auch noch motorische Fasern, aber dorsalwärts laufende, die sich zum Vagus als motorische Trurzel wenden. Die Zellsäule der Torderhörner bleibt num weiter hinauf bestehen, ilır entwachsen höher oben die motorischen Fasern zum Facialis und diejenigen, welche mit dem Trigeminus austreten. Wahrscheinlich übrigens handelt es sich beim Facialiskern um eine andere Zellgruppe als bei dem Vaguskerne. Hier kommt es mir zunächst nur einmal darauf an, in kurzen Zügen zu zeigen, wie aus dem Rückemmarksgrau dasjenige des verlängerten Markes hervorgeht.

Und nun können wir uns zu einem complicirteren Objecte wenden an dem sich einige besonders wichtige Terhältnisse des Oblongataanfanges demonstriren lassen.

Ich lege hier einen schnitt durch den untersten Theil der Oblongata 
von Cephaloptera, einem grossen Rochen, vor. Das Präparat hat in natura etwa den Umfang eines menschlichen Rückenmarkes.

Nou bemerken Sie wieder, wie in der vorigen Torlesung, die Tentralsäulen, aus denen hier Nerven stammen, die als oberste c'ervicalnerven abgehen und etwa das Gebiet rersorgen, das bei höheren Thieren von dem zwölfien Hirmmerven, dem Hypoglossus innervirt wird. Bei den Reptilien, Tögeln und Säugern, namentlich bei den letzteren zwei, entspringt der Hypoglosuss aus grossen Zellen, die beiderseits dicht neben den Centralkanal in langer Säule angeordnet sind. bei den Fischen hat sich aber hierfür noch keine so scharfe Trennung entwickelt. Die Tög'el haben übrigens - Koch - noch einen ventraler liegenden Trsprungskern neben dem dorsalen. sie nähern sich hierdurch noch den unteren Klassen, wo der Hypoglossus ganz wie ein anderer spinalnerv seine Fasern aus Zellgruppen in verschiedener Lage der Torderhörner bezieht.

Auch die Dorsalsäulen sind noch sichtbar, aber es wird Ihnen schon schwerer werden, sie denjenigen ähnlich z! finden, welche ich frïher von anderen Riickenmarkell demonstrirt habe. sie haben sich nämlich sehr verbreitert, sind aus einander gefallen in netzförmig zerstreute graue Substanz und, was sofort auffällt, es sitzt ihnen

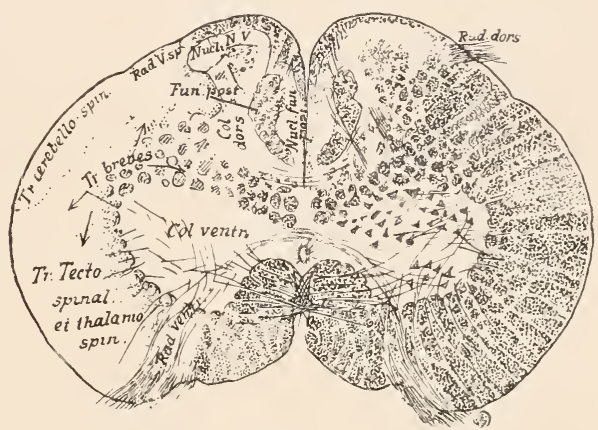

Fig. 41.

Schnitt durch die Oblongata ron Cephaloptera Jumpus. ein im Querschnitt halbmondförmiger Kern aut. Das Auftreten dieses rinnenförmigen langen Gebildes, welches bis hoch hinauf unter das Kleinhirn reicht, ist charakteristisch für den oberen Rïckenmarkabschnitt und die Oblongata. Stärkere Vergrösserung lässt erkennen, dass dieser merkwürdige Kern auf seinem ganzen Terlaufe feine Fasern aus der dunklen Markfasermasse anfinimmt, die seiner Peripherie anliegt und wenn man diese nach oben hin verfolgt, kamn man sie bis dahin treffen, wo der Trigeminus aus dem Ganglion Gasseri in das Hirn hinein strömt. Nun erst erkennt man, um was es sich handelt. um ein mächtiges Bündel aus jenem sensiblen Ner'ven, welches vom Ganglion weithin in das Rückenmark hinabzieht um dort in dem erwähnten Kerne zu enden. Das Bündel heisst Radix spinalis Trigemini, der Kern an der Spitze des Dorsalhornes (Substantia gelatinosa Rolandi) ist sein Endkern. Medial ron diesem Kerne liegen Fasern aus den Hintersträngen. Sie umgeben wieder grane Massen, die, in der Verlängerung der frïheren Hintersäulen gelegen. hier als Kerne der 
Hinterstränge bezeichnet werden. Bei den Vögeh und säugern ist die Existenz von Kernen. in welche ein guter Theil der von hinten her aufsteigenden Dorsalstrangfasern eimmündet, völlig ansser Zweifel gestellt und ich verweise gerade hier für das Nähere auf die Darstellung in späteren Torlesungen, aber bei den Fischen und Amphibien ist die Annahme, dass die erwähnten granen Massen wirkliche Hinterstrangkerne sind, noch nicht absolut sicher. Es fehlen noch die beweisenden Degenerationsversuche. Desshalb bezeichne ich bei ('ephaloptera diese Kerne nur mit Reserve als Hinterstrangkerne.

Tras aber unseren Querschnitt so sehr von demjenigen der früher demonstrirten Rückenmarke unterscheidet, das ist der L'mstand. dass überall in dem Raume. der zwischen Vorder- und Hinterhörnern liegt, zahllose Commissurenzellen aufgetreten sind, Zellen, die ihre mächtigen Axencylinder zu kleinen Bündeln geordnet hinauf zur oblongata, ja bis in das Mesencephalon und das Diencephalon senden. Es handelt sich hier wahrscheinlich um ein mächtiges Associationssystem. welche kürzeren mnd längeren Terlaufes einzehne Höhen des Centralapparates mit dem frontalen Rückenmarkende und anch unter sich rerknüpft. Dieses system, das bei allen Thieren an gleicher stelle vorhanden ist. charakterisirt das Nachhirn und ist wohl geeignet. der Träger jener complicirten zusammenordnenden Functionen zu sein, deren Torhandensein an die Existenz des verlängerten Markes geknüpft ist. In der Figur ist dieses Gebiet als Tractns breves bezeichnet.

Offenbar handelt es sich um eine Zunahme jener schon für das Rückenmark geschilderten Cellulae commissurales und der ihnen entspringenden Bahnen. Ganz wie im Rückenmark existiren hier gekreuzte und ungekreuzte Fasern kurzen Terlaufes. Natürlich nimmt bei solcher Zumahme des ganzen systemes in der Oblongata jene im Rückemmark noch schmale rentrale Commissur sehr zu; sie erstreckt sich auf eine längere dorso-ventrale strecke und ist ron hier ab bis hinauf unter die Tierhügel als Raphekreuzung zu verfolgen.

Innerhalb der Raphe kreuzen natiirlich, ganz wie es auch schon fïr die Tordercommissur des Rückenmarkes angegeben wurde, noch eine Anzahl anderer Fasercategorien. Wir werden später von ihnen zu sprechen haben.

Das Associationsfeld der Oblongata ist bei den niederen Vertebraten ganz ebenso stark wie bei den höchsten entwickelt wie z. B. ein Tergleich der Fig. 11 mit der Fig. 230 lehrt. Es handelt sich hier offenbar um die anatomische Grundlage für vital ungemein gleichartige Torgänge.

Durch das Associationsfeld werden die Fasern. Welche aus dem Rïckenmarke zum Kleinhirnund zum II ittel-sowie Z wischenhirn ziehen, lateralwärts an die Peripherie gedrängt. Sie finden die Lage der Tractus cerebello-spinales und der Tr. tecto-et thalamospinales im Seitenstrang in Fig. 41 markirt. 
Die Tractus tecto-spinales enthalten, wie frïher gezeig't wurde. gekreuzte Bahnen aus den Endkernen. in welche die sensiblen Fasern der Rückenmarkswurzeln mündeten. sie sind also wohl eine secundäre sensible Bahn aus jenen Kernen zum Mittelhirndache. Hier oben in der Oblongata gesellen sich ihnen die noch weit mächtigeren Fasern aus den Endkernen der Hirnnerven hinzu, so dass man das nun mächtige Bündel. welches oft - Fische z. B. - in viele Abtheilungen zerlegt werden kann. zweckmässig nun unter dem Namen Tractus tecto-spinales et bulbares vereint. Es trägt seit langem den kürzeren Namen: Schleife, L a queus.

Die schleifenschicht erfährt aber in der Oblongata noch eine weitere Termehrung. Sie stammt im Wesentlichen. Wie Sie nun schon wissen. aus den Kernen der Rückenmarks- und Hirmnerven auf der gekrenzten Seite. Nun erinnern Sie sich, dass bei vielen Tertebraten ein guter Theil der Hinterwurzelfasern nicht im Grau endet, sondern in den Hintersträngen hinauf zur Oblongata steigt. Dieser Theil der sensiblen Faserung ist also oben am Beginn des Oblongata noch ungekreuzt. Er mïndet in die Kerne der Hinterstränge ein, welche am Oblongata-Anfang die Hinterhörner selbst ersetzen, aber viel breiter sind als jene. Bei den Vögeln und den Sängern, wo jene Kerne sehr mächtig sind, erkennt man num mit sicherheit. dass aus denselben ein mächtiges system von Bogenfasern entspringt. welches die Oblongata durchquert und in der Raphe kreuzt, um sich damn den Tractus tecto-spinales et tecto-bulbares anzuschliessen, welche zu beiden Seiten der Mittellinie hirnwärts ziehen. Ganz die gleichen Bogenfasern werden auch bei den niederen Tertebraten beobachtet so z. B. Fig. 40 $B C$, aber hier ist ihr Ursprung aus Hinterstrangkernen nicht ganz sicher gestellt.

Die erwähnten Fasern, Fibrae arcuatae internae Medullae obl. sind. wie sie sofort erkennen, auch nichts anderes als eine secundäre Bahn aus stätten, mo Hinterwurzelfasern enden. sie führen also den im Rückenmark noch nicht gekreuzten Rest der sensiblen Faserung hinüber auf die andere Seite, wo er sich mit dem bereits gekreuzten vereint.

Die so vermehrten Tractus tecto-spinales et bulbares bilden mun ventral und lateral an der Oblongata ein breites Feld, die Schleifenschicht.

Wohl im gleichen Areal verlaufen die Tractus thalamo-spinales et bulbares. Durch Degeneration sind sie nur von den Säugeru her sicher gestellt, aber es zeigen Längsschnitte durch Fische, Amphibien, Reptilien und Vögel, dass aus dem Zwischenhirn Zïge bis in die Oblongata und das Riickenmark herabziehen.

Es handelt sich also hier um Bahnen. welche vom Mittelhirn kommend zu den Endstätten der sensiblen Rückenmarksnerven im Bogen gekreuzt herantreten. Halten sie das fest, denn wir werden num in der Oblongata. wo die einzelnen Nerven sehr mächtige Kerne haben. immer wieder solchen Bogenfasern zu den Kernen begegnen und immer wieder sie in die Schleifenschicht verfolgen kïmnen. 
In der Oblongata des reifen Triton, die ich desshalb wähle, weil ich rorhin diejenige der nah verwandten Salamander-Larven Ihnen vorgelegt habe. sehen sie die Bogenfasem ans der Gegend der Hinterstrangkerne deutlich entwickelt und sie erkennen auch, dass sie in das mit reichen Querschnitten erfüllte Areal beiderseits ron der Mittellinie übergehen, indem ein guter Theil dahin kreuzt. Die Terfolgung auf einem einzigen schnitte ist allerdings nicht gut möglich; desshalb zeigt die Abbildung Bogenfasern und Kreuzung nur in spärlichem Zusammenhang.

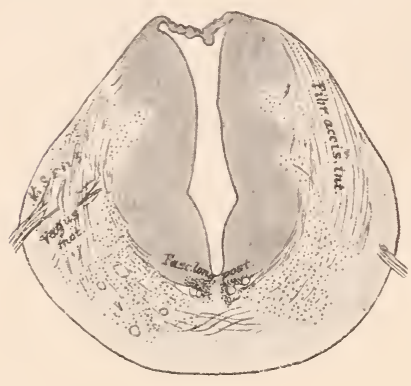

Fig. 42.

Frontalschnitt durch die Oblongata eines reifen Triton.

Da nun ein gewisser Ueberblick über die wichtigeren Bestandtheile des Querschnittes am unteren Oblongataende gewonnen ist, wird es leicht sein, den hier gleichzeitig vorgelegten Schnitt durch die Oblongata des Alligators zu verstehen. Er ist verhältnissmässig einfach auf die noch vom Rückenmark her bekannten Verhältnisse zuriickzufühıren.

Die Ventralsäule erkemnen Sie sofort, denn sie giebt einem mächtigen Nerven, dem Hypoglossus Ursprung, aus der Dorsalsäule ist im Wesentlichen der Endkern des Trigeminus hervorgegangen, jenes mächtige halbmondförmige Gebilde, dem sich ganz dorsal und lateral die Trigeminuswurzel aulegt. Zwischen der rechten und linken Dorsalsäule findet man die Kerne der Hinterstränge, in denen die aus den Dorsalwurzeln aufsteigenden Bïndel zunächst enden.

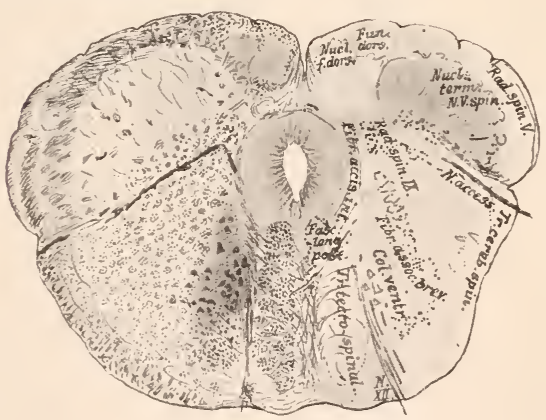

Aus den dorsalsten Zellen der Ventralsäule entspringt der Accessorius. Das Associationsfeld ist mächtig entwickelt und iiber die Lage der Tractus tecto-spinales u. s. w. orientiren leicht die eingeschriebenen $\mathrm{Be}$ zeichnungen. Die ganze Figur ist wohl dazu geeignet, dass Sie an ihr sich einmal die Einzeltheile der Oblongata klar machen.

Noch ist nicht der Vorderstrangfasern gedacht, die wir im Rïckenmarke kennen lernten. An dem Schnitte durch CephalCaudales Oblongataende ron Alligator lucius.

optera liegen sie noch ganz an der gleichen Stelle wie im Rïckenmarke. Ein Theil dieser Fasern, geräth wohl in die Schleife, die Mehrzahl aber, gerade jene dicken Stränge, die sofort auf allen abgebildeten Schnitten auffielen, zieht, genau an der gleichen Stelle bleibend, weiter hinauf durch die Oblongata, ja er nimmt dort noch an Tolum zu. Dieses Bündel, 
Fasciculus longitudinalis posterior ist bis in die Tiefe des Diencephalon zu verfolgen, aber es scheint aus allen motorischen Kernen, in deren Xähe es auf seinem langen Laufe vorbeizieht, Fasern zu beziehen. Die Fasern sind, wenigstens lehren Degenerationsversuche an sängern es, vielfach nur kurzen Verlaufes. Bei den Fischen, den Amphibien und den Reptilien ist das hintere Längsbündel eines der allermächtigsten Bündel der Oblongata. Es schimmert weiss am ganzen Boden des vierten Tentrikels durch, wie Sie z. B. bei dem stör Fig. 39 sehr gut sehen.

Nitten in dem erwähnten Tractus verlaufen bei den wasserlebenden Thieren jene früher geschilderten dicken Fasern aus der Acusticusgegend zur Schwanzmuskulatur, die Fibrae acustico-spinales. Sie erkennen sie gut auf den meisten der heute demonstrirten Schnitte und sehen auch auf Fig. 40 $D$ die Kreuzung und einen Theil der grossen Endzelle, aus welcher jederseits die Faser entspringt.

So wären Thnen denn die meisten Bündel, welche sie rom Rückenmark her kemnen, am Anfange der Oblongata wieder begegnet, zum Theil allerdings in beträchtlicher Verlagerung. Nur ein wichtiger Zug blieb

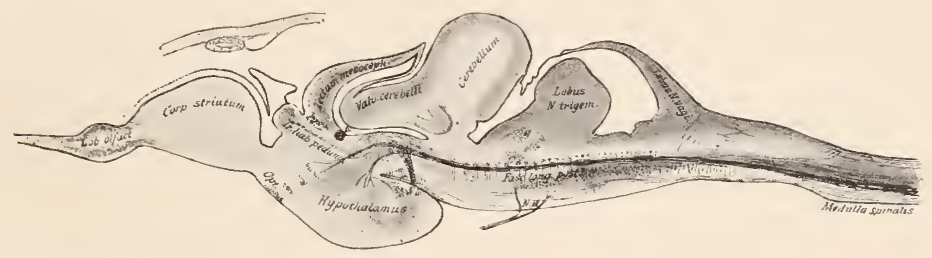

Fig. 44.

Sagittalschnitt durch das ganze Gehirn eines jungen Cyprinoiden von $4 \mathrm{Cm}$. Länge. Zunächst zur Demonstration des Verlaufes des Fasciculus longitudinalis posterior.

unerwähnt, der Tractus cortico-spinalis. Dieser ist aber nur bei Säugern vorhanden und fehlt schon den Vögeln - eigene Degenerationsversuche beweisen mir das. so soll er erst in späteren Vorlesungen, welche speciell vom Säugergehirn handeln, näher beschrieben werden. Hier sei nur angeführt, dass seine Fasern bei Säugern oben am Oblongatabeginn zu gutem Theil kreuzen und dann als zwei mächtige Stränge Pyramiden - ventral von den Vordersträngen und der Schleife liegen. Sie bilden da eine einfache Addition zu dem Bilde, welches ich Ihnen von den niederen Vertebraten demonstrirt habe. Manchmal werden Kinder ohne Grosshirn geboren. Thnen fehlen dann die Pyramidenstränge und desshalb gleicht ihre Oblongata ganz derjenigen der anderen Vertebraten.

Alle diese Fasersysteme also sind am caudalen Oblongataende vereint. Jan trifft sie auf allen Schnitten weiter hirnwärts, bis sich die cerebellaren Bahnen zum Kleinhirn, die spinalen Antheile von Hirnnerven hinaus zur betreffenden Wurzel wenden. Fortwährend enden weiter aufwärts auch Züge aus dem Associationsfeld der Oblongata und fortwährend 
beginnen neue, die dann erst weiter cerebral enden. Doch ändert sich im Ganzen das Querschnittsfeld, soweit die besprochenen Antheile in Betracht kommen, nur wenig.

Aber ein anderes Noment erzeugt sehr grosse Teränderungen in dem Oblongatabau, je weiter man hirnwärts diesen studirt. Das sind die Ke r ne der Hirnnerven und die Bogenfasern, welche in diese aus der Schleife und aus dem Kleinhirn eintreten.

Das Studium der Nervenkerne in der Oblongata ist wieder einmal sehr lehrreich für die Anschauung, die ich Ihnen früher vorgetragen, dass nämlich nicht die Rede von einem durchweg höher oder tiefer entwickelten Gehirn in der Thierreihe sein kann. Nur einzelne Hirntheile sind bald da, bald dort mehr ausgebildet und diese Ausbildung hängt keineswegs etwa ron der Stellung eines Thieres in der phylogenetischen Reihe ab, sondern ganz allein von den Bedïrfnissen, resp. den somatischen Eigenschaften, die ein Thier etwa auf dem oder jenem Gebiete erworben hat. Sie werden später sehen, dass z. B. die Knochenfische ein ungemein einfaches Grosshirn besitzen, einen Hirntheil. der mit dem gleichen des Nenschen gar nicht mehr vergleichbar ist; aber diese Thiere besitzen nicht nur sehr viel mächtigere Endstätten für den Sehnerven als irgend ein Sänger, sondern es haben auch die Nervenkerne in ihrer Oblongata eine solche Ausbildung und eine solche Complicirtheit erfahren. dass die gleichen Theile von Vögelı, Reptilien und Säugern im Vergleich zu ihnen sehr einfach und klein nur erscheinen.

Die anatomischen Bilder der Hirnnervenkerne variiren also sehr durch die ganze Thierreihe hindurch. Dennoch will ich versuchen, hier Einiges von dem mitzutheilen, was allen im Principe gemeinsam ist. Teil die Anlage dieses kleinen Buches ein Eindringen in die zahlreichen Details rerbietet, so sollen neben dem Typus nur solche Verhältnisse hervorgehoben werden, welche ein besonderes morphologisches oder physiologisches Interesse bieten.

Wir wollen die Hirnnerven eintheilen in eine caudale Gruppe, zu welcher der Hypoglossus, der Accessorius und der Tagus sammt dem Glossopharyngeus gerechnet seien und in eine frontale, welche den Facialis, den Acusticus und den Trigeminus umfasst. So gewimnen wir den Vortheil, zunächst einmal die einfacher gebauten Kerne studiren zu kömmen, ehe wir uns Regionen zuwenden, welche durch den Eintritt der zwei mächtigsten Nerven des Hinterhirnes, des grossen Gefühlsnerven für den Kopf und des Gleichgewichtsnerven zu den complicirtesten Hirntheilen geworden sind.

Wenn man die Kopfnerven nur nach ihren centralen Trsprungsverhältnissen betrachtet, dann findet man durch die ganze Thierreihe hindurch eine erstaunliche Gleichartigkeit. Fische haben z. B. ganz die gleichen Hirnnervenursprünge wie die Säuger. Nur die Art. wie die Wurzeln abgehen, variirt nicht wenig. Es finden da nach dem Kernursprung die verschiedenartigsten Zusammenlegungen der Wurzelfasern statt, und es ist die richtige Benenung der an der Anssenseite des Gehirnes bei nie- 
deren Wirbelthieren sichtbar werdenden Nervenfasern eine Aufgabe, an der die vergleichende Morphologie noch immer arbeitet. Beispielsweise sei erwähnt. dass der Nervus facialis zuweilen so dicht sich den Fasern des Trigeminus beimengt, dass er nur durch die Tertheilung in der Peripherie, in den Muskeln, sich ron diesen als eigener Nerr abscheiden lässt.

Sie haben als Ursprungsort der motorischen Nerven im Rückenmarke die lange rentral liegende Säule grosser Ganglienzellen kennen gelernt und es lässt sich in der That rom Sacraltheile bis hinauf in die Oblongata die gleiche Zellsäule nachweisen. Sie besteht aus hinter einander geordneten Nervenkernen, die zwischen sich noch die Commissurzellen besitzen. Zweckmässig zerlegt man diese Säule in zwei Reihen, deren eine mehr rentral (Torderhornzone His), und deren andere mehr lateral (Seitenhornzone) liegt. Aus der ersteren kommen der Nerrus Hypoglossus und alle vorderen Wurzeln des Rückenmarkes für die Muskeln des Stammes; aus der letzteren stammen (Gaskell) wesentlich Fasern, welche mit der motorischen Innerration ron Eingeweidemuskeln betraut sind. Diese Seitenhornfasern treten nur in der Oblongata getrennt von den Vorderhornfasern als motorischer Tagus und als Accessorius aus dem ('entralorgan heraus. Weiter unten im Rückenmark verlassen sie dasselbe mit anderen Fasern der Torderwurzeln; nach Gaskell treten dam jene in die gemischten Nerven, diese in den Symphaticus ein. Die centralsten Antheile der motorischen Kernsäule entsenden aus ihrem lateralen Abschnitt den N. facialis. Die Kaumuskelwurzel des Trigeminus bekommt ihre Fasern aus Zellen, die dem lateralen und rentralen Abschnitte der motorischen Säule angehören.

Auch die Dorsalsäule graner Substanz, in welche sie bei der Betrachtung des Rückenmarkes die sensiblen Wurzeln sich einsenken sahen, setzt sich in die Oblongata fort. Dort dringen in sie aus ihren Ganglien der Tagus, der Glossopharyngeus, der Acusticus und der Trigeminus ein. Bei Trigla sahen sie schon, dass. wenn am Rumpftheil irgendwo die sensiblen Nerven besonders stark sind, die Endkerne enorm hypertrophireu. Das ist nun ganz allgemein der Fall an den Endkernen der mächtigen Oblongatanerven. Einen. den langgestreckten Endkern der spinalen Trigeminuswurzel. kennen Sie ja schon. Hier handelt es sich um einen Zug, der aus seinem [rsprungsort, dem Ganglion Gasseri, weithin hinabsteigt, ehe er im Halstheile des Rückenmarkes endet. Man bezeichnet derartige Bahnen als absteigende Wurzeln. Alle sensiblen Nerven der' Oblongata haben solche, aber bei keinem ist der absteigende Theil so mächtig wie bei dem Trigeminus, bei keinem deshalb auch so gut bekaunt. Weil sie wissen, dass alle Bahnen aus den spinalganglien in die Dorsalwurzeln, am Rückenmark angekommen, je einen absteigenden Zweig zu einem weiter caudal liegenden Theil des Endgrau entsenden, wird Ihnen das gleiche Torkommen an den Hirnnervenwurzeln nicht auffallen. Der caudalste Hirmerr, der Hypoglossus, ist bereits besprochen. Er entspringt aus einer Zellgruppe in den Torderhörnern. Fig. 43. Ans dem 
gleichen Grau, aber von einer mehr lateralen Zellgruppe. stammen bei Reptilien, Tägeln und Sängern Fasern, die seitlich am Rückemmark abgehend als Accessorius bezeichnet werden. Fig. 43. Bei den niederen Vertebraten entspringt der gleiche Nerv fast ebenso, aber seine Fasern gehen zumeist erst höher oben mit dem Vagus ab, dessen motorischem Theil sie sich anschliessen. Nichts aber steht dem entgegen, dass man dort die caudalsten Wurzeln des motorischen Vagus dem Accessorius gleichstelle.

Der Vagus selbst tritt überall am dorsolateralen Rande der Oblongata ans dem Cgl. jugulare an diese heran. Er durchbohrt die Faserung, welche ihm hier im Wege liegt, so die aus den Hinterstrangkernen stammenden Fibrae arcuatae internae, oft auch die hier aufsteigende spinale Quintuswurzel und endigt dann in einer beträchtlichen Verbreiterung der granen. weiter caudal den Hintersäulen angehörigen Substanz. Das ist sehr leicht an den Schnitten, welche ich hier ron der Oblongata eines
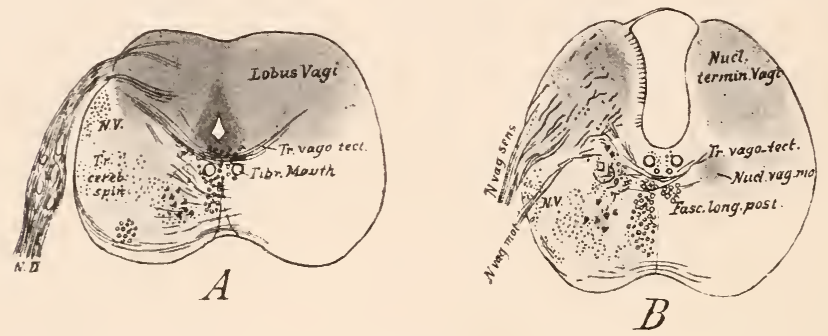

Fig. 45.

Zwei Schnitte aus der Oblongata des Goldfisches, Cyprinus auratus, $4 \mathrm{Cm}$. langes junges Thier. $A$ weiter caudal als $B$.

kleinen Karpfen vorlege, zu erkemen. Auf der Abbildung sehen Sie, dass die graue Substanz, der Vaguskern, bei dem Fische rerhältnissmässig sehr gross ist. Sie hat da einen viel mächtigeren Nerven aufzunehmen als bei den anderen Tertebraten. Ein wahrer Tumor - Lobus Nervi Vagi entsteht hier. An dem Störgehirn, Fig. 39, ist der Taguskern nur als langer Trulst sichtbar und bei den Tögeh und Säugern bildet er gar nur eine schwache Erhöhung am Boden des vierten Ventrikels. Aber öffnen sie eimnal ein Karpfengehirn. dam erblicken Sie ein Anderes, da liegt beiderseits von dem Ventrikel und dessen Seitenwände bildend ein mächtiger Körper, der Lobus X. vagi, in dem der unscheinbare kleine Kern, ron dem die Rede war, nicht wieder zu erkennen ist. S. auch Fig. 52.

Ton der ventralen Seite her treten in den Taguskern immer Fasern ein, welche ihn von der anderen Seite her kreuzend erreichen. Diese Kreuzung ist bei Fischen so mächtig, dass man mit blossem Auge überall ilure weissen Massen erkemnen kann. Es handelt sich da um den Faser. zug zum Tractus der schleife, welchen alle Hirnnervenkerne besitzen. 
Ansserdem erhält der sensible Taguskern noch einen wieder. bei Fischen besonders mächtigen Zuwachs aus dem Cerebellum, der dort gekreuzt entspringt (Mayser). Bei den höheren Vertebraten existirt ebenfalls ein Tractus Vago-cerebellaris, aber — bei den säugern wenigstens - sehe ich ihn mit den Wurzelfasern direct austreten. Da er aber verhältnissmässig diimn ist und die Verhältnisse bei den Knochenfischen sehr klar erscheinen, so wäre für die höheren Thiere immerhin ein Irrthum möglich. Bei den Fischen und Amphibien versorgt ein Theil der Vagusfasern auch die äussere Körperhaut ganz wie andere sensible Spinalnerven; bei den höheren Vertebraten aber enthält der erwähnte Theil des Vagus nur sensible Bahnen aus den Eingeweiden.

Der Gesammtvagus enthält auch motorische Bahnen. Sie erimneru sich, dass Fig. 34 Thnen Fasern aus Torderhornzellen zu sensiblen Wurzeln zeigte. Damals, als ich diese Figur demonstrirte, habe ich sie darauf aufmerksam gemacht, dass es sich hier wohl um motorische Elemente zu visceralen Bahnen handeln möge. Es ist ein grosses Verdienst von Gaskell, dass er nachgewiesen hat, wie die motorischen Bahnen zum Vagus anch nichts Anderes sind als diese schon für die Spinalnerven gefundene Faserart. Vergleichen sie einmal Fig. 34 mit Fig. 46. Ganz wie beim Huhne jene multipolare Zelle nahe am Vorderhorne ihren Axencylinder hinaus in die

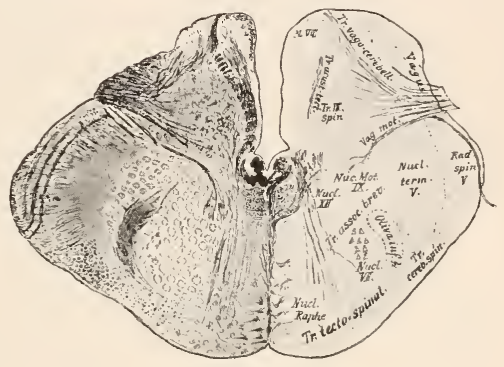

Fig. 46.

Motorischer un 3 sensorischer Vaguskern von Alligator misisippensis. Dorsalwurzel sendet, so schickt der am gleichen Orte gelegene motorische Vaguskern seine Züge zu der einer Hinterwurzel gleichwerthigen sensiblen Vaguswurzel. Die motorischen Vagusfasern sind principiell gleich den motorischen Fasern in den Hinterwurzeln. Sie entstammen einem Kerne, welcher bei den Fischen dorsal vom Hypoglossuskern liegt, bei Amphibien, Reptilien und Vögehn aber diesem mehr lateral und ventral anliegt. Manchmal ist allerdings der Ursprung der motorischen Vagusfasern von denjenigen der Hypoglossusfasern gar nicht scharf abgeschieden. Der Kern ist der motorische Vaguskern. Es sendet Wurzelfasern nach der gleichen und auch nach der gekreuzten Seite. Die Kreuzung erfolgt ganz nahe am Rautengrubenboden.

Dass ein Theil der Taguswurzeln als absteigende Bahn erst in dem etwas caudal rom Eintritt liegenden Grau endet, wurde schon oben erwähnt.

Im Vagusbereiche treten eine ganze Anzahl von Wurzelfasern an die Oblongata heran. Es ist noch nicht mit sicherheit entschieden, ob 
man es hier mit einem einzigen Nerven oder mit einer rerschmolzenen Gesammtheit zu thun hat. Nur die frontalste der sensiblen Taguswurzeln, die immer etwas getremnt ron den übrigen eintritt, hat man als eigenen Nerven, N. glossopharyngeus, abzuscheiden müssen geglaubt. Dieser Glossopharyngeus entspringt nun schon bei den Knochenfischen. aber auch bei allen anderen Vertebraten, nur zu geringem Theil direct in dem $\mathrm{Ob}$ longatagrau. Ein grösserer Antheil senkt sich zugleich mit einigen Yaguswurzehn in geschlossenem Zuge rückemmarkwärts und ist iiberall als ge-

Molecularschicht Parkinje'sche Zellen Körnerschicht

Nucl. globos. cerebelli

Nucl. Deiters Nucl, N. VIII. Tub, acusticum

Tr. acust.-cerebellaris Nucl. N. YiII dorsal.

Nucl. N. abducentis Nucl. terminal. N. glossoph.

N. acusticus

Tr, bulbo-spin. N. V,

N. glossopharyngeus Nucl. N. facialis Nucl. d. Raphe

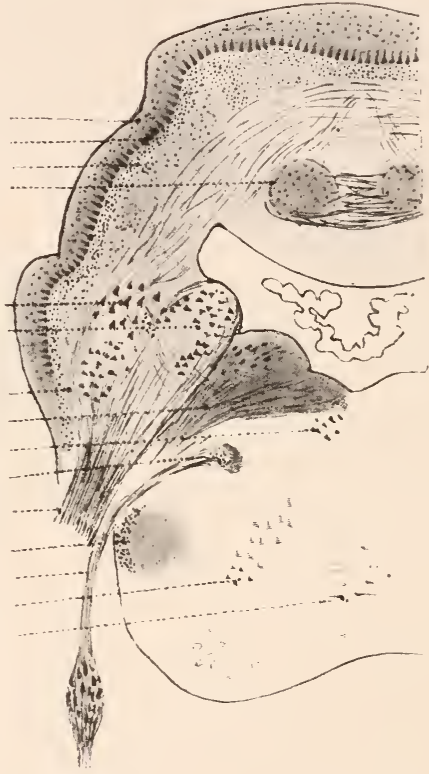

Fig. 47.

Gegend des Glossopharyngeuseintrittes von einem jungon Sperling, bei dem die Markscheidenentwicklung noch nicht vollendet ist.

sondertes Bündel bis in die Höhe der obersten Cervicalnerven zu verfolgen. Die Radix bulbo-spinalis Tagi et Glossopharyngei senkt sich ganz wie die bulbo-spinale Trigeminuswurzel allmählich ein in eine dünne Säule grauer Substanz, welche auf ihrem ganzen Wege neben ihr liegt. Das ist der bulbo-spinale Endkern jener Nerven. Das ganze Bündel ist immer leicht, rentral vom sensorischen Taguskerne, zn erkemnen.

Das rerlängerte Nark bietet, namentlich bei den Fischen. mehrfach gute Beispiele für die schon bei der Schilderung des Rückemmarkes vorgetragene Thatsache, dass sich aus rorhandenen kleinen Anlagen je nach 
dem wechselnden Entwickeln peripherer Gebilde gelegentlich ganz colossale, nur schwer auf ihren kleinen Ursprung beziehbare Formationen ausbilden. Der Anglerfisch, Lophins pescatorius, besitzt an seinem grossen Kopfe, an den Seitenlinien und Flossen zahllose zierliche blattförmige Anhänge der Haut, welche den träge daliegenden Fisch völlig maskiren, so dass es aussieht, als hätten Florideen und Corallineen einen flachen Stein dicht ïberwachsen. So liegt das Thier im Schlamme und lässt hoch über sich seine Angel spielen, ein weiches Gebilde, das bald wurmförmig aussieht, bald einem grossen Insekte gleicht. Es ist an einer weit auf den Kopf vorgeschobenen Flosse befestigt, wie der Köder an der Angel. Der ganze hier etwa in Betracht kommende Hautbezirk wird bei den anderen Fischen vom Vagus und Trigeminus versorgt. Nun hat Fritsch, dem wir so viele Aufklärung über das Fischgehirn verdanken, gefunden, dass den Kernen der genannten Nerven beim Lophius, und nur bei diesem, nngeheure mit blossem Auge sichtbare Ganglienzellen anliegen, die ihre dicken Axencylinder in die Nerven hinein senden. Es handelt sich nach der Lage offenbar um eine Weiterentwicklung der grossen Dorsalzellen, von denen schon bei der Schilderung des Rückenmarkbaues erwähnt wurde, dass sie in geringer Zahl gelegentlich an der hinteren Peripherie des Markes gefunden

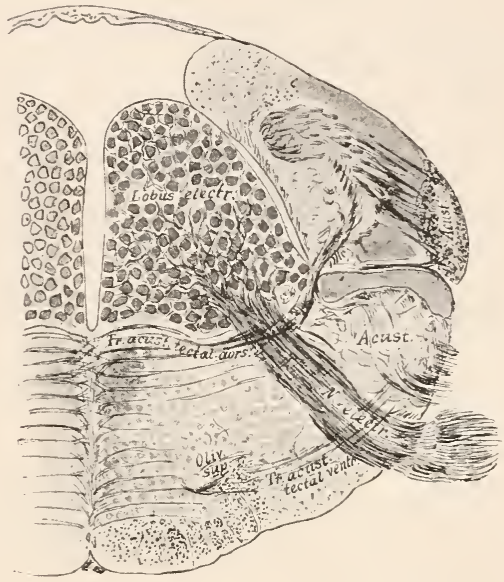

Fig. 48.

Oblongata von Torpedo. Schnitt in der Gegend der Vaguskerne. Ifan sieht ausser den eintretenden Vagusfasern and deren Kern noch dorsal von dem letzteren den elektrischen Lappen, aus dem sich zahlreiche Fasern entwickeln, welche ein wenig frontal von der abgebildeten Schnithöho anstreten. werden. Die Lophiuszellen sind so gross, dass sie zu ihrer Ernährung eigener kleiner Capillarschlingen bedürfen, welche überall in sie hineindringen.

Noch viel interessanter aber, und viel untersucht ist der grosse Kern, welcher bei den Rochen weit hinauf in den Hohlraum des vierten Tentrikels ragend, dem elektrischen Nerven jederseits Ursprung giebt. Dieses paarige, vorn manchmal zusammengewachsene Gebilde enthält neben einigen kleineren multipolaren Zellen eine grosse Henge ganz ungeheurer Ganglienzellen, die alle ihren Axencylinder hinaus in den elektrischen Nerven senden. Es ist bei unserer heutigen Kenntniss der Kerne im Selachiergehirn schwer, ihm eine sichere Position zu geben, aber es spricht die grösste Wahrscheinlichkeit dafür, dass es sich hier um gar Nichts anderes 
handelt als um die Hypertrophie eines Theiles des motorischen Taguskernes. Das elektrische Organ der Rochen geht aus umgewandelter Kopfmuskulatur herror. Engelmann konnte sogar neuerdings zeigen, wie sich seine Platten ganz direct aus der Plattenformation der quergestreiften Muskeln entwickeln.

\section{Siebente Vorlesung.}

\section{Die Oblongata. Fortsetzung.}

In der Höhe. wo die Glossopharyngeuswurzeln sich lateralwärts begeben. um an die Oberfläche hinaus zu gelangen, erkennt man medial ron ihnen einen neuen Kern, einen Acusticuskern. Wir gerathen hier in das Ursprungsgebiet desjenigen Hirmnerven. dessen Verhältnisse bei niederen Tertebraten am wenigsten geklärt sind. Die Untersuchungen der letzten Jahre haben den Acusticus bei den Säugern endlich besser verständlich gemacht, aber schon bei den Tögehn und mehr noch bei den niederen Thieren sind wir zunächst nur auf schnittbilder angewiesen. Noch hat Niemand rersucht, diesen so ïberaus complicirten Nerven degenerativ oder entwicklungsgeschichtlich hier zu studiren. Die Schnittbilder allein aber geben in dieser Höhe, wo so Vielerlei die Oblongata erfüllt, nur zu leicht zu Missdeutungen Teranlassung. So will ich mich auf das Wenige beschränken, was sich sicher sagen lässt, späterer Zeit bessere Darstellung überlassend.

Der Acusticus enthält immer einen Faserantheil zum Vorhof und einen solchen zur Schnecke. Der erstere, welcher das Labyrinth rersorgt, ist, wie zahlreiche Tersuche nachgewiesen haben, in hohem Maasse für die Erhaltung des Körpergleichgewichtes wichtig. Ewald's Versuche haben bekanntlich gezeigt, wie jede Schwankung der Labyrinthflüssigkeit durch Termittlung dieses Nerven zu Gleichgewichtsstörung führt. Sie haben auch nachgewiesen, wie der Testibularis speciell wichtig ist für die Erhaltung des Muskeltonus am gesammten Körper. Die Schnecke ist bei den Fischen kaum entwickelt und erreicht erst bei den Tögeln eine gewisse Ausdehnung. Dem entsprechend geht die Mehrzahl der Hörnervenfasern an das Labyrinth und die Säcke. Erst bei den Säugern wird der zur Schnecke gehende Fasertheil gross.

Im Gehirn kamn man erkemnen, dass bei allen niederen Vertebraten die Hauptmasse des Hörnerven in einem grossen Höcker endet, welcher seitlich an der Oblongata da liegt. wo sich die Kleinhirnarme zu ihr senken. Eingeklemmt in den Winkel zwischen Mark und Kleinhirn und bis hinauf zu den Vögeln, immer bedeckt ron einer der Cerebellumrinde ähnlichen Formation. liegt dieser mächtige lange Acusticushauptkern da und nimmt an seiner rentralen seite die Hörnervenfasern auf. Diese theilen sich sofort in auf- und alsteigende Aeste und durchziehen in dichten Bündeln jenes Ganglion. ehe sie in ihm anfsplitternd enden. 
Diese Fasern stammen wohl alle ans den Ganglienzellen im Gehörorgan. Vergleiche Fig. 40 $D$, wo das an dem Amphibienembryo leicht sichtbar ist. Ebenso Fig. 16 b.

Ein Querschnitt durch den seitlichen Theil der Oblongata in der Gegend. wo der Acusticushauptkern roll entwickelt ist, zeigt, dass hier unter der Rinde dieses Körpers ungemein viele Faserquerschnitte liegen, es hat sich ein eigenes, lateral von der ïlrigen Oblongatafaserung liegendes Feld gebildet, das als Acusticusfeld (Ahlborn) bezeichnet werden mag. Die Mehrzahl der Fasern, die hier liegen — sie alle kommen aus dem Acusticus - wendet sich, soweit sie nicht im Hauptkerne endet oder als caudale Wurzel abwärts zieht, hinauf dem Kleingehirn zu und lier endet ein Theil in einem weiteren Kern, dem Nucleus a custicocerebellaris. der sich direct nach vorn und dorsal dem Hauptkerne anschliesst.

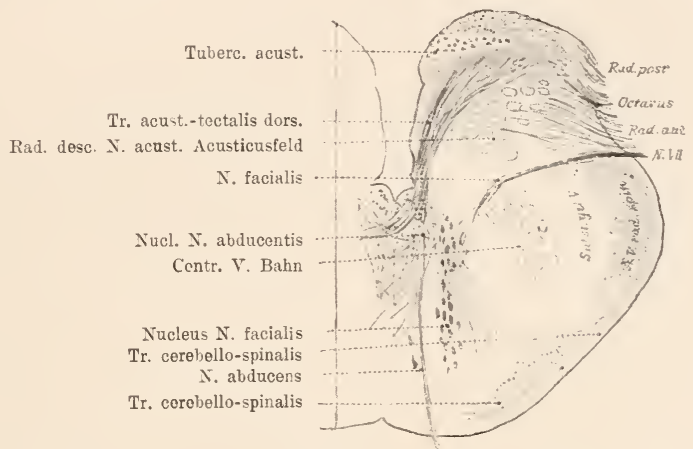

Fig. 49.

Caudalster Abschnitt der Acusticuskerne. Alligator lucius.

Die beiden erwähnten Acusticuskerne sind durch zahlreiche Faserzüge mit dem Kleinhirn selbst wieder verknüpft, speciell mit zwei rundlichen dicht ïber dem Dache des Tentrikels liegenden Kernen, den Dachkernen des Cerebellum, wo eine starke Kreuzung stattfindet. Aber einige Kleinhirnfasern gerathen ganz direct in den Hörnerv selber. - Directe sensorische Kleinhirnbahn.

Von den Reptilien an erkennt man, dass ausser den beiden erwähnten Kernen neue auftreten, die bei den Fischen und Amphibien nur eben spurweise vorhanden sind. Diese Kerne bilden eine grössere ganz lateral von dem Hauptkern liegende Masse, die wesentlich aus grossen Zellen besteht. Man kann sie bei den Tügehn und Säugern sehr wohl abscheiden. Sie werden bei den letzteren als ventraler Kern und Tuberculum acusticum bezeichnet und sind hier mächtiger als der Hauptkern, der bei den niederen Tertebraten das Bild beherrscht. Dieses letztere heisst 
bei den Säugern Nucleus dorsalis. Ich muss aber sagen, dass eine derartige Homologisirung noch anf sehr schwachen Füssen steht. Könnte ich auch über die Hörnervenkerne einzehner Vertebraten Ihnen noch weitere Details mittheilen, so möchte ich doch davon abstehen und für den Hörnerven einstweilen nur auf die bei den säugern gegebenen Darlegıngen, sowie auf einige Abbildungen. wo er angegeben ist, Fig. 49, 52, 53, verweisen.

Die Endstätten des Hörnerven hängen aber nicht nur mit dem Cerebellum zusammen. Es existiren vielmehr eine ganze Anzahl von Terbindungen mit anderen Gehirntheilen und es ist speciell die ganze Gegend der Oblongata, welche seitlich den Hörnerven anfnimmt, durchzogen und erfüllt von Fasern und Kernen, die direct oder durch Collateralen zum Octavus in Beziehung stehen. Für die Sänger sind auch hier die Verhältnisse num annähernd bekannt, für die niederen Tertebraten vermag ich das Folgende nur anszusagen:

An der medialen Seite der Acusticuskerne entspringen immer ich sah es bei Selachiern, Teleostiern, Reptilien und Vögeln - Fasern, welche sich einwärts in die Oblongata begeben und dort zu einem kleinen Ganglion, Oliva superior, in Beziehnng treten. Für die Säuger ist diese Terbindung als Corpus trapezoides längst bekannt. Dort auch ist nachgewiesen, dass es sich $1 \mathrm{~m}$ einen Theil des Tractus acusticotectalis handelt, der centralen Acusticusverbindung zum Mittelhirndache. Zweifellos aber besteht noch eine andere centrale Terbindung ebendahin bei den niederen Thieren, welche nicht ihren Weg durch die Trapezoidesfasern nimmt. Diese ist weitaus die mächtigere bei allen Thieren unterhalb der Sänger. Es handelt sich um dicke Fasern, welche gut sichtbar, Fig. 49, aus dem Hauptkerne in dickem starkem Zuge entspringen und direct sich nahe dem Boden des Ventriculus quartns zur Mittellinie begeben, wo sie nahe dem Fasciculus longitudinalis post. und anch durch diesen hindurch auf die andere Seite treten. Sie gelangen wahrscheinlich auch in das Tectum des Mittelhirnes. So hätten wir einen Tractus acustico-tectalis ventralis, der durch die Oliven in die Schleife gelangt, und einen ebensolchen Tractus acustico-tectalis dorsalis, welcher ebendahin auf anderem Wege gekrenzt zieht. S. Fig. 4s und Fig. 49.

Dorsal rom Acusticushanptkerne liegt, schon von den Fischen ab. eingebettet in den ventralsten Abschnitt des Kleinhirnes ein mächtiger Kern multipolarer Ganglienzellen, welcher, in enger Terbindung mit dem Ursprungsgebiet der Tonusnerven, seine Axencylinder durch das Acusticusgebiet hindurch rïckenmarkswärts sendet. Der Kern - Deiters'scher K e r'n der Säuger - (Nincleus tract. acnst.-spinalis) ist vielleicht ein Theil des Apparates, welcher erforderlich ist, die via Labyrinth erhaltenen Eindrücke auf die Körpermusknlatur zu ïbertragen. s. Fig. 47. - Nicht uninteressant wird Ihnen sein zu vernehmen, dass bei den Knochenfischen ein Ast ans dieser Gegend nicht mit dem Acusticus, sondern mit dem 'Trigeminus das Hirn rerlässt. Er betheiligt sich (stannius) an jenem 
grossen Nerven der Seitenlinie, der für schwimmende Thiere so überaus characteristisch, ein mächtiges simnesorgan der Hautoberfläche versorgt. Die Bedeutung dieses Hautsimnesapparates als statisches Organ wird durch dies anatomische Verhältniss recht wahrscheinlich gemacht.

Wenn ich num noch eimmal daran erinnere, dass gerade in der Acusticushöhe der Oblongata jene langen II a thner'schen Fasern entspringen, die wir schon im Riickenmark kennen lernten, die Tractus acusticospinales, die Fasern, welche erst in der schwanzgegend enden, Fig. 29 und Fig. 40, dass die grossen Endzellen dieser Riesenfasern mit ihren Dendriten das Acusticusendgebiet förmlich durchflechten, dann wird Ihnen klar seiu, welch ein wichtiger Associationspunkt für die mannigfachsten Körpergegenden und für die mamnigfachsten Innervationsbahnen im mittleren Theile des verlängerten Markes liegt. Die physiologischen Versuche

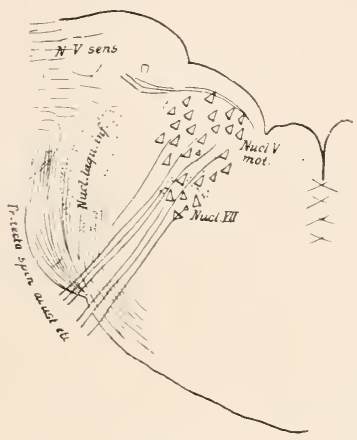

Fig. 50.

Schnitt durch die Oblongata von Alligator lueius in der Höhe des mot. Trigeminuskernes. Nur die

Contouren der Nervenaustritte angegeben.

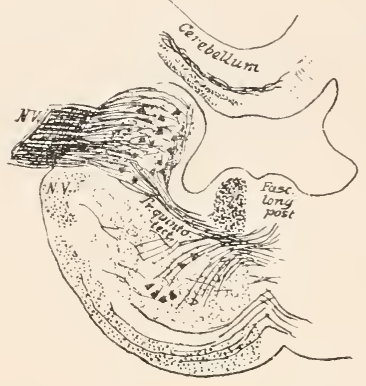

Fig. 51.

Lacerta agilis. Gegend des Trigeminusaustrittes.

und die Erwägungen, welche sich an diese anatomischen Verlıältnisse anknüpfen lassen, führen zu dem Schluss, dass der eben geschilderte Theil der Oblongata ein wichtiges Centrum für die gesammte Körperstatik darstellt.

In der Höhe der Hörnervenkerne ist die motorische Säule, welche vom Rückemmark aus hirmwärts reicht, noch nicht erschöpft. Man stellt sich dieselbe am besten als eine dïnne Platte vor, welche, zur Sagittalebene leicht geneigt, etwas von der Mittellinie entfernt in der Oblongata liegt. Aus dem dorsalen Theil dieser Platte ist nahe dem Rückemmark der Hypoglossus hervorgegangen. In der Acusticushöhe entspringt ebenda der A bducens, dessen Verlauf gut auf dem Schnitt Fig. 49 erkembar ist. Der ventrale Abschnitt sendet seine Fasern nicht direct hinaus. Er sammelt sie vielmehr für eine längere Strecke zı kleinen Bündeln, die sich damn alle dorsalwärts wenden, um, nahe den Bodengrau angekommen, lateral umzubiegen. Dieser eigenthümliche knieförmige Verlauf ist uns schon beim 
Accessorius, Fig. 43, begegnet, einem Nerven, der aus dem gleichen Zellengebiet nur weiter caudal abging, auch ein Theil der motorischen Tagusäste, Fig. 46, verhielt sich so. Nun aber kommen wir zu den beiden Nerven, welche aus dem Haupttheil der ganzen Zellsäule entspringen, zum Facialis und zum motorischen Trigeminus. Beide können nicht immer scharf von einander in ihren Turzelgebieten getiennt werden. Bei den niederen Vertebraten ist der Facialis gewöhnlich viel weniger mächtig als der Kauast des Trigeminus, wahrscheinlich wegen der geringen Ausbildung der Antlitzmuskulatur.

Figur 49 zeigt die Lage des Facialis und des Abducenskernes beim Alligator und in der folgenden Figur lege ich einen weiter vorn gemachten Schnitt vor, der die motorische Säule da trifft, wo sie im dorsalen Abschnitt zum motorischen Trigeminuskerne gewaltig anschwillt.

Vergleichen Sie z. B. den dünnen Facialis des Alligators Fig. 49 und den mächtigen Nerven. welcher für die grossen Kiefermuskeln bestimmt im Trigeminnsgebiete der hier angeschwollenen motorischen Zellsäule entspringt, Fig. 50.

Der Facialiskern der Tertebraten ist kein einheitlicher. Sowohl in der Längs- als in der antero-post. Richtung zeigt er Unterbrechungen. Man wird desshalb leicht für das eine oder andere Thier verschiedene Zellgruppen als Ursprungscentren für den Facialis auffinden können. Sie gehören aber alle der gleichen Masse grosser multipolarer Zellen an, deren Ausläufer hinein in die Nerven der Muskeln ziehen, welche die Kopfoberfläche da und dort in dünner Schicht bedecken.

Am frontalen Ende der Oblongata schwillt die grane Iasse, welche am latero-dorsalen Rande die sensiblen Nerven aufnahm, noch eimmal gauz enorm an. Hier tritt in sie der Nervus trigeminus.

Doch endet in diesem froutalen sensiblen Trigeminuskern wur ein Theil der aus dem Gauglion Gasseri stammenden Massen, ein grösserer wendet sich spinalwärts, um allmählich in das Gran einzutauchen, dem wir auf allen Schnitten rom oberen Rückenmarksende bis herauf zum Quintuseintritt begegnet sind. Diesen absteigenden Theil haben Sie schon als bulbo-spinale ITurzel kemen gelernt. Bei den Ǩnochenfischen versorgt der Trigeminus ein besonders ausgebreitetes sensibles Feld, die ganze Nasse der Kanäle, welche mit Simnesepithelien da und dort rersehen, den Kopf und einen Theil des Rumpfes ïberziehen. Die Kerngrösse hat desshalb bei einigen dieser Thiere sehr zugenommen, es ist eine Art accessorischer neuer Quintuskern hier entstanden, der als mächtige Gewebsmasse mit dem gleichen Kerne der anderen Seite verbunden mitten in dem Tentriculus quartus liegt. Durch das gerade bei diesen Thieren stark entwickelte Cerebellum ist er ganz caudalwärts ans den eigentlichen Trigeminusebenen heransgedrïckt. Er liegt zwischen den Tagusursprüngen, die er wieder seinerseits lateral drückt.

Besser als eine Beschreibung wird sie Fig. 52 - 54 über den Lobus Trigemini und seine Beziehungen zu den Quintuswurzeln orientiren. 
Bei den Tögeln und besonders bei den gepanzerten Reptilien ist der frontale sensorische Trigeminuskern viel weniger entwickelt als bei den anderen Thieren.

Lobus $\mathrm{N}$. trigemini.

Lobus N. vagi.

Tr. vago-cerebellaris et tectalis.

Nucl. mot. N. vagi.

Radices N. vagi.

Fasc. longit. post. u. Tr. tecto-spinalis

Rad. mot. N. vagi.

Vagus desc. et Tr. vago-cerebellaris.

Tr. bulbo-spinalis $\mathrm{N}$. trig.

Tr. assoc. breves et Fibr. arcif. ext.

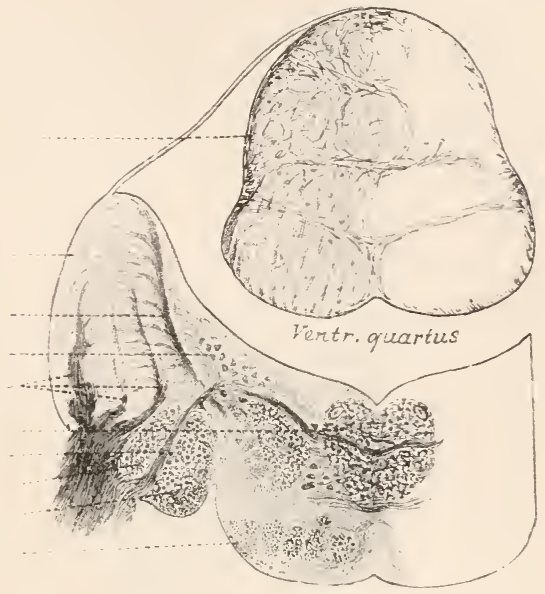

Lobus N. trigemini.

Radices lobares N.?

Caudalster Theil desAcusticusfeldes mit absteigenden Acusticuswurzeln.

Tr. acust. tect. vontr., Corpus trapez. et Oliv sup.

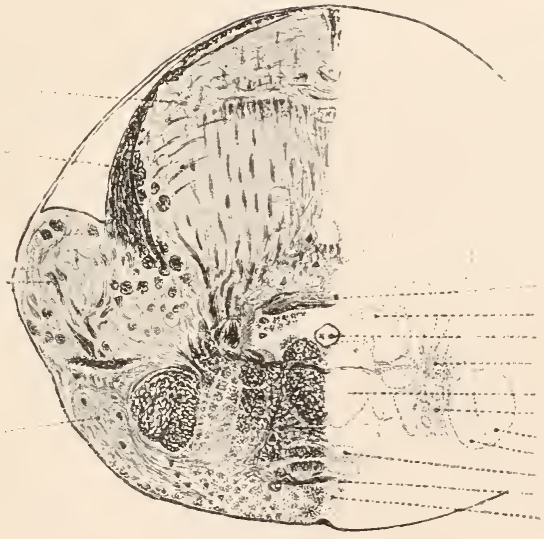

Decussatio (acust

Divertic. ventr. quart.

Soc. Bahn aus dem Lobus $z$ Cerebellum u. z. Tectum. Tr. quinto-cerebellares et tect. Fsc. long. post.

$\operatorname{Tr}$. assoc. breves.

Tr. bulbo-spinalis $\mathrm{N}$, trig. Tr. vago-cerebellaris.

Fig. 52-53.

Aus der Oblongata von der Barbe, Barbus fluviatilis. Vagus- und Quintuswurzeln.

Mit jedem Nervus trigeminus tritt noch ein Faserzug aus dem Gehirne, welcher dem Dache des Mittelhirnes entstammt. Diese Radix mesencepha lica Trigemin i entstammt mächtigen birntörmigen Zellen. welche bei säugern nahe dem Aquäducte liegen. Wahrscheinlich ist 
dieser Fern identisch mit einem ans ganz gleichen Zellen bestehenden, welchen man bei Amphibien und Reptilien ziemlich in der Nittellinie des Tectum opticum findet. Dachkern des Mittelhirnes, besonder's gross bei den Schildkröten.

Alle Trigeminuskerne erhalten bedeutende Zuzïge aus dem Schleifenareal. Diese treten, wie anch zu den anderen Nervenkernen, gekreuzt an sie heran. Ausserdem bekommen sie einen Kleinhirnzurachs, ron dem es unsicher ist ob er im Kerne endet oder mit dem Nerren direct das Gehirn verlässt. Der Kleinhirnzuwachs zum Lobus trigemini ist besonders gross.

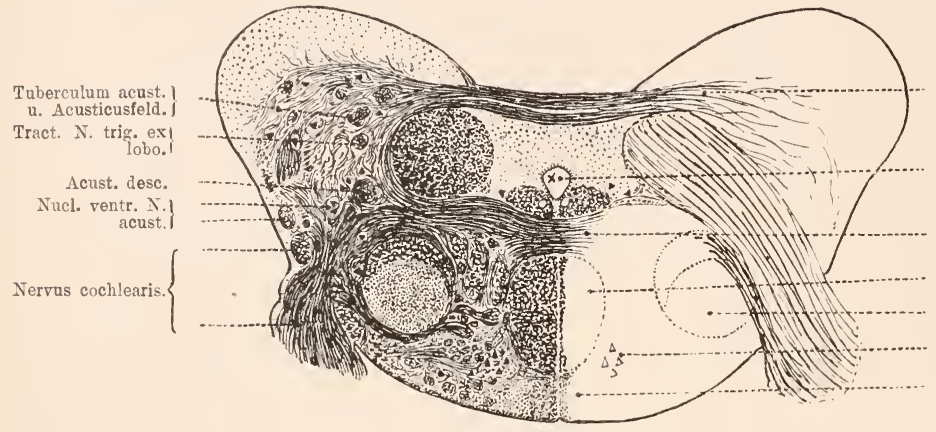

$\left\{\begin{array}{l}\text { Kreuzung } 2 w . d, \\ \text { Tub. acust. }\end{array}\right.$

Tuberculum acust.
u. Acusticusfeld.

Tract. N. trig. ex

Acust. desc.

Nucl. ventr. N.l

acust.

Fig. 54.

Aus der Oblongata ron Barbus fluviatilis. Vagus- und Quintuswurzeln.

Wir haben bisher der Einfachheit der Darstellung halber angenommen, dass die Oblongata keine anderen Elemente enthalte. als die Hirmnervenkerne mit ihren Znzügen und Terbindungen, ron denen vor Allem die mächtigen Tractus tecto-nucleares zur schleifenmasse in Betracht kommen, und ans den rom Rückenmark her durchtretenden Massen, imnerhalb deren anch wieder der Tractus tecto-spinalis zur Schleifenfaserung und die Faserung des Fasciculus longitudinalis posterior die mächtigsten sind. Es gelangen aber in die Oblongata anch noch Fasern aus dem Rückenmarke zum Krleinhirn und aus dem Kleinhirn zu Kernen in der Oblongata selbst. Ansserdem enthält das verlängerte Mark neben der Masse ron Zellen und Fasern des Associationsystemes noch eine Anzahl ihm eigenthümlicher Ganglien. Ein einziges nur, die Oliva superior' ist anlässlich der Acusticusbeschreibung genannt. Nun aber giebt es bei allen Wirbelthieren noch einige andere Kernanhäufungen. Bei den Säıgern ist die grösste jene als Oliva inferior bezeichnete Gruppe, welche zu der Kleinhirnfaserung in fester, später zu schildernder Beziehung steht und eben dadurch characterisirt wird. Bisher ist, wenn man an dieser Characterisirung festhält, noch bei keinem Wirbelthier ausser bei den Säıgern eine untere Olive nachgewiesen. Wohl kemnen wir ron Rep- 
tilien und Vögelı, vielleicht auch ron Amphibien Kerne, die so wie die Olive in der Oblongata gelagert sind, bei Reptilien auch s. Fig. 46 sehr ähnlichen Bau haben, aber eine sichere Stellung ist diesen Gruppen einstweilen noch zu geben. Das gleiche gilt für Kerne, welche ïberall am ventralen Rande der Oblongata, besonders in deren caudalem Gebiete naclıweisbar sind. Hier findet man bei Sängern die Nuclei arciformes.

Noch andere Ker'ne und namentlich noch andere Fasersysteme könnte ich Ihnen hier aufzählen, welche in hoch ausgebildeten Oblongaten, namentlich in derjenigen der Knochenfische und der selachier gefunden werden, ich will aber, wo noch so viele U'nsicherheit herrscht und die Beziehungen noch so wenig erkannt sind, diese Dinge nicht im Detail besprechen. Halten sie nur fest, dass die zahlreichen längsverlaufenden Bündel deren Querschnittesie auf allen Oblongataschnitten in den ventralen und lateralen Partieen begegnen, a nsser den Zïgen des Associationsystemes namentlich noch Terbindungen zum Mittel- nnd zum Zwischenhirne enthalten. Der Zwischenhirnfaserung zum Rückenmarke sind wir schon früher bei Betrachtung der seitenstränge begegnet, anch in der Oblongata liegt dies bei den Fischen besonder's g'ut abscheidbare Bündel in den seitentheilen. Es ist viel mächtiger als im Rückenmarke und nimmt spinalwärts ständig ab.

Zwei Fasersysteme der Oblongata miissen wir aber doch nun etwas genaner betrachten, schon weil sie physiologisch besonders wichtig sind.

Das eine ist die Faserung a s den Kernender Hinterstränge zur Schleife, die frontalsten Züge der Tractus tecto-spinales also. Sie sind Thnen schon oben als Fibrae arcuatae internae Fig to und Fig. 42 demonstrirt worden. Diese Bahn, welche erst bei den säugern ihre volle Mächtigkeit erreicht, ist wahrscheinlich schon bei den Fischen vorhanden. Sie ist ein Stïck jener mächtigen centralen Faserung ans den sensiblen Endkernen. Nach der Kreuzung zieht sie in der Schleifenschicht hirnwärts und ihr gesellen sich allmählich alle jenen gekrenzten Zïge ans den Hirnnervenkernen, die Tractus tecto-nucleares zu. Mit ihnen zusammen bildet sie die Schleifenschicht. der sie anf allen Abbildungen begegnen, die ich Ihnen heute demonstrirte.

Das zweite wichtige Fasersystem gehört dem lateralen Oblongatarande an. Hier liegt, wie sie sich erinnern, rentral von der spinalen Trigeminuswurzel der Tractus cerebello-spinalis. Er stammt auch aus Endstätten von sensiblen Fasern im Rïckenmarke, aber er wendet sich nicht zur Schleifenschicht, sondern zieht frontalwärts bis dahin, wo der Acusticus abgeht und wendet sich dort dorsal hinauf zum Kleinhirn. Unterwegs aber hat er aus den Hintersträngen und auch aus ihren Kiernen Terstärkungen - Fibrae arciformes externa - nachgewiesen bei Fischen, Amphibien und Vögeln - aufgenommen. Das vereinte Bündel heisst nun Corpus restiforme, unterer Kleinhirnarm. Nur bei den Sängern ist es ganz genau studirt, dort enthält es auch noch andere Faserelemente. 
Nur wenige derselben, so die Acusticuskleinhirnbahn und der Zug aus dem Deiters schen Kerne zum Rückenmarke sind auch bei Tögeln und Reptilien bereits wiedergefunden. Wo eine Olive nachweisbar ist, verlaufen die Fasern aus ihr in jenem unteren Kleinhirnarme.

Bei Fischen, Amphibien, Reptilien und Vögeln liegt dicht dorsal und frontal vom Trigeminusursprunge ein grosses Ganglion, das, eingebettet zwischen seitlichen Kleinhirnrand und Dach des Mittelhirnes, von Stieda als Uebergangsganglion bezeichnet wurde. Dieser Figur 65 gut sichtbare Körper ist bisher noch nicht bei Säugern aufgefunden worden. Ich sehe bei den Knochenfischen und Reptilien in ilm ein Faserbündel enden, das einer Commissur hinter dem Opticuschiasma entstammt. Perlia erkannte, dass es bei Vögelı atrophirt, wenn ein Opticus exstirpirt wird, und dass es einen eigenen Zug aus dem Sehnerven aufnimmt. Zwischen dem rechtsseitigen und dem linksseitigen Ganglion ist eine nicht unbedeutende Faserkreuzung zil sehen. Dieser grosse Zellcomplex an so prominenter Stelle, welcher nur bei den Thieren mit hoch ausgebildeten Opticusendstätten sichtbar ist, verdient eingehendere weitere Untersuchung. Der Spalt zwischen Cerebellum und Mittelhirn wird in der menschlichen Anatomie als Istlı mus bezeichnet. Da das Ganglion gerade an dem seitlichen Raude jenes Spaltes liegt, mag es als $\mathrm{g}$ a $\mathrm{ng} \mathrm{l} \mathrm{i}$ o $\mathrm{n} \mathrm{I}$ s $\mathrm{th} \mathrm{m}$ i zunächst bezeichnet werden. Es ist bei Sängern noch nicht anfgefunden worden.

Am frontalen Ende der Oblongata wenden sich die Tractus tectobulbares et spinales dorsalwärts, um in das Mittelhirndach einzutauchen. Hier ist ihnen immer ein Kern eingelagert, Fig. 50, der Schle if en kern, welcher vielfach in mehrere Unterkerne zerfällt. Die Bahnen zum Cerebellum sind hier längst nach oben getreten, diejenigen zu und aus den Hirnnervenkernen nur noch zu geringem Theile vorhanden. Was hier ausser den erwähnten Zïgen noch rorhanden ist. beschränkt sich auf Antheile, die von oben her in das Kleinhirn herabziehen, dann auf Bahnen, die aus dem Mittelhirn und dem Zwischenhirn oblongatawärts treten. Sie liegen in den ventralen Abschnitten und sind noch nicht sicher von der Schleife bei den niederen Vertebraten zu scheiden. Ausserdem aber liegt dorsal noch der Fasciculus longitudinalis posterior und über die ganze Breite der lateralen Felder vertheilt, das System der Commissurzellen mit den kurzen Bahnen, welche einzelne Höhen der Oblongata und des Mittelhirnbodens hier verkniipfen.

Bei den Säugern aber, soweit ich heute sehe, nur bei diesen. dringt noch eine Bahn aus dem Grosshirn hierher herunter, die zum Theil in den später als Brückenganglien zu schildernden Kernen bleibt, zum Theil in den Kernen der Hirnnerven mit ihren letzten Ausläufern auch im Rückenmarke endet, wo wir sie bereits als Tractus cortico-spinalis kennen gelernt haben.

Wir können unsere Uebersicht über den Bau der Oblongata hier zunächst abschliessen. Nun, wo sie erfahren haben, welche wichtigen Ursprungs- und Endkerne hier liegen, welche mächtigen Associationssysteme das Ganze erfüllen und alle seine Höhen unter einander und mit höheren mod tieferen Centren verknïpfen, welche wichtigen Verbindungen aus der oblongata zu anderen Hirntheilen laufen, nun wird es Ihnen wohl be- 
greiflich werden, warum gerade dieser Hirntheil der wichtigste für die Fortexistenz des Lebens ist. Man kann einerseits einem niederen Wirbelthiere Alles entfernen. was vor der Oblongata liegt, ohne seine vitalen Functionen so zu beeinträchtigen, dass der Tod einträte und kann andererseits das ganze Rückenmark entfernen, ohne dass zunächt mehr sichtbar würde, als complete motorische und sensible Lähmung. Nur den Ausfall des rerlängerten Markes. des mächtigen Ursprungscentrums der wichtigsten Nerven und des grossen Coordinationscentrums erträgt kein Wirbelthier länger.

Der Wichtigkeit der Oblongata fül die Existenz des Thieres entspricht auch der Umstand, dass dieser Hirntheil früher als irgend ein anderer der Ausbildung sich nähert. Wenn im ganzen frontalen Hirnabschnitt noch keine Faser markhaltig ist, umgeben sich schon die Hirnnerven mit Nark und bald nachher auch ihre centralen Bahnen, die Tractus tectonucleares. Nur das hintere Längsbündel ist um diese Zeit schon markhaltig. Das allein erleichterte, bei den Fischen z. B., die Verfolgung der Hirmnervenbahnen. Nicht uninteressant ist, dass der elektrische Nerv bei Torpedo von $11 \mathrm{Cm}$. Körperlänge schon neben den anderen Hirnnerven seine Markscheiden hat, also wohl fungirt.

\section{Achte Vorlesung.}

\section{Das Kleinhirn.}

Dorsal von der mächtigen Oblongatafaserung liegt, mit ihr immer durch einige Züge verbunden, das Kleinhirn. Es geht caudal in den Plexus choroides ventriculi quarti und frontal in eine dünne Platte, das Velum anticum iiber. Welche hinïber zum Dache des Mesencephalon fïhrt.

Wenn Sie die Fig. 55 abgebildeten Schnitte durchmustern, so wird Ihnen auffallen, dass kein Hirntheil, ausgenommen etwa das Vorderhirn, so viele Variationen der Ausbildung aufweist, als dieser. Aber das Kleinhirn ist nicht, wie das Vorderhirn, bei höheren Thierklassen weiter ausgebildet, als bei niederen. Wir begegnen vielmehr bei nahe verwandten Arten sehr bedentenden Differenzen. Die einfachste Form. in der wir ein Kleinhirn finden, weisen die Cyclostomen und die Amphibien auf; die dem Mittelhirn zugewandte Seite des Hinterhirndaches ist zu einer d ï nnen, quer über den Ventrikel gestellten Platte verdickt. Auch die Reptilien besitzen kein wesentlich höher stehendes Organ. Aber bei denjenigen unter ihnen, welche schwimmen (Alligator, Krokodil, Chelone midas, Fig. 57 B). ist die Platte 1 m das Doppelte vergrössert und erstreckt sich auch auf die caudale Seite des Daches. Die grossen Schwimmer, die Knochenfische und besonders die Selachier, besitzen eine Kleinhirnplatte, die so enorm ausgebildet ist, dass sie sich in massenhafte Querfalten legen 
muss (Fig. 55 A), ja bei den Teleostiern sich unter das Mittelhirndach in den Aquäduct linein rorstuilpt (Fig. $55 \mathrm{C}$ ). Im Schlamm lebende Fische (Dipnoi) naben wieder ein kleineres Cerebellum.

Ein Blick auf Fig. 55 zeigt, dass durch die Umbengung der Kleinhimplatte eine Fortsetzung des Ventriculus quartus in das Innere des Organes zu Stande kommt. Dieser Tentriculus cerebelli ist auch daum noch nachweisbar, wemn, wie bei den Vögeln und Sängern, die Gewebsmasse des Kleinhirnes sehr zugenommen hat. Nur ist er dann sehr enge und in den periphersten Partieen kommt es gewöhnlich zu völligem Schwinden des kleinen spaltes.

In das Cerebellum der Fische, Amphibien und Reptilien gelangen Züge aus dem Zwischen- und Mittelhirı, desgleicheu solche aus dem Rückenmark. Dieselben Züige finden wir bei Vögeln und säugern wieder. Aber bei den letzteren ziehen auch sehr starke Faserbündel aus dem
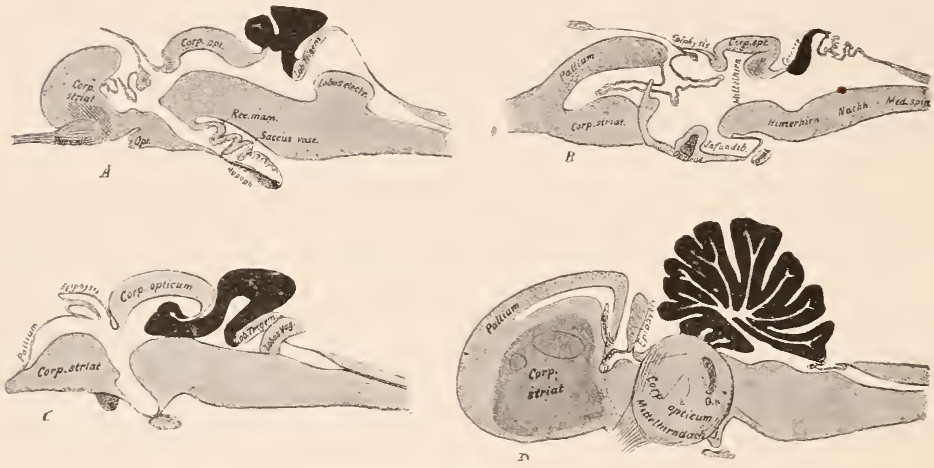

Fig. 5 อ.

Halbschematische Sagittalschnitte durch Tertebratengehirne. Das Cerebellum geschwärzt, um dessen relative Grösse zu zeigen.

A. Ein Rochengehirn. B. Ein Amphibiengehirn. C. Forellenembryo. D. Vogelhirn.

Vorderhirn dort hinein. Diese gelangen in eigene, jederseits rom Mittelstïck neu auftretende Bildungen, die Hemisphaeria cerebelli. Sie entwickeln sich bei den Säugern, gleichzeitig mit dem Auftreten einer Brïckenformation, zu Theilen, welche das Nittelstïck (ron nun an W 1 r m, Termis genannt) an Grösse weit übertreffen. Das Mittelstück behält aber bis hinauf zum Menschen den ihm durch die Querfaltung der Cerebellarplatte seit den Selachiern gewordenen Charakter. Direct caudal rom Cerebellum begegnen wir im Hinterhirndache noch Ganglienmassen, welche Trigeminus- und Acusticusfasern anssenden. Meist mit dem Kileinhimn fest verschmolzen, bilden diese bei den höheren Wirbelthieren nubedeutenden Kerne bei den Fischen doch recht ansehnliche Lappen.

Der Vermis cerebelli erreicht nirgendwo in der Thierreihe so colossale Ausbildung wie bei den grossen Schwimmern und den Vögeln. Dieser Tmstand 
und die gerade dort auch besonders mächtigen Verbindungen mit dem Tonusnerven des Labyrinthes und mit dem Trigeminus lassen schon als sehr wahrscheinlich erscheinen, dass das Cerebellum irgendwie zur Aufrechterhaltung des Gleichgewichtes und des Muskeltonus in einer Beziehung stehen muss, die sich in seiner Gesammtentwicklıug ausdrückt. Bekanntlich weisen auch die Ergebnisse physiologischer Versuche darauf hin, dass in dem Cerebellum derartige Functionen localisirt sind. Es wird Sie interessiren zu hören, dass höchst wahrscheinlich das Cerebellum einer der ältesten Hirntheile ist. Soweit mir Versuche über das obere Schlundganglion der Gliederthiere bekannt geworden sind, weisen sie alle darauf hin, dass es ähnliche oder die gleichen Functionen wie das Cerebellum erfülle.

Im Ganzen wissen wir aber über die Kleinhirnfunction noch recht wenig. Nur für das Organ der Säuger fangen wir an klarer zu sehen. Das hängt mit einem merkwïrdiger Weise immer übersehenen Umstande zusammen. Wir können bei niederen Thieren noch nicht beobachten. Störungen dort miissen schon ungewöhnliche sein, wenn wir sie als solche erkennen sollen. Wie viele Jahrtausende ärtlichen Beobachtens waren allein erforderlich, bis wir gelernt hatten, beim Menschen, den wir doch täglich vor Augen haben, pathologische Gangarten abzuscheiden und zu unterseheiden. Wer von uns kenut z. B. das Schwimmen der Fische so genau, dass er auch nur analoge Störungen bei solchen, wie sie nun beim Meuschen von Jedermamn gesehen werden, zu erkennen sich getraute. Die Art physiologischer Beobachtung, welche bisher geiibt wurde, ist da völlig unzureichend.

Zweifellos also ist das Kleinhiru ein sehr wichtiger Hirntheil und es lohnt sich sehr, wenn wir uns mit seinem Bau etwas beschäftigen.

Merkwïrdig einfach und bei allen Thieren gleichartig ist es nun aufgebaut. Immer wiederholt sich der gleiche histologische Typ.

Sie haben schon friiher erfahren, dass das Kleinhirn sich ontogenetisch aus einer einfachen Platte entwickelt und heute haben Sie gesehen, dass es auch phylogenetisch sich gleichartig verhält. Durch Fältelung der Platte entstehen alle die mannigfachen Kleinhiınformen, immer aber handelt es sich im Tesentlichen nur um eine Oberflächenvergrösserung. Mag die Platte oben oder unten hin kommen, mag sie isoliert und klein oder zu mächtiger Ausbildung gediehen sein, immer ist sie gleichartig gebaut. Nehmen wir als Ausgangspunkt weiterer Betrachtung das Cerebellum der Reptilien, weil es eine einfache dünne Platte ist, welche quer über dem Ventrikel senkrecht zur Längsaxe des Gehirnes scheitelwärts ragt. Wir kömnen damn eine Facies frontalis unterscheiden, welche dem Mittelhirudache zugewendet ist und eine Facies caudalis. Ein Schnitt lässt sofort erkennen, dass beide verschiedenen Aufbau habeu. Der hintere Abschnitt besteht aus einer an Gauglienzellen reichen Platte, der vordere nimmt im Wesentlichen nur Dendriten aus dem hintereu auf.

Gerade auf der Grenze beider Schichten liegt eine Lage grosser und bei allen Wirbelthieren ausserordentlich ähulich gebauter Zellen, die Schicht der Purkinje'schen Zellen. Diese senden ihre Dendriteu zum grössten Theile froutalwärts. wo sie dann mächtig aufzweigen und mit ihrem Geäste die frontalste Schicht, die Molecularschicht des Kleinhirnes erfüllen. Thre Axeucylinder aber senden diese Zellen rück- 
wärts. Sie bilden ein mächtiges Faserwerk, dessen Enden in die Kleinhirnarme gerathen. Diese Arme treten bei den Reptilien von beiden Seiten her an das Cerebellum heran und was sie ihm ron Fasern zuführen. verläuft in dem Plexus, den sie theils dicht unter den Purkinjeschen Zellen, theils in der candalen Kleinhirnschicht der Körnerschicht erkennen.

Die kleinen multipolaren Ganglienzellen, welche die Körnerschicht erfiillen, scheinen ihre Axencylinder alle in die Molecularschicht hinauf zu senden, doch giebt es gerade in dieser Schicht und auch dicht über den Purkinjeschen Zellen noch einige andere Zelltypen, die zwar von

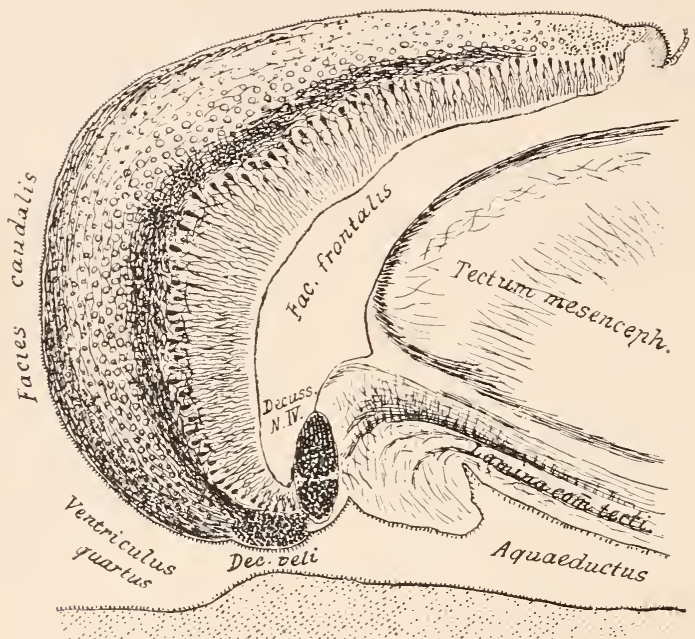

Fig. 56.

Sagittaler Medianschnitt durch das Cerebellum der Wüsteneidechse.

Varanus griseus.

Tögeln und Fischen schon bekamnt, am besten aber bei den Säugerm studirt sind. Desshalb muss ich auf die Darstellung in einer späteren Vorlesung verweisen.

Die Masse der in das Cerebellum dringenden Fasern ist bei Amphibien und Reptilien so gering, dass sie über dem Ventrikelepithel kaum eine eigene Schicht bilden, sondern sich sofort in das feine Netz der letzteren auflösen; bei den Knochenfischen, den Selachiern und höheren Wirbelthieren aber ist das anders. Dort gelangen eine solche Menge markhaltiger Fasern in das Cerebellum, dass man immer zwischen dem Tentrikelepithel und Körnerschicht eine eigene, zuweilen recht beträchtliche Schicht, die nur von ihnen gebildet wird. wahrnimmt. Das ist das 
Marklager des Cerebellum. Unsere Abbildung von Varanus zeigt das Marklager eben nur in Spuren. In dieses Marklager treten Züge aus dem Mittelhirn und Zwischenhirn ein, die bei den Fischen besonders kräftig ausgebildet sind, aber auch bei allen anderen Thieren sich nachweisen lassen. Der feinere Zusammenhang all dieser Theile, besonders der Zellen wird für die Säuger eingehender geschildert werden, für die niederen Vertebraten liegt noch nicht ausreichendes Beobachtungsmaterial vor, doch zeigt, das was bekannt ist (Knochenfische Schaper, Vögel, R. y Cajal, Kölliker und eigene Untersuchungen), dass wahrscheinlich überall auch die feinsten Verhältnisse denen der Säuger ähnlich sind.

Im Wesentlichen stellt sich heraus, dass im Kleinhirn Fasern münden und entspringen und dass durch die Fortsätze der verschiedenen dort liegenden Zellen sehr reichliche Möglichkeit zu Coordination von solchen Vorgängen gegeben ist, welche in dem Kleinhirn sich abspielen.

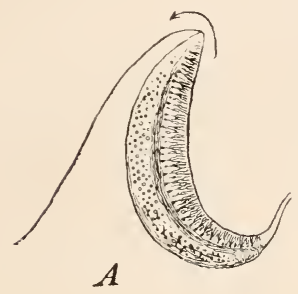

$A$

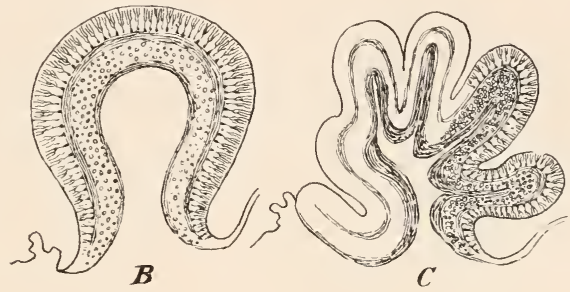

Fig. 57.

Etwas schematisirte Sagittalschnitte durch $A$ Eidechsengehirn, $B$ Typus von Chelone und Alligator, sowie Crocodilus, $C$ Typus der Vögel und Säuger. Zur Demonstration der Vergrösserung des Kleinhirnes mittelst Umbeugen der Cerebellarplatte in der Richtung des Pfeiles über $A$.

Ein Schnitt durch das Kleinhirn eines Vogels oder Säugers oder auch schon der äussere Anblick des grossen Organes, welches die Fische bieten, lässt nun vermuthen, dass das Cerebellum ein sehr complicirtes Gebilde sein müsse. Wir können aber von dem einfachen, eben für Varanus geschilderten Typ ganz gut die meisten anderen Kleinhirntypen ableiten. Es handelt sich nur um zwei Factoren um die Entwicklung der Rinde und diejenige des Marklagers. Wenn die Rinde sich vergrössert, legt sich das ganze Kleinhirn in Falten. Fig. 57 zeigt, wie sich der einfache Eidechsentyp bei dem schwimmenden Alligator und bei der Chelone verdoppelt und wie durch weitere Faltung der gleichen Platte der Typ ableitbar ist, welchen Vogel- und Säugerwurm zeigen. Bei den Knochenfischen ist die Oberfläche wesentlich grösser als bei den Amphibien und Reptilien, es ist auch dadurch, dass die Körnerschicht dicker ist und besonders dadurch, dass ungewöhnlich viele Verbindungsarme hier in das Cerebellum gerathen, der Markkern dicht über dem Ventrikel sehr vermehrt. So kommt ein anscheinend massiver Körper, 
Fig. 44 im Sagittalschnitte, zu Stande. dessen unter dem Mittelhirndach liegender Theil als Valvula cerebelli bezeichnet wird.

Es ist schon oben erwähnt worden. dass sich der eigentlichen Kleinhirnmasse am caudalen Ende noch Theile beigesellen. welche speciell zu

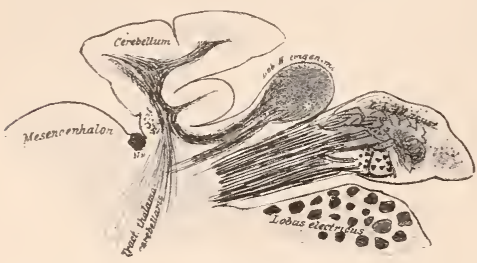

Fig. 58.

Sagittaler_Schnitt, etwas seitlich von der Mittellinie, durch das Cerebellam eines kleinen Rochens, Rajaart.

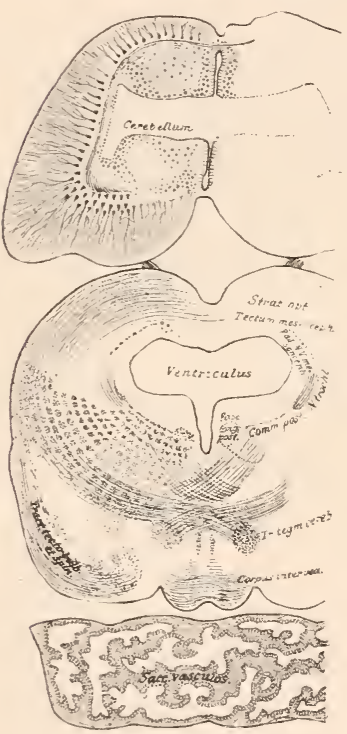

Fig. 59.

Frontalschnitt durch das Mittelhirn eines Haies, Scyllium canicula. $30 \mathrm{Cm}$. Körperlänge. Zeigt die Kreuzung der Bindearme, Tractus tegmento-cerebellares. den Kernen des Acusticus und des Trigeminus in Beziehung stehen. Die Tremnung dieser Gebiete vom Cerebellum ist bei den meisten Vertebraten noch nicht scharf durchzuführen, aber bei den Selachiern sind sie durch deutliche Querfurchen abgeschieden. so. dass man da ron einem echten Lobus cerebellaris Acustici u. Lob. c. Trigemini sprechen kamn.

Bei den Knochenfischen und auch bei den Selachiern legt sich die Cerebellarrinde eine Strecke weit caudalwärts über diese accessorischen Kleinhirntheile hinweg. Bei den Vögehn und Säugern sind sie ganz in die Cerebellarformation hinein geriickt und liegen als medialste Theile im Vurme.

Eigenkerne des Kleinhirnes kann man Kerngruppen nennen, welche bei Säugern und Vögeln gut, bei den Reptilien und Amphibien noch kaum gekannt, bei den Fischen aber wenigstens in einer Gruppe gut abscheidbar sind. Diese letztere Gruppe besteht aus zwei rundlichen mächtigen ziemlich caudal liegenden Kernen, den Nuclei globosi cerebelli Fig. 47. Sie liegen so sehr in der Ebene der nucleo-cerebellaren Bahnen und sind so sehr von deren Zügen umfasst, dass sie wahrscheinlich diesen letzteren zugerechnet werden müssen. Bei den Vögeln, wahrscheinlich in geringem Masse schon bei den Reptilien, liegen lateral von ihnen noch kleine Zellanhäufungen. die Nuclei laterales Vermis und bei den säugern findet man nicht nur in der gleichen Gegend mehrere kleine Kerne, sondern namentlich ganz lateral. schon in den Hemisphären einen mächtigen vielgefalteten Kern, die Oliva cerebelli, den Nucleus dentatus. Er nimmt den rorderen 
auf relativ einfach durchsichtige Weise zu Stancle kommen. Es münden immer in die äusserste Schicht mit zahllosen feinen Endpinseln die Fasern des sehnerven und auch in einigen tieferen Schichten verbreiten sich noch solche Endpinsel. Dort treffen alle massenhaft auf Dendriten von Zellen, die in mehreren Höhen angeordnet daliegen. Eine kleine Anzahl solcher Zellen scheint Fasern hinab in die Sehnerven selbst zu senden, die Mehrzahl aber, ganz besonders eine lange Schicht sehr grosser Zellen, entsendet ihre Axencylinder in die Tiefe, ventrikelwärts, un hier bilden sie damn die schicht des tiefen Markes. In diese Schicht treten aber auch, ganz wie in die Opticusschicht, zahlreiche Fasern ein. Sie kommen von anderen Endstätten her. Durch diesen A fufba ist eine a usserordentlich reicheGelegenheit zur Tebertragung von Lichteindrücken a uf die allgemeine Gefïhlsbahn gegeben. Denn das tiefe Mark steht, soweit heute bekamnt. nu mit Endpunkten anderer sensibler Nerven in Terbindung.

Wollen Sie num eimmal einen Blick auf Fig. 64 u. 71 werfen. Da erkennen sie, wie am caudalen Ende des Mittelhirnes der in früheren Vorlesungen als Schleifenfaserung bezeichnete Complex der Tractus tecto-spinales und tecto-bulbares dicht ror dem Cerebellum sich hinauf in das Mittelhirn begiebt und da in die Schicht des tiefen Markes eintritt. So haben wir wieder den Anschluss an ein Ihnen bekanntes Bündel gefunden und kömmen num den übrigen Zügen aus dem gleichen Systeme unsere Aufmerksamkeit schenken.

Es ist natiurlich nicht ganz leicht.

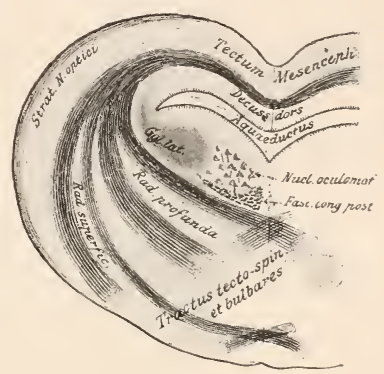

Fig. 67.

Der Verlauf der Faserung aus dem tiefen Marke. Schema. in all dem Faserwerke, welches den ventralen Abschnitt des Mittelhirndaches erfüllt, klar die Einzelbeziehungen zu erkennen. Ganz ummöglich aber scheint es, diese Aufgabe an erwachsenen Thieren zu lösen. Da bieten sich nun als willkommenes. höchst einfaches Object die Larven der Amphibien und die Embryonen der Reptilien und Vögel. Hier entwickelt sich nämlich vor allen anderen Fasersystemen des Mittelhirnes, also namentlich auch vor dem Opticus, das System des tiefen Markes. Es hat Markscheiden in einer Periode, wo - ausser etwa den Kernen der Hirmmerven und dem hinteren Längsbiindel - in jener Gegend kein anderes System markhaltig ist. Geht man bei der Betrachtung eines Frontalschnittes hier von dem Tentrikelepithel nach aussen, so gelangt man erst zu einer schicht lockeren, zellarmen Gewebes, dem Ependym, dam zu einer solchen mit grossen Ganglienzellen und iber ihr in die einzige markhaltige schicht der Dachplatte, in die schicht des tiefen Markes; weiter dar über linaus erkennt man 
nur noch Zellen und marklose dünne Fäserchen. Es lässt sich nun leicht erkennen, was aus diesem Marke wird, Fig. 77. Ein Theil gelangt direct an der Seite des Mittelhirnes herab zur Himbasis und zieht da caudalwärts, ein zweiter geht den gleichen Weg. kreuzt aber erst die Mittellinie. ehe er sich abwärts wendet. Diese Kreuzung heisst bei älteren Autoren Commissura ansulata. Diese beiden Theile zusammen stellen die laterale Abtheilung des tiefen Markes dar. Es giebt aber auch eine mediale. Die zu innerst, dem Tentrikel zunächst liegenden Fasern wenden sich nämlich nicht an die Himbasis. Sie ziehen eine Strecke der Tentrikelwand parallel und spalten sich dam, ganz wie die laterale Abtheilung in einen Theil zur gleichen und einen solchen zur gekreuzten Seite.

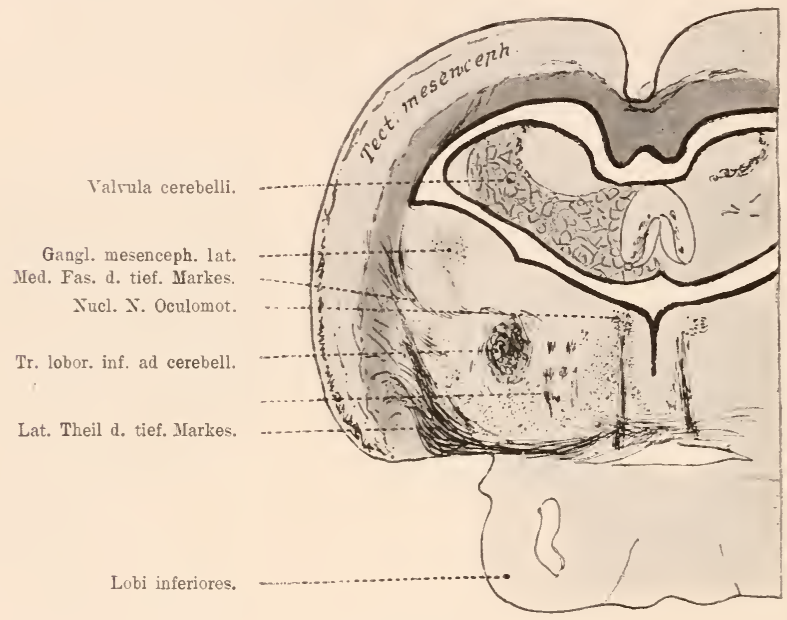

Fig. 6s.

Frontalschnitt durch das Mittelhirn eines Knochenfisches, Rhodeus amarus.

Der Theil, welcher gleichseitig bleibt, endet zum guten Theile in einem Ganglion, dem Ganglion laterale Mesencephali, der gekreuzte andere Abschnitt umfasst den Tentrikelboden, der hier immer eine schmale spalte nur bildet, und formirt unter ihm in schön geschwungenen Linien die .,Haubenkreuzung“*. Nachher zieht er dicht an der Mittellinie, rentral von den Fasern des hinteren Längsbündels, siehe Fig. 91, caudalwärts.

Das alles sind also Bündel, welche das tiefe Mittelhirndach mit weiter caudal liegenden Abschnitten rerbinden. Sie enden wohl zumeist in der Oblongata, in den Hinterstrangkernen und in dem Rückemmarkgrau. Tractus tecto-spina les et tecto-bulbares.

Bei erwachsenen Thieren wird das Mark des Mittelhirnes am besten da studirt, wo es besonders gut entwickelt ist. bei den Tögeln oder bei 
den Fischen. Es gewähren jedoch die Knochenfische noch den besonderen Vortheil, dass die Gegenden, in welche sich das Mark begiebt, relativ einfach gebaut sind, so dass eine Verfolgung möglich wird. Hat man aber eimmal die Verhältnisse bei den Knochenfischen richtig erkannt, dann findet man sie leicht überall bis hinauf zu den Säugern wieder.

Auf der Abbildung Fig. 6s finden sie leicht einige der vorhin angegebenen Züge wieder. Nur die Kreuzung der medialen Abtheilung ist nicht sofort zu erkennen. Bei der enormen Ausdehnung des Daches, welche bei den Knochenfischen eingetreten ist, haben diese Fasern eine andere Lagerung bekorumen. Sie liegen jetzt direct der Kreuzung anf, welche die laterale Abtheilung des Markes macht, und vergrössern so die Commissura ansulata. Auf Horizontalschnitten kann man bei den Fischen sehr gut die beiden Abschnitte der Commissur tremen. Fig. 91.

Das Mark aus dem Dache erfüllt also einen guten Theil der Fusspartie der basalen Mittelhirnabtheilung, umgreift und durchflechtet sie. Dieser" vielen Querfasern wegen ist die Mittelhirnbasis auch schon als Pars commissuralis bezeichnet worden.

Das Mittelhirndach giebt in den gleichen Schichten aber noch einem anderen Systeme Lrsprung. Es sind das Fasern, welche, in ihrer Gesammtheit viel mächtiger als die erwähnten Antheile, ïberall im ganzen

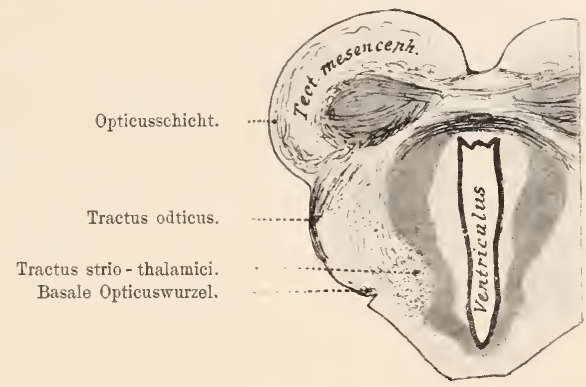

Fig. 69.

Frontalschnitt durch das Mittelhirn der Kröte, Bufo cin.

Bereiche des Daches in coronaler Richtung von der rechten zur linken Seite ziehen. Durch diese Fasern wird in der Mittellinie die Dachkreuzung des Mesencephalon gebildet. Lamina commissuralis Mesencephali. Diese Kreuzung ist ungemein constant und von Petromyzon bis zum Menschen ganz gleich vorhanden. Auf Figur 65 ist sie gut sichtbar. Sie schliesst sich vorn ganz direct an die Querfasern an, welche als Commissura posterior am frontalen Ende des Mittelhirndaches einherziehen, Fig. 69, aber durch das dïnnere Faserkaliber und die etwas dorsalere Lage sind ihre Züge immer wohl von der hinteren Commissur zu scheiden.

Der Sehnerv entspringt bei allen niederen Vertebraten vornehmlich 
aus dem Mittelhirndache. Fig. 64 und 70 geben Ihnen ein gutes Bild von diesem Ursprunge. Nur bei den höheren säugern scheint, soweit Degenerationsversuche vorliegen, die Opticusendigung in den Ganglien des Thalamus. die bei den niederen Vertebraten ganz unbedeutend ist. eine grössere Rolle zu spielen. Das Mittelhirndach ist ein Kugelabschnitt. An diesen tritt nun von unten aussen her. aus dem Chiasma kommend, der Opticus heran und umgreift die ganze Masse mit mannigfaltigen Zügen. Die Mehrzahl derselben geräth auf die Oberfläche; gleich wie die Finger einer leicht gekrümmten Hand umfassen sie die Kugelschale, aber eine kleinere Anzahl von Bündeln. namentlich solche, welche für caudaler liegende Dachabschnitte bestimmt sind, tritt dicht vor dem Mittelhirndache in die Tiefe und sucht ihren Endpunkt zu erreichen, indem sie die Basis des

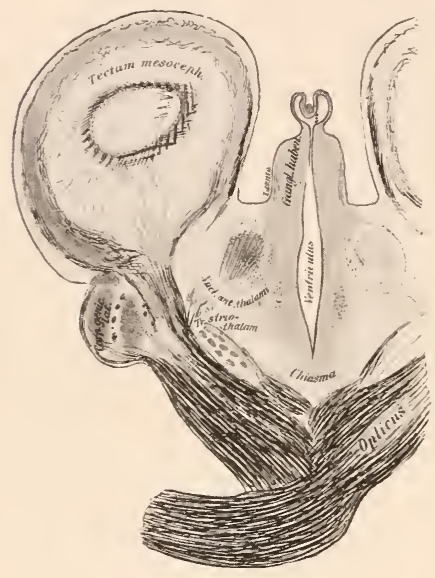

Fig. :0.

Frontalschnitt von Rhodeus amarus, durch die Gegend des Chiasma. Man sieht den Opticus die frontale Seite des Tectum mesencephali überziehen. Die Hirntheile in der Mitte gehören dem Zwischenhime an. Nittelhirndaches durchbricht, also gewissermassen unter demselben einherzieht. Namentlich einige mediale und einige laterale Opticuswurzeln gehen diesen Weg.

Nan hat diese einzelnen Bündel als verschiedene . Wurzeln" beschrieben, als eine laterale, eine mediale etc., aber es hat wenig Zweck, solche Unterscheidungen zu machen, da eben doch alle, wenn auch auf verschiedenen Wegen, dem gleichen Ende zuziehen.

Nur zwei Bündel lassen sich bisher wirklich abscheiden. Das eine ist ein ganz medial am Sehnerven liegendes, welches nacher auch im Mittelhirndache beiderseits neben der Mittellinie liegen bleibt, um schliesslich nicht im Mittelhirne, sondern in der Gegend des Ganglion isthmi zu enden (Vögel, P e r l i a) und ein zweites, das ganz lateral und ventral im Sehnerven liegt. Es kann bei allen Thieren - für die Säuger ist mir der Nachweis noch nicht geglückt - vom

Chiasma an rückwärts verfolgt werden bis an ein Ganglion an der Zwischenhirnbasis, das Corpus ectomamillare. $\mathrm{Ob}$ es sich hier um ein echtes Sehnervenbuindel handelt, um eine basale Opticuswurzel, das vermag erst die Degenerationsmethode zu entscheiden.

Da der Tractus opticus an das frontale Ende des Mittelhirnes herantritt, so wird man ihm schon an sehr weit rorn liegenden Schnitten begegnen. Einen solchen von Rhodeus, einem Knochenfische, stellt Fig. 70 dar.

Das Tectum mesencephali steht durch einen mächtigen Faserzug, den Tractus tecto-thalamicus. bei allen niederen Vertebraten in inniger 
Verbindung mit einem grossen Kerne des Zwischenhirnes. Der Zug ist so mächtig, dass er zweifellos auch noch bei den Säugern gefunden werden wird. Er löst sich zwischen den Dachschichten auf. Auch eine Torderhirnverbindung besteht, bei den Reptilien mit grosser Wahrscheinlichkeit, bei den Vögeln und Säugern aber völlig sicher. Ihrer werden wir später zu gedenken haben.

Nit der Schilderung des tiefen Markes, der Decussation und der Opticusfaserung, ist aber noch nicht das erschöpft, was wir über die Bestandtheile des Mittelhirndaches wissen. Nur das wichtigste sollte hier mitgetheilt werden. Es liegen da noch mehrere Faserarten und Kerne, ron denen ich nur einen, weil er bei der Untersuchung der niederen Tertebratengehirne besonders bervortritt, nennen will, den grosszell igen Dachkern. Es handelt sich um einen beiderseits von der Mittellinie,

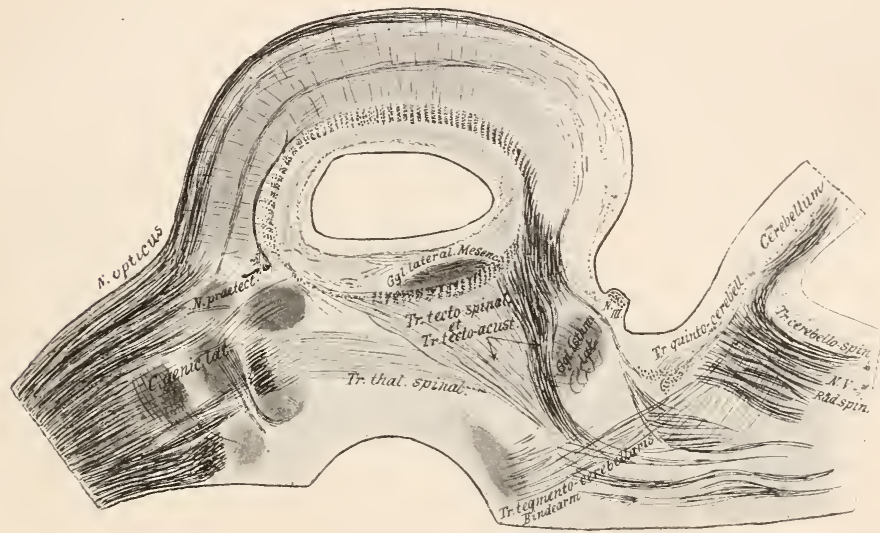

Fig. 71.

Sagittalschnitt durch ein Eidechsengehirn, Zur Demonstration der Lage des Nucleus lat. Mesencephali. Der gleiche Schnitt zeigt gut die verschiedenen Opticusendzüge und den Verlauf der Fasern aus dem tiefen Marke in die Schleife - Tractus tecto-bulbares et spinales.

dieser dicht benachbart liegenden Kern ganz mächtiger Zellen, der nicht die ganze Dachlänge einnimmt. Bei den Säugern ist er nicht vorhanden, dort aber begegnet man seitlich rom Aquaeducte einer Ansammlung ganz der gleichen Zellen, von denen durch Degeneration festgestellt ist, dass sie der Trigeminusfaserung angehören, Radix mesencephalica Nervi V, Es ist wahrscheinlich, aber nicht bewiesen, dass es sich hier um den nach der Tiefe verschobenen Dachkern landelt.

Die Basis des Mittelhirnes ist ausgezeichnet durch die zahlleichen Krenzungen, die in ihr liegen - wir haben ja schon einige solcher Kreuzungen anlässlich der Betrachtung der Faserung aus dem Marke des Daches besprochen, dann dadurch, dass in ihr einige wichtige Bündel 
aus dem Zwischenhirne caudalwärts dahinziehen, und schliesslich durch das Torhandensein einiger Eigenkerne.

Bei den Vögeln und den Fischen, wo sie wegen des grossen Daches breit auseinander gezogen ist, wo auch der Tentrikel einen nicht unerheblichen Theil berührt, ist sie besonders gut zu studieren. Man erkemnt da zunächst, dass das centrale Grau, welches überall den Tentrikel einfasst, natürlich auch die Seite der Mittelhirnbasis überzieht, welche rentrikelwärts liegt. In diesem Grau, also im dorsalsten Abschnitte der Mittelhirnbasis, liegen mehrere wichtige Kerne. Immer nachweisbar ist, ganz medial, beiderseits von der Mittellinie, eine Anzahl kleiner Zellhäufchen, welche rentralwärts die Fasern des Nervus oculomotorius entsenden. Siehe Fig. 65. Diese treten an der Hirnbasis immer an gleicher Stelle als zwei schon bei den niedersten Tertebraten nicht unbeträchtliche Nerven ab, um sich dann vorwärts der Augenhöhle zuzuwenden. Dicht caudal ron den Oculomotoriuskernen findet man Zellanhäufungen, Fig. 65, denen der Trochlearis entstammt. Der Nerv kreuzt bei allen bis heute untersuchten Thieren im Velum medullare posticum zur anderen Seite hinüber, Fig. 60. Um diese dorsal gelegene Kreuzung zu erreichen, müssen seine Fasern gleich nach dem Ursprunge etwas rückwärts ziehen und sich dann dorsal wenden. Der also ganz dorsal abgehende Nerr erscheint dann immer in dem engen Spalte, der zwischen Mittelhirndach und Cerebellum bleibt. Siehe Fig. 56 und Fig. 7 4.

Lateral vom Kerngebiete dieser Nerven liegt mitten im centralen Grau ein mächtiger Kern, der Nucleus lateralis Mesencephali. Das dünne, von einem feinen Nerrennetze erfüllte Grau um den Aquaeduct, welches die Säuger besitzen, lässt kaum rermuthen, welch mächtige Anordnung hier in Rückbildung noch vorliegt. Präparirt man am Gehirne eines Knochenfisches das Mittelhirndach ab. so erblickt man unter demselben zunächst den hierher eingestülpten Theil des Cerebellums als mächtigen, median getheilten Wulst, siehe z. B. Fig. \$6. Lateral von diesem aber trifft man jederseits auf eine längliche, etwas gekrümmte Hervorragung, die nicht, wie das Cerebellum. rom Mittelhirnboden abgehoben werden kann, diesem vielmehr selbst angehört. Der Wulst war schon den alten Anatomen bekannt und ist ron ihnen als Torus semicircularis bezeichnet worden. Es entsteht der Torus durch Einlagerung des erwähnten, bei Fischen ganz besonders mächtigen lateralen Mittelhirnkernes in den lateralen Theil des centralen Mittelhirngraues. Der gleiche Kern ist auch bei den Tögeln noch nachweisbar, wenn schon er da nicht mehr die relative Grösse erreicht, die er bei den Knochenfischen hatte. Bei den Selachiern ist mir sein Vorkommen noch zweifelhaft. aber bei den Reptilien ist er deutlich und bei den Amphibien wenigstens durch die Lagebeziehungen zu erkenmen. Fig. 72 . Aus dem Nucleus lateralis mesencephali entspringt immer ein sehr mächtiger Faserzug, das laterale Längsbün del. Es ist durch die ganze Oblongata hindurch zu rerfolgen und geräth wahrscheinlich in die Seitenstränge des Rückenmarkes. 
Dass ein Theil der Längsfasersysteme in der Mittelhirnbasis dem Thalamus entstammt, Fig. 71, wurde schon oben erwähnt. Drei der hier liegenden Bündel aber verdienen besondere Würdigung, jetzt schon, ehe wir den Thalamus betrachten, weil sie längst gut studirt, dem Markweiss der Basis sein Charakteristikum geben. Das erste ist der Fasciculus long itudinalis posterior, Fig. 44, das hintere Längsbündel. Es entspringt mit seinen vordersten Fasern ans einem eigenen Kerne des caudalsten Thalamusabschnittes, verstärkt sich aber in seinem Zuge nach rückwärts, namentlich während es die Kerne der Augenmuskehnerven passirt, sehr. Der Zug liegt beiderseits von der Mittellinie ganz dorsal, in die erwähnten Kerne eingebettet nnd ventral von ihnen, Fig. 65. Ebenfalls aus einem Kerne, der bei allen niederen Vertebraten sehr deutlich im ventralen Theile des Zwischenhirnes abzugrenzen ist, dem Nucleus

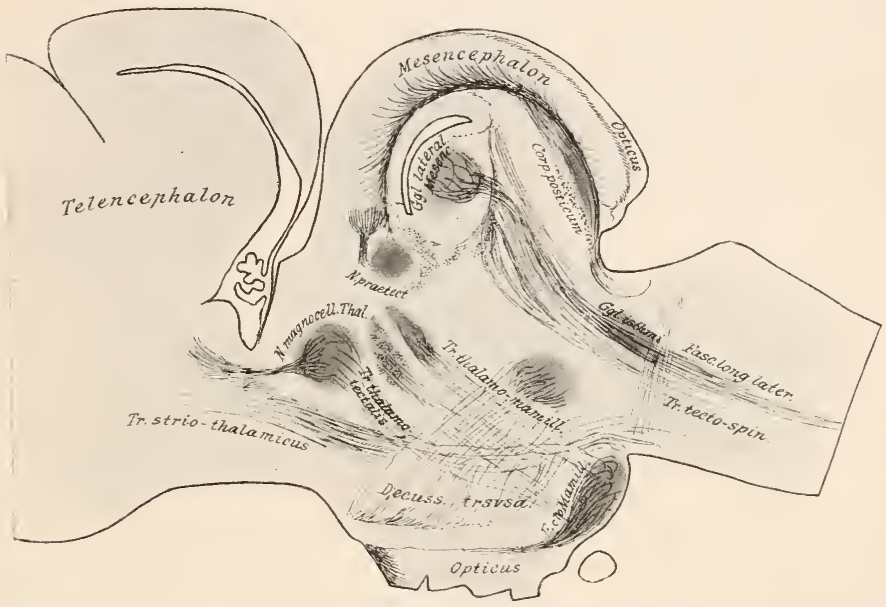

Fig. 72.

Huhn, 8 Tage nach dem Verlassen des Eies. Noch nicht alle Fasern markhaltig. Sagittalschnitt. Zur Demonstration des Ursprunges des Fasc. long. lateralis.

tegmenti, stammt der Tractus tegment 0 -c erebellaris, der Bindearm zum Kleinhirne. Er durchzieht nur auf eine ganz kurze Strecke das Mittelhirn und kreuzt, dicht hinter den letzten Oculomotoriuswurzeln zur anderen Seite. Fig. 65, wo die Kreuzung gut sichtbar ist, (die grossen Zellen lateral gehören nicht dem Haubenkerne an, der bei den Reptilien viel weiter frontal liegt). Die Kreuzung der Bindearme liegt dorsal von den Kreuzungen der Schleifenbahnen aus dem Dache, der Commissura ansulata.

Das dritte Längsbündel der Mittelhirnbasis entstammt der mächtigen Commissura posterior, Fig. 69 u. 73, deren Schenkel nach der Kreuzung ganz vorm am Mittelhirndache sich hufeisenförmig rückwärts wenden. 
Das caudale Ende ist noch unkekanut. Manches spricht dafür, dass in den lateralen Theilen des hinteren Längsbündels Fasern aus jener Commissur weithin rückwärts ziehen. Das ganze System soll - Kölliker u. A. einem Kerne entstammen, der, in der Gegend des Nucleus fasciculi post. liegend. von mir aber nicht von jenem getrennt werden kann. Die Beziehungen des hinteren Längsbïndels zur hinteren Commissur bedürfen noch weiterer Klärung. die wohl nur desshalb noch nicht erreicht ist, weil beide Züge sich so schwer in Continuo zur Degeneration bringen lassen.

Ganz ventral in den frontalen Abschnitten der Mittelhirnbasis liegt ein flach linsenförmiges Ganglion, welches Züge, darunter solche, aus dem Stammganglion des Vorderhirnes aufnimmt. Es ist, soweit ich bis jetzt sehe, am besten bei den Reptilien charakterisirt und wohl auch bei den

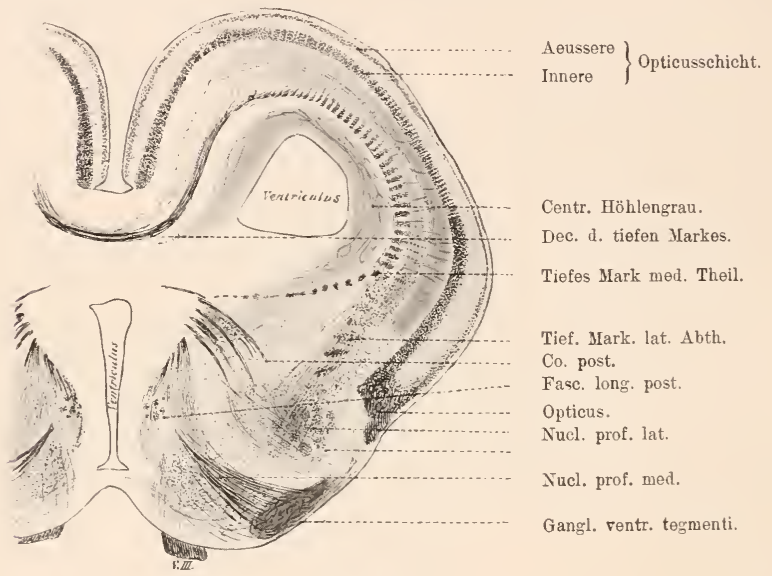

Fig. 73.

Frontalschnitt durch das Mittelhirn von Lacerta.

Tögeln. Die Säuger haben an gleicher Stelle zwei Ganglien hinter einander, von denen das vordere Corpus subthal a micum. das caudaler liegende Substantia nigra genannt wurde. Welchem der beiden Körper das Ganglion an der Basis bei den niederen Vertebraten entspricht, ist noch unsicher. Es ist Fig. 73 vorläufig als $G g l$. ventrale tegmenti bezeichnet.

Zu den Eigenganglien des Zwischenhirnes müssen dann noch zwei nicht scharf nach aussen abgegrenzte Zellhaufen gerechnet werden; ein in den lateralen Abschnitten der Basis liegender und ein dicht an der Mittellinie nachweisbarer. In beide gehen Abtheilungen des tiefen Markes, in den lateralen die ungekreuzten, in den medialen die gekreuzten Fasern der medialen Abtheilung des Markes. Man kann die Kerne als la teralen und medialen tiefen Mittelhirnkern bezeichnen. Fig. 73. 
Die Mittellirnbasis wird natürlich auch noch von denjenigen Faserbalınen durchzogen, welche - bei Fischen - zum Cerebellum aus dem Thalamus hinauf ziehen, ausserdem noch von dem Systeme, der Decussatio transrersa, Fig. 72, Fasern, die caudal vom ('hiasma kreuzen und dann sich beiderseits in der Hirnwand rückwärts wenden, bis sie in den caudalsten Ebenen des Mittelhirndaches, wahrscheinlich im Ganglion des hinteren Hügels oder im Ggl. isthmi enden. Hier, wo ich Ihnen nur die allmähliche Entwicklung des Mittelhirnes vorführen möchte, soll ihre nähere Schilderung unterbleiben.

Nachdem so vielerlei Elemente, die in die Zusammensetzung des Nittelhirnes eingehen, nun geschildert worden sind, lohnt es sich, noch einmal kurz das. Wesentliche zusammenzufassen, das ein Querschnittsbild hier bietet:

Aus dem Dache stammt also der Opticus, und aus Zellen, die mit seinen Endstätten in Zusammenhang stehen, sowohl die mächtige Dachcommissur als die Faserung zu den sensiblen Endkernen in der Oblongata und im Rückenmarke. Aus dem Grau an der ventraleu Seite des Aquaeductus stammen die Fasern für die Augenbewegungsnerven und diejenigen für das laterale Längsbündel.

Die Basis wird vorwiegend von Längszügen eingenommen, Zügen zum Rïckenmarke und Zügen zum Kleinhirne, und das Ganze wird an der ventralen Seite umfasst von Kreuzungen des tiefen Markes, lateral auch von den ungekreuzten Zügen desselben, der Schleifenfaserung.

Der Aufbau des Mittelhirnes ist, soweit er bisher geschildert ist, überall derselbe. Nur kann man beobachten, dass namentlich der aus dem Hirndache abwärts ziehende Theil der Faserung, die Schleifen und der Opticus also, bei vielen niederen Fischen und Vögeln sehr viel mächtiger entwickelt sind, als bei den säugern. Bei den letzteren hat also eine relative Rückbildung stattgefunden.

Aber es hat an anderer Stelle auch wieder eine Zunahme des Mittelhirnvolums eingesetzt. Freilich nicht bedingt durch den Mittelhirnmechanismus selbst, der bleibt immer der gleiche, sondern durch vorbeiziehende Bahnen. Bei den Säugern entstammen dem Vorderhirne mächtige Strahlungen zur Brücke und zum Rückenmarke. Diese finden zum Verlaufe in den geschilderten Apparate keinen Raum mehr. Sie ziehen ventral von ihm dahin. So entstelt hier eine neue, ganz aussen rentral liegende Schicht, die Faserung des Hirnschenkelfusses. Damn nennt man das, was dorsal ron ihr liegt, die Haubenfaserung. Alle niederen Vertebraten haben nur die Haubenfaserung, der Fuss ist ein novum additum, das erst sehrspät in der Thierreihe erscheint.

So bietet auch die Betrachtung des Mittelhirnes wieder ein gutes Beispiel dafür, dass keineswegs in der Thierreihe etwas stattfindet, das man eine durchgehend fortschreitende Entwicklung des Gehirnes nemnen könnte. Es constituirt sich allmählich ein bestimmter Mechanismus, der kann kräftiger oder schwächer sich ausbilden, bei sehr hoclsstehenden Gehirnen 
z. B. recht schwach angelegt sein kann. und diesem Mechanismus gesellen sich hier und da neue Bahnen hinzu, welche ron Hirntheilen herkommen, die gerade bei der einen oder anderen Art besser ausgebildet oder auch neu angelegt sind.

\section{Zehnte Vorlesung.}

\section{Das Zwischenhirn.}

Ireine Herren! Der anatomische Apparat, den wir nun kennen gelernt haben, ist so beschaffen, das er im Wesentlichen als in sich geschlossen angesehen werden kann. Nur ganz wenige Züge gehen aus den bisher geschilderten Centren frontalwärts und, auch aus weiter nach rorn gelegenen Hirngebieten treten, wenigstens bei den niederen Vertebraten, nur vereinzelte schwache Bahnen in die Ganglien. welche im Nittel- und Nachhirne oder in die Centren, welche im Rückenmarke liegen. Dementsprechend zeigen denn auch Fische, Amphibien und Reptilien. denen man ror der Commissura posterior alle Hirntheile abgetrennt hat, nie so dentliche störungen. wie sie eintreten, wenn man etwa das Mittelhirn mit seinen grossen Associationsgebieten und wichtigen Bahnen verletzt, oder wenn man die Oblongata oder das Rückemmark lädirt.

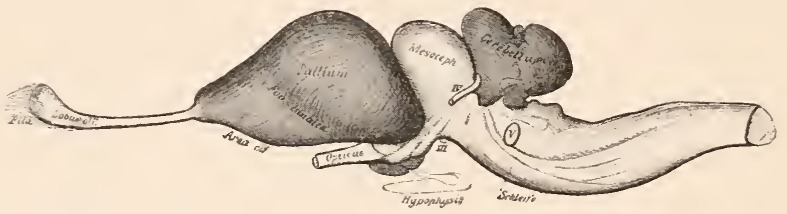

Fig. 74.

Das Gehirn des Nilkrokodiles, nat. Grösse. Das Vorderhirn deckt von vorne her, der Tractus opticus von der Seite her den Thalamus zu, so dass nur ein kleiner Theil des Hypothalamus sichtbar bleibt.

Wir wissen über die physiologische Bedeutung der Theile, welche zwischen dem Mittelhirne und dem Vorderhirn liegen, der Theile des Diencephalon, also so gut wie gar nichts und anatomisch stehen wir hier erst im Beginne ordnender Erkenntniss.

Zweifellos aber handelt es sich bei dem Zwischenhirn aber doch um ein wichtiges Hirngebiet. Denn ron Petromyzon hinauf bis zu den Vertebraten trifft man, wie schwach auch der eine oder der andere Hirntheil da und dort ausgebildet sein mag. immer an gleicher Stelle vor dem Mittelhirne den Zwischenhirnkörper. Er ist bei der Betrachtung. des Gehirnes von aussen kaum je gut sichthar, denn wenn auch hier und da keine Bedeckung durch die Hemisphären stattfindet, so ragt doch andererseits zumeist das Nittelhirndach über ihn hinweg; und ror Allem wird er an den Seitentheilen völlig zugedeckt durch die mächtige Opticusstrahlung. welche lier rom Mittelhirndache zum Chiasma hinabzieht. 
Man geht bei der Betrachtung am besten ron dem sehr einfach gebauten Zwischenhirne der Amphibien aus. Das ist ein länglicher Körper von etwa eiförmigem Querschnitte, welcher frontal direct in das Telencephalon, caudal in das Mesencephalon übergeht. Dicht hinter dem Plexus choroides des Torderhirnes sitzt ihm jederseits ein kleines Ganglion, das Corpus habenulae, auf, und dieser Abschnitt wird als Epithal amus bezeichnet. An der ventralen Seite liegen mehrere Ausstülpungen und Ganglienansammlungen, die sich zum Theile wohl vom übrigen Thalamus abscheiden lassen und desshalb als Hypothalamus zusammengefasst werden. Der zwischen beiden liegenden Hauptmasse bleibt der Name Thalamus. Im wesentlichen sind auch bei allen Thieren diese drei Abschnitte nachweisbar, aber nur der Epithalamus ist in seinem Aufbau constant, die anderen beiden Theile sind je nach der Thierart recht wechselnd.

Der Hohlraum des Diencephalon wird dorsal durch einige Falten der gleichen Epithelplatte abgeschlossen. aus welcher in früher Zeit das ganze Encephalon bestanden hat. Siehe Fig. 1s u. 20. Ausserdem verlaufen über ihn hinweg noch die Fasern einer kleinen Commissur, der Commissura habenularis.

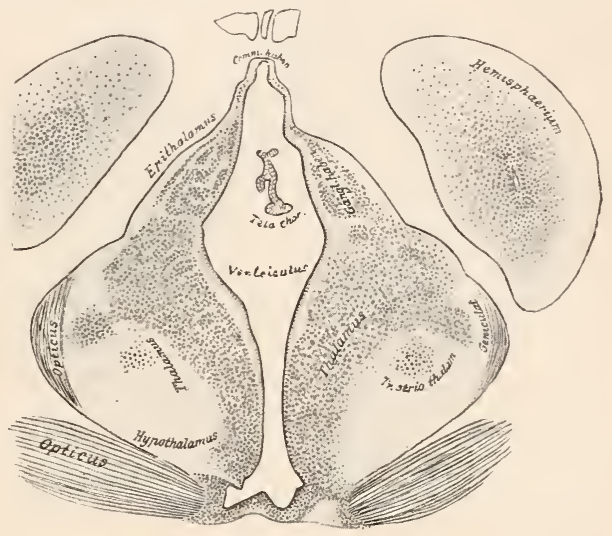

Fig. 75.

Schnitt durch das Diencephalon von Bufo, Kröte.

Frontal wird das Zwischenhirn vom Schädelraume geschieden durch die Lamina terminalis. Siehe Vorlesung 4, S. 4s. Sie ist immer nur schmal, und es führt jedẹseits von ihr eine Oeffnung in den Hohlraum der Hemisphären, welche sich ja in der Embryonalzeit an dieser Stelle dorsolateral ausgestiilpt haben.

Die Schlussplatte des Gehirnes zieht, ehe sie sich rückwärts zur Dachbildung des Zwischenhirnes wendet, zunächst ein Stück dorsalwärts Lamina supraneuroporica — und senkt sich dann hinab zu der bei den allermeisten Thieren segelartig in das Gehirn herabhängenden Tela chorioidea, aus der durch frontalwärts gerichtete Ausstiilpungen die Plexus chorioidei der Ventrikel herrorgehen. Bei einigen Amphibien, Fig. 55 s, und bei den dipnoischen Fischen, deren Gehirn überhaupt sich kaum von einem echten Amphibiengehirne unterscheidet, wuchert die Tela mächtig: in den Hohlraum des Zwischenhirnes mit zahlreichen Zapfen ein. Immer 
liegen dicht neben dem Epithel reiche Blutgefässplexus, deren Schlingen jenes Epithel bedeckt. Es ist sehr wahrscheinlich, dass es sich hier um einen Absonderungsapparat handelt. Caudal von der Tela chorioidea liegen eine oder manchmal auch mehrere dorsalwärts gerichtete Ausstïlpungen, die man als Paraphysis (Selenka), die caudalere auch als Zirbelpolster bezeichnet, weil auf ihr die dritte Ausstülpung des Zwischenhirndaches, die Epiphysis, die Zirbel aufliegt. S, auch Fig. $\$ 6$.

Diese Paraphyse ist in ihrer Bedeutung noch völlig unerkannt, sie scheint entweder selbst ein fungirendes Organ zu sein oder doch mindestens der Aus-

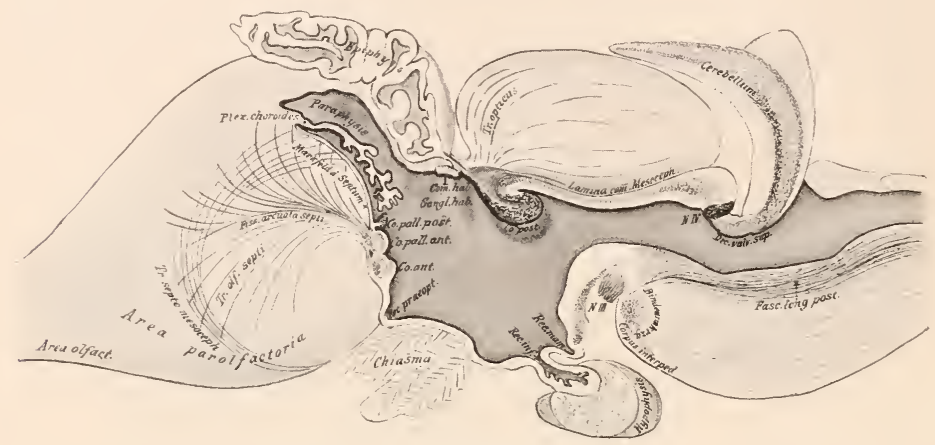

Fig. 76.

Genau medianer Sagittalschnitt durch das ganzo Gehirn der Wüsteneidechse, Varanus griseus.

gangspunkt für die Fntwicklung eines solchen werden zu können, denn bei einigen Reptilien (Ichthyophis Burkhardt) erlangt sie eine bedeutende Complication der Ausbildung.

Dicht vor der Epiphysenausstülpung - ihr Eingang ist auf Fig. 76 nicht getroffen - liegt regelmässig die Commissura habenularis. Sie gehört dem Systeme der in die Ganglia habenulae eindringenden Fasern aus dem hinteren Riechgebiete an und wird später noch zu betrachten sein.

Sehr constant ist der Epiphysenschlauch. Bei einigen Selachiern und bei vielen Reptilien tritt derselbe durch eine Lücke des Schädels hindurch zu einem unter der Haut liegenden sinnesorgane, das auffallende Aehnlichkeit mit eimem Auge hat. Nan kann eine Cornea und Linse, eine Retina und eine in und unter dieser liegende Pigmentschicht an diesem unpaaren ..Parietalorgane* erkennen. Seine Entdeckung verdanken wir Graf und Spencer. Bei den übrigen Wirbelthieren findet man, wenn sie ausgewachsen sind, keinen Zusammenhang mehr zwischen dem Epiphysenschlauche und dem Sinnesorgan. Er hat sich in die Tiefe des Schädels zurückgezogen, und es geht damn auch das Parietalange, wie Uebergangsformen bei Amphibien nnd Reptilien zeigen, so verloren, dass bei Vügeln und säugern keine Spur von ihm mehr gefunden wird. 
Das stumpfe, oft aufgeknäuelte Ende des Schlanches bleibt als Knötchen, „Glandula pinealis“, vor dem Mittelhirne übrig.

Auch an der Basis ist - in der Mittellinie wenigstens - das Zwischenhirn durch eine nur dïmne Membran vom Schädel abgeschlossen. In ihr und unter ihr weg verlaufen aber mächtige Querfaserungen, und dicht neben der Mittellinie verdickt sich der Hypothalamus zu verschieden gestalteten Gebilden. Tentral von dem Commissurengebiete des Vorderhirnes stülpt sich die Schlussplatte zu einer kleinen Ausstülpung aus, die, vor dem Chiasma gelegen, als Recessus präopticus bezeichmet wird. sie überzieht dann die basale Wand, das Chiasma opticum, durch das sie hier kräftig ron aussen eingestïlpt wird, Fig. 76 , und senkt sich dicht dahinter zum Recessus postopticus herab. Nun folgt weiter caudal ständig eine tiefe Einsenkung, die oft in einem nur fadendiunnen schlauche endet, der Recessus infundibularis, der Trichter. Die Hervorragung, welche er an der ventralen Fläche des Gehirnes macht, heisst Tuber cinereum. An den Endschlauch des Trichters legt sich die Hypophysis, welche aus dem Rachenepithel hierher an die Schädelbasis gewachsen ist, fest an. Bei den Säugern rerwächst sie so fest mit ihm, dass man hier das Schlauchende als Hirutheil der Hypophyse zu bezeichnen sich gewöhnt hat.

Bei den meisten Vertebraten entsteht die Hypophysis durch eine dorsal gerichtete Ausstïlpung der Mundschleimhant, die sich an die Unterseite des Gehirnes anlegt nnd später, wenn die Schädelbasis sich ausbildet durch diese geschieden wird, um am Processus infundibularis Hypothalami festzuhaften. Nun hat in den letzten Jahren Kupffer eine Entdeckung gemacht, die geeignet ist, auf die phylogenetische Bedeutung dieser Ausstiilpung ein neues Licht zu werfen. Bei den Embryonen niederer Vertebraten - Petromyzon, Stör, u. A. existirt eine Zeit lang ein eigenthiimliches Darmstück, welches dorsal von der Mundhöhle gelegen iiber dieser nach vorn sich ansstiilpt. Er bezeichnet diesen später verschwindenden Theil als präoralen Darm. Man erkennt, dass beim Stör von der Aussenhaut her ein Gang in diesen Darm hineinführt, ein eigener Mund also ïber dem später bleibenden Munde angelegt ist. Dieses ganze Gebilde, der Mundgang und der präorale Darm, in welchen er mündet, wird zur Hypophysis. Bei Petromyzon eröflinet die von der Aussenwand her einwachsende Hypophysiseinstülpung allerdings nicht den Darm, aber bei ihren nahen Verwandten, den Myxinen, bleibt der alte Mund, dessen Reste nach einer Hypothese von Kupffer wir in der Hypophysis hätten, zeitlebens bestehen. Die innerhalb der Mundhöhle der cranioten Wirbelthiere nachgewiesene Einstïlpung wäre, wenn $\mathrm{Kupffer}$ Recht hat, der Rest jener alten Mundbucht.

Dorsal rom Recessus infundibularis stülpt sich bei den niederen Vertebraten die Rückwand des Infundibulum zu einem ungemein dünnen, langen Epithelschlauche aus, dessen Wände von eindringenden massenhaften Blutgefässen in zahlreiche Falten gehoben werden. Der ganze Apparat heisst Saceus vasculosus (siehe Fig. 59 und $7 \overline{7}$ ). Damn erkemnt man immer, dass auch da, wo die ventrale und caudale Wand des Zwischenhirnes sich an die mächtige Mittelhirnbasis anschliessen, eine weitere kleine Ausbuchtung, der Recessus mammillaris liegt. Bei den Selachiern 
enthält er mächtige Epithelleisten und Zotten und bildet offenbar ein functionsfähiges und immer reich rascularisirtes Gebilde.

Wir können uns num, nachdem der dorsale und der ventrale Abschnitt des Zwischenhirnes geschildert ist, zur Betrachtung der Seitentheile wenden. Das Dach, das oben beschrieben wurde, wird dem Epithalamus zugerechnet. Dicht an der epithelialen Decke liegen beiderseits die

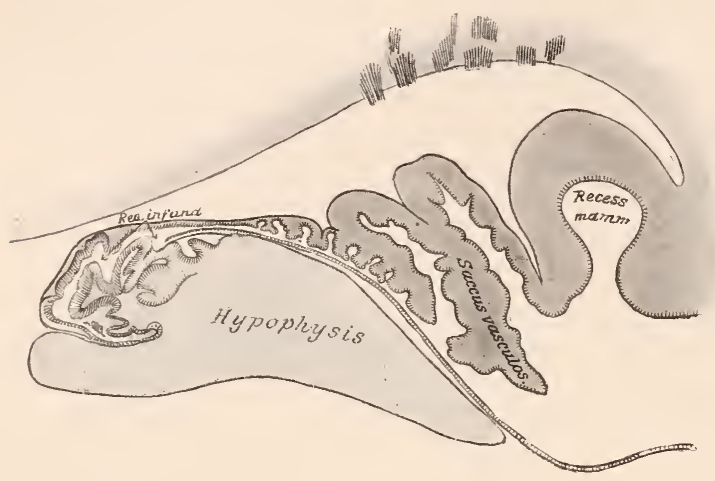

Fig. 77.

Sagittalschnitt durch die Trichterregion eines Haies, Scyllium canicula.

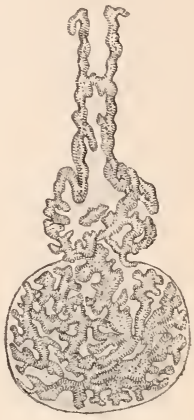

Fig. 7S.

Horizontalschnitt durch die Hypophysis von Raja clavata.

Ganglia habenulae, Fig. 75, die Eigenganglien des Epithalamus. Bei vielen niederen Tertebraten ist das rechte und linke Ganglion verschie-

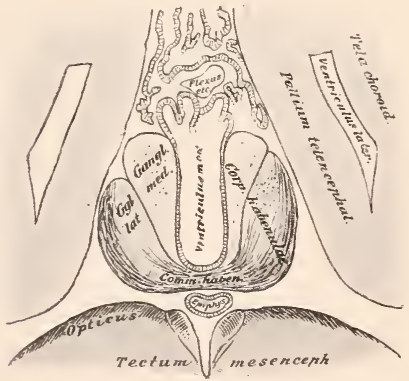

Fig. 79.

Horizontalschnitt durch die Ganglia habenulae einer Schildkröte, Emys europ. den gross, aber sonst bieten gerade die Ganglia habenulae ein gutes Beispiel für einen durchaus constanten, weder in Ausbildung, noch Rückbildung wesentlich variirenden Hirntheil. Ton Petromyzon bis zu den Säugern, immer findet man sie beiderseits von der Epiphysenausstülpung, etwas frontal von derselben. Sie bestehen aus zwei Körpern, einem lateralen und einem medialen, und sind ron dem Epiphysensacke caudal getrennt durch die ständig rorhandene Com missura habenularis.

Fig. 76. 79, s6. Bei den Amphibien und Reptilien, wo die iibrigen Thalamusganglien noch relativ wenig entwickelt sind, oder bei den Fischen, wo sie mehr rentral gerückt sind, erscheinen die Ganglia habenulae als die frontalsten Zwischenhimganglien. Wenn sich bei den Vögehn und 
Säugern die anderen Bestandtheile des Thalamencephalon mehr und mehr ausdehnen, schieben sie den Epithalamus etwas caudal, so dass zwischen ihn und das Torderhirn das ganze übrige Zwischenhirngebiet sich einlagert. Die Lagebeziehungen zur Epiphyse bleiben dabei unberührt. Gleich constant wie die Entwicklung sind die Faserzüge zum Epithalamus. Zunächst erhält er immer von vorn her, aus dem Riechgebiete des Torderhirnes, einen Zuzug, den Tractus olfacto-habennlaris. Diesem gesellt sich von den Amphibien an aufwärts noch ein Bündel aus dem Hirmmantel zu, der Tractus cortico-habenularis. Beide zusammen bilden die Thänia thalami. Siehe Fig. 100. Einige kleinere Zuzüge zı diesem überaus constanten Bündel bleiben hier unerwähnt. Behalten Sie nur, dass im Ganglion habenulae ein wichtiger Verbindungszug endet, der sich aus Fasern zum hinteren Riechlappen und aus solchen zur Riechrinde zusammensetzt.

Ein guter Theil der Thäniafasern endet nicht direct in dem gleichseitigen Ganglion, sondern begiebt sich durch die Commissura habenularis

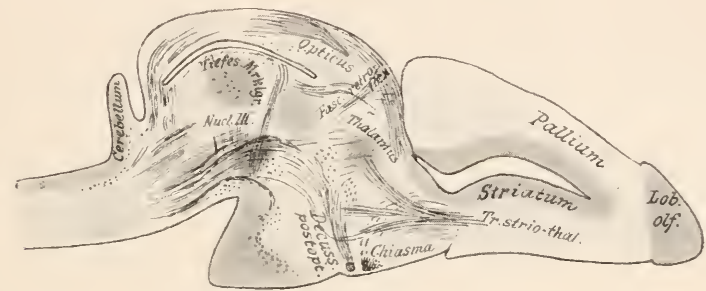

Fig. 80 .

Sagittalschnitt durch das ganze Gehirn von Triton, lateral von der Jittellinie. Zeigt die Endigung des Tractus strio-thalamicus an 3 Stellen des Zwischenhirnes.

zu demjenigen der gekreuzten Seite. Die Thänia besteht aus einem markhaltigen und einem marklosen Antheile, ebenso die Commissur. Siehe Fig. 99 und Fig. 100, das Schema der Terbindungen des Riechapparates und des Ganglion habenulae.

Das medialere der beiden Ganglien entsendet nun einen neuen Zug. ventralwärts, den Tractus habenulo-peduncularis, Fasc. retroflexus. Siehe Fig. 64 und so. Seine Fasern durchqueren die ganze Zwischen- und Mittelhirnbasis und enden nicht weit hinter dem Abgange des Oculomotorius in einem kleinen, ganz ventral an der Basis des Nachhirnes liegenden Ganglion, dem Corpus interpedunculare, Fig. 65. Hier splittern sie auf, und ihre Endfäden kreuzen mit denjenigen der anderen Seite. Der Faserzug und das Corpus interpedunculare sind absolut constant durch die ganze Thierreihe hindurch.

Diese Constanz aller mit den Ganglien des Epithalamus zusammen hängenden Gebilde weist darauf hin, dass es sich hier um eines der Grundsysteme des Gehirnes handelt, die früh erworben, immer zu dessen zweckmässiger Thätig- 
keit erforderlich bleiben. Die Verbindung mit dem Riechapparate lässt annehmen, dass es sich um einen dahin gehörigen Mechanismus handelt. Da er aber auch solchen bei Säugern vorhanden ist, die kaum Riechnerven haben Lotheissen - , so kann das System der Ganglien nicht ein Bestandtheil des Riechapparates selbst sein, muss vielmehr nur $\mathrm{zu}$ ihm in einer festen Beziehung gedacht werden. Thierversuche - das Ganglion ist bei grossen Reptilien und Fischen leicht erreichbar — wären sehr erwïnscht.

Die Eigenganglien des Thalamus kömnen nur bei Säugern und Tögeln von denjenigen scharf abgetrennt werden, die man dem Hypothalamus zurechnet; bei den niederen Tertebraten gehen beide Theile dicht in einander über. Ja bei den Knochenfischen ist der allergrösste Theil der Thalamusganglien durch die enorme Entwicklung des Mittelhirndaches so sehr nach unten gedrängt, dass zu beiden seiten der Basis grosse

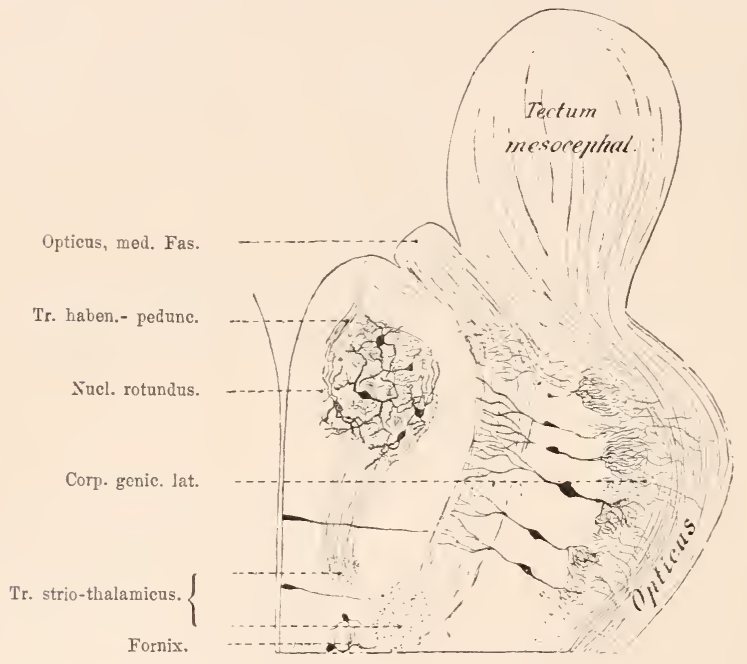

Fig. 81.

Frontalschnitt durch den dorsalen Abschnitt des Thalamus opticns der Blindschleiche, Anguis fragilis. Golgibehandlung.

Höcker erscheinen, die Unterlappen. Fig. 69 und $\$ 6$. Diese Lobi inferiores des Teleostiergehirnes, die bei Selachiem kaum angedeutet sind, differiren für die einzelnen Arten etwas, aber es ist allen hierher gehörigen Bildungen gemeinsam, dass sie als zweigelappte Wülste an der Himbasis beiderseits vom Tuber cinereum erscheinen.

Der Thalamus der Amphibien, der oben als der wenigst differenzirte schon bezeichnet ist. lässt im TTesentlichen nur erkennen, dass um den Hohlraum des Tentrikels graue Substanz gelagert ist, in welche von vorn Züge aus dem striatum eintreten, während sie von caudalwärts her Zu- 
züge aufnimmt, die den Tractus thalamo-spinales et bulbares angehören. S. Fig. 64 u. ১o. Nur durch das Studium dieser Züge gelingt es, mindestens zwei Kerne, einen frontalen und einen caudalen, abzuscheiden. Medial aber gehen diese ganz direct in das Grau über, welches den Tentrikel umgiebt, das centrale Höhlengrau. Siehe Fig. 75 und so.

Bei allen anderen Thieren kann man aber sehr leicht im Thalamus eine ganze Anzahl ron Ganglien abscheideu.

Am besten ist mir der Thalamus der Reptilien bekannt, und da von diesem aus sich Tebergänge zu dem gleichen Hirngebiete bei den Tögeln und den Säugern auffinden lassen, wird es zweckmässig sein, ihn zunächst einmal genauer zu betrachten.

Von rorn her tritt in denselben aus dem Corpus striatum des Torderhirnes ein mächtiges Bündel, der Tractus strio - th a la m i c u s. das basale Torderh i r n b ü nd el. Seine Züge spalten sich dann so auf, dass ein jedes der gleich zu nennenden Ganglien Fasern erhält, die ihm gesondert zustreben. Das charakterisirt alle Thalamusganglien.

Zunächst fällt ein grosser runder Kiern sehr auf, der, aus mächtigen multipolaren Zellen bestehend, auf einzelnen Schnitten fast die Hälfte

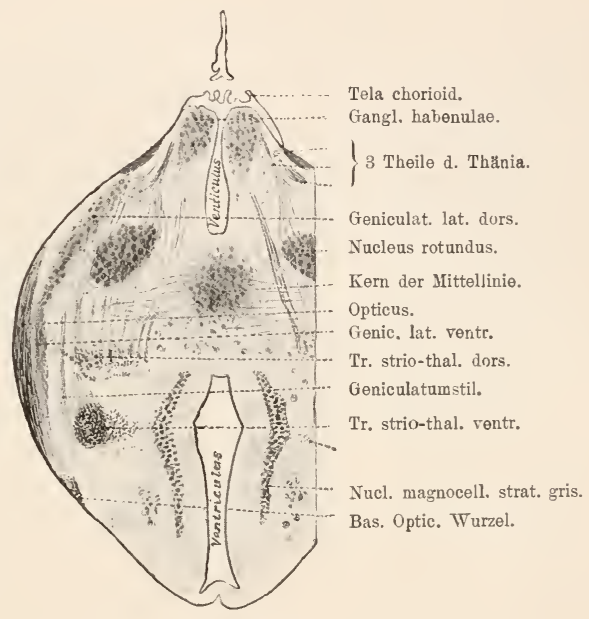

Fig. 82.

Frontalschnitt durch den ganzen Thalamus opticus von Alligator lucius, junges Thier.

des ganzen Querschnittes einnimmt, der Nucleus rotundus thalami. Er kehrt in gleicher Teise bei den Tögeln wieder, hier mit retortenförmig candal gerichtetem Fortsatze und ist auch bei den Fischen ein mächtiges Ganglion. Im Nucleus rotundus splittern die Züge des Tractus strio-thalamicus zu feinen Pinseln auf. Fig. s1, und aus ihm entspringt ein Bündel, das rückwärts ziehend im Mittelhirndache endet, der Tractus thalamo-tectalis. Siehe Fig. S3. Das Aussehen dieses Kernes und seine Verbindungen sind überaus charakteristisch und überall unverändert.

Etwas frontal ron dem Nucleus rotundus und dorsal von ihm, benachbart dem Ganglion habenulae, liegt der Nucleus anterior, Fig. 70, 33. Auch ihm entstammt ein für Reptilien. Vögel und Säuger charakteristischer Faserzug, welcher, den ganzen Thalamus durchquerend, ziemlich pa- 
rallel dem Tractus habenulo-peduncularis zur Basis zieht und sich in dem dort liegenden Corpus mammillare verliert. Das ist der Tractus thala mo-mammillaris. (Tiq. d'A zyr'sches Bündel der Säuger.) Fig. \$3.

Ventral von den beiden erwähnten Kernen findet man bei Reptilien und Vögeln, wahrscheinlich auch bei den Fischen, mitten in dem Gran, das als centrales Höhlengrau den Ventriculus medius umgiebt, noch einen langgestreckten Kern grosser Zellen, den Nucleus magnocellularis strati grisei. Fasern aus ihm sind es wahrscheinlich, welche sich ventralwärts begeben, um dicht iiber dem Infundibulum als Decussatio suprainfundibularis zu kreuzen, ausserdem entsendet er wahrscheinlich noch Züge caudalwärts.

Bei vielen Reptilien, besonder's bei den schildkröten, dann bei den Säugern (und bei den Vögeln?) verschmelzen mitten im Thalamus die beiden Seiten der Ventrikelwand für eine kurze Strecke mit einander, es entsteht eine Commissura grisea thalami-Commissura mollis der säuger. Hier liegt bei den Krokodiliern, Schildkröten und Schlangen ein mächtiger Kern, der Kern der Medianlinie, Fig. ১2, dessen Faserbeziehungen noch nicht klar sind. Er empfängt jedenfalls Züge aus dem Striatum und entsendet Fasern lateralwär.ts. Der Kern der Medianlinie ist nicht scharf abgegrenzt, es liegen vielmehr im Grau des Thalamus, ihm benachbart und entfernter zahlreiche, wie es scheint, ähnliche Zellen, die alle anderen besser abgegrenzten Kerne umgeben. Ich will ihre Gesammtheit zunächst als Nucleus diffusus thalami bezeichnen.

Wie schon vorhin erwähnt wurde, ist fast die ganze Aussenseite des Thalamus von den über sie herabziehenden Opticusfasern bedeckt. Zwischen dem Tractus opticus und den bereits erwähnten Thalamusganglien liegt noch ein zweigetheilter Gangliencomplex, der, ungemein constant, wohl zu den Grundganglien des Opticussystemes zu rechnen ist, das Corpus geniculatum laterale, Fig. \$1, \$2, \$3, s4. Bei allen Thieren ist es vorhanden. Bei Vögeln, Reptilien und Sängern unterscheide ich an ihm einen frontal-ventralen ron einem mehr caudalen und dorsalen $\mathrm{Ab}$ schnitte, siehe Fig. 52. Es ist möglich, dass der letztere übergeht in das, was man bei Säugern Corpus geniculatum mediale nennt, aber da die Verbindungszüge noch nicht sicher sind, muss die Frage noch offen bleiben. Aus dem Corpus geniculatum laterale entspringt immer, ans dem mediale wahrscheinlich, ein rückwärts gewendeter Stilus corp. geniculati. der sich in den caudalsten Abschnitten des Mittelhirndaches verliert, vielleicht aber auf diesem Wege in Beziehungen zu dem später zu nemnenden Nucleus prätectalis tritt. Bei den Vögeln mit enorm entwickeltem Geniculatum ist er sehr mächtig.

In Geniculatum endet ein Theil des Sehnerven mit mächtiger Aufsplitterung, und mitten in diese Faserung tauchen die Dendriten langgestreckter Doppelpyramiden. Das mediale Ende dieser Pyramidenzellen splittert auf in einem Zuge, der wahrscheinlich auch dem optischen Systeme angehört. Fig. \1 ist das Alles gut zu sehen. 
Mitten zwischen all diesen Ganglien enden die von hinten kommenden Tractus thalamo-bulbares et spinales, ohne dass es bis jetzt möglich ist, gerade den einen oder den anderen Kern als specielle Endstätte zu bezeichnen. Fig. 64, Rad. thal. Wemn ich noch den Nucleus en to pe duncular is erwähne, eine Ansammlung grösserer Ganglienzellen, medial von den Tractus Strio-thalamici, die sich von den Selachiern aufwärts findet, so habe ich Ihnen diejenigen wichtigsten Ganglien genannt, welche im Thalamus der niederen Thiere die characteristischsten sind.

Ich will Thnen noch eine schematische Darstellung der Thalamuskerne ron der Taube vorlegen, weil sie eine gute Uebersicht ïber diese bei den Vögeln immerhin schon complicirteren Dinge giebt, die bisher nur wenig bekannt sind.

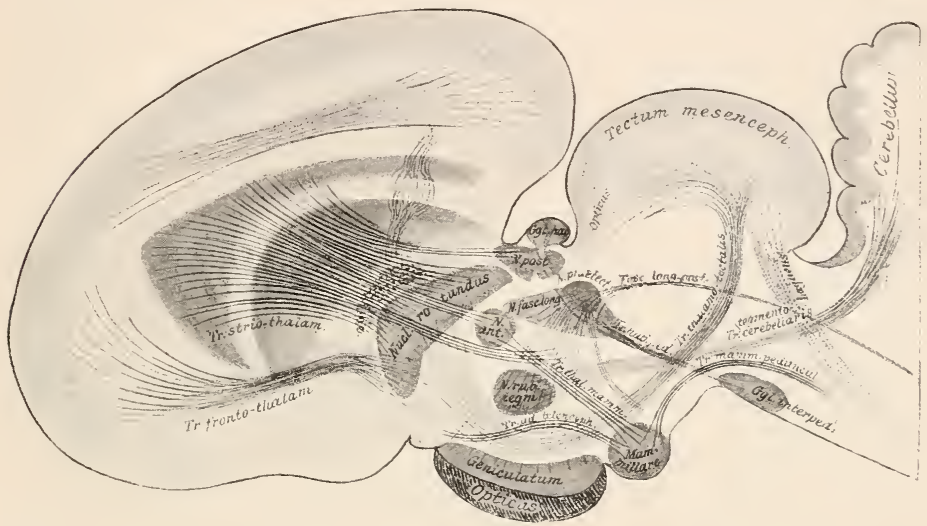

Fig. 83.

Schema einiger Thalamuskerne bei der Taube.

Die Diagnose der einzelnen Kerne bei den Vögeln wird dadurch etwas erschwert, dass an beiden Seiten des Zwischenhirnes nicht nur die Optici, wie bei den anderen Thieren, herabziehen, sondern dass sich dahin auch die Seitentheile der enorm entwickelten Lobi optici, des Mittelhirndacles also, anlegen. So wird es verlohnen, wenn Sie einmal auf den folgenden Sagittalschnitt durch das Zwischenhirn der Taube einen Blick werfen, der, mit Weglassung mancher feinen Netze und kleinen Kernansammlungen, Ihnen zeigt, wie in Wirklichkeit die Lagebeziehungen der Kerne zu einander sind.

Fassen wir noch eimmal zusammen, was sich als allen Thalamuskernen der niederen Vertebraten gemeinsam erkennen lässt, so ist es im wesentlichen das Folgende: Die Kerne des Thalamus nehmen aus dem Stammanglion des Vorderhirnes Fasern auf und geben rückwärts neue Bahnen an tiefere Centren ab. Ausserdem 
sind sie mit den Ganglien des Hypothalamus durch mannigfache Anordnungen rerknüpft.

Fasern in das Mittelhirndach und solche nach der Oblongata und dem Rückenmarke sind schon erwähnt. Wir werden gleich nachher sehen, dass aus den Kernen des Hypothalamus auch solche Bahnen zum Cerebellum und zu anderen Gebieten des Mittelhirnes als zum Dache führen. So miissen wir denn im Thalamus ein grosses Centrum erblicken, das durch Eigenzüge in sich geschlossen, zwischen einen wichtigen Theil des Grosshirnes und fast alle anderen Hirntheile eingeschaltet ist.

Commis, ant

Tr. strio-thal, medialis.

Tr. strio-thal. lat. Linsenkernschlinge.

Tr. septo-mesencephalicus.

Nuclus rotundus thalami.

Med. Opt. Bdl. z. Ggl. isthmi.

Partes corp. genic. lat.

$$
\begin{array}{r}
\text { Bindearmkreuzung. } \\
\text { Bindearm. Tr. tegmento-1 } \\
\text { cerebellaris. } \\
\text { Corpus restiforme. } \\
\text { Schleife. }
\end{array}
$$

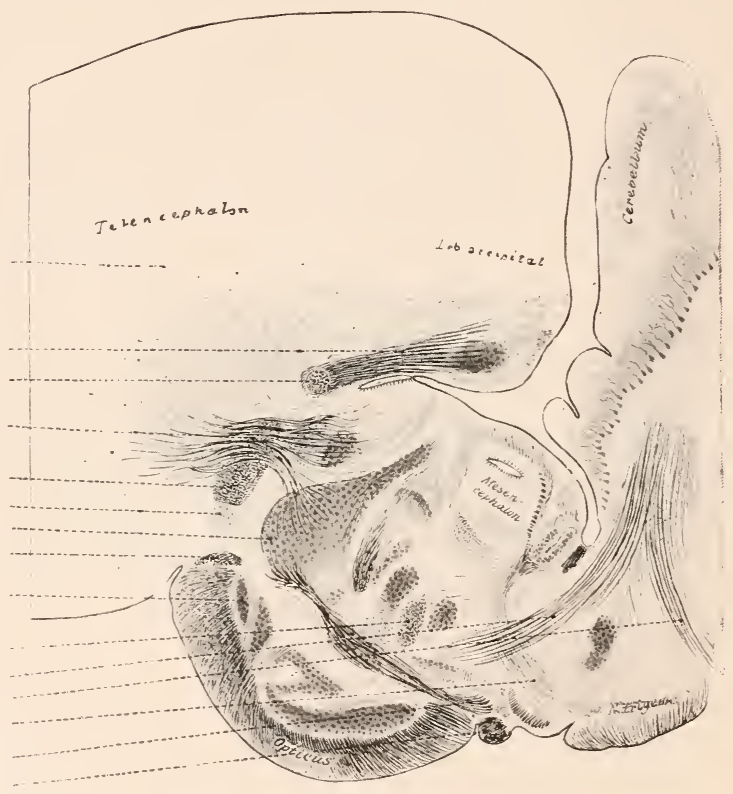

Fig. 84.

Sagittalschnitt durch den Thalamus opticus von Columba domestica. Hämatoxylinfärbung.

Spuren einer fortschreitenden Entwicklung des Thalamus finden sich schon bei den Reptilien, wo aus der Hirnrinde am Stirmpole ein Zug abgeht, der, im Thalamus endend, eine directe Rinden-Thalamusbahn herstellt. Bei den Tögeln ist derartiges schon deutlicher. und man kann erkennen, wie mit der Entwicklung einer ausgedehnteren Hirnrinde mehr und mehr Züge auftreten, welche aus dieser in die Ganglien des Thalamus einstrahlen. Bei den Säugern haben diese Tractus cortico-thalamici eine so mächtige Ausdehmung erhalten, 
dass ihr Complex, der stabkranz des Thalamus. nun das mächtigste System des ganzen Zwischenhirnes ist. Mit dieser Tmänderung der relativen Terhältnisse geht noch etwas Anderes Hand in Hand. Es vergrössern und vermehren sich die Ganglien. so ist es nicht mehr möglich, die relativ einfachen Terhältnisse, welche bei den Reptilien vorliegen, wieder zu entdecken, die grossen Thalamuskerne der Säuger auf die rorhin erwähnten Kerne mit sicherheit zu beziehen. Es wird da noch viel Arbeit bedürfen, bis wir erkennen, was neu zugekommen ist, und was nur der Vergrösserung von bereits Vorhandenem entstammt. Vorläufig ist es noch nicht möglich gewesen, mehr zu ermitteln. als dass auch bei den säugern in allen oder fast allen Thalamuskernen Fasern aus den Tractus strio-thalamici enden. und dass aus einem der ventraler liegenden Kerne die Tractus thalamo bulbares et spinales - Thalamusschleife sich entwickeln.

Nur einige Kerne lassen sich anf gleiche Kerne bei niederen Vertebraten zurückführen, und die möchte ich Ihmen näher schildern, weil wir an ihnen den ganzen Vorgang der Addition ron Grosshirnbahnen zu Systemen, welche bei niederen Thieren auch ohne solche existiren können, kennen lernen. Da ist zunächst der Kern des Geniculatum. Bei allen Thieren münden in ihn Selnnervenfasern. Ton den Tögeln an aufwärts bildet sich nun eine Bahn aus der Grosshirnrinde zu den Sehnervencentren aus. Ob sie schon bei den Tögeln das Geniculatum erreicht, das wissen wir nicht, dass sie aber bei säugern dahinein wächst, das ist ganz sicher nachgewiesen. So sehen Sie, anatomisch erkennbar, wie ein primäres Endcentrum eines Simnesnerven bei höheren Thieren mit Bahnen in Beziehung tritt, welche dem Organe des Gedächtnisses und der Erinnerung, dem Organe der Associationen u. s. w. entstammen.

Auch für den ventralen Kern. in dem die Zïge zur Oblongata und zum Rückenmarke enden, hat man ein ähnliches Terhältniss bei den Säugern erkannt. Hier erhält er Zuziige aus der Hirnrinde, und zwar aus den psychomotorischen Gebieten, aus Rindenfeldern, deren Verlust die Fähigkeit beeinträchtigt, erlernte oder associativ angeregte Bewegungen auszuführen.

Diese Kerne existiren schon bei den niederen Vertebraten, und erst bei den allerhöchsten addiren sich ihnen die Grosshirnbahnen zu.

So viel über die Eigenganglien des Thalamus. Es bleibt uns jetzt ein enges Gebiet zu betrachten übrig; das gewöhnlich auch jenen zugerechnet wird, das Grenzgebiet von Zwischen- und Mittelhirn, der Metathalamus.

Dicht vor dem Mittelhirndach, diesem fest eingeordnet und nur frontal in den Thalamus hineinragend, finden wir den Nucleus prätectalis allenthalben. Nır für die Säuger fehlt sein Nachweis noch, doch glaube ich, ihn in den frontalsten Abschnitten des bisher zum Grau des vorderen Hügels gerechneten Ganglions wiederzufinden. Dieses Kernes ist schon früher gedacht, Fig. 71,72 , und auch des Umstandes, dass in ilm wahrscheinlich Züge aus dem stile des Geniculatum enden. Fig. \$3. 
Medial ron ihm liegt ein nicht sehr scharf begrenzter Kern, ans dem sich die Züge des Commissura posterior zu entwickeln scheinen, Nucleus commiss. posterioris, und ventral ron jenem findet man in der ganzen Thierreihe wieder sehr constant den Ursprungskern des hinteren Längsbündels, Fig. 44, eine senkrecht gestellte längliche Kernplatte, welche der Mittellinie zu beiden Seiten nahe anliegt. Ans ihr entwickeln sich die frontalsten Fasern des Fasciculus longitudinalis posterior, des Bündels, dem wir schon rom Rückenmarke an immer wieder begegnet sind. Dass es später aus den Kernen der Hirmnerven noch Züge aufnimmt, habe ich wohl schon erwähnt. Ein Theil dieses Bündels entspringt übrigens gekreuzt.

Der Kern des hinteren Läugsbündels liegt schon ziemlich weit ventral, und er kann in der That ebensogut dem Hypothalamus zugerechnet werden; bei den Fischen gehört er diesem sicher an. Lateral ron ihm, in den Seitentheilen also des caudalsten Thalamusabschnittes, liegt der Nucleus ruber tegmenti, eine meist wohl abgegrenzte Kernmasse, aus welcher Fasern entspringen, die sich bald nach ihrem Ursprunge kreuzen, um dann dorsalwärts zu ziehen und im Cerebellum zu enden. Diese Züge werden als Bindearm - Tractus tegmento-cerebellaris - zusammengefasst. Siehe den Kern Fig. S3, den Zng Fig. 71 u. St und die Krenzung Fig. 53, S4. Ein klares Bild ron der Bindearmkreuzung giebt Fig. 65.

Alle diese Kerne und Züge sind überaus constant. Nur bei den Knochenfischen, deren Thalamus überhaupt noch durchaus weiterer Durcharbeitung bedarf, sind sie zu gutem Theile noch nicht diagnosticirt. Die Selachier haben alle die erwähnten Züge, es ist mir aber - an dem relativ kleinen Materiale, das mir zu Verfügung gestanden hat - nicht gelungen. aus dem allgemeineu Thalamusgran Einzelganglien abzuscheiden. Man hat da mehr den Eindruck, dass, wie bei den Amphibien, aus dem noch wenig differenzirten Centralgran um den Tentrikel sich die Tractustegmento-cerebellares entwickeln, Fig. 92 u. s. w.. Bessere Methoden werden sicher weiter führen. Der ganze Mechanismus muss zu den niederen Grundmechanismen des Gehirnes gehören. Trotz seiner Constanz nimmt derselbe, soweit wir heute wissen, keine Zuzüge aus der Rinde des Torderhirnes auf.

Wollen sie nun dem Apparate an der Basis des Zwischenhirnes, dem Hypothalamus Thre Anfmerksamkeit schenken.

Es ist schon oben erwähnt, dass dieser Hirntheil desshalb sich bei Fischen nicht scharf ron dem dorsaleren Thalamus abgrenzt, weil Theile, die bei allen anderen Tertebraten in dem Thalamus selbst oder im Metathalamus liegen, bei den Knochenfischen und den Ganoiden stark ventralwärts rerschoben sind. Dort bilden sie zusammen mit bisher noch zu wenig studirten Hirnabschnitten beiderseits ron dem Infundibulum die Lobi inferiores, zwei mächtige Höcker, welche immer die Unterseite des Fischgehirnes charakterisiren. Die Lobi inferiores, welche namentlich von Fritsch und später von $\mathrm{Her}$ rick näher studirt sind, 
enthalten, soweit ich nach eigenen Untersuchungen urtheilen kann, zum mindesten 4 Ganglien. Nur eines, das fronto-dorsalste, ist bekannteren Thalamusganglien heute schon zu homologisiren. Es ist nämlich der runde Kern, den ich oben von der Eidechse schon demonstrirt habe, mit seinen grossen Zellen, Fig. 95. Dicht ihm benachbart, ihn zum Theil umgreifend findet man einen kleinzelligen Kern. Diese beiden Gebilde ragen nur mit ihrem caudalen Abschnitte in die Lobi inferiores hinein; bei einzelnen Arten liegen sie ganz dorsal von ilmen. Die Lobi selbst sind aus 2 Ganglien, einem frontalen und einem caudalen, zusammengesetzt. Das frontalere enthält ein ausserordentlich reiches Geflecht markhaltiger Nervenfasern, das caudalere entsendet in dieses Geflecht massenhaft Zuzüge. In diesen Ganglien endet ein Zug ans dem Striatum, ganz wie in allen Thalamusganglien der Thiere, den man als Tractusstrio-lobaris oder thalamicus bezeichnen könnte.

Dorsalwärts aber entsenden sie mehrere zum Theil marklose Zïge in die Hirnbasis. Wir kennen nur von einigen den Verlauf, der sie in
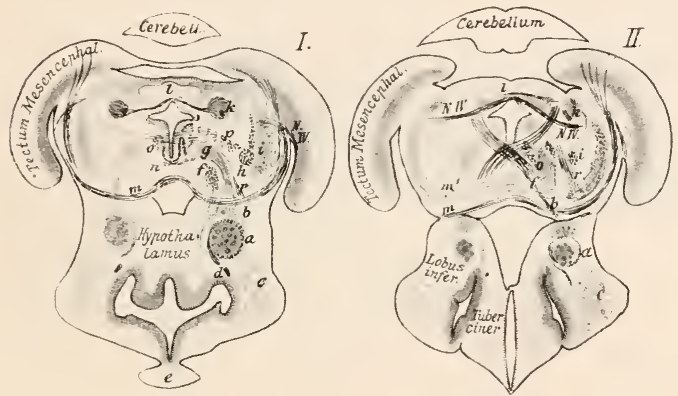

Fig. 85.
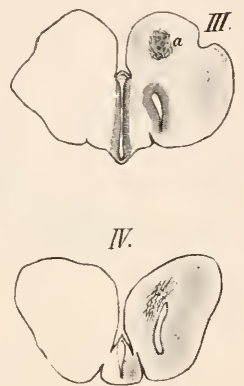

4 Frontalschnitte durch die Stelle, wo die Mittelhirnbasis an die Lobi inferiores grenzt. Von Zoarces viviparus, jugendl. Exemplar $3 \mathrm{Cm}$. lang. Wahrscheinlich nur ein Theil der Markscheiden entwickelt. $a$ Nucleus rotundus thalami, $b$ Nebenganglion desselben, $c$ Ggl. post. lobi inf, $e$ Infundibulum, $f$ Tract. lobo-cerebellaris frontalis, $g$ idem caudalis, $h$ Commiss. Fritsch, $i$ Gangl. prof. mesenc. lat., $k$ Gangl. lat. mesencephal. Torus semic, $l$ Valyula cerebelli, $m m^{\prime}, n$ Einzelne Abschnitte der Faserung aus d. Dache, vergl. Schema Fig 67, o Nucl. N. oculomot. und Fase. longit. post., $p$ Commiss. post.

das Cerebellum führt. Tractus lobo-cerebellares frontales et caudales.

Zwischen die Ganglien des Lobus inferior ragt der von centralem Höhlengrau ausgekleidete Ventrikel des Zwischenhirnes weit hinein, mit lateralen Ausstülpungen noch eimmal Seitenventrikel des Hypotha lamus bildend. Rückwärts verlängert er sich in den bei Fischen immer vorhandenen Saccus vasculosus und weiter ventral in clie Recessus mammillares, Fig. S5 III u. IV.

Ich will, da wir doch eben vom Knochenfischgehirne sprechen, noch ein Ganglion aus dem Hypothalamus erwähnen, das bei diesen gefun- 
den wird. bei höheren Tertebraten aber noch nicht sicher zu identificiren ist. Das ist der Nucleus anterior Tuberis cinerei. Fig. $\mathbf{5 6 .}$ Er liegt in den frontalen Abschnitten der Seitenwand des Tuber und giebt da einer mächtigen Kreuzungsfaserung Crsprung, die wir nachher noch kemnen lernen werden. Ton del oben erwähnten Thalanusganglien der Reptilien und Tögel kaum bei Fischen noch mit einiger Wahıscheinlichkeit der Nucleus auterior thalami indentificirt werden. Fig. 70.

Wenn ich hier den Versuch mache, den Thalamus der Fische trotz aller Verschiedenheit seines Aussehens dem der höheren Vertebraten anzunälıern, so muss ich lhre Nachsicht sehr erbitten. Denn es liegen die Vorbedingungen zn derartigem Beginnen noch recht unsicher, und ich muss gestehen, dass von allen Hirntheilen niederer Vertebraten, die ich im Laufe der Jahre studirt habe, keiner annähernd so grosse Sclıwierigkeiten fïr das Erkemnen geboten hat, wie der Thalamus der Knochenfische.

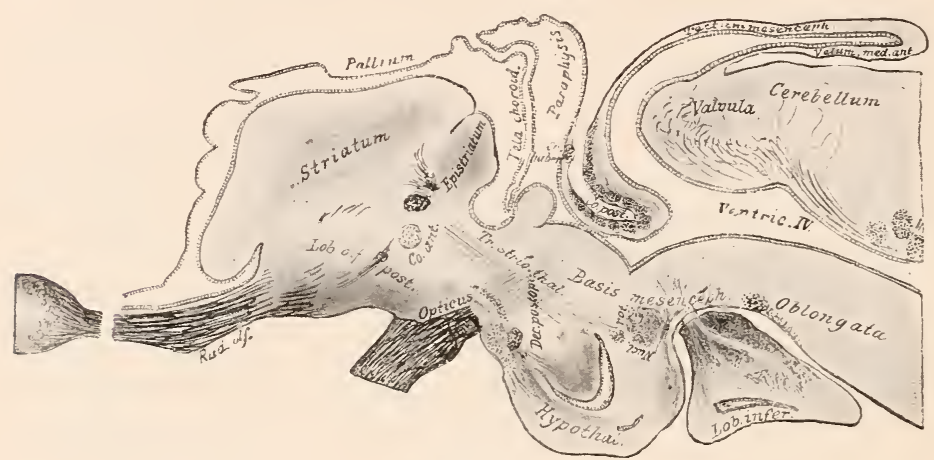

Fig. 86.

Sagittalschnitt durch Vorder- uud Zwischenhirn der Barbe, Barbus fluviat.

Welche Hirntheile den Lobi inferiores der Knochenfische bei den anderen Vertebraten homolog sind, dass wissen wir noch nicht. Die enge Beziehung dieser grossen Gangliencomplexe zum Kleinhirne, das bei ebendenselben Thieren besonders hoch entwickelt ist, giebt rielleicht einen Fingerzeig für ihre physiologische Würdigung. Das Experiment lat sich bisher noch nicht mit ihnen beschäftigt.

Zwei Ganglien sind, soweit ich sehe, bei allen anderen Wirbelthieren an der Hirnbasis regelmässig rorhanden. Dicht hinter dem Tuber cinereum, wie die resentlich aus centralem Höhlengrau bestehende Aussackung des Tentriculus tertius in den Recessus infundibuli heisst, findet man medial das Corpus manuillare und lateral ron diesem einen Kerı, den ich als Corpus ektomammillare bezeichnen möchte.

Die Corpora mammillaria liegen in den seitenwandungen des Recessus mammillaris. Sie nehmen bei Amphibien, Reptilien, Vögelı und säugern jenen Zug aus dem Nucleus auterior thalami auf, den ich Ihnen 
oben schon als Tractus thalamo-mammillaris geschildert habe. Von vorn her empfangen sie immer einen Zuzug aus der Hirmrinde, und zwar aus demjenigen Antheile, welcher als Riechfeld der Rinde bezeichnet werden muss. Dieser Zug heisst Fornix. Siehe Fig. 100. Nach hinten entsenden sie den Tractus mammillo-peduncularis in die basalsten Abschnitte des Hinterhirnes, der beiderseits vom Corpus interpedunculare herabziehend, sich weiter riickwärts an noch unbekannter Endstätte verliert. Siehe das Schema der Fig. $>3$.

Einen sehr distincten Körper bildet das - für die Säuger noch nicht nachgewiesene - Ganglion ectomammillare, Fig. 72 und Fig. 57. Es enthält ziemlich grosse Zellen und entsendet jederseits einen Zug

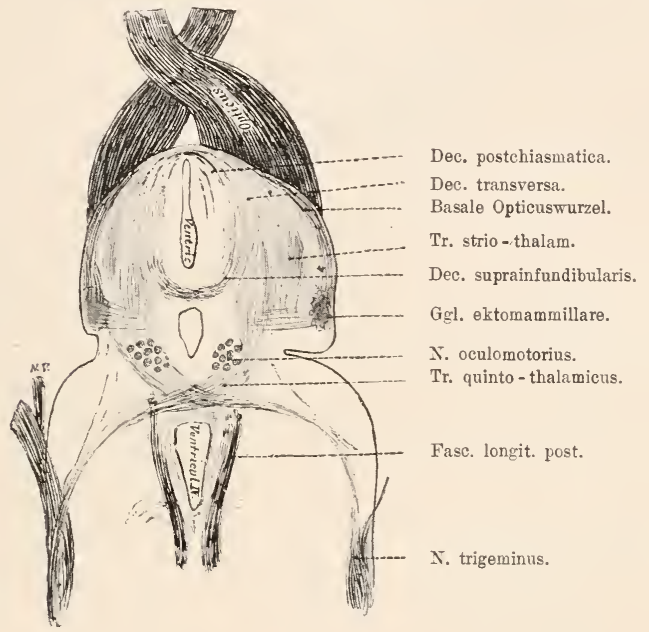

Fig. 87.

Eidechse. Horizontalschnitt durch den Hypothalamus, das Chiasma und die Oblongata.

dicker Nervenfasern, der den Hypothalamus aussen umschlingt, um sich vor demselben, direct hinter dem Chiasma N. opticorum mit dem gleichen Zuge der anderen Seite zu vereinen. Ob Fasern aus diesem schon als basale Opticuswurzel gedeuteten Zuge wirklich in den Sehnerven gelangen, weiss ich nicht sicher. Er liegt mit dem grössten Theile seines Verlaufes dem Tractus opticus ventral als wohlgesondertes Bündel, Fig. S2, an und wendet sich erst dicht hinter dem Chiasma medialwärts. Aus den gleichen Kernen ziehen Fasern direct medialwärts. Es ist möglich, dass sie einem Fasersysteme angehören, das aus dem Nucleus praetectalis stammt, doch fehlt es noch an Degenerationsbildern, die das sicher stellen.

Sind die Ganglien des Hypothalamus schon wenig gekannt, so gilt das noch mehr von den Fasermassen, die hier liegen. Fast alle stehen 
zu Commissuren und hreuzungen in Beziehung. Aber noch ron keiner einzigen der mannigfachen Kreuzungen am Boden des Zwischenhirnes wissen wir heute sicher Anfang und Ende.

Ich will Thnen desshalb nur die constantesten nemnen, diejenigen, welche überall wiedergefunden werden können. Als Ausgangspunkt der

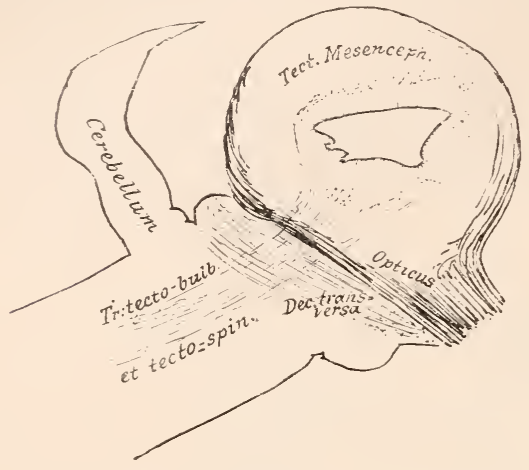

Fig. 88 .

Sagittalschnitt sehr weit lateral durch das Gehirn von Varanus griseus, zeigt den Verlauf der Decussatio transversa vom Chiasma bis zu ihrer Endstätte.

Darstellung mag die Abbildung eines Horizontalschnittes durch ein Eidechsengehirn (Fig. Si) dienen.

Ganz vorn dicht an der Grenze von Zwischen - und Torderhirn liegt die Kreuzung der Tractus optici, das Chiasma, und dicht an dasselbe schliessen sich einige andere Commissur- oder Kreuzungssysteme an. Thren Querschnitt wollen Sie in Fig. 70, 72, $>0,56$ aufsuchen, auch Fig. 20 und 76 , wo die in den Hohlraum des Hypothalamus hineinragende Commissurenplatte der Regio chiasmatica deutlich ist. Wie ein kräftiger Wulst verläuft sie gewöhnlich über den Boden des Zwischenhirnes weg, diesen einstülpend. Direct

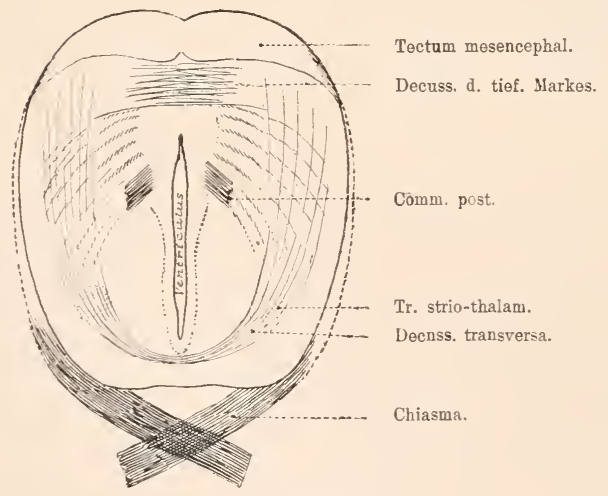

Fig. 89.

Frontalschnitt durch das Mittolhirn von Scyllium canicula.

hinter dem Chiasma. diesem sehr imnig eingefügt, liegen die Tractus aus dem Ganglion ectomammillare, deren Gesammtheit wir als Commissura postc h i a s m a tic a bezeichnen wollen.

Etwas dorsal ron ihnen und in dem rorliegenden Schnitte kaum getroffen, finden Sie die Züge der De cussatio transversa, der „Guddenschen Kreuzung". Sie stammen aus dem caudalsten Abschnitte des Nittelhirnes vielleicht aus dem Ganglion Isthmi, das dicht unter dem Cerebellum liegt (Fig. ss). Weiter dorsal liegt eine stark- 
faserige Kreuzung, deren Bestandtheile aus dem centralen Höhlengrau des Ventriculus tertius hierher herabsteigen, die Decussatio suprainfundibular is.

Am Gehirne der Selachier und der Amphibien gelingt es leicht den grössten Theil der Decussatio transversa in einen einzigen Schnitt zu bekommen, wie Fig. $>9$ lehrt, an der sie gleichzeitig noch einmal die Bestandtheile einiger anderer frïher erwähnter Kreuzungen im Mittelhirne stıdiren können.

$\mathrm{Zu}$ diesen 3 Systemen kommen nun bei den Fischen noch mehrere andere. Zunächst giebt es bei den Sela-

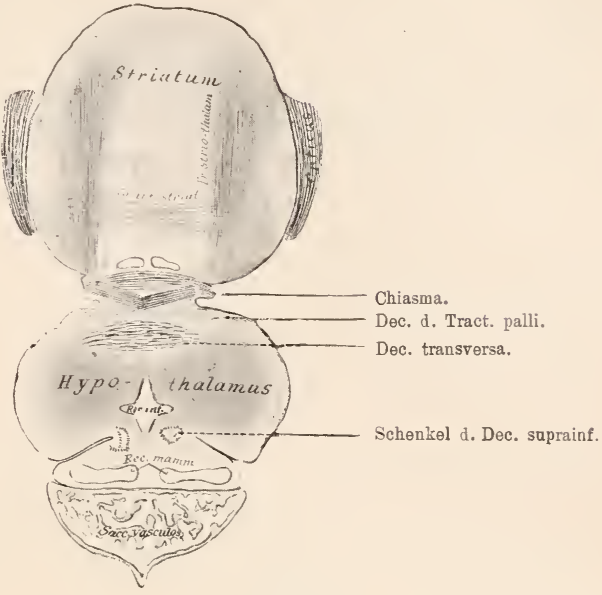

Fig. 90.

Horizontalschnitt durch den Thalamus eines Haies, Syllicum_can, reif. chiern eine mächtige, dicht hinter dem Chiasma liegende Kreuzung, deren vordere Enden aus dem Telencephalon stammen, das sie als Mantelbündel, Fig. 122, verlassen. Diese Kreuzung der Mantelbündel ist bei den meisten Knorpelfischen die mäch-

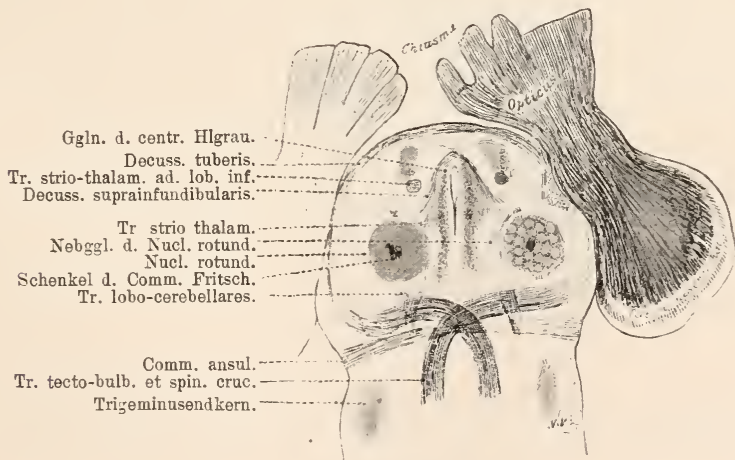

Fig. 91.

Horizontalschnitt durch den Thalamus eines Knochenfisches, Gobio fluviatilis.

tigste Kreuzung nächst dem Chiasma. An gleicher Stelle findet man auch bei den Teleostiern eine mächtige Kreuzung, D e cuss. tuberis. Aber diese stammt nicht 
aus dem Vorderhirne, sondern sie bezieht ihre F'asern jederseits aus einem Bündel, das aus dem Ganglion anterius des Trichters entspringt, Fig. 86. Dann kommt bei Knochenfischen noch eine Kreuzung von Fasern oder ein Commissurbogen vor, der, dem Tectum opticum entstammend, mit mächtigen dicken Fasern von rechts nach links zieht. Er ist von Fritsch entdeckt und mag Fritsch'sche Com missur heissen.

Von allen diesen Zügen aber kennen wir bei den Teleostiern mit Sicherheit kaum mehr als das Mittelstuick. Dass ihrer noch mehr existiren, als ich hier erwähne, ist sicher. Herrick, dem wir die genauesten Untersuchungen

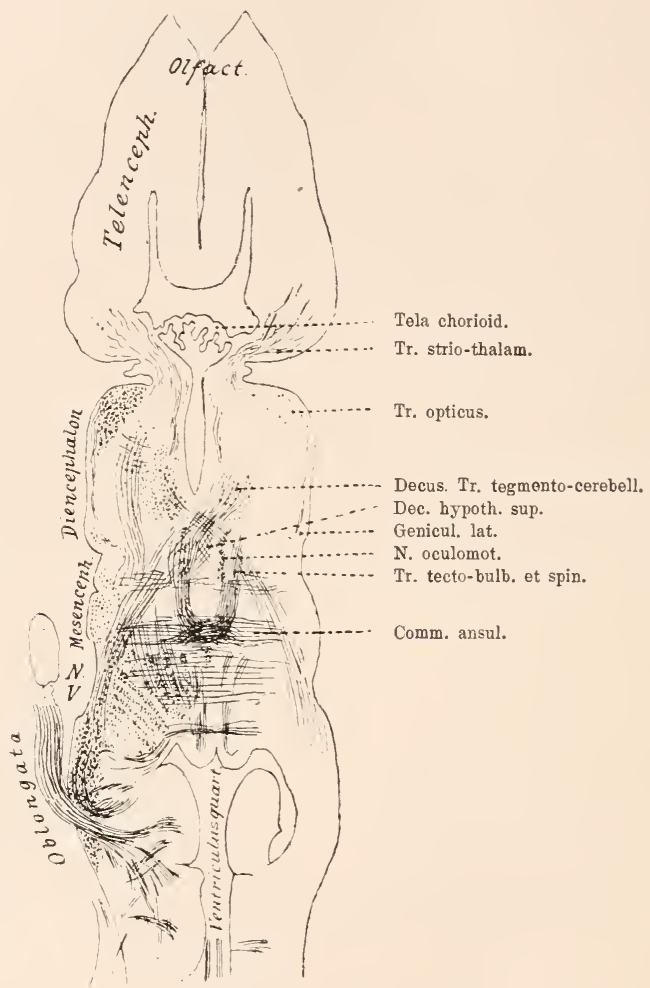

Fig. 92.

Horizontalschnitt durch das ganze Gehirn eines Haies, Scyllium canicula zur Demonstration der Kreuzung aus den Nuclei praetectales und anderer Kreuzungen am Boden des Gehirnes.

über diese Dinge verdanken, zählt allein in der Frontalwand des Hypothalamus nicht weniger als 6 Kreuzungen, $\mathrm{zu}$ denen dann als siebente noch das Chiasma käme.

Auch im caudalen Abschnitte des Hypothalamus der Fische liegen mehrere 
Commissuren oder Kreuzungen. Ganz constant ist die Decussatio supra-infundibularis, die ihre Ziige beiderseits aus den Seitenhälften der Regio infundibularis bezieht. Ihr schliesst sich dicht caudal die Kreuzung der Bahnen aus den Ganglia ecto mammillaria an, die nur bei Amplibien, Reptilien und Vögeln bisher nachgewiesen ist. Als Decussatio hypothalamica superior will ich eine überall vorhandene Kreuzung bezeichnen, die in zwei getrennte Abschnitte zerlegbar ist, in einen Zug, der aus den Nuclei prätectales des Nittelhirnes stammt, erst medialwärts zieht und dann mit dem gleichen von der anderen Seite kreuzt, und in einen zweiten, der etwas weiter caudal liegend wahrscheinlich den Fasciculi longitudinales post. angehört. Er scheint aus deren Kern zu stammen und in das gekreuzte Bündel zu gerathen.

Alle diese Zïge sind noch recht wenig geklärt. Wenn ich hier das Wort Decussation. dort das Wort Commissur gebraucht habe, so geschah das dem bisherigen Sprachgebrauche folgend. Fs muss aber constatirt werden, dass wir von keinem einzigen Zuge sicher wissen, ob er nur krelzende Fasern enthält oder ob er Hirngegenden verbindet. Querfasern wäre die einzige heute brauchbare Bezeichnung.

Von dem etwas unerquicklichen Bilde, das der heutige stand unserer Kenntnisse vom Hypothalamus der niederen Vertebraten gewährt, will ich sie nun hinwegführen zu einem erfreulicheren.

Zı den wenigen wirklich gut bekannten Bahnen im Gehirne gehören die dem Sehacte dienenden. Zwar ist des Sehnerven schon nenlich anlässlich der Beschreibung des Mittelhirndaches gedacht worden, aber da wir dicht vor dem Hypothalamus alle seine Fasern endlich vereint beisammen finden, verlohnt es sich einmal, den ganzen Nerven im Zusammenhange zu betrachten.

Wir wissen heute, dass (S. R. y. Cajal, Monakow), ans den grossen Ganglienzellen der Retina Theile des Sehnerven stammen, und wir wissen anch, dass ein anderer Theil aus dem Nittelhirndache selbst herabzieht, ım in der Retina erst aufgesplittert zu enden. Die Retina selbst darf als ein System von iiber einander gebauten Neuronen angesehen werden, die theils direct, wie eben angegeben, zum Opticus in Beziehung stehen, theils sich an andere Zellen, in zweiter, in dritter und vierter Categorie den Reiz fortpflanzend, anlegen. Dazwischen liegen damn viele Zellen, die nach der Ausbreitung ihrer Ausläufer offenbar Einzeltheile der Netzhaut unter sich verknüpfen. Ich verweise Sie für diese sehr interessanten Dinge, die hier nicht genauer dargestellt werden können, auf die prächtige Monographie S. Ramon y Cajal's ïber die Netzhaut, von der eine deutsche Uebersetzung durch Dr. Greef vorliegt.

Aus dem Bulbus treten die Sehnerven in die Schädelhöhle. Das sind bei den Fischen, deren Augen oft viel grösser, als die menschlichen sind, anch bei den Vögeln, ganz enorme Bündel. die, wem sie eimmal in das Gehirn eintreten und dort auseinander fahren, das ganze Structurbild beherrschen. Siehe Mesencephalon. An der Schädelbasis krenzen sie Chiasma - dicht vor dem Hypothalamus; bei den allermeisten Thieren vollständig, aber bei einigen Tögeln und wahrscheinlich bei der Mehr- 
zahl der Säuger nur zum Theil. Das hängt wohl mit der Stellung der Augen zusammen, die bei absolut lateraler Lage, wie bei den Fischen, Reptilien u. s. w.. keinen einzigen Theil des Gesichtsfeldes gemeinsam laben, während sie bei der Stellung, die wir bei den Eulen. den Affen und dem Menschen kennen, nur in den lateralen Abschnitten ganz getrennte Theile der Aussenwelt abbilden, die Bilder der medialen Abschnitte sich aber zum Theil decken. So erklärt es sich, dass sorgfältige Tntersuchungen über das Chiasma zu sehr widersprechenden Resultaten über die Kreuzung geführt haben, je nachdem man an dem einen oder dem anderen Thiere untersuchte. Vielleicht sind sogar für einzelne Individuen der gleichen Art die Verhältnisse wechselnd. Ganz sicher ist die partielle Krreuzung bisher nur für die Säuger, besonders für den Menschen. wo Degenerationen im Sehnerven nach Verlust der Augen mit den Sehfeldbildern verglichen werden konnten, die während des Lebens aufgenommen worden waren.

So einfach wie die Kreuzung Fig. $\varsigma_{7}$ und $s 9$ dargestellt ist, ist sie aber nicht. Es durchflechten sich immer die Bündel mehr oder weniger, ja bei einigen Fischen tritt ein Nerr durch eine mächtige Spalte des anderen hindurch.

Vom Chiasma aus aber ziehen die nunmehr geeinten Bündel immer rückwärts und aufwärts, Fig. ss, überziehen den Thalamus, Fig. 64, 70 und 71, und geben dabei einen mächtigen Theil ihrer Fasercollateralen in das Geniculatum laterale ab, dass an dessen Aussenseite liegt. Vergl. Fig. \$1 und \2. Dadurch wird aber der Tractus nur wenig faserärmer. Er zieht nun, sich in zahlreiche Aeste spaltend, in das Mittelhirndach. Dort haben sie ihn schon kennen gelernt. Man kann diese Aeste als Tierhügelarme bezeichnen, wie das bei den Säugern geschah, aber es ist zweckmässiger, den Namen Wurzehn beizubehalten, weil die Vierhügelarme der Säuger auch noch Fasern aus dem Grosshirne führen, deren Zuwachs erst sie charakterisirt. In das Mittelhirndach treten nun die einzelnen Bündel ein, und dort splittern sie auf, ron dorther ziehen auch aus Zellen andere Fasern in den Opticus hinein.

An der Figur 66 sehen sie einen Theil der Endigungen. Sie erkennen hier auch, wie sie in naher Contactbeziehung zu den Bahnen stehen, die aus dem tiefen Marke des Mittelhirnes entspringen. Nicht nur tauchen die Dendriten der Zellen, aus welchen jene Züge zu den sensiblen Keruen des Nachhirnes und des Rückenmarkes stammen, mitten in die Opticusfaserung ein, sondern es erheben sich auch aus der sensiblen Faserung Züge von Axencylindern in die Opticusschicht.

Auf die physiologische Bedeutung dieser nahen Beziehungen der sensiblen centralen Bahnen zu den optischen Bahnen ist bisher verhältnissmässig noch wenig Gewicht gelegt worden. Doch kennen wir schon Phänomene, welche durch sie erst ihre Erklärung finden. So z. B. die merkwürdige Verkürzung der Netzhautzapfen und Stäbchen, wenn bei verdeckten Augen die Haut besonnt wird - Engelmann, van Genderen Stort. - Wenn ich oben das Mittelhirndach als ein grosses Associatonscentrum für sensible 
Eindriicke bezeichnet habe, so lag dem die Erkenntniss zu Grunde, dass hier so ïberaus wichtige Bahnen in directem Contacte stehen. Die schweren Motilitätsstörungen, die Zwangsbewegungen, welche nach Verlust des Mittelhirndaches eintreten, die schweren Störungen in dem Gesammtverhalten der Thiere, die dieser Eingriff nach sich zieht, Störungen, die viel gewaltiger sind, als die nach Verletzung des Grosshirnes oder des Thalamus, fiuden wohl in anatomischen Anordnungen, wie ich sie hier schilderte, ihre Erklärung.

Bei den Säugern endet die Mehrzahl der Sehnervenfasern im Geniculatum laterale und nur eine Minderzahl in dem Tectum Mesencephali.

Wir wollen die Betrachtung des Zwischenhirnes nicht verlassen, ohne uns daran zu erimnern, dass dieser Hirntheil im Wesentlichen, bei den niederen Vertebraten wenigstens - nur durch relativ geringe Bahnen mit dem Torderhirne zusammenhängt. Desshalb lege ich, ehe wir gemeinsam an die Beschreibung des Torderhirnes herangehen. Ihnen noch zum Schlusse der heutig'en Torlesung einen Schnitt vor. den ich durch

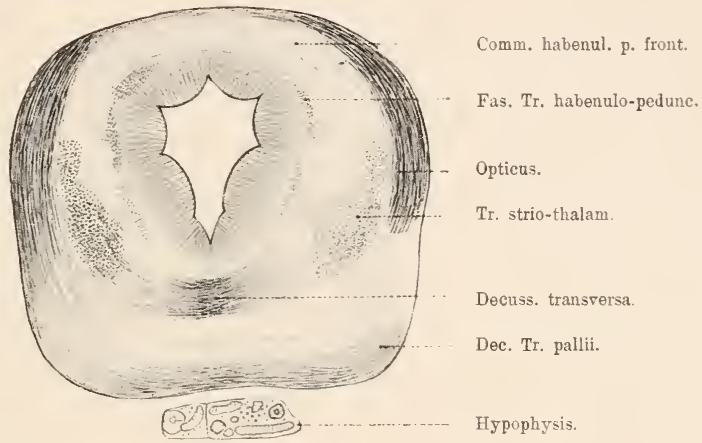

Fig. 93.

Schnitt durch den frontalsten Abschnitt des Thalamus von Seyllium canicula.

das frontalste Zwischenhirngebiet von Scyllium canicula gelegt habe, dicht hinter dem Ganglion habenulae. Da sehen sie demn, dass so ziemlich Alles, was den schnitt erfült, dem Opticus und den auf ihn folgendeu Commissuren angehört, einige Fäserchen auch dem Systeme der Ganglia habenulae entsprechen, dass aber zum Vorderhirne hier nur die beiderseits ziemlich ventral liegenden Bündel der Tractus strio-thalamicae hinausziehen. Wenn einmal bei den höheren Thieren die Hirnrinde sich einstellt, so gesellen sich diesen Fasern jene zu, welche aus der Rinde in den Thalamus ziehen, und jene, welche aus der Rinde weiter hinabwandern. Aber immer, bis hinauf zu den Sängern kann man aus der grossen Fasermasse, rrelche dam an der hier angeschnittenen Stelle als Capsula inter'n a auftritt. die Züge aus dem Striatum noch abscheiden. Nur spielen sie dann ihrer Grösseordnung nach nur noch eine untergeordnete Rolle 


\section{Elfte Vorlesung.}

\section{Das Endhirn, Telencephalon, Vorderhirn in engeren Sinne, Grosshirn.}

1. Riechapparat und stammlappen.

II. H.! Aus den Hirngebieten, welche wir bisher kenmen gelernt haben, treten für die verschiedenen Thierklassen sehr verschiedene directe Bahnen in den frontalsten Abschnitt. in das Grosshirn ein. Bei den Fröschen ist nur das Zwischenhirn mit demselben verbunden, bei den anderen Vertebraten ausserdem noch das Mittelhirn, bei den Säugern kommt es schliesslich auch zu einer Verbindung mit den bei anderen Thieren viel unabhängigeren C'entren, mit dem Rückenmarke. Eine directe Grosshirnbahn zum (erebellum ist nicht bekannt, aber auch hier ist bei den Säugern auf den Wegen über den Haubenkern und über die Ponsganglien eine Verbindung möglich. Der Einfluss, den das Vorderhirn auf die tieferencentren direct ansïben kann, ist also ein verschieden grosser, je nach der Thierklasse. Diese Thatsache, welche die rergleichend anatomische Untersuchung sofort in die Augen springen lässt, blieb bisher merkwürdiger Weise bei der Deutung physiologischer und psychologischer Erscheinungen fast völlig unberücksichtigt.

Es ist natïrlich auch wichtig, zu unterscheiden, welche Theile des Torderhirnes mit anderen Hirntheilen in Verbindung treten. Sie werden gleich sehen, dass gerade besonders wichtige Bahnen, diejenigen ans der Hirmrinde, erst relativ spät in der Reihe auftreten und noch viel später erst eine gewisse Vollkommenheit erreichen; ja, dass solche Bahnen erst bei den Säugern zu der Mehrzahl der anderen Hirntheile in Beziehung treten.

Wir können uns ein schematisches Torderhirn leicht vorstellen, wemn wir anmehmen, dass die etwa eiförmige Blase, welche sich beiderseits neben der Schlussplatte aus dem gemeinsamen Ventrikel ansstïlpt, an der Basis sich verdickt, dass sie lier einen grösseren Körper entwickelt, den Stammlappen. In den Boden der Blasenwand münden die Riechnervenfaserungen, ihn können wir desshalb gleich als Riechapparat rom Stammganglion trennen. So gewinnen wir einen zweiten wohl charakterisirten Abschuitt. Was num noch als Dach und als Seitenwände von dem angenommenen Höhlkörper zurückbleibt, das heisst II a n t el$\mathrm{P}$ a $11 \mathrm{i} 11 \mathrm{~m}$.

Das Pallium kann entweder ganz aus einer einfachen Epithelplatte bestehen - Krnochenfische. oder es können sich mindestens die Seitentheile zu nervösen Gebieten verdicken - Cyclostomen. oder es können auch Seitenwände und Torderwand in die Terdickung eingehen, wie das bei manchen Selachierarten der Fall ist. oder es kamn schliesslich fast das gesammte Pallium sich in Hirnsubstanz umwandehn. wo damn nur der aller- 
caudalste Abschnitt als Tela chorioidea den rein epithelialen Charakter behält. So ist der Hirmmantel bei den Amphibien und Reptilien, den Vögehn und den Säugern gebaut. Gerade die Mantelentwicklung ist ron besonderem Interesse. Aus minimalen Anfängen bei den Knochenfischen entwickelt er sich zu jenem enormen Organe, das sie beim Menschen als die Hemisphären kemnen. und mit dieser Entwicklıng schreitet die Entwicklung der Fähigkeit zu höheren seelischen Handlungen voran.

Der Stammlappen und der Riechapparat hingegen weisen, wie das Rückenmark, das Kleinhirn und das Nittelhirn durch die ganze Reihe hindurch wenig wesentliche Unterschiede auf.

Figur 20 zeigt zehr gut die einzelnen Theile des embryonalen menschlichen Gehirnes, die hier, da es sich auf dem abgebildeten Stadium nur um Gebilde handelt, die allerwärts wieder vorkommen, gewissermassen als Prototyl dienen mögen. Ausserdem wollen Sie auf Fig. 55, an den vier dort abgebildeten Sagittalschnitten die verschieden grosse Mantelentwicklung schon jetzt beachten. Wir müssen aber natürlich die einzelnen Abschnitte nun viel näher studiren.

Ausser dem Ganglion habenulae und dem systeme des Opticus existirt kein Hirntheil, der überall im Wesentlichen so gleichartig wiedergefunden wird, wie der Riechapparat.

Nur die Grössenverhältnisse wechseln, die Aufbaurrincipien bleiben, und sie sind gerade durch Untersuchungen, die in den letzten Jahren von S. R. y Cajal, r. Gehuchten, Kölliker und mir ansgeführt wurden, endlich übersichtlich darstellbar.

Aus den Epithelien der Nasenschleimhaut, Fig. 16 A, laufen lange Endfäden rückwärts. Sie heissen Fila olfactoria md treten, die Siebplatte durchwandernd, in den Schädelraum ein. Diesen durchziehen sie auf einer, je nach der Thierart längeren oder kürzeren Strecke, bis sie an dem frontalen Gehirnende ankommen. Dort senken sie sich ein. Der ganze Strang, der gelegentlich auch in zwei und mehr Theile zerfallen kam, heisst Nervus olfactorius.

Morphologisch richtiger wäre Radix olfactoria. Denn ein eigentlicher peripherer Nerv, der, wie andere periphere Nerven distal von der Ursprungszelle liegt, existirt hier nicht. Der Riechnerv ist vielmehr - vergl. das Schema S. 41 nur den Wurzeln der anderen Nerren zu vergleichen.

Diesen Riechfäden kommt nun eine frontalwärts gerichtete A u s stülpung der Vorderhirnblase entgegen. Sie bildet an der Basis einen mehr oder weniger langen Schlauch, der fast bei allen Thieren hohl bleibt. Dieser Schlanch heisst Lobus olfactorius anterior. Von der Stelle etwa ab, wo er sich in die Hirnbasis einsenkt, beginnt das caudale Riechgebiet, das bei Säugern als Lobus olfactorius posterior bezeichnet wird. Wir wollen, da bei den niederen Vertebraten der Vergleich noch nicht absolut sicher möglich ist, den vorderen Abschnitt einfach Lobus olfactorius nemnen und den hinteren. welcher die ganze Basis des Gehirnes einnimmt, als Riechfeld, Area olfact 0 ria bezeichnen. 
An der stelle, wo die Riechnervenfädchen das frontale Ende des Riechlappens erreichen, splittern sie alle, zuweilen nach Ceberkreuzungen und Faseraustansch zı ganz feinen Endpinseln auf. Diese treten in die Lobusspitze ein. und hier kommen ihnen. aus dort liegenden Zellen stammend, andere Pinsel entgegen, die kräftigeres Kaliber haben. Die reichen Pinsel aus dem 1. Neuron des Riechapparates gerathen dabei in engen Contact mit den stärkeren Pinsehn, die nichts Anderes sind, als Dendritenausläufer der Zellen, in denen das 2. Neuron beginut.

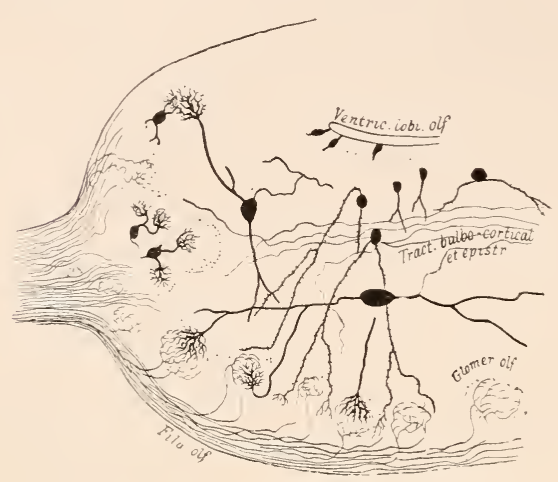

Fig. 94.

Sagittalschnitt durch den Bulbus olfactorius eines Frosches. Einige Zellen durch Silber geschwärzt. Nach P. R. y Cajal.

Die vereinten Endpinsel sind auf allen Schnitten, welche die Lobusspitze treffen, dicht unterhalb der Riechnervenfädchen schon bei schwachen Vergrösserungen als kugliche Gebilde zu sehen. Man heisst sie Glomeruli olfactorii. Aus den Riechzellen zweiter Ordnung entspringen nun wieder nene Axencylinder, und diese wenden sich rïckwärts zu anderen Gebieten.

Die eintretenden und sich vielfach immer überkreuzenden Fila olfactoria, die Dendriten der Riechzellen und die Glomeruli olfactorii zusammen erzeugen an der Lobusspitze ein eigenthümliches Bild, das auf allen schnitten durchans charakteristisch wiederkehrt. Diese ganze Formation, welche die Lobusspitze iiberzieht, wollen wir als $\mathrm{F}$ or m a tio bulbaris bezeichnen. Bei den meisten Thieren macht sie eine Anschwellung vorn am Riechapparate, die man als Bulbus olfactorius bezeichnet hat. Doch ist zuweilen die Lobusspitze weiter rïckwärts als der sichtbare Bulbus reicht, mit Formatio bulbaris überzogen. Namentlich zeigen einzelne Amphibien und Reptilien an der medialen Lobusseite noch eine etwas candal gerïckte, etwa eiförmige Platte von Bulbusformation.

Aus dem caudalen und dem lateralen Pole des rundlichen Bulbus sieht man dann immer die Riechbahn zweiter Ordnung, die Riechstrah lu $u$ g, Tractus olfact., hervortreten, welche den Lobus olfactorius zunächst überzieht, sich aber dann in einem oder mehreren Strängen zumeist an seiner lateralen seite ansammelt und nun rïckwärts zieht. Diese secundäre Riechstrahlung ist so mächtig, dass sie fast inmer makroskopisch als dicker weisser Zug zu erkemnen ist. Bei einigen Knochenfischen ist der Bulbus olfactorius sehr gross und weithin nach vorn in den Schä- 
del verlagert. Dann ziehen die erwähuten Tractus als zwei mächtige weisse Stränge jederseits rïckwärts zum Gehirıe, und es ist von dem nur ganz dünnen Lobus, den sie ïberziehen, nur bei genaner Untersuchung etwas zu finden. Solche Stränge kömnen leicht für die Riechnerven selbst gehalten werden.

Man kann einem Strange der an der Schädelbasis von der Nasengegend her dem Gehirne zuzieht, nicht ohne Weiteres ansehen, ob er Riechnerv oder Riechstrahlung ist. Nur die Lage des Bulbus entscheidet hier. Was in diesen von vorn her eintritt, ist Riechnerv. was ihn hinten verlässt, um in das Gehirn zu ziehen, ist immer Riechstrahlung. Die Riechnerven sind wohl immer marklos, die Riechstrahlung aber ist zu allermeist markhaltig.

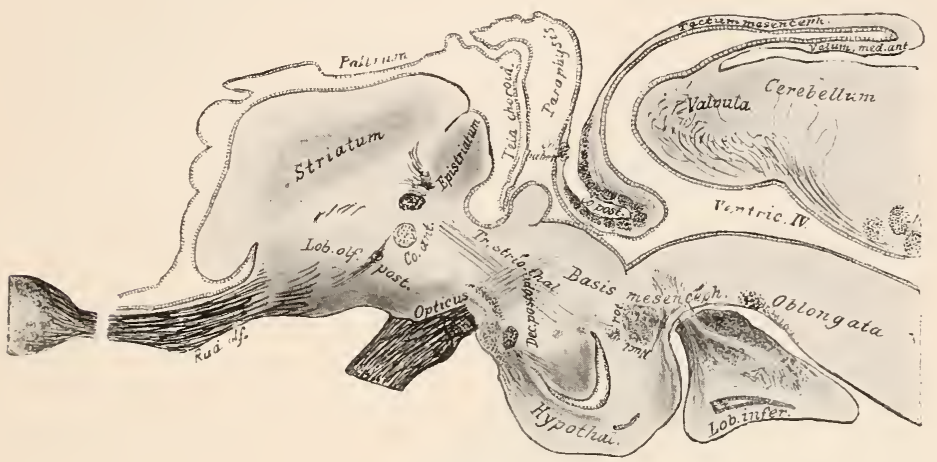

Fig. 95.

Gehirn von Barbus fluviatilis. Sagittalschnitt nahe der Mittellinie.

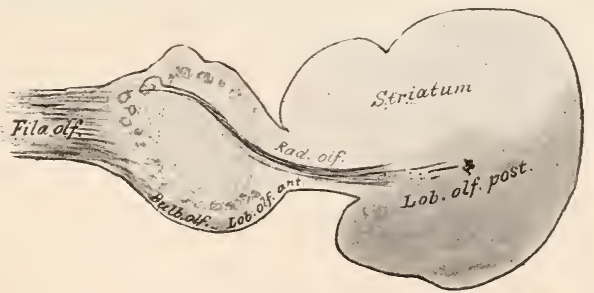

Fig. 96.

Gehirn von Perca fluviatilis. Sagittalschnitt, ziemlich lateral. Nur der Stammlappen abgebildet.

An dem Gehirn der Barbe, Fig. 95, sehen Sie diesen langgestreckten Verlauf der Tractus und das Eintreten der Fila in den Bulbus, der weit frontal von dem übrigen Gehirne liegt. Gleichzeitig demonstriere ich in Fig. 96 ein Barschgehirn, an welchem der Bulbus dem Gehirne dicht aufsitzt und demgemäss die Tractus nur kurz sind. 
Das caudale Ende der secundären Riechfaserung war lange unbekannt, bis C. L. Herrick zeigen konnte, dass ein Theil basal im Lobus olfactorius posterior, ein anderer weiter dorsal in einem dem Stammlappen aufliegenden Hirntheile ende. Ich lıabe dann diese Verhältnisse bei Fischen und Reptilien genauer studirt und gefunden, dass es sich hier um etwas Principielles, in gleicher Weise bei so artentfernten Thieren Wiederkehrendes handele. Den neu abgegrenzten Hirntheil, der immer dem Striatum dicht anliegt. habe ich Epistriatum genannt.

Für die Reptilien, wo der Körper ziemlich lateral liegt, wäre vielleicht Ektostriatum bezeichnender. Gerade bei den Reptilien hatte schon früher M e y er einen Faserzug aus dem Riechapparate in das gleiche Ganglion gesehen.

Das Epistriatum ist bei den Reptilien am schärfsten ausgeprägt und vou den übrigen Hirntheilen durch den Bau gut abscheidbar. Es handelt sich um eine zur Halbkugel gerundete Platte grosser Ganglienzellen, die bei einigen Arten s. die Abbildung von Varanus Fig. 97 - sogar noch eine Oberflächenvergrösserung durch Fältelung erfährt. Bei den Schildkröten ist die Platte kleiner als bei den anderen Reptilien. Hier aber erkennt man deutlich, was bei den anderen weniger gut nachweisbar ist, dass nämlich die ganze Zellenlage sich in die ähnliche Zelllage der Rinde direct fortsetzt, Fig. 118. Da bei den Fischen ein Epistriatum, aber keine Rinde vorhanden ist, so muss jener Körper unabhängig von dem rindenbedeckten Mantel entstanden sein.

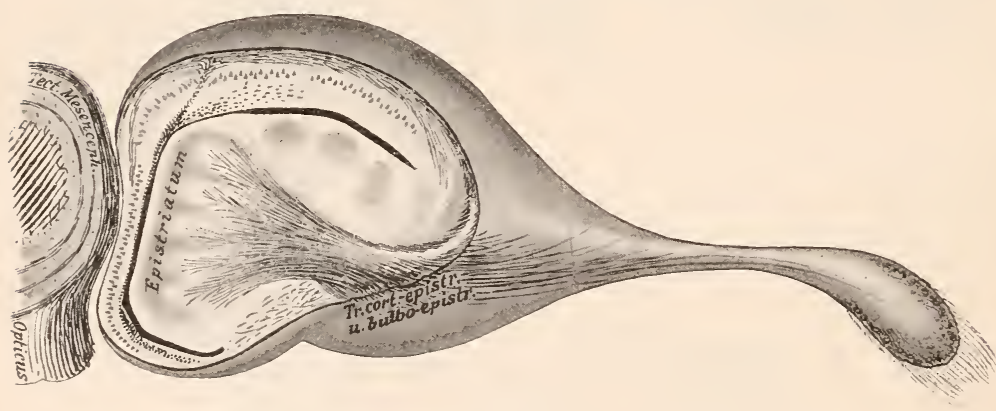

Fig. 97.

Ein Varanusgehirn ca. 1:10 vergr., seitlich angeschnitten. Markscheidenfärbung. Zeigt den Verlauf der medialen Faserung aus dem Bulbus olfactorius.

Die Riechstrahlung ist bei den Amphibien zu gutem Theile marklos und bei den Tögehn ungemein spärlich, da liese nur einen ziemlich atrophischen Geruchsapparat haben. Desshalb ist es noch nicht gelungen, bei beiden den Terlanf der erwähnten Züge und die Lage des Ganglion epitriaticum sicher zu stellen. Bei den Sängern sind die Tractus aus dem Bulbus wohl bekannt. Man sieht sie an der Hirnbasis rïckwärts ziehen und erkennt. dass sich aus ihnen fortwährend Züge in den Lobus olfactorius posterior einsenken, vielleicht auch in die Rinde des Lobus olfactorius anterior. Die candalsten Enden sind noch nicht ganz sicher ge- 
stellt. Es ist möglich, dass das, was man Mandelkern nemnt. dem Epistratum der niederen Thiere entspricht.

Es endet also der medial liegende Theil der secundären Riechbahn im Epistriatum.

Ein anderer, der laterale, findet in weiter ventral gelegenen Theilen des Hirnstammes, im Lobus olfactorius posterior sein Ende. Schon bei den Knochenfischen, dem Karpfen z. B., sieht man, dass lateral von den mächtigen Zügen zum Epistriatum, die als mediale Riechstrahlung bezeichnet werden könnten, dünnere aber noch immer kräftige Faserbündel sich in die Area olfactoria einsenken. Diese laterale Riechstrahlung verschwindet in sanft ansteigendem Zuge imnerhalb des Lobus olfactorius posterior, der iibrigens bei oberflächlicher Betrachtung nicht vom Striatum, dessen ventralen Abschnitt er bildet, zu trennen ist.

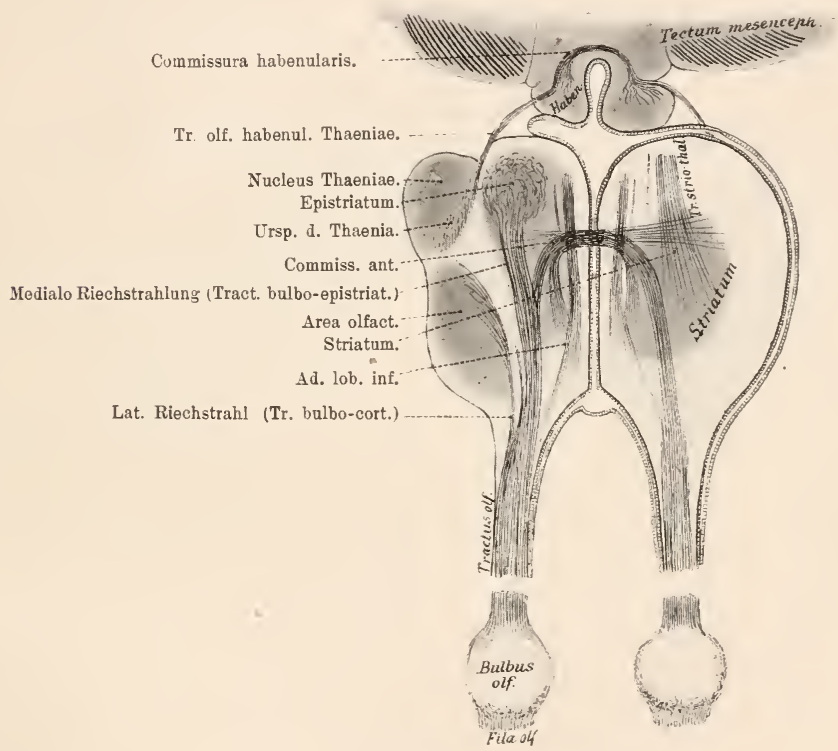

Fig. 98.

Schema eines Horizontalschnittes durch das Gehirn von Cyprinus carpio. Nach Untersuchungen, die ich gemeinsam mit Frl. Dr. A. Hamilton angestellt habe. Zeigt einzelne Unterabtheilungen des Stammlappens und den Verlauf der Riechfaserung. Alle Theile in eine Ebene projicirt.

Der Riechapparat der Amphibien ist noch ziemlich unbekannt, aber bei den Reptilien und bei den Säugern kann man sehr deutlich erkemnen, dass sehr viele Fasern sich in die Basis des Hirnstammes, in den Lobus olfactorius posterior einsenken, und kann auch constatiren, dass in der Rinde des Lobus olfactorius anterior solche Bahnen verschwinden. Sie 
tauchen da ein, um zu feinen Pinseln aufzusplittern, denen auch hier Dendriten grosser Zellen - hier Rindenpyramiden genannt, entgegenziehen. Demgemäss hätten wir heute in der secundären Riechstrahlung mindestens 2 Faserarten anzunehmen: Die Tractus bulbo-epistriatici und die Tractus bulbo-corticales, von den letzteren wären noch solche in die vordere und solche in die hintere Abtheilung der Riechlappen zu unterscheiden. Schliesslich besteht mit IVahrscheinlichkeit - wenigstens bei den grossen Reptilien -- noch eine Terbindung zwischen Riechlappenrinde und Epistriatum, der Tractus cortico-epistriaticus.

Der Riechapparat ist also bis zu den Hirntheilen hin, die wir kennen gelernt haben, zum mindesten aus 2 Neuronen zusammengesetzt, dem peripheren, das von der Nase bis in den Bulbus reicht, und dem centralen, welches ron hier zu den mehrgenannten Endstätten führt. Aber von da leiten nun andere Bahnen weiter, die Riechbahnen dritter und höherer Ordnungen. Zunächst ist der centrale Riechapparat regelmässig durch eine Faserbahn mit dem Epithalamus, speciell mit den Ganglia habenulae verbunden. S. Fig. 95.

Aus dem caudalsten Theile des hinteren Riechlappens, dem Gebiete also, wo ein guter Theil der Riechstrahlung um Ganglienzellen herum aufsplitternd geendet hat, erhebt sich bei allen Wirbelthieren ein kräftiges Faserbündel dorsalwärts. Es entspringt meist aus einer eigenen Kernansammlung, dem Nucleus Thaeniae. Das Bündel zieht rückwärts nnd aufwärts, bleibt frontal vom Opticus und geht schliesslich in die Ganglia habenulae ein, die Sie bei der Betrachtung des Epithalamus kennen gelernt haben. Dort betheiligt es sich an der Commissura habenularis, die wahrscheinlich nur ein gekreuzter Ursprung desselben ist. Der Zug heisst Tractus olfacto-habenularis. Mit anderen Bündeln vereint, bildet er die Thaenia thalami optici.

Auf dem Wege vom basalsten Gebiete des Vorderhirnes hinauf zum Epithalamus bleibt die Thaenia bei allen Thieren immer frontal vom Tractus opticus. Bei den niederen Vertebraten liegt sie diesem dicht benachbart, ist zuweilen streckenweise schwer von ihm abzuscheiden, bei den höheren aber, wo die Thalamusganglien so grosse Ausdehnung erlangt haben, wird durch jene der vom Mittelhirne zum Chiasma herabziehende Sehtractus von der Thaenia abgeschoben. Dann verlaufen beide Züge, durch die Thalamusbreite von einander getrennt, die Thaenia medialer als der Opticus.

Eine zweite Verbindung geht der centrale Riechapparat mit der Hirnrinde ein.

Diese Verbindung fehlt sicher den Fischen, ist wahrscheinlich, aber nicht sicher, bei den Amphibien vorhanden und tritt jedenfalls bei den Reptilien und den Säugern kräftig in Erscheinung. Für die Vögel ist sie sehr wahrscheinlich, aber noch nicht mit wünschenswerther Sicherheit festgelegt. Die Fasern, um die es sich hier handelt, mögen als Tractus cortico-olfactorii bezeichnet werden. Sie entspringen an der medialen Seite des Gehirnes aus dem Lobus olfactorius anterior und aus dem Riechfelde und erheben sich, an der Scheidewand der Hemisphären hinaufziehend, zu der dorsaler gelegenen Rinde. Fig. 76 Tr. olf. septi.

Die Rindenriechapparatbahn ist, wie Sie später sehen werden, die älteste Verbindung, welche die Hirminde mit einem simnesapparate ein- 
ging. Es wird ihrer, schon dieser principiell wichtigen Stellung wegen, später noch zu gedenken sein, wemn wir die Entwicklung des Hirmmantels besprechen.

Das Rindencentrum des Riechapparates erreicht bei den Säıgern seine höchste Ausbildung. Hier entwickeln sich in ihm zahllose Associationsapparate, es vergrössert sich seine Oberfläche ganz enorm, und es kommt zur Abscheidung ganzer Lappen - Lobus cornu Ammonis, Lobus pyriformis.

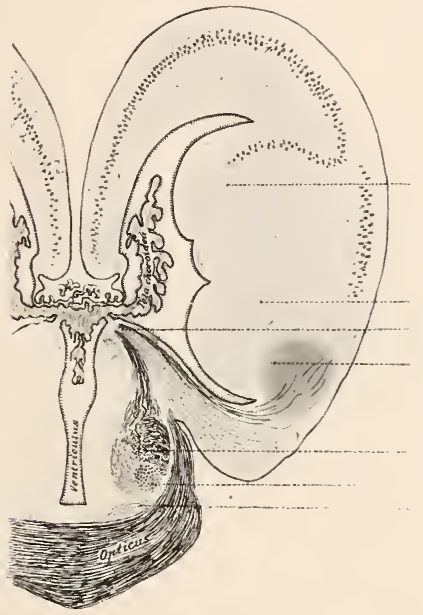

Epistriatum.

Regio part. caud. Striat.

Thaenia, mit 3 Ursprungsbündeln.

Nucleus Thaeniae.

Tr. strio-thalamicus.

Tr. septo-mesenceph.

Decuss. trsvsa.

Fig. 99.

Frontalschnitt durch den caudalsten Abschnitt des Vorderhimes, von der Sumpfschildkröte, Emys lutaria. Dorsal das Pallium mit der Rinde, ventral links das Uebergangsgebiet zum Thalamus mit dem unten liegenden Chiasma, rechts das caudale Ende des Riechfeldes, aus dem sich die Tractus olfacto-habenulares erheben.

Diese Hirntheile sind aufzufassen als hochorganisirte Centren, die ihre Anregung zwar aus dem niederen, bei den Fischen isolirt vorhandenen Riechmechanismus erhalten, aber durch ihren Bau zu ausgedehnter Eigenthätigkeit befähigt sind. Es addirt sich also in der Thierreihe zu dem niederen Riechmechanismus, allmählich an Ausdehmung zunehmend, noch ein lı̈herer.

Nachdem nun so eine Uebersicht über das gegeben ist, was hente fïr den Riechạpparat der Wirbelthiere bekannt ist, lege ich Ihnen in Fig. 100 die Abbildung eines idealen Sagittalschnittes durch ein Eidechsengehirn vor, an welchem Sie noch einmal alle die einzeln geschilderten Theile in ihrem Zusammenhange studiren wollen. Die Faserung wird Ihnen nun ohne Weiteres klar sein, wenn sie sich einmal mit den Umrissen vertraut gemacht haben. Vorn liegt der Riechlappen, bedeckt von der 
Formatio bulbaris. in welche die Riechnervenfäden, aus den Zellen der Nase kommend, münden. Hinter ihm an der Basis die Area olfactoria mit dem ganz caudal liegenden Nucleus thaeniae und über dieser das Epistriatum, dem sich medial und rorn das Striatum anschliesst. Ueber das Ganze spannt sich der Mantel aus, welcher die Rinde trägt. Das Schema ist für alle Wirbelthiere gültig, wenn Sie die Mantelverbindung. weglassen, die, wie erwähnt, erst bei den Amphibien auftritt. Dass jene Rindenverbindung zum Riechen an sich nicht absolut nöthig ist, das beweisen die Fische, welche, mit vortrefflich ausgebildetem Geruchapparate begabt, doch keinerlei Rindenverbindung besitzen.

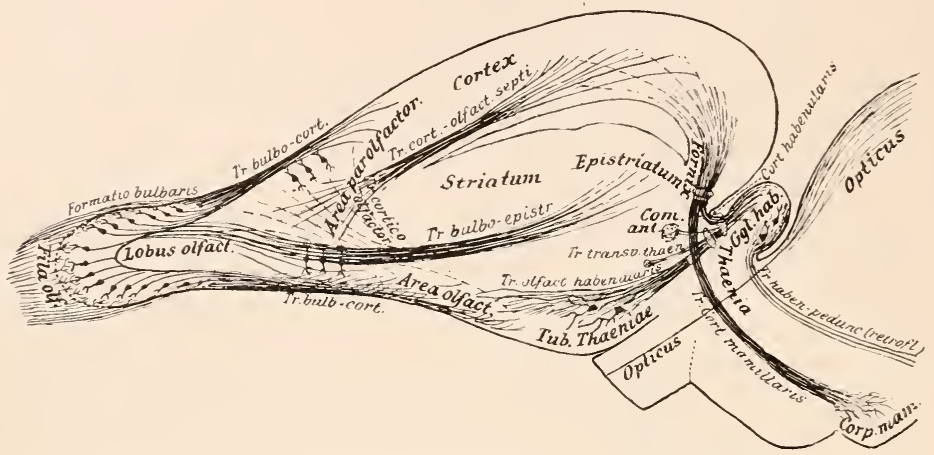

Fig. 100.

Sagittalschnitt durch ein Eidechsengehirn. Schema mit eingezeichneten Geruchsbahnen.

Alle Hirntheile, welche irgendwie zum Geruchsapparate in Beziehung stehen. sind mit den gleichartigen Theilen der gekreuzten Seite durch kräftige Faserzüge verbunden. Diese Züge kreuzen alle an einer einzigen Stelle vereint die Mittellinie. Die Kreuzung, die man, alle Züge zusanmenrechnend, als Commissura anterior bezeichnet, liegt in der Lamina terminalis, nahe deren Basis, Figuren 15 u. $\mathbf{7 6}$, und ist überaus constant. Die verschiedenen Züge sind bisher am besten von den Reptilien bekannt. Doch spricht Alles, was man bisher weiss, dafür, dass bei den übrigen Vertebraten die Dinge sich gleich wie bei jenen rerhalten.

Man kann bei den Reptilien unterscheiden: Einen Zweig, der die Lobi olfactorii beider Seiten unter einander verkniipft. Ramus connectens Lob. olf. Dieser entspringt mit seinen frontalsten Aesten schon ganz vorn, dicht an der Formatio bulbaris, und zieht dann rïckwärts, um in der Lamina terminalis auf die andere Seite überzugehen. Ein Horizontalschnitt dieses bestcharakterisirten Zweiges gleicht etwa einem Hufeisen, dessen Schenkel in die Riechlappen ziehen, Fig. 98. Ein zweiter Zug verknüpft, direct von rechts nach links hiniiberstreichend, die Corpora epistriat. untereinander. R a mus epistriaticus. Schliesslich liegt innerhalb des Systemes der Commissura anterior noch ein Faserzug, welcher dem basalsten Rindengebiete lateral vom Striatum angehört, R a mus 
c orticalis. Dieses Rindeugebiet werden wir erst später zu studiren haben, wenn ich Ihnen den Hirnmantel beschreibe. Dann wird auch des zweiten Systemes von Riechcommissuren zu gedenkell sein, desjenigen, welches die gesammte Riechrinde der einen Seite mit derjenigen der anderen verknüpft. Es sind das Fasern, welche, da sie dem Mantel entstammen, dorsal von der Commissura anterior einherziehen und den Fischen noch völlig fehleu. Sie sind in der Fig. 101 als Commissura pallii ant. und posterior bezeichnet. Gewöhnlich werden sie Psalterium genannt.

Es ist wahrscheinlich, dass bei den Fischen und Amphibien Fasern aus (dem Olfactoriusschenkel?) der Commissura anterior rïckwärts in den Hypothalamus ziehen. Diese sind auf dem Schema, Fig. 101, nicht aufgenommen.

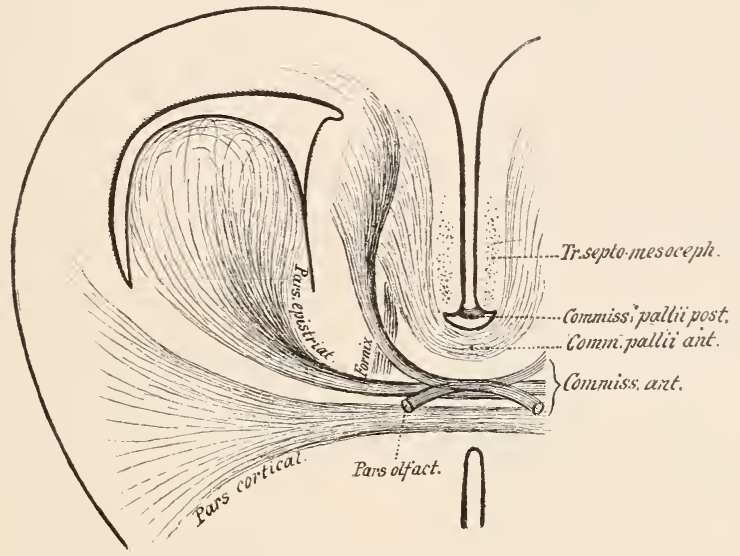

Fig. 101.

Schema der Commissuren bei einem Reptil. Vergl, auch Fig. 98.

Dem Riechapparate liegt das Stammganglion, Corpus striatum auf. Das ist ein etwa eiförmiger Körper, der von der Hirnbasis in die Höhle der Ventriculi cerebri hineinragt und immer, von den Fischen bis hinauf zum Menschen, an der gleichen Stelle liegt.

Er ist, weil der Hirnmantel über ihn hinwegzieht, gewöhnlich nicht am unverletzten Gehirne sichtbar, liegt vielmehr am Boden des rom Pallium bedeckten Tentrikels. Nur bei den Teleostiern. wo das Pallium aus einer dümnen Membran besteht, ist er durch diese hindurch wohl erkennbar. Er bildet da den Hirntheil, den man gewöhnlich als Torderlappen bezeichnet. Je mehr sich - bei Säugern — das Pallium und seine Faserung entwickelt, um so unbedeutender erscheint der bei niederen Vertebraten relativ so mächtige Körper. Auf der Abbildung des schellfischgehirnes, Fig. 3〉, erkennen Sie das Stammganglion in der mächtigen grossen Anschwellung am Stirnende. Wollten Sie diese Abbildung etwa in ein Sängergehirn überführen, so müssten Sie sich die Hemisphären, welche den Knochenfischen ganz fehlen, darïber zeichnen. Das abge- 
gebildete Fischgehirn ist morphologisch einem menschlichen Gehirne zu vergleichen, dem man die Hemisphären mit Schonung des Striatum abgetragen hat.

In dem mächtigen Vorderlappen der Fische hat Herrick schon eine Anzahl Einzelganglien abgeschieden. Soweit ich sehe, besteht er im Wesentlichen aus dem basal und lateral liegenden Lobus olfactorius posterior, aus dem dorsal und melir candal liegenden Epistriatum und aus dem echten Striatum, das zwischen beide eingefïgt liegt. Ausserdem keilt sich in den Raum, welcher

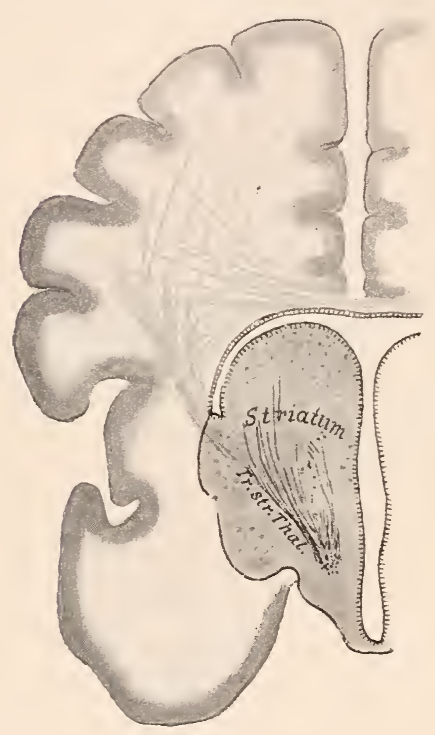

Fig. 102.

Frontalschnitt durch das Vordorhirn eines Teleostiers, Corvina nigra, nach hinten unten schräg ubfallend. Eingezeichnet in die Contour eines Săugergehirnes, um das Verhältniss von Stammganglion und Mantol zu zeigen. lateral zwischen Epistriatum und Riechlappen frei blieb, ein vorn spitzer, hinten breiter werdender Körper ein, der in der caudalen Verlängerung des Riechlappens liegt, diesen hinten weithin überragt und, weil er die Thänia zum Ganglion habenulae sendet, als Nucleus thäniae zu bezeichnen wäre. Diese 4 Ganglien setzen also den Vorderlappen zusammen. Die Beziehungen der zum Riechapparate gehörendeı kennen Sie nun schou. Was uns hier wesentlich interessirt, ist das Striatum. Siehe Fig. 9S.

Meine Untersuchungen an Reptilien und diejenigen ron Ge huch ten an Knochenfischen ergaben, dass in den grossen multipolaren Zellen, welche gerade im Centrum des Striatums liegen, mächtige Faserbündel entspringen, und dass auch Fasern, die von hinten herkommen. im Striatum aufgesplittert enden.

Die ganze Faserung habe ich frïher als basales Vorderhirnbündel bezeichnet. Da alle ihre Züge in den Ganglien des Thalamus und des Metathalamus enden, so ist der Name Tractus Strio-thalamici der zweckmässigere. Wir sind diesen Tractus schon bei der Beschreibung des Zwischenhirnes begegnet, und ich bitte Sie, jetzt noch eimmal die Figuren 72 und so zu studiren, wo sie gut erkennbar sind. Durch die Tractus strio-thalamici wird das stammganglion des Vorderhirnes auf das imnigste mit den Ganglien des Zwischenhirnes rerknüpft. Sie sind ungemein constant, und wenn sie auch bei den Knochenfischen wegen Fehlens einer anderen Faserung aus dem Vorderhirne besonders leicht erkemnbar sind, so ist es doch gelungen, sie bei den Amphibien, Fig. 75 u. so, bei den Reptilien, Fig. 72, \$1, \$2, den Tägeln, Fig. \$3, St. und den Säugern nachzuweisen. Natiurlich treten sie gerade bei den letzteren, wo die Faserung aus der Rinde 
in das Zwischenhirn und in candaler gelegene Hirntheile besonders stark ausgebildet ist, zurïck. Es war erst möglich auf entwicklungsgeschichtlichem Wege und dann auch durch Studium ron Degenerationen sie da aufzufinden. Nimmt man einem Hunde das ganze Nantelgebiet weg Monakow ist es an Neugeborenen, Goltz an erwachsenen Thieren gelungen, derartig Verstümmelte lange am Leben zu erhalten - so degeneriren alle aus diesem stammenden Züge, und es bleibt nur die Striatumfaserung erhalten, die damn bei Färbung der Schnitte sofort klar in die Augen springt. In Figur 102 habe ich versucht, weil Ihnen ja die Terhältnisse am Menscheu wohl bekannter sind, einen Schnitt durch das Stammganglion eines Kinochenfisches in die mehr schematisch gehaltenen Contouren eines menschlichen Gehirnes einzuzeichnen. Sie sehen sofort, dass dann die Striatumfaserung in das Gebiet fällt, welches bei Säıgern als vorderer Schenkel der Capsula interna bezeichnet wird. Bei dem Knochenfische verschwindet das dünne Mantelgebiet gegenüber dem Striatum fast ganz, bei dem säuger ist das Verhältniss fast umgekehrt, bei den Tögeln aber, wo gerade das Stammganglion besondere Grösse erreicht, macht dieses trotz Torhandensein eines nerrösen Mantels doch die Hauptmasse des ganzen Torderhirnes aus.

Bei den Amphibien, den Schlangen, den Eidechsen und dem Alligator ragen die beiden Theile des Stammlappens von der Hirnbasis aus frei in den Ventrikel hinein, die Rinde ist nur lateroventral anf eine kurze Strecke ihnen fest verbunden; ein breiter Spalt, ein laterales Horn des Seitenventrikels liegt auf dem grössten Theile der Aussenwand zwischen Stammlappen und Mantel. Erst un-

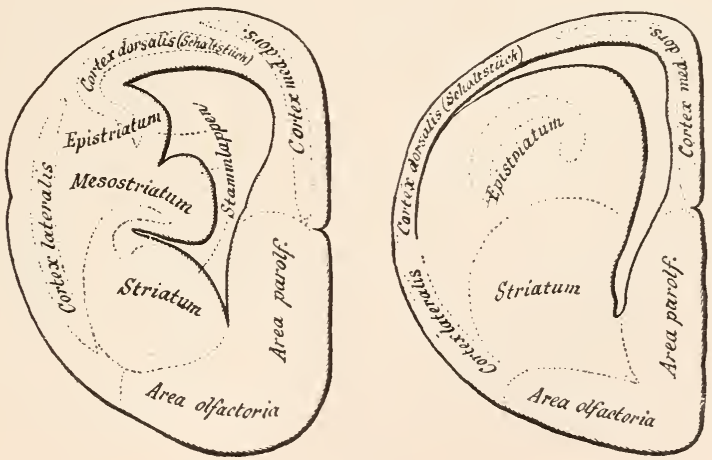

Fig. 103.

Typus eines Frontalabschnittes durch das Gehirn. $a$. einer Chelono, $b$. einer Eidechse.

weit der Hirnbasis verschmelzen beide zu einer Masse. Hier grenzen dann Mantel und Area olfactoria dicht aneinander. Die Rinde, welche an dieser Stelle in nicht ganz regelmässiger Lage über den Stammtheil des Gehirnes aussen hinwegzieht, ist bei den Vögeln und den Säugern längst als ein Besonderes aufgefallen und als Streif enh ïgehrinde etc. beschrieben. 
Anders aber verhält sich das Gehirn der grossen Sehildkröten. Das Epistriatum ist hier nämlich enorm entwickelt und der Stammlappen auf die allergrösste Ausdehuung mit der lateralen Mantelwand verbunden. Es existirt kaum ein laterales Ventrikelhorn. Bei den Schildkröten sind auch Striatum und Epistriatum durch eine tiefe Furche geschieden. Das Epistriatum ist hier so enorm entwickelt, dass es auf eine lange Strecke hin, in den Ventrikel sich umbeugend, iberhängt. Auch das Striatum ist sehr gross. In ihm vermag man bei Emys und Chelone wieder 2 Abtheilungen, eine dorsale und eine ventrale, zu unterscheiden. Die erstere, welche ebenfalls durch eine Längsfurche von der ventralen geschieden ist, mag vorläufig als Mesostriatum bezeichnet werden. Dieser wenig präjudicirende Name ist absichtlich gewählt. Aber ich habe gegrïndete Vermuthung, dass hier jene Theilung des Linsenkernes in Einzelglieder, sich bemerkbar maclit, welche bei den Säugern zur Trenuung in Putamen und Globus pallidus geführt hat. Dem Putamen und dem Kopfe des Caudatus entspricht, wie die durch die Thierreilie hindurch fortgesetzte Vergleichung und die Beziehungen der abgehenden Faserung zeigt, das Striatum allein.

Die enorme Entwicklung des Stammganglionapparates bei den Schildkröten, namentlich die Ausbildung eines Mesostriatums und des grossen Epistriatums, das Verschwinden des seitlichen Ventrikelhornes und das so völlig von den der anderen Reptilien verschiedene Hirnquerschnittbild erinnern sehr an das Vogelgehirn. In der That findet man dort ganz ähnliche, nur noch weiter entwickelte Anordnungen. Das Verhältniss von Hirnrinde zu Stammlappen bei den Eidechsen nimmt schon bei den Schildkröten sehr ab zu Ungunsten der Rinde. Das Schildkrötengehirnmit seinemenormenstamme und der geringen Entwicklung des Mantels ist dem Vogelgehirne ähnlicher als irgend ein anderes Reptiliengelirn. Seine Hauptmasse besteht, ganz wie die des Vogelgehimes, aus dem enormen Stammlappen, über den sich ein nur kleines Mantelstiick legt.

Das Stammganglion der Tögel und der säuger ist bisher nur in seinen hauptsächlichsten Anordnungen klar, viel fehlt noch. das wir es, namentlich auch seinen Unterabtheilungen nach. völlig übersehen. Nur eines ergiebt sich jetzt schon aus meinen Degenerationsversuchen: Weder bei Reptilien, noch bei Tögeln, noch bei säugern kann man durch Entfernung des Stammganglions Theile zur Degeneration bringen, welche weiter caudal als das Mittelhirn liegen. Es spricht Alles dafür, dass der mächtige und constante Hirutheil des striatums seine Faserung im Wesentlichen im Thalamus und im Hypothalamus erschöpft. Die einzelnen Bündel der Tractus strio-thalamici sind natürlich rerschieden stark ausgebildet je nach der Grösse der Thalamusganglien, zu denen sie gehen. Beispielsweise ist bei den Knochenfischen der Zug zu dem mächtigen Hypothalamus dieser Thiere ganz enorm, Tr. strio-hypothalamicus, während er bei den übrigen 'Thieren oft nur schwer' aufzufinden ist.

Die höheren Tertebraten. die Tögel und die säuger. lassen im Aufbane des stammganglions noch eine besondere Gliederung erkennen. Bei den säugern zerfällt es nämlich durch die Fasern aus der Rinde. welche es durchschneiden, in einen lateralen und in einen medialen Abschnitt. Der erstere wird als Putamen, der letztere als Nucleus caudatus bezeichnet. Dem Putamen liegen aber medialwärts noch einige Ganglien an, die, in ihrem Tresen noch unverstanden, sich so dicht an jenes gliedern, 
dass man sie - Globus pallidus - ihm zurechnet und den ganzen Complex als Nucleus lentiformis bezeichnet. Davon wird in einer späteren Vorlesung ausführlicher die Rede sein. Heute will ich nur erwähnen, das bei den Tögeln das Putamen und die beiden Glieder des Globus pallidus sich nachweisen lassen, dass aber die Tremnung dieses ganzen Apparates von dem medialer liegenden Nucleus caudatus dort nicht so scharf ist, wie bei den Säugern, weil eben die Strahlung aus der Rinde, welche bei den Säugern als Capsula interna beide trennt, bei den Tögeln nur gering entwickelt ist. Immerhin kann man mit Sicherheit bei den Vögeln erkennen, dass aus dem ganz lateral liegenden Putamen ein dicker Zug sich einwärts begiebt, wo er auf die Fasern trifft, welche aus dem übrigen Theile des Striatums stammen. Die beiden Bündel zusammen begeben sich dann in die Thalamuskerne. Fig. $\ .3$, \$4 und 104. Die Tractus strio-thalamici setzen sich also auch bei den Vögeln, ganz wie bei den Säugern zusammen aus einem medialen Bündel und einem solchen, das von aussen her jenem sich zugesellt.

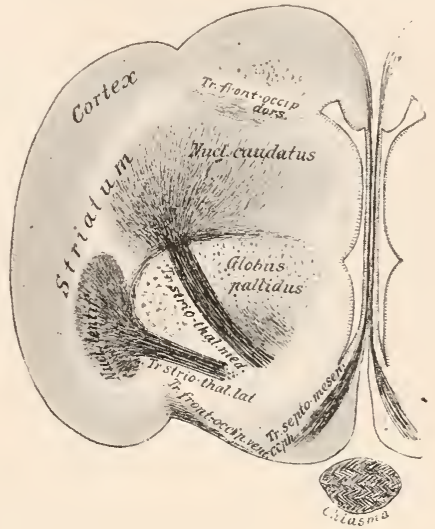

Fig. 104.

Frontalschnitt durch das Gohirn eines Papagei, Psittacusart. Mehrere Schnittebenen in einer Zeichnung vereint. Etwas schematisirt.

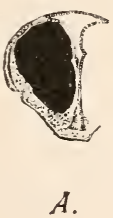

A.

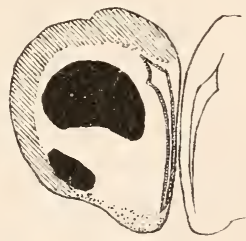

$B$.

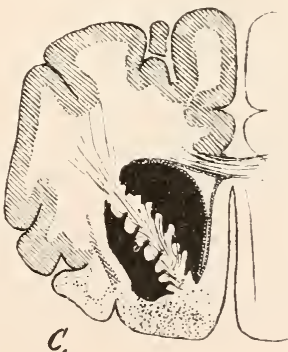

C.

Fig. 105.

Schematische Frontalschnitte durch das Vorderhirn, um dio Stollung des Striatum und seiner Faserung im Gesammtplan zu demonstriren. A. Von einem Knochenfische. B. Von einem Vogel. C. Von einem Säuger.

Das laterale Bündel umgreift bei den Säugern an der Hirnbasis den grössten Theil der Faserung, welche aus der Rinde herabströmt. Es wird dort Linsenkernschlinge genaunt. Das mediale entspricht bei Vögeln und Säugern nach seiner Lage ganz demjenigen, welches ich Fig. 102 von 
einem Kinochenfische abgebildet habe. Es befindet sich also unter den Fasermassen, welche man als Capsula interna bezeichnet.

Ueber die physiologische Bedeutung des Stammganglions wissen wir noch gar nichts. Alle Tersuche, welche bisher an den Gehirnen der Fische angestellt sind, haben nur Riechstörungen ergeben wemn die Torderlappen abgetrennt wurden. Es sind bis heute noch nie Thiere längere Zeit beobachtet. denen man striata isolirt abgetragen hatte. Das ist allerdings bislang nur bei den Ḱnochenfischen möglich, wo eben kein nerröser Mantel die Operation erschwert.

Auch für den Riechapparat stehen noch so ziemlich alle aufklärenden Tersuche aus. Es ist ja erst durch die Tntersuchungen der letzten Jahre möglich geworden, ihn in der anatomischen Dignität nach rerschiedene Gebiete zu tremnen. Wahrscheinlich wird die vergleichende Beobachtung ron Thieren ohne und ron solchen mit corticalem Riechapparate die erwünschten Aufschlüsse bringen. Die Fragestellung ist: Riechen die Fische anders als die höheren Vertebraten, verwerthen sie ihre Geruchseindrücke anders, vermögen sie dieselben ebenso wie höhere Tertebraten im Gedächtnisse zurückzubehalten?

\section{Zwölfte Vorlesung}

\section{Das Vorderhirn.}

\section{Der Hirnmantel.}

Mit Riechapparat und Stammganglion haben wir das geschildert, was den Vorderhirnen aller Vertebraten gemeinsam ist. Wir können uns nun zur Behandlung des rariablen Theiles des Torderhirnes, des I a n tels. wenden.

Als Pallium haben wir alle die Wandtheile der Vorderhirnblase bezeichnet, welche nicht dem Riechapparate und dem Stammganglion angehören, also den dorsalen und seitlichen Abschluss des Vorderhirnes. Dabei wurde anch schon erwähnt, dass bei einigen niederen Vertebraten sein grösster Theil ron einer einfachen Epithellage gebildet wird. Für den epithelialen Mantel der Knochenfische geben Fig. 56 und 107 ein ausreichendes Bild. Bei den Cyklostomen ragen beiderseits rom Stammganglion noch Wandstücke dorsalwärts, die erst etwas weiter dorsal ihren Abschluss durch eine gefältelte Epithelmembran finden. Studniczka hat diese Theile neuerdings als seitliches Palliumgebiet in Ansuruch genommen. Ihr feinerer Bau aber ist noch zu ungenügend bekannt. Möglicher Weise handelt es sich doch nur um dorsal gerichtete Ausläufer des Stammganglions. Bei den Rochen und den Haien hat sich aber das Mantelgebiet wohl ausgebildet, ja es ist gerade die frontalste Partie so enorm verdickt, und es ragen auch die seitentheile so weit einwärts. dass es im grösseren Theile des Vorderhirnes der Selachier zu einer förmlichen Ver- 
ödung des Tentrikels kommt, und dieser, bei den Rochen z. B., nur im allercaudalsten Gebiete noch nachweisbar ist. Bei den meisten Haien ist er vorhanden, und auch seine Ausläufer in die Lobi olfactori sind da zu erkemnen. Da aber auch hier die Vorderwand des Gehirnes ganz unförmlich dick augeschwollen ist, ragt sie meist weithin über die Ursprungsgegend der Riechlappen hinaus, so dass diese nicht wie bei den übrigen Tertebraten vorn. sondern seitlich und entfernt vom Stirnpole entspringen. Dadurch gewinnt das Selachiergehirn etwas rom Gehirne anderer Thiere
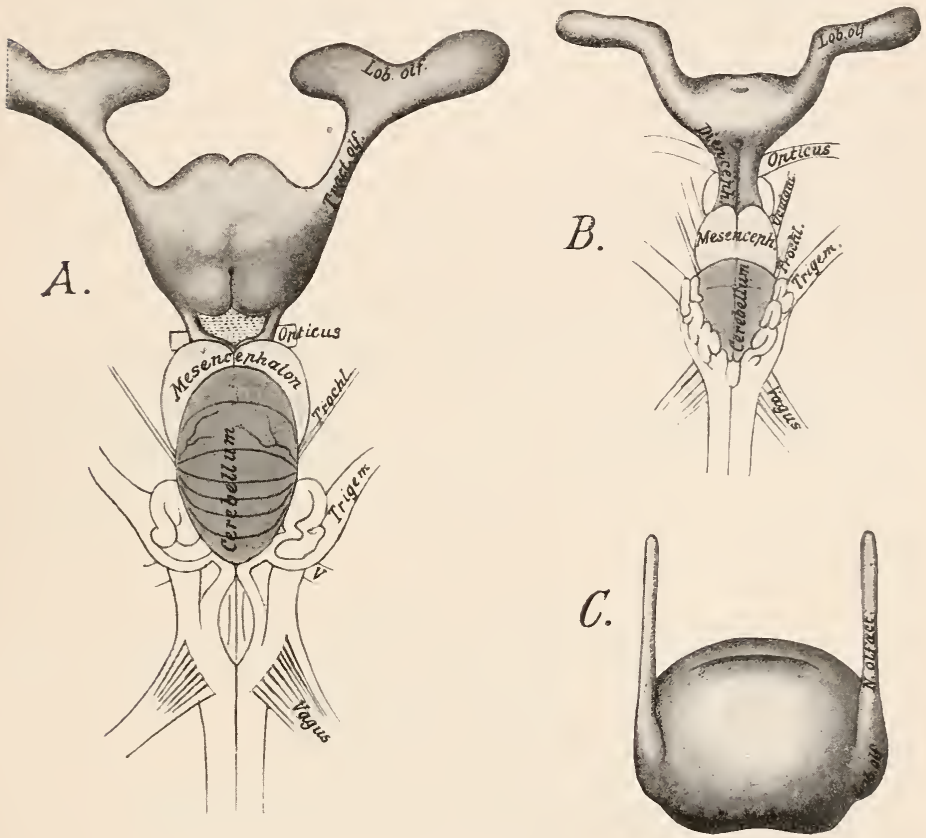

Fig. 106.

Einige Selachiergehirne, von oben gesehen zur Demonstration der verschiedenen Entwicklung, die bei verschiedenen Arten der Hirnmantel erfahrt. $A$ von Galeus canis, $B$ von Raja miraletus, $C$ von Carcharias (nur Vorderhirn), alle in natïrlicher Grösse (nach Rohon), An $A$ hinter dem verdickten Vorderhirn die dünne Platte der Tela Chorioïdea entfernt, so dass man in die Tiefe der (schraffirten) Zwischenhöhle hineinblickt.

sehr Abweichendes. Fig. 106. Dazu kommt, dass bei der Terdicknng der Wände die Theilung in 2 Hälften, welche bei den höheren Tertebraten vorhanden ist, so weit unsichtbar wird, dass sie nur auf mikroskopischen Präparaten erkemnbar ist, vornehmlich noch dadurch, dass ein feiner Faserzug und ein ganz dünner gefässerfüllter spalt zwischen der rechten und der linken Seite verlaufen. 
Am Pallium aller anderen Vertebraten trennt ein tiefer Einschnitt die rechte von der linken Hemisphäre. Er reicht rückwärts bis an die Lamina terminalis, neben der die Torderhirnblasen sich ja ausgestiilpt haben.

In der Schlussplatte verlaufen alle Commissuren, welche die Hemisphären und den Hirnstamm unter einander verkniipfen, siehe Fig. 101; erst bei den Säugern treten dann noch dorsal und frontal von der Lamina terminalis spät in der Entwicklungszeit neue Querfasern auf, die bestimmt sind, echte Mantelgebiete unter einander zu verknüpfen, die Balkenfasern.

Das Pallium der höheren Tertebraten unterscheidet sich von dem der Knochenfische und Ganoide durch etwas sehr Wesentliches. Es ist nicht mehr rein epithelial, besteht vielmehr aus zahlreichen Zellen. die Nervenfasern aufnehmen und aussenden, es ist also der Träger eines nervösen Apparates. Dieser Apparat, der bei den Amphibien noch nicht sehr scharf ausgejrägt ist, tritt bei den Reptilien zuerst als völlig deutliche Hirnrinde, abgeschieden von anderen Mantelschichten hervor. Ich wüsste keinen anderen Theil des Gehirnes Ihnen zu nemmen, der, wenn man die Thierreihe aufsteigend durchmustert. annähernd so grosse Teränderungen, Fortbildungen, Rückbildungen u. s. w. aufweist, wie die Rinde, und da an diese, wie sie wissen, die Existenz gewisser höherer seelischer Thätigkeiten geknüpft ist, so wollen Sie nun gemeinsam mit mir dieses vielleicht interessanteste Gebiet der Himanatomie durchgehen.

Zunächst noch Einiges zur äusseren Form. Schon das, was ich Ihnen vorhin ïber den Selachiermantel mitgetheilt habe, hat gezeigt, dass bei jenen niederen Tertebraten nur das frontale Nantelgebiet nervöser Natur ist, dass aber in nach Arten wechselnder Weise grössere oder kleinere Stïcke auch des caudalen Nantelabschnittes die einfach epitheliale Be-

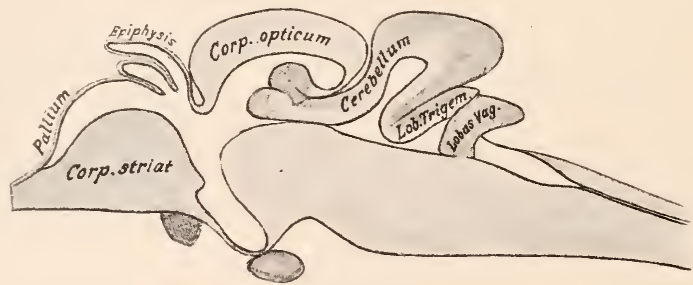

Fig. 107 .

Schemat. Sagittalschnitt durch cin embryonales Forellengehirn.

schaffenheit aufgegeben haben. Burkhardt hat gezeigt. dass es zweckmässig ist, von den Notidanusarten auszugehen, dass man von ihnen zu relativ hoch entwickelten Gehirnen ohne Zwang kommen kamn. Jedenfalls haben wir von den Amphibien an überall ein Pallium, das, im allergrössten Theile seines Umfanges nervöser Natur, als etwa eiförmige Blase erscheint, die nur an der medialen Seite dicht über der Schlussplatte in eine einfache Epithelplatte ïbergeht.

Wollen sie in Fig. 107. einem Forellengehirne den dünnen Mantel rer- 
gleichen mit der enormen Verdickung, die das frontalste Palliumgebiet bei dem Fig. 105 abgebildeten Rochengehirne erfahren hat, und damn an

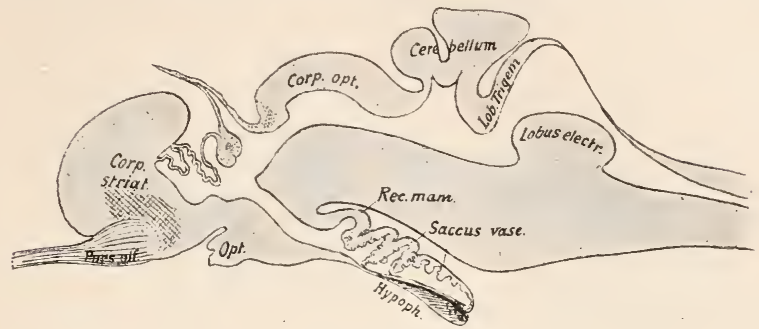

Fig. 108.

Sagittalschnitt durch ein Rochengehirn.

Fig. 109 constatiren, dass bei den Amphibien sich jene Verdickung viel weiter rückwärts erstreckt, bis dam Fig. 110 das Reptiliengehir'n mit seinem

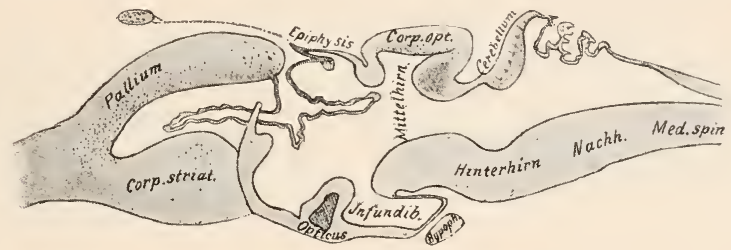

Fig. 109.

Sagittalschnitt durch ein Amphibiengehirn.

schön entwickelten rindendurchzogenen Mantel den Uebergang zu den Gehirnen der Tögel einerseits, der Säuger, Fig. 111, 112 andererseits bildet.

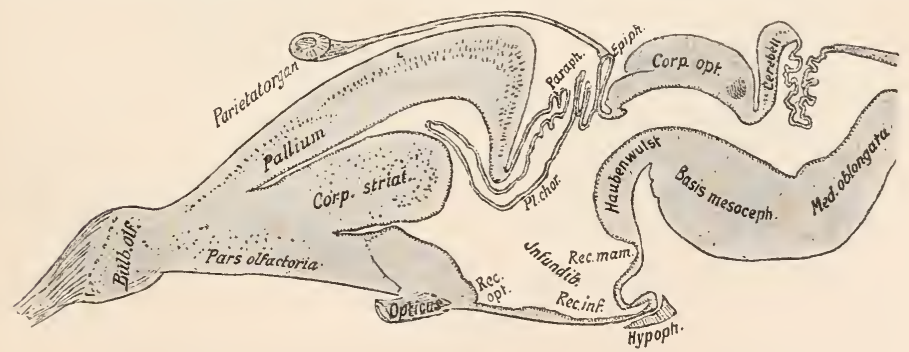

Fig. 110.

Reptiliengehirn. Schema eines Sagittalschnittes.

Wir gehen bei der Beschreibung der Hemisphären, die wir also von den Amphibien an aufwärts immer finden, am besten von der einfachen Form eines Eies aus, indem wir annehmen, dass die Eiform frontal sich 
in die Lobi olfactorii verlängert. während an der medialen Seite, derjenigen, welche der anderen Hemisphäre zugewendet ist, eine so starke Abplattung stattfindet, dass nur ein senkrecht verlaufender Spalt zwischen beiden Hirnhälften bleibt.

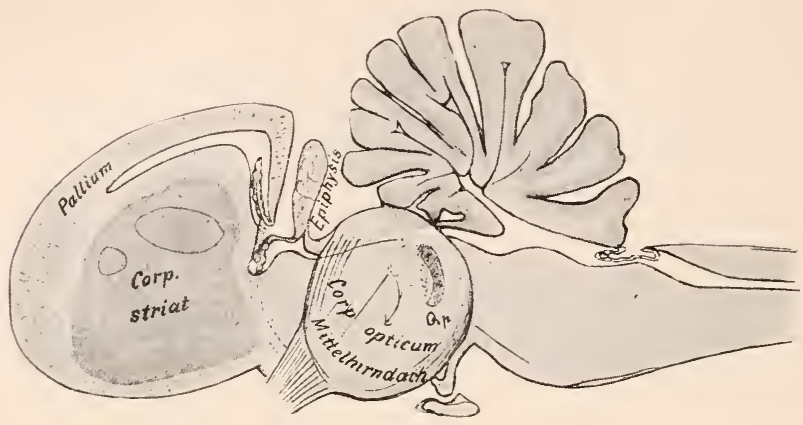

Fig. 111.

Vogelgehirn. Schema eines Sagittalschnittes.

Mitten in diesem Spalte sind die beiden Hirnhälften unter sich durch die unpare Schlussplatte verbunden, welche in nach vorn convexer Linie von oben nach unten verläuft. Aber die Hemisphären haben sich nicht nur nach vorn von der Schlussplatte hin entwickelt, wie das in der ent-

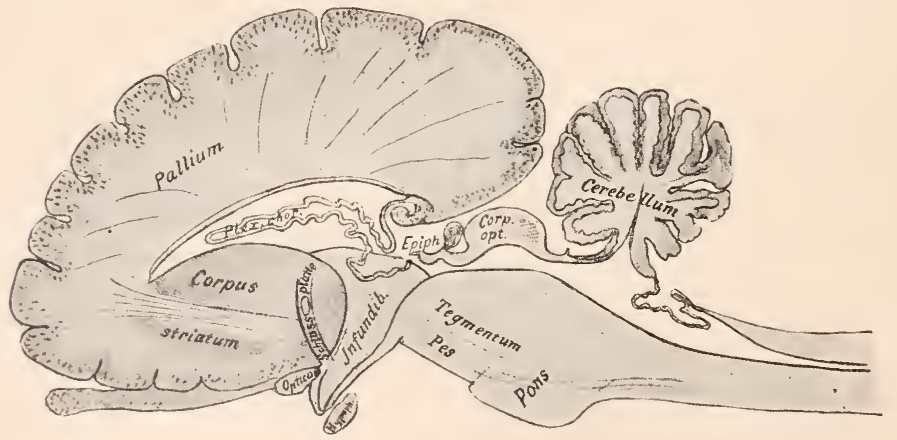

Fig. 112.

Sagittalschnitt durch ein Săugergehirn. Schema.

wicklungsgeschichtlichen Einleitung gesagt worden ist. Sie delmen sich vielmehr sowohl dorsal als rentral von ihr gewöhnlich noch ein Stück aus. Das dorsale stiick ist occipitalwärts gerichtet und mag als Polus occipitalis palli i bezeichnet werden, das ventrale, das bei Amphibien und Reptilien nur in kleiner Andeutung vorhanden ist, siehe Fig. 113, 
soll Polus temporalis heissen. In beide erstreckt sich natïrlich der Hohlraum der Hirnblase hinein, so dass dieser auch ein Hinter horn und ein $\mathrm{T}^{\top} \mathrm{n}$ terhorn erhält.

Die wirklich fast eiförmigen Hemisphären der Amphibien sind diesem schematisch beschriebenen Gehirne am ähnlichsten. Aber schon bei den Reptilien weist die äussere Form, je nach den Familien, recht deutliche Unterschiede in der Entwicklung auf, und wenn man gar zu den Tögeln und Säugern aufsteigt, so begegnet man bald den allermannigfachsten Formen.

Zunächst ist eine bei den Amphibien kaum angedentete Furche zwischen Lobus olfactorius und Pallium zu erkennen, die aussen unten am Palliumrande verlaufend, als Fovea limbica bezeichmet wird. Sie trennt, bei den Säugern am deutlichsten, jedesmal den Riechapparat vom

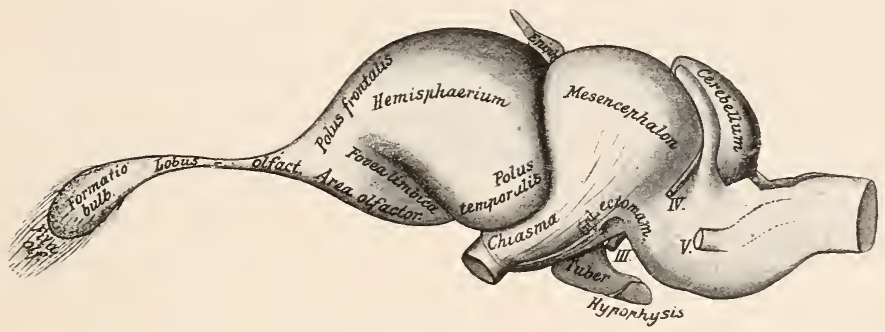

Fig. 113.

Aeussere Form des Eidechsengehirnes. Varanus griseus, ca. $4: 1$.

Mantel. Damn bietet die Entwicklung der einzelnen Pole wesentliche Differenzen. Man hat den Polus frontalis der niederen Vertebraten auch schon als Stirnlappen, den Polus occipitalis als Schläfenlappen u. s. w. bezeichnen wollen. Das ist aber falsch. Denn das. was bei den Säugern diese Namen fülrt. hat sich erst selır spät entwickelt.

Der Lobus occipitalis, der Säuger.z. B., existirt bei den Reptilien noch gar nicht, er tritt erst bei den Vögeln auf. Was bei den Reptilien occipital liegt, entspricht, wie unten gezeigt werden soll, ganz anderen Hirnpartien. So entständen, wollte man etwa den schon bei den Reptilien Occipitallappen genannten Hirntheil weiter aufwärts in die Thierreihe verfolgen, die allergrössten Schwierigkeiten. Lobus occipitalis, um bei dem einmal gewählten Beispiele zu bleiben, ist nicht allein eine Hervorragung am Occipitalpole, sondern eine ganz bestimmte Hirnpartie mit specieller Rindenbeschaffenheit und festen Beziehungen zum Sehnervenursprunge. Ein Lobus frontalis tritt iberhaupt erst bei den Säugern auf, ja bei den niedersten derselben fehlt er wohl noch ganz, um sich bei den Primaten, ja erst beim Menschen zu seiner vollen Höhe zu entwickeln. Der Mantel am Stirnpole der Reptilien hat rein gar nichts mit dem nun einmal Lobus frontalis genamnten Hirmabschnitte gemeinsam.

So kommt es, dass schon bei niederen Tertebraten die einzelnen Familien verschiedene Hirnform erkennen lassen. Tenn Sie z. B. das 
oben abgebildete Eidechsengehirn mit demjenigen einer Schildkröte vergleichen, so wird Ilmen die gedrungene Form bei der letzteren sicher sofort auffallen. Sie ist einerseits durch die Einwicklung des Striatums bedingt, welche. wie ich in der letzten Vorlesung Ihnen mitgetheilt habe, das Schildkrötengehirn dem Vogelgehirne sehr nähert, andererseits aber ist sicher auch die Ausbildung des Schädels nie ohne Einfluss.

Bei den höheren Tertebraten kommt es zu einer grösseren Ausbildung des Palliums. und damit treten dann einzelne Furchen auf. Da sie wesentlich am Säugergehirne entwickelt sind, werden sie erst in einer späteren Vorlesung näher zu schildern sein. Das Gehirn der meisten Reptilien besitzt nur die limbische Grube als Grenze zwischen zwei verschiedenen Mantelgebieten. Doch erkennt man bei den grossen schlangen und noch besser bei den Schildkröten noch eine weitere flache Grube. welche den oberen Mantelrand auf grössere oder kleinere Länge etwas lateral begleitet. Bei den Vögeln ist dann diese Fovea collateralis deutlicher ausgebildet. Eine eigentliche Furche, wie diejenigen, welche das Sängergehirn durchqueren, ist sie nicht, es handelt sich vielmehr um eine ventrale und dorsale Vorwulstung des Palliums, welche durch die Entwicklung des Striatums bedingt wird. Zwischen beiden IVülsten bleibt die Vertiefung des Fovea collateralis.

Etwas complicirter, als die Aussenseite der Hemisphären ist die Anordnung der medialen Wand. Auch sie hat bei den Amphibien so wenig Differenzirung noch erfahren, dass sie bei einzelnen Arten, ja bei Exemplaren der gleichen Art auf verschieden lange Strecken mit der ihr anliegenden anderseitigen Scheidewand, beim Frosch z. B., verkleben kann.

Aber bei den Reptilien ist das anders. Finden sich auch alle nun für diese zu schildernden Verhältnisse schon bei den Amphibien angedeutet, so treten sie doch erst bei den hochorganisirten Gehirnen dieser Thiere deutlich in Erscheinung. Hier kann man nämlich sehr gut einige Unterabtheilungen machen, Unterabtheilungen, welche, wie später die Beschreibung des Säugergehirnes ergeben wird, der Ausgangspunkt für wichtige Weiterentwicklungen sein werden.

Man kann abtheilen: 1. Die mediale Fläche des Riechapparates nahe der Basis, Area parolfactoria. In sie erstrecken sich bei den Reptilien immer deutliche Ganglienansammlungen (Meyer), hinein, die Faserbündeln Ursprung geben. 2. Caudal und etwas weiter dorsal liegt der als septum bezeichnete Wandabschnitt, welcher bei den Reptilien auch ein Ganglion enthält, bei den Vögeln aber stark atrophirt, während er bei den Säugern - Septum pellucidum - wieder ein — im Vergleiche zum Gesammtmantel allerdings minimales - Ganglion enthält. 3. Dorsal ron den beiden genannten Abschnitten der Rindentheil der Innenwand.

Im dorsalen Abschnitte der Area parolfactoria beginnt regelmässig eine tiefe Furche, welche bis zur Lamina terminalis am oberen Rande des Septums dahinlaufend, die ganze Innenseite in einen dorsalen und einen ventralen Abschnitt gliedert. Nur der dorsale ist von Rinde überzogen. Diese Furche, 
welche also die Hirnrinde ventral abgrenzt, bleibt durch die ganze Theilreihe bestehen. Sie heisst auf unserer Abbildung $114 \mathrm{Fiss}$. arcuata septi, bei den Säugern aber wird sie als innere Randfurehe bezeichnet. Sie liegt hier zwischen Ammonsrinde und Fornix. Da sich in der caudalen Verlängerung der gleichen Furche die Himblase zum Plexus choroides verdiunnt, so bezeichnet die Entwicklungsgeschichte sie als Fis s u r a c lı o r io idea. Die Fissura arcuata septi ist bei den Vögeln ausserordentlich kurz und nul dicht vor Beginn des Plexus chorioides nahe der Schlussplatte aufzufinden. Bei den Säugern ist sie in ihrem rorderen Abschnitte durch die Balkenentwicklung zu gutem Theile verwischt.

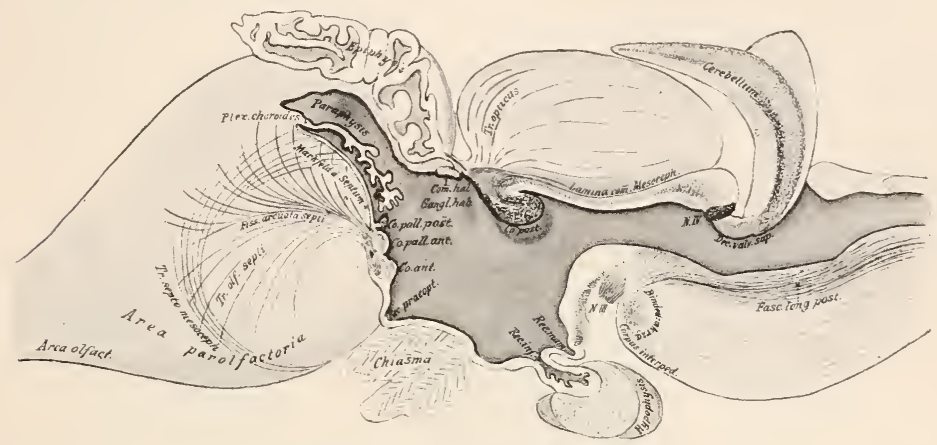

Fig. 114,

Die Innenwand eines Reptiliengehirnes, Varanus griseus.

In die Rinde, welche den dorsalen Abschnitt der Scheidewand überzieht, mïndet regehmässig ein wichtiger Faserzug, der Tractus olfactorius septi. Er stammt aus dem Riechapparate an der Hirnbasis, tritt in dessen Bereiche breit fächerförmig an die mediale Hirnoberfläche und zieht damn hinauf und rückwärts in die Hirnrinde. Das Gebiet, in welchem er endet, muss, eben dieses Zusammenhanges wegen, als „Riechrinde“ bezeichnet werden. Bei Amphibien nur unsicher nachweisbar, ist der Faserzug bei den Reptilien und Säugern immer mächtig. Vergl. Fig: 114 Bei den Vögehn aber wird er verschleiert durch einen anderen gerade bei diesen Thieren ungewöhnlich stark entwickelten Faserzug, den Tractus septo-mesencephalicus, welcher aus dem dorsalsten $\mathrm{Ab}$ schnitte der Rinde, nahe deren Umschlagkante zur Aussenseite, breit entspringend die Innenseite des Vogelhirnes wie ein breiter weisser Fächer - Markbündel der Scheidewand - überzieht. An der Hirnbasis angekommen, umgreift er diese in nach aussen gerichtetem Faserzuge und zieht dann dicht vor dem Opticus, den er an der lateralen Seite des Gehirnes erreicht, wieder aufwärts und rückwärts, um schliesslich im frontalsten Abschnitte des Mittelhirndaches zu verschwinden. Di es er F a s e rzug verbindet also das Mittelhirn mit einem bestimmten Rindenbezirke. Er ist bei den Reptilien angedeutet, bei den Säugern aber noch nicht aufgefunden. Fig. 115.

Edinger, Nervöse Centralorgane. 5. Auflage. 
Nacht man Frontalschnitte durch das Torderhirn irgend eines höheren Wirbelthieres, so geben die frontaleren immer die annähernd eiförmige Form eines geschlossenen Ringes, an dessen Basis die Terdickung des Hirnstammes liegt, siehe Fig. 103, weiter hinten Fig. 101 trifft man auf das Septum an der Innenwand, die hier ihr bisher einfaches Querschnittsbild rerliert, und schliesslich kommt man, Fig. 99, an die Stelle. wo das Pallium medial in den Plexus chorioides übergeht und rein häutig wird, Fig. 120. In dieser Schnitthöhe ist gewöhnlich an der Hirnbasis die Grenze ron Torder- und Zwischenhirn erreicht, und erblickt man auf dem Schnitte die Bahnen. welche beide Hirnabschnitte rerbinden.

Ich nehme an, dass diese kurze Darstellung mit ihren Abbildungen Sie nun im Wesentlichen über die äussere Form des Endhirnes orientirt hat. und will jetzt von einigen Theilen, rom Pallium wenigstens, schildern, wie sie aufgebant sind.

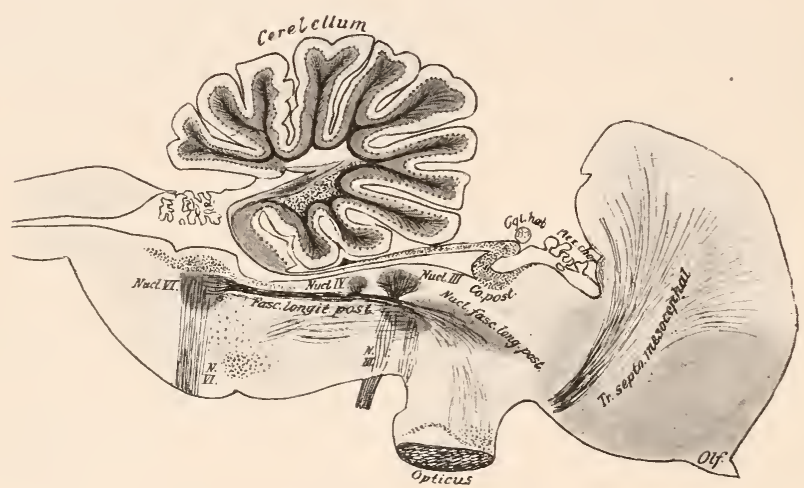

Fig. 115.

Sagittalschnitt durch das Gehim eines Huhnes.

Wie das ganze Amphibiengehirn auf Querschnitten dem embryonalen Hirne der übrigen Tertebraten ausserordentlich ähnlich ist, so wird auch am Torderhirne ein Auf bau gefunden, welcher bis hinauf zu den Säugern in der Entwicklungszeit immer wiederkehrt. Man kann nämlich auf einem Schnitte durch die Hirnwand zunächst gewöhnlich mur 2 Schichten unterscheiden, eine imnere an Zellen sehr reiche und eine äussere zellarme Schicht. An einigen Stellen des IIantels, so nahe am Riechapparate, in der Regio parolfactoria vorn und damn im caudal- medialen Mantelgebiete zeigt die innere Schicht besondere Tortreibungen, offenbar grössere Entwicklung der Zellen, welche sie zusammensetzen. Gute Schnitte, zweckmässige Färbungen lassen erkemnen, dass die Innenschicht zunächst dem Tentrikel ron Epithelzellen gebildet wird, die ihre langen Schwänze durch die ganze Nanteldicke unter Terzweigungen bis an die äussere 
Oberfläche senden und so ein Gerüstwerk für den Hirnmantel darstellen. Siehe Fig. 116 links am Rande. Dieses Gerüstwerk aus Epithelendfäden ist übrigens in allen Hirntheilen weiter caudal auch vorhanden und wird auch bei den Reptilien noch dauernd gefunden. Bei den Vögeln und Säugern verschwindet ein guter Theil der Endfäden im nachembryonalen Leben. Dann folgen nach aussen zahlreiche Zellen, die zu gutem Theile noch nicht als Ganglienzellen diagnosticirbar sind, vielmehr den Charakter von Neuroblasten zeitlebens behalten. Zwischen ihnen aber liegen echte Ganglienzellen mit reich verzweigten Dendriten und dünnen Axencylindern. Die Mehrzahl der letzteren ist nach der Hirnoberfläche hin gerichtet, eine geringe Minderzahl aber legt sich - das ist der erste Anfang eines sub cortica le n II arklagers - zwischen die Zellen und die Epithelien. Wohin sie bei den Amphibien gerathen, wissen wir noch nicht. Wahrscheinlich zum grösstem Theile in die Commissuren des Mantels. Aus einzelnen Fasern, die aus diesem kleinen Marklager nach aussen treten, und aus denjenigen, welche die Zellen selbst nach der Hirnoberfläche zu senden, bildet sich. ganz aussen nahe dieser Oberfläche ein feines Flechtwerk, das tangentiale Netz. An dem Zustandekommen dieses Faserwerkes betheiligen sich übrigens zu nicht geringem Theile Axencylinder aus Zellen, die, zumeist quergestellt, in der Tangentialschicht selber liegen.

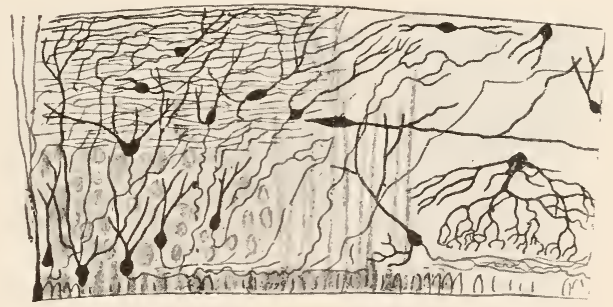

Fig. 116.

Schnitt durch das Pallium eines Frosches, wesentlich nach Pedro Ramon y Cajal. Nur ein Theil der Zellen sichtbar.

Ian muss wohl diesen ganzen unregelmässig disponirten Apparat als den Ausgangspunkt einer Hirnrinde ansehen. Denn bei den Reptilien findet man ganz die gleichen Elemente, aber in selır viel grösserer Zahl und Dichtigkeit, auch regelmässiger zu förmlichen Platten geordnet, und bei diesen Thieren kann gar kein Zweifel mehr bestehen, dass man es mit einer echten Rinde zu thun hat, einer Rinde, von der, wie wir später selien werden, sich ein ganz bestimmtes, bei den höheren Vertebraten längst bekanntes Rindengebiet ableiten lässt.

Es ist wohl eines der grössten Verdienste von denen, welche sich s. Ramon y Cajal um die Hirnanatomie erworben hat, dass er den Typus nachwies, welcher im Aufbaue der Hirnrinde bei allen Thierklassen 
wiederkehrt, dass er also das feststellte, was eine Hirnrinde charakterisirt. Meine eigenen Untersuchungen an Amphibien und Reptilien bestätigen durchaus die wichtige Entdeckung des spanischen Gelehrten. Man kann, das ist das Tesentlichste, immer erkennen, dass in der Hirnrinde Fasern entspringen. dass ebensolche da enden, und dass ausserordentlich viele Associationsmöglichkeiten zwischen beiden Faserarten gegeben sind.

Die corticalen Fasern stammen zunächst aus den sog. Rin den pyramiden, die z. B. bei den Reptilien in mehrfacher Schicht im Mantel gelagert ihre Axencylinder zum grösseren Theile medialwärts entsenden, wo sie unter dem Ventrikelepithel eine dïmne, nach der Art übrigens wechselnd dicke Schicht, das Marklager, bilden. Eine kleinere Anzahl der Pyramiden sendet ihre Neuriten peripherwärts in die Gegend dicht unter der Oberfläche, wo sie mehrmals aufzweigen, ehe sie frei enden. Die Rindenpyramiden haben aber auch mächtige, reich verzweigte Dendriten. Und diese lösen sich zu kleinerem Theile nahe ihrem Ursprunge, zu viel grösserem als reiches Geäst in dem über der Zellschicht

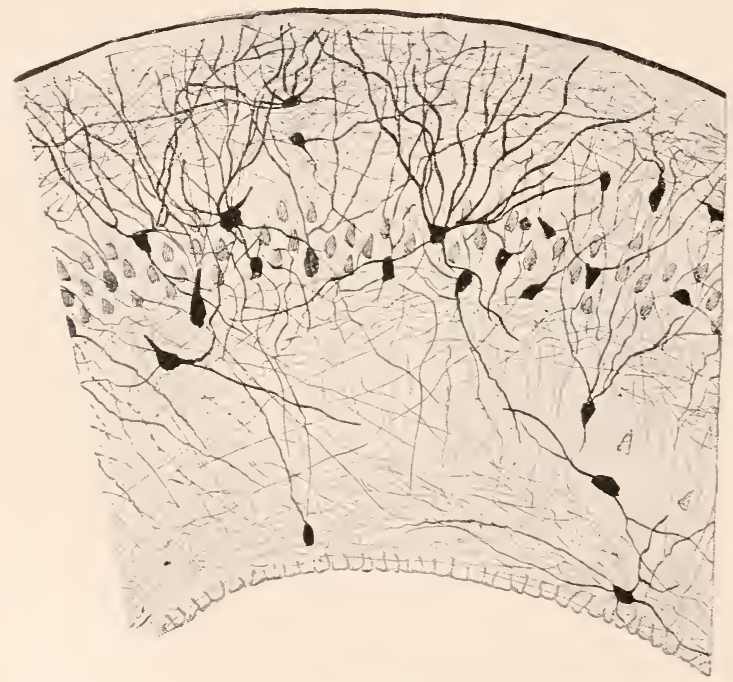

Fig. 117.

Schnitt durch ein Stückchen der Rinde nahe der Mantelkante von Lacerta agilis. Golgipräparat.

liegenden Stratum moleculare auf. In diese Schicht aber tauchen auch die Enden derjenigen Fasern ein, welche von anderen Stellen des Nervensystemes her in die Rinde eintreten. Diese Faserenden bilden mit den aus den Pyramiden aufsteigenden Axencylindern zusammen einen eigenen Plexus, der iiberall von den hier heraus tretenden Dendriten der Pyramiden durchfurcht ist. Man sieht, dass durch diese Anordnung ein reicher Contact unter den bisher erwähnten Rindenelementen schon ermöglicht ist. Dazu kommt nun aber, dass in der allerperiphersten Zone der Molecularschicht sich ein noch viel dichterer Plexus findet, 
der zum Theile gebildet wird von den Elementen, die eben erwähnt worden sind, zum Theile aber auch von solchen, die dort liegenden Zellen - Zellen der T angentialfaserschic ht - entstammen. Dieser Plexus der Tangentialfasern ist geeignet, sehr grosse Gebiete der Hirnoberfläche unter sich und mit entfernteren Rindengebieten zu verknïpfen. Aber es giebt schon von den Reptilien ab aufwärts noch weitere intracortical e Associationsapparate. Zunächst erkenne ich dicht unter der Schicht der Pyramidenzellen noch einen Plexus, der aus Collateralen der Pyramidenaxencylinder und aus Axencylindern von dort liegenden Zellen stammt, den Plexus subcorticalis. Er ist auch bei den Säugern vorhanden und wahrscheinlich auch bei den Vögeln. Von aussen nach innen könnte man desshalb in der Hirnwand der Reptilien unterscheiden: Tangentialschicht, Molecularschicht, Pyramidenzellschicht, Schicht des Plexus subcorticalis, Marklager, Ventrikelepithel.

Dieser, nach der eben etwas cursorisch gegebenen Schilderung relativ einfache Apparat ist, wie ein Blick auf die nun $z u$ demonstrirende $A b$ bildung, Fig. 117, zeigt, doch schon so beschaffen, dass erschon bei so niederen Vertebraten, wie die Reptilien es sind - eine fast unendlich grosse Möglichkeit giebt zur Verbiudung von einzelnen Zellen und Bahmen.

Die Rinde iiberzieht aber nun keineswegs in völlig gleichmässiger Schicht den ganzen Hirnmantel. Man kann schon bei den Reptilien verschiedene ..Rindenplatten" von einander trennen.

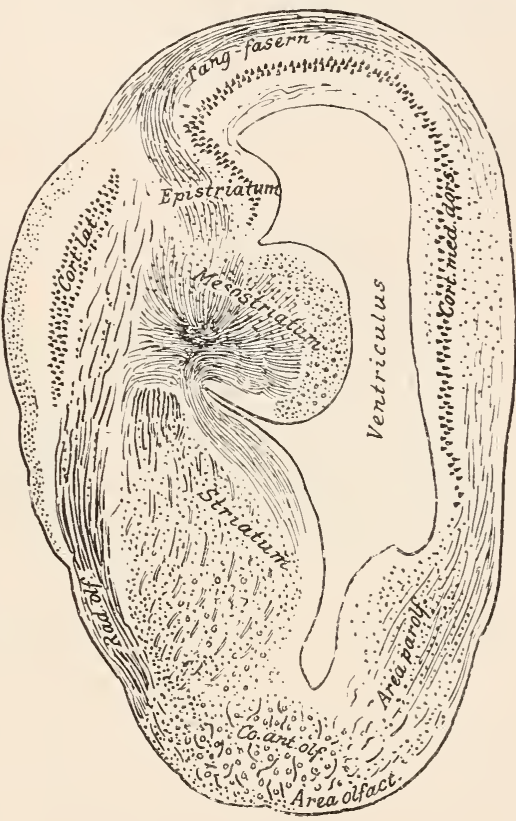

Fir. 118.

Frontalschnitt durch eine Hemisphäre der Riesenschildliröte, Chelone midas.

Ich unterscheide da min-

destens drei einzelne Platten, siehe Fig. 103, zn denen damn noch als vierte die Rinde am Conus frontalis pallii käme, die vielleicht dem Riechapparate zugehört, zum Theile aber desshalb von ihm gesondert wurde, weil sie ein eigenes, wahrscheinlich im Thalamus endendes Bündel entsendet. Ton den Fig. 103 abgebildeten Rindentheilen interessirt besonders der als dorsomediale Platte bezeichnete. Er ïberzieht die ganze mediale Seite des Gehirnes, geht ïber die Hirnkante hinweg anf die äussere Oberfläche ïber lund nimmt jenes Riechbündel auf, ron dem in der letzten Vorlesung die Rede war. Nach anssen von ihm und immer 
durch einen feinen Spalt ron ihm geschieden, liegt wieder ein interessantes Rindenstück. Dieses, die dorsale Platte, überzieht nämlich nicht nur den dorsalen Abschnitt der Aussenwand, sondern wendet sich an seinem ventralen Ende medialwärts, um dem Epistriatum einen Ueberzug zu geben. Der Zusammenhang ist bei den Schildkröten zeitlebens gewahrt. Auf Fig. 115 können Sie das gut sehen. Wollen Sie auf dieser Figur auch beachten, wie die bei so grossen Thieren, wie es die Riesenschildkröten sind, immer markhaltige Tangentialfaserschicht sich mit der Rinde einwärts nach dem Epistriatum zu krümmt. Auch den Tractus bulbo-epistriaticus, der gerade hier gut zu sehen ist, wollen sie beachten. Ventral von der dorsalen Platte liegt die laterale Platte, die dicht am Striatum klebend vielleicht identisch mit dem ist, was man bei Säugern als Claustrum bezeichnet.

$A$

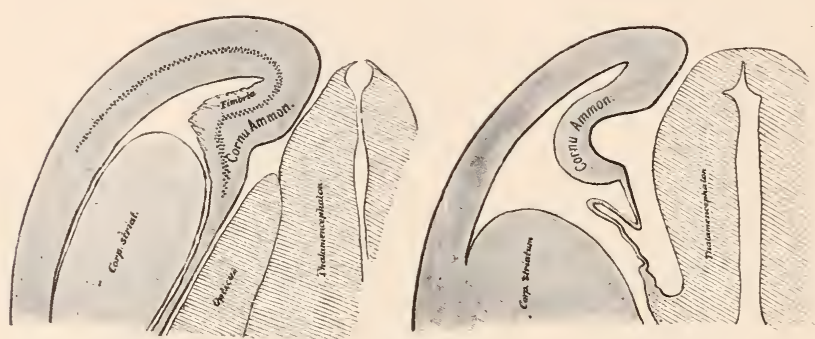

Fig. 119.

Schnitt durch den caudalen Abschnitt der 1. Hemisphäre. A von der Wüsteneidechse, Varanus griseus. $B$ von einem Mausembryo.

Es ist num sehr interessant; dass die Rindenplatte, welche das mehr erwähnte Riechbündel aufnimmt, nicht nur bei den Reptilien, sonderu auch noch bei allen Säugern am Hemisphärenimnenrande liegen bleibt. Sie ist bei den meisten Reptilien glatt gestreckt, bei einigen aber erkennt man, dass sie durch Faltung eine Oberflächenvergrösserung erfährt. Solche Faltumg geht bei den Säugern bis zu förmlicher Einrollung der ganzen Rinde, wenigstens bei den erwachsenen Thieren; bei den embryonalen verhält sich die mediale Rinde wie bei den Reptilien. wo sie zuerst charakteristisch in Erscheinung tritt. Siehe Fig. 119.

Dieses eingerollte Rindenstïck, das immer ein Bündel aus dem Riechapparate aufnimmt, bezeichnet man seit langem als Cornu Ammonis.

Die Untersuchung des Amphibiengehirnes lässt es als sehr wahrscheinlich erscheinen, dass ganz die gleiche Gegend der Mantelwand Riechverbindungen besitzt.

Broca und später Zuckerkandl haben nachgewiesen, dass bei den Säugern. deren sie eine grosse Zahl unter einander vergleichen komnten, die Ausdehnung des Ammonshornes und der ror ihm, unter der Fissura 
limbica liegenden Rinde ganz genau abhängig ist von der Entwicklung des Riechapparates, so abhängig, dass bei den Wassersäugethieren mit verkümmerten Olfactoriis dieses Rindengebiet nur in Spuren noch nachweisbar ist, während es bei den dicht am Boden kriechenden Nagern u. s. w. eine geradezu enorme Ausdelnung erfahren kann.

Durch diese Untersuchungen scheint der Nachweis erbracht, dass die erwähnte Rindenpartie das Rindencentrum für den Geruch, vielleicht auch für die ihm verwandten Gefühle - Geschmack - darstellt. Es ist möglich, dass die Rinde, welche bei den Säugern noch frontal von der Einrollung zum Ammonshorne liegt, auch schon in der Lamina cort. medio-dorsalis der Reptilien vertreten ist.

Schon die Ammonsrinde der Reptilien ist relativ complicirt. Es liegen namentlich in ihrer Tangentialfaserschicht grosse Plexus, die dem Querschnitte ein charakteristisches Aussehen geben. Das medialste Stück hat bei den Säugern ein besonders charakterisirtes Ausselien. Es ist als Gyrus dentatus bezeichnet worden.

In die Ammonswindung mündet nicht nur ein Fasersystem, sondern es entspringen auch daselbst Faserbündel und es treten Commissurenfasern in sie. Eine ganze Anzahl von Faserarten tritt also in Beziehung zu diesem Rindenfelde. Sie alle vertheilen sich, ehe sie eintreten, längs dem ventralen Rande und bilden da eine mächtige Ansammlung von Nervenfasern, die Fimbria. Die Fimbria liegt immer an der gleichen Stelle bei allen Thieren, sie begleitet den ventralen Rindenrand und ist desshalb bei den Reptilien dorsal von der Fissura arcuata septi gelegen. In caudalen Hemisphärenabschnitt, wo die mediale Hirnwand in den Plexus chorioides übergeht, legt sich die Fimbriafaserung zwischen diesen und die Rinde. Fig. 120. In Figur 114 gehören alle Fasern, welche dorsal von der Fissura arcuata septi sichtbar sind, der Fimbria an.

Das Bündel aus dem Riechapparate zur Fimbria und zum Ammonshorn kennen sie num schon. Die in der Riechrinde entspringenden Fasern und dann die Commissurenfasern aber müssen wir noch etwas näher betrachten.

Die Reptilien und Säuger, welche deutlich ausgobildete Riechrinde haben, wahrscheinlich aber auch die Amphibien und die Tögel, bei denen die einschlägigen Verhältnisse noch weniger klar liegen, besitzen zwei Faserzüge, welche dieses Rindengebiet durchaus charakterisiren und immer an gleichem Orte gleich angelegt wiederkehren. Die beiden Züge werden gewöhnlich als Fornix zusammengefasst. Es ist aber zweckmässiger, sie nach ihren Endstätten etwas zu tremnen. Aus dem caudalen Gebiete der Riechrinde hervortretend, ziehen sie zunächst eine kurze Strecke gemeinsam ventralwärts bis etwa zur Höhe der Commissura anterior und damn wenden sie sich caudal. Hier nun spaltet sich der bisher meist geeinte Stamm in einen Zug zum Ganglion habenulae, T ractus corti cohabenularis und in einen solchen zum Corpus mamillare an der Basis des Hypothalamus, den Tractus cortico-mamillaris. Siehe Fig. 100. Namentlich der letztgenannte ist ein kräftiges, in seinem Verlaufe immer gut abscheidbares Bündel. das längst bei den Säugern als F o r n ix- 
säule bekamnt ist. Bei den Vögeln ist er ungemein dïnn. Bei den Reptilien und Vögeln geht der Fornix iu ziemlich geradem Laufe von seinem Ursprunge zu seiner Endstätte. Bei den Säugern aber, wo durch die grosse Entwicklıng des Palliums die Riechrinde weit caudal rïckt und zum Theile sich nach unten krïmmt, Fig. 132, 133 1. 143, muss der Tractus cortico-mamillaris, dem Hemisphärenrande folgend, erst einen langen, ziemlich bogenförmigen Terlauf machen, ehe er sich dicht hinter der Commissura anterior in die Tiefe zum Corpus mamillare wenden kann.

Bei den höheren Säugern verlaufen in Folge der Balkenentwicklung die Fornixfasern aus dem Ammonshorne getrennt von denjenigen, welche aus den weiter vorn liegenden Theilen der Randwindung - so bezeichnet man die Rinde an der Innenwand des Gehirnes dicht über dem Plexus chorioides - entspringen. Die letzteren werden dort Fornix longus genannt. Bei den Reptilien, wo das ganze Gebiet noch nicht in zwei scharf unterschiedene Theile, einen glatten und einen eingerollten, getremnt ist, verlaufen die Bahnen des Fornix noch in einem Bündel. Vergleichen Sie Fig. 114 mit der Fig. 144 vom Kaninchen.

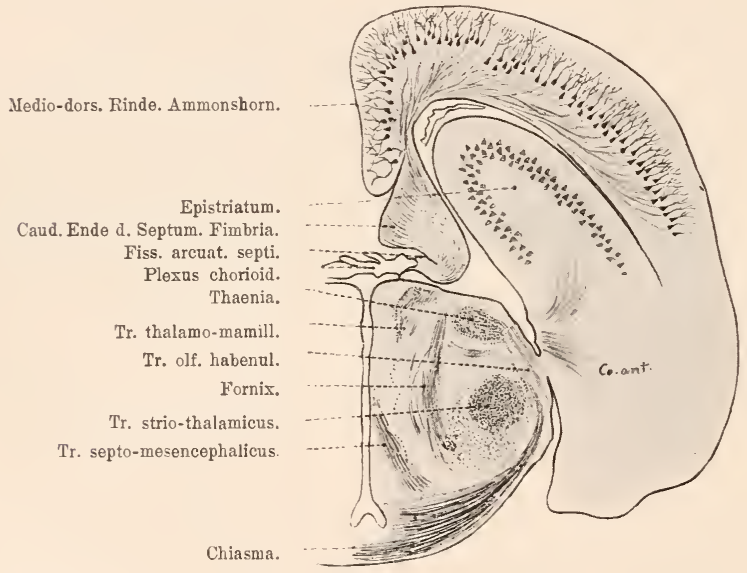

Fig. 120.

Frontalschnitt durch die caudale Grosshimpartie einer Riesenschlange, Python bivittatus. Dorsal der Mantel, ventral das Uebergangsgebiet zum Thalamus. Ursprung des Fornix und der Yantelcommissuren am medialen Palliumrande.

Ausser dem systeme des Formix ist die Riechrinde noch durch ein Commissurensystem charakterisirt, welches die rechte mit der linken Seite verbindet. Seine Züge sind Fig. 101 als Commissura anterior und posterior palli bezeichnet. Bei den Säugern heisst der ganze Complex Psalterium. Er bildet bei den niedersten derselben die einzige Mantelverbindung (Symington. Elliott Smith), bei den höheren kommt dazu noch eine zweite, das Corpus callosum. Diese verknüpft Mantelgebiete, die nicht dem Riechapparate angehören und ist meistens, besonders deut- 
lich beim Menschen, sehr viel mächtiger als die Commissuren des Riechmantels, weil, wie wir nachher sehen werden, in der Thierreihe allmählich das bisher noch nicht näher besprochene Mantelgebiet sich sehr viel mehr entwickelt, als das bei den Reptilien der Fall ist. Das Corpus callosum, der Balken, liegt immer dorsal ron den Riechcommissuren und ist natïrlich um so länger und dicker, je mehr das Pallium an Ausdehnung gewinnt. Am längsten ist es bei den Affen und dem Menschen, am kürzesten bei den Nagern und den Insektenfressern.

Die physiologische Bedentmng der Hirminde ist durch eine grosse Anzahl vortrefflicher Arbeiten iiber das Sängergehirn im Laufe der letzten 25 Jahre erst erkannt worden. Die Thierexperimente und die bald sich an diese anreihenden Beobachtungen am Menschen, Beobachtungen, die fortgehen und täglich zu neuen interessanten Ergebnissen führen, haben ergeben, dass die Rinde aufgefasst werden darf als derjenige Theil des Gehirnes, welcher den höchsten geistigen Functionen zur Unterlage dient. An die normale Existenz der Hilnrinde sind alle Fähigkeiten gebunden, welche erlernt werdenkönnen, fast alle welche nnter Benutzung von Erinnerungsbildern ausgeführt werden. und an sie sind vor Allem die geistigen Vorgänge geknüpft, welche man als Associationen bezeichnet.

Man kann den ganzen Rindenapparat anffassen als ein ungeheures Associationscentrum, dem von aussen anf relativ dünnen Bahnen solche Eindrücke zugeleitet werden können, die bereits in tiefer unten liegenden Centren - primäre Hirncentren - ihre erste Endstätte gefunden haben. Aus diesem Centrum gehen Bahnen hinab, wieder zu tieferen Hirngebieten, die geeignet sind, Bewegungen u. s. w. in jenen auszulösen. Die Summe dieser Bahnen bezeichnet man als Stabkranz der Rinde.

Was die Mächtigkeit, die Ansdehnung des rindenüberzogenen Mantels bedingt, das sind aber nicht jene meist dünnen Züge, sondern das ist die Entwicklung der Associationsbahnen, welche die Möglickeit geben die ankommenden simneseindrücke in der allermannigfachsten Weise aufzunehmen, zurückzuhalten, zu verwerthen und mit anderen früher anfgenommenen in Terbindung zn bringen, das Handeln einzurichten nach den erworbenen Erinnerungsbildern.

Wir wissen auch, dass bestimmte Leistungen von einzelnen Rindengebieten ansgeführt werden, dass die Rinde in eine Anzahl von Einzelteritorien zerfällt, die sich funktionell unterscheiden. Zahlreiche Tntersuchungen der letzten Jahre haben uns mit der Oberfläche des Säugermantels genauer bekannt gemacht. Ihre Ergebnisse lehrten, dass je nach der Thierart bestimmte Rindengebiete mehr, andere weniger ausgebildet sind. Noch ist unser Wissen ron der physiologischen Bedeutung dieser Rindenterritorien in vielen Fällen recht gering, aber es ist eine Aufgabe der nächsten Zukunft, die Entwicklung dieser Rinden- 
felder zu studiren, eine A ufgabe, die erfreulicher Weise a uch schon für einzelne Säuger in Angriff genommen ist.

Da also nach dem hentigen stande unseres Wissens die Rinde als der Sitz derjenigen seelischen Functionen aufgefasst werden darf, die mit Teberlegung unter Benutzung von Erimmerungsbildern bewusst ausgefïhrt werden, so hat der Nachweis eines Rindenzuges zu den Kernen eines bestimmten Sinnesapparates hohes Interesse in vergleichend phychologischer Beziehung.

Desshalb scheint es mir das wichtigste Ergebniss unserer bisherigen Betrachtung, dass wir nachweisen komnten. wie die Rinde da, wo sie zuerst in der Thierreihe deutlich auftritt, im Wesentlichen Riechrinde ist. Riechrinde ist die Rinde der dorsomedialen Platte desshalb, weil eben hier die Faserung aus den Endstätten der sekundären Riechbahn endet. Für die anderen Rindengebiete der Reptilien ist eine Terkniipfung, die Licht auf ihre funktionelle Bedeutung werfen möchte, noch nicht gefunden. Sie können dem Riechapparate angehören, mïssen es aber nicht.

Dass die älteste Rinde im wesentlichen nur ein einziges Simnescentrum darstellt, das Centrum für den Geruch, dass alle Associationen, welchen sie als Unterlage dient, alle Erimnerungsbilder, dis sie bewahren mag, solche sind, die vorwiegend dem Riechen dienen, das giebt einen Ausgangspunkt für neue Untersuchungen auf dem Gebiete der vergleichenden Psychologie, welcher fester ist, als einige der bisher verwendeten. Thierpsychologische Studien sind bisher so gut wie immer an zu komplicirten Erscheinungen angestellt worden. Wir mïssen erst wissen, welche Sinneseindriicke ein niederes Thier bekommen kann, welche es zurückzuhalten weiss, und welche es, allein oder unter den Zeichen associativen Denkens, zu verwerten vermag. Dann erst kömnen wir an die komplicirteren Probleme gehen, welche bisher zumeist in Angriff genommen sind.

Nun lassen sie uns wieder zurïckkehren zu den rein morphologischen Dingen und zunächst untersuchen, wie sich im Terlaufe der Thierreihe zu den corticalen Riechbahnen andere Bahnen gesellen, wie allmählich der mächtige Apparat entsteht, den das säugergehirn uns zeigt.

Es ist leider nur Weniges, was ich heute hier berichten kann; überall sind noch der Liicken viele, und iiberall bedarf es desshalb fleissiger Mitarbeit an dem erst vor Kurzem eröffneten Arbeitsfelde.

Wir haben das Riechcentrum abgeschieden, indem wir die Verbindungen studirten. welche der Riechapparat mit der Rinde einging. Kömnen wir nun auch bei den Reptilien nicht gerade mit sicherheit eine reitere derartige Terbindung finden, so bietet uns doch zunächst das Togelgehirn eine Anzahl anderer Faserzüge, welche die Rinde mit weiter caudal gelegenen Hirntheilen verknïpfen.

Als der für die rergleichende seelenlehre interessanteste erscheint mir ein Faserzug; der ganz im occipitalen Hirngebiete entspringend vorwärts zieht, um damn scharf abbiegend sich hinab und rückwärts zu den Endstätten des Sehnerven im Nittelhirndache zu wenden. Dieser Tractus occipito-mesencephalicus ist bei der Taube so enorm entwickelt. dass 
er als eines der allerstärksten Bündel des ganzen Gehirnes anzusehen ist. Die Reptilien besitzen, wie es scheint an gleicher Stelle, schon einen dümneren Zug, doch ist das nicht absolut sicher. Eine Taube, der man dieses Bïndel durchtremnt hat, erscheint annähernd wie gekrenzt blind, sie orientirt sich nur noch sehr schwer und immer mit dem Auge, das noch einen unverletzten centralen Sehapparat hat. Wir wissen nun, dass bis hinauf zu den Sängern und dem Menschen immer eine solche Bahn aus den primären optischen Centren zum Hinterhauptlappen existirt, und ich werde Ihnen später zı zeigen haben, wie an die Intactheit der occipitalen Rinde bei Säugern alle die Functionen geknïpft sind, die wir als Sehen mit Verständniss, mit Wiederkennen u. s. w. auffassen. Bei den Vögelnalso würde, zuerst in der Reihe, der primäre optische A pparat mit demjenigen der Rinde verbunden. Zweifellos wird dadurch eine grössere Leistungsfähigkeit des ersteren ermöglicht.

Das Bündel wird erst Wochen nach dem Auskriechen aus dem Ei markhaltig, ganz wie die Sehbahn der Säuger, welche gleichen Ursprung und gleiche Endstätten hat. Der Verlauf wurde sicher gestellt durch Schnittserien und vor allem durch Degenerationsversuche. Es gelang, 3 Tauben, denen das Occipitalhirn abgeschnitten war, 3 Wochen lang am Leben $z u$ erhalten. An diesen fand sich dann das Bündel völlig degenerirt.

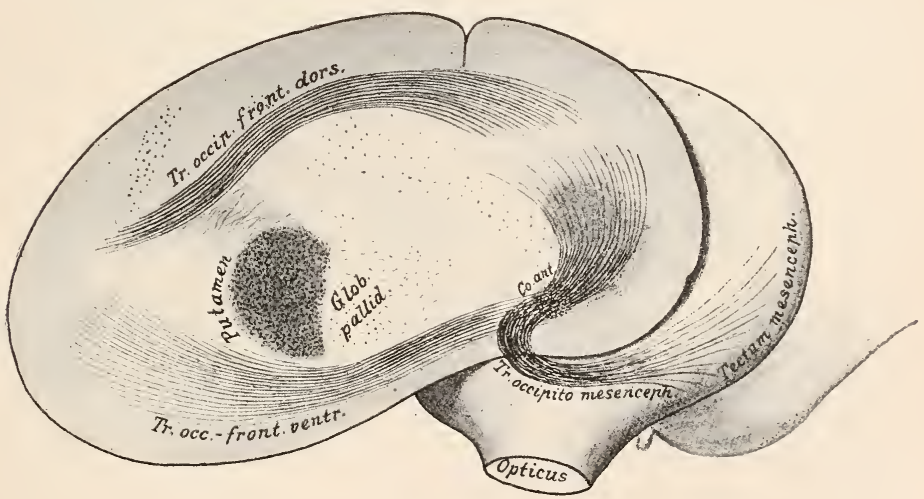

Fig. 121.

Sehrere laterale Sagittalschnitte aus dem Taubengehirne in eine Abbildung combinirt, um den vollständigen Verlauf des Tractus'occipito-mesencephalicus zu demonstriren.

Es wird nun für die Tögel leichter verständlich, wie sie zum Theile mit sehr ausgebildetem optischen Erinnerungsvermögen arbeiten. Den an der Erde haftenden niederen Vertebraten mag für des Lebens Nothdurft zunächst noch die Verwerthung von Geruchseindrücken genïgen, für die Tögel ist aber eine solche kaum rortheilhaft. Umgekehrt miissen sie, hoch über ihrer Nahrung, ihren Wohnsitzen u. s. w. schwebend, in der Lage sein, diese optisch zu erkennen 
und vor Allem sie ron etwa bewegten nahrungsähnlichen Körpern zu unterscheiden. Ich erimnere an das sichere Herabstossen des Raubvogels auf die Beute, an die Tanderung, das Wiederfinden der Nester u. s. w.

Auch das andere Bündel, welches bei den Vögeln als aus der Rinde stammend schon erwähnt worden ist, der Tractus septo-mesencephalicus, Fig. 115, steht mit den Endstätten des Sehnerven und mit dem sensorischen Apparate des Mittelhirnes in nahem Connexe. Wir wissen aber über die Funktion, deren Träger es ist, noch nichts Sicheres. Sehstörungen macht seine Durchschneidung nicht - Jensen. Auch treten danach keine zweifellosen motorischen Störungen auf.

Wir sind noch sehr weit entfernt ron der Beantwortung der Frage, die sich nach diesen Beobachtungen sofort aufdrängt, der Frage, welche Fähigkeiten die primären Endapparate der sinnesnerven im Gehirn, ihre tiefen Centren also, an und für sich haben, wir wissen nur, was auftritt, wenn sie bei den Säugern ihrer Verbindung mit dem Rindencentrum beraubt werden. Nun ist aber gar nicht unwahrscheinlich, dass in dem Maasse, wie sich das psychiche Arbeiten mit der Rinde vermelurt, die Arbeit mit den tieferen Centren zurücktritt. Zum Glücke besitzen wir in den Knochenfischen Wesen, welche gar keine Rinde und nur die niederen Centren besitzen. An ihnen hätten neue Beobachtungen einzusetzen. Es ist direct zu fragen: was rermag ein Reptil im Geruchsbereiche, in der Terwerthung seiner Geruchsempfindungen mehr zu leisten als ein Fisch, nachdem einmal nachgewiesen ist, dass dem Geruchsapparate der Reptilien sich ein corticales Centrum zuaddirt hat. Aehnliche Cntersuchungen sind zu verlangen für den sehapparat. Denn es muss ein C'nterschied bestehen zwischen dem Sehen eines Knochenfisches. dessen Optici in dem Mittelhirn ihr Ende finden, und demjenigen eines Vogels oder Säugers, welcher von der primbären optischen Endstätte eine Bahn zum Grosshime besitzt, die dort einen mächtigen Associationsapparat trifft.

Die Hirnrinde geht noch mit einer Anzahl ron Gebieten Terbindungen ein, die weitab vom Grosshirne gelegen sind. Diese treten in voller Mannigfaltigkeit zwar erst bei den säugern in Erscheinung, und wir werden sie dann näher zu studiren haben. Aber schon bei den Reptilien findet man einen aus dem Stirnpole kommenden und wahrscheinlich im Thalamus endenden Stabkranztheil, einen Tractuscortico-thalamicus, und gerade diese Rindenthalamusverbindung wird später, wie ich schon anlässlich der Beschreibung der Zwischenhirnkerne erwähnte, sehr stark. Auch andere Stabkranzbiindel, aber nur selı dünne, kommen noch bei Vögehn vor, ihre Aufzählung würde, da die Endstätten noch ungenügend bekannt sind, heute nur wenig Interesse für sie haben.

Giebt es auch bei Reptilien und Tögeln noch keine Rindenverbindungen zu Theilen, die caudal rom Thalamus liegen, so kommt es doch bei den säugern in anfsteigender Weise mehr und mehr zu solchen Verknïpfungen. Immer grösser, immer wichtiger für die 'Thätigkeit des Gesammthieres wird die Rinde. werden, wie wir uns auch schon aus- 
drücken dürfen. die Terrichtungen, welche unter dem Einflusse der Einübung und des Gedächtnisses vollzogen werden. Die Brücke wird zuerst erreicht, dann aber in nach Sängerarten wechselnder Intensität auch das Rüickenmark. Tractus cortico-spinales u. s. w.

Erst bei den Säugern entwickelt sich also mit der grösseren Ausdehnung des ganzen Rindengebietes auch ein mächtiger Stabkranz aus demselben. Ehe wir denselben betrachten, soll aber nicht unterlassen werden zu erwähnen, dass schon bei den Selachiern ein Zug bekannt ist, der, aus dem Mantel kommend, hinter dem Chiasma eine mächtige Kreuzung eingeht. Wohin er dann weiter geräth, das können erst secundäre Degenerationen entscheiden. Dieses Mantelbïndel der Selachier ist jedenfalls das älteste markhaltige Bündel, das in der Thierreihe dem Mantel entstammt. Untersuchungen über dasselbe wären desshalb sehr erwünseht.

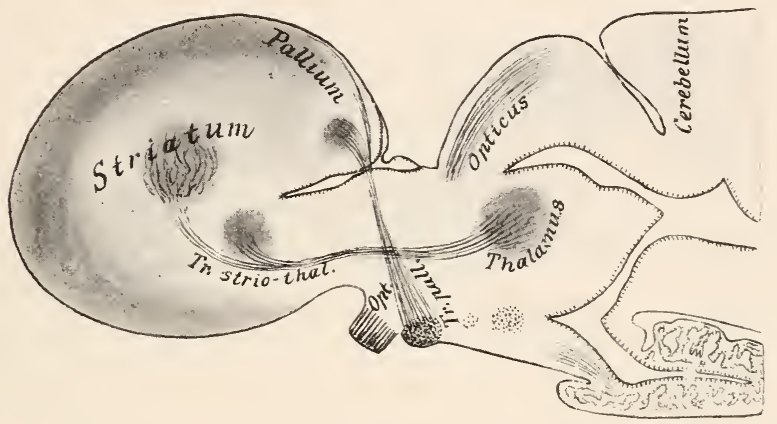

Fig. 122.

Sagittalschnitt durch das Gehirn eines erwachsenen Rochens, Raja.

Die grosse Bedeutung der Hirnrinde für die associative Thätigkeit erhellt nicht nur aus den Beobachtungen, die man an rindenberaubten Thieren und rindenkranken Nenschen gemacht hat, sondern auch ganz klar aus ihrem Baue. Denn, wie sie schon gesehen haben. bietet die Rinde schon der Reptilien eine ausserordentlich grosse Möglichkeit zu Verknüpfung von in sie gelangenden Eindrücken. Unzähliche Contacte verbinden da die Zellen und die Bahnen der rerschiedensten Provenienz. Bei den Vögehn, mehr aber noch bei den Säugern treten dazu noch eigene lange Bündel, welche von einer stelle der Rinde zu einer entfernteren verlaufen. Man nemnt diese Associationsbiindel. In Fig. 121 sehen Sie die bei der Taube vorhandenen zwei hierher gehörigen Züge abgebildet, welche geeignet sind, den frontalen mit dem occipitalen Mantelabschnitt zu verknüpfen. Das dorsale verläuft dicht unterhalb der Rinde, das ventrale aber zieht, ganz wie die Fasern der Rindenassociationsschicht, über die Manteloberfläche hinweg. Siehe auch Fig. \$3.

Das Pallium der Vögel ist, soweit wir heute wissen, nicht wesentlich ausgedehnter als dasjenige der Reptilien. Nur im Stirntheile und 
dam in dem lier erst auftretenden Occipitallappen weist es wesentliche Fortschritte auf. Immerhin kommt die Hauptmasse dessen, was zunächst bei der ersten Betrachtung des Togelhirnes auffällt, auf die relativ bedeutende Ausdehmung des Striatums und des Mesostriatum.

Damit sie nun einmal ganz klar das Auswachsen des Hirnmantels, die Zunahme des Rindenareales, erkennen, will ich Ihnen in Figur 123 ein Reptiliengehirn rorlegen. das ich in ein Säugergehirn eingezeichnet habe. Es wurde natürlich ein Tertreter der niedersten Säuger gewählt, ein Beutelthier. In die Abbildung eines Thylacinusgehirnes ist ein Reptilien-

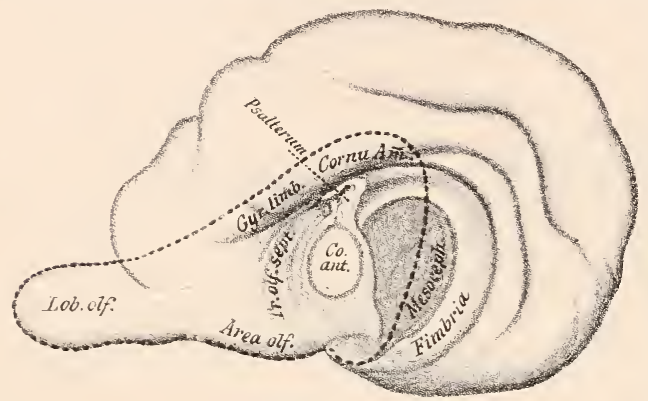

Fig. 123:

Gehirn von Thylacinus nach Flow er. Die Contour eines Reptiliengehirnes ist eingezeichnet. Für Detail vergleiche man noch Fig. 114, S. 161. gehirn so eingezeichnet, dass die beiden Psalterien sich decken. Nun springt sofort die Aehnlichkeit beider Gehirne ins Auge, man sieht, wie der Ammonswindung des einen der gleiche Zug im anderen entspricht, ja, man erkennt sogar, dass das Riechbündel, welches von der Basis vorn in das Ammonshorn einstrahlt, sich in beiden Abbildungen genau deckt. Tergleiche namentlich Fig. 114, wo im Taranusgehirne dieses Bündel ganz ebenso aussieht. Der hier angestellte Tersuch hat seine Bedeutung aber nicht allein nach der rein morphologischen Seite. Er soll nämlich auch zeigen. nach welchen Richtungen hin das Gehirn sich weiter entwickelt, wenn man von den Reptilien einmal ausgeht. Nan erkennt zunächst, dass von dem Marsupialiergehirne zu demjenigen der Reptilien ein viel geringerer Schritt ist, als von dem Beutlergehirne hinauf zu demjenigen des Menschen. Terhältnissmässig unbedeutend nur ist das Tachsthum des Hirnmantels, verglichen mit demjenigen, welches innerhalb der Säugerreihe erst eintritt. Vergl. Fig. 123 mit Fig. 133.

Erst bei den Säugern aber wird der Nantel mit seiner Rindenlage zu einem mächtigen Gebilde, welches das Stammganglion ganz in den Grössenverhältnissen zurücktreten lässt und auswachsend sich über das caudaler gelegene Zwischen- und Mittelhirn (beim Menschen auch das Hinterhirn) hinweglegt. Sehr hochstehende Gehirne zeigen ausser diesem Wachsen nach hinten noch eine Krümmung der caudalen Nantelhälfte nach unten. Fig. 136.

Der rorderste Theil der Hemisphäre, der Frontallappen, tritt (Meynert) erst bei den höheren Säugern, namentlich beim Menschen, in gesonderte Erscheinmmg.

Aus der mächtigen Rindenausbreitung des Säugethiermantels kommt 
eine sehr grosse Menge von Fasern. andere münden darin aus. Ihre Gesammtheit, der Stabkranz also, zieht aus der Rinde caudalwärts, um im Zwischenhirne, Hinterhirne und Nachhirne und im Rückenmarke zu endigen. Andere mächtige Bündel durchziehen die Hemisphären, einzelıe Gebiete ihres Mantels mit einander verknüpfend. Alle diese zusammen bilden unter der Rinde ein grosses Lager weisser Marksubstanz; seine Ausdehnung ist beim Menschen die relativ grösste, bei niederen Säugethieren ist sie nur klein, und bei manchen. bei der Maus zum Beispiel, nur ganz unbedeutend.

Indem der Stabkranz rückwärts zieht, geräth er zwischen die beiden Kerne des striatums und gesellt sich hier zu der aus jenen entspringenden Faserung. Der ganze Complex wird als Capsula interna bezeichnet. Wie die Kapsel sich aus den Rinden und den Striatumfasern zusammensetzt, das wird ganz gut sichtbar an der Fig. 102, welche die ersteren von einem Säuger, die letzteren ron einem Fische in einander zeichnet.

Alle diese aus- und einstrahlenden Fasern liegen aber enge zu einem vor'n sich verbreiternden Bündel geordnet im Hirnmantel. Ist der Rindenaplarat unverhältnissmässig grösser, in seinen Eigenzügen mächtiger entwickelt, so muss er sich über diese kleinere Einstrahlung hinweg in Falten legen; solche Hirnwindungen fehlen nur bei wenigen Säugethieren (Lissencephale Säuger), bei allen anderen sind sie mehr oder weniger reichlich rorhanden (Gyrencephale säuger). Die Anordnung der Falten, welche für die einzelnen Thiere in gewissen Grenzen constant ist, hängt wohl von zwei Factoren ab: von der Ausdehmung der Hirmrinde, die sich die betreffenden Arten im Laufe der stammentwicklung erworben haben, und von den Maassverhältnissen des Schädelraumes, die natïrlich mit jener nicht gleichen Schritt halten müssen, da sie auch noch von anderen Factoren abhängig sind. Man kann desshalb auch keine aufsteigende Entwicklung: der Hirnfurchung innerhalb des Thierreihe oder auch nur innerhalb einer einzelnen Familie erkemnen.

Bei den niederstehenden Monotremen hat Ornithorhynchus ein ganz glattes, Echidna ein ziemlich reich gefurchtes Gehirn. Ja es giebt noch unter den Primaten einen Affen-Hapale-, dessen Gehirn fast völlig windungslos ist. Die relativ kleine Schädelhöhle in dem riesigen Kopfe des Elephanten, auch diejenige der Wale, welche ähnliche relative Verhältnisse hat, birgt ein sehr windungsreiches Gehirn.

Nicht nur auf den Tindungsreichthum, sondern auch auf den Verlauf der Tindungen haben die beiden erwähnten Terhältnisse einen Einfluss. Wenn Ihnen die Hirnoberfläche des Menschen näher bekannt ist, damn wird es zweckmässig sein, einmal einen Blick auf die rerschiedenen Furchungsrichtungen in der Thierreihe zu werfen.

In der heutigen Vorlesung kam es mir nur darauf an, Ihnen zu zeigen wie aus unscheinbaren Anfängen sich das grosse Organ entwickelt, das als Träger der höchsten psychischen Thätigkeit sich über die niederen Hirncentren schaltet.

Diese Torlesung soll, an solchen Punkten angekommen, auch die rergleichend anatomischen Darlegungen beschliessen. 
Wenn ich Ihnen die Entwicklung des Gehirnes in der Thierreihe bisher in Umrissen geschildert habe, so geschah es, weil ich zeigen wollte, wie das hochorganisirte Gehirn der Säuger, das wir nun in den nächsten Torlesungen näher studiren werden, geworden ist.

Sind Sie meiner Darlegung aufmerksam gefolgt, so werden Ihnen zwei Punkte nicht entgangen sein. Einmal, dass bei verschiedenen Klassen die verschiedenen Hirntheile sehr verschieden stark entwickelt sein können. Das Mittelhirn der Fische und der Vögel ist zweifellos mächtiger entwickelt, als dasjenige der Säuger, und mit dem enormen Kleinhirnwurme der Selachier und der Knochenfische kann sich der gleiche Gehirntheil bei keinem anderen Thiere vergleichen.

Dann aber geht aus der bisherigen Betrachtung hervor, dass es wirklich niedrig organisirte Gehirne giebt, solche, bei denen kein einziger Theil eine hohe Ausbildung erreicht hat. Solche haben nur die Cyklostomen und die Amphibien. Den letzteren darf ich gleich, das haben Fulliquet's und Burkhardt's Untersuchungen über allen Zweifel erhoben, die Dipnoer anreihen.

Das Gehirn und das Rückenmark der urodelen Amphibien ist überhaupt nur ganz wenig unterschieden von demjenigen älterer Larven von höheren Thieren. Rückenniark und Oblongata speciell entsprechen etwa menschlichen Stadien aus dem 2.--3. Fötalmonate. In der That lehrt auch die Beobachtung der Amphibien, namentlich der geschwänzten - die Frösche nehmen etwas höheres Niveau schon ein - dass sie ein ungemein seelenloses Traumleben führen, und dass sie kaum zu uns heute erkennbaren Thätigkeiten fähig sind, die etwas Ueberlegung fordern. Schrader, der enthirnte Frösche sehr lange am Leben halten komnte, hat, wenn eimmal die ersten Reizerscheinungen verschwunden waren, eigentlich gar keinen deutlichen Unterschied gegenïber solchen Fröschen gefunden, welche ihre Hemisphären noch hatten. Ich zweifle kaum, dass, wenn derartige Versuche einmal so angestellt werden, dass der basale Riechapparat erhalten bleibt, auch die letzten Differenzen gegenüber dem normalen Thiere schwinden werden. Jedenfalls ist unsere heutige Beobachtungskunst noch nicht weit genug vorangeschritten, um etwaigen durch den Hemisphärenverlust bedingten Ausfall zu erkennen. Aber bei diesen cerebral niedrig organisirten Thieren sind doch die Functionen, welche vom Rückemmarke ausgeführt werden, und diejenigen des verlängerten Markes nicht wesentlich von denen höherer Thiere verschieden. Nur die Beeinflussbarkeit derselben von höheren Centren her ist noch nicht erkennbar.

Noch stehen wir in vergleichend psychologischen Fragen ganz im Anfange unseres Wissen. Dass auch die anatomische Forschung hier Nutzen bringend mitarbeiten kann, ja dass es ihr vergönnt ist. gerade da, wo die echt psychologische Beobachtung noch nicht hin reicht, einen gewissen Einblick zu schaffen, das zeigen vielleicht die Vorlesungen, in denen wir die Genese des Gehirnes verfolgt haben. 


\section{THEIL.}

\section{SPECIELLE ANATOMIE DES SÄUGERGEHIRNES}

MIT BESONDERER

BERÜCKSICHTIGUNG DES GEHIRNES DES MENSCHEN. 



\section{Dreizehnte Vorlesung.}

\section{Die Formverhältnisse des Gehirnes beim Menschen.}

M. H.! Mit den Grundlinien bekannt, welche das Centralnervensystem der Vertebraten charakterisiren, wollen Sie nun gemeinsam mit mir dem Gehirne der Säuger speciell Ihre Aufmerksamkeit schenken. Es wird Ihnen nun, da sie gesehen haben, wie es sich langsam und durch eine lange Reihe ron Uebergangsfor'men hindurch entwickelt hat, gewiss willkommen sein, einmal an dem Beispiele der höchststehenden Gehirne den ganzen Aufbau etwas genauer durchzuarbeiten. Die bisherige Darstellung hat wesentlich in morphologischer und wohl auch in psycho-physiologischer Beziehung Ihr Interesse verlangt. Nun aber mïssen wir den Anforderungen gerecht zu werden versuchen, welche die Medicin, weit vorangeschritten, wie sie bereits in der Diagnostik der Nervenkrankheiten ist, an den Arzt stellen muss.

Die alten Aerzte haben ganz vorwiegend das menschliche Gehirn studirt und beschrieben. So haben wir von dessen Formverhältnissen die beste Kemmtniss, und die zahlreichen Untersuchungen an Gehirnen, deren Träger intra vitam an nervösen Störungen gelitten hatten, Untersuchungen die wir wieder fast ausschliesslich den Aerzten verdanken, haben unsere Kenntnisse soweit vertieft, dass es heute möglich ist, das Centralnervensystem des Menschen wenigstens in seinen wichtigsten Anordnungen einigermassen zu überselıen und genauer zn beschreiben.

Wenn sich nun auch diese Vorlesungen nicht an den Anfänger, sondern an Hörer richten, welche bereits im Allgemeinen mit den gröberen Formverhältnissen des menschlichen Gehirnes bekannt sind, so wird es doch nicht ganz überflüssig sein, wenn Sie sich heute wieder einmal diese Verhältnisse als klares Bild vor Threm geistigen Auge erstehen lassen. Die Tmrisse der Karte, in die wir später alle die Punkte und Strassen, welche von Wichtigkeit sind, einzeichnen wollen, werden durch eine kurze Wiederbelebung des frïher Erlernten nochmals zweckmässig fixirt. Orientirt durch die Entwicklungsgeschichte werden sie sicher leicht die morphologischen Verhältnisse verstehen, welche das Organ des erwachsenen Menschen bietet.

Ein frisches Gehirn wird auf seine Basis gelegt. Den grossen Hirnspalt, welcher die Hemisphären trennt, und die Fossa Sylvii, welche mit der Ausbildung des Schläfenlappens entstand, werden Sie leicht auffinden. 
Da das Torderhirn die meisten anderen Hirntheile überwachsen hat (s. Fig. 19), so könnte man sich diese letzteren ron hinten her ansichtig machen, wenn man die Hemisphären aufhöbe, von ihnen abdeckte; auch dadurch könnte es geschehen. dass man die letzteren abtrüge, zum 'Theil entfernte. Dieser letztere Modus bietet den Tortheil, dass wir auch die Seitenventrikel und das Corpus striatum besser zu Gesicht bekommen. Gehen wir deshalb ihm folgend vor!

Das horizontal gelegte Messer durchzieht immer beide Hemisphären gleichzeitig und trägt von ihnen $2-3 \mathrm{~mm}$ dicke Platten ab. Die erste

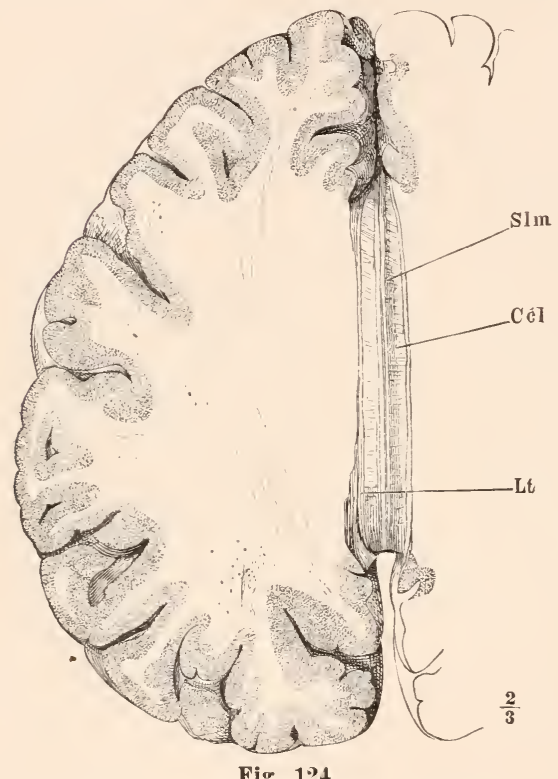

Fig. 124 .

Vorderhirn $\nabla$ on oben. Die Hemisphären auf das Nivean des Balkens ( $\mathrm{Ccl}$ Corpus callosum $=$ Balken) abgetragen. Der weisse Raum zwischen $\mathrm{C} c l$ und Rinde ist das Centrum semiovale. $L t$ Ligamentum tectum, Stria longit. Lancisi, ein Theil der dem Balken benachbarten Hirnrinde; S $l \mathrm{~m}$ Striae longitudinales mediales, weisse Längsfaserzüge, die sich mehrfach unter einander verflechten, auf der Balkenmitte. Nach Henle. und die zweite dieser Platten enthalten sehr viel graue Rinde und relativ wenig von ihr unschlossene weisse Substanz, aber schon in der dritten Platte hat man beiderseits ein grosses, weisses Markfeld mitten in der Hemisphäre blossgelegt, das Centrum semiovale. In ihm verlaufen alle Faserziige. welche von der Rinde nach abwärts ziehen, und ein Theil der Fasern, welche verschiedene Rindengebiete unter einander rerbinden. Wenn man die Fig. 22 betrachtet, sollte man beim Weiterschneiden erwarten, dass in der Mitte zwischen beiden Hemisphären nur noch eine dümne Epithelschicht über den Ventrikeln liege. Dem ist aber nicht so. In einer späteren Embryonalperiode sind dicke Fasermassen quer über die Tentrikel von Hemisphäre zu Hemisphäre bei a der Fig. 22 gewachsen. So kommt man demn in der Tiefe des grossen Hirnspaltes nicht auf die Tentrikel, sondern auf den Balken (Corpus callosum). wie die Masse der Querfasern bezeichnet wird. Der Balken wird nun durchtremnt und, nachdem auch in beiden Seitenhälften, was noch von weisser Substanz iiber den Ventrikeln stehen geblieben ist, entfernt wurde, vorn und hinten abgeschnitten. Dabei zeigt sich, dass er mit seiner Unterfläche an dünnen weissen Faserzïgen festklebt, welche, die Tentrikelhöhle ïberspannend, 
vorn und hinten in die Tiefe der Ventrikel hinabziehen. Sie gehören dem Gewölbe (Fornix) an.

Der Fornix ist eine Combination von Faserbündeln, die immer dem Hemisphärenrand entlang ziehen. Sie entwickeln sich als Crura for-

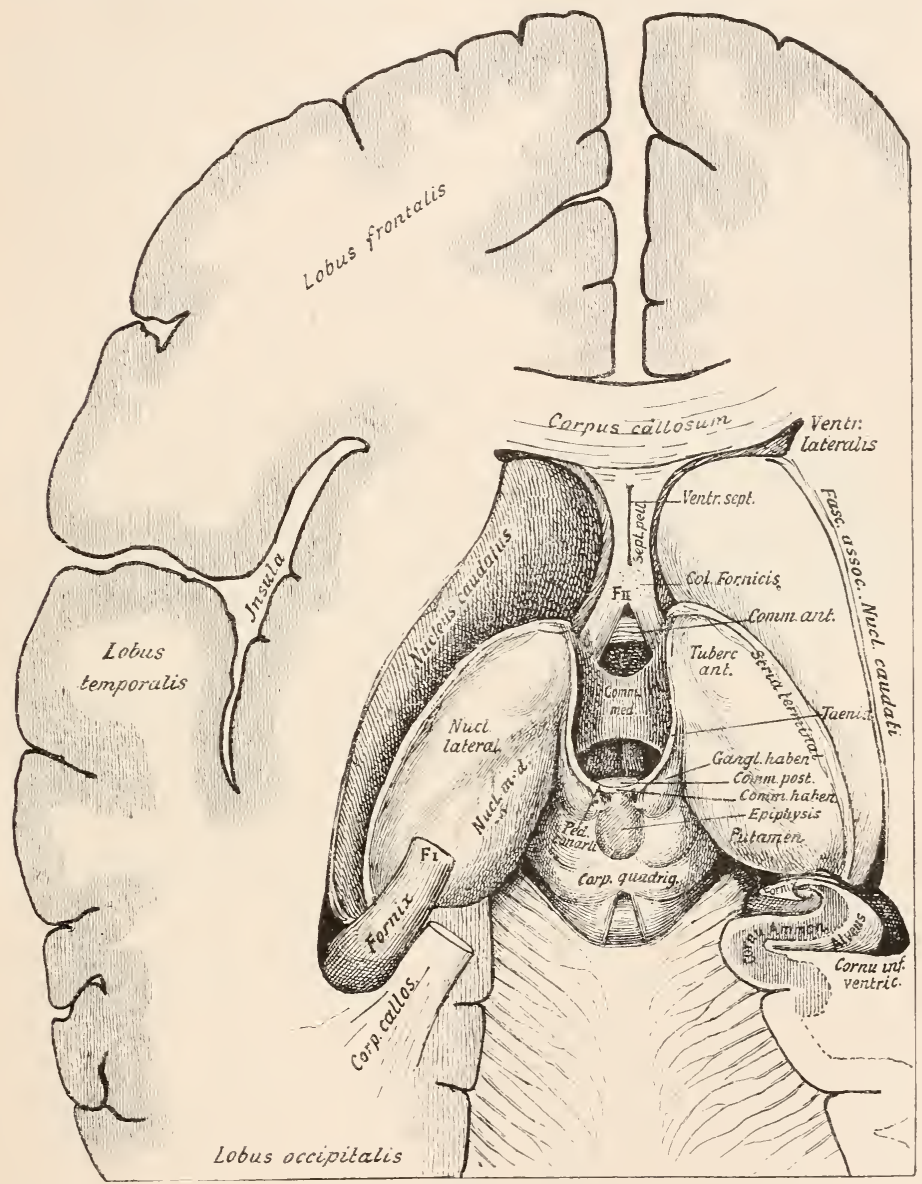

Fig. 125.

Das Gehirn von oben her durch einen Horizontalschnitt geöffnet. Die beiden Hemisphären etwas durch Zug von einander entfernt.

nicis beiderseits aus dem medialen Rande des Unterhorns (Fig. 125 hinten), treten dann convergirend über den hinteren Theil des Thalamus 
und rereinigen sich iiber dem Ventrikel zu einem breiten Zuge (Corpus fornicis). In dem Winkel, wo sie zusammenstossen, ziehen eine Anzahl Querfasern dahin, diesen so zu einem Dreiecke ausfüllend. Das Dreieck heisst Lyra Davidis, Psalterium. Es liegt unter dem caudalen Balkenende und ist mit diesem meist rerklebt. Der Balken liegt also hier dem Hemisphäreurande dicht an. Gelegentlich kommt es vor, dass er doch etwas entferut von ihm bleibt; dann erkennt man zwischen Fornix und Balken einen kleinen Hohlraum (Teutriculus Verga). Im vorderen Theile des Gehirns aber tritt der Balken ganz regelmässig vom Hemisphärenrande zurïck, und es bleibt zwischen ihm und dem Tentrikel ein Stïck der sagittalen Hemisphäreninnenwand zurïck. Dieses unter (auf unserem Horizontalschnitte hinter) dem Balken liegende Stiick der medialen Hemisphärenwand ist das Septum pellucidum. Der zwischen dem rechteu und linken Septum bleibende Theil des Hemisphärenspaltes wird Ventriculus septi pellucidi genannt. Wenn Sie sich auf der Fig. 125 ein-

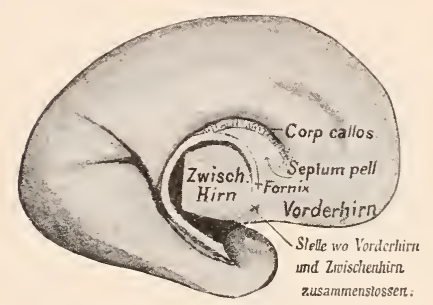

Fig. 126.

Innenansicht der auf Fig. 23 abgebildeten embryonalen Hemisphäre; zeigt den inneren unteren Rand der Hemisphäre, welcher zum weissen Markstreif des Fornix rerdickt ist. Derselbe wird aber erst nach der Geburt markweiss. mal den Balken hinwegdenken wollen, so wird Ihnen sofort die Fortsetzung der Hemisphäreuwand in das Septum und die Bedeutung des Tentriculus klar sein. Dieser ist kein eigentlicher Tentrikel, sondern nur das durch den Balken überdeckte Stück des Spaltes zwischen den Hemisphären.

Der Fornix begrenzt natiirlich auch diesen Theil der Hemisphärenwand. Er spaltet sich am vorderen Ende des Corpus wieder in zwei Züge, Columnae fornicis, die als caudale Terdickung jedes Blattes des Septum pellucidum vor dem Thalamus in die Tiefe ziehen und an der Grenze von Vorder- und Zwischenhirn in der Hirnbasis ein vorläufiges Ende erreichen.

In Fig. 125 ist das Corpus fornicis mit dem Balken weggenommen, und nur der frontale und caudale Abschnitt des Gewölbes sichtbar geblieben. Rechts, wo der Schnitt durch die weisse Substanz etwas tiefer liegt, ist der Fornix in seinem als Fimbria bezeichneten Theile durchtrennt, er liegt da noch seiner Ursprungsstätte, dem Ammonshorne, dicht an. Links liabe ich ihn erst da durchschnitten, wo er sich über die Thalamusoberfläche weg wölbt.

Tremn Sie die Punkte $F^{\prime}$ und $F^{\prime \prime}$ der Figur durch einen sanft über dem Thalamus wegziehenden Bogen rerbinden, so haben Sie den Verlanf des Fornix wiederhergestellt. An dem beistehenden medianen Längsschnitte durch ein embryonales Gehirn werden Sie sich leicht deu Verlauf des Fornix klar machen können. Sie erkennen da, dass er, aus 
der Spitze des Schläfenlappens entspringend, im Bogen das Zwischenhirn überspannt und sich vor diesem zur Zwischen-Torderhirngrenze herabsenkt.

Nachdem der Fornix und der an ihm hängende Plexus chorioideus durchtrennt und abgeschnitten sind, blickt man in die geöffneten Tentrikel (Fig. 125). Der medialst liegende, unpaare ist der Hohlraum des primären Vorderhirns, jetzt Ventriculus tertius genannt. An seinem vorderen Ende steigt aus der Tiefe der Fornix auf. Jederseits rom Fornix liegt dann die Fortsetzung des Ventriculus medius in die Ventriculi laterales (Foramen Monroi). Der Theil dieses Ventrikels, welcher im Stirnlappen liegt, heisst Vorderhorn, der im Occipitallappen Hinterhorn, der Hohlraum des Schläfenlappens wird Unterhor'n genannt. Sie können leicht den Finger in jedes dieser Hörner einführen. Die basalen Gebiete beider Hemisphären sind durch die Commissura anterior unter einander verbunden. Ihr markweisses Faserbündel sehen Sie vor den Fornixschenkeln dahinziehen.

Aus dem Boden des Seitenventrikels erhebt sich der Nucleus caudatus; weiter nach hinten werden Theile sichtbar, die nicht mehr zu den Hemisphären gehören, das Zwischenhirn (Thalamus opticus) und das Mittelhirn (Corpora quadrigemina). Hinter diesem zeigt sich das Dach des Hinterhirnes, das Cerebellum.

Der Hohlraum zwischen beiden Thalamis, der Ventriculus medius, ist der Hohlraum der einstigen Zwischenhirnblase. Nach oben ist er von dem gefalteten Plexus chorioides abgeschlossen, an dessen caudalem Ende die nun solid gewordene Zirbelausstïlpung, C o r p u s p in e a le, liegt. Der Boden des Zwischenhimes, der nach vorn natïrlich durch die embryonale Schlussplatte gebildet wird, besteht aus grauer, sich trichterförmig nach der Schädelbasis hinabsenkender Substanz. Diese Ausstïlpung heisst Tuber cinereum, ihr Hohlraum Infundibulum, Trichter. In Fig. 125 ist sie nicht sichtbar, wohl aber auf dem Medianschnitte der Fig. 133 und auf 135, Lam. t. vor dem Chiama.

Die Furche zwischen Thalamus und Nucleus caudatus wird von einer langen Vene durchzogen, unter der man regelmässig einen dïnnen weissen Faserzug, Stria terminalis, Taenia semicircularis findet. An der Oberfläche des Thalamus kann man bald mehr, bald weniger deutlich einzelne Einbuchtungen erkennen, welche Höcker der Oberfläche von einander scheiden. Diese Höcker entsprechen den Thalamuskernen. Immer nachweisbar ist vorn das Tu berculum ant erius, die gewölbte Oberfläche des Nucleus anterior thalami. Auch die Scheidung zwischen einem medialen und einem lateralen Thalamuskerne ist zuweilen ansgesprochen. Innen ist der ganze Thalamus bedeckt vom centralen Höhlengrau, das auf eine kurze Strecke sich mit dem Grau der anderen Seite zur Commissura mollis vereint. In dieses Grau tauchen ganz vorn die Fornixsäulen ein. Nahe der Stelle, wo dies geschieht, sieht man jederseits ein Faserbïndelchen sich aus der Tiefe erheben, das auf die Thalamusoberfläche gelangt und dicht an der medialen Kante rïckwärts zieht. Es taucht dann ror dem Mittel- 
hirne zum grössten Theile ein in einen langgestreckten Körper am dorsalen Thalamusrande, das Ganglion hab enula e. Das Bündel heisst Ta enia thalami und bildet einen Zuzug aus dem Riechapparate an der Hirnbasis zum Zwischenhirne.

Ein Theil der Taenia zieht, noch andere Fasern aufnehmend, weiter bis hinter das Ganglion habenulae und begiebt sich direct vor der Zirbel anf die andere Seite. Dies Stück von dem Ganglion bis zur Zirbel heisst Pedunculus conarii, weil an ihm die Zirbel aufzusitzen scheint. Die direct vor der Epiphyse liegende Kreuzung der Bündel wird als Commissura habenularum bezeichnet. Diese Kreuzung liegt direct dorsal und frontal von der Commissura posterior, von der sie meist gar nicht getremnt wurde. S. auch Fig. 144.

Die graue Masse des Thalamus ist von weissen Fasern (Stratum zonale, welche zum Theile zum Nervus opticus gelangen, überzogen. Einen Hauptursprungspunkt für diesen Nerven bildet eine Anschwellung am hinteren Theile des Thalamus, das Pulvinar. In diesem Ganglion und in einem Höcker der auf seiner Unterseite liegt (Corpus geniculatum laterale), verschwindet der grösste Theil des Nervus opticus.

Die Faserzüge aus den Hemisphären, welche zwischen diesen und dem Zwischenhirne in der Tiefe gelagert waren, treten caudal rom Zwischenhirue zum grossen Theile aus der Hirnmasse heraus und liegen dann als zwei dicke Stränge frei an der Unterfläche der folgenden Hirnabtheilung; des Mittelhirnes. Sie heissen in ihrer Gesammtheit Hirnschenkel, Pedunculi cerebri.

Hinter der Zirbel beginnt das Mittelhirndach, als dessen vordersten Theil wir die Commissura posterior ansehen, deren Schenkel durch das Mittelhirn candalwärts ziehen. Die hinter dieser Commissur sichtbar werdenden Vierhügel werden wir später noch genauer kennen lernen.

Ton dem Corpus striatum ist, wenn das Gehirn von oben her, wie wir es eben gethan, geöffnet wird, nur der mediale Theil, der Nucleus caudatus, sichtbar, der laterale, der Nucleus lentiformis, liegt tiefer und ist von den Markmassen bedeckt, die über ihn weg in die Capsula interna ziehen. Man könnte ihn zu Gesicht bekommen, wenn man nach aussen vom Nucleus caudatus in die Tiefe ginge. Besser aber werden sie sich über seine Form orientiren, wenn ein Frontalschnitt quer durch das ganze Gehirn da gelegt wird, wo in Fig. 125 hinter dem dicksten Theile (Caput) des Nucleus caudatus der Thalamus beginnt, also dicht hinter den aufsteigenden Fornixschenkeln.

Es ist nicht sehr schwer, sich über das so entstehende Querschnittsbild Fig. 127 zll orientiren. wenn Sie sich der in Fig. 22 gezeichneten Verhältnisse erimnern. Die Hirnwand ist wesentlich dicker als zur Fötalzeit, vom Boden her ragt aber noch wie auf jenem Schnitte das Corpus striatum in die Ventrikelhöhle. Der äussere Spalt ist jetzt dadurch verlegt, dass die Stabkranzfaserung aus der Rinde im spätembryonalen Leben sehr zugenommen hat. In der Tiefe des grossen Hirnspaltes wird, wie Sie sehen. 
der Ventrikel durch die dicke Querfaserung des Balkens gedeckt. Zu diesem steigen aus der Tiefe die zwei Fornixsäulen, zwischen den dünnen Blättern des Septum pellucidum den Tentriculus septi pellucidi frei lassend. Sie ragen frei in einen Hohlraum hinein, den Seitenventrikel. Dieser wird nach aussen begrenzt rom Corpus striatum. Gerade hier sehen sie sehr schön, wie das Corpus striatum von den dicken Fasermassen der inneren Kapsel durchbrochen und anscheinend in zwei Ganglien getheilt ist. Im Linsenkerne. also in dem äusseren Theile des Corpus striatum, unterscheiden Sie leicht drei Abtheilungen; nur das änssere dieser drei Glieder, das

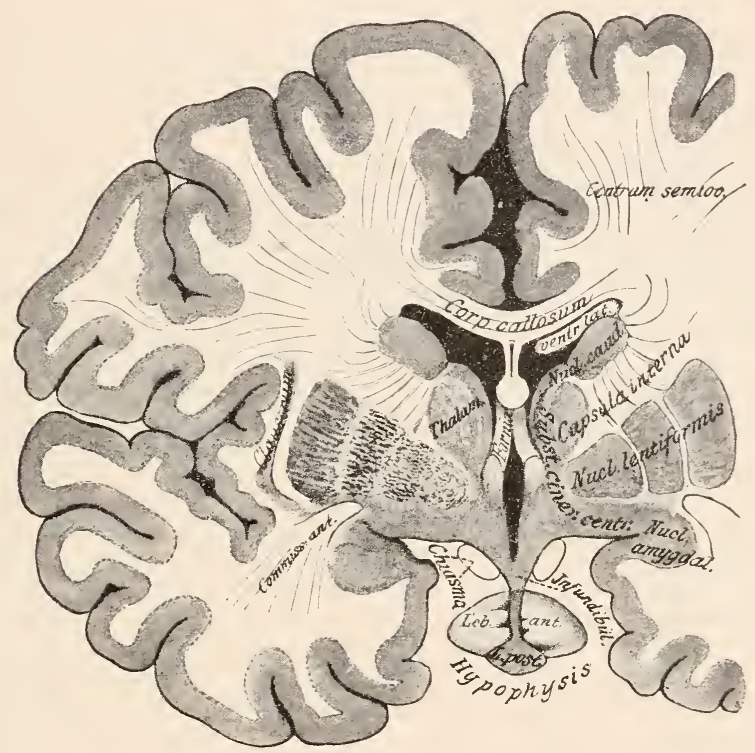

Fig. 127.

Frontalschnitt durch das Gehirn des Erwachsenen. Erkłärung im Text.

dunkler gezeichnete, Put a u en genannt, ist gemeinsam mit dem Schwanzkerne als Ursprungsgebiet ron Fasern bekannt. Die beiden inneren (Globus pallidus) sind in ihrer Bedeutung noch unklar. Der Globus pallidus besteht zuweilen aus drei und mehr Abtheilungen. Nach aussen von dem Linsenkerne liegt noch eine dünne grane Masse in der Hemisphärenwand, die Tormaner. Claustrum. Der Raum zwischen ihr und dem Linsenkerne heisst Capsula externa. Weiter nach aussen folgt dann die Rinde der Insel. Die grane Masse am Boden des mittleren Ventrikels gehört der Wand des Infundibulums, dem Tu be r cine re un an. Man bezeichnet sie und ihre Fortsetzungen als centrales Höhlengrau. 
Da. wo dieses und die Rinde des schläfenlappens an einander grenzen, liegt ein grosser rundlicher Kern. der Nucleus a my galae, Mandelkern. Er steht wahrscheinlich in Beziehungen zu dem Ursprungsapparate des Riechnerven. Aus der Gegend des Mandelkernes, wahrscheinlich aus dem Kerne selbst, entspringt ein Theil der Faserbiindel, die als stria cornea zwischen Thalamus und schwanzkern dahinziehen.

Aus vergleichend anatomischen Erfahrungen wissen wir, dass die noch dem centralen Höhlengrau zugezählte horizontale Partie der Abbildung zwischen Trichter und Mandelkern ein beim Menschen sehr atrophirtes Rindengebiet ist. Man bezeichnet sie als Riechfeld.

Zwischen den Fornixschenkeln sehen Sie in Fig: 127 die vordere Commissur. Ihre Fasern krümmen sich, indem sie durch das Corpus striatum treten, nach rückwärts. so kommt es. dass wir dicht unter dem äusseren Gliede des Linsenkerms ihrem Querschnitte nochmals begegmen. Fig. 127 links unten.

Ich kann Ihnen, meine Herren. nicht eifrig genug empfehlen, alle in der heutigen Torlesung genannten Gebilde am frischen Gehirne aufzusuchen und sich über ihre Lage durch eigene Präparation zu orientiren. Die Darstellung durch Bild und Wort wird Ihnen hierbei wohl einen festen Anhalt geben, sie kamn aber nie das ersetzen. was durch Studium am frischen Präparate gewonnen wird.

Wir wollen jetzt ein anderes Gehirn romehmen und die Windungen und Furchen der Grosshirnoberfläche betrachten.

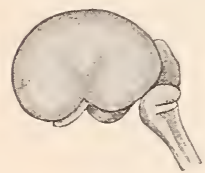

Fig. 128.

Gehirn einer menschlichen Frucht aus der 13. Woche.

Es ist noch nicht so lange her. dass die Anatomen wenig und die terzte gar kein Interesse der Lehre von der Gestaltung der Hirnoberfläche entgegenbrachten; noch ist nicht so gar riel Zeit rerflossen, seit Ordnung gebracht wurde in das anscheinend so unregelmässige Chaos der Hirnwindungen, dass klare Abbildungen an die Stelle jener älteren Tafeln getreten sind. ron denen ein Autor mit Recht sagt, dass sie eher eine Schüssel roll Maccaroni, als ein Gehirn darstellten. Für das menschliche Gehirn speciell ist das Interesse erst recht lebhaft geworden, als die Physiologie und bald genug auch die Pathologie gezeigt hatten, wie rerschiedenartig Reizungen. Exstirpationen. Erkrankungen sich äussern, je nachdem sie die eine oder die andere Windung der Hemisphärenoberfläche treffen.

Nur durch das Wort und die Zeichnung wird es mir nicht gelingen, Sie mit den Windungszügen so, wie wïnschenswerth ist, vertraut zu machen. Tollen sie deshalb ebenfalls ein Gehirn zur Hand nehmen und, meinem Tortrage folgend, Furche für Furche. Windung für Windung sich aufsuchen.

Die ursprünglich linsenfürmigen Hemisphären wachsen, wie Sie wissen, nach rorn und hinten aus. Nur in der Mitte, da. wo imnen das Corpus 
striatum liegt, folgt die Wand nicht so rasch dieser Ausdehnung und geräth so allmällich mehr in die Tiefe. Die flache Depression, welche dadurch am Stammtheile der Hemisphäre entsteht, heisst Fossa śylvii, und jene Partie, welche in der Grube liegt. der Stammlappen oder die Insula Reili. Die Insel ist also diejenige Rindenpartie, welche den Grosshirnganglien anssen anliegt. Sie ist anfangs noch ganz unbedeckt, wird aber später mehr und mehr von dem auswachsenden Grosshirne verborgen.

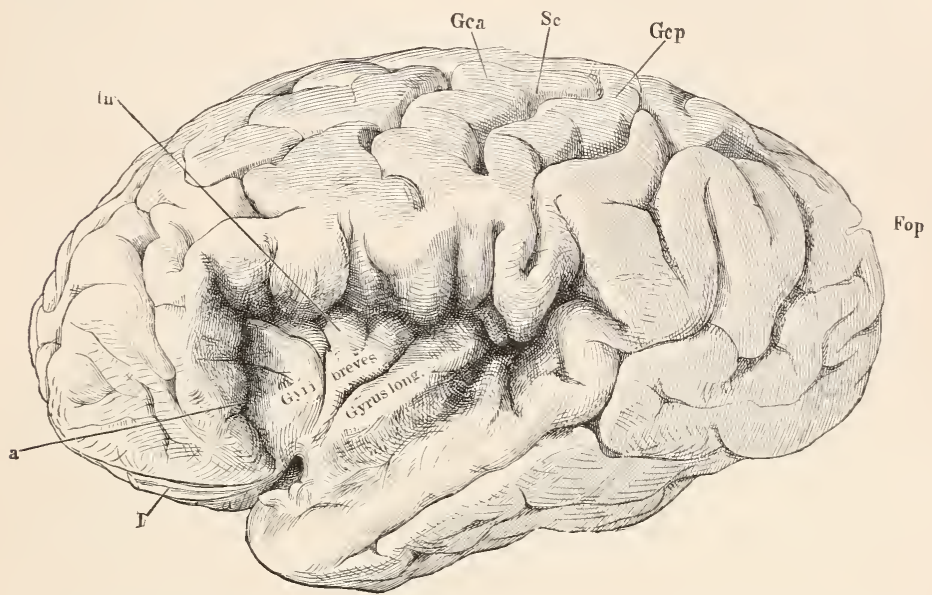

Fig. 129.

Die linke Hemisphäre mit auseinandergezogener Fissura Sylvii, um die Windungen der Insel $I n$ zu zeigen. Sc Sulcus centralis. Gica, Gicp Gyrus centralis anterior und posterior. Fop Fiss. parieto-occipitalis. Nach Henle.

sie finden leicht am ausgebildeten Gehirne diese Grube und ihre caudale Verlängerung, die grösste der Hirnfurchen, die Fissura Sylvii auf und entdecken, wemn sie dieselbe auseinanderziehen, in ihrer Tiefe die Insel, die, wie sie dann sehen, von einigen senkrecht und schräg gestellten Furchen durchzogen ist. Im fïnften Schwangerschaftsmonate sind die Theile der Sylvischen Spalte. ein vorderer und ein hinterer, schon sehr deutlich. Das übrige Gehirn ist noch glatt. (Tgl. Fig. 23.)

Von dieser Entwicklungszeit ab treten auf der Hirnoberfläche durch locale Erhebungen der Hemisphärenrinde Furchen (Sulci) auf, welche in den späteren Monaten sich mehr und mehr ausbilden, bis damn zur Zeit der Geburt fast alle Furchen und Windungen dentlich ansgeprägt sind, welche das Gehirn des Erwachsenen besitzen wird.

Die folgenden rein schematischen Abbildungen mögen Ihnen als Vegweiser beim Studiren der Hirnoberfläche dienen. Nur die wichtigeren constanten Windungen und Furchen sind darin aufgenommen. Das einfache Schema prägt sich leichter dem Gedächtnisse ein, als Abbildungen 
der wirklichen Hirmoberfläche, welche alle die kleineren Windungen, die seichteren Furchen, welche inconstant sind, neben den tieferen constanten Gebilden wiedergeben. Wollen Sie zunächst die Fissura Sylvii aufsuchen. Sie trennt den grössten Theil des Schläfenlappens rom übrigen Geliirne. Man unterscheidet einen langen hinteren und einen oder zwei kurze vordere, nach oben gerichtete Schenkel an ihr. Die Gehirmmasse, welche da liegt, wo jene zusammenstossen, deckt die Insel zu und heisst Operculum. Wenn man die Hirntheile, welche die Sylvische Spalte umgeben, auseinanderzieht, wie es an dem Fig. 129 abgebildeten Präparate geschehen ist, so bietet sich die Insel frei dem Blicke. Man erkennt, dass sie durch ein tiefe, schräg von vorn nach hinten über sie aufwärts ziehende Furche, sulcus centralis insulae, in 2 Iäppchen getheilt wird. In dem

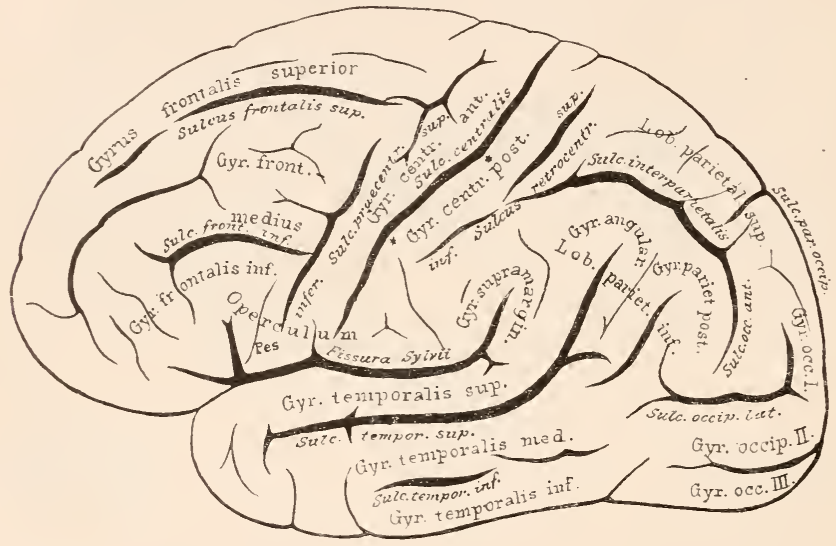

Fig. 130.

Seitenansicht des Gehirnes. Der Gyri und Lobuli sind mit Antiquaschrift, die Sulci und Fissurae mit Cursivschrift bezeichnet.

vorderen breiteren bilden melırere fast senkrecht gestellte Furchen 3-4 Gyri breves insulae, das hintere ist eigentlich nur ein einziger längerer Windungszug, der Gyrus longus. Er grenzt direct an den Schläfenlappen. In dem Operculum begimnt eine wichtige Furche, die von da zur Hirnkante aufsteigt, oft auch in diese einschneidet, der Sulcus centralis, die Centralfurche. Nicht selten theilt eine kleine Uebergangswindung in der Tiefe der spalte diese in eine untere und eine obere Hälfte. Die neueren chirurgischen Operationen am Gehirne, ebenso die aus physiologischen studien gewomnene Erkenntniss haben es wünschenswerth gemacht, die Länge der Furche in Theile zu zerlegen. Als Anhaltspunkte dienen die beiden auf der Abbildung mit * bezeichneten Ḱniee, das obere und das untere Knie der Centralspalte. Suchen sie sich die Furche in Fig. 130 auf. Sie tremnt den Lobus frontalis rom Lobus parie- 
talis. Was nach unten von der sylvischen spalte liegt, lieisst Lobus temporalis. Tor dem sulcus centralis liegt die vordere Centralwindung '), hinter ihm die hintere Centralwindnng ${ }^{2}$ ). Das Gebiet vor der vorderen Centralwindung, der stirnlappen, wird durch zwei Furchen, die obere und die untere stirnfurche, in drei Windungen, die obere, mittlere und untere Stirnwind ung, getheilt. Diese Stirnwindungen sind nicht immer in der ganzen Länge des Stirnlappens scharf von einander geschieden, da die stirnfurchen oft genug nach kurzem Verlaufe durch Querbrïcken unterbrochen werden. Sie finden leicht an jedem Gehirne diese drei ïber einander liegenden Theile des Stirnlappens und bemerken wohl auch, dass sie mit der vorderen Centralwindung durch mehrere Uebergangswindungen zusammenhängen. Geschieden werden sie ron dieser Windung durch eine in ihrer Länge und Tiefe sehr veränderliche Furche, den sulcus praecentralis, von dem neben einem constanteren unteren zuweilen ein kïrzerer oberer Abschnitt nachweisbar ist. Das Verhältniss, welches hier die Abbildung der Figur 130 bietet, soll nach Untersuchungen ron schnopflı gen das häufigste sein.

An der sehr breiten mittleren Stirnwindung wird neuerdings ein medialer von einem lateralen Abschnitte unterschieden. Die untere Stirnwindung wird von den beiden kurzen vorderen Aestchen der Fissura Sylvii eingeschnitten. Sie vereinen sich in Form eines $V$ am Hauptaste. Die Gegend dieses V ist der als Pars opercularis bezeichnete Abschnitt der Windung. Hier kommen je nach der Höhe der intellectuellen Entwicklung nicht unbeträchtliche Variationen vor. Speciell der Abschnitt, welcher zwischen dem caudalen Schenkel des V und der vorderen Centralwindung liegt, der Fuss der unteren Stirnwindung, ein einfacher Windungszug, zeigt oft Einkerbungen, Verbreiterungen u. dergl. Am Gehirne Gambetta's, bekanntlich eines hervorragenden Redners, war er links zur Doppelwindung geworden (H e rvé).

Das Gehirn der anthropoiden Affen ist an Windungszügen dem des Menschen ausserordentlich ähnlich. Was es aber von jenem ganz besonders scheidet, das ist die Entwicklung der Stirnwindungen. Die obere und die mittlere sind immer sehr viel kürzer, die untere ist nur in Rudimenten nachweisbar. Es ist sehr wahrscheinlich, dass dies der anatomische Ausdruck für geringere Intelligenz und besonders auch für das ganz unentwickelte Vermögen zu artikulirter Sprache ist. Da wir wohl unserem Sprachvermögen die Ausbildung unserer Intelligenz verdanken - nicht das Individuum, sondern die Gesammtheit ist gemeint so kann man vielleicht in der mangellıaften Ausbildung der unteren Stirnwindung die Ursache der geringeren Entwicklung des ganzen Stirnhirnes der Affen finden.

Der Schläfenlap pen ist von mehreren Furchen durchzogen, welche parallel mit der Fissura Sylvii laufen und eine obere, mittlere und untere Temporalwindung mehr oder weniger scharf von einander tremnen. Meist sind nur die beiden ersten in ihrer ganzen Länge deutlich abscheidbar.

Suchen Sie jetzt das Gebiet hinter der Centralfurche, nach oben rom Schläfenlappen auf; es heisst Parietallappen. In ihm wird durch

$\left.\begin{array}{l}\text { 1) Circonvolution frontale ascendente } \\ \text { 2) Circonvolution pariétale ascendente }\end{array}\right\}$ der französchen Autoren. 
eine Furche. Sulcus interparietalis, welche im Bogen um die Enden der Fossa sylvii und der ersten Schläfenfurche herumlänft, ein oberer und ein unterer Parietallappen abgeschieden. Der obere ist durch nichts vom grössten Theile der hinteren Centralwindnng geschieden, wenn nicht, was übrigens oft rorkommt, ein Zweig des Snlcus interparietalis nach der Hemisphärenkante linanfsteigt und so die Verbindıng bedeutend verschmälert.

Dieser Ast, Fissura retrocentralis sup., kommt auch getreunt von der Interparietalspalte vor. Die Interparietalspalte lässt drei, gelegentlich auch gesondert auftretende Abschnitte erkennen. Der frontale Abschnitt wird als Fissura retrocentralis inf., der caudale als $S$ uleus oceipitalis anterior oder pérpendicularis bezeichnet.

Den Theil des unteren Scheitellappens, welcher das Ende der Fissura Sylvii umkreist, nennt man Gyrus marginalis, den dahinter liegenden Theil, welcher um die obere Schläfenfurche zieht, Gyrns angularis. Den ersteren sehen Sie an jedem Gehirne sofort, den letzteren Gyrus müssen

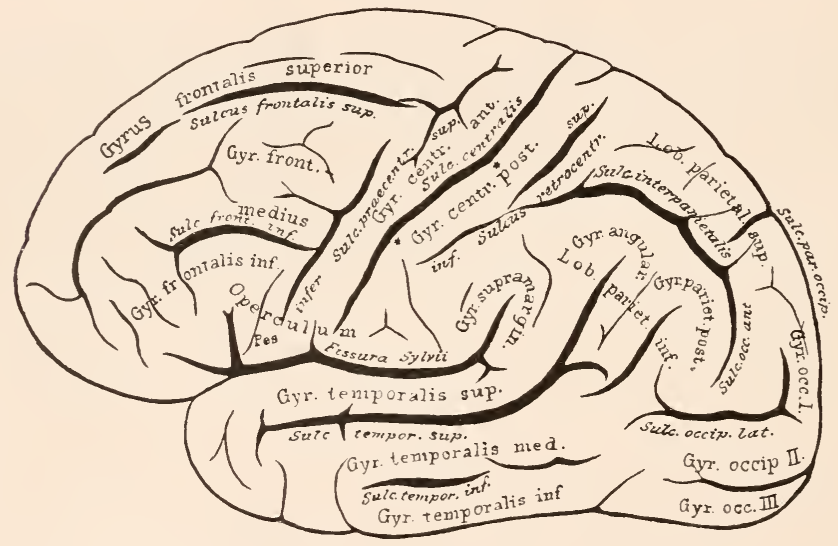

Fig. 131.

Seitenansicht des Gehirnes.

Sie sich mit etwas mehr Mühe anfsnchen. sie finden ihn in dem Raume, welcher von der Interparietalfnrche nach oben, von der oberen Schläfenfurche, resp. deren Ende nach inten abgeschlossen ist; eben um dieses Ende schlägt sich ja sein hinterer Theil herum. Die Gegend des Gyrms angularis ist localisatorisch wichtig. Es ist deshalb vortheilhaft, sie gnt begrenzen zu können. Der kleine Windungszug, direct caudal von derselben, lässt sich als Gyrus parietalis posterior bezeichnen.

Der Occipitallappen ist aussen nicht in allen Gehirnen so gleichmässig gefurcht, dass man immer die ron den Autoren angegebene obere, 
mittlere und untere Occipitalwindung leicht und ohne Künstelei wiederfinden könnte. Ton dem scheitellappen ist er gewöhnlich durch die vordere Occipitalfurche, welche senkrecht hinter dem Lobus parietalis inferior herabzieht, geschieden. Eine oder zwei etwa horizontal gestellte kleine Furchen trennen die kleinen Windungen unter sich.

Haben sie alle diese Furchen nnd Windungen gefunden, so schneiden sie das Gehirn, dem grossen Längsspalte zwischen den Hemisphären folgend. mitten durch und studiren nun die mediale Seite desselben.

Die wichtigsten Theile der medialen Hemisphärenwand haben wir schon in der 2. Vorlesung kennen gelernt, als wir die Entwicklungs-

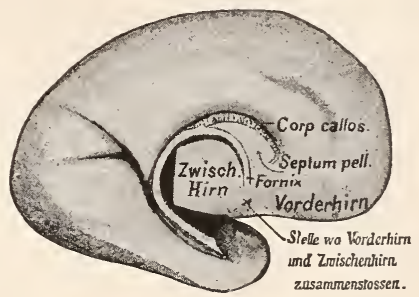

Fig. 132.

Innenansicht der auf Fig. 23 abgebildeten embryonalen Hemisphäre; zeigt den inneren unteren Rand der Hemisphäre, welcher zum weissen Markstreif des Fornix verdickt ist. Derselbe wird aber erst nach der Geburt markweiss. geschichte derselben studirten. Ich erimere Sie nochmals daran, dass wir damals erfuhren, dass der Hemisphärenrand zum Fornix verdickt in einem Bogen der nach hinten und unten auswachsenden Hemisphäre folgt, dass vorn, da wo der Balken durchbrach, noch dasjenige Stück der Innen-

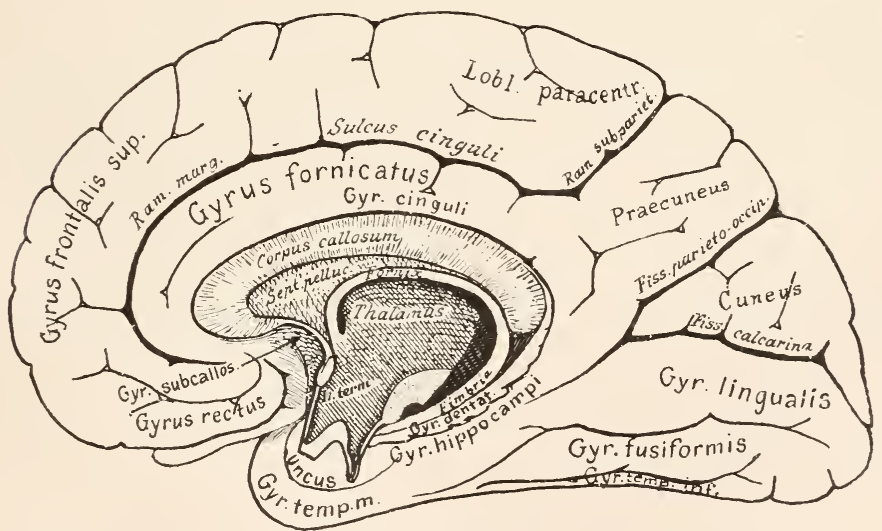

Fir. 133.

Längsschnitt durch die Nitte eines Gehirnes vom Erwachsenen. Der hintere Theil des Thalamus, die Hirnschenkel u. s. w., sind abgetrennt, um die Innenseite des Schläfenlappens frei zu legen.

wand, welches zwischen ihm und dem Fornix lag, als Septum pellucidum erhalten blieb.

Durch die Entwicklungsgeschichte orientirt, verstehen sie leicht den 
vorhin angefertigten Schnitt durch das Gehirn des Erwachsenen. An dem Präparate, nach welchem vorliegende Zeichnung Fig. 133 gefertigt wurde, sind, ebenso wie hier an dem wieder demonstrirten embryonalen Gehirne (Fig. 132), alle Theile, welche hinter der Mitte des Thalamus liegen, abgeschnitten, weil sie die Unterseite des schläfenlappens verdecken und ein Verfolgen der Fornixzüge nicht gestatten.

Sie erblicken also jetzt auf dem Längsschnitte in der Mitte das Zwischenhirn. resp. seine laterale Wand, den Thalamus opticus. An der Grenze zwischen ihm und dem Grosshirne zieht der zu einem weissen Markstreifen verdickte Hemisphärenrand, der Fornix. im Halbbogen dahin. In der grauen Substanz hinter der Lamina terminalis tritt er wahe der Hirnbasis zuerst auf, steigt als Columna fornicis dorsalwärts, begleitet den Rand der Hemisphäre dann immer weiter. krümmt sich mit ihm in den Schläfenlappen und endet erst an dessen spitze.

Die horizontale Masse quer durchtrennter Fasern über dem Fornix gehört dem Balken (Corpus callosum) an; an diesem erkennen Sie vorn das Knie, Genu, hinten das Splenium, den Wulst, und in der Mitte den Körper. Zwischen Balken und Fornix liegt das dreieckige Feld des Septum. Ausserdem erkennen sie dicht vor dem Fornix unten die Commissura anterior auf dem Querschnitte. Sie liegt mitten in der Lamina terminalis, die sich damn ventralwärts in den Boden des Zwischenhirnes fortsetzt und hier durch das quer getroffene Chiasma etwas eingestülpt wird. Ich habe absichtlich diese zum Theile nur häutigen Gebilde an unserem Präparate stehen lassen. damit Sie sich hier wieder eimmal den ventralen Abschluss des mittleren Ventrikels ansehen können. Auch die Hinterwand. das Infundibulum und ihren Uebergang in das ventrale Nittelhirngebiet. den Haubenwulst. habe ich nicht abgeschnitten. Wollen Sie aber an ihrem Präparate alle diese grauen Theile abheben und beobachten, wie der Fornix hinter der mit Lncus bezeichneten Stelle sein Ende findet.

Der Theil der Hemisphärenscheidewand, welcher über dem Balken liegt, ist von wenigen und ziemlich constanten Furchen durchzogen.

Zunächst zieht dem Balken parallel der Sulcus cinguli. Hinten wendet er sich nach oben zur Hemisphärenkante und endet dort in einem kleinen Einschnitte caudal von der hinteren Centralwindung.

Der Sulcus cinguli, welcher auch die Namen Sulcus callosomarginalis, Randfurche, Fissura limbica, Fissura splenialis führt, besteht eigentlich aus drei hinter einander liegenden, nicht selten wirklich getrennten Stücken.

Was nach vorn und oben von dieser Furche liegt, rechnet man zur oberen Stirnwindung; der Windungszug, welcher zwischen der Furche und dem Balken einherzieht. heisst Gylus fornicatus. Ein Blick auf ein Präparat oder auf unsere Abbildung zeigt Ihnen. dass der Gyrus fornicatus sich in seinem hinteren Theile nach oben hin verbreitert und iiber die Hemisphärenkante hinweg direct in den Lobus parietalis superior übergeht. Diese Verbreiterung heisst Praecuneus. Direct vor dem Prae- 
cuneus liegt eine Rindenpartie, welche aussen an beide Centralwindungen anstösst und diese unter einander verbindet. Sie wird als Paracentrallappen bezeichnet.

Hinten erreicht der Praecuneus sein Ende an einer tief einschneidenden, immer etwas auf die Aussenseite der Hemisphäre übergreifenden Furcle, der Fissura parieto-occipitalis. Diese Fissura parieto-occipitalis greift manchmal sehr weit über die Imnenfläche hinaus und verläuft als tiefe, senkrechte Furche, Fiss. perpendicularis ext., aussen über die Hemisphäre. Das ist namentlich häufig bei Idiotengehirnen der Fall. An fast allen Affengehirnen beginnt in der Fiss. par.-occ. (oder dicht hinter ilnr. Ziehen und Kükenthal) eine breite spalte, welche über den grösseren Theil der lateralen Hirnoberfläche herabzieht und in sehr auffallender Weise den scheitellappen von dem Schläfenlappen trennt. A ffenspalte.

In die Fissura parieto-occipitalis mündet in spitzem Winkel die Fissura calcarina. Diese Furche liegt gerade in der Aussenwand des früler genannten Hinterhorns des Seitenventrikels. Die durch sie eingestïlpte Hirnwand markirt sich als länglicher Wulst in den Hinterhorne. Dieser Wulst wird als Calcar avis bezeichnet. Der dreieckige, von den beiden letztgenannten Furchen eingeschlossene Rindentheil heisst Cu u eus. Suchen Sie sich jetzt die Spitze desselben auf. so finden Sie oben oder auch mehr in der Tiefe einige kleine Uebergangswindungen zum Ende des Gyrus fornicatus. der vorn an der Spitze des Keiles vorbeizieht. Behalten sie diese ziemlich schmale stelle, den Hilus des Gyrus fornicatus, in Auge; Sie sehen, dass derselbe sich von da als sich rasch wieder verbreiternde Windung bis zur Spitze des Schläfenlappens fortsetzt, wo er mit einer hakenförmigen Umbiegung; dem Uncus oder Gyrus uncinatus, eldet.

So umfasst diese Windung also den ganzen Hemisphärenrand. In der That bezeichnet man sie als Randwindung, wo dann nur der frontale Abschnitt den Namen Gyrus fornicatus behielte, während dem caudal und ventral bleibenden Theile der Name Gyrus hippocampi gegeben ist. Ton hinten mündet, wie sie an der Figur gut sehen, noch ein kleiner länglicher Gyrus des Occipitallappens in den Gyrus Hippocampi; er heisst Gyrus lingualis (zungenförmige Windung).

Wie ich Ilmen vorhin gezeigt, bildet der Fornix den Rand der Hemisphäre. Das erste anf diesen folgende Stück der Hirnwand ist der eben genannte Gyrus Hippoca mpi, der also dem Fornix dicht anliegt. Nach aussen von ihm liegt der Hohlraum des Tentrikels, das Unterhorn.

Von der schädelhöhle ist der Tentrikel an dieser Stelle nur durch eine dünne, Gefässe führende Membran, die Fortsetzung des ja ïberall an den Fornix grenzeuden Plexus choroideus getrennt.

Der Gyrus Hippocampi ist noch von Rinde ïberzogen, aber jenseits, nach dem Unterhorne hin, hört die Rinde auf, und es liegt dicht am Tentrikel das weisse Mark bloss, nicht mehr grau überzogen, wie auf der ganzen Aussenseite des Gehirns. Dieses Mark, ein langer, dïnner. weisser 
Streif. setzt sich direct nach oben in den Fornix fort; es heisst Fimbria (Fig. 133).

Die Randwindung ist durch eine Furche ihrer äusseren Óberfläche, die Fissura Hippocampi, in den Hohlraum des Unterhorns vorgetrieben: der dadurch längs des ganzen Tnterhornbodens entstehende Wulst fïhrt seit Alters den Namen Cornu Ammonis oder Pes Hippocampi major.

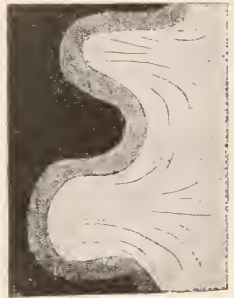

Fig. 134 a.

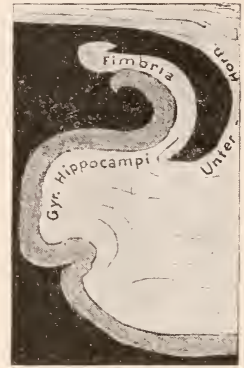

Fig. $13 \pm b$.

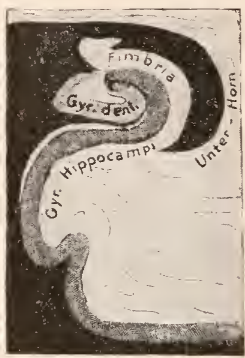

Fig. $134 c$,

Dadurch, dass die Rinde des Gyrus Hippocampi, ehe sie iiberhanpt aufhört und das Markweiss frei lässt, noch durch jene Furche eingestiilpt wird, entsteht ein eigenthümliches, etwas complicirtes Bild, wenn man sie quer durchschneidet. Teber die Himoberfläche zielt die Rinde sonst continuirlich dahin, wie es auf Fig. 134 a abgebildet ist, am Randwulste aber endigt sie, wie Fig. $134 \mathrm{~b}$ es andeutet, nahe dem Ventrikel und lässt den weissen, etwas umgebogenen Saum (die Fimbria) frei. Die Einstillpung, welche sie erfährt, ehe sie dort endet, soll Fig. 134 b zeigen. Zwischen Gyrus Hippocampi und dem freien Markrande der Hemisphäre (Fimbria - Fornix) liegt aber noch ein kleiner, bislang absightlich unerwälnter Windungszug, der vom Balkenende hinab zur Spitze des Schläfenlappens zieht und also ebenfalls in die Configuration des Ammonshornes eingeht. Auf dem vorhin demonstrirten Sagittalschnitte wollen Sie diese als Gyrus dentatus sive Fascia dentata bezeichnete dimne Wiudung aufsuchen, um sich deren Lage zu Fornix und Ammonswindnug ganz klar zn machen. Sie legt sich, wie Sie dort sehelı, gerade vor die durch die Furche gebildete Einrollung der Ammonsrinde, deren Querschnitt also nicht durch Fig. 134 b, sondern richtiger durch Fig. $134 \mathrm{c}$ wiedergegeben wird.

Das Ammonshorn ist also die Vorstülpung, welche im Ventrikcl dadurch entsteht, dass der Gyrus Hippocampi durch die gleiclmamige Fissura eingebogen wird. Dadurch, dass die Gyrusrinde gerade an dieser Stelle endigt, dadurch, dass das Hemisplärenmark als Fimbria und der Gyrus dentatus iiber diese Einstiilpung hin verlaufen, entsteht das complicirte Quersehnittsbild des Cornu Ammonis.

Die Lage der Ammonswindung zum Unterhorne des Seitenventrikels wird am leichtesten klar, wenn Sie ilıre Querselmitte auf den grossen Hirnabschnitten verfolgen, welche Fig. 175, 185, 156, 157 gezeichnet sind.

Der Gyrus fornicatus und seine Fortsetzung, der Gyrus Hippocampi, werden beim Embryo ziemliclı früh angelegt. Es tritt nämlich dorsal vom Hemisphärenrande (Fornixbogen) bei allen Säugethieren eine Furche auf, dic, dem Rande parallel, auch mit ihm in den Schliafenlappen hinabzieht, die $\mathrm{R}$ a $\mathrm{n} \mathrm{d} \mathrm{fur} \mathrm{el}$ e, 
Fissura limbica, Der Windungszug, den sie zwischen sich und dem Fornix lässt, ist die Randw in dung. In dem frontaleren Hirngebiete brechen zwischen dieser und dem Fornix die Balkenfasern durch; dort heisst sie Gyrus fornicatus, in der caudaleren grenzt aber die num als Gyrus Hippocampi, Ammonswindung, bezeichnete Windung fast direct an den Fornix. Bei den meisten Säugethieren ist der Balken und mit ihm der Gyrus fornicatus sehr kurz.

Tenn Sie nun noch einmal sich die Oberfläche des Balkens betrachten wollen, so erblicken Sie auf diesem jederseits einen dünnen, grauen Längsstreifen (Fig. 124 Lt.). Das ist die Fortsetzung jener schon im Ammonshorne atrophischen Windung, des Gyrus dentatus. Man bezeichnet sie als stria longitudinalis La neisi.

Am hinteren Ende des Balkens sieht man manchmal einen kurzen Windungszug in der Richtung nach dem Fornix sich erstrecken, mit dem er verschmilzt. Das ist der Gyrus callosus, der beim Menschen nur als sehr atrophisches, nicht einmal constantes Gebilde vorkommt.

Am frischen Gehirne wollen Sie an der Spitze des schläfenlappens immen den Gyrus uncinatus aufsuchen und von da an den Gyrus Hippocampi nach oben verfolgen. Damn suchen Sie den leicht findbaren Bogen des Fornix über dem hinteren Theile des Thalamus und constatiren, wie er in die Fimbra übergeht, welche bis nahe an die Spitze des Cornu Ammonis als weisser Markstreif sichtbar ist. Schliesslich legen Sie einen Frontalschnitt an, der über die Lage der genannten Gebilde zum Unterhor'n Aufschluss geben wird.

An der Basis des Gehirnes finden sich ausser der Fissura Hippocampi, die eigentlich der Innenseite angehört, nur noch wenige wichtige Furchen. An der Unterfläche der Stirnlappen liegen die Sulci orbitales und olfactorii. Die Windungen zwischen ilnen werden als Fortsetzungen der Stirnwindungen mit dem Namen der betreffenden an sie grenzenden Windung bezeichnet.

Die basale Stirnlappenrinde grenzt an das dem Riechapparate zugehörende Grau der Hirnbasis, das wir erst später zu besprechen haben. Zwei kleine von ihr aus sich dicht neben der Medianlinie dorsalwärts erstreckende Wülste, der Gyrus rectus und der hinter diesem liegende Gyrus subcallosus gehören vielleicht dem Riechapparate an. Jedenfalls entsteht der letztere vornelımlich durch die Hervorwölbung, welche ein unter ihm daherziehendes Bündel erzeugt, welches aus den Endstätten der Riechstrahlung hinauf iber das Septum in den Fornix zieht. Es ist das jenes Bündel, welchem ich bei den niederen Vertebraten so grosse Bedentung für die Dentung der medialen Hirnrinde glaubte beilegen zu müssen. Siehe Fig. 100 und 76, Tr. cortico-olfactorius septi.

Schläfenlappen und Hinterhauptlappen lassen sich an der Basis nicht von einander trennen. Längsgerichtete Furchen in geringer Zahl durchziehen das gemeinsame, im Tesentlichen im Temporallappen zugerechnete Gebiet. Die mittlere Temporalwindung reicht nur zu geringem Theil nach der Basis, was sichtbar ist, gehört fast ganz der unteren - dritten - Schläfenwindung an. Diese wird durch eine fast immer melngetheilte und ziemlich flache Furche, den Sulcus temporalis inferior, abgeschieden von einem langen, spindelförmigen Windungszuge, der, immer 
gut nachweisbar, als Gyrus fusiform is bezeichnet wird. Dieser Gyrus grenzt ganz direct an den langen Gyrus Hippocampi. Geschieden wird er ron ihm durch eine lange tiefe und schon sehr früh im Embryonalleben auftretende Spalte, die Fissura collateralis, welche über die ganze Unterfläche des Gehirnes rom Hinterhauptlappen bis zur Spitze des schläfenlappens dahinzieht.

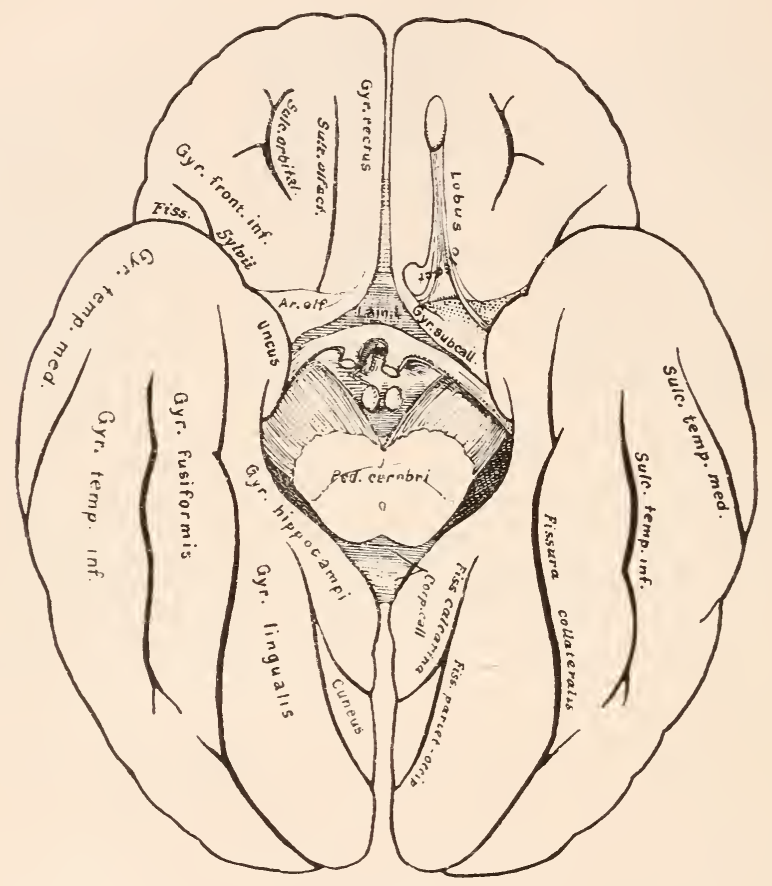

Fig. 135.

Die Windungen an der Hirnbasis (schematisirt). Das Chiasma zurückgeschlagen.

Man kann die Hirnfurchen besonders leicht dem Gedächtnisse einprägen, wenn man sie statt am reifen Gehirne eimmal am werdenden Organe studirt. Dabei ergeben sich noch als Nebengewinn einige morphologisch sehr interessante Dinge.

Betrachtet man das ganz frühe Gehirn, welches Fig. 20 abgebildet ist, so erkennt man, dass längs dem grösseren Theile des Innenrandes, an der Stelle, wo die Vorderhirnwand in die dünne nur aus Epithel bestehende Deckplatte übergeht, eine Furche läuft, deren beide Wände eben ron jener Epithelplatte gebildet werden Diese Furche lat $\mathrm{His}$ als $\mathrm{F}$ is - 
sura chorioidea bezeichnet. Sie wird im späteren Leben von den hier einwachsenden Gefässen ausgefïllt und ist dann, weil ihre Wände den Ueberzug des Plexus chorioides bilden, nicht mehr nachweisbar.

schon innerhalb des zweiten und dritten Nonates begegnet man damn einer zweiten Furche, der Bogenfurche, Fissura arcuata. Etwas dorsal von der Fissura chorioidea, welche gewissermaassen den Hemisphäremrand markirt, läuft sie an der Imnenseite des Gehirnes im Bogen um diesen Rand hermm, so an der Imnenseite des Gehirnes die Anlage der Randwindung, des Gyrus cinguli abscheidend. Aus dem frontalen Abschnitte der Kandwindung wird später der Gyrus fornicatus, aus seinem caudalen der Gyrus Hippocampi. Wollen Sie. wenn sie hier erfahren, wie frül sich voul der Hirnwand das Gebiet der Randwindung abhebt, sich erimnern, dass bei den Amphibien und Reptilien das gleiche Hirngebiet als dasjenige geschildert wurde, welches sich des phylogenetisch ältesten Rindenbelages erfrent.

Noch ist das Gehirn, welches wir betrachten, auf der Aussenseite glatt und auf der medialen eben durch die Bogenfurche leicht differenzirt. Nun aber, etwa zu Anfang des dritten Monates, zeigt sich eine schöne Bestätigung des Satzes, den ich Ihnen früher mittheilte, dass nämlich die Hirnfurchen resultiren aus der Differenz zwischen dem Wachsthume des Schädeldaches und den Wachsthumanlagen, welche dem Gehirne innewohmen. Es treten nämlich, nur bei den Primaten, deren Gehirn ja allmählich die grösste Ausdehnung erlangt, Furchen auf, welche an der Innen- und auch an der Aussenseite des Gehirnes fächerförmig angeordnet sind. Sie convergiren nach der Schädelbasis zu und haben, variirend in ihrer Zahl und wesentlich auf der medialen Wand ausgebildet, ganz den Verlauf, wie man ilm fordern muss, wenn das Gehirn einem Drucke in seiner Mantelausdehnung begegnet.

Im Verlaufe des vierten Monates etwa, in der gleichen Zeit, wo sich die Balkenfasern zwischen den Hemisphären entwickeln, verschwinden diese ersten Furchen wieder, und zu Anfang des fünften Monates ist die ganze Hemisphäre wieder glatt. Bei anderen Säugern hat man diese transitorischen Furchen noch nie gefunden, aber ich kann Ihnen die interessante Thatsache mittheilen, dass unter Umständen, bei abnormen Wachsthumsvorgängen des Gehirnes Furchen von gleichem Verlaufe die Oberfläche des reifen Gehirnes bedecken. Gerade rein mechanische Störungen führen $\mathrm{zu}$ solcher Radiärfurchung, wie das Beispiel, welches ich Fig. $137 \mathrm{ab}$ bilde, Ihnen sofort zeigt.
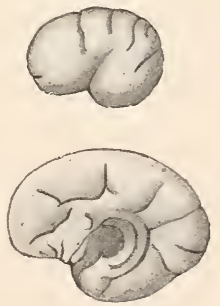

Fig. 136.

Transitäre Hirnfurchen nach Cunningham.

Gehirne von Föten der 11. und 13. Woche.

Auch bei einigen niederen Säugern, bei den Beutelthieren, findet man hier und da solche radiär gestellte Furchen am Gehirne.

sind die transitorischen Furchen nun auch im fünften Monate wieder gewöhnlich verschwunden, so bleibt doch eine gewisse Tendenz zu ähnlicher Furchenentwicklung bestehen. Es entwickelt sich nämlich sehr früh die Fissura parieto-occipitalis, siehe Fig. 132, ganz im Terlaufe einer solchen längst vieder ausgeglichenen Furche, und auch auf der Aussenseite des Gehirnes findet man, bei den Affen wenigstens, eine wohl von ihr ausgehende 
Verlängerung, die Fiss. perpendicularis ext. Auch die Fissura calcarina, welche sehr früh nachweisbar wird, liegt in der Richtung dieser alten vergänglichen Furchen.

Nun aber, wohl gegen Ende des fünften Monates, beginnt die Entwicklung der Furchen. welche wir vorhin vom reifen Gehirne kennen gelernt haben. Die Sylvische Grube, deren Entstehen frïher dargelegt wurde, wird enger, die Hirnwand um sie herum wächst und hängt bald ron allen Seiten über sie hinab. Die Insel fängt an in der Tiefe zu rerschwinden, die Ränder der Grube nähern sich mehr und mehr, und gegen Ende des Fötallebens berühren sie sich; die Fissura Sylvii mit ihren

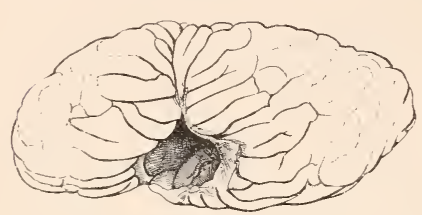

Fig. 13i.

Grosse Narbe an der Aussenseite eines Grosshirnes, nach Ziegler. Alle Windungen convergiren nach dem Punkte, wo sich das Gehirn nicht ausdehnen konnte.

Aesten vermittelt allein noch den Zugang in die einstmals breit offene Grube ïber der Insula Reilii.

Schon am Ende des fünften Nonates ist dorsal ron ihr die Anlage der Centralfurche aufgetreten.

Allmählich, im Laufe des sechsten und siebenten Monates gesellen sich num zu diesen wenigen Furchen alle anderen. Aber sie sind noch so wenig verzweigt, noch so einfach angelegt. dass ein Blick auf das

Fötalgehirn von Ausgange des siebenten Monates, welches ich hier vorlege, genïgt, um mit einem Nale die wichtigsten Theile der Hirnfurchung zu übersehen. Es ist wie ein Schema der Hirnfurchen, was hier vor uns

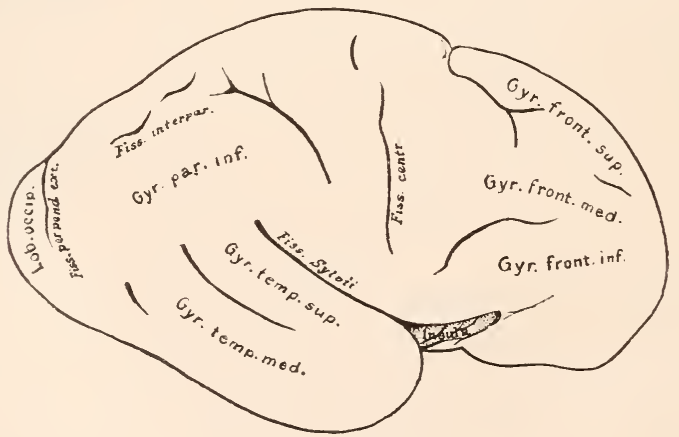

Fig. 135.

Gehirn aus dem Ende des siebenten Monates.

liegt. Die Centralwindungen vor und hinter der Centralfurche, die drei Stirnwindungen, noch recht unvollkommen von einander getrennt, der obere und der mntere Theil des Scheitellappens, zwischen denen die drei Componenten der Fissura interparietalis sichtbar sind und schliesslich der 
dreigetheilte Schläfenlappen, das Alles springt herror und ermöglicht Ihnen - eimmal gut begriffen — sehr leicht ein Zurechtfinden später am reifen Gehirne.

Das hohe Interesse, welches man der Ausbildung der Hirnfurchen schenkt, ist aber nicht durch das rein Morphologische bedingt. Seit man iiberhaupt das Gehirn wissenschaftlich studirt, hat man die Frage zu beantworten gesucht, ob etwa in der Ausdehnung der Grosshirnoberfläche sich die geistige Bedeutung ihres Trägers irgendwie wiederspiegele. Gall schon glaubte sich berechtigt, den Satz aufzustellen, dass geistig besonders hochstehende Menschen ein grösseres und windungsreicheres Grosshirn hätten als andere, und dass vorwiegend die Stirnlappen bei den ersteren besser entwickelt seien.

Hier liandelte es sich aber mehr um einen allgemeinen Eindruck als um das Ergebniss exact messender und vergleichender Beobachtung. Wirklich emste Studien in dieser Richtung datiren erst von dem Tage an, wo Rudolf Wagner 1860 der Göttinger Gesellschaft der Wissenschaften den Bericht über die Untersuchungen vorlegte, welche er an dem Gehirne des berühmten Mathematikers Gauss und an einigen anderen Gehirnen von Gelehrten und Denkern angestellt hatte. Seitdem sind wir in den Besitz einer sehr grossen Anzahl von Windungsschilderungen gekommen.

Es giebt kaum eine Furche, kanm eine Windung, die nicht schon eine eigene kleine Literatır aufzuweisen hätte. Von allen sind die typischen Verlaufsverhältnisse und eine gewisse Anzahl von Variationsmöglichkeiten gut bekannt. Wir besitzen Schilderungen der Hirnoberfläche nicht nur von Europäern, sondern auch von Angelı̈rigen vieler fremden Völker; die anthropoiden Affen sind zum Gegenstande sehr zahlreicher Arbeiten gemacht, und auch den anderen Affen ist ein sehr eifriges Studium von vielen Seiten gewidmet worden. Wir kennen fïr den Menschen und für viele Affen auch die Entwicklung der Windungen nun ganz genau. Bei diesen Studien, hat sich herausgestellt ( $\mathrm{Cunningham}$ ), dass keineswegs bei allen Individuen die embryonalen Furchen und Windungen gleichzeitig auftreten oder anch nur gleiche Configuration haben, wemn sie einmal dentlich vorhanden sind. Diese Thatsache ist deshalb sehr wichtig, weil sie den Beweis entlält, dass die Hirurinde, der Träger der höheren Seelenthätigkeit, schon in der Anlage für verschiedene Individuen verschieden ansgedehnt ist.

Wenn ich Ihnen nun bei der Schilderung der Hirnwindungen des erwachsenen Menschen gar keine Nittleilung vou allen diesen zahlreichen Untersuchungen gemacht liabe, welche uns die Variationen kennen lelrten, denen die einzelnen Windungen unterworfen sind, so geschah es, weil diese Dinge einstweilen einfach nur zu registriren und noch in keinerlei Zusammenhang mit der Ausbildung der einzelnen seelischen Facultäten zu bringen sind. Denn es fellt noch ganz an Hirnuntersuchungen, welche gleichzeitig mit der Windungsansbildung das gesammte geistige Wesen eimes einzelnen Individuums berücksiclitigen. Selbst jetzt, wo zahlreiche fleissige Arbeiten endlich eine gewisse Uebersicht geschaffen haben, wird man an derlei noch kaum herangehen können. Aber man wird jetzt schon versuchen müssen, für die bekannt localisirbaren Fähigkeiten die entsprechende Rindenentwicklung zu untersuchen. Es wird damn hoffentlich einmal die Zeit kommen, wo man Windungen nicht mehr einfach als solche, sondern nur in Zusammenlang nit den Fragen, welche ihre Entwicklung jedesmal im Einzelfalle aufwerfen lässt, beschreibt. Von den Trägern fast aller bisher beschriebenen und abgebildeten Gehirne wissen wir gar nichts. So scheint mir ein sehr grosser Theil des angesammelten Naterials zunächst und wohl auch später als völlig unverwerthbar fïr die Frage von der man ausging, für das Aufdecken von Beziehungen zwischen der Hirnform und der geistigen Stellung des Trägers. 
Nun hat man zwar anch versucht, durch IT ägung die Frage zu entscheiden, ob der grösseren Intelligenz etwa ein grösseres Gehirn entspräche. Tausende und Abertausende solcher Wägungen sind gemacht worden, aber auch das grosse Material, welches hier gewonnen worden ist, birgt nur sehr geringen Werth in sich. Zunächst ist in vielen Fällen schon die Körpergrösse unberücksichtigt geblieben. Diese aber nimmt nach ganz anderen Verhältnissen zu als das Gehirn; immerhin besteht doch zwischen beiden Grössen ein gewisser Zusammenhang. Dann aber, und das scheint mir das Wichtigste, ist die Ausbildung des Grosshirnes als Ganzes gar nicht zu einem Masse der Gesammtintelligenz brauchbar. Es ist ein Gewinn erst des letzten Jahrzehntes, dass wir gelernt haben, dass verschiedene Gehirne ganz verschiedene Entwicklung ihrer Einzelteritorien haben können. Noch aber können wir diese Rindenterritorien nicht so von einander abscheiden, dass man sie morphologisch oder wägend vergleichen könnte. Das Hirngewicht schwankt für die Mehrzahl der Männer zwischen 1300 und 1450 Gramm, für Frauen ist es um ein weniges geringer. Nun kommen ungewöhnlich schwere Gehirne gelegentlich bei geistig nicht besonders hoch Entwickelten vor, und umgekehrt hat man bei Menschen, die sehr hervorragend waren, relativ niedere Gewichte gefunden. Wir aber sind gewöhnt, die geistige Bedeutung eines Menschen nicht nach ihrer Gesammtheit, die ja fast nie prüfbar ist, sondern zumeist nach irgend besonders hervorragenden Eigenschaften zu messen, welche dem Individuum Ansehen, Stellung u. s. w. gaben. Solche Eigenschaften können sehr wohl auf besondere Zunahme eines einzelnen Rindengebietes zurückfülırbar sein, ohne dass dies gerade in dem Gesammthabitus der Windungen oder in der Wägung sich ausdrückt. Es könnte Jemand mit enormem Sehgedächtnisse, Sehphantasie u. s. w. versehen und mit aller geistigen Begabung, die den grossen Maler kemmzeichnet, eine geradezu einzige Stellung: eimnehmen, und doch würde die Vergrösserung des Occipitallappens, oder nehmen wir einen Musiker, wo wahrscheinlich der Schläfenlappen in Betracht käme, des Schläfenlappens also, bei einer Wägung dann keine wesentliche Abweichung vom Durchnittsgewichte erzeugen, wenn etwa andere Centren auch nur um ein Geringes weniger entwickelt wären. Ein grosser Redner ein energischer Mann und ein genialer Führer muss nicht geradezu ein grösseres Gehirn besitzen. Jene Eigenschaften können sehr wohl auf ganz kleine locale Vergrösserungen eiuzelner Rindenfelder basirt sein. G a mbettàs Gehirn, z. B., von dem wir die Sprachgegend schon als ungewöhnlich entwickelt bezeichnen konnten, s. o., wog kaum mehr als der Durchschnitt kleinerer Gehirne. Wir wissen noch so sehr wenig über die Rindenfelder, dass man im Allgemeinen heute kaum mehr sagen kann, als dass häufig gerade besondere Entwicklung der Stirnlappen mit hohen geistigen Eigenschaften einhergeht, und dass bei abnorm kleinen Stirnlappen verhältnissmässig häufig unzureichende Begabung, ja Idiotie gefunden wird. Was noclı völlig fehlt und heute aucl noch gar nicht realisirbar ist, das ist eine Wägung getrennter Rindenterritorien. Sie werden es bei diesem Stande der Dinge begreiflich finden, wemn ich Ilmen von den Gewichtsverhältnissen des Centralnervensystemes heute nichts Näheres mittheile.

Meinem $\div$ Freunde $\mathrm{Perls}$ ist zuerst anfgefallen, dass eine verhältnissmässig grosse Anzahl geistig bedeutender Menschen nach dem Gesichtstypus den Eindruck machen, als wäre bei ihnen in frïher Jugend ein Hydrocephalus abgeheilt. Er äusserte die Vermuthung, dass wenn ein mässiger Hydrocephalus in Rückbildung iibergehe, dem Gehirnwachsthum durch den einmal erweiterten Schädel ein verhältnissmässig geringerer Widerstand entstehen werde. Ich habe diese mündliche Anregung später verfolgt und in einer nicht ganz kleinen Anzahl von Fällen Belege für ihre Richtigkeit gefunden. Beispielsweise zeigte $\mathrm{Ru}$ binstein's gewaltiger Schädel bei der Section nach Zeitungsberichten ganz 
deutliche Zeichen alter Rachitis, und ron $\mathrm{Cuvier}$ wissen wir sogar, dass er, der ein ungewöhnlich schweres Gehirn hatte, in der Jugend hydrocephalisch gewesen war. Wer ein gutes Portraitwerk durchstudirt, dem werden, wenn er mit mir der Perls'chen Anregung folgen will, zahlreiche Stirnen von offenbar hydrocephalischem Habitus gerade bei geistig besonders bedeutenden Menschen begegnen. Natürlich sind nicht alle geistig hochstehenden Menschen abgeheilte Hydrocephalen, so wenig wie jeder abheilende Hydrocephalus bessere Entwicklung des Gehirnes zur Folge haben muss.

\section{Vierzehnte Vorlesung.}

\section{Vom Gehirne der Säugethiere und vom Riechapparate.}

I. H.! In den ersten Vorlesungen komnten die Terhältnisse des Säugervorderhirnes nur ganz allgemein besprochen werden. Heute, wo sie mit dem Aufbaue des Gehirnes beim Menschen besser bekannt sind, wird es sich lohnen, einmal einen Blick anf die ïbrigen säugergehirne zu werfen. Vieles ron dem, was wir über die Faserung us. s. w. wissen, ist ja nicht am Menschen, sondern durch Studium von Thiergehirnen gewomen worden, und gar Manches, das am menschlichen Gehirne kaum verständlich erscheint, tritt uns am Thiergehirne in viel besserer Ausbildung entgegen.

Wem wir die enormen Unterschiede wohl verstehen wollen, die in der Ausbildung des Vorderhirmmantels bei den verschiedenen Säugern sich finden, so müssen wir auf einen Umstand Rücksicht nehmen, dessen bisher noch nicht ausführlich gedacht ist. Der Hirnmantel ist nicht ein functionell einheitliches Organ. Er setzt sich vielmehr zusammen aus einer ganzen Anzahl verschiedener Theile-Centren hat man sie genannt - und zahlreiche physiologische Versuche haben gelehrt, dass Bewegungen, die erlernt werden müssen, und wohl die meisten seelischen Combinationen, durch die Existenz solcher Centren erst möglich werden.

Die einleitenden Vorlesungen haben Sie nun darüber orientirt, dass die eigentlichren motorischen und sensiblen Centren der peripheren Nerven tief unten, vom Rückenmarke bis zum Mittelhirne, sitzen, und dass diese, auch wenn das Vorderhirn fehlt, durch reichlich vorhandene, friih schon vorgebildete Verknüpfungsreihen zu zweckmässiger Thätigkeit an sich schon ausreichend sind.

Die Experimentalphysiologie aber zeigt, dass viele der tiefen Centren mit höher oben in der Rinde gelegenen derart verbunden sind, dass Reizung der letzteren Bewegung auslöst. Darüber schwebt namentlich der Streit, voll welcher Natur und Wichtigkeit der Einfluss der höheren anf die tieferen Centren sei. Deshalb bemüht man sich, möglichst genau die Erscheinungen zu studiren, welche nach Wegnahme von Rindenpartien auftreten. Zweifellos ist die Dignität der Hirnrinde bei verschiedenen Thieren eine verschiedene. Während Wegnahme des ganzen Grosshirnes bei niederen Thieren die Fähigkeit, gröbere Bewegungen mit guter Kraft auszuführen, nicht aufhebt, treten bei Säugethieren nach Zerstörung circumscripter Partien der motorischen Zone rasch vorübergehende 
Lähmungen auf, und beim Menschen führt gar die Erkrankung auch relativ kleiner Theile der Rinde oft zu dauernden Lähmungen. Offenbar kön nen alle motorischen und viele sensorisch-psychischen Functionen von tiefer liegenden Hirntheilen ausgeführt werden. Je höher man aber in der Thierreihe aufsteigt, um so mehr wird beider Gehirnthätigkeit die Rinde mit in Anspruch genommen, um so mehr spielt das Bewusstsein mit. Der Mensch hat in dieser Beziehung eine Stufe erreicht, auf der viele der betreffenden Functionen gar nicht mehr olne Theilnahme der Rinde ausgeführt werden kömnen. Bei den Säugethieren werden alle möglichen Uebergangsstadien beobachtet. So erklärt es sich, dass zwar bei den letzteren durch Reizung der Rinde die einzelnen Muskeln u. s. w. beeinflusst werden können, dass die betreffenden Rindenpartien aber für die betreffenden Bewegungen noch nicht unentbehrlich sind. Beim Menschen ist der grössere Theil der Vorderhirmoberfläche unentbehrlich geworden.

Morphologisch verrätl sich dies Verhältniss durch ganz verschiedene Entwicklung der einzelnen Theile des Hirnmantels. Noch sind wir erst für wenige Thiere in der Lage, die wesentlichen Theile des Mantels von einander zu scheiden, doch erkennen wir schon, dass in der säugethierreihe die Ausbildung der Rinde noch in fortwährendem Flusse ist. Es existiren da die allergrösten Verschiedenheiten und die wechselndsten Grössenverhältnisse. Aber für einige derselben kann doch schon heute die Terthigkeit gezeigt werden, welche sie im Gesammtplane eimnehmen. Schon eine oberflächliche Betrachtung der Säugergehine lehrt, dass namentlich ein Centrum, das Riechcentrum. sehr wechselnde Grössenverhältmisse zeigt, so bedeutende, dass manchmal das ganze ïbrige Mantelgebiet nur ein kleines Anhängsel des Riechlappens zul sein scheint.

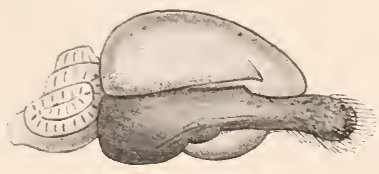

Fig. 139.

Gehirn eines Gürtelthieres, Dasypus villosus, von der Seite gesehen. Der Riechapparat schattirt.

sie erinneren sich. dass das Riechhirn derjenige Theil der Rinde ist, welcher in der Thierreihe zuerst in Erscheinung tritt, und dass sich diesem erst später andere Rindengebiete zugesellen. In vielen niederen Säugeru kennen wir Thiere, die von dem nicht zum Riechapparate gehörigen Mantelgebiete nur erst relativ kleine Theile besitzen. Hier nimmt der Riechlappen, und was sonst zu dem Riechapparate der Rinde gehört, oft fast die Hälfte der ganzen Torderhirnmasse ein.

Was wir ïber die Lebensweise solcher ,Riechthiere" wissen, stimmt gut mit dem überein, was ihr Hirnban lehrt. So verbringt z. B. das kleine Gürtelthier, dessen Gehirn ich oben abbilde, seine ganze Existenz im Gemülm und unter dem Laube der tiefdunkeln Urwälder dahinkriechend. Fiir die Auswahl seiner Nahrung, für das Finden desselben, wird ihm kein Simnesapparat so wichtig sein, wie der Gernch. Die gleichmässigen kleinen Bewegungen des plumpen Körpers werden viel weniger erlernter und überlegter Handlungen bediirfen, als etwa die Greifhand eines Affen. Bei dem letzteren werden wir deshalb viel grössere Entwicklung der eigentlich psychischen Centren für die Oberextremitäten 
erwarten dürfen, als bei dem kleinen wühlend lebenden Wesen. Das triftt in der That zu. Ja noch mehr, man kann heute schon gelegentlich aus der Entwicklung einer bestimmten Rindengegend auf eine seelische Leistungsfähigkeit in besonderer Richtung schliessen. Der Elephant z. B. besitzt in der Rindengegend, wo bei höheren Säugern das Facialisgebiet localisirt ist, ein besonders grosses Rindenfeld, welches dem Nashorn und dem Tapir völlig fehlt. Wiissten wir gar nichts von der wunderbaren Fïhigkeit des Thieres, seinen Riissel zu den mannigfachsten Verrichtungen einzuiiben, so dürften wir doch aus dem Vorhandensein des erwähnten Feldes im Antlitzgebiete vermuthen, dass von hier aus Muskeln innervirt werden, die ganz besonderer Einübung fähig sind.

Alle Untersuchungen über den Hirmmantel drängen zu der Annahme, dass er aus Einzelfeldern zusammengesetzt ist, welche an relativer Grösse wechseln kömnen. Ein Theil dieser Centren steht in Beziehung zu motorischen und sensorischen Processen, ein anderer, bisher nur beim Menschen studirter, enthält nach der schönen Entdeckung Flechsig's nur Associationsgebiete, die durch ihren Bau wohl geeignet sind, zahllose Terbindnngen in sich und mit anderen Centren einzugehen. Es ist nach Flechsig. wahrscheinlich, dass auf der hohen Ausbildung der .. Associationscentren“, das geistige Tebergewicht der Primaten beruhe. Im Ganzen nimmt der Hirnmantel in der That so zu, dass man wohl bei den intelligenteren Thieren einen grösseren Mantel findet, als bei den geistig besonders einseitigen und tief stehenden, und es wird Sache fortgesetzter Untersuchungen sein, nachzureisen, wie die Einzelbestandtheile wachsen. In dieser Fragestellung liegt auch das Interesse begruindet, das die Untersuchungen iber die vergleichende Anatomie der Hirnwindungen wirklich haben. viel mehr als im rein Morphologischen.

Ganz allmählich nimmt dann der Mantel in der Thierreihe aufsteigend an Umfang zu. In der Klasse der Primaten hat er bei den Affen eine Ausdehnung erlangt, welche nahe an die Terhältnisse beim Nenschen grenzt. Aber noch unterscheidet ihn, ausser unwesentlicheren Verhältnissen, ein wichtiges Moment von der beim Menschen erreichten Stufe. Der Stirnlappen, der bei den niederen Affen noch sehr klein ist, erreicht bei den höheren schon eine grosse Ausdehnung; bleibt aber noch immer sehr zurück gegen den Stirnlappen des Menschen. Ta beim Menschen ist dieser Entwicklungsgang noch keineswegs abgeschlossen. Es finden sich gerade im Stirnlappengebiete noch Differenzen, welche auf die Möglichkeit einer weiteren Tervollkommnung' schliessen lassen. Ganz besonder's kommt hier das ventrale Gebiet in Betracht, welches, die Sprachcentren enthaltend, sehr wesentliche Terschiedenheiten in der Ausbildung zeigt.

ITo ein kleiner Mantel vorhanden ist, kann natiirlich auch die von ihm ausgehende Faserung nur gering sein. In der 'That ist die Strahlung aus der Rinde bei vielen kleineren Säugern so gering, dass ein eigentliches Centrum semiovale gar nicht zu Stande kommt, dass vielmehr die ganze Faserung sich auf einen relativ dünnen Belag unter der Rinde beschränkt, der dann dicht an den Tentrikel angrenzt und ron den Fndfäden seines Epithels durchzogen wird. 
Damit wird auch die Hauptcommissur desjenigen Mantelgebietes, das nicht Riechapparat ist, der Balken, so gering, dass sie nur eine relativ kurze Strecke auf der medianen Hemisphärenseite einnimınt. Ja bei einigen Monotremen und bei den bisher untersuchten Marsupialen fehlt ein Balken ganz (Symington, E. Smith).

Ebenso ist die aus dem Hirnmantel stammende Faserung zu tiefer gelegenen Theilen, besonders die zur Brücke und zum Rückenmarke, die Fussfaserung, bei allen Thieren sehr viel geringer entwickelt, als beim Nenschen.

Meistens ist der Riechapparat sehr viel kräftiger ausgebildet, als wir ihn vom Menschen kennen, aber er kann auch, so bei den im Wasser lebenden Säugern. ganz enorm atrophiren, soweit zurïckgehen. dass er fast verschwindet. Danach hat man die Sänger eingetheilt in osmatische und anosmatische. Die Untersuchung einer sehr grossen Reihe von Thiergehimen lehrt. dass sich Riechapparat und Pallium ganz unabhängig von einander phylogenetisch entwickeln, dass der eine atrophiren, das andere einen höheren Ausbildungsgrad erreichen kamn und umgekehrt. Die erhöhte Ansbildung des Riechapparates zeigt sich nicht nur in der kräftigeren Entwicklung der Riechlappen und der Riechgebiete des Nantels, sondern auch durch eine ganz besonders starke Entwicklung bestimmter, zu diesem Apparate gehöriger Zellgruppen und Fasern in den übrigen Theilen des Gehirnes an.

Wir werden deshalb zunächst den Riechapparat als Ganzes betrachten. Beim Menschen nur in relativ atrophischen Resten vorhanden, kann er an vielen Säugeru leichter studirt werden.

Ich lege Thnen hier die Abbildung der Basis eines Kalbgelirnes und einer solchen rom Gürtelthiere ror. Sie sehen, dass ein mächtiger Lappen lier liegt, der vorn von einer Auschwellung kappenartig bedeckt ist und hinten ziemlich direct in die Ammonswindung ïbergeht. Das ist das Riechhirn. Bei dem Dasypus, aber auch bei dem Hunde, dem Kaninchen und bei vielen anderen Säugern ist es noch viel mächtiger, als bei dem abgebildeten Kalbe. Es nimmt dann immer ziemlich die ganze Hirnbasis ein. Dies ist der gleiche Hirntheil, der bei den Reptilien zunächst als einziges Gebiet des Mantels anfgetreten ist. S. Torl. 12, S. 166.

In den vorderen Theil treten, hier zottig abgeschnitten, die Fila olfactoria ein. Sie treffen zunächst auf den Bulbus olfactorius. Dieser sitzt dem Lobus olfactorius anterior auf, dem frontalen Abschnitte des ganzen Apparates. Der Lobus olfactorius anterior geht dam in den Lobus olfactorius posterior über, der bei dem Dasypus besonders schön abgegrenzt ist. In der Fig. 141 ist er als spatium olfactorium, Riechfeld. Espace quadrilatère Broca bezeichnet.

An diesen ganzen Apparat schliesst sich caudal das Rindenfeld des Riech apparates an. welches wegen seiner Figur als Lobus py r iformis bezeichnet worden ist. Dieser birnförmige Lappen geht medial ganz direct in das Gebiet der Ammonswindung über. 
Die lange Fissura $1 \mathrm{imb}$ ic a tremnt das Riechhirn rom übrigen Pallium.

Die Riechnervenfasern tauchen in den Bulbus ein. Ein Schnitt durch denselben zeigt deutliche Schichtung verschiedener Gewebsarten. $\mathrm{Zu}$ äusserst liegen natürlich die Riechnervenfäserchen, dann folgt eine grauweisse Zone, in der zahlreiche kleine Kügelchen, Glomeruli olfactorii, schon mit blossem Auge sichtbar sind. Glomerulusschicht. Nach innen von dieser liegt die graue Ganglienzellenschicht, die dann allmählich durch eine "Körnerzone" in das Riechmark iibergeht. In den Bulbus hinein erstreckt sich eine feine Ausbauchung des Seitenventrikels. Ihr Epithel grenzt unmittelbar an die schicht der markhaltigen Fasern.

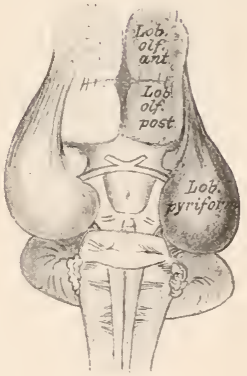

Fig. 140.

Gehirn von Dasypus villosus. Basalansicht.

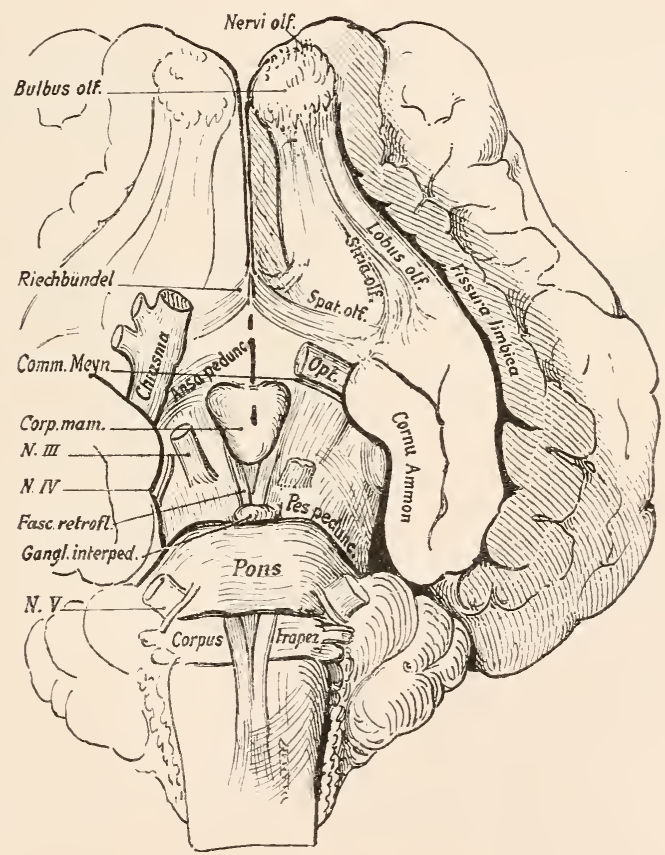

Fig. 141.

Basis des Gehirnes vom Kalbe. Der Ventrikel absichtlich von unten her eröffnet, um seine Recessus R. opticus, infundibuli, mamillaris - zu zeigen. 
Cntersuchungen ron Golgi. S. und P. Ramon y Cajal, ferner solche von Gehuchten und Kölliker haben uns die Elemente dieser schichten und den sehr interessanten Zusammenhang einiger dieser Elemente mit den Riechnervenfasern kennen gelehrt.

Die Fasern des Riechnerven sind nichts Anderes, als die centralwärts gerichteten Endausläufer der Sinneszellen der Riechschleimhaut. Darauf ist ja bei der Darstellung der Entwicklungsgeschichte schon hingewiesen worden.

Nachdem diese Fa-

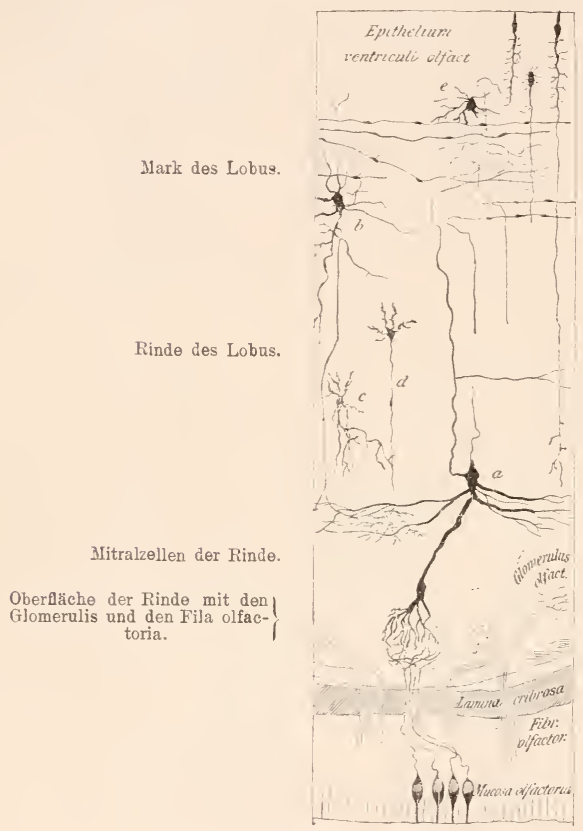

Fig. 142.

Schnitt durch die Riechschleimhaut, das Siebbein und den Bulbus olfactorius. Die Combinirung ist schematiseh, die Lage der einzelnen Elemente, namentlich auch ihre Verzweigung und Form, nach Präparaten. sern die Siebbeinplatte passirt haben, gehen sie, an der ventralen Bnlbusfläche angelangt, mehrfache Ueberkrenzungen ein und senken sich dann in die Hirnsubstanz. Dort zerfährt alsbald jeder Axencylinder $\mathrm{zu}$ einem feinen Endbäumchen. Diese Aufzweigung trifft auf die dicken Aeste eines ebenfalls aufoezweigten Dendritenfortsatzes, und beide Faserarten, die sich innig aneinander legen, bilden zusammen einen rundlichen Complex, eben den Glomerulus olfactorius. Der Dendritenfortsatz stammt von einer Ganglienzelle $a b$, welche reichliche derartige Ausläufer entsendet. Nur einer tritt immer in die geschilderte Beziehung zu den Riechnervenfasern. Jede dieser Hiruzellen steht mit einer ganzen Anzahl von Olfactoriusfasern in Verbindung. Solche Zellen, mannigfach geformt, von wechselnder Grösse, liegen in grossen Hengen in

der grauen Schicht unter den Glomerulis. Sie senden ihren Stammfortsatz centra!wärts, und man kann ilın bis in das Lager der Markfasern verfolgen. Auf dem Wege giebt er zuweilen Collateralen ab. Hier nun haben Sie einmal ein gutes Beispiel für das in der Vorlesung iiber die Gewebszusammensetzung der Centralorgane Gesagte. Sie sehen die primäre und die secundäre Olfactoriusbahn direct vor sich und erkemnen, dass die Verbindung hergestellt wird durch Aufsplitterung: des Stammfortsatzes der primären Bahn und Anlegen an die Dendritenfortsätze aus der secundären Bahn.

Es wurden in der Rinde des Riechkolbens noch eine Anzahl anderer Elemente gefunden, deren nervöse Natur noch nicht über allem Zweifel ist. Zwischen den erwähnten Zellen und der Markfaserschicht, zum Theile auch innerhalb derselben, 
liegen, die bisher als ,Körner" bezeichneten Zellen, von denen ich in $a, b, c$ drei verschiedene Typen in das beistehende Bild eingezeichnet habe. Ausserdem kommen an allen Stellen Zellen $e$ mit sehr weit verzweigtem Axencylinder vor.

Das Faserwerk, welches alle diese Elemente bilden, wird dadurch natïrlich noch sehr viel complicirter, dass anch die Neurogliazellen iberall zwischendurch liegen und dass die Ausläufer der Ventrikelepithelien weithin in die Substanz des Bulbus olfactorius hineinreichen. Die Abbildung, welche hier wesentlich aus Zeichnungen van Geluchten's combinirt ist, wurde möglichst einfach und ïbersichtlich gehalten. Sie miissten sich das Alles sehr viel dichter, reicher an Fasern und Zellen vorstellen.

Die ganze Formation des Bulbns lässt sich unschwer auf den gewöhnlichen Rindentypus zurïckfïhren. Wollen Sie Fig. 142 einmal umkehren und mit Fig. 152 vergleichen, dann springt das sofort in die Augen. Der Text links ron Fig. 142 soll den Tergleich erleichtern. Die ganze Bulbusformation ist da als Lobusrinde bezeichnet.

Die graue Masse des Bulbus sendet rückwärts die centralen secundären und tertiären Bahnen des Riechapparates. Zunächst gelangt immer eine solche auf die Oberfläche des Lobus. wo sie. bald in mehr, bald in weniger strahlen gespalten, rïckwärts zieht. Dabei senken sich aus dieser lateralen Riechstrahlung fortwährend Fäserchen in die Tiefe der Lobusrinde. Doch erschöpft sich die Bahn dabei nicht, es gelangen vielmehr ihre Fasern. ïber das Riechfeld wegziehend, weiter hinten bis in die Region des Mandelkernes. Alle diese Fasern haben starkes Kaliber und sind seit langem als Riechnervenwurzeln bekannt.

Bei der Beschreibung des niederen Vertebratengehirnes haben wir sie näher verfolgt und constatiren können, dass ein Theil allerdings sich in die Rinde der Riechlappen einsenkt, ganz wie wir es eben bei den Sängern sahen, dass aber neben diesen Tractus bulbo-corticales noch ein Faserzug vorkommt, welcher, gleichen Verlaufes, sich bald abtrennt und im Epistriatum endet. Dieses Epistriatum ist noch nicht bei den Säugern gefunden, weil es eben erst gesucht werden kann, seit man scine bei niederen Gelirnen so deutliche Existenz kennt, aber es ist selır wahrscheinlich, dass wir in denjenigen Faserziigen, welche in das caudalere Gebiet, in den Lobus pyriformis und in die Gegend des Mandelkernes gelangen, gute Wegweiser zu jenem noch unentdeckten Hirntheile besitzen.

Ton den Riechstrahlungen ans dem Bulbus muss man das unterscheiden. was bisher ihnen gleichberechtigt galt und als mediale Riechnervenwurzel bezeichnet wurde. Es entwickeln siclı nämlich aus dem Marke des Bulbus zahlreiche feinere Nervenfasern, die unter der Rinde weg in das Mark des Lobus ziehen. In ihm mischen sie sich den Markfasern des Lobus in einer heute noch nicht trennbaren Weise bei. Am hinteren Lobusende, dicht vor dem Riechfelde aber verlässt ein Faserzug, der in ihrer Fortsetzung liegt, den Lobus und zieht unter der dünnen Rinde des Riechlappens, diese etwas vorwölbend, hinauf an der Innenfläche des Gehims. Diese mediale Riechstrahlung gelangt, an der medialen Seite des Gehirnes zum Septum pellucidum ziehend, über dieses hinweg in den Fornix, und von da in das Ammonshorn. Sie ist immer wegen des dümmen Rindenüberzuges nicht so rein weiss wie die laterale strahlung. 
Eine Furche trennt den Lobus olfactorius posterior von dem Lobus Hippocampi. Dieses bei den osmatischen Thieren immer ungemein mächtige Gebilde enthält an seinem medialen Rande die Ammonseimrollung. Nit der kleinen relativ atrophischen Ammonswindmng beim Menschen ist es kaum zu vergleichen. Der Ammonslappen folgt dem ganzen Hemisphärenrande an der Basis, erhebt sich dann hinten hinauf zur Medialfläche des Gehirnes und läuft hier eine Strecke nach vorwärts. Sein Subicnlum, die Rinde, welche nicht eingerollt direct an der Hirnbasis liegt, geht dann unmittelbar in den Lobus silpracallosus - Gyrus fornicatus des Menschen - iiber. hinauf.

Die Ammonswindung reicht beim Menschen nicht bis unter den Balken

Da der Lobus supracallosus sich vorn zur Basis herab wendet und mit seinem frontalsten Ende das Riechfeld wieder zu erreichen scheint, so bildet dieses ganze Rindenstück eine Art von Bogen um den Rand der ganzen Hemisphäre. Broca. der zuerst entdeckte, dass die rerschiedenen in ihn eingehenden Rindenzüge alle in directem Grössenverhältnisse zur Entwicklung des Riechapparates stehen, hat den Lobus limbicus, wie er ihre Gesammtheit nannte, direct als Riechrinde bezeichnet. gehört.

Es ist mir fraglich geworden, ob der Gyrus fornicatus zum Riechapparat

Der Lobus limbicus wird rom übrigen Gehirne immer durch eine eigene mächtige Furche geschieden, die Fissura limbica. Trir sind ihrem oberen Bogenstiicke schon beim Menschen begegnet als Sulcus cinguli. Zum Lobus limbicus muss auch, nach den Untersuchungen von Zuckerkandl, die imnerste Ammonswindung, der Gyrus dentatus und ihre Fortsetzung auf die Balkenoberfläche der Lancisi'sche Streif gerechnet werden. Alle diese Windungstheile, die so den Hemisphäremrand umfassen, der Lobus olfactorius, der Gyrus Hippocampi und der Gyrus fornicatus, der Lancisi'sche Streifen und die Fascia dentata, sind bei Thieren mit sehr ausgebildetem Riechorgane stark entwickelt, bei solchen welche, wie die Menschen, kleine Riechlappen haben, ziemlich atrophisch, und beim Delphin, der gar keinen Riechlappen hat, sind sie aufs Höchste zurückgebildet (Broca, Zuckerkandl). Diese also offenbar dem Riechapparate zugehörigen Hirntheile fasst man nach einem Vorschlage von Turner mit dem Lobus olfactorius als Rhinencephalon zusammen. Die Bestandtheile des Rhinencephalon, die Furchen und Windungen, lassen sich bei allen Säugern mit einer gewissen Constanz der Anordnung nachweisen.

Die einzelnen Theile des Lobus limbicus der rechten und der linken Seite sind durch ein mächtiges Commissurensystem unter einander verbundelı. Dies system ist die Commissura anterior. Ihr vorderer Schenkel entspringt im Lobus olfactorius der einen Seite und zieht an der Hirnbasis hufeisenförmig gekrümmt hinüber zum Lobus der anderen Seite. 
Ein caudaler Schenkel verbindet die Lobi cornu Ammonis oder doch die Rindengebiete, welche direct nach aussen von der Ammonseinrollung liegen, und schliesslich kennen wir schon für viele Säuger einen aufsteigenden Ast der vorderen Commissur, der, in der Capsula externa verlaufend, geeignet ist, den dorsalen Theil der Randwindung mit dem gegenüberliegenden zu verbinden.

Die Ammonshörner selbst besitzen noch eine eigene Verbindung unter einander. Ein mächtiges Fasersystem spannt sich zwischen ihnen aus, die Ammonscommissur, das Psalterium.

Das Ammonshorn ist mit den Riechlappen verbunden durch die bereits erwähnte mediale Riechstrahlung. Als Tractus cortico-olfactorius septi haben wir sie zuerst bei den Reptilien auftreten sehen, und in Fig. 144

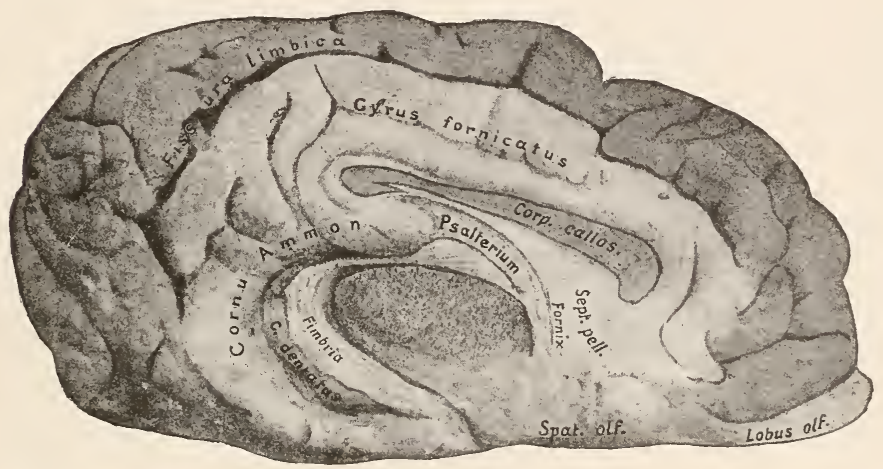

Fig. 14 .

Sagittaler Medianschnitt durch das Kalbsgehirn Der Lobus limbicus heller gehalten.

finden sie auch den grössten Theil ihres Verlaufes sichtbar. Bei den höheren Säugern und bei dem Menschen ist aber der Zug nicht so ohue Weiteres zu erkennen wie bei dem Marsupialengehirne der Fig. 123. Aber es ist doch Zuckerkand l sein Nachweis in völlig befriedigender Weise und namentlich auch ganz unabhängig von den - viel jüngeren — vergleichend anatomischen Erwägungen geglïckt. Er hat ihn Riechbündel des Ammonshornes genannt.

Der grössere Theil stammt jedenfalls ans dem Marke des Riechfeldes. Der mächtige Faserzug entspringt an der Unterseite des Gehirnes in der Rinde des Riechfeldes, wendet sich dann iiber dieses hinweg medialwärts (s. Fig. 141 u. 144) und zieht unter dem Gyrus subcallosus, Fig. 135 u. 133, hinweg hinauf zum Septum pellucidum dorsalwärts. Im Septum sehe ich einen Theil der Fasern kreuzen, einen anderen direct sich rïckwärts begeben. Beide Bïndel vereint treffen am candalen Septumrande auf den Fornix nnd verlaufen in ihm rückwärts weiter bis zum Marke des Ammonshormes.

Für das Folgende vergl. bes. Fig. 144 . 
Der Riechlappen und das Riechfeld haben im wesentlichen die Zuzüge aus dem Bulbus olfactorius, also Riechnervenbahnen zweiter Ordnung aufgenommen. Sie haben in früheren Vorlesungen erfahren, dass diese beiden Hirntheile von den Fischen an aufwärts ïberall vorhanden sind.

Der Lobus pyriformis und das Ammonshorn aber sind Hirntheile, die zwar mit dem Riechapparate zusammenhängen. durch ihren Bau aber sich als eigene mächtige Gebiete charakterisiren, welche in sich die allermannigfachsten Associationen u. s. w. herstellen kömnen.

Sie sind höchst wahrscheinlich, dafür spricht auch ihre ganze Grössenentwicklung - die Rindenfelder für den Geruch.

Sehen wir nun näher zı, welche Bahnen sie aufnehmen, welche anderen sie aussenden.

Durch das Riechbündel einerseits, durch oberflächliche in der'Tangentialfaserschicht verlaufende Fasern andererseits erhält also das Rindenfeld des Geruches seine Bahnen. Es sendet aber auch welche aus. Diese sammeln sich an seinem medialen Rande als Fim bria, Fig. 143, und ziehen nun frontalwärts. Bald erkennt man, dass siemindestens zwei verschiedenen Systemen angehören. Ein grosser Theil nämlich trennt sich am vorderen Ende der Ammonswindung und auch schon etwas weiter caudal ab und zieht hiniiber zum Ammonshorne der anderen Seite. Diese Verbindungsfasern heissen in ihrer Gesammtheit Psalt e riu m. Es sind das die medialer liegenden Fasern. Aus den lateraleren aber sammelt sich ein weiteres Bïndel. Zumeist längsgerichtete Zïge treten hier nach vorn, legen sich neben das hier eintretende Riechbündel für eine kurze Strecke an, rerlassen es aber bald wieder, $1 \mathrm{~m}$ sich in nach abwärts gerichtetem Verlaufe rïckwärts zu begeben. Das ist der Fornix. Er endet in dem Corpus mamillare und anch gekreuzt im Thalamus, nahe der Hirnbasis. Der Fornix ist also der Theil des Markes ans der Ammonswindung, welcher, nicht zu Commissuren verbraucht, dieses Mark mit dem Zwischenhirne verbindet. Dem ,absteigenden Fornix“, wie dieser Theil im Gegensatze zu dem vom Ammonshorne nach vorn längsverlaufenden Bündel, dem „aufsteigenden Fornix“ heisst, gesellt sich aber noch ein Faserzug zu, welcher aus demjenigen Theile der Randwindung, welcher nicht zum Ammonshorne sich einrollte, stammt, aus dem Gyrus limbicus. Seine Züge müssen, um hinab zum Fornix zı gelangen, den Balken, der den Ventrikel der Sänger immer bedeckt, durchbrechen. Das Bündel heisst F ornix longus. Seine Fasern liegen immer dicht unter dem Balken und wenden sich vorn als die medialsten Bündel der Fornixsäule hinab mit dieser zur Tiefe des Zwischenhirnes.

Es ist sehr wahrscheinlich, dass sowohl der absteigende Fornix als auch der Fornix longus auf dem Wege durch das Psalterium anchFasern aus der gekreuzten Riechrinde erhält.

Bei den kleineren Säugern sind die Verhältnisse der Fimbria und des Psalteriums sowie des Fornix besser bekannt als beim Menschen. Einestheils deshalb, weil sie bei den untersuchten osmatischen Thieren relativ viel mächtigere Ge- 


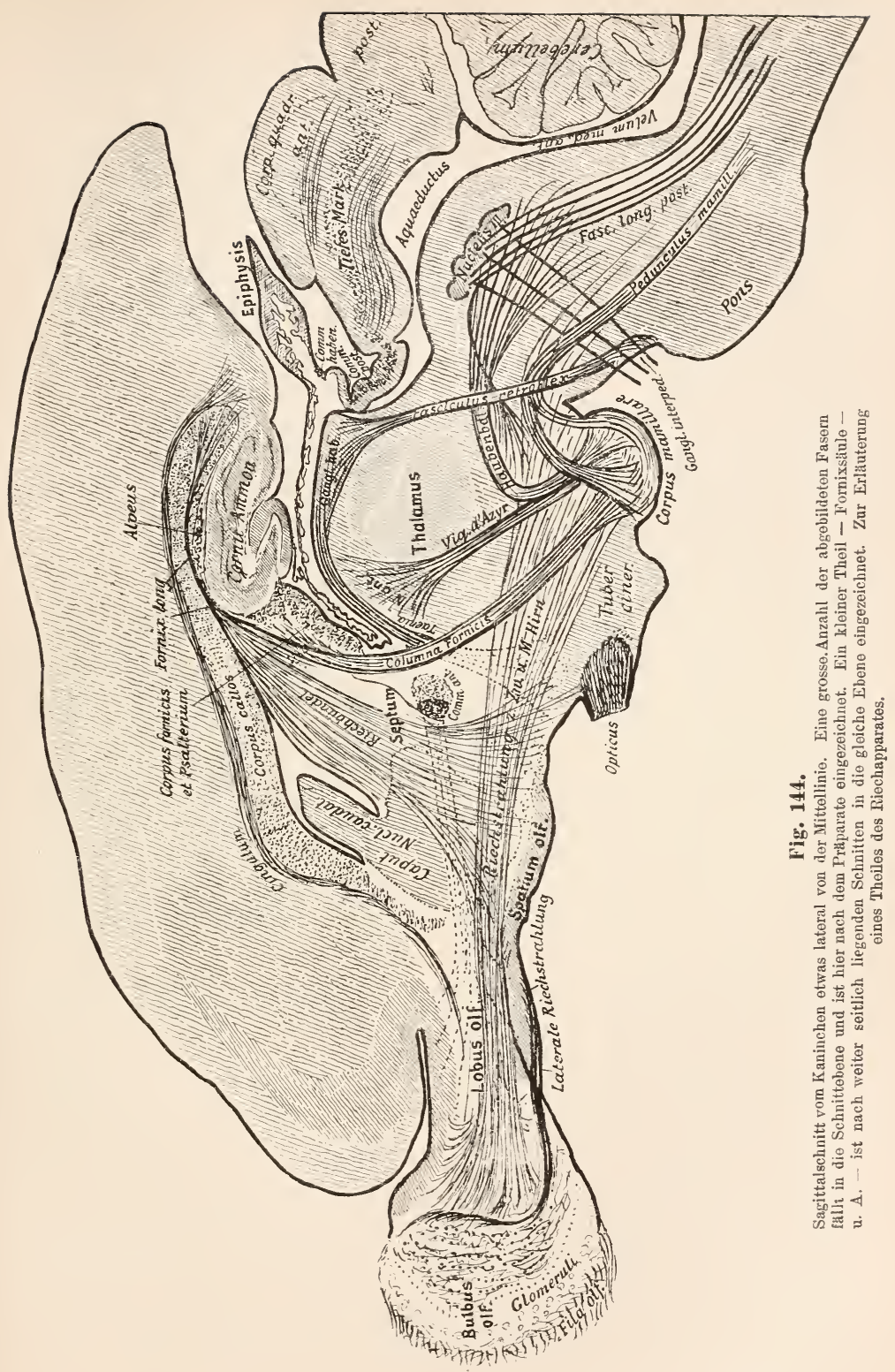


bilde sind als beim Menschen, andererseits auch deshalb, weil Gud den's experimentirende Meisterhand gerade auf dem Gebiete der Fornixanatomie vielfach Klarheit durch den Thierversuch schaffen konnte.

Der Fornix longus ist beim Menschen erst vor kurzem durch $\mathrm{K}$ öliker nachgewiesen worden.

Bei vielen kleineren Thieren bilden die Fasern des Psalterium, die Kreuzungen in ihm, die Kreuzung der Fornices longi und die Umbeugungsstelle der Crura fornicis in die Tiefe des centralen Höhlengraues zusammen eine einzige dicke Masse, die man als Corpus fornicis bezeichnet hat.

Der Riechlappen und der Ammonslappen besitzen noch eine weitere Anzahl ron Faserzügen, die sie unter einander oder mit anderen Gegenden zu verknüpfen geeignet sind. So läuft ganz medial ïber die volle Balkenlänge jederseits ein feines Bündel dicker Fasern, die Stria longitudina lis medialis. die in den dorsalen Gegenden der Ammonsrinde entspringend rorn über den Balken herabbiegt und in das Septum pellucidum einstrahlt. Damn wissen wir, dass ein langes. im Gyrus fornicatus verlaufendes Faserbündel, das Cingulum. Ziige sowohl in den Riechlappen als in die ïbrigen 'Theile der Randwindung' sendet.

Alle diese Züge gehören den Rindencentren des Riechapparates an. Es giebt aber auch Beziehungen des Riechapparates zum Zwischenline. die sehr wichtig sein miissen. Weil sie bei allen Thieren, auch solchen ohne Hirnrinde, sich wohl ausprägen und inmer und überall nachweisbar sind. Um sie zu rerstehen, mïssen wir noch eimmal zum Marke des Lobus olfactorius zurückkehren. sie wissen, dass dieses zum guten Theile aus dem Bulbus stammt. Nach hinten setzt es sich ganz direct in das Mark des Riechfeldes fort. Eine Verbindung dieses ..t iefen Riechmarkes" habell wir bereits als Riechbündel zum Ammonshorne kennen gelernt.

Das Riechmark besitzt aber noch mindestens zwei weitere Terbindungen. Ein Zug desselben, wesentlich aus feinen Fasern bestehend. läuft rïckwärts und kann bis in die Gegend des Corpus mamillare verfolgt werden. Er muss auf seinem Trege die rentralsten Gegenden des Corpus striatum durchbrechen, bezielıt aber aus diesen keine Fasern - wie man schon angenommen.

Einzelne dieser Fasern gehen noch weiter caudalwärts, bis in die Gegend des Gangl. interpedunculare, vielleicht auch bis in die Schleife.

Ein zweiter Zug. wesentlich aus dem Marke des Riechfeldes in den lateralen Partieen stammend. erhebt sich. den vorderen Theil des Thalamus durchbrechend, zur Innenfläche des Tentrikels und zieht dieser entlang rückwärts zum Ganglion habenulae. Es ist die Taenia thalami.

Bei einem Hunde, dem 1 s Monate ror dem Tode die ganze Ilirurinde entfernt worden war, und dem infolge davon die ganze Strahlung aus dem Mantel fehlte, war nur die Rinde des Riechfeldes erhalten geblieben. Aus dieser konnte man sehr klar und deutlich die Riechstrahlung rückwärts zum C. mamillare und aufwärts als Taenia thalami zum Ganglion habenulae verfolgen. Die Fasern müssen im Riechfelde selbst ihre Ursprungsstätten haben, denn es war die Taenia nicht entartet, obgleich sie dicht vor dem Ganglion habenulae zufällig bei der Operation beiderseits sehr lädirt worden war. 
Zunächst haben wir so die Riechfasermng einerseits bis in die Hirnrinde und andererseits bis in das Ganglion habenulae und (in?) das Corpus mamillare verfolgt. Wir werden später sehen, dass mit diesen Ganglien noch andere Ganglien des Mittel- und Zwischenhirnes in enger Verbindung. stehen.

Der Thaenia zum Thalamus mischen sich bei den Säugern (Lo theissen) anch Fasern aus dem Fornix bei, ganz wie bei den Reptilien s. oben.

so erscheint der ganze Riechapparat als ein ungeheurer, den grössten Theil des Gehirnes durchziehender Complex von Ganglien und Kernen Wir werden in den folgenden Torlesungen seinen einzelnen Theilen immer wieder begegnen.

II. H. Sie haben gesehen, dass ein nicht unbeträchtlicher Theil der Hirnoberfläche in seiner Ausbildung wesentlich abhängt von der Entwicklung des Riechapparates. Alle hierher gehörigen Windungen und Züge sind immer an gleichem Orte, in gleicher Lagerung nachweisbar.

Viel weniger constant ist die Entwicklung des übrigen Mantelgebietes und der in ihm verlaufenden Furchung. Wollen Sie sich daran erinnern, dass die Entwicklung des Gehirns ron anderen Momenten als diejenige der Schädelkapsel bedingt ist, dass das Torhandensein und der Terlauf der Furchung durch die Resultante aus mindestens zwei verschiedenartigen Entwicklungsrichtungen gegeben ist, wie ich das Thnen in der vorigen Vorlesung dargelegt habe.

Furchen, die beim Nenschen tief und lang sind, können nahestehenden Thieren ganz fehlen, andere, dort nur angedentete, sind zuweilen bei Thieren stark entwickelt.

Bei einigen Säugern ist die Fissura Sylvii z. B., sonst eine der am häufigsten vorhandenen Furchen, nicht oder doch nur durch eine flache Einsenkung angedeutet. Die anderen Furchen der Oberfläche können die verschiedensten Richtungen einnehmen. Im Allgemeinen kamn man aber erkennen, dass es im Wesentlichen doch 3 Hauptrichtungen giebt: dem Längsspalte des Gehirns parallel verlaufende Furchen, sagittale, dann solche, welche sich um die Sylvische spalte herumkrümmen, B o g e nfurchen. Fissurae arcuatae, und schliesslich Furchen von mehr oder weniger senkrecht aufsteigendem Typus, Fissurae coronales. Am menschlichen Gehirne haben sie für die letzteren in der Centralfurche ein gutes Beispiel, sagittale Furchen durchziehen da den Stirnlappen, und Bogenfurchen umgeben im Schläfen- und Scheitellappen die Sylvische Spalte. Gerade die senkrechten Furchen sind bei Thieren meist nur wenig ausgebildet. An dem Bärengehirne, dass ich Ihnen hier vorlege, ist die Centralfurche allerdings relativ lang. Benutzen Sie diese Ihnen ja nun wohlbekannte Furche, um sich den Vergleich mit dem Menschengehirne zu erleichtern. Sie sehen, dass der ror ihr liegende Stirnlappen sehr viel weniger entwickelt ist, als der in Fig. 130. Die Homologisirung der Stirnfurchen fällt schwer. Die ('entralfurche verläuft, wohl wegen der mangeln- 
den Stirnlappenausbildung, viel steiler, ebenso sind alle hinter ihr liegenden Theile gewissermassen in die Höhe gerückt, die Fissura Sylvii steht fast senkrecht. Bogenfurchen umgeben sie, in denen Sie bei der Vergleichung mit Fig. 130 unschwer die gleiche Anordnung erkemnen, wie in den Schläfenfurchen und der Interparietalspalte, falls Sie sich einen Augen-

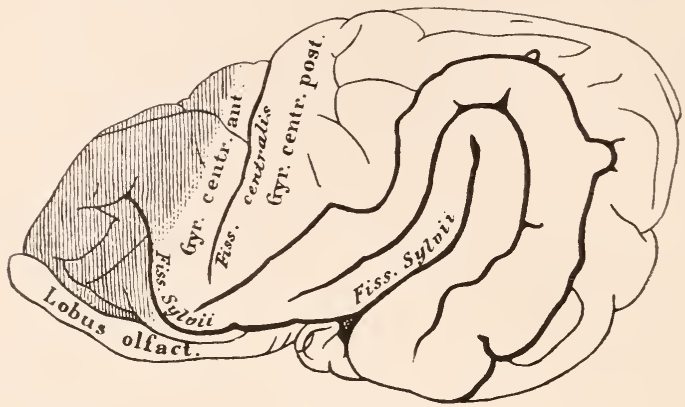

Fig. $14 \overline{5}$.

Bärengehirn nach Turner. Die Stimlappen schraffirt.

blick vorstellen wollen, diese gingen in einander über. Die Sylvische Spalte steht bei allen Thiergehirnen senkrechter als beim Menschen; sie ist um

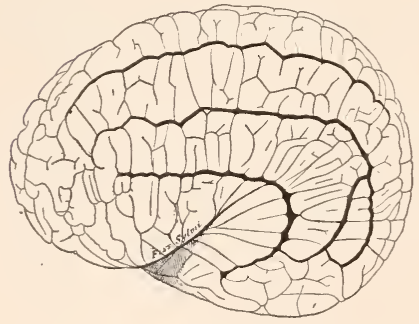

Fig. 146.

Gehirn von Monodon monoceros nach Turner. so wagerechter, je ausgebildeter der Stirnlappen ist. Gewöhnlich ist sie auch relativ kurz.

Bogenfurchen kommen häufiger als andere Furchen in der Thierreihe vor. An dem windungsreichen Gehirne der Wale bilden sie den Typus der Gesammtfurchenbildung. (Fig. 146).

Man numerirt sie von der Sylvischen Spalte aus zählend als erste, zweite u. s. w. Bogenfurche oder benemnt sie auch als: Fissura ectosylvia, F. suprasylvia u. s. w. An dem Gehirne des Hundes, welches hier folgt, erkennen Sie wieder eine Anzahl dieser Furchen an Form und Lage. An der hinteren Grenze des Stirnlappens zieht eine kurze Furche senkrechten Terlaufs herab, die Fissura cruciata. Sie entspricht wahrscheinlich der Fissura centralis. Doch ist die Identität beider Furchen nicht unbestritten. Wie schon in der zweiten Torlesung erwähnt wurde, sind viele Thiergehirne ganz glatt. An anderen finden Sie nur Andeutungen von Furchen. An vielen, z. B. den Pferde- und Rindergehirnen, ist nur in den der Sylvischen Spalte zunächst liegenden Gebieten der Bogentypus dentlich. Nach der Hirnkante zu haben die Furchen einen mehr sagittal 
gerichteten Terlauf. Es würde uns hier zu weit fortführen, wenn ich Ihnen mittheilen wollte, was über die Furchenrichtung'en bei den verschiedenen Thierklassen bereits bekannt ist. Die gegebenen Beispiele sollen nur einige 'Typen vorfïhren und eine Einleitung für eigene Studien sein.

Unsere Kenntniss vom Terlaufe der Hirnwindungen entstammt Untersucluugenvon $\mathrm{B} \mathrm{u} \mathrm{r}$ dach (mediale Seite), Leuret. Gratiolet, II eynert (vergleichend anatomisch), $\mathrm{B}$ is $\mathrm{c}$ h $0 \mathrm{f} \mathrm{f}$,

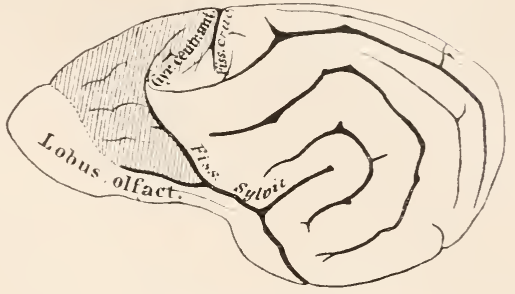

Fig. 147.

Hundegehirn. Der Stirnlappen schraffirt.

Ecker, Pausch (wachsendes und reifes Gehirn). Ausserdem existiren zahlreiche Untersuchungen über einzelne Rindengebiete; über die am Hirnrande verlaufenden Züge, z. B. von Broca und von Zuckerkandl, über die Stirnwindungen von Eberstaller und von Hervé, über die Insel von Guldberg, feruer genaue Studien über Entwicklung: und Verlauf einzelner Spalten von Rüdinger, Cunningham und An. deren. Daneben besitzen wir sehr viele Ionographien über die Hirnobertäche verschiedener Säuger; anthropomorphe Affen von Bisch off, Waldeyer u. A., Lemuren von Flower und Gervais. Wale von Guldberg, Ziehen und Kïkenthal, Ungulaten von Krueg, Ellenberger, Tenchini und Negrini, Raubthiere von IC ynert, Spitzka u,A. Kritische Zusammenstellungen, Sichtung und Vergleichung verdanken wir in neuester Zeit namentlich Turner, dann Ziehen und Kikenthal. Die zahlreichen Abweichungen von dem beschriebenen Typus, wie sie normal oder durch Missbildungen vorhanden sein können, haben von den meisten der oben erwähnten Autoren, dann aber auch von besonderen Bearbeitern, Richter, Sern ow u. A., Berïcksichtigung erfahren.

Für den Riechapparat liegen ältere Arbeiten von Me snert, Ganser, BevanLevis u. A. vor. Die Darstellung im Texte folgt eigenen, gemeinsam mit Dr. Flatow gemachten Untersuchungen. Neute wichtige Arbeiten stammen von Kölliker. S. auch im Texte.

Es liegt, meinc Herren, nicht im Plane dieser Vorlesungen, die reiche Fiille von Thatsachen mitzutheilen, welche die Pathologie über die Functionen der einzelnen Hirntheile ermittelt hat. Die Lehre von der Function der Hirnrinde ist noch durchaus im Werden begriffen, ist noch nach keiner Seite hin abgeschlossen. Im Allgemeinen kann man sagen, dass über die Erscheinungen, welche nach Verletzung der Rinde auftreten, mehr sicher gestellt ist für den Menschen als für das Thier. Das Folgende enthält eine nur ganz kurze Uebersicht dieser Symptome:

Störungen, welche den normalen Aufbau und das normale Functioniren der Hirnrinde treffen, erzengen beim Menschen je nach der Stelle, wo sie sitzen, verschiedene Symptome. Es sind bislang schon mehrere hundert gut beobachtete Fälle von Rindenerkrankung bekannt, und man kann durch Vergleichung der einzeluen unter einander zu folgenden Schlüssen kommen:

Von jedem Punktc der Hirnrinde aus können motorische Reizerscheinungen (von Zuckungen einzelner Muskeln bis zur Epilepsie) zu Stande kommen. Es existirt aber eine Zone des Gehirnes, die beiden Centralwindungen, bei deren Erkrankung fast immer Störungen der Motilität in der gekreuzten Körperhälfte auftreten. Diese Störungen zerfallen in Reizerscheinungen und Ausfallerscheinungen. Die Reizerscheinungen äussern sich durch Krämpfe, die Ausfallerscheinungen durch mehr oder weniger hochgradiges Unvermögen, die Muskeln durch den 
Tillen in Bewegung zu setzen, oft nur durch ein Schwächegefühl oder durch Ungeschicktheit zu complicirteren Bewegungen.

Durch genaue Analysirung der bekannten Krankheitsfälle lässt sich feststellen, dass bei Erkrankung des oberen Theiles beider Centralwindungen und des Paracentrallappens rorwiegend in dem Beine die Bewegungsstörungen sich geltend machen, dass, wenn das untere Ende der Centralwindungen befallen ist, das Facilalis- und das Hypoglossusgebiet getroffen werden, und dass Bewegungsstörungen in der Oberextremität namentlich durch Erkrankung etwa des mittleren und eines Theiles des oberen Drittels der betreffenden Windungen erzeugt werden können. Die Tremnung der einzelnen ,Centren" von einander ist keine scharfe.

Vollkommene Zerstörung einzelner Theile der Centralwindungen kamn beim Menschen zu daueruder Lähmung der von ihnen abhängigen Muskeln führen. Fast immer gerathen die gelähmten Muskeln in Contractur.

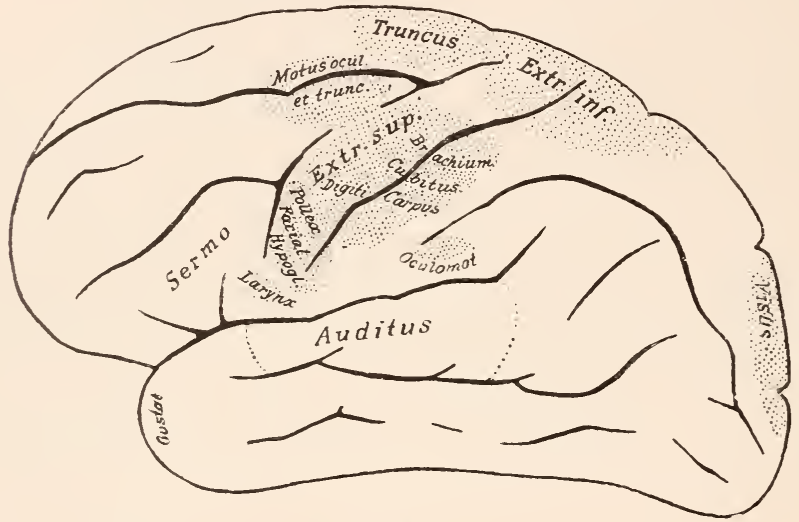

Fig. 148 .

Die bis heute bekannten Projectionsfelder der Rinde.

Erkrankungen, welche die Rinde der unteren Stirnwindung oder der Insel treffen, führen, wenn sie links sitzen, meist dazu, dass der Befallene die Sprache mehr oder weniger vollkommen verliert, obgleich seine Sprechwerkzeuge noch ganz normal innervirt werden kömmen, und er Gesprochenes oft noch ganz wohl versteht. Das Verstehen des lant Gesprochenen scheint dann unmöglich zu werden, wem die obere Temporalwindung zerstört ist. Die Fähigkeit, Gelesenes zu verstehen, hat man wiederholt verloren gehen sehen nach Herden, welche zwischen der Spitze des Hinterhauptlappens und dem hinteren Ende der Sylvischen Furche ihren Sitz hatten. Vielleicht handelt es sich aber hier um tiefe Bahnen und nicht um Rindenlocalisation.

Erkrankungen im Bereiche eines Hinterhauptlappens können zu Sehstörung führen, welche sich als Sehschwäche oder Blindheit auf der änsseren Seite des Auges der erkrankten und der inneren Seite des Auges der gekreuzten Seite äussert (s. u.). Namentlich scheint ein Intactbleiben des Cuneus für das Verstehen des Geselienen wichtig.

Die Sensibilität kann bei Hirnrindenerkrankungen auch leiden. Häufig worden Gefühle von Taubheit, von Schwere, dann hochgradige Störungen des Muskelgefühls beobachitet. Fuir den Tastsimn ist es die Regel, dass er zunächst 
abgestumpft erscheint, so weit die Beurtheilung des Gefïhlten in Frage kommt, dass aber doch ganz feine Reize als Tastreize erkannt werden, wenn sie nur recht einfacher Natur sind. (Berühren mit einer Flaumfeder, einer Nadelspitze u. s. w.) Stellen der Hirmrinde, von denen aus häufiger als von anderen Störungen der Sensibilität entstehen, sind nicht sicher bekannt. Jedenfalls können bei Erkrankungen, die im Bereiche der Centralwindungen und ihrer Nachbarschaft sitzen, Sensibilitätsstörungen auftreten. Es ist sehr wahrscheinlich, dass Herde im Ammonshorne, vielleicht auch in den iibrigen Theilen der Randwindung Geruchsstörungen erzeugen.

Die Lähmungen, welche nur durch Erkrankungen der Hirnrinde entstehen, sind nie so complet wie die, welche durch Zerstörung der peripheren Nerven oder ihrer nächsten Enden im Rïckenmarke erzeugt werden. Bei Thieren gelingt es überhaupt nicht, durch Wegnehmen der Rinde in der motorischen Zone oder des ganzen Hirnstiickes, welches diese Zone enthält, dauernde Lähmung zu erzielen. Wohl aber kann man bei ihnen durch Reizung der Hirurinde an circumscripten Stellen fast jedesmal von der gleichen Rindenstelle aus die gleichen Muskeln zur Contraction bringen.

Und nun, iiber die wohl studirte Lage der corticalen Centren beim Menschen orientirt, werfen Sie einen Blick auf die Abbildungen der Figur 140, welche nach Versuchen von Mann zeigt, welche Theile der Oberfläche des Gehirnes bei Säugern jetzt in ihrer functionellen Bedeutung bekannt sind. Damit kommen wir
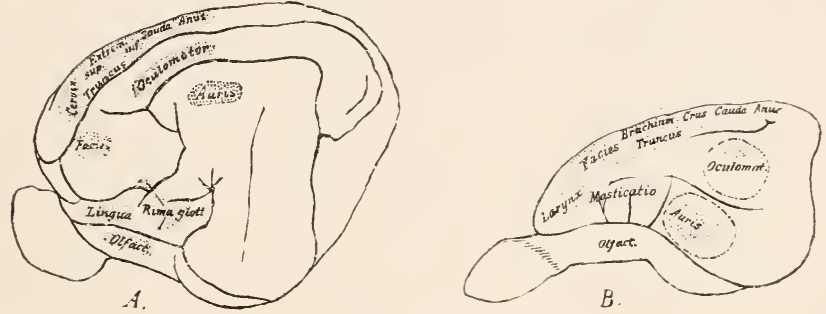

Fig. 149.

Die Rindenfelder, soweit sie durch Reizung nachweisbar sind. $A$ ron dor Katzo. $B$ vom Kaninchen. Nach Mann.

auch zu dem zurïck, was in der 12. Vorlesung über die Bedeutung des Mantels als einer Summe von Einzelcentren und Associationsfeldern mitgetheilt wurde. Sie erkennen auch sofort, wie Vieles sich im Primatengehirne findet, das bei niederen Säugern noch nicht oder unnachweisbar klein vorhanden ist.

Für die physiologische Stellung des Hirnmantels wollen, wie namentlich noclimals das Seite 169 Vorgetragene vergleichen und ausserdem sich erimnern an die S. 43 erwälnten Versuche von Ewald, welche zeigen, wie vielerlei zum geordneten Zustandekommen eingelernter Bewegungen erforderlich ist, wie aber eines oder das andere Moment gelegentlich da ersetzend einzutreten vermag, wo Ausfälle vorhanden sind.

Man kann wohl sagen, dass der Hirnmantel sich in dem Maasse relgrössert, als anfsteigend in der Thierreihe neue Centren in ihm sich anlegen, Rindengebiete, die zur Einübung von Bewegungen zum Zurïckhalten, Erkennen mod Wiederverwerthen von simneseindrücken und — wohl in ihrer Hauptmasse - zur Association verwendet werden. 


\section{Fünfzehnte Vorlesung.}

\section{Die Rinde des Vorderhirus und das Markweiss der Hemisphären, die Commissuren und der Stabkranz.}

I. H.! Sie haben nun einen allgemeinen Ceberblick über die äusseren Formverhältnisse des Gehirnes bekommen. Die heutige Stunde soll Sie näher bekannt machen mit dem Baue der Hirnrinde, sie soll Ihnen einen Einblick geben in die Terbindungen der Rindengebiete unter sich und mit tiefer gelegenen Gebilden.

ITir kemnen den feineren Aufbau der Rinde nur erst in seinen Elementen. Noch fehlt uns das Wissen von den Verbindungen dieser Elemente unter einander und damit leider noch das eigentliche Verständniss für die anatomische Grundlage des grossen Seelenorgans. Es unterliegt kaum noch einem Zweifel. dass wir die Hirmrinde als Ganzes, als den Ort ansehen dürfen. wo sich die meisten derjenigen seelischen Processe abspielen. die uns zum Bewusstsein kommen, dass in ihr der Sitz des Gedächtnisses ist, dass von hhr die bewussten Willensacte ausgehen.

Die ganze Hemisphäre ist ron der Rinde iiberzogen. Dieselbe hat an der Convexität nicht überall genau den gleichen Bau. Wenn auch eine Art Grundtypus existirt, so lassen sich doch je nach der Hirnregion, die man untersucht, geringere oder grössere Differenzen in den Schichten auffinden, in welche die Ganglienzellen und Nervenfasern der Rinde angeordnet sind. Nie geht ein Rindentypus plötzlich in einen anderen über. Da aber diese anatomischen Terschiedenheiten in ihrer Bedeutung noch ganz unverstanden dastehen, so wollen wir uns heute nur die Rinde einer Region, des Stirnlappens, betrachten. Dort liegt dicht unter der Pia, noch bedeckt von einer dickeren Neuroglialage, ein dichtes Flechtwerk ron meist parallel zur Oberfläche dahinziehenden feinen markhaltigen Fasern -1 der umstehenden Figuren, Schicht der Tangentialfasern. Ihr sind Zellen in relativ geringer Menge eingelagert. Direct unter ihr aber beginnt die schicht der eigentlich für die Rinde typischen Pyramidenzellen, zunächst mit einer sehr zelhreichen Lage kleinerer Gebilde 2, die dam aber in 3, die Schicht der grossen Rindenpyramiden übergeht. Alle diese senden nach der Oberfläche und nach verschiedenen Seiten ihre Dendriten als spitzenfortsatz, Lateralfortsätze u. s. w. und zumeist - nach der Tiefe des Narklagers ihren Axencylinder. Die Schicht der grossen Pyramidenzellen ist im Stirn- und Scheitellappen die breiteste der Rinde. Die einzehnen Zellen sind um so grösser, ihr Spitzenfortsatz um so länger, je tiefer die Zelle von der Oberfläche abliegt. Die vierte unter den Pyramiden liegende Zelllage besteht wieder aus kleineren, nicht regelmässig liegenden Zellen. Sie sind eingeklemmt zwischen der Masse in die Rinde eindringender Markfaserstrahlungen.

Ausser den erwähnten Pyramidenzellen giebt es noch in der Rinde eine grosse Masse kleinerer, in allen Höhen rertheilt liegender, polygo- 
naler Zellen, deren Axencylinder sich ungemein rasch völlig aufzweigt. Auf Fig. 150 erscheinen diese Zellen als viele helle, überall in der Umgebung der Pyramiden liegende polygonale Gebilde.

Un den Bau der Hirnrinde kennen zu lernen, bedarf es der Anwendung mehrerer Methoden. Jede zeigt ein anderes Bild, und nur aus der Vereinigung des so Gewonnenen ergiebt sich das Gesammtblid. Da auf der linken seite der Fig. 151 nur ein geringer Theil der Zellen sichtbar ist, so lege ich Ihnen hier in Fig. 150) eine Zeichnung vor, die $\mathrm{N}$ is s l nach einem Alkoholpräparate absolut naturgetren hergestellt hat. Sie wird Ihnen bei praktischen Arbeiten von gutem Nutzen sein können.

Die Markstrahlen zerfahren, in der Rinde angekommen, in zahlreiche feine Züge, und diese lösen sich allmählich in weiter aussen liegenden Lagen auf. resp. treten in Terbindung mit den Axencylindern der Zellen. Sie sehen ausser diesen Ziigen noch zahlreiche andere markhaltige Nervenfasern in der Rinde.

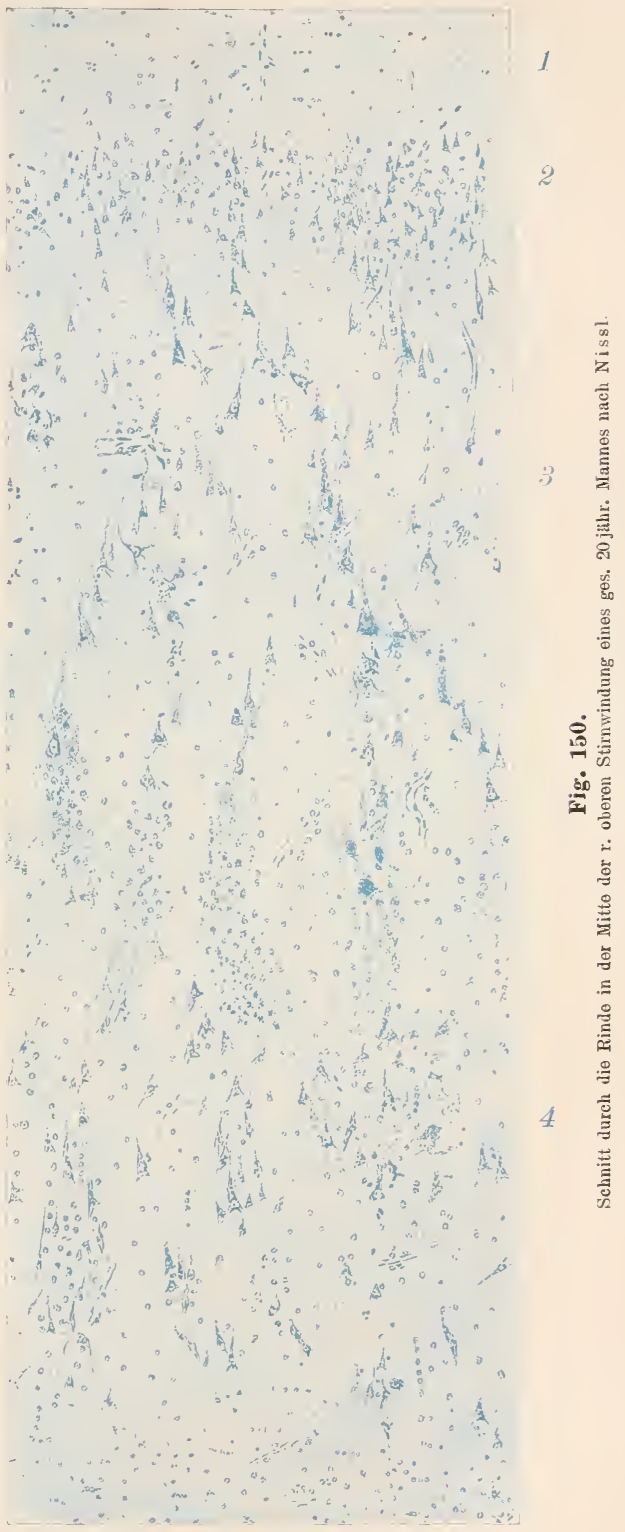


Woher diese Fasern kommen, wohin sie gehen, das war vor Kurzem noch ganz unbekannt. Nenerdings aber haben uns Untersuchungen von Golgi,

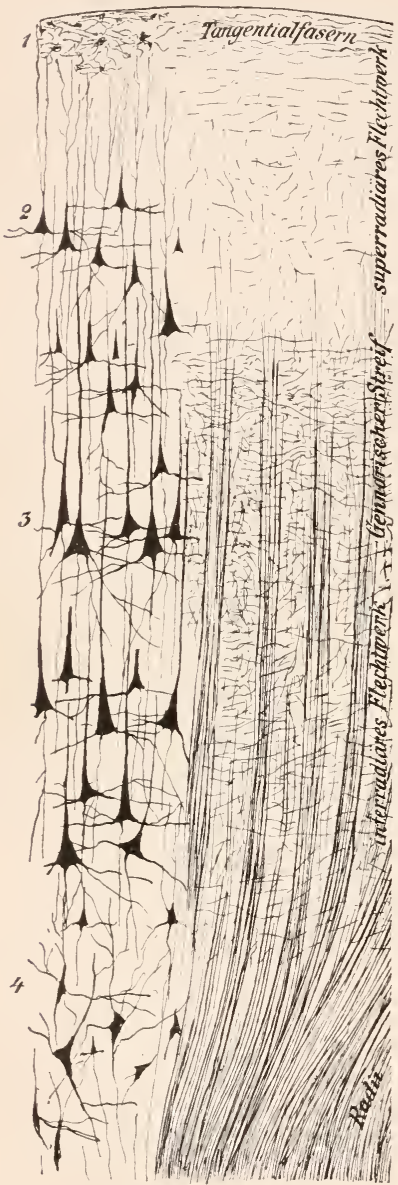

Fis. 151.

Schnitt durch die Rinde einer Stirnwindung. Rechts nach einem mit Weigert'schem Hämatoxylin gefärbten Präparate, links nach Präparaten, die nach Golgi nit Sublimat behandelt waren. Rechts sind nur die Fasern, links nur die Zellen deutlich. Der letzteren sind mehr vorhanden, als gezeichnet wurden. Da sich bei der Golgi'schen Methode Hohlräume um Zellen und Ausläufer erfüllen, so erscheinen diese grösser als sie wirklich sind. ron Martinotti und ganz besonders solche ron $\mathrm{S}$. Ramon y Cajal eine grosse Anzahl neuer Terhältnisse in der Hirnrinde kemnen gelehrt, so dass es jetzt wohl möglich erscheint, die einzelnen Elemente in ihrem Zusammenhange zu betrachten. Allerdings sind die meisten Facta an der Hirnrinde kleiner Sänger erkannt, und nur für wenige ist anch beim Menschen die Bestätigung gefunden. So bleibt noch viel Arbeit zu thun übrig. Was aber bekannt wurde, bringt uns einen so guten Schritt vorwärts, dass ich es Thnen mittheilen muss. Ich habe hier, um meine Beschreibung kurz fassen zu können, auf einer einzigen Abbildung die wichtigsten Funde combinirt dargestellt (Fig. 152).

Die äusserste Schicht enthält zahllose, zumeist in tangentialer Riclitung verlaufende Nervenfasern. Diese stammen aus Ganglienzellen $a, b, c$, welche alle mehrere Axencylinder besitzen, und aus kleinen, spindelförmigen Zellen $d$, einer tiefer liegenden Schicht. In diese äusserste Zone aber treten noch zweierlei Elemente ein; dicke, zum grössten Theile von Markscheiden umgebene Fasern $e$, welche aus dem Marklager in die Rinde treten, werden in ihren äussersten Verzweigungen bis dahin verfolgt. Sie müssen Ganglienzellen entstammen, welche an anderen Stellen des Gehirns liegen. Für ihre Herkunft aus der Ferne spricht namentlich ilur Faserkaliber. Dann enden dort in reichen und dichten Verzweigungen die Dendritenausläufer der tiefer gelegenen Pyramidenzellen $f$. Jedem einzelnen Aestchen sitzen noch zahllose feine, in Kölbchen auslaufende Nebenästchen auf. Die Verzweigung ist eine so dichte, dass ïberans reichliche Gelegenheit zu Contacten der Dendritenanslïnfer tiefer Zellen mit den gleichen Ausläufern und den Axencylindern der an Ort und Stelle liegenden Zellen gegeben ist. Solch einen Reich- 


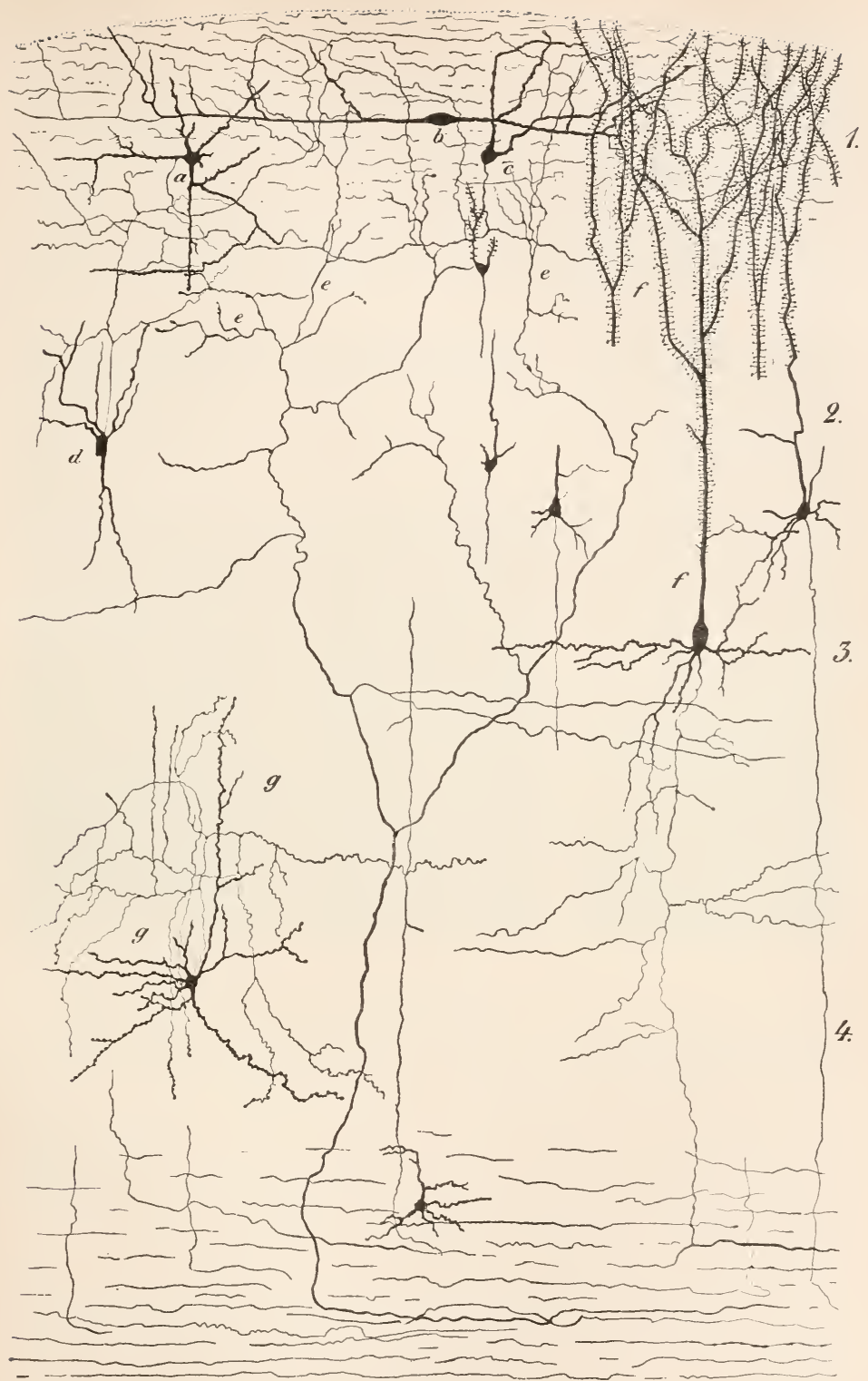

Fig. 152.

Schnitt durch die Hirnrinde bei einem Säugethier. Combinirt nach Präparaten von S. Ram on y Cajal. 
thum an Verbindungsmöglichkeiten zwischen den Ausläufern ganz verschieden gelagerter Zellen, wie er hier enthüllt worden ist, hat selbst die kïhnste Plıantasie speculirender Psychologen sich kaum träumen lassen. Ind dennoch ist und bleibt nicht nur hier, sondern auch sonst überall in der Rinde jede Zelle als selbständiges Individuum bestehend. Nirgendwo erkennt man directe Verbindungen, überall zeigen sich nur Anlagerungen.

Unter der Tangentialfaserschicht liegt die Schicht der kleinen Pyramidenzellen. Sie geht ganz allmählich in 3, die der grossen Pyramiden iiber. Die Axencylinder all dieser Zellen ziehen in der Richtung nach dem Marklager.
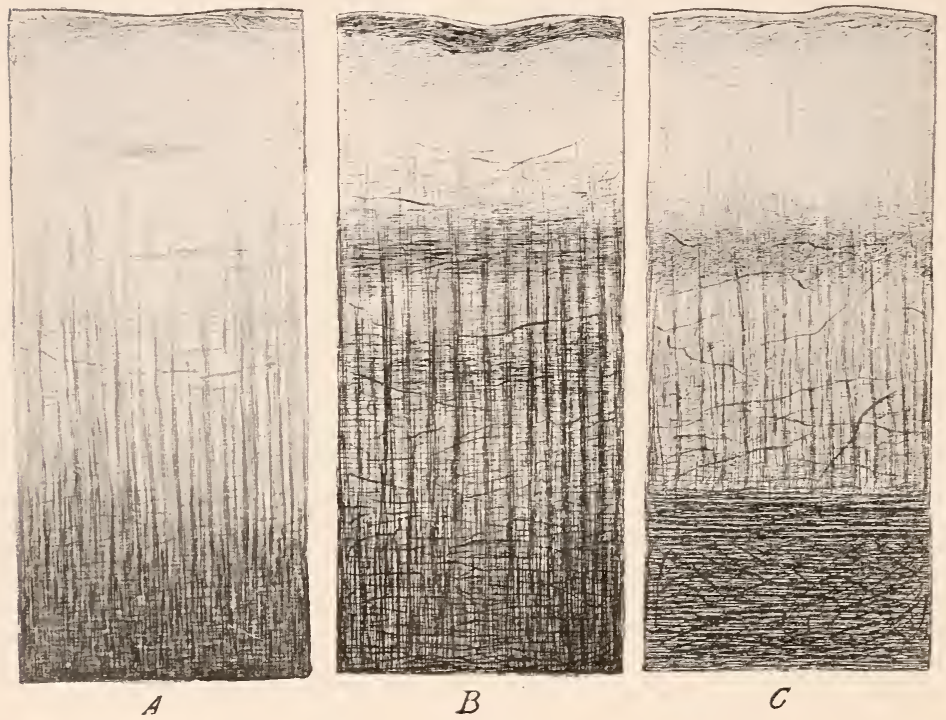

Fì. 1 วั3.

Drei Schnitte durch die Rinde der vorderen Centralwindung nach Kaes. $A$ von einem $11 / 4$ J. alten Kinde. $B$ von einem 36 jähr. Manne. $C$ von einem Manne von 53 Jahren. Markscheidenfärbung. Controlpräparate haben gezeigt, dass die Differenzen wesentlich durch das Alter hedingt sind, doch kann die Möglichkeit, dass verschiedene Einüibung des betreffenden Rindengebietes in etwas zur Differenz beiträgt, nicht von der Hand gewiesen werden.

Sie geben zahlreiche Nebenästchen ab. Viele spalten sich nahe dem Marklager in einen horizontalen und in einen absteigenden Ast. Aus diesen Fasern werden die Züge, welche die Hirnrinde mit tiefer liegenden Centren, und diejenigen, welche sie mit ferner liegenden Rindenstellen verbinden.

Die Dendritenfortsätze ragen periplerwärts mehr oder weniger weit nach aussen, enden zum Theile erst unter der Pia.

Nahe dem Marklager, unter den wohlausgeprägten Pyramiden, liegen zahlreiche Zellen von unregelmässiger dreieckiger, auch kleinpyramidaler Form. Sie verhalten sich im Verlaufe ihrer Axencylinder, wie in dem ihrer Dendritenfortsätze analog den Pyramiden, bieten nur unregelmässigere Formen und ärmere Verzweigung. In dieser tiefsten Schicht findet man damn noch zahlreiche multipolare Zellen $g$, deren Axencylinder in den verschiedensten Richtungen, horizontal, 
auf- und absteigend verlaufen kann. Er zeichnet sich aber immer dadurch aus, dass er nach kurzem Verlaufe sich in ein weites, complicirtes Geäst auflöst, dessen Fäserchen alle frei enden. Solche Zellen kommen übrigens auch noch in fast allen anderen Schichten der Hirnrinde vor. Auch sie sind mit ihrer weiten Auszweigung wieder sehr geeignet, andere Zellgebiete unter einander physiologisch zu verknipfen.

Die mzähligen Axencylinder mit ihren Terzweigungen, die Seitenästchen, welche sie aussenden, dann die zahlreichen, von anderen Stellen des Gehirnes in die Rinde eintretenden Fasern, sie alle zusammen bilden natiirlich ein ausserordentlich dichtes Gewirr. Es zu entwirren, war durch den glïcklichen Emstand möglich, dass die Golgi sche Methode zumeist in den gleichen Präparate immer nur relativ wenige Zellen schwärzt. Die gleichen Fasergewire, wie sie in Fig. 151 Thnen die Markscheidenfärbung gezeigt hat, lassen sich mit der Zellfärbung demonstriren, nur sind sie im letzteren Falle noch viel dichter. Es scheint, dass die Axencylinder der allermeisten Zellen in der Hirnrinde, ebenso die Collateralen, welche aus den Axencylindern der Pyramiden entspringen, eine Markscheide besitzen. Solange wir alle diese Fasern ihrem Wesen nach noch nicht richtig benennen können, wird es behufs Terständigung, bei pathologischanatomischen Untersuchungen z. B., zweckmässig sein, provisorische Namen für sie einzuführen. Wir wollen unterscheiden 1. Radii, Markstrahlen, 2. interradiäres Flechtwerk, zumeist aus der Oberfläche parallelen Fasern bestehend, 3. superradiäres Faserwerk und 4. Tangentialfasern. An der Grenze zwischen dem superradiären und dem interradiären Flechtwerke verdichtet sich das letztere besonders stark. Diese überall auch mit blossem Ange als weisser Streif sichtbare schicht ist namentlich im Bereiche des Cuneus so dicht, dass sie dort besonders leicht erkannt wird. Man bezeichnet sie als Gennari'schen Streif oder nach ihrem späteren Wiederbeschreiber meist als Baillarger'schen, speciell im Cuneus als Ticq d'Azyr'schen streifen. Doch liegt im Occipitallappen der streif etwas tiefer in der dritten Schicht, näher der vierten, nicht so hoch oben, wie er in Fig. 151 fiir den Stirnlappen abgebildet ist.

Die Markscheiden im superradiären Flechtwerke entstammen wohl zımeist den in die Rinde einstrahlenden Fasern. Sehr fraglich ist, ob die Zellen mit verzweigtem Axencylinder markscheidenhaltige Ausläufer haben. Der Gen nar i sche Streif wird ganz ron Seitenzweigen aus Pyramidenaxencylindern gebildet. Das interradiäre Flechtwerk besteht ebenfalls aus Axencylindercollateralen gleicher Herkunft, vielleicht auch aus dem Geäste der Zellen mit verzweigtem Axencylinder.

Man darf nun nicht erwarten, dass man alle diese Streifen u. s. w. immer wohl ausgebildet finde. Abgesehen davon, dass sie je nach der Rindenzone verschieden stark entwickelt sind, ergeben auch entwicklungsgeschichtliche Untersuchungen, dass ganz erhebliche Unterschiede je nach dem Alter bestehen kömnen. Wahrscheinlich wird sich, wenn wir nur erst eimmal für alle Rindentheile und für alle Altersstufen einen gewissen Typus kennen, auch herausstellen, dass bestimmte Beziehumgen zwischen der Intelligenz und dem Faserreichthume in der Rinde bestehen. 
Tiel in dieser Beziehung rersprechend sind die Entdeckungen von Kiaes. Dieser komnte nämlich durch zahlreiche genaue Messungen nachweisen, dass die Hirnrinde noch weithin, bis in das 40. Lebensjahr und länger, an Faserreichthum zunimmt. Ganz besonders kommen in Betracht Zïge, die imnerhalb des basalen Abschnittes der Markstrahlen in zur Oberfläche paralleler Richtung einherziehen, Fibrae arcuatae intracorticales, und dann Faserzüge, welche innerhalb des superradiären Flechtwerkes liegend, sich dicht an die Tangentialfaserschicht anschliessen. Hier kommt es in einigen Rindenpartien noch sehr spät zur Narkumscheidung, so dass allmählich ein sehr grosser Theil der Rinde unter der Tangentialfaserschicht ron feinen Fäserchen durchquert wird. Dazu gesellen sich nach $K$ a es noch dickere Markfasern, die man im Laufe der Jahre ganz allmählich aus den Schichten, welche dem Narke zunächst liegen, nach der Rindenoberfläche hin sich verbreiten sieht. Es sind wohl die zum Theile recht starken Fasern dieses Plexus, welche Bechterew beschrieben, und von denen er einen eigenen, dicht unter den Tangentialfasern liegenden Streif - ..Bechterew'scher Streif“ - gebildet sah. Fig. 153, die ich der Freundlichkeit von Dr. Kaes verdanke. lässt den rerschiedenen Typus der Rinde an rerschiedenen Stellen und zu rerschiedener Lebenszeit gut erkennen.

Soweit man bis jetzt sehen kann, sind das Alles ne ue Associa ti onsbahnen oder doch solche, die, spät erst in Gebrauch genommen, sich mit Mark umkleiden. Vielleicht auch handelt es sich nur um Collateralen, die mit der grösseren Inanspruchnahme durch vermehrte Associationen erst num ihre völlige Ausbildung bis zur Markscheidenumkleidung erhalten. Wir wissen, dass auch in anderen Geweben durch eine rermehrte Inanspruchnahme der Elemente Steigerung ihres Wachsthums eintreten kann. So hätte der gleiche Torgang in der Hirnrinde Nichts, was ron den bekannten Naturvorgängen abwiche. Man kamn sich wohl vorstellen. dass der Mensch sich durch cerebrale Arbeit neue Bahnen in diesem Sinne schafft, dass der vermelnten Leistungsfähigkeit, welche die Uebung des Gehirnes schafft, als anatomisches Substrat die Neubildung oder Terstärkung vorhandener Bahnen entspräche.

Wie ich vorhin erwähnte, ist die Hirmrinde nicht an allen Stellen der Oberfläche gleich gebaut. Die Rinde der Umgegend der Fissura c a lcarina ist $z$. B. ausser durch den Genn ari'schen Streifen anch charakterisirt durch ein Torherrschen der kleinen polygonalen, meist hellereren Zellen und eine relative Armuth an grossen Rindenpyramiden.

Eine besondere Betrachtung verdient die Ammonsformation. An der Hirnbasis ganz median wendet sich hier die Rinde erst nach aussen und dann direct wieder nach imnen, um dann sich wieder ein kleines Stïck nach aussen zurück zu krümmen. s. Fig. 154. Die Pyramidenzellen der Ammonswindung gehen dam aber nicht ummittelbar in diejenigen des Grrus dentatus ïber. Sie enden vielmehr umregelmässig durch einander 
geworfen (bei a der Fig. 154), und dieser unregehmässige Haufen wird dann von dem Halbbogen der regelmässig stehenden Zellen des Gyrus dentatus umschlungen. Wir können jetzt ohne Zwang die schichten der Ammonsformation auf die reguläre Rindenschichtung zurückführen (Me y nert und besonders $\mathrm{Sch}$ affer), sie bieten aber in ihrem Gesammtausehen doch so viele Eigenthümlichkeiten, dass man bei Beschreibungen die Namen, welche sie früher erhalten haben, noch anwendet.

Wollen sie an der folgenden Abbildung von unten nach oben gehend zunächst die Rinde verfolgen.

Der Theil des Ammonslappens, welchem die eigentliche Aufrollung: aufliegt. wird als Subiculum cornu Ammonis bezeichnet. Er ist von

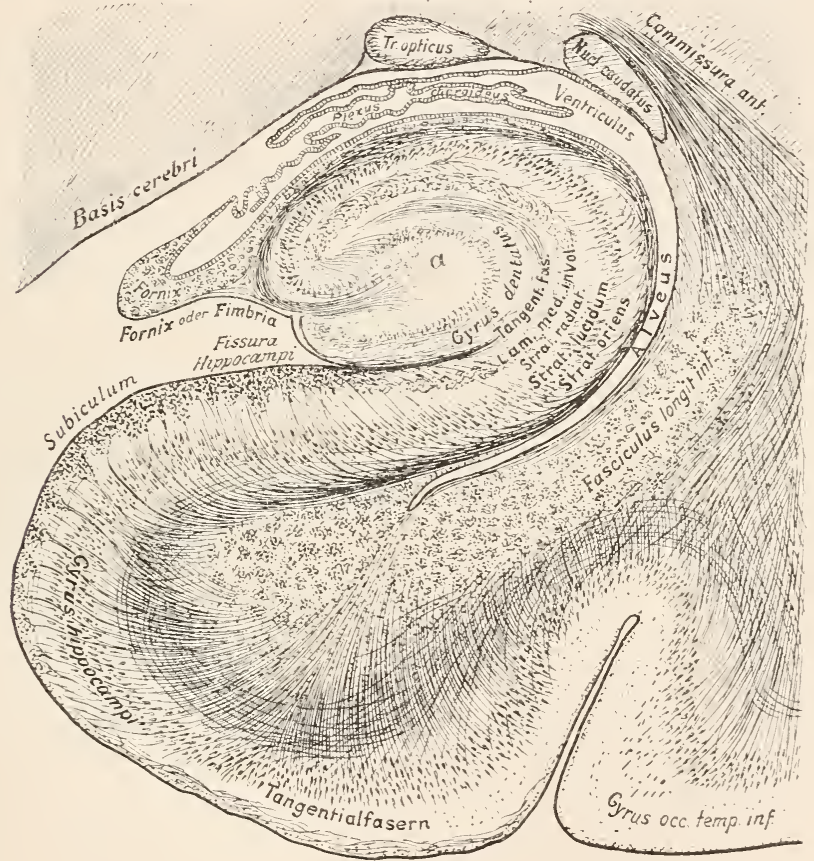

Fig. 151.

Schnitt durch die Hirnbasis und die unter ihr liegende Ammonswindung. Nach einem mit Hämatoxylinkupferlack gefärbten Präparat. Der Plexus chorioides etwas einfacher gezeichnet, als er es beim Erwachsenen ist. Man beachte, dass und wie er den Tentrikel rom Schädelraum abschliesst.

einer ungewöhnlich starken schicht ron Tangentialfasern bedeckt, deren netzförmige Anor(hnung schon am frischen Gehirne auffällt. Tiele von diesen Fasern scheinen, die ganze Rinde durchbohrend, bis in das Marklager der Windung zu gelangen. Da, wo die Einrollung beginnt, wird die Tan- 
gentialfaserschicht dünner, sie begleitet aber die ganze Ammonswindung weiter und liegt, wie ein Blick auf die Figur zeigen muss. der Rinde des Gyrus dentatus direct auf. Auch diese besitzt eine Tangentialfaserschicht. Beim Menschen ist es schwer, die Tangentialfasern des Gyrus Hippocampi von denen des Gyrus dentatus zu sondern. Sie bilden gemeinsam eine einzige Schicht. In diese tauchen, ganz wie es auf Fig. 152 von der iibrigen Rinde gezeichnet ist, die Dendriten der Rindenzellen ein; von der einen Seite die Dendriten aus der Dentatusrinde, von der anderen diejenigen der Ammonsrinde. Unter der Tangentialfaserschicht liegt im Bereiche der Ammonswindung eine zweite mächtige Schicht markhaltiger Fasern. Diese gewundene Platte. Lamina medullaris circumvoluta, ist ein Associationssystem von Fasern, die im Ammonshorn entspringen und da enden, wo es rom Gyrus dentatus umfasst wird.

Sie müssen der Rinde selbst angehören und nicht erst dahin eindringen, denn bei einem Hunde, dem von der ganzen Hirnrinde nur die eine Ammonswindung geblieben war, liess sich dies System völlig erhalten nachweisen.

Die Lamina med. circumvoluta liegt schon im Bereiche der langen Dendritenfortsätze. welche die Zellen der Ammonswindung aussenden. Die Richtung so vieler langer Fortsätze nach aussen giebt diesem Stratum ein leicht gestreiftes Ansehen auf dem Schnitte. Man hat es deshalb als Stratu m r a di a t u m bezeichnet. Die Zellen selbst scheinen an gehärteten Präparaten in grossen Hohlräumen zu liegen. So erscheint ihr langer gewundener Zug als helle Schicht und hat den Namen Stratum lucidum erhalten. Sie senden ausser ihren Dendriten theilweise auch, ganz wie in der übrigen Rinde, ihre Axencylinder hinaus zur Tangentialschicht. Der grössere 'Theil der Axencylinder aber tritt ventrikelwärts, und es bilden diese und andere Fasern dann ein richtiges Marklager, den Alveus, der dicht unter dem Tentrikelepithel liegt. Der schmale Raum zwischen dem Stratum lucidum und dem Alveus wird von zahlreichen, in das Ammonshorn eindringenden und aus ihm abziehenden Fasern erfüllt. Er entlaält unzählige Fasertheilungen und eine Anzahl sehr merkwürdiger Associationszellen, die wir erst neuerdings durch Ramon y Cajal kemen gelernt haben. Sie sind durch ihren vielverzweigten Axencylinder, der in die Zelllage des Stratum lucidum eindringt, geeignet, die Pyramidenzellen der Ammonswindung unter einander wohl zu verknüpfen. S.Fig. 9. Die ganze ganze Lage wird als Stratum oriens bezeichnet.

Alle Untersuchungen der Ammonsrinde lehren, dass hier ein Zellreichtlıum, eine Namnigfaltigkeit der Faserbeziehungen existirt, welche in der ganzen ïbrigen Rinde, so weit wir wissen, nicht mehr ihres Gleichen findet.

Hat man eimmal das erfasst, was typisch ist am Aufbaue der Hirnrinde. so fällt es auch nicht schwer, den Typus in Gebieten zu erkennen, wo er weniger dentlich ist. Ganz unverstanden war z. B. früher der Bulbus olfactorius. Temn Sie nun Fig. 142 eimmal umdrehen und mit Fig. 152 vergleichen wollen, so springt die Aehnliclıkeit sofort in die Augen. 
Es handelt sich hier um eine Rinde, in deren Molecularschicht aufsplitternd die Riechnervenfaseru sich inseriren. Nur ist das Ganze mehr condensirt. Auch verleiht das Eindringen von Riechnervenfasern in die Tangentialschicht der Oberfläche und das dadurch bedingte andersartige Aufsplittern der Dendriten ans den Rindenpyramiden dem Ganzen einen Anblick, der die Erkenntniss, dass es sich hier um nichts anderes als gewöhnliche Rindenformation handelt, bisher erschwert hat.

Die Oberfläche der Grosshimrinde ist beim Menschen (Weigert) ron einem dichten Glianetz bedeckt, von dem zahlreiche spärlicher gestellte Zïge bis hinab in die Gegend der kleineren Pyramiden strahlen. Dann wird das Glianetz immer dïnner, und in den tiefsten Rindenlagen fehlt es fast ganz. Schon innerhalb der Radii sind nur noch vereinzelte Fäserchen walınehmbar. In der Markschicht liegt damn wieder die relativ dichte Gliaansammlung, welche uiberall die markweissen Fasern umspinnt.

Wenn die Nervenelemente des Grosshirnes - bei der Paralyse z. B. zu Grunde gehen, so tritt an ihre Stelle eine Gliawucherung, die sich nicht nur durch ihr Auftreten an abnormem Orte, sondern auch durch die Dicke der Fasern auszeichnet, welche das sonst Normale noch weit übertreffen. Nur im höheren Alter, wo - wohl auch infolge des senilen Schwundes - etwas mehr Glia in der Hirnrinde ist, kommen noch solche Fasern vor. Wo viele eines der Gliaplättchen kreuzen, entstehen die Astrocythen und Deiter'schen ,Zellen", denen man deshalb gerade bei der Paralyse besonders oft begegnet.

Fine möglichst genaue Kenntniss der Hirnrinde wird eben von allen Seiten mit Recht angestrebt. Bereits hat sich die Psychiatrie erfreulicher Erfolge zu rühmen, die bei solchen Studien herangereift sind. Ich erinnere nur an die Entdeckung von Tuczeck, der nachwies, dass bei der progressiven Paralyse der Irren zunächst das Netz der Nerven in Schicht 1 untergeht, und dass dann successive auch die Fasern in den tieferen Schichten bis in die vierte hinein schwinden. Aehnliches ist später für andere Psychosen nachgewiesen, und neuere Funde haben gelehrt, dass auch in tieferen Theilen des Gehirns bei der Paralyse, Schwund feiner Fasern zu Stande kommt. Derselbe wird, wie der Verlauf seiner Ausbreitung erschliessen lässt, hier und da durch secundäre Degeneration von in der Rinde bereits unterbrochenen Fasern bedingt.

Die Nervenfasern in der Hirnrinde bekommen erst sehr spät ihr Mark. Es tritt im 9. Fötalmonate zuerst im oberen Scheitellappen und der hinteren Centralwindung auf, im 1. Lebensmonate kommen hierzu einzelne Fäserchen in der vorderen Centralwindung, später, im 2.-3., beginnt im Occipitallappen die Markbildung der Rinde. Es ist wahrscheinlich, dass diese Verhältnisse mit der Zeit in Beziehung stehen, in der der Mensch in den einzelnen Hirngebieten Erinnerungsbilder abzulagern beginnt, dass sich mit dem Erwerben von Sehvorstellungen z. B. erst die Rinde der Sehphäre entwickelt.

Im späteren Leben werden immer ausgedehntere Bezirke markhaltig, s. S. 223.

Unter der Rinde liegt das Markweiss der Hemisphäre. Das gleichmässige Weiss, welches ein Schnitt durch das Centrum semiovale dem blossen Ange bietet, wird rom Mikroskope aufgelöst in eine grosse Anzahl sich in mannigfachen Richtungen kreuzender, nur schwer zu verfolgender Fasern. Tersuchen wir es, unter diesen, soweit dies bislang möglich, uns zu orientiren.

Wenn sie Schnitte durch das frische Gehirn eines neugeborenen Kin- 
des machen, so sehen Sie, dass unter der Rinde fast überall eine eigenthümliche, grauroth durchscheinende Masse liegt, in der nur an einer schmalen Stelle, unter dem oberen Theile der hinteren Centralwindung' und in ihrer Nachbarschaft. weisse Nervenfasern zu finden sind. Erst im Laufe der ersten Lebensmonate umgeben sich auch andere Nervenbahnen mit Mark; zunächst meist solche, die ron der Rinde nach abwärts ziehen, bald aber auch Ziige, die einzelne Rindengebiete mit einander rerknüpfen. Die letzteren, die Fibrae propriae der

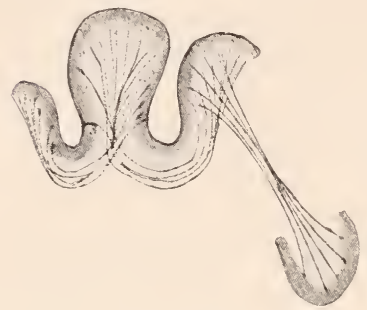

Fig. 155.

Schema der Fibrae propriae der Rinde. Rinde, sind am ansgewachsenen Gehirne ungemein zahlreich, iiberall spannen sie sich ron Windung zu Windung, zur zunächstliegenden und zu entfernteren, ganze Lappen verbinden sie unter einander. Der Gedanke liegt nahe, dass diese .Associationsfasern" erst durch die Einilbung zweier Hirnstellen zu gemeinsamer Action entstehen, resp. sich als dentlich markumgebene Züge aus der indifferenten Nerrenfasermasse herausbilden, wenn sie häufiger als andere Züge in Gebrauch genommen werden. Diese Associationsfasern liegen zum grossen Theile dicht unter der Rinde. zu einem anderen Theil im Narklager der Hemisphären. Ein solches System ist, wie Sie sehen, durchaus geeignet, alle Theile des Gehirnes unter einander in Terbindung zu bringen. Die mannigfachen Associationsvorgänge im Denken, in der Bewegung und der Empfindung, denen das Gehirn dient. finden möglicher Weise hier ihr anatomisches Substrat.

Nicht unwahrscheinlich ist es, dass diese Fasern bei der Ausbreitung der epileptischen Anfälle eine wichtige Rolle spielen. Es ist möglich, bei Thieren durch Reizung einer Rindenstelle zunächst Zuckungen in den hierher gehörigen Muskeln, bei Steigerung des Reizes Krämpfe in der ganzen betreffenden Seite hervorzurufen; Krämpfe, deren Verlauf der Anordnung der betreffenden Centren in der Hirnrinde entspricht. Bei der Ausbreitung dieses Reizes wird nie ein benachbarter motorischer Punkt uibersprungen. Die Krämpfe befallen, wenn sie sich völlig über die eine Körperhälfte verbreitet haben, unter Umständen (Intensität des Reizes, Disposition des Versuchsthieres) die andere Hälfte. Exstirpation der einzelnen motorischen Centren bedingt eine Ausschaltung der betreffenden Muskelgruppen aus dem Krampfbilde. Es ist nicht nöthig, dass die Rindenstelle, von der ein solcher Krampfanfall ausgelöst wird, gerade der motorischen Region angehört. Die erzengten Krämpfe haben die grösste Aelınlichkeit mit dem Bilde der partiellen oder allgemeinen Epilepsie beim Menschen. Bei diesem kennt man, seit den Arbeiten von $\mathrm{Hughlings} \mathrm{Jackson} \mathrm{namentlich,} \mathrm{Epilepsie-}$ formen, welche mit Zuckungen oder Krämpfen in einem Gliede beginnen und sich zuweilen über mehrere Glieder oder den ganzen Körper verbreiten, im letzteren Falle das ausgeprïgte Bild des epileptischen Anfalles darstellend. Das Bewusstsein schwindet, solange der Anfall partiell bleibt, durchaus nicht immer. Nach dem Anfalle bleiben manchmal Lähmungen meist in dem zuerst betrofienen Theile localisirt zurück. Diese partielle oder Rindenepilepsie ist nicht von der 
klassischen Epilepsie zu trennen. Die letztere stellt wahrscheinlich nur eine in ihren ersten Anfängen rascher verlaufende Form dar.

Doch ist es nicht nöthig, dass die Ausbreitung eines Reizes von einer Rindenstelle auf eine andere oder auf das ganze Gehirn gerade auf dem Wege der Fibrae popriae erfolgt. Gar manche Wege bieten sich dar: so der durch das feine Nervennetz an der Oberfläche der Rinde; dann kann ja auch die ganze Rinde gleichzeitig beeinflusst werden durch eine Schwankung des Blutgehaltes ihrer Gefässe, und auch der anderen Wege liesse sich noch mancher finden.

Die Terfolgung der Fibriae propriae zwischen zwei benachbarten Rindenbezirken ist, wemn man sich der Abfaserungsmethode bedient, nicht allzu schwer. Die Darstellumg der Terbindungen weiter von einander liegender Rindengebiete ist viel schwieriger und führt gar leicht zu Kunstproducten, welche nur zum Theile dem wirklichen Faserverlanfe entsprechen. Einigermaassen sicher sind nur wenige Züge zu verfolgen. So das Haken bündel, Fascicnlus uncinatus, das Bogenbïndel, Fasciculus arcuatus, das nntere Längsbündel. Fasciculus longitudinalis inferior, die $Z$ winge. Cingulum, und wenige andere.

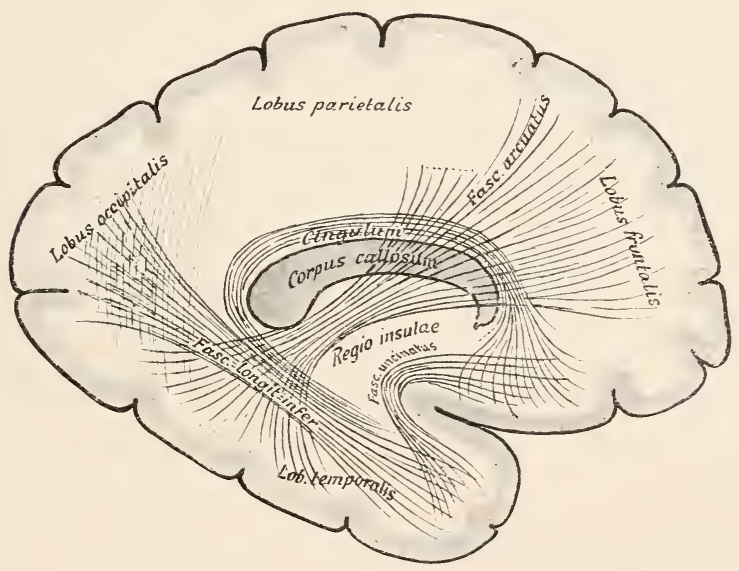

Fig. 156.

Schema des Verlaufes der langen Associationsbahnen.

Das Hakenbündel entspringt aus der Rinde des Schläfenlappens, zieht nahe dem ventralen Inselrande nach vorn und zerfährt in den ventralsten Gebieten des stimlappens. Figg. 170-172. Ueber den dorsalen Theil der Insel weg verlänft der Fasciculus arcuatus aus dem caudaleren Theile des Schläfenlappens zur Rinde des scheitel- und Stirnlappens. Mit ihm ziehen (fraglich) Fasern einher, die im stirnlappen entspringend in der Rinde des Occipitallappens enden. Figg. 169-172.

Die Zwinge, das Cingulmm, ist ein langer Zug. der in der Randwindung - Gyrus fornicatus - von der Rinde des Ammonshornes zu der 
rentralsten Gegend des Stirnlappens und rielleicht auch zum Riechlappen - Hund und Kaninchen - verläuft. Er besteht wohl (Beevor) aus melnreren Einzeltheilen und ist nicht durch Durchschneidung ganz zur Degeneration zu bringen. Figg. 169-172.

Das untere Längsbündel, der Fasciculus longitudinalis inferior, ein sehr mächtiger Faserzug; rerbindet den Schläfenlappen mit dem Occipitalhirne. Figg. 156-1ss.

Déjèrine, welcher das Bündel besonders genau in seinen Bezielıungen zu vielen anderen Theilen der Hirnfaserung studirt hat, sah es in einem Falle von reiner Wortblindheit degenerirt. Sein Verlauf und dieser Befund machen es sehr wahrscheinlich, dass er im Wesentlichen der Vermittlung optischer Eindrücke auf andere Hirntheile dient. Er ist auch bei anderen Primaten vorhanden. Neuerdings sieht sich Flechsig auf Grund entwicklungsgeschichtlicher Studien gezwungen, dieses Bündel ganz aus der Reihe der Associationsbahnen zu streichen. Es soll nämlich nicht im Schläfenlappen enden, sondern nahe von dessen Spitze hinauf zum Thalamus biegen, so dass es also ein Theil der Radiatis occipitothalamica wäre.

Mit Recht hebt Sa chs herror, dass eigentlich nur der Schläfenlappen durch lange Züge mit allen Theilen des übrigen Gehirnes in Terbindung: steht. In ihm ist, wie die Erfahrungen der Pathologie zeigen, das Klangbild der Sprache localisirt. Der Wichtigkeit, die diese beim menschlichen Denken habe, entspräche die mannigfach reiche Terbindungsmöglichkeit.

Auf dem Schema der Figur 156 sind die bisher erwähnten langen Associationsbahnen combinirt. Nur ein Zug ist dort nicht aufgenommen, weil es bis ror Kurzem sehr fraglicl war, ob er wirklich eine lange Associationsbahn darstelle. Das ist der Fasciculus fronto-occipitalis. Aus dem Markbelage des Hinter- und Seitenhornes des Tentrikels stammend, ziehen seine Fasern in wohl geschlossenem Zuge lateral rom Seitenventrikel nach rorn. immer dicht unter dem Balken und an der dorsalen Kante des Schwanzkernes sich haltend. Figg. 170-172.

Es ist derselbe Zug, den ich frïher als Associationsbündel des Schwanzkernes, Fig. 16s, bezeichnete. Untersuchungen von Déjèrine, von Rietz und von II uratow haben aber gelehrt, dass es sich hier wirklich, wie es Forel und 0 nufrowicz vermuthet hatten, um ein Associationsbündel zwischen dem Marke des Occipitallappens und demjenigen des Stirnpoles handele. Demgemäss werden Sie in den grossen Frontalschnitten durch das ganze Gehirn, welche ich später vorlegen will, das Bündel als Fasciculus fronto-occipitalis markirt finden. Dieser Faserzug ist übrigens wie alle längeren Associationsbündel nur zu geringerem Theile aus Fasern ganz langen Verlaufes zusammengesetzt, zu weitaus grösserem aus solchen, welche einzelne Abschnitte seines langen Verlaufareals unter einander verbinden.

Man thut ganz gut, alle diese langen Züge als interlobäre Assoc i a t i o ns b ï n de l zu bezeichnen und sie solchen gegenüberzustellen, welche einzelne Theile des einen oder anderen Lappens innerhalb des Lappens selbst unter einander verknüpfen. Diese intralobären Züge sind bisher noch wenig studirt. Am besten noch für den Occipitallappen, wo durch sachs, Ternicke. Viault u. A. Faserbahnen nachgewiesen sind, 
welche die Rinde in den mannigfachsten Richtungen und Höhen untereinander zu rerknüpfen geeignet sind.

Zu diesen Zügen, welche Theile einer Hemisphäre unter sich rerbinden, kommen weiter Fasern, welche eine Hirnhälfte mit der anderen Hälfte verknüpfen. Diese Fasern verlaufen fast alle im Balken und in der vordere $n \mathrm{Commissur}$. also quer durch beide Hirnhälften, von einer zur anderen ziehend.

Indem ich die makroskopischen Verhältnisse des Balkens, seine allgemeine Gestalt da, wo er frei ron anderer Hirmmasse ist, bei Ihnen, meine Herren, als bekannt roraussetzte, bleibt mir nur wenig zur Erläuterung der nebenstehenden Fig. 15 z zu sagen übrig.

Sie müssen sich denken, dass ebenso wie auf diesem etwa durch das Chiasma geführten schnitte die Balkenfaserung querziehend zu sehen ist, auch in dem ganzen Hirngebiete über den beiden Seitenventrikeln solche Fasern laufen. Auch rom Stirnlappen her bekommt der Balken jederseits einen kräftigen Zuzug, der vorı ïber das Dach des Seitenventrikels, an dessen lateraler Seite ihm zuwächst. Die Balkenfasern aus dem Occipitallappen umschliessen das Hinterhorn dicht wie eine Kappe. Ihre Strahlung wird als Forceps major bezeichnet. Forceps minor nemt

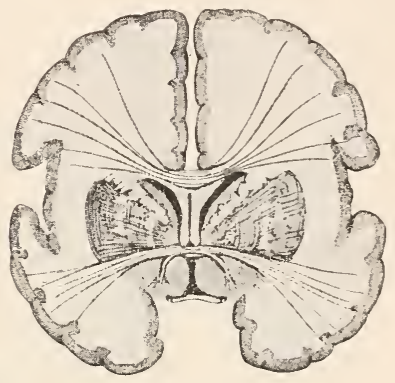

Fig. 157.

Frontalschnitt durch das Vorderhirn. Schema des Verlaufes von Balken und Commissura anterior.

man den an der lateralen Seite des Unterhornes zum Schläfenlappen ziehenden Antheil des Balkens. Die Imnenseite des Hinterhornes und des Unterhornes ist ron einer weissen Markfaserschicht ausgekleidet, dem T a p et u m. Vergl. die Schnitte durch die Balkenfaserung. Figg. 169-174 und Figg. 155-15s.

Die friiher angewendeten einfachen Schnittmethoden liessen diese ganze Schicht als der Balkenfaserung entstammen, gewissermaassen als die medialste Ausstrahlung der Forcepsfasern erscheinen. Neuerdings aber lassen die Lntersuchungen der oben, anlässlich des Fasciculus fronto-occipitalis citirten Autoren es wahrscheinlich werden, dass das Tapetum nicht in den Balken einstrahlt, dass es vielmehr die caudalste Ausstrahlung jenes langen Associationszuges ist. Die Ausstrahlung des Fasciculus fronto-occipitalis liegt direct unter dem Epithel des Ventrikels, dem Hohlraume zunächst und erst nach aussen von ihr liegen die caudalen Balkenstrahlungen.

Immerhin scheinen mir reichlich Balkenfasern beigemischt. Wenigstens decken die relativ geringen Markbündel, welche beim Hunde dell Fasciculus frontooccipitalis bilden, nicht die ganze Menge der Tapetumfasern. Als wichtigster Grund, der das Tapetum vom Balken scheiden liess, erscheint der Umstand, dass man es selbst in Fällen von Balkenmangel erhalten gesehen hat, und dass es bei Balkendurchschneidung nicht degenerirte. 
Bei den osmatischen Säugern, wo das Ammonshorn bis hoch hinauf an die Balkenunterfläche reicht, erkennt man deutlicher als beim Menschen, dass das caudale Balkenende sich wieder nach vorn biegt. Es bildet dadurch eine eigene Faserlage dorsal von dem Psalterium, die auf Schnitten nur durch ihr dünneres Kalibervon den aus dem Ammonshorne stammenden Fasern zu trennen ist. Dieser Balkentheil wird ebenso wie der dorsale Abschnitt, s. Fig. 144, von den Zügen des Fornix longus durchbohrt.

Die vou der Innenseite des Gehimes dargestellte Balkenfaserung bietet das nachstehende Bild (Fig. 155) dar, mit dessen Hülfe Sie sich dann leicht eine Gesammtvorstellung von der Balkenstrahlung machen können.

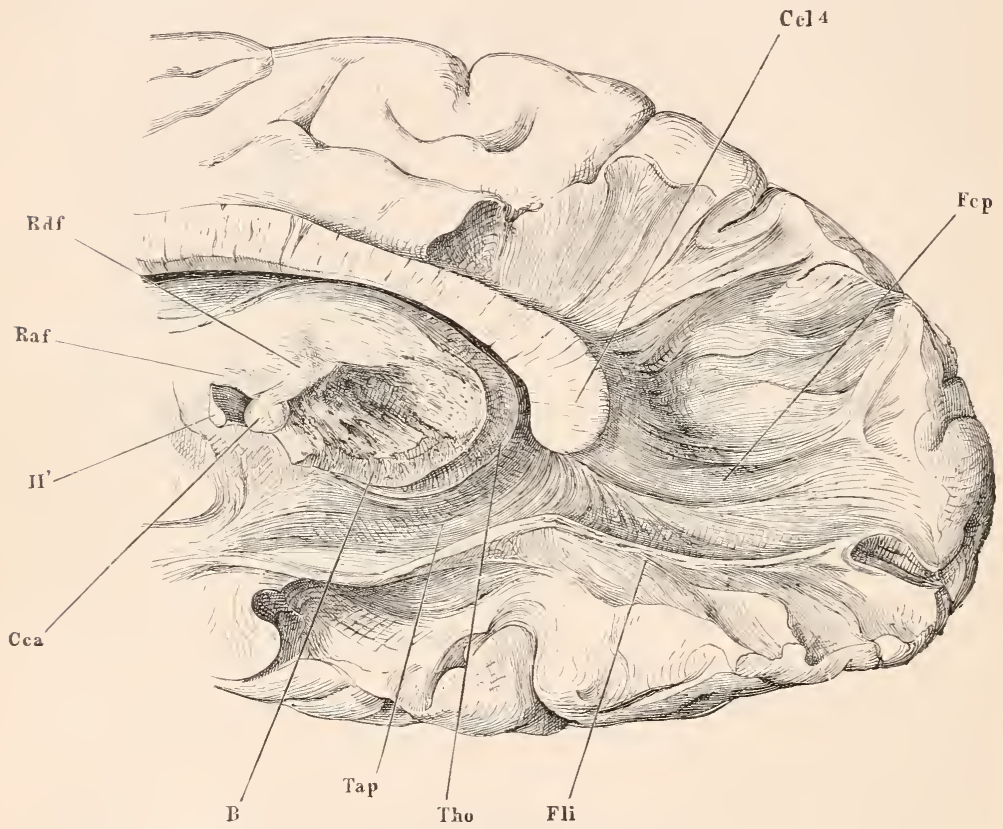

Fig. 15S.

Hinterer Theil der rechten Hemisphäre von innen gesehen. Durch Abbrechen mit der Pincette ist die Strahlung des hinteren Balkenendes, S pleniu m Ccl${ }^{4}$, dargestellt. Die runde Masse unter dem Balken ist der Thalamus opticus Tho. An der Wand des ihn umgebenden Ventrikels das Tapetam Tap. Auf dem Bilde ist auch ein Theil des Fasciculus longitudinalis inferior Fli zu sehen. Der Thalamus hat unter sich den Hirnschenkelfuss B. Die anderen Buchstabenbezeichnungen betreffen im Text später zu Erwähnendes: Rdf Vicg d'Azyr'sches Bündel, Raf Fornix, Cca Corpus candicans, 11. Nerrus opticus. Fcp, Forceps.

Die Commissura anterior hat schon früher anlässlich der Schilderung des Riechapparates eine Darstellung erfahren. Beim Menschen zieht sie als kräftiges Faserbündel nahe dem Boden des Ventrikels vor den Fornixschenkeln daher. Sie lässt sich nicht so. wie oben in der halbschematischen Figur angedeutet, auf einem Querschnitte verfolgen. Ihre Fasermasse 
krümmt sich vielmehr, indem sie das Corpus striatum durchzieht, beiderseits in Halbkreise nach unten und hinten und verliert sich im caudalsten Marke des Lobus temporalis. Auf Fig. 127 ist dieser Bogen rechts und links aussen unter dem Nucleus lentiformis angeschnitten.

Der grösste Theil der vorderen Commissur beim Menschen führt nur Fasern, welche rïckwärts bis in die Gegend lateral von den Ammonshörnern, vergl. Fig. 154, verfolgt werden können. Ton der Riechlappencommissur ist nur ein kleines Bündelchen - man sieht es in Fig. 157 abwärts ziehen - nachgewiesen.

Aus allen Theilen der Torderhirmrinde entspringen zahlreiche Fasern, welche das Torderhirn mit den tiefer liegenden Theilen des Centralnervensystems verknïpfen. Sehr viele dringen in das Zwischenhirn ein, andere lassen sich bis zu den grauen Massen des Mittelhirns und bis zu den Nervenkernen der Brücke verfolgen, in denen sie zunächst zu enden scheinen. Eine Anzahl zieht weiter hinab durch die Kapsel, den Hirnschenkel, die Brücke und das rerlängerte Mark bis zum Rückenmarke, wo die Fasern in rerschiedenen Höhen in die graue Substanz eintreten.

Diese von der Rinde nach abwärts ziehenden Fasern bezeichnet man in ihrer Gesammtheit als $\mathrm{S}$ t a b kranz. Sie machen sich kein schlechtes Bild ron diesem, wenn Sie sich einmal den Sehhiigel losgelöst unter der frei darïber schwebenden Kappe der Hemisphärenrinde denken und nun annehmen, dass von allen Theilen dieser Rinde gegen ilm hin Nervenfasern verlaufen. Ton diesen dringen Züge aus dem stirnlappen, dem Parietallappen,

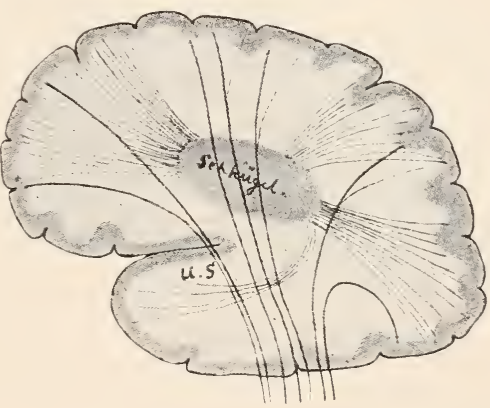

Fig. 159.

Schema der Stablranzfaserung; der Stabkranz zum Thalamus besonders berücksichtigt. $U$. S. unterer Stiel. dem schläfen - und Hinterhauptlappen in ihn ein. Vielleicht auch noch Faserzïge aus der Rinde am Eingange der Fossa Sylvii und welche aus dem Ammonshorne (im Fornix verlaufend). Ein anderer Theil der Züge des Stabkranzes geht aber nicht in den Thalamus, sondern ror ihm, nach aussen vor ihm und nach hinten von ihm rorbei, weiter hinab, tieferen Endstationen zu.

Der Stabkranz setzt sich also zusammen aus Fasern, die zum Thalamus, und aus Fasem, die zu tiefer liegenden Theilen gehen.

1. Zum Tha lamus gelangen fast aus der ganzen Rindenoberfläche Fasern, und nicht nur so wenige Bündel, wie das vorstehende schema 
zeigt. Diese Fasern rereinen sich nahe am Sehhïgel zum Theile zu dichteren Bündeln. welche man als stiele des Sehhïgels bezeichnet.

Monakow hat auf Grund zahlreicher Fälle ron secundärer Degeneration nachweisen können. dass jedem der Thalamuskerne eine ganz bestimmte Rindenzone ihre Fasern sendet. Wir werden später noch daron zu handeln haben, hente wollen wir nmr einiger der wichtigsten Züge aus dieser Gruppe der T'ractus cortico-thalamici gedenken. Da ist zunächst die corticale Schleifenbahn. Sie stammt ans der Gegend caudal von der vorderen Centralwindung und endet in den rentralsten Thalamuskernen. Dorthin gelangen damn aus dem Rïckemmarke und der Oblongata die Schleifenfasern. Deshalb diirfen wir in der erwähnten Bahn die Fortsetzung eines beträchtlichen Theiles der sensiblen Strahlung zur Rinde erblicken. Im caudalen Gebiete des Thalamus liegt ein Theil der primären Endstätten des Sehnerven. Auch zu ihnen sind die corticalen Zuzïge wohl bekannt. Sie ziehen, aus dem Narke des Hinterhauptlappens sich sondernd, in fast horizontaler Richtung vorwärts und enden in Gangliengruppen des caudalen Thalamusgebietes. Anf Fig. 160 ist diese "Sehstrahlung* nach einem Horizontalschnitte durch das Gehirn eines 9 wöchentlichen Kindes eingezeichnet.

Ihre Zerstörung beim Menschen führt zu homonymer Hemianopsie, s. unten. Bei Thieren scheint sie von so grosser Wichtigkeit nicht zu sein, denn man kann die Hinterhauptrinde beiderseits zerstören, ohne dass dauernd wirkliche Blindheit eintritt. Auch für den Sehact liegen also die eigentlichen Centren tiefer; er kann fortbestehen, wenn nur diese erhalten sind, er erfährt aber doch eine Beeinträchtigung, wemn die Verbindung dieser Centren mit der Pinde zerstört wird: Am wichtigsten ist diese, wohl psychischen Processen dienende Verbindung beim Mensehen, von anscheinend geringerer Wichtigkeit bei anderen Säugethieren; niederen Thieren, den Fischen z. B., fehlt sie ganz. Diese sehen, ohne ïberhaupt - die Teleostier wenigstens - etwas Anderes als eine dünne Epithelblase an Stelle eines Grosshirnes zu besitzen.

2. In das Mittelhirn gelangen Rindenzüge theils ans dem Occipitallappen innerhalb der eben erwähnten Sehstrahlung, theils aus dem Temporallappen zu den Endstätten der secundären Hörnervenstrah$1 \mathrm{ng}$. Bis hinanf zu den Ganglien des Nittelhirnes ragt nämlich die ans den Endkernen des Acusticus stammende Faserung. Dort endet sie zunächst, aber aus den Endstätten entwickelt sich der corticale Tractus.

3. In der Gegend ventral rom Thalamus geht zmächst weiterer Verfolgung verloren ein Zug, den Flechsig als Habenstrahlung bezeichnet hat. Ans der Rinde des oberen Parietallappens (und der hinteren Centralwindung?), vielleicht auch aus noch weiter hinten liegenden Rindengebieten, gelangen seine Fasern in die imnere Kapsel und ziehen zum Theile unter dem Thalamus weg nach dem Rückenmarke, zum Theile senken sie sich in den Linsenkern ein. Sie durchziehen die beiden Innenglieder desselben und rereinigen sich dann wieder nahe der Hirnbasis zu einem dichteren Strange, dessen Terlauf wir später kemnen lernen werden. Diese Fasern sind die ersten. welche sich im Grosshirne mit Mark mmgeben. Sie 
allein sind bei Föten aus dem \. Bis 9. Monate als dümne. weisse Züge in der inneren Kapsel, die zu dieser Zeit grau aussieht, zu erkemen (Fig. 2.)

Aber damit ist die corticale Faserung noch nicht erschöpft. Thre caudalsten Ausläufer gelangen in die Brïcke, in die Oblongata und in das Riickenmark.

4. Die Tractus corticis ad pontem zerfallen nach Flechsig in die frontale Brückenbahn aus dem stirnlappen und die caudale aus dem Occipital- und Temporallappen. Die Fasern enden in der Brücke in mächtigen Ganglien, aus denen dann Arme zum Kleinhirne entspringen.

5. Zu den Kernen der beim siprechen nothwendigen Nerven in der Oblongata gelangt die sprachbahn, Tractus cortico-bulbaris. Thr Ursprung in der Rinde der unteren Frontalwindung: ihr Terlauf durch das Marklager aussen am Schwanze des Nucleus caudatus dahin und ihre Endigung in den betreffenden Kernen ist aus genau secirten. klinisch beobachteten Fällen erschlossen. Direct anatomisch dargestellt ist sie noch nicht. Die spraclibahn liegt da, wo sie über den rorderen Theil des Nucleus lentiformis dahinzieht, der centralen H y oglossusbahu sehr nahe. In ihr liegen höchst wahrscheinlich auch die kleinen Züge, welche der willkürlichen Stimmbandbewegung dienen.

6. Die 'Tractus cortico-spinales entstammen nur der Rinde der' Centralwindungen und des Paracentrallappens. sie ziehen hinab bis in die Seiten und Torderstränge des Rückenmarkes, Pyramidenbahn.

Es existiren zweifellos noch eine ganze Anzahl verschiedener stabkranzsysteme. Für Untersuchungen, die auf ein Finden solcher gerichtet sind, bilden Gehirne mit frischen apoplektischen Herden ein vortreffliches Material. Ca. 3 Tochen nach dem Eintritte eines solchen Herdes wird man bei Anwendung der Narchi'schen Osmiummethode immer absteigend degenerirende Faserzüge finden kömmen, die weitab rom Herde dahinziehen. (Hoche).

Auch die Gehirne von Kindern aus den ersten Lebensjahren sind sehr lehrreich. Dort umkleiden sich die Fasern zu verschiedenen Zeiten mit Mark, und am Ende des zweiten Jahres ist, soweit wir jetzt wissen, der ganze Stabkranz markhaltig geworden.

Gelegentlich solcher Untersuchungen hat nun Flechsig den sehr interessanten Befund erhoben, dass keineswegs ron allen Theilen der Hirnrinde Stabkranzfasern ausgehen, dass es vielmehr weite Gebiete giebt, die iln Markweiss wesentlich durch Associationszüge bilden. Ma n kann danach das Mantelgebiet in zweigrosse, dem Baul nach rerschiedene Abtleilungen bringen. Die erste enthält ausser den erwähnten Stabkranzbündeln. unter denen an Masse die Tractus corticothalamicae überwiegen, noch Associations- und Balkenfasern in Menge. Ton hier stammen die sensorischen Faserumgen. auch die zur Muskel- und Sprachinnervation. Das ganze Gebiet nemnt Flechsig simnescentren. Es umfasst die Sehsphäre im Areale des cumeus, die Hörsphäre im hintersten 
Theile der ersten schläfenwindung, die Riechsphäre im Gyrus hippocampi und am ventralen Theile des Stirnlappens und endlich jenes grosse Feld, welches die hinteren Abschnitte aller Stirnwindungen und die Centralwindungen umfasst, dasselbe Feld. aus dem die Tractus cortico-spinales und die corticale Bahn zur Schleifenendigung hervorgeht. Alle diese Areale bekommen ihr Mark früher als diejenigen Rindentheile. welche im Wesentlichen nur Associationsfasern enthalten. Flechsig nemnt sie Associationscentren. Sie umfassen vier grosse Gebiete: das vordere Stimhirn, den grössten Theil des Schläfenlappens, den hinteren Scheitellappen und die Insel. Zahlreiche Associationssysteme rerkü̈pfen diese Theile mit je zwei und noch mehr benachbarten simnessphären. Die sprachcentren scheinen sämmtlich in den Grenzgebieten von Sinnes- und Associationscentren zu liegent.

Sie sehen, auch schon die kurze Beschreibung, welche ich Ihnen von den im Markweiss verlaufenden Zügen hier geben konnte, lässt dieses als recht complicirt gebant erscheinen. In der That zeigen Schnitte, an irgend einer Stelle angelegt, nie oder fast nie eines der Systeme allein, fast immer sind mindesteus durchkreuzende Fasern, aus den Associationsbündelı oder auch aus dem Balken stammend oder aus den anderen Commissurensystemen, vorhanden, vielleicht spielen auch die Collateralen, deren Abgang aus Fasern des Stabkranzes bei der Maus leicht durch die Golgimethode nachweisbar ist, hier eine Rolle bei der Complicirung. Immerhin erkennen sie schon jetzt, wie sich das Hirnbild belebt, wenn sie sehen. dass aus den einzelnen Rindenarealenganz bestimmte Faserzüge zu ganz bestimmten Endpunkten gerathen.

Nit der Histologie der Hirnrinde und mit den feineren anatomischen Verhältnissen ihres Aufbaues haben sich zahlreiche Forscher beschäftigt. Je mehr bisher da gearbeitet wurde, um so schwieriger erschien die Lösung des Problems. Immer neue, immer rerwickeltere Verhältnisse wurden bekannt. Baillarger, Bevan Lewis, Clarke, Mr ey nert, Golgi, Bellonci, S. Ramon y Cajal. Kölliker und viele Andere haben die wichtigsten Punkte klarzustellen versucht. Die Rinde des Ammonshornes wurde speciell von Meynert, Kölliker, Henle, Duval, Schaffer, Golgi, Sala, R. y Cajal untersucht. Die Faserung im Iarkweiss der Hemisphären wurde bereits von $\mathrm{F}$. A rnold, Reil und Burdach durch Abfaserung vielfach erkannt, die mikroskopischen. Untersuchungen von Meynert, von Sachs, von Brissaud und von Déjèrine, namentlich aber die entwicklungsgeschichtlichen Studien von Flechsig, dann zahlreiche experimentelle Arbeiten von Gudden, Löwenthal, Monakow und Anderen haben zur Aufklärung kräftig vorangeholfen. Nicht zu unterschätzen ist anch der Nutzen, den die Anatomie dieses Gebietes durch Untersuchungen am erkrankten Giehirne erfahren hat. Solche haben angestellt: Wernicke, Charcot. Férè, Pitres, Friedmann, Sioli, Monakow, Richter, Zacher, Déjérine u. A. 


\section{Sechzehnte Vorlesung.}

\section{Die Capsula interna, das Corpus striatum und die Ganglien des Zwischenhirues.}

M. H.: Auf ihrem Wege nach abwärts treten die Stabkranzfasern in wichtige Beziehungen zu dem Corpus striatum und dem Thalamus opticus.

Sie convergiren naturgemäss und gelangen so in den Raum nach aussen rom Thalamus. Die Fasern aus den vorderen Hirntheilen müssen, um dahin zll kommen, das Corpus striatum durchbrechen. An dem vorstehenden, horizontal durch das Grosshirn gelegten Schnitte wird Ihnen das klar werden.

$\mathrm{Er}$ ist etwa einen Finger breit unter dem in Fig. 124 gezeichneten angelegt. Sie müssen sich rorstellen, dass die beiden Halbkugeln der Hemisphären zum Theile abgetragen sind, und dass deren Stabkranzfaserung in den knieförmig gebogenen weissen Streif der inneren Kapsel von oben her zog. Die Antheile der Kapsel aus dem Stirnund Hinterhauptlappen fallen zum Theile in die Schnittebene. - Nur

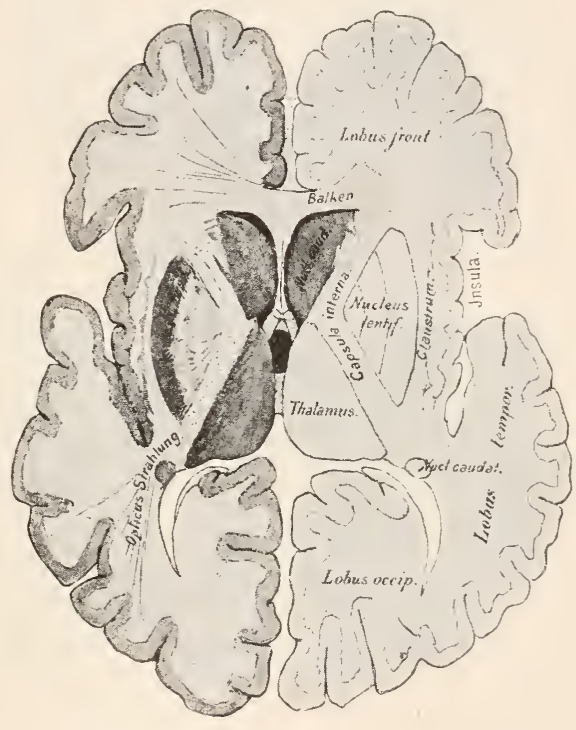

Fig. 160 .

Horizontalschnitt durch das Gehirn, nach den Seiton otwas abfallend. wenige Worte zur Erläuterung dieses Schnittbildes.

Stirnlappen, Hinterhaupt- und schläfenlappen erkennen sie sofort. Der letztere legt sich vor den Stammlappen und verbirgt so zum Theile die Insula. Wie in Fig. 125, sehen Sie vorn den quer abgeschnittenen Balken, ihm sich anschliessend das Septum pellucidum, an dessen hinterem Ende die Fornixsäulen aufsteigen.

Vorn, nach aussen rom septum, liegt der diesmal angeschnittene Kopf des Nucleus caudatus. Sein Schwanz, der auf Fig. 125 längs dem Thalamus einherzog, ist nicht zu sehen. Er ist in der weggenommenen Hirmpartie enthalten. Nur ganz hinten aussen, nahe am Ammonshorne, sehen sie 
noch ein stück von ihw. Wie das zu Stande kommt, zeigt die folgende Skizze, welche einen frei präparirten Nucleus caudatus darstellt.

Der Schwanz des Nucleus caudatus krümmt sich nämlich in leichtem Bogen um den ganzen Hirnstamm und ist bis fast in die Spitze des Unter-

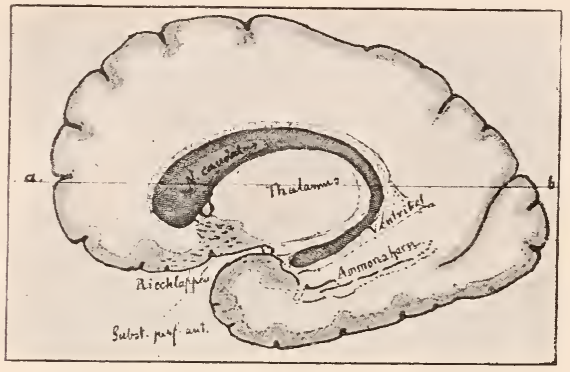

Fig. 161.

Nucleus caudatus in seiner ganzen Länge frei gelegt (schematisirt). hornes zu verfolgen. Der ganze Kern muss also auf jedem Horizontalschnitte, wie ihn z. B. die Linie $a b$ der Fig. 161 darstellt, in den tieferen Ebenen des Gehirnes zweimal getroffen werden.

Nach aussen rom Kopfe des Nucleus caudatus sehen sie dicke Faserzüge. Sie kommen ron der Rinde des Stirnlappens und enthalten den betreffenden Theil des Sehhügel-Stabkranzes und die StirnhirnBrückenfasern.

Diese Fasermasse muss, wie sie aus der Abbildung Fig. 160, ersehen, um zum Thalamus und in die Brïcke zu gelangen, das ihr in Wege liegende Ganglion des Corpus striatum durchschneiden. Der Theil, der nach innen liegen bleibt, ist eben der $\mathrm{Nu}$ cleus caudatus, der Theil, der nach aussen zu liegen kommt, ist der Nucleus lentiformis. Beide sind übrigens durch die Fasern aus dem Stirnhirne nicht absolut von einander geschieden; es ziehen vielmehr zahlreiche Terbindungsbrücken zwischen ihnen hin. Die genannten Stabkranzfasern zum Thalamus, die Stirnhirnbrückenfasern, die Züge zwischen dem Kopfe des Schwanzkernes und dem Linsenkerne, schliesslich noch Fasern aus dem Schwanzkerne zu dem Thalamus und dem Linsenkerne, alle diese Fasern zusammen constituiren die in unserem Horizontalschnitte getroffene weisse Fasermasse der Capsula interna.

Der Fig. 162 abgebildete Frontalschnitt soll das Bild ergänzen, welches der Horizontalschnitt von diesen Terhältnissen gab. Er trifft, sehr weit rorn liegend, wesentlich die Ganglien des Corpus striatum und zeigt ebenfalls deutlich die sie trennenden Fasern der Capsula interna.

Gestalt und Lage des Nucleus caudatus werden Thnen wohl jetzt klar sein, schwerer wird es Ihnen fallen, von der eigenthümlich keilförmigen Figur des Linsenkernes sich ein Bild zu machen. Das Studium des Horizontalschnittes und des Frontalschnittes, Fig. 162, wird Ihnen dabei von Nutzen sein. Diesem Ganglion lagern nach imnen zu noch zwei weitere, etwas heller graue Ganglienmassen an, die in enger Faserverbindung mit ihm stehen. Man spricht daher gewöhnlich von dem dreifach geggliederten Linsenkerne, wobei das breite dnnklere äussere Glied, das Putamen, 
wahrscheinlich allein dem Nucleus caudatus morphologisch gleichwerthig ist. Dieser sendet seine Fasern, wie oben angedentet wurde, durch den vorderen Schenkel der inneren Kapsel zu den zwei inneren Gliedern des Linsenkernes und durch sie hindurch weiter hinab. Ganz ebenso verlaufen auch die Fasern des äusseren Gliedes des Linsenkernes.

Nach aussen rom Corpus striatum liegt die Rinde der Insula Reili In dem schmalen Streifen weisser Substanz, der zwischen Rinde und Ganglion liegt, in der Capsula externa, ist noch eine Ganglienzellen-

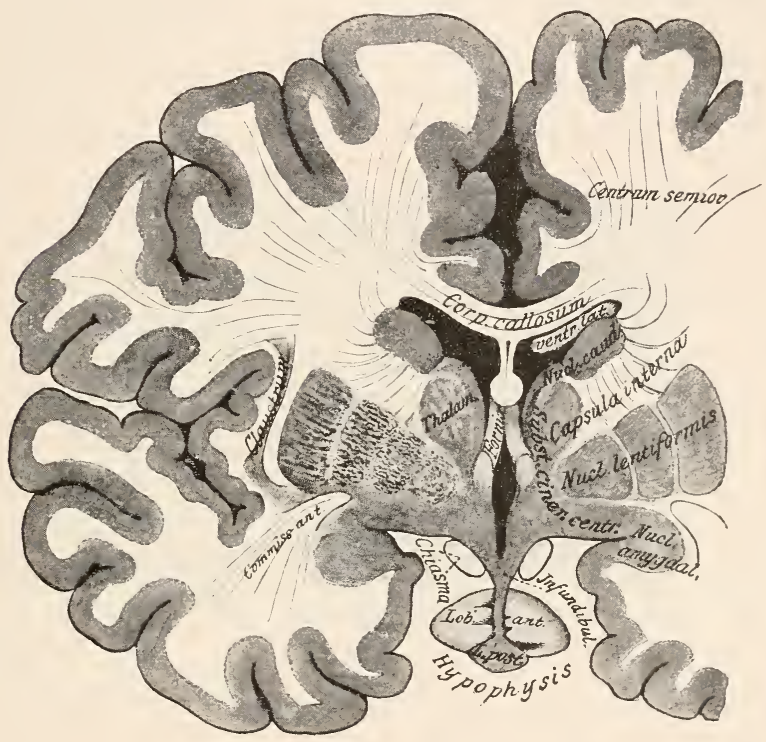

Fig. 162.

Frontalschnitt durch das Vorderhirn dicht hinter den Fornixsäulen.

anhäufung, das Claustrum, eingelagert, die anatomisch sich etwas von der benachbarten Rinde unterscheidet und ventral sich bis in das Riechfeld erstreckt.

Hinter dem Nucleus caudatus geht der Horizont alsch nit t, Fig. 160, durch den Thalamus, das Zwischenhirn. Vor diesem entsteigen die Fornixsäulen der Tiefe; die Com m issura media, ein dünnes Band aus graner Masse, spannt sich zwischen beiden Sehhügeln aus. Nach aussen vom Thalamus liegt der hintere schenkel der inneren Kapsel. Die Stelle, wo beide Schenkel zusammenstossen, hat man $K$ nie d e r Kapsel genannt. Prägen Sie die eigenthümliche, im Winkel abgebogene Form der Capsula interna Ihrem Gedächtnisse wohl ein! Die Lage der 
einzelnen Stabkranzantheile zu den beiden Winkeln ist wahrscheinlich annähernd constant und desshalb klinisch überaus wichtig. Im hinteren Schenkel liegt, meist nicht weit rom Knie, die Faserung aus der motorischen Zone für die Extremitäten (Pyramidenbahn), dicht vor ihr Züge, die zum Facialis - und Hypoglossuskern in Beziehung stehen und aus dem unteren Ende der vorderen Centralwindung stammen.

Hinter der Pyramidenbahn werden. etwa im letzten Drittel des Schenkels oder etwas mehr nach vorn, die als Haubenstrahlung bezeichneten Züge getroffen, und nach hinten sich ihnen anschliessend liegt der Zug: aus dem Occipitallappen zum Opticusursprung. In dieser Gegend mïssen sich, klinischen Thatsachen zufolge, auch Fasern von der Temporalrinde zum Acusticuskern befinden und auch solche rertreten sein, welche irgendwie zum Geruch in Beziehung stehen. So treffen im letzten Drittel des

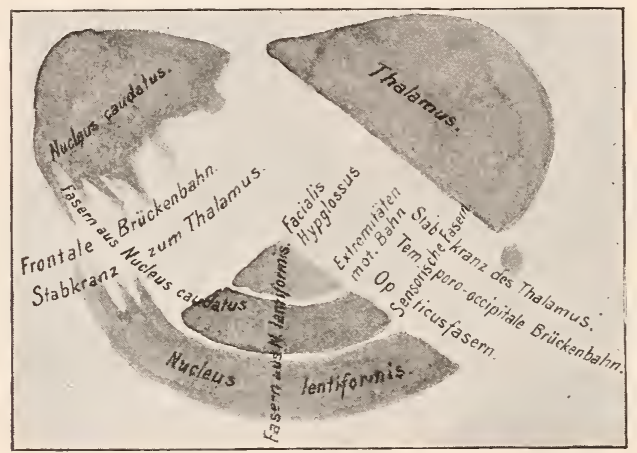

Fig. 163.

Schema der Capsula interna, in welches die Lage der meisten Faserzüge, welche in sie eingehen, eingeschrieben ist.

hinteren schenkels der imneren Kapsel alle Fasern für das Gefühl und die Sinnesnerven zusammen. Ansserdem aber liegen hier noch Stabkranzfasern zum Thalamus aus der Schläfen- und Occipitalrinde und die temporo-occipitale Brïckenbahn. Die vorstehende Figur giebt die Lage der einzelnen, die Capsula interna zusammensetzenden Züge zu einander schematisch wieder.

Alle diese Fasermassen streben also aus der Rinde couvergirend zusammen nach der Gegend, welche lateral vom Thalamus liegt. Ein Theil von ihnen tritt in den Sehhïgel ein (Stabkranz des Sehhügels), ein weiterer - und das ist der grösste - zieht unter den Thalamus, wo er in Ganglien endet, oder weiter hinab zum liückeımark. Erkrankungsherde, welche in dem Centrum semiovale liegen, miissen daher einen Theil der Stabkranzfasern trefien. Sie machen aber durchaus nicht immer Symptome, welche eine I'nterbrechung der Leitung von der Rinde zur Peripherie vermuthen liessen. Wahrscheinlich deshalb, weil gröbere, unserer heutigen Diagnostik zugängliche Ausfallsymptome 
nur entstehen, wem die ganze betreffende Bahn zerstört wird. Es scheint, dass ein kleiner erhaltener Rest ausreicht, den Willensimpuls von der Rinde zu den tieferen Sectionen zu leiten, resp. Empfindungen von der Peripherie zur Rinde zu fülıren.

Namentlich bleiben Herde, die nicht im Marklager unter den Centralwindungen liegen, oft symptomlos, d. h. Herde, welche die Rinden-Brickenbahnen und die Haubenstrahlung treffen. Herde aber, welche die Pyramidenbahn treffen, erzengen Lähmung der gekreuzten Körperhälfte. Erkrankungen im Marklager unter der unteren Stirnwindung fülıren oft zu Aphasie. Uebrigens sind eine Anzahl Fälle bekannt, die es sehr wahrscheinlich machen, dass Unterbrechung der Haubenstrahlung zu halbseitigem Sensibilitätsverluste führen kann. Zwei von mir nenerdings beobachtete Fälle lehren, dass Schmerzen, welche nach Apoplexien auftreten, zuweilen durch Nachbarschaft voll Erkrankungsherd und Haubenstrahlung erklärt werden können.

Es scheint ziemlich sichergestellt, dass Erkrankungen, welche die Gegend hinter dem Knie der Kapsel treffen, resp. die Fasern dort leitungsunfälig machen, die Bewegungsfähigkeit der ganzen gekreuzten Kör-

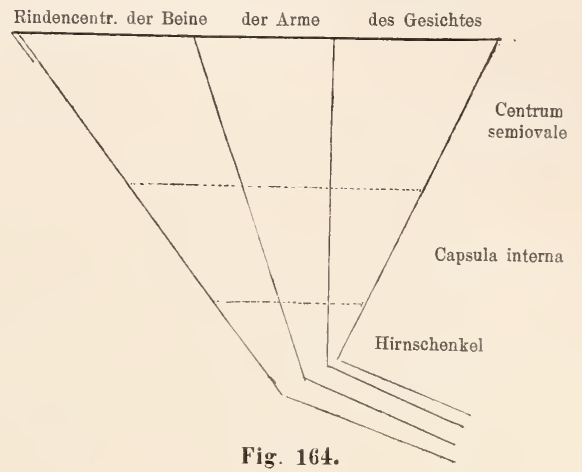
perhälfte aufheben, dass

Herde, die in den beiden letzten Drittelı des hinteren Schenkels sitzen, die Sensibilität der gegenïberliegenden Körperhälfte zerstören oder doch sehr beeinträchtigen. In den meisten Fällen leidet auch der Gesichtssinn Noth, und wahrscheinlich zuweilen auch das Gehör. Die Störung des Gesichtssinnes tritt in Form der Hemiopie auf.

Wenn Sie bedenken, dass, wie ich wiederholt erwälnte, alle Fasern radiär von der Rinde nach der Kapsel zusammenstrahlen, so wird es Ihnen leicht begreiflich sein, dass in der Kapsel schon kleine Herde dieselben Symptome machen können, wie grössere im Centrum semiovale, oder noch ausgebreitetere in der Rinde. Hier liegen eben die Fasern enge beisammen, die dort über einen grösseren Raum ausgebreitet sind. Beispielsweise wird ein sehr ausgedelintes Rindengebiet (beide Centralwindungen und die dicht an sie grenzenden Partien der Stirnund Parietalwindungen) ausfallen mïssen, wenn complete gekreuzte Hemiplegie entstehen soll. Im Centrum semiovale dürfte schon ein kleinerer Herd im Marklager unter den Centralwindungen denselben Effect haben. In der inneren Kapsel aber reicht die Zerstörung einer kleinen Stelle im hinteren Schenkel allein aus, um den Symptomencomplex hervorzurufen. Bei Hemiplegien wird man deshalb immer zunächst an Herde, die der inneren Kapsel benachbart sind oder in ihr liegen, denken, wenn nicht andere Symptome ganz direct auf andere Hirngebiete hinweisen. Hemiplegien nach Rindenherden sind selır selten, Hemiplegien, die vom Mittelhirne oder von noch tiefer liegenden Stellen ausgehen, noch viel seltener und meist mit Hirmnervensymptomen verknïpft, welche auf ihren Sitz hinweisen. Andererseits lehrt uns die anatomische Betrachtung und die klinische Erfahrung, dass cerebrale Affectionen einzelner Körpertheile, einer Hand z. B., 
nur sehr selten von Herden in der Kapsel erzeugt werden, eben weil da die Fasern bereits so dicht zusammengeflossen sind, dass ein Erkrankungsherd kaum einzelne isolirt treffen kann. Wohl aber entstehen nicht allzu selten von der Rinde aus Monoplegien und Monospasmen. Dort kann ein Jerd schon relativ gross sein, ehe er ein benachbartes Centrum trifft. Das vorstehende Schema wird Ihnen das Gesagte leicht einprägen. Es zeigt, warum Monoplegien häufiger von der Rinde, Hemiplegien häufiger von tiefer gelegenen Hirntheilen ausgehen, demn man sieht anf den ersten Blick, dass ein Herd von bestimmter Länge in der Rinde leicht nur ein Centrum, weiter unten die Fasern aus vi el en Centren treffen kann.

Welche Symptome eintreten, wem allein Associationsfaserstränge erkranken, ist wegen der Nachbarschaft dieser Fasern zum Stabkranze bislang nicht zu eruiren gewesen. Wahrscheinlich gehören gewisse Formen der Sprach-, Lese- und Hörstörungen hierher. Auch iiber Symptome bei Functionsausfall des Balkens wissen wir wenig. Es scheint, dass er unter Umständen ganz zerstört werden kann, ohne dass Störungen der Motilität, der Coordination, der Sensibilität, der Reflexe, der Sinne, der Sprache eintreten, ohne dass sich eine irgend erhebliche Störung der Intelligenz zeigt. Einmal wurde bei Balkenerkrankung unsicherer Gang ohne eigentlichen Schwindel oder Ataxie beobachtet.

Von den Stabkranzfasern bleibt also ein grosser 'Theil im Zwischenhirne, im Thalamus opticus. Die anderen ziehen in der Kapsel weiter hinab und nach hinten. So gelangen sie hinter dem Thalamus zu einem grossen Theile frei an die Unterfläche des Gehirnes. Diese dort aus der Hirmmasse hervortanchenden dicken weissen Bündel werden als Fuss des Hirnschenkels. Pes Pedunculi. bezeichnet. Fig. 165 links unten.

Wie Sie an dem nachstehenden Frontalschnitte sehen, liegt dieser freie Theil der Kapsel, dessen Fasern caudalwärts als Hirnschenkel abbiegen, ventral rom Thalamus. In diesen Fusstheil des Hirnschenkels gelangen die Zïge der Stimhirnbrïckenbahn, der Temporalhirnbrïckenbahn und der Pyramidenbahn. Die Stabkranzfasern des Opticus und die Haubenstrahlung treten nicht in den Fuss ein. Weiter caudal, in der Vierhügelgegend. liegen dorsal rom Fusse, an der Stelle. wo jetzt der Thalamus sich befindet, die Nervenfasern. welche aus dem Thalamus und aus anderen Hirntheilen kommen. auch die aus der Haubenstrahlung. Es scheiden sich dort die Fasem aus dem Vorder-, Zwischen- und Mittelhirne in eine ventrale Partie, den Fuss, und eine dorsale, die Haube.

Es kann ein sehr lehrreicher Schnitt angefertigt werden, welcher ein Bild von der Entstehung der Fasern im Fusse giebt. Nehmen Sie ein frisches Gehirn, und schneiden Sie den Hirnschenkel senkrecht ein, bis Sie anf die Substantia nigra treffen. Nun wenden Sie das Messer und schmeiden mit schräg aufwärts und vorwärts gerichteter Schneide horizontal durch beide Hemisphären gerade hindurch. So ist die Grundlage der Abbildung angefertigt, welche Fig. 256 wiedergiebt. Den Uebergang aus der Kapsel in den Fuss s. auch Fig. 175.

Die Bahnen aus der Rinde bilden die Hamptmasse des Fusses. Thmen ist dorsal ein kleiner $\mathrm{Zug}$ aufgelagert. welcher, aus dem Stammganglion kommend, in einem dorsal vom Fusse gelegenen Ganglion. der Substantia nigra, endet. stratum intermedium pedunculi.

Wir wollen num eimmal dem stammganglion und der aus ihm entspringenden Faserung unsere Aufmerksamkeit zuwenden. 
Das mächtige, an der Basis des Vorderhirnes gelegene Ganglion wird, wie Sie wissen, durch die aus der Rinde stammende Faserung der Kapsel in den lateral bleibenden Nucleus lentiformis und in den dorsal mnd medial liegenden Nucleus caudatus getheilt. Der Nucleus lentiformis besteht aus einem Aussengliede, dem Putamen, und zwei oder melıreren Innengliedern, dem Globus pallidus. Aus dem Putamen und aus dem Nucleus caudatus entspringt die Eigenfaserung des Stammganglions. Ausserdem wird dann das Ganglion durchzogen von einer aus der Rinde entspringenden Faserung, der Haubenfaserung.

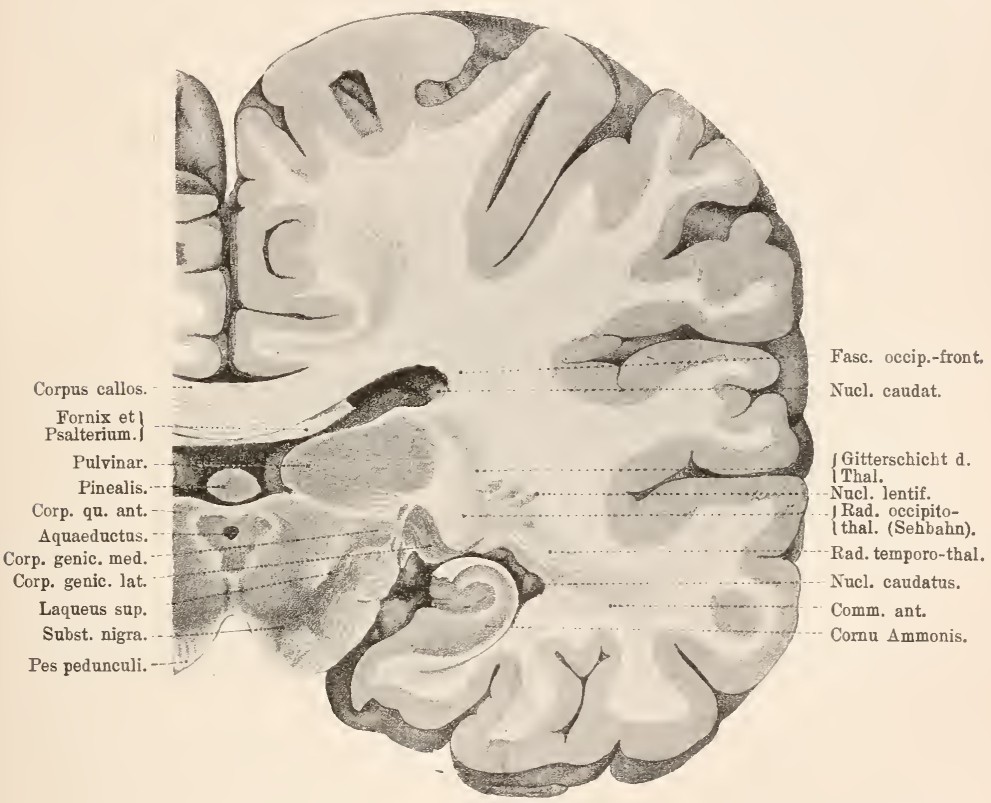

Fig. 165.

Frontalschnitt durch das Vorder- und Zwischenhirn nahe an der Stelle, wo Fasern der-Capsula interna zum Fusse des Hirnschenkels werden.

Die Eigenfaserung des Stammganglions verbindet dasselbe mit den Ganglien des Zwischenhirnes. Sie zieht zum Theile im vorderen Kapselschenkel, zum Theile - soweit sie aus dem Putamen kommt - unter der Kapsel an der Hirnbasis hinweg, dem Zwischenhirne zu. Dabei muss sie die Stelle, wo die Kapselfasern frei als Hirnschenkelfuss an die Hirnbasis gelangen, ungreifen. Dieser Theil wird als Linsenkernschlinge, Ansa lentiformis, bezeichnet. Er enthält wesentlich die Fasem aus dem Putamen. 
Es handelt sich hier um einen sehr alten und offenbar für den Gesammtmechanismus des Gehirnes sehr wichtigen Faserzug. Denn bei allen Wirbelthieren, von den Fischen bis hinauf zu den Säugern, lässt sich ein starkes Faserbündel nachweisen, das im Corpus striatum entspringt und zum Theile in einem Zwischenhirnkern endet, zum Theile weiter hinabzieht. Beim Menschen ist es schwer aufzufinden, weil sich zu viele Züge aus dem Mantelgebiete, der Rinde, ihm zugesellen. Doch habe ich dieses basale Vorderhirnbündel bei frihen Embryonen erkannt, und es sind wahrscheinlich seine Fasern, die Wernicke und Flechsig, als aus dem Corpus striatum entspringend, beschrieben laben. Der Letztere hat auch die Verbindung mit dem Thalamus erkannt. Es ist schon in den vergleichend anatomischen Vorlesungen geschildert und dort als Tractus striothalamicus bezeichnet.

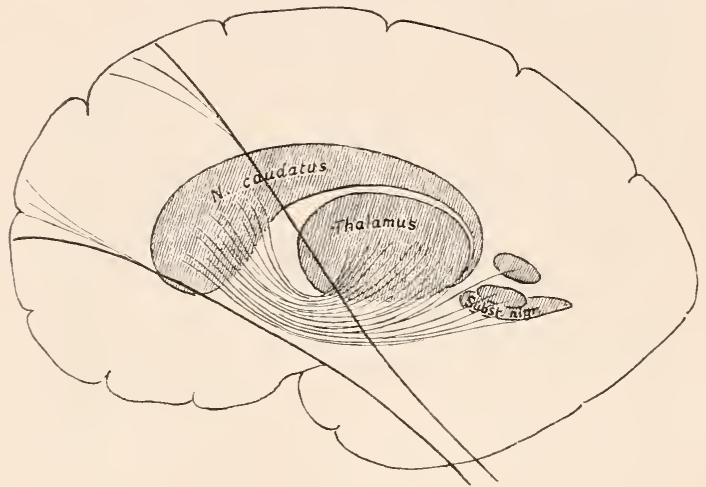

Fig. 166.

Die aus dem Schwanzkerne entspringende Faserung zu den Ganglien des Zwischen- und Mittelhirnes. Radiatio strio - thalamica. Die Linsenkernfaserung weggelassen, sie würde vom Beschauer nach dem Thalamus hin verlaufen.

Neuerdings ist mir aber an dem oben erwähnten, absolut entrindeten Hunde der volle Nachweis des Verlaufes der aus dem Stammganglion entspringenden Faserzüge geglückt. Bei diesem Thiere war die ganze aus der Rinde kommende Stabkranzfaserung secundär degenerirt und fast verschwunden. Man erkannte da mit aller Sicherheit, dass aus dem Kopfe des Schwanzkernes und aus dem Putamen sehr mächtige Fasermassen sich entwickelten, die im frontalen Abschnitte der Kapsel basalwärts und zugleich etwas caudalwärts zogen. Der grösste Theil dieser Fasermasse wendete sich rasch nach innen und löste sich in den Thalamusganglien auf; was weiter hinab gelangte, zog allmählich auch immer mehr medianwärts, um in den Ganglien der Gegend unter und hinter dem Thalamus zu verschwinden. Im Bereiche der hinteren Vierhügelgegend war die ganze vorn so mächtige Faserung in die Ganglien übergetreten. Ihre letzten Züge hatte die Substantia nigra aufgenommen. Die Arbeiten von Ma haim und von Monakow über secundäre Degenerationen nacl Erkrankung im Bereiche des Stammganglions zeigen, dass die dort entspringende Faserung auch beim Menschen sich so verhält, wie sie das Schema oben wiedergiebt. 
Es bildet also die Radiatio strio-thalamica einen mächtigen Verbindungsweg zwischen dem Stammganglion und den Ganglien des Zwischen- und Wittelhirnes.

Aus der Rinde treten zwischen die Glieder des Globus pallidus die Fasern der Haubenstrahlung. Sie durchlaufen dieselbe als weisse Streifen und sammeln sich an der Basis des Linsenkernes zu einem eigenen Bündel, das dorsal von der Linsenkernschlinge ganz wie diese medialwärts zieht. Es gelangt später in die Medulla oblongata.

Die meisten seiner Fasern ziehen nach imnen in die Gegend, welche unter dem Thalamus opticus liegt und als Regio subthalamica bezeichnet wird.

Die nebenstehende $\mathrm{Ab}$ bildung zeigt an einem Schnitte durch das Gehirn einer achtmonatlichen Frucht das Verlalten der Haubenfasern zum Linsenkerne. In dieser Entwicklungsperiode sind ausser den gezeichneten Faseru im ganzen Grosshirne noch keine markhaltigen Züge vorhanden. Namentlich fehlen auch die Fasern, welche im Nucleus caudatus und im Putamen selbst entspringen, noch ganz. Nur durch die Untersuchung des fötalen Gehirnes war es möglich, mit Sicherheit das Verhalten

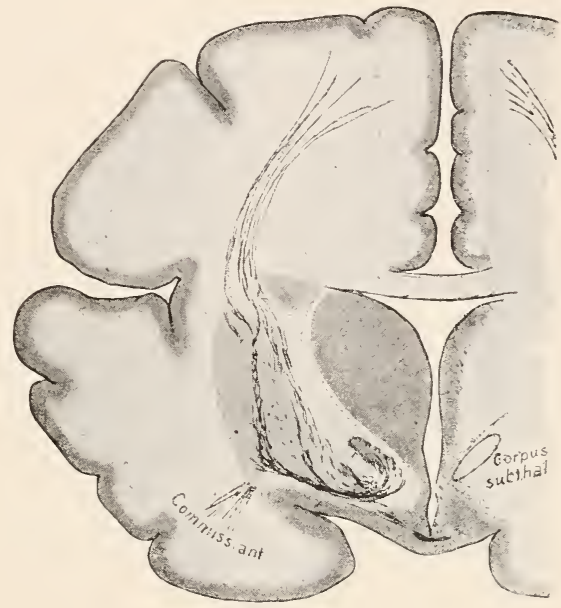

Fig. 167.

Frontalschnitt durch das Gehirn eines Fötus von etwa 32 Wochen. Alle markhaltigen Fasern durch Hămatoxylin schwarz gefärbt. Haubenstrahlung (oben', Linsenkernschlinge (unten) und vordere Commissur (aussen unten) sind markhaltig. Im Putamen und Nucleus caudatus noch keine markhaltigen Fasern.

von Linsenkern und Haubenstrahlung zu einander zu eruiren.

Bei den Sängern existirt ein kleiner Faserzug; welcher lateral rom Schwanzkerne auf dessen ganzer Länge einherzieht. Er beginnt vor dem Kopfe des Ganglions mit wenig Fasern, die aus diesem selbst zu kommen scheinen, verstärkt sich weiter hinten mehr und melı, nimmt dann aber wieder, entsprechend der Düme des Schwanzes, ab und ist nicht weiter als das Ganglion selbst zu rerfolgen. Das Bündel liegt in dem Winkel, den die Schwanzkernoberfläche mit dem Ventrikeldache macht, und wird von den Balkenfasern direkt überstrahlt. Seine Fasern scheinen mir aus dem Schwanzkerne selbst zu kommen und in ihn wieder zurückzukehren. Associationsbündel des Nucleus caudatus. (Sachs.) Ich kann es aber nicht scharf tremnen von dem fronto-occipitalen Associationsbündel, das ihm dicht anliegt. 
Sie haben jetzt, meine Herren, einen guten Theil der Fasern, die das Vorderhirn aufbauen, in ihrem Ursprungstheile kennen gelernt. Lassen Sie uns jetzt den Gebieten uns zuwenden, wo die Mehrzahl der Grosshirnmarkzüge ein Ende findet.

Hinter dem Grosshirne liegt das Zwischenhirn. Seine Seitenwände sind die Thalami optici. Diese bestehen aus mehreren nicht ganz scharf unter einander abgegrenzten grauen Kernen. Weisse, markhaltige Fasern, das Stratum zonale (Gürtelschicht), überziehen den Thalamus. Sie sind zu einem Theile in der Richtung nach der Hirnbasis in den sehnerven hinein zu verfolgen, zum anderen scheinen sie aus den caudalen Theilen der Capsula interna, vielleicht aus der Sehstrahlung, zu stammen. Alle senken sich in die Tiefe des Thalamus, wo sie sich zwischen dessen Ganglien in Zügen sammeln und so diese scheinbar von einander tremnen. Die mikroskopische Untersuchung zeigt, dass sie in das feine Nervenfasernetz, das diese Ganglien erfüllt, eindringen. Man kamn in jedem Thalamus unterscheiden: einen medialen (inneren) Kern, der in den Ventrikel hineinragt, einen lateralen oder äusseren Kern und zwischen beiden den vorderen Kern. Der laterale ist der grösste, der vordere gleicht einem mit dem stmmpfen Ende nach vorn zwischen die beiden anderen Ganglien eingedrängten Keile. Dies vordere dickere Ende, welches auf der Thalamusoberfläche als Erhebung vorn sichtbar ist, haben wir früher schon als Tuberculum anterius kennen gelernt.

An den medialen Kern grenzt und ist beim Menschen nicht leicht von ihm abscheidbar das Pulvinar, ein mächtiges Polster, das, den ganzen caudalen Abschnitt des Thalamus einnehmend, als Wulst in den Ventrikel hineinragt. Am medialen Rande des immeren Kernes liegt das schon erwähnte Ganglion habenulae.

Monakow, der neuerdings die Thalamuskerne wieder genauer studirt hat, will auf Grund des Baues und der Einstrahlungen das ventrale Gebiet des lateralen Kernes abscheiden und mit einigen anderen kleinen ventral liegenden Kerngruppen als ventralen Thalamuskern bezeichnen. Caudal am Thalamus liegt ventral und aussen vom Pulvinar ein Ganglion ron eigenthïmlicher, grauer Zeichnung, das Corpus geniculatum laterale. Es ragt weit in die Thalamussubstanz hinein und entsendet eine grosse Anzahl von Trsprungsfasern zum Tractus opticns.

Nach aussen grenzt der Sehhïgel an die innere Kapsel (Fig. 160). Zahlreiche Züge, der Stabkranz des Thalamus, ziehen aus ihr in ihn hinein. Sie kommen aus rerschiedenen Richtungen und kreuzen sich, indem sie im sehhügel zusammenstrahlen. Zwischen dem Netze der sich kreuzenden Fasern bleiben Herde grauer Substanz. Die äussere Zone mit diesen Kreuzungen wird ihres Aussehens wegen als Gitterschicht bezeichnet. Da die meisten markhaltigen Fasern in den äusseren Kern einstrahlen, so sieht dieser heller aus als die anderen Kerne des Sehhügels.

Die Thalamusganglien atrophiren zu gutem Theile, wenn das Rindengebiet, aus dem sie ihre Einstrahlung empfangen, zu Grunde geht. 
Monakow's auf diese Verhältnisse speciell gerichtete Untersuchungen lehren, dass die am meisten frontal und medial liegenden sehlı̈̈gelabschnitte mit den Windungsgruppen des Stirnlappens, die lateralen Kerngruppen mit den Parietalwindungen und die ventralen mit dem Operculum zusammenhängen. Ueber die physiologische Bedeutung dieser Bahnen ist uns bis heute nicht das Geringste bekannt. Klarer sehen wir schon für einige andere Einstrahlungen in den Thalamus. Da sind zunächst die Fasern aus der Parietalgegend zu dem ventralen Kerne. Sie müssen, wie ich schon früher Ihnen mittheilte, den Antheil der sensorischen Faserung enthalten, welcher von diesem Kerne, wo ein Theil der Schleife endet, corticalwärts leitet. Dann wissen wir, dass der grösste Theil der in die hinteren Thalamusabschnitte, speciell in das Pulvinar und das Corpus geniculatum lat. einstrahlenden Fasern aus dem Occipitallappen stammt und der Träger der secundären Bahn aus den primären optischen Endstätten zur Rinde ist.

Die Innenseite des Thalamus ist durch gleichmässig graue Substanz rom Ventrikel getrennt. Diese heisst centrales Höhlengrau des mittleren (III.) Ventrikels und besteht aus einem zellreichen und von sehr vielen feinen, markhaltigen Nervenfasern in allen Richtungen durchzogenen Gewebe.

Sch ïtz, der diesem Grau beim Menschen eine Studie gewidmet hat, fand, dass es Zuzïge aus fast allen den dritten Ventrikel umgebenden Ganglien enthält und, was besonders interessant, dass es gleich den Fasern der Hirnrinde bei der progressiven Paralyse degenerirt. Einen meist besonders gut abgrenzbaren Zug markhaltiger Fäserchen, der im Grau vom dritten Ventrikel ab bis hinab zu den Kernen des Hypoglossus sich verfolgen lässt und immer dicht unter dem Ventrikelepithel liegt, bezeichnet er als dorsales Lä des centralen Höhlengrau.

In der Mittellinie des Gelirnes bildet das Hölılengrau den Boden des Ventrikels. Dort verlaufen in ihm von einer Seite des Gehirnes zur anderen mehrere dünne Faserüberquerungen, von denen eine, die M e ynert'sche Commissur, am besten charakterisirt ist. Ihr Anfang und Ende sind nicht genügend sicher bekannt. An dem Hunde mit vollständiger Zerstörung der Rinde war sie erhalten. Die frontal und ventral von ihr liegende Gudden'sche Commissur werden wir später genauer kennen lernen. Bei den Reptilien stammt die Me ynert sche Commissur aus dem grosszelligen Kerne des centralen Höhlengraues.

Das centrale Höhlengrau an der medialen Fläche des Thalamus verklebt auf eine ca. $3 / 4 \mathrm{Cm}$. lange Strecke mit dem der gegenüberliegenden Seite zur Commissura mollis oder media.

Wenige markhaltige Fäserchen verlaufen beim MLenschen in ihı, ob eine bei niederen Wirbelthieren an analoger stelle vorhandene, viel faserreichere Commissur mit der Commissura media identisch ist, bleibt noch festzustellen, s. Fig. \$2.

Fïr das Kaninchen hat $\mathrm{X}$ issl nachgewiesen, dass jeder der Thalamuskerne wieder in 3-4 Unterkerne zerfällt, die sich nach dem Verhalten ihrer 
Zellen zu Farben sehr gut unterseheiden. Er hat ausserdem bei diesem Thiere noch beschrieben: einen Kern der Gitterschicht und, frontal vom Ganglion habenulae, den Kern der Mittellinie. Dazu käme dann noch in den frontalsten Thalamusebenen der kleine Nucleus magnocellularis. Mo n a k ow hat gezeigt, dass das Corpus geniculatum laterale in 5 Kerne zerfällt, einen dorsalen und einen ventralen, die je zweigetheilt sind, und in einen lateral-ventralen. Von diesen gehört die caudale Abtheilung des dorsalen Kernes der Retinafaserung an, während die übrigen Kerne Zuzüge aus der Rinde zu den primären optischen Endstätten aufnehmen. Jeder dieser letzteren Kerne steht zu einem eigenen Abschnitte Zder Sehsphäre in Beziehungen.

Der Thalamus ist ganz wesentlich eine Aufnahmestation fü $r^{\circ}$ die Fasern einerseits aus der Hirnrinde - Stabkranz des

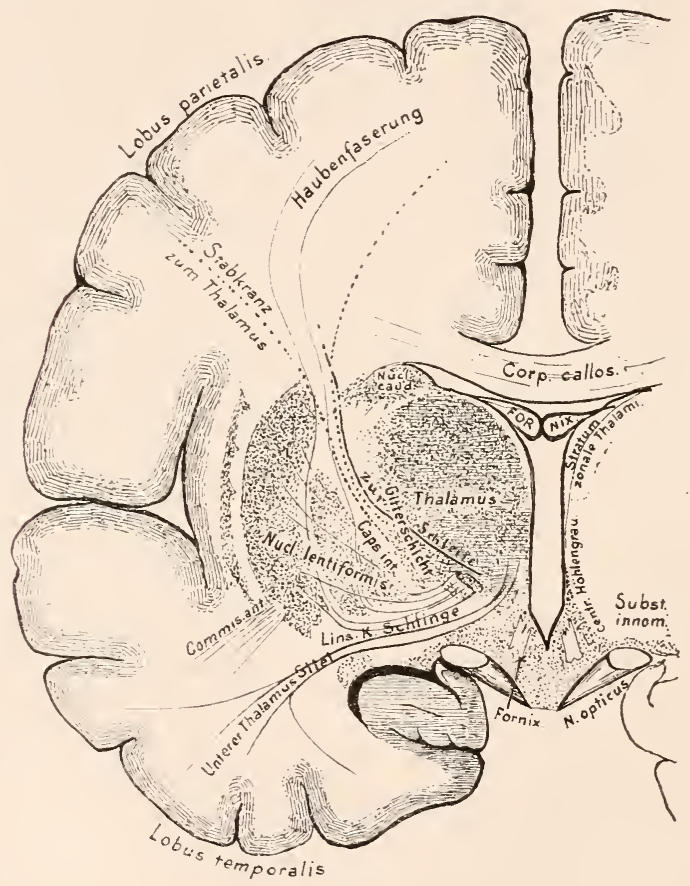

Fig. 168.

Frontalschnitt durch das Gehirn dicht hinter dom Chiasma, schematisirt.

Thalamus - und andererseits aus dem Stammganglion Radiatio strio-thalamica, Linsenkernschlinge u. s. w. Er entsendet im Terhältnisse zu seiner ungeheuern Masse nur sehr wenige Fasern abwärs.

Die aus den Ganglien entspringenden Züge rerlanfen zum grösseren 
Theile in zwei ihre Masse durchziehenden weissen Querscheiden, der Lamina medullaris externa und interna. Die Thalamusfasern gelangen nur zu einem selır geringen Theile weiter hinab. Hauptsächlich ein einziges aus der Stria med. externa und besonders aus dem ventralen Kerne sich sammelndes Bündel, die obere schleife, kann bis in das Ende der Oblongata, vielleicht auch in die Seitenstränge des Rückenmarkes verfolgt werden. Die Stria med. int. ist nicht über das Mittelhirn hinaus

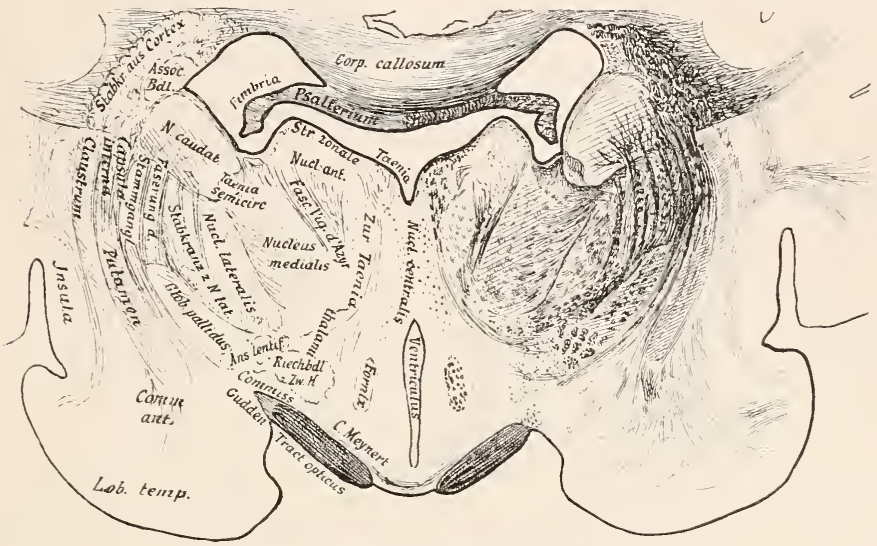

Fig. 169. (Vom Hunde.)

Frontalschnitt, der etwa durch das vordero Thalamusdrittel geht. Er bedarf wie dio folgenden Schnitte, da alle Bezeichnungen eingeschrieben sind, nur weniger Worte zur ergänzenden Erklärung. Aus dem Nantel treten rechts oben dio Fasern, lateral vom Stammganglion, herab zur Capsula interna. Sie treffen da auf die mächtige Faserung aus dem Nucleus caud., durchbrechen sie und strahlen zum Theile als Stabkranz in das laterale Thalamu-ganglion. Die Mehrzahl aber bleibt an der erwälinton Stelle liegen und zieht rückwärts. Dieser Theil nuss von der Stammganglionfaserung umfasst worden, wenn dieselbe einwărts zu ihrer Endstätte in den Zwischenhirnyanglien tritt. Zu den umfassenden Zügen gesellen sich naho der Basis - dio Züge aus dom Putamen und bilden mit ihnen zusammen die Ansa lentiformis. Medial von dem hior bereits getroffenen Bündol ior Ansa liegt die zarte Strahlung aus dem Riechfelde zum Corpus mamillaro. Aus der Riechstrahlung löst sich in dieser Höhe und woiter hinten das dorsalwärts aufstcigende Bündel dor Taenia thalami los. Man sieht es bis zur Thalanusoberfläche ziehen und sich damı rückwärts zum Ganglion habenulae wenden. Zum Riochapparato gehört wahrscheinlich auch das Vicq d'Azyr'sche Bündel, das sich aus dor Markkapsel des lier angeschnittenen, vorderen Thalamuskernes entwickelt.

verfolgbar. Aus dem caudalsten Thalamusgebiete entspringt die Radiatio thalami ventralis mit völlig unbekannter Endstätte (Oblongata Riickenmarkseitenstränge).

An der vorstehenden, selır schematisch gehaltenen Abbildung. Fig. 16s, ist die Lage des Thalamus zum Hirnboden. zum Höhlengraı, zur Capsula interna und zum Nucleus lentiformis zu studiren.

Wollen Sie an diesem schnitte noch etwas beobachten, das bislang nur kurz Erwähnung finden konnte. Es ist die Gegend innen rom Linsenkerne, ventral vom Thalamus. Dort sammeln sich mehrere, ziemlich parallel laufende Faserstränge, welche den unteren Theil der Capsula interna zum Theile im Winkel durchsetzen, zum Theile über ilın wegziehen. Die oberen 
dieser Fasern gehören der Linsenkernfaserung an, es ist die früher erwähnte Linsenkernschlinge, die unteren sind die Stabkranzfasern zum Thalamus, welche, aus dem Occipital- und Temporallappen kommend, als unterer Stiel des S S h h ïgels bezeichnet werden (U.S. des Schema Fig. 159). Die Gesammtheit der ventral vom Linsenkerne in Fig. 165 rom Schnitte getroffenen Fasern heisst substantia innominata. Gleich hinter der Substantia innominata treten die Fasern der Kapsel, welche zum Fusse des Hirnschenkels werden, frei an der Hirnbasis hervor. Die Substantia innominata begrenzt den Hirnschenkel am frontalen Ende. Sie gleicht einer vorn über ihn gelegten Schlinge und wird deshalb auch als Ansa peduncularis bezeichnet.

Das Schema (Fig. 169) liegt iibrigens von dem wirklichen Bilde so weit ab, dass es zweckmässig ist. wenn Sie der beifolgenden Abbildmng eines wirklichen Schnittes durch den Thalamms des Hundes (Fig. 169) Ihre Anfmerksamkeit etwas schenken.

Sie werden durch diese und die folgenden Schnittabbildungen ein besseres Bild vom Aufbaue des Zwischenhimes bekommen, als ich es bisher geben konnte. Sie enthalten etwas mehr Detail (Stiele der Thalamuskerne u. s. w.) als im Texte angeführt wurde, weil sie die Möglichkeit gewähren sollen, wirkliche Schnitte eingehender zu studiren. Ich bitte, diese Zeichnungen nach Schluss der 16. und 17. Vorlesung zur Repetition zu benutzen.

Nun habe ich Thnen, m. H., in den letzten 2 Vorlesungen so vielerlei nene einzelne Hirntheile einzeln schildern müssen, dass ich fürchte, es möchte mir kaum gelungen sein, Ihnen auch ein zutreffendes Bild von der Gesammtlage der einen zn den anderen zn verschaffen. Ein solches Bild aber müssen sie sich dmrchaus verschaffen, weil eine bessere Kenntniss der Faserung und Ganglien, als ich sie zu geben vermochte, wenig nur nützen wird. wenn sie ein Gehirn topographisch stndiren wollen. So ist denn der Zeitpunkt gekommen, wo ich Ihnen einmal eine Reihe von Frontalschnitten durch eine reife Hemisphäre vorlegen muss. Sie mag Ihnen als Wegweiser bei eigenen Untersuchungen dienen.

Zum topographischen Studium rathe ich Ihnen, ein ganzes unzerschnittenes Gehirn in 10 procentige Formolmischung (Blum) einzulegen und nach 4 bis $S$ Tagen mit einem Rasirmesser dasselbe in etwa $1 \mathrm{Cm}$. dicke Scheiben zu zerlegen. So sind die Schnitte angefertigt, deren Bilder ich hier vorlege. Hier und -da wird sich Betrachtung mit der Lupe unter Wasser empfehlen.

Der erste Schnitt (nicht abgebildet), den ich anlege, geht wenige Centimeter hinter dem Stirnpole des Gehirnes dahin. Er enthält, umgeben von den hier noch kleinen Windungen, eine gleichmässig weisse Masse, welche im Wesentlichen zusammengesetzt ist: dicht unter der Rinde aus kurzen Associationsbündehn, darunter dann aus den Stabkranzfasern zum Thalamus und zur Brücke, welche schon hier nach abwärts zu ziehen begimnen, und schliesslich aus den frontalen Enden längerer Associationssysteme.

Der zweite Schnitt, Fig. 170, ist wenige Millimeter hinter dem Balkenanfange angelegt. Er durehquert gerade das Balkenknie, die frontalsten Verbindungsfasern beider Hemisphären. Ein grosser Theil dieser Fasern ist seitlich abgeschnitten, es sind diejenigen, welche sich in leichtem Bogen stirnwärts gewendet hatten und so natiirlich mit ihrer Hauptmasse in dem weggeschnittenen Stücke 
blieben. Direct lateral von den Balkenfasern ist die graue Substanz angeschnitten, welche den Seitenventrikel, resp. sein Vorderhorn iberzielıt, ja an einigen kleinen Punkten ist dieser selbst schon eröfinet.

Das Faserweiss, lateral von dem ectoventriculären Grau, wird zunächst von den Zügen aus dem Frontallappen zum frontalen Schenkel der inneren Capsel gebildet, es ist die Gegend etwa, welche mit "Ad crus ant. " bezeichnet ist. Dies quergetroffene Bündel wird dann ventral umfasst und zum Theile durchflochten von

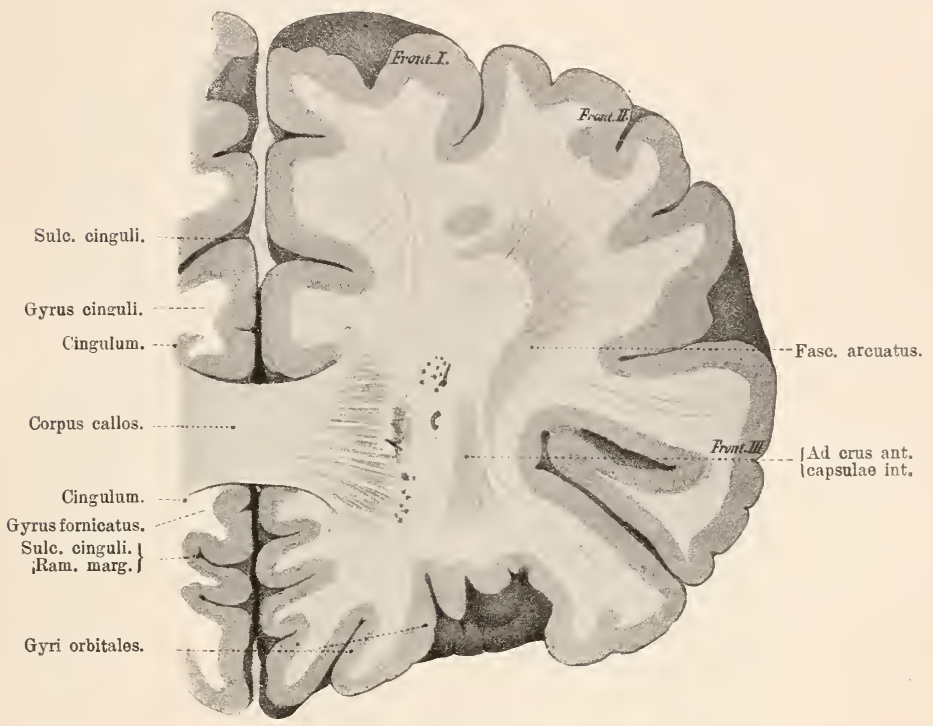

Fig. 170 .

Balkenfasern und von langen Associationsfasern, die dem Fasciculus uncinatus angehören, dorsal von ilım liegt der durch leichte Schattirung angedeutete Bezirk, in welchem der Fasciculus arcuatus sich ausbreitet. Dazu kommen dann, dicht unter der Rinde, die Bogen der knrzen Associationsbahnen und ïber das ganze Feld verbreitet noch zahlreiche Fasern, theils zum Thalamus, theils unbekannten Verlaufes, wahrscheinlich zu gutem Theile noch Associationsbahnen. Schon auf dieser Schnitthöhe kann man - anf in Chromsalzen gehärteten Präparaten dicht iiber und unter dem Balken das quergetroflene Cingulum und dorsomedial von der Stabkranzfaserung zur Capsel die frontale Ausbreitung des fronto-occipitalen Associationsbündels antreffen.

Dicht hinter dem Balkenknie ist der nächste Schnitt, Fig. 171, angelegt. Er geht dorsal durch den Balkenkörper, ventral trifit er noch die unteren Balkenschenkel in ihrem caudalsten Stiickchen, das Rostrum corp. call. Zwischen diesen beiden Theilen liegt die Hemisphäreninnenwand, deren ventraler Abschnitt als Area Brocae, deren dorsalerer als Septum pellucidum bezeichnet wird. Zwischen beiden Septumblättern ist der Ventricnlus septi sichtbar. Hier ist nun das Vorderhorn des Ventrikels breit cröfinet und der Kopf des Schwanzkernes in seiner grössten Ausdehnung getroffen. Lateral von ihm ziehen die Fasern der Capsula 
interna vom Stirnpole herab, denen sich gerade in diesem Gebiete die mächtige Faserung aus dem Schwanzkerne zum Thalamus, Radiatio strio-thalamica beimengt.

Nach aussen von der hier noch von vielen grauen Zügen durchbrochenen Kapsel liegt der frontalste Theil des Putamen, dann folgt lat. die Capsula externa und die Vormauer, Claustrum, und danm das Mark und die Rinde der Insula. Im ersteren löst sich der Fasciculus uncinatus auf. Der Schnitt trifft hier schon das vordere Ende der Sylvischen Spalte.

Die ganze dorsale Hälfte des Schnittes wird eingenommen von den Markmassen, die hier ans den drei Stirnwindungen entspringen. Es sind zum aller-

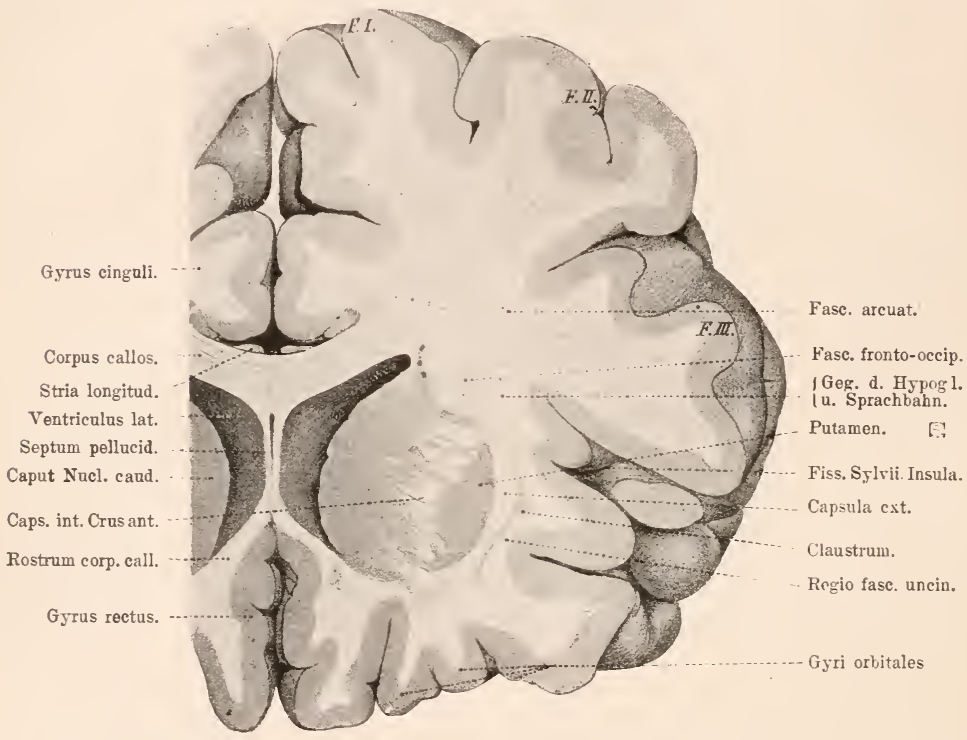

Fig. 171.

grössten Theile Associationsiaseru, die Hemisphärengebicte unter sich verbinden, ganz besonders solche, die dem Stirnlappen speciell angehören, aber auch einige längere, so der Fasciculus arcuatus und Cas fronto-occipitale Associationsbündel. Dazu kommt noch, dass hier das ganze Markweiss von Balkeufasern durelıquert ist. Nur wenige weisse Fasern gelangen aus dieser Gegend in die Capsula interna, von klinisch wichtigen Zïgen wesentlich nur die Stabkranzfaseru aus dem Facialisund dem Hypoglossuscentrum und die Sprachbahn, dereu Quersehnitt etwas lateral von dem Fasciculus fronto-occipitalis anzunelımen ist. Das ventrale Rindengebiet gehört den (iyri orbitales, uiber die der Piechlappen linweg zieht.

Ein nur wenig weiter caudal gelegter Schnitt geht durch den hintersten Abschnitt des Septum pellucidum und schneidet schon die da verlaufenden Fornixsäulen an. Ich lege einen solchen, Fig. 172, vor, weil er auch geeignet ist, den Verlauf der Commissura anterior, das Sclımalerwerden des Schwanzkernkopfes und die Ausbreitung des Linsenkernes auf dem Querschnitte zu zeigen.

Die graue dreieckige Masse zwischen Commissur und Schwanzkern gehört 
bereits dem centralen Grau an, das den Thalamus iberzieht. Der weisse Faserzug, der sie bedeckt und frei in den Ventrikel ragt, ist die Stria terminalis, speciell der Theil derselben, welcher aus der Com. ant. stammt.

Dicht caudal liegen an gleicher Stelle in gleichem Verlaufe die Ziige der Taenia thalami. Ventral beginnt das Riechfeld aufzutreten.

Ein Schnitt, Fig. 173, der direct da angelegt ist, wo der Riechlappen sich der Hirnbasis einpflanzt, trifft weiter dorsal den hinteren Abschnitt des Septums, wo sich die Fornixsäulen befinden. Vom caudal ventralen Abschnitte des Gehirnes kommen sie hierher gezogen. Man wird ihren Querschnitten in allen folgenden Ab-

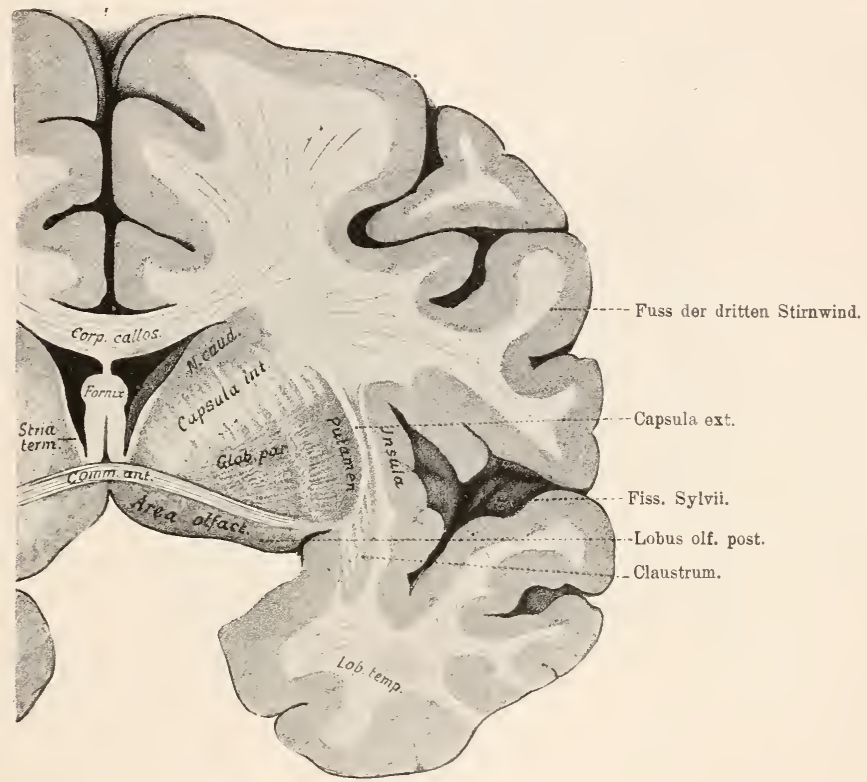

Fig. 172.

bildungen begegnen, bis sie sich hier vorn nach der Basis zu wenden und ganz ventral in das centrale Höhlengrau eintreten. Ihre ovalen Frontalabschnitte liegen im Grau direct vor dem Querzuge der Commissura anterior.

Lateral von den Fornixsäulen liegt der hier nur spaltförmige Seitenventrikel, in den der frontalste Abschnitt des Thalamus, der Nucleus anterior hineinragt. Er ist von weissen Fasern ïberzogen, die auch in sein Inneres dringen und ihn hier von dem Nucleus lateralis thalami trennen. An seinem lateralen und an seinem ventralen Ende nimmt der Thalamus hier Fasern auf. Die lateralen stammen aus der Capsel und gehören ebenso wie die ventralen der Faserung aus der Rinde sowohl als auch dem Stammganglion an. Speciell der Eintritt am ventralen Ende wird deutlich gebildet von dem unteren Stiele aus dem Schläfenlappen und der Linsenkernschlinge aus dem Corpus striatum.

Der inneren Kapsel haben sich in dieser Schnitthöhe die Fasern aus der vorderen Centralwindung zu gutem Theile schon beigemengt, sie enthält mindestens 
sclıon die Stabkranzfasern für das Gesicht, die mot. Sprache, den Hypoglossus und einen Theil der Pyramideufaserung für Arm und Hand. Fasern aus dem Schwanzkerne, die ventrocaudalwärts ziehen, durchbrechen ihre aus dem Mantel stammenden Züge. Das Markweiss ist im wesentlichen noch zusammengesetzt wie auf den vorhergehenden Schnitten.

Lateral von der Kapsel ist jetzt die grösste Ausbreitung des Corpus striatum getroffen, das Putamen und die 2 Glieder des Globus pallidus. Zahlreiche

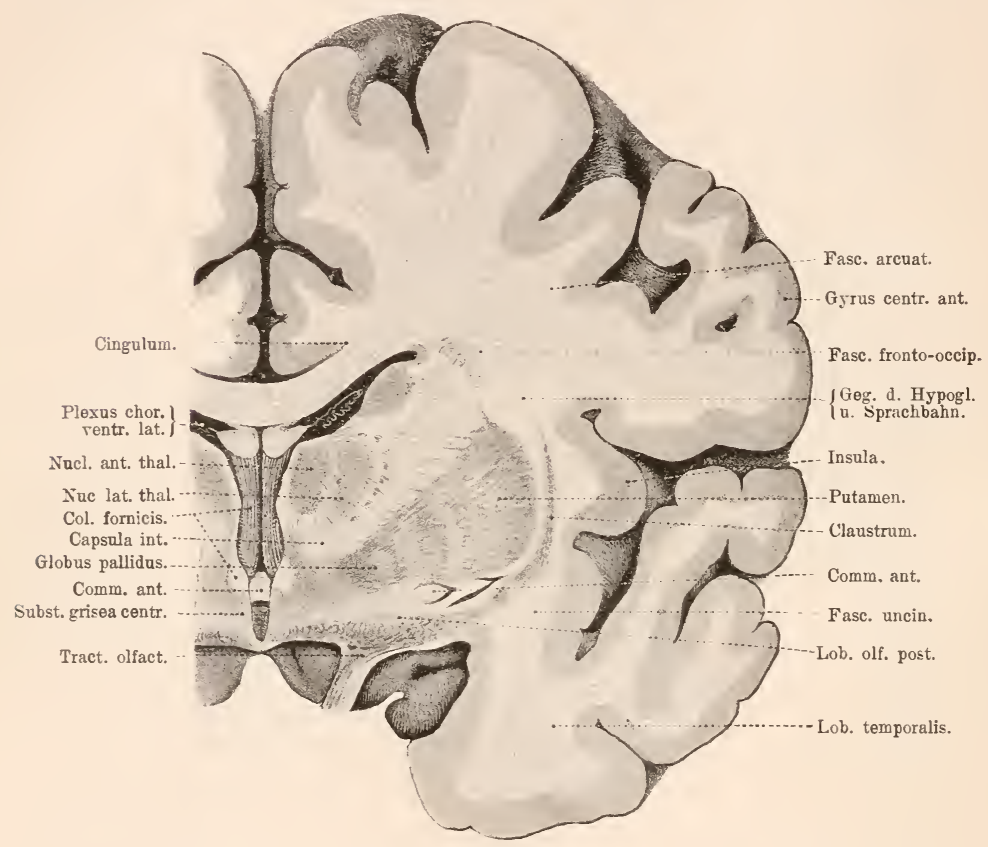

Fig. 173.

Markstrahlen entspringen in dem ersteren, sie gelangen zum guten Theile in die Linsenkernschlinge. Ventral rom Corp. str. erkennt man den Querschnitt der Commissura ant. Er liegt diclit über der Riechformation, deren Rinde und Mark hier wohl abscheidbar ist. Der Eintritt der Riechstrahlung in sie ist zu erkennen. Aus dieser Gegend erhebt sich die Taenia thalami dorsal und geht in den weissen Ueberzug ein, der die mediale Thalamusseite bedeckt. Doch ist der Verlauf auf diesem Schnitte nicht ganz zu übersehen.

Der Schnitt 5, Fig. 174, ist direct frontal von dem Chiasma angelegt. Dieses ist nicht durchtremnt, sondern ventralwärts umgelegt. Der enge, spaltförmige Ventrikel verlängert sich ventral in das Infundibulum. Er ist in seinem unteren Drittel von der Commissura media überquert. Die von dem Stratum zonale und der Taenia bedeckten Thalami ragen in ihn hinein, und oben wird er abgeschlossen von den Fornixsäulen, über denen der Balken liegt. Das laterale Ende jeder Säule 
setzt sich, wie Fig. 173 zeigt, direct in den Plexus chorioides ventriculi lat. fort. Dicht neben der Com. mollis erblickt man im centralen Grau die quer getroffenen absteigenden Fornixschenkel, die sich hier, das Grau des Infundibulum durchsetzend, caudal und ventral zum Corpus mamillare wenden.

Vom Thalamus ist jetzt der Nucl. anterior, der Nucl. medialis und der Nucl. lateralis, auch die Gitterschicht sichtbar. Aus dem ersteren entwickelt sich der Tractus thalamo-mamillaris-Viq d'Azyr'sches Bündel. Seine Ursprungsbündel und Fasern aus dem Stratun zonale, sowie Fasern noch unbekannter Herkunft erzeugen um den Nucleus ant. eine förmliclıe Narkkapsel. Der laterale Theil dieser Kapsel und ein Stück des ventralen können weithin riickwärts als Lamina medullaris interna thalami verfolgt werden.

Vom Stammganglion ist dorsal und ventral der Schwanz des Nucl. caudatus sichtbar. Er hat an seiner medialcn Seite den Zng der Stria terminalis. Ferner der Linsenkern mit seinen drei Gliederu, aus denen man gerade in dieser Höhe

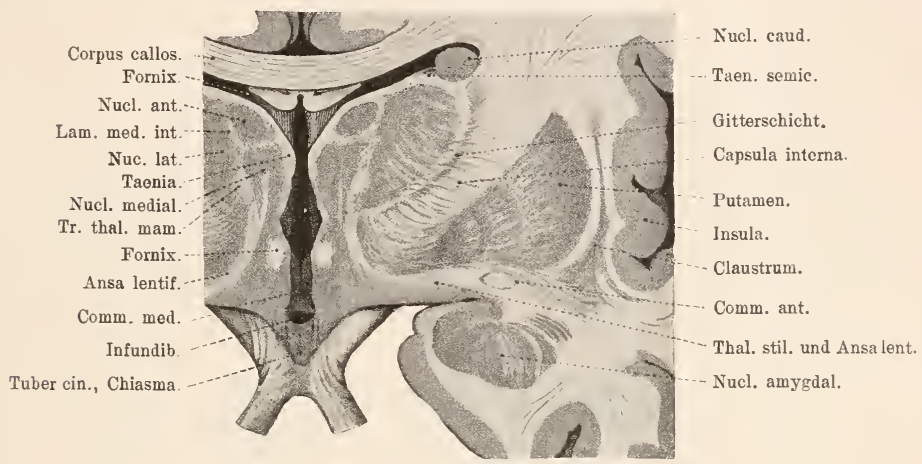

Fig. 174 .

sich die Fasern der Linsenkernschlinge entwickeln sieht. Sie. gelangen an den basalen Theil der Capsula interna, den sie durchqueren, um von unten her in die Thalamusganglien einzutreten. Fast auf diesem ganzen Wege liegen sie der Faserıng auf, welche aus dem Schläfcnlappen als unterer Thalamusstiel ebenfalls in den Thalamus zieht.

Die innere Kapsel enthält hicr ziemlich die ganze motorische Faserung. Ausserdem die Balnen aus dem Stirnhirne zur Brïcke. Viele Stabkranzfasern treten aus ihr in den Thalamus. Die mot. Sprachbahn liegt noch an gleicher Stelle wie in der vorigen Figur. Ventral vom Linsenkerne liegt die Com. ant., und unter dieser erblickt man den Mandelkern.

Die Sehhügel liegen so nahe überall der inneren Kapsel auf, dass nur selten Erkrankungen zur Beobachtung kommen, welche nur die Thalami betreffen, and auch bei solchen bleibt es oft zweifelhaft, wieviel von den auftretenden Erscheinungen darauf $z$ beziehen ist, dass indirect die benachbarten Fasern der Kapsel in ihren Functionen gestört wurden. Deshalb ist es noch nicht möglich gewesen, die Symptome sicher festzustellen, welche von einer Sehhügelerkrankung erzeugt werden. Nach Meynert werden dabei die Innervationsgefühle der oberen Extremitäten gestört. Dadurch sollen Wahnideen über die Haltung dieser Glieder und aus diesen wieder Zwangsstellungen entstehen. Motorische Lähmung wird wahrscheinlich nicht durch Sehhüget- 
zerstörung erzeugt, ebensowenig sensible. Sehstörungen in Form der homonymen lateralen Hemianopie, vielleicht auch der gekreuzten Amblyopie, wurden wiederholt beobachtet. Ebenso wurden bei Sehhügelerkrankungen nicht so ganz selten die Symptome der Hemichorea, der Athetose, des halbseitigen Zitterns gesehen. Diese sind auch schon bei Herden an anderen Stellen des Gehirnes beobachtet worden, doch kam gewöhnlich mit dem Thalamus zusammenhängende Faserung in Betracht.

Die gleiche Schwierigkeit liegt vor, wenn es gilt, die Symptome bei Erkrankung des Corpus striatum festzustellen. Was bislang als solche beschrieben wurde (Hemiplegie z. B.), kann ebensowohl durch Mitbetheiligung der nahen Capsula interna entstanden sein. Es ist ein Fall von Zerstörung beider Putamina bekannt, der ohne ein darauf zu deutendes Symptom verlief.

\section{Siebzehnte Vorlesung.}

\section{Metathalamus und Hypothalamus.}

Die Regio subthalamica und die Gebilde an der Hirnbasis.

II. H. Schon am schlusse der letzten Vorlesung haben wir uns einer Gegend des Gehirnes genähert, welche, ausserordentlich complicirt im Aufbaue, bisher zu den am wenigsten aufgeklärten Theilen gehört. Heute nun beabsichtige ich, Thnen die wichtigsten Gebilde dieser Regio subthal amica rorzufuihren.

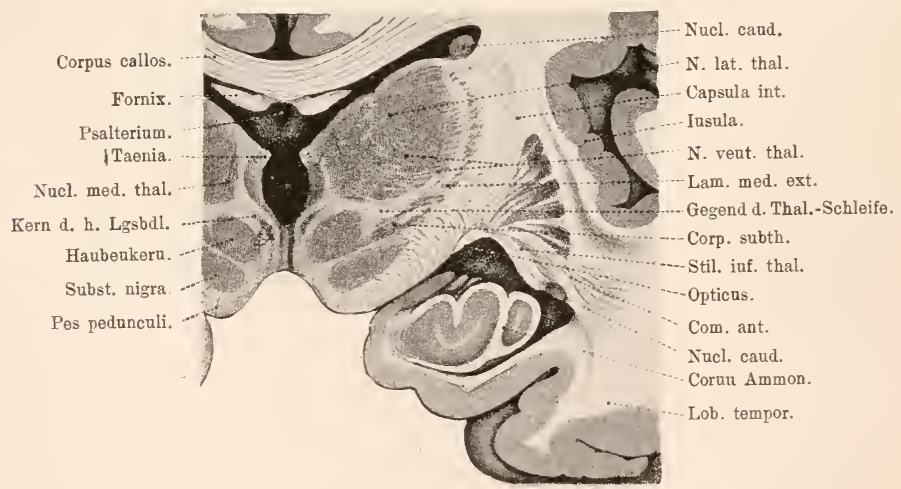

Fig. 175.

Schuitt durch die Gegeud der Regio subthalamica.

Temn Sie Fig. 173 oder Fig. $17 t$ betrachten, so erscheint es, dass der Thalamus auf der imneren Kapsel aufliegt. Weiter nach hinten hört dies Terhältniss auf. Es schieben sich zwischen ihn und die Kapsel mehrere kleine graue Ganglienmassen, in welche zahlreiche Faserzïge aus dem 
Nucleus lentiformis, aus der Kapsel und dem Thalamus selbst einstrahlen. Das hintere basale Zwischenhirngebiet, wo das geschieht, hat den Namen Regio subthalamica erhalten. Der Metathalamus ist genauer erst durch die Untersuchungen von Luys, von Forel, dann durch solche von Flechsig. Wernicke. Monakow und Kölliker bekannt geworden. Doch sind wir noch weit von einem Terständniss der complicirten Terhältnisse entfernt, welche auf dem kleinen Raume vorliegen, wo sich Fasern verschiedenster Provenienz treffen, verschlingen und kreuzen. wo graue Massen liegen, die zum Theil selbst wieder von einem engen Netz sich kreuzender, markhaltiger Fäserchen erfüllt sind.

- Fig. 175 zeigt einige Details eines Schnittes durch diese Gegend. Inter dem Thalamus ist ein rundliches Ganglion, der $\mathrm{Nucleus}$ tegmenti, der rothe Kern der Haube, nach aussen von diesem ist das fast linsenförmige Corpus subthalamicum (Luys'scher Körper) aufgetreten. Der Nucleus tegmenti wird caudalwärts noch viel grösser in den Querschnitten erscheinen. Er ist die Ursprungsstätte eines mächtigen Bündels zur gekreuzten Kleinhirnhälfte, des Bindearmes, Tractus tegmento-cerebellaris. Ventral von ihm und medial von dem Corpus subtlalamicum findet man - auch in caudaleren Ebenen noch stärker entwickelt - ein drittes Ganglion, die Substantia nigra Sömeringi, eine Anhäufung von meist grau pigmentirten Zellen. Sie liegt dicht über der hier schon zum Fusse gewordenen Faserung aus der inneren Kapsel.

Von der Regio subthalamica an bis hinab zum Ende des Mittelhirnes ist dies dunkel rauchgrau gefärbte Ganglion immer über dem Fuss nachweisbar.

In der Substantia nigra endet, als Stratum intermedium pedunculi bezeichnet, der letzte Rest der Faserung aus dem Stammganglion.

Zwischen den ventralen Sehhügelkern und die erwähnten Ganglien strahlen eine Menge weisser Fasern ein. Sie stammen aus mehreren Quellen und sind auch annähernd schichtenweise geordnet, so dass man die einzelnen etwas abscheiden kann. Immerhin waren es nur Degenerationspräparate, an denen man klar die Unterscheidung vornehmen konnte. Am weitesten lateral liegen die für den rentralen Thalamuskern bestimmten Zïge der Ha ububahn. Man hat lange geglaubt, dass einige von ihnen direct abwärts zum Nachhirn sich wendeten, und diesen Theil als obere oder Rindenschleife bezeichnet, auch jetzt wird noch von einigen Seiten an dieser Auffassung festgehalten, s. auch meine ältere Fig. 165. Aber es ist in den letzteren Jahren gelungen. nachzuweisen, dass der Faserzug aus der Rinde schon im Thalamus endet, dass aber von da eine neue Bahn entspringt, der Tractus thalamo-bulbaris, die obere Schleife, welche hinab bis in die Kerne der Hinterstränge verfolgt werden kann. Das ist ein Stück der Gefühlsbahn, von dem wir jetzt also 2 Theile, das Rinden-Thalamusstück nnd das Thalamus-Oblongatastück kennen. Beide mïssen, ausserordentlich nahe an einander endend, in imnigem Contacte innerhalb des rentralen Thalasmuskernes stehen (M on a kow, Mahaim, Bielschofsk y).

Die obere schleife findet man auf dem abgebildeten schnitte ventral vom Thalamus nahe dem Nucleus tegmenti. Aber ron diesem ist sie durch ein dickes Markbündel geschieden. den Tractus cortico-teg- 
mentalis, das Stabkranzbündel des Haubenkernes (Déjèrine). Obere Schleife und Stabkranzbündel bilden lateral um den Nucleus tegmenti eine richtige Markkapsel, die Lamina medullaris nuclei tegmenti.

Die Strahlungen zum Haubenkerne und zur oberen Schleife bilden aber nicht die einzigen Bestandtheile des Markes der Regio subthalamica. Auf dem Fig. 176 abgebildeten Schnitte vom Hunde, der etwas weiter frontal fällt als Figur 175, auch nachher auf Fig. 17s sehen sie noch mächtige Fasermassen in mehrere Bündel geordnet hierher strahlen. Sie stammen alle aus dem Stammganglion und enden, soweit wir heute wissen, in den Kernen der Zwischenschicht, namentlich in der Substantia nigra

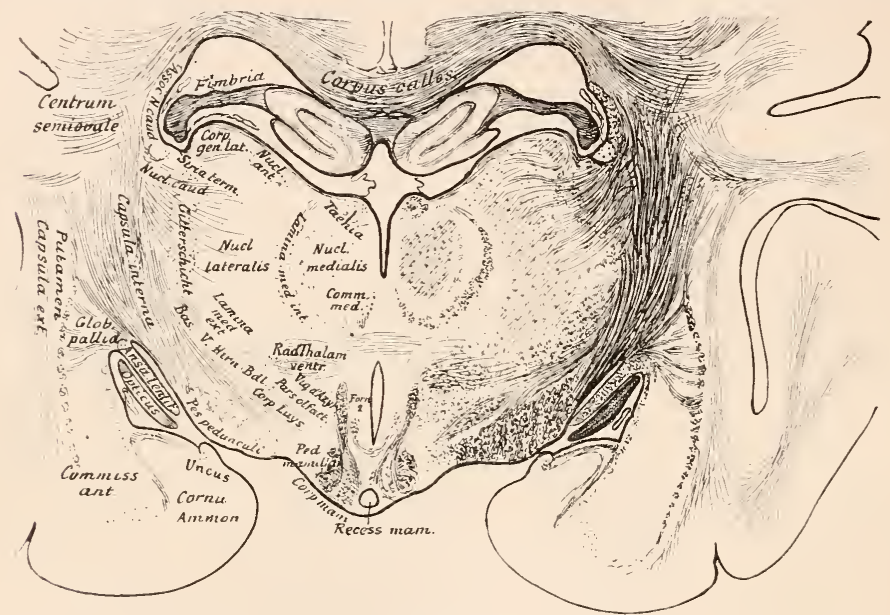

Fig. 176.

Hund. Frontalschnitt durch circa die Mitte der Thalamuslänge. Unter dem Balken liegen die Frontalenden beider Ammonshörner, verbunden durch das Psalterium, jederseits die mächtige Fimbria aussendend. Im Thalamus Nucleus medialis und lateralis in ihrer grössten Breite, von einander getrennt durch die quer getroffene Lamina medullaris interna, dorsal begrenzt durch die Taenia thalami, in welche Fasern aus dem Stratum zonale gelangen, durch den caudalen Theil des Nucleus anterior und das dorso-frontale Ganglion des Ganglion habenulae. Ganz lateral und dorsal der Schwanz des Nucleus caudatus und sein Assiociationsbündel. A us der Capsula interna tritt der Stablranz des Nucleus lateralis und des Nucleus anterior herein; zwischen Nucleus lateralis und Capsula entwickelt sich aus dem ersteren die Lamina medullaris externa. An der Basis das Corpus mamillare, in welches auf dieser Schnitthöhe das Vicq d'Azyr'sche Bündel aus dem Nucleus anterior und das Haubenbündel vereint eintreten. Lateral entwickelt sich der Pedunculus mamillaris, dorsal, direct unter dem Ventrikel, die Decussatio subthalamica anterior. Die Capsula interna wird an der Unterfläche als Hirnschenkelfuss frei ; ihre medialsten Fasern stammen hier aus dem Vordorhirnbündel und enden im Corpus Luys, Dorsal vom Corpus Luys die Fasern des tiefen Riechmarhes und, diesen dicht auf liegend, die Radiatio thal. ventr. Lateral von der Capsula interna der Linsenkern, aus dem die Schlinge sich dicht an den Fuss legt. Zwischen Schlinge und dem ventralen Theile des Ammonshornes der Nervus opticus.

und im Corpus subthalamicum oder doch in dessen Nachbarschaft, wo man noch mehrere andere kleine Ganglienanhäufungen - Ganglien der Zwischenschicht - findet. Diese Strahlung ist nichts Anderes als das caudale Ende der Tractus strio-thalamici, denen wir so oft nun von den Fischen bis hier zum Menschen begegnet sind. Sie stammt ans 
der Ansa lentiformis, kommt an der medialen Kante des Striatum zum Vorschein, iiberquert die Kapsel und strahlt so, von der Seite kommend, in die einzelnen Ganglien der Zwischenschicht ein.

Dass diese als einzelne $\mathrm{Str}$ a t a der $\mathrm{Z} w$ is $\mathrm{ch}$ en s e hic ht bezeichneten Faserbiindel aus dem Stammganglion mindestens zum grossen Theile stammen, entnehme ich den Präparaten vom Hunde ohne Vorderhirn, dessen mehrfach hier gedacht wurde.

Die Gegend ventral von den Thalamusganglien und der Ansa peduncularis - Fig. 169 - wird von feinen Längsfasern durchzogen, welche, aus dem Riechlappen stammend, in gerader Linie hierher gelangen. Wir wollen sie als die Riechbïndel des Zwischenhirnes bezeichnen. Sie können bis in die Gegend eines Gangliencomplexes verfolgt werden, der, an der Zwischenhirnbasis gelegen, da als kleine Halbkugel an die Schädelbasis hervorragt.

$\mathrm{Er}$ heisst Corpus mamillare und ist bei osmatischen Thieren sehr viel mächtiger als bei den Primaten vergl. Fig. 141. In Fig. 176 und 17s fällt er gerade in die schnittlinie.

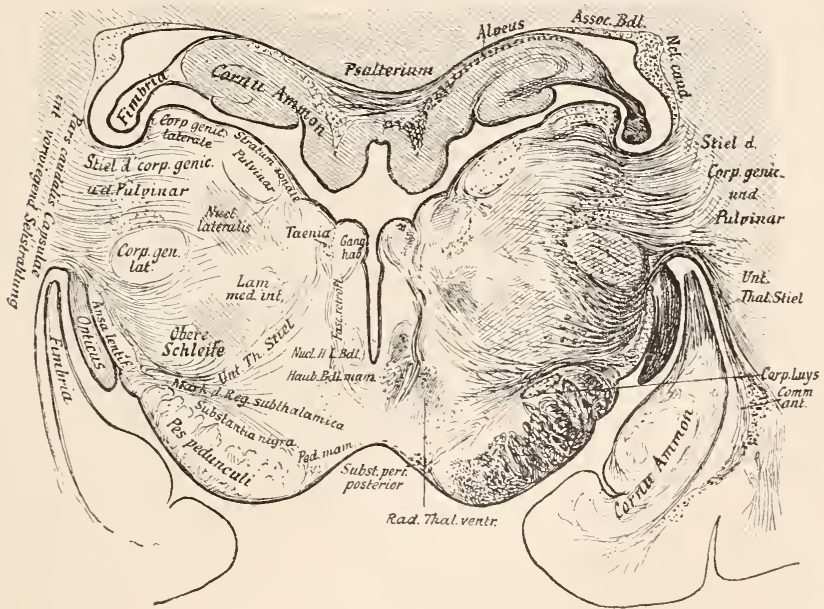

Fig. 177 .

Hund. Frontalschnitt durch das Zwischenhirn in der Gegend des caudalen Thalamusdrittels. Erklärung des grössten Theiles der Figur, s. Fig. 169. Auf diesem Schnitte im Vergleich zu dem der Fig. 169 zu beachten das Ganglion habenulae, in dem die Taenia verschwindet, der untere Thalamusstiel, die Einstrahlung der Ansa lentiformis in das Mark der Regio subthalamica, das Corpus Luys und das Absondern der oberen Schleife aus den Markmassen lateral und ventral vom Thalamus. Medial vom Corpus geniculatum lat. tritt das Pulvinar auf.

Nach dem Corpus mamillare herab ziehen durch das centrale Höhlengrau die Bündel der Fornixsäule aus dem Ammonshorne und der Randwindung. Sie scheinen in ihm gekreuzt und ungekreuzt zu enden. Die kleine Kreuzung dorsal vom Corpus mamillare, welche, zum Theil werigstens, Fornixfasern enthält, heisst vordere Kreuzung der Regio sub- 
thalamica. Wollen Sie auf Fig. 133 u. 134 den Verlauf des Fornix rom Ammonshorne an bis herab zur eben beschriebenen Gegend rerfolgen und diese Figur auch für die folgende Schilderung fortwährend zu Rathe ziehen.

Das Corpus candicans besteht, wie Gudden's Tersuche zeigten, aus 3 Kernen. Der lateralste sendet seinen Stiel (Pedunculus corporis mamillaris) bis weit hinab in die Oblongata; aus dem caudal liegenden der beiden medialen Kerne entspringt ein dickes Bündel, das in den Thalamus hinaufsteigt und sich in dessen Tuberculum anterius verliert. Dieser Tractus thalamo-mamillaris (Vicq d'Azyr'sches Bündel) ist in Fig. 144 ganz und in Fig. 17t in einem Theile seines Verlaufes sichtbar geworden. Neben ihm steigt, aus dem frontaleren Ganglion kommend. ein Fasersträngchen nach dem Thalamus zu auf, das sich aber bald von seinem Begleiter trennt und im Winkel caudalwärts abbiegend in die Haube hinter der Vierhügelgegend gelangt, wo es bis in die Ganglien. die unter dem Aquaeductus Sylvii liegen, verfolgt werden komnte. Das ist das Haubenbündel des Corpus mamillare.

S. Ramon y Cajal und Kölliker geben neuerdings an, dass aus dem Corpus mamillare nur ein einziges Bïndel entspringe, dass dorsalwärts ziehe und in einiger Entfernung vom Ursprung seine Axencylinder theile. Die frontalen Theiläste endeten als Tractus thalamo-mamillaris im Nucleus anterior. die candalen als Haubenbündel in einem Kerne der Brückenhaube. Kölliker lässt auch den Fornix nicht im Mamillare enden, sondern nach Durchquerung desselben sich via Decussatio hypothalamica ant. in den gekreuzten Thalamus begeben, wo er innerhalb der ventralen Kerngruppen enden soll.

Durch die Substantia nigra wird die Faserung, welche aus dem Vorderund Zwischenhirn nach abwärts zieht, in zwei, ihrer physiologischen Bedeutung nach verschiedene Partien getheilt, den Fuss und die Habe.

Noch sei kurz der Glandula pinealis (Zirbel), Epiphysis. gedacht, die mit ihren an der Innenfläche des Thalamus verlaufenden Stielen ein Stück des Zwischenhirndaches darstellt (s. Fig. 20 und 21). Sie besteht wesentlich aus soliden Epithelschläuchen, die durclı Wucherung der primären Ausstïlpung entstanden sind.

Die Zirbel enthält ausser den Schläuchen und reichlichen Gefässen noch den Hirnsand, kleine Concremente von geschichtetem Bau, die wesentlich aus Kalksalzen und geringer organischer Grundlage bestehen.

Ueber die Lage der Glandula pinealis am hinteren Thalamusende, zwischen den Tierhügeln, orientirt Sie Fig. 125.

Ich möchte Sie noch einmal an das erimnern, was Seite 120 über die Bedeutung der Zirbel bei den Reptilien gesagt wurde.

Bis zu der Zirbel scheinen Fasern aus den Zügen der Taenia Thalami zu gelangen. Die Taenia erhebt sich vorn neben dem Fornix aus der Tiefe des Riechfeldes und endet, nachdem sie einen Zuzug aus dem Fornix aufgenommen hat, am medialen Thalamusrand entlang ziehend, in dem dicht vor der Epiphyse (s. Fig. 177) gelegenen Ganglion habenulae. Man hat den caudalen Abschnitt der Taeniabündel auch als Pedunculi conarii bezeichnet. Zwischen beiden Pedunculi conarii verläuft die zarte $\mathrm{Commissura} \mathrm{habenularis,} \mathrm{wahr-}$ 
scheinlich ein Kreuzungszug aus den Taeniae habenulae, Fig. 144 sehr deutlich im Querschnitt. Dort ist auch zu sehen, wie der beim Menschen fast massive Zirbelkörper noch beim Kaninchen als Ausstülpung des Vorderhirndaches erscheint und in den Plexus chorioides übergeht.

Ganz wie bei den niederen Vertebraten, so zieht auch aus dem Ganglion habenulae der Säuger ein kräftiger Zug hinab zur Basis des Mittelhirnes, der Tractus habenulo-peduncularis.

Nun will ich wieder die Demonstration der Hirnschnitte aufnelımen, welche am Schlusse der letzten Vorlesung unterbrochen wurde. Sie soll Thnen zu eigenem Nachstudium des heute Vorgetragenen und zur Orientirung behülflich sein. Der Schnitt Fig. 17s folgt ganz direct auf denjenigen der Figur 174.

Nucl. caudat.

Nucl, ant. thal. Lam. med. int.] Tr. thal. mamill. Corp callos. Nucl. lat. Taenia.

Nucl. ventr. Nucl. med. Lamina med. ext. Ansa lentif. Zona incerta. Corpus subthal. Pes pedunculi.

Col. fornicis. Corpus mamill d!arkkapsel d. I corp. mam.

Tuber cinereum.

Chiasma.

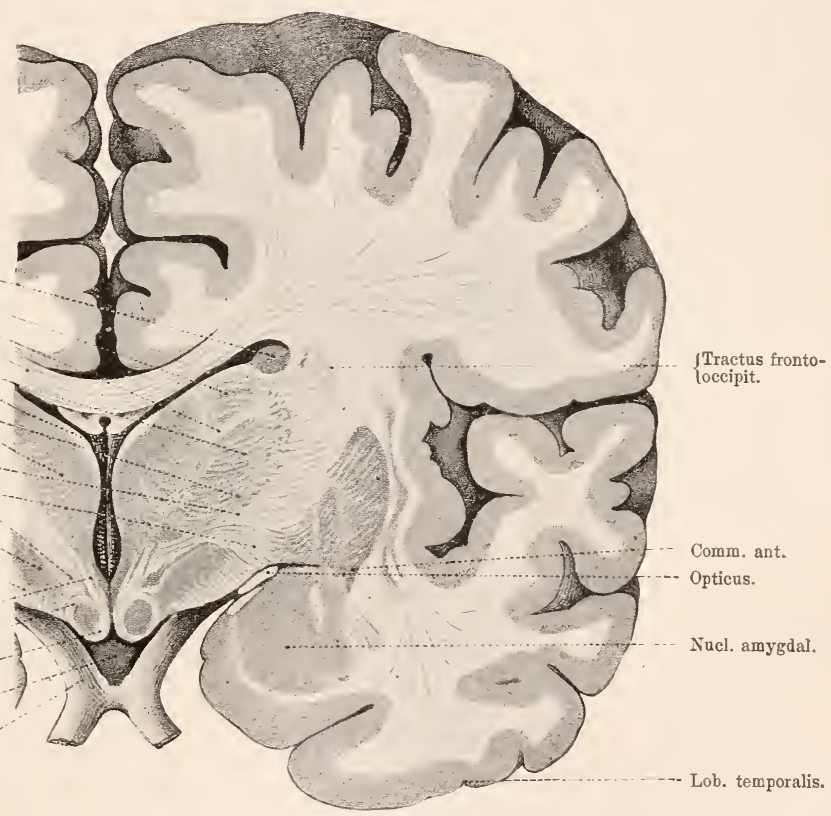

Fig. 178.

Dicht hinter dem Chiasma angelegt, zeigt er einerseits die volle Breitenentwicklung des Thalamus, andererseits als wichtiges Moment das Vortreten der Kapselfaserung an die Hirnbasis, die Anlage des Fusses. Zwischen Fuss und Thalamus legt sich die Regio subthalamica an, und in dieser liegen neve Ganglien. Das ,Ganglion der Zona incerta", das Corpus subthalamicum (Lu ys) und ventral die Gangliengruppe des Corpus mamillare. Die letztere ist umfasst von ihrer Markkapsel, in welcher der Fornix sich zunächst aufgelöst hat, und entsendet nach oben das Haubenbiindel Tr. mamillo-tegmentalis und den Tractus thalamo-mamill. Vicq. d'Azyr Bündel, die zunächst vereint einherziehen. 
Der Nucleus lateralis und medialis thalami lassen dorsal zwischen sich noch dem caudalen Ende des Nucleus ant. Raum, rentral fliessen sie zusammen. Hier beginnt die Region des Nucleus rentralis. Der caudalste Antheil der Ansa lentiformis strahlt hier ein, und andere Fasern aus dem Stammganglion wenden sich $\mathrm{zu}$ den grauen Kernen der Regio subthalamica. Die Lamina medull. interna thalami ist viel faserreicher geworden, .nnd zwischen Gitterschicht und seitl. Kern entwickeln sich die Ziige der Lamina med. externa thalami. Das Stratum zonale ist wesentlich verschmälert, und die Taenia nun reiner zu erblicken. Linsenkern, Vormauer, Kapseln, Inselrinde bieten ausser etwas veränderten Formen nicht etwas wesentlich von frïher gezeigten Schnitten abweichendes. Im Markweis dürfen die langen Associationszüge noch immer an den gleichen Stellen gesucht werden, wo sie in Schnitt Fig. 174 lagen.

Caudal von der Gegend des vorigen Schnittes legen sich in der Regio subthalamica und in der hier erwachsenden Haube die einzelnen Bestandtheile so enge an einander an, dass sie ohne Färbung und Vergrösserung zumeist nicht abscheidbar sind. Es wird deshalb an den Abbildungen weiter vorn im Texte Vieles klarer sein als in Fig. 179, s. speciell auch die Figuren vom Hunde.

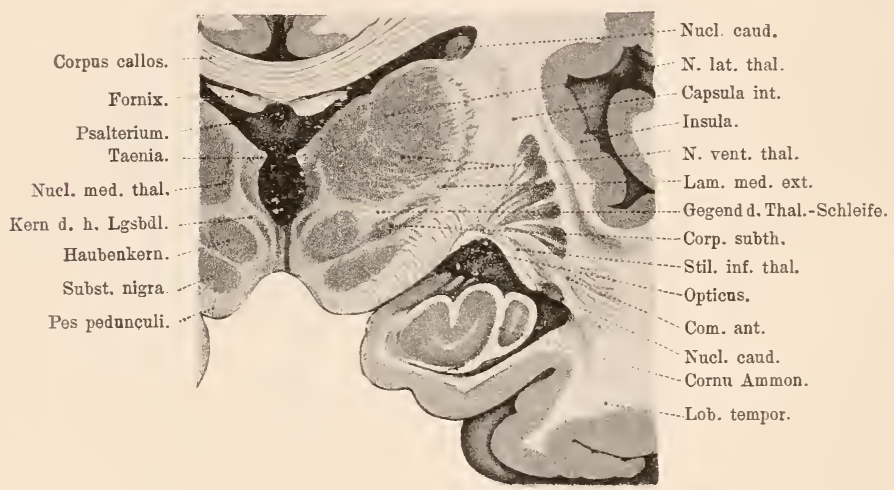

Fig. 179.

Schnitt durch die Gegend der Regio subthalamica.

Die Thalamusganglien sind fast ganz unter einander verschmolzen. Nur die Form der Zellen und degenerative Vorgänge gestatten noch die Abscheidung specieller Kerne. Am meisten haben der Nucleus lateralis und der Nucleus ventralis an Ausdehnung gewonnen, der mediale und der vordere Kern sind ganz verschwunden. Hier, nahe von dem Eingange in den Aquäduct, verbreitert sich auch die Schicht des centralen Höhlengraues. Dicht nach aussen von ihr treten die ,sagittalen Kerne des Zwischenhirnes", die Kerne des hinteren Längsbündels auf. Dann folgt lateral der rotle Haubenkern und an der Stelle, wo im letzten Schnitte das Corpus subthalamicum gelegen hat, die Substantia nigra. Das erst genannte Ganglion ist bis auf einen kleinen weiter lateral liegenden Rest verschwunden. In dem hellen Felde ventral vom Thalamus sammeln sich Fasern aus dem caudalsten Gebiete der Stammganglionfaserung, eine Kapsel um den rothen Kern bildend, zum Theile in ihn eintretend, dann die Züge der Lamina medullaris externa und von dieser noch durch Grau getrennt im ventralsten 
Die Basis des Gehirnes. Der Sehnerv und sein Trsprung. Die Vierhügel. 263

Thalamuskern die Fasern der oberen Schleife. Die innere Kapsel enthält an dieser Stelle wesentlich die Haubenstrahlung zum Thalamus und Ziige aus dem candalen Schläfenlappengebiete zum Thalamus, auch solche von ebendaher zum Hirnschenkelfusse, und zwar zu dessen lateraler Abtheilung.

Ventral von dem hier erheblich verkleinerten Putamen erkennt man die Ausstrahlung der Commissura anterior in die Umgebung des Unterhornes. In das Unterhorn selbst sieht man nun die frontalste Partie des Ammonshornes sich einstiilpen. Das Dach des Unterhornes enthält hier auch den nach unten gekrïmmten Schwanz des N. candatus, dann natïlich die Faserung aus dem Schläfenlappen zum Thalamus. Ausserhalb des Ventrikels und von diesem durch den Plexus chorioides geschieden, liegt der Tractus opticus. Der Hirnschenkelfuss ist von dem der anderen Seite durch die Substantia perforata posterior getrennt.

Die beiden Fornixsäulen rereint eine kurze dünne, bereits dem Psalterium angehörige Platte.

\section{Achtzehnte Vorlesung.}

\section{Die Basis des Gehirnes. Der Sehnerv und sein Ursprung. Die Vierhïgel.}

Bis heute haben wir noch keine Gelegenheit genommen, die Hirnbasis eingehender zu betrachten. Jetzt, wo uns die Herkunft mehrerer dort liegender Gebilde bekannt ist, mag es an der Zeit sein, ein Gehirn, mit der Basis nach oben gekehrt, sauber von der Pia und den Gefässen zu befreien und das Präparat zu studiren.

Die nachstehende Abbildung kam dabei als Wegweiser dienen. Zunächst sehen Sie aus der Masse des Grosshirnes die Hirnschenkel hervortreten. Dicht vor ihnen, in dem Raume, der hier zum grössten Theil vom Sehnerv verdeckt ist, liegt die Substantia innominata, welche die Linsenkernschlinge und den unteren Thalamusstiel enthält, s. auch Fig. 174. Früher demonstrirte Frontalschnitte laben Sie belehrt, dass die weisse, hier sichtbare Masse, der Fuss, die directe Fortsetzung von Faser'n der inneren Kapsel ist. Nach kurzem Verlanfe wird der Hirnschenkel bedeckt von dicken Fasermassen, welche quer über ihn hin von einer Kleinhirnhälfte zur anderen zu ziehen scheinen. Diese werden als Brückenfasern, Fibrae pontis, bezeichnet. Jenseit der Brïcke tritt ein Theil der im Hirnschenkelfuss enthaltenen Fasern als Pyramiden wieder zu Tage, ein anderer Theil hat in Ganglien, welche zwischen die Brückenfasern eingesprengt sind, sein Ende gefunden.

Die graue Substanz zwischen den Hirnschenkeln heisst Substantia perforata posterior. Sie grenzt innen an die Regio subthalamica. Vor ihr liegen die Corpora mamillaria, jene beiden rundlichen Ganglien, welche wir vorhin auf dem Querschnitt kennen lernten, dieselben, zu denen das Vicq d'Azyr'sche Bündel aus dem Thalamus gelangt, dieselben, in denen der Fornix endet.

Vor den Copora mamillaria wölbt sich der Boden des mittleren Tentrikels, welcher hier als Tuber cinereum bezeichnet wird, nacls unten 
ror, so dass ein Trichter entsteht, dessen Lumen nur die Fortsetzung des Tentrikels ist. Unten am spitzen Ende dieses Trichters, des Infundibulum, hängt die Hypophysis, s. Fig. 162.

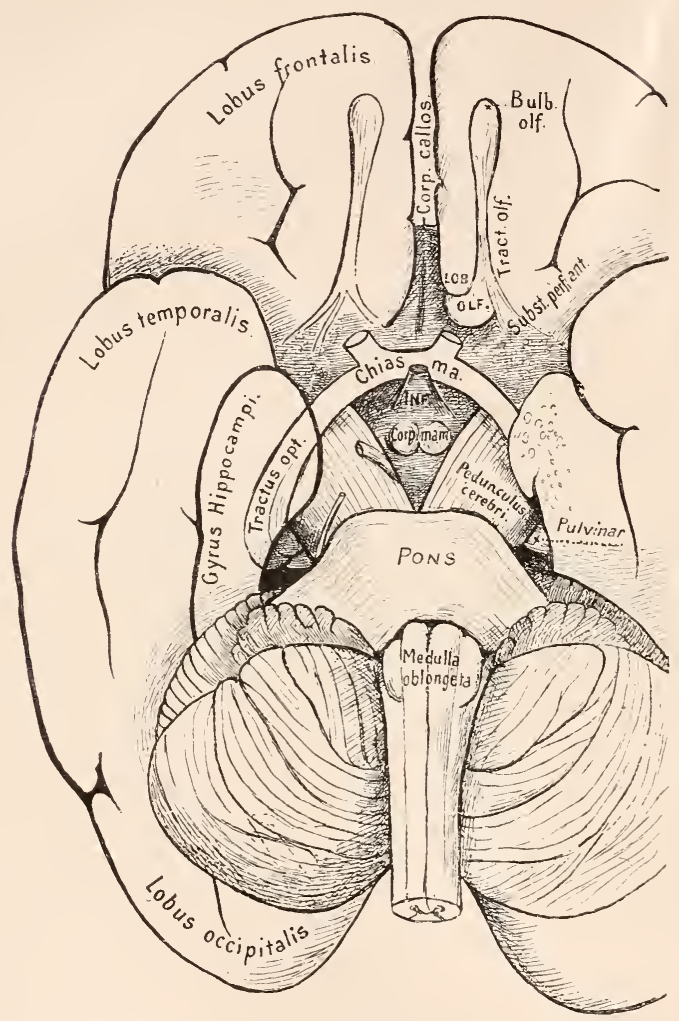

Fig. 180.

Die Basis des Gehimes; der linke Lobus temporalis z. Th. durchsichtig gedacht, um den ganzen Verlauf des Tractus opticus erkennen zu lassen.

Die Hypophysis, ein etwa kirschgrosser Anlang der Hirnbasis, besteht zunächst aus der Fortsetzung des Ventrikelbodens, Lobus infundibuli, Lobus posterior, welche nicht sicher nervöser Natur ist. Vor diesem liegt der Vorderlappen, ein aus Epithelschläuchen gebildeter Knäuel, welcher fest mit dem Lobus infundibuli verwachsen ist und, wie sie wissen, aus der Rachenschleimhaut stammt. Neuere Untersuchungen (Flescli, Dostojewsky) liessen in ihm zweierlei Zellen, kleinere lıelle und grössere körnig trübe, erkennen. Da bekanntlich ganz ähnliche Elemente in melıren sehr activen Drüsen vorkommen, so wird es wahrscheinlich, dass auch die Hypophysis noch irgend eine physiologische Function erfiillt. Eben darauf weist auch die in mehreren 
Die Basis des Gehimes. Der Sehnerv und sein Ursprung. Die Vierhiigel.

Fällen von Myxödem bisher nachgewiesene Grössenzunahme des epithelialen Theiles hin. Zwischen dem pharyngealen und dem cerebralen Hypophysislappen findet man noch eine Anzahl weiterer epithelbedeckter Schläuche, deren Hohlraum, soweit ich bisher sehen kann, weder mit dem einen, noch anderen Hypophysistheil zusammenhängt. Der beistehende Sagittalschnitt durch die Hypophysis einer 4 Monate alten menschlichen Frucht zeigt sehr deutlich alle 3 Hypophysistheile.

In weitem Bogen um das Infundibulum und über die Hirnschenkel weg ziehen in der Richtung nach dem Pulvinar des Thalamus die Tractus optici. Beiderseits, durch den Lobus temporalis verdeckt, krïmmen sie sich um den Ursprung der Hirnschenkel nach oben aussen zum Corpus geniculatum laterale und dem Pulvinar hinauf.

Vorn vor dem Infundibulum vereinigen sie sich $\mathrm{zu}$ dem Chiasma, aus dem nach Kreuzung eines Theiles ihrer Bündel die Nervi optici herrorgehen.

Vor den Tractus, nach aussen vom Chiasma, liegt dicht unter

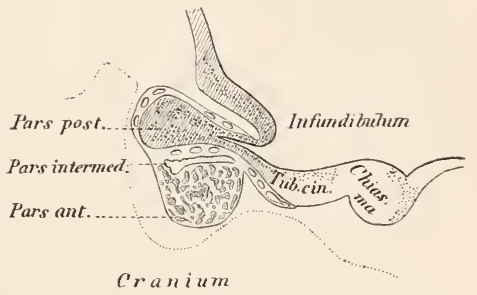

Fig. 181.

Sagittalschnitt durch den Hirnboden und die Hypophysis vom viermonatlichon menschlichen Embryo Combinirt aus drei auf einander folgenden Schnitten. dem vorderen Theil des Corpus striatum diesubstantia perforata anterior, eine graue, von zahlreichen Piagefässen durchbrochene Masse. Vor ihr beginnt das Gebiet des Lobus olfactorius.

Die Substantia perf. ant. ist nichts anderes als das beim Menschen sehr atrophisch gewordene Riechfeld. Mit dem ganzen Riechapparat ist bei den Primaten auch der Lobus olfactorius atrophirt. Ton ihm hat sich beim Menschen nur der caudalste 'Theil noch, Fig. 172 u. 173, mit Rindenstructur erhalten, der vordere ist zu einem unscheinbaren grauten Strang, dem Tractus olfactorius, geschwunden, dem vorn der kleine Bulbus olf. aufsitzt. Aus dem Bulbus entspringen aber, gerade wie bei den Thieren, noch immer die mächtigen Faserzüge der Riechstrahlung. Indem sie rïckwärts zur Rinde des Lobulus olfactorius und der Gegend der Ammonswindung ziehen, müssen sie über den Tractus hinweg, dem sie an der Tnterfläche eine weisse Farbe verleihen. Am Riechfeld - lier also Substantia perforata ant. - angelangt, spalten sich aber, ganz wie bei den osmatischen Thieren, die hier allerdings wesentlich dïnneren Züge auf und ziehen als weisse stränge — frïher Olfactoriuswurzeln genannt über die graue Substanz weg. Man kann gewöhnlich einen lateralen Zug, oft in zwei gespalten, ron einem medialen trennen. Der erstere senkt sich nahe am Gyrus hippocampi allmählich in die Tiefe. Zuweilen sieht man ein dïnnes helles Querbaud über die Substantia perf. ant. hinweg von aussen nach imnen oben ziehen. Es ist nichts anderes als der atrophische Rest des Riechbündels zum Ammonshorn, das bei den osmatischen Thieren 
hier so schön zu sehen ist. Wollen Sie, ehe Sie die Betrachtung der Hirnbasis aufgeben, noch einmal die Figur 144 aufschlagen, weil hier am osmatischen Gehirne so viele Verhältnisse klarer und kräftiger sich ausgebildet zeigen. Namentlich der Riechapparat wird Ihnen dann klarer werden.

Am medialen Rande der Substantia perf. ant. senkt sich die Balkenfaserung bis an die Hirnbasis hermnter. Die Erhebung, die sie hier an der Imnenrinde der Hemisphäre bis nahe an die Basis macht, wird als Gyrus subcallosus bezeichnet. Zwischen beiden Gyri subcallosi liegt eine graue Platte, die nach oben bis an das Balkenknie verfolgt werden kann. Es ist die Lamina terminalis. In ihr müssen wir noch einen Rest der embryonalen Schlussplatte erkemnen, jener Wand, welche einst das primäre Vorderhirn abschloss, derselben, aus der die jetzt so mächtigen Hemisphären sich vorgewölbt haben. Jetzt ist sie nur noch eine kleine graue, wenig gewïrdigte Stelle, die am vordersten Punkte der Grosshirnbasis liegt. Fig. 133.

Wenn eine Affection lediglich die Hirnbasis vor dem Pons betrifft, werden die Symptome, welche durch Reizung oder Lähmung der dort liegenden Nerven erzeugt werden, die zur Diagnose weitaus wichtigsten sein. Dazu können sich noch, wenn die Hirnschenkel mit betroffen werden, Motilitätsund Sensibilitätsstörungen in den Extremitäten einstellen; eine genaue Analyse der Symptome an Hand einer Abbildung der Hirnbasis führt oft zu recht scharfer Localdiagnose.

Die Tractus optici krümmen sich um die Hirnschenkel herum und verschwinden weiter dorsal in der Gegend der Corpora qu adrigemina, besonders in einem kleinen, jenen seitlich anliegenden Ganglion. dem Corpus geniculatum laterale. Tollen Sie den wirklichen Endpunkt der Sehnerven nun näher kennen lernen, so müssen Sie zunächst diesen eben erwähnten Theilen des Mittelhirnes Ihre Aufmerksamkeit schenken.

Die folgende Abbildung zeigt die Vierhügel von oben gesehen. Sie liegen auf den Hirnschenkeln etwas zwischen die Thalami hineingeschoben. Hinter ihnen kommt jederseits ein starker Faserzug aus der Tiefe, der sich in das Kleinhirn einsenkt. Es ist der Bindearm oder vordere Kleinhirnschenkel. Er entspringt aus dem Nucleus ruber tegmenti, welcher unter dem Thalamus und den Vierhügeln in der Haube liegt.

Ian unterscheidet die vorderen von den hinteren Vierhïgeln; doch nur bei vielen Säugern ist die Unterscheidung dem blossen Auge leicht, bei allen anderen Vertebraten sind die vorderen so mächtig, dass die hinteren als kleines Ganglion in der Tiefe unter ihmen verschwinden. Aus den vorderen Vierhügeln entspringt ein Theil der Sehnerven. Sie erhalten, wie der Thalamus, Fasern aus dem Gebiet des Hinterhauptlappens, welche in der Selistrahlung zur inneren Kapsel verlaufen und von da als vorderer Vierhügelarm zu ihnen aufsteigen. In eben diesem Arm rerlaufen nach abwärts Fasern zum Tractus selbst. 
Die Basis des frehirnes. Der Sehnerv und sein Ursprung. Die Vierhügel. 267

Der vordere Vierliügelarm, welcher also aus Fasern von der Rinde und aus solchen zum Tractus zusammengesetzt ist, tritt nur mit den Gehirnfasern in den Vierhügel ein, seine Sehnervenfasern überziehen dessen grane Oberfläche als Stratum zonale und senken sich dort in die Tiefe.

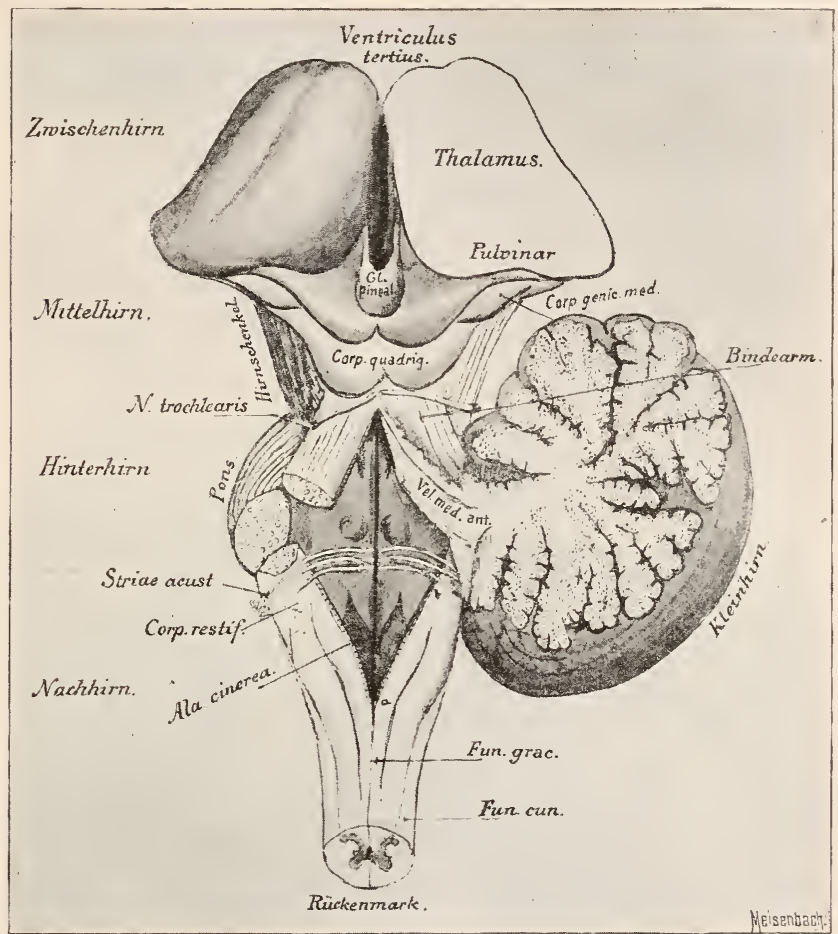

Fig. 152.

Die Gehirntheile vom Thalamus bis zum Rückenmark (der "Hirnstamm"). Das Cerebellum gespalten und links abgetragen.

Der hintere Vierhügel scheint zwar anch zunächst mit dem Tractus opticus in Verbindung zu stehen, es ist aber sehr unwahrscheinlich, dass er Fasern enthält, die beim Sehacte benutzt werden. Sein Arm stammt aus dem Corpus geniculatum mediale und aus der bisher noch nicht erwähnten Commissura inferior (Gudden'sche Commissur), welche mit dem Tractus opticus zum hinteren Winkel des Chiasma gelangt.

Seinen Stabkranz erhält er (Monakow) aus dem Lobus temporalis. Die ausserordentliche Entwicklung des hinteren Hügels bei Walthieren und die mächtigen Züge, welche bei diesen Thieren von dort zum gekreuzten Acusticus- 
kern ziehen, machen es wahrscheinlieh (Spitzka), dass dies Ganglion in irgend einer Beziehung zum Hörnerven steht. Die Resultate darauf gerichteter experimenteller Untersuchungen stehen damit in Einklang. Es atrophirt nach Zerstörung der Hörnervenkerne deren secundäre Faserung bis zu den hinteren Hügeln (Baginsky, Bumm).

Ton der Seite her ist die Lage der Vierhügelarme zu den Ganglien und zum Tractus opticus ganz deutlich, ebenso die Lage der Corpora geniculata, des C. g. mediale, das dem hinteren Arm eng anliegt, und C. g. laterale, welches zwischen Pulvinar und Tractus opticus eingeschaltet zu sein scheint, und dessen schon bei Besprechung des Thalamus gedacht wurde.

Aus dem letzteren Ganglion bekommt der Tractus opticus Fasern, ausserdem solche aus dem Pulvinar thalami und von dessen Stratum zonale.

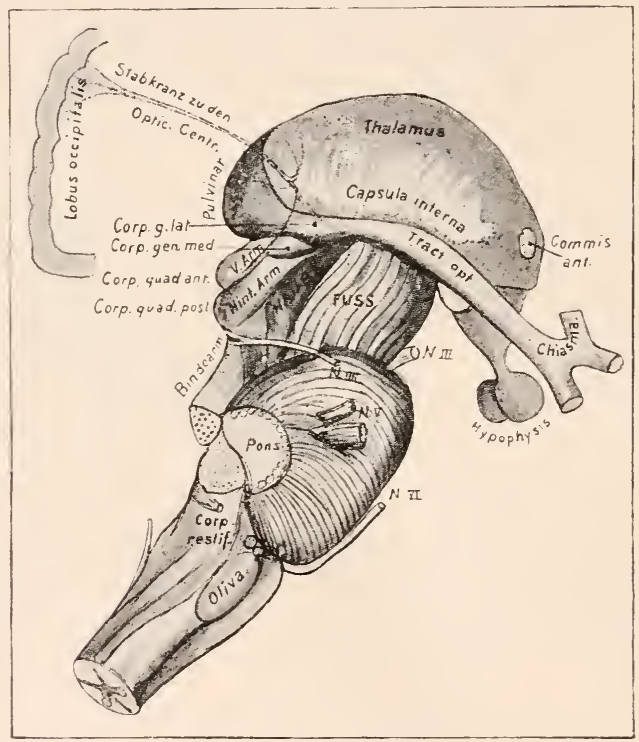

Fig. 153.

Thalamus und Corpora quadrigemina von der Seito gesehen. Das Vorderhirn da abgetrennt, wo seine Stabkranzfasern in die Capsula interna treten. Schematisch ist das Verhalten dor Sehstrahlung zam hinteren Theile der Kapsel und za den Ursprungsstellen des Opticus angedeutet.

Die Opticusfasern aus den vorderen Tierhïgeln wurden vorhin erwähnt. Sie verlaufen wohl zum grössten Theil im Arm des vorderen Hügels.

Bei den niederen Wirbelthieren entspringt der Sehnerv zum grössten Theile aus den vorderen Vierhiigeln, die anderen Ursprungsorte treten dagegen sehr zurück. Je mehr sich aber die occipitale Hirnrinde ausbildet, welche ihre 
Faserung wesentlich in die anderen Endstätten sendet und den Vierhügel nur mit einem relativ geringen Zuzug versieht, um so mehr Sehnervenfasern entspringen aus jenen und um so weniger aus den Vierhïgeln. Das geht noch in der Säugethierreihe so fort. Der noch beim Kaninchen sehr mächtige Antheil des Opticus aus dem vorderen Hügel ist beim Mensclien ganz bedeutend atrophirt. Umgekehrt stammt bei dem Menschen die Hauptmasse des Sehnerven aus dem Corpus geniculatum laterale.

Man kamn das so ausdrücken: Thiere, die auf das Selien mit den primären Endstätten allein oder fast allein angewiesen sind, haben vorwiegende Ausbildung des Vierhiigelastes des Sehnerven. Sobald aber das Rindensehen sich mehr entwickelt, treten die zur Rinde in engerer Beziehung stehenden Endstätten - Pulvinar, Corpus geniculatum laterale — in den Vordergrund, und verringert sieh relativ die Vierhügelportion des Opticus.

So stellt sich der Sehnervenursprung am Präparat vom erwachsenen Menschen dar. Nach J. Stilling kommt dazu noch eine im Hirnschenkelfusse aus der Oblongata aufsteigende Wurzel. Es sind nun aber alle diese Fasern und Kerne beim Menschen so schwierig richtig zu deuten, dass wir uns fragen mïssen, wie weit die betreffenden Befunde durch Untersuchungen an anderen Objecten gestïtzt werden. Zunächst bietet die vergleichende Anatomie in dem Mittelhirne der Fische und Vögel Opticuscentren von solcher Mächtigkeit, dass dort die Verhältnisse viel leichter als bei Sängern studirt werden können. Bei diesen Thieren, aber auch bei den Reptilien und Amphibien, erkennt man leicht, dass der Sehnerv in seiner Hauptmasse sicher in dem vorderen Vierhügel endet, und dass er auf seinem Laufe über das Corpus geniculatum laterale hinweg zahlreiche Collateralen in dieses schickt. Experimentelle Untersuchungen ( $\mathrm{G}$ u d d en, Ganser, Monakow) an Säugern ergeben, dass nach früher Ausrottung eines Auges der vordere Vierhïgel, gewisse Schichten des Corpus geniculátum laterale und Fasern aus dem Pulvinar entarten. Das Pulvinar ist übrigens bei den meisten Säugern sehr klein und erreicht erst bei den Primaten einige Grösse.

Schon aus dem Vorstehenden erhellt, dass mannigfache Untersuchungsmethoden angewendet worden sind, um den Verlauf und das Ende der Sehnervenfaserung zu ermittelı. Ich habe Ihnen das absichtlich etwas genauer mitgetheilt, weil die Geschichte unserer Kenntnisse hier lehrt, wieviel durch Anwendung vieler Methoden auf ein Object $\mathrm{zu}$ gewinnen ist, dann aber auch, weil ich noch über neue Fortschritte zu berichten habe, die, der zielbewussten Anwendung der Degenerationsmethode entstammend nnd durch die Ergebnisse der Entwicklungsgeschichte gestiitzt, über die Zusammensetzung und die histologische Endigungsweise des Opticus sehr Wichtiges lehren.

Sie wissen, dass nur solche Fasern entarten, welche von ihrer Ursprungszelle getrennt sind. Je nachdem man den Sehnerv an seinem Augenende zerstört oder in seinen Endpunkten schädigt, erhält man ganz verschiedene Degenerationsbilder. Das Studium soleher variirter Präparate hat nun Monakow zu dem Schlusse gelangen lassen, dass die Mehrzahl der Sehnervenfasern gar nicht aus Zellen des Gehirnes, sondern aus den grossen Ganglienzellen der Retina stammen muss. Die dort entspringenden Axencylinder ziehen im Opticus rückwärts und enden beim Menschen zumeist im Corpus geniculatum laterale und im Pulvinar, wahrscheinlich in pinselförmiger Aufsplitterung um die dort gelegenen Zellen herum. Die weissen Linien, welche das Grau des äusseren Kniehöckers durchziehen, bestehen zum Theile aus solchen Fasern, die direct aus der Retina kommen. In der That haben P. und S. Ramon y Cajal bei Wirbelthieren aller Klassen im Mittelhirndache und 
im Corpus geniculatum laterale solche pinselförmig um Zellen herum endende Opticusfasern nachweisen können. S. auch Fig. 66 u. $\delta 1$.

Es giebt aber im Opticus auch Fasern, die aus dem Gehirne entspringen. Aus den Zellen, welche in der oberfächlichen grauen Schicht des vorderen Vierhügels liegen, entspringen beim Kaninchen und der Katze sicher, beim Menschen sehr wahrscheinlich Opticusfasern, die sich dann nach der Retina begeben und dort, wahrscheinlich in einer Aufzweigung um die Zellen der Köruerschicht herum enden. Der Sehnerv enthält also Fasern, die aus der Retina, und solche, die aus den primären optischen Centren stammen. Entwicklungsgeschichtliche Studien von $\mathrm{Ke}$ ibel und $\mathrm{His}$ haben gelehrt, dass ein Theil der Opticusfasern aus den grossen Zellen der Retina hirnwärts auswächst.

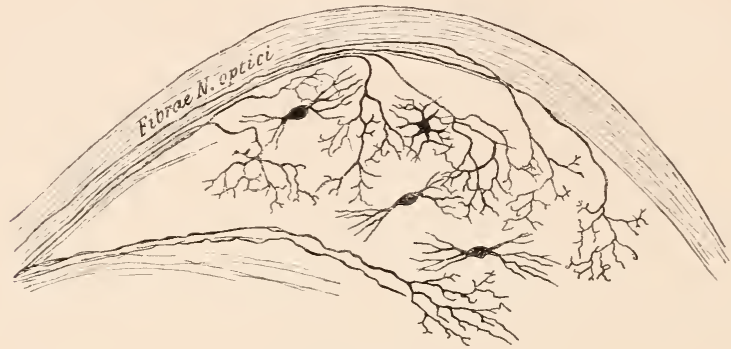

Fig. 184.

Schnitt durch das Corpus genic. lat. der Katze. Versilberung. Einstrahlen der Opticusfasern und Auflöson derselben in Pinsel. Nach P. Ramon y Cajal.

Während die behaupteten Opticuswurzeln aus dem Corpus subthalamicum und aus dem Hirnschenkel einstweilen noch nicht so wie nöthig durch verschiedene Untersuchungsmethoden bestätigt sind, können wir heute als gesichert wohl ansehen, dass Sehnervenfasern entspringen und enden: im Corpus geniculatum laterale, im oberflächlichen Marke des vorderen Vierhügels und in den äussersten Schichten des Pulvinar. Diese letztgenannten grauen Massen bezeichnet man als primäre Opticuscentren.

Für diese Centren ist in befriedigend sicherer Treise ein Zusammenhang mit der Rinde des Occipitallappens nachgewiesen. Die betreffenden Fasern bilden die Radiatio thalamo-occipitalis, Sehstrahlung, Gratiolet's Bündel, einen nicht unbeträchtlichen Faserzug, der sich aus den primären Centren in gesonderten Bündeln entwickelt und von da rückwärts zieht, um sich in der Rinde des Cuneus und der Gegend etwa der zweiten und dritten Occipitalwindung zu verlieren.

In ihrem Ursprungsgebiet, der Rinde, und auf dem nächsten Verlaufe ron da weg lassen sich die Stabkranzfasern zu den einzelnen optischen Endstätten nur schwer von einander sondern. Weiter frontal aber erkennt man, dass die Fasern zum Pulvinar den dorsalen, die zum 
Geniculatum laterale den ventralen Abschnitt eimnehmen. Erst im caudalsten Abschnitte der inneren Kapsel dicht vor dem Eintritte in die primären Centren - Fig. 165 - sind die einzelnen Theile der Sehstrahlnng scharf ron einander gesondert. Der stiel zum Corpus geniculatum laterale liegt diesem als laterales Narkfeld dicht an. Es stammt aus dem Cuneus, vielleicht auch noch aus dem Lobus lingualis. Dorsal von ihm treten die aus den beiden Occipitalwindungen stammenden Fasern der Sehstrahlung in das Pulvinar. Ihnen sind weiter dorsal Züge angelagert, welche sich in der Gitterschicht des Thalamus verlieren.

Auf einem Frontalschnitte, der durch den vordersten Theil der Vierhiigel geht, sind diese Verhältnisse der centralen Sehbahn wohl zu erkeunen.

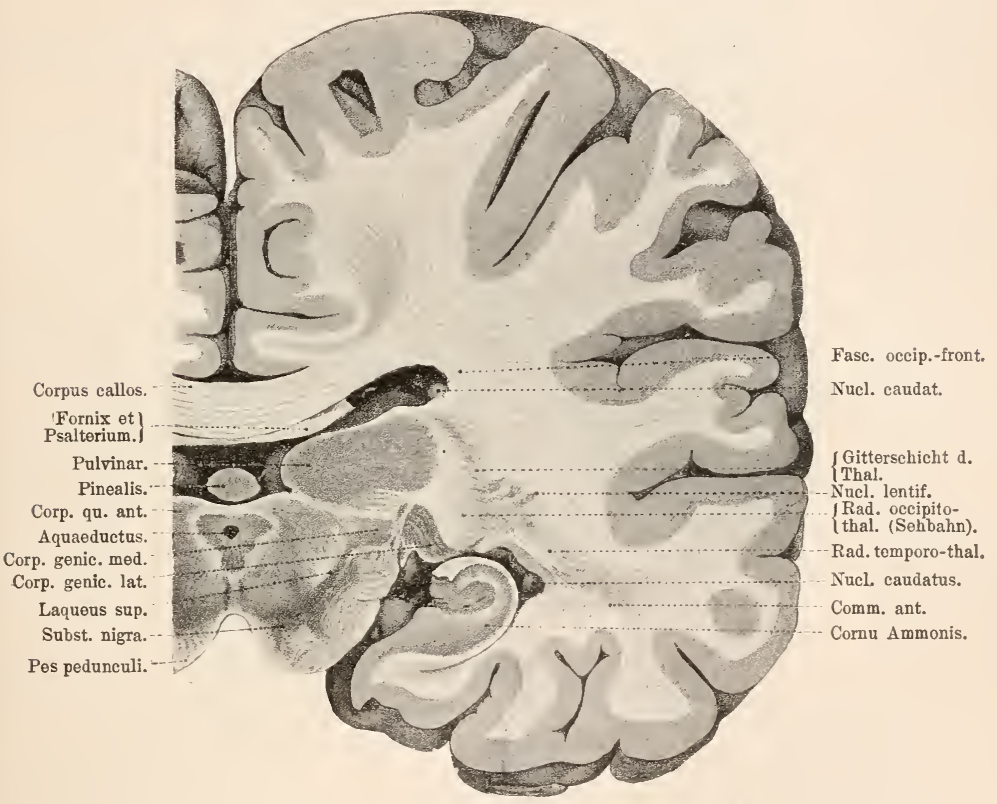

Fig. 185.

Frontalschnitt durch das Vorder- und Zwischenhirn nahe an der Stelle, wo Fasern der Capsula interna zum Fusse des Hirnschenkels werden.

Da ich Ihnen noch keinen Schnitt aus dem Mittelhirngebiete vorgelegt habe, so bedarf Figur $185 \mathrm{zum}$ Anschluss an die friiher demonstrirten Hirnabschnitte vom Menschen noch einiger Worte der Erklärung.

Der weiter vorn nur vom Epithel des Plexus dorsal abgeschlossene Ventrikel hat sich nämlich hier im Bereiche des Mesencephalon zum Aquäductus Sylvii verengert. Ueber diesem liegen als Dach die vorderen Vierhiigel. Da diese, wie Figur 125 Ihnen zeigte, etwas frontalwärts zwischen die hinteren Thalamusenden hineinragen, so sind denn auch beiderseits von den Vierhügeln die caudalsten 
Thalamusganglien, diejenigen des Pnlvinar angeschnitten. Dieser Thalamusabschnitt erreicht gerade hier seine grösste Ausdehnung. Unter ihm hegegnen Sie, wie schon ein Blick auf Figur 1 \$ 3 ergiebt, dem Corpus geniculatum laterale und dem Corpus geniculatum mediale.

Das Geniculatum mediale liegt in der directen Verlängerung des Nucleus ventralis thalami. Es hat die Schleifenfaserung medialwärts, zu der sich in diesen Ebenen schon Fasern aus dem Mittelhirndache gesellen.

Im ventralen Gebiete des Geniculatum laterale erschöpft sich der Tractus opticus fast ganz, einzelne Bündel, die uiber das Genic. mediale weg zum Stratum zonale der Vierhiigel ziehen, abgerechuet.

Fissura centr. Gyrus centr. post. Gyr. centralis ant.

Gyrus cinguli.

Tapetum.

Fasciola cinerea.

Splenium. c. callos.

Pulvinar.

Epiphysis.

C. genic. mediale.

Aquaeductus.

C. genicul. Iat.

Haube.

Fuss d. Hirn- \{ schenkels.

Gyrus lingualis.

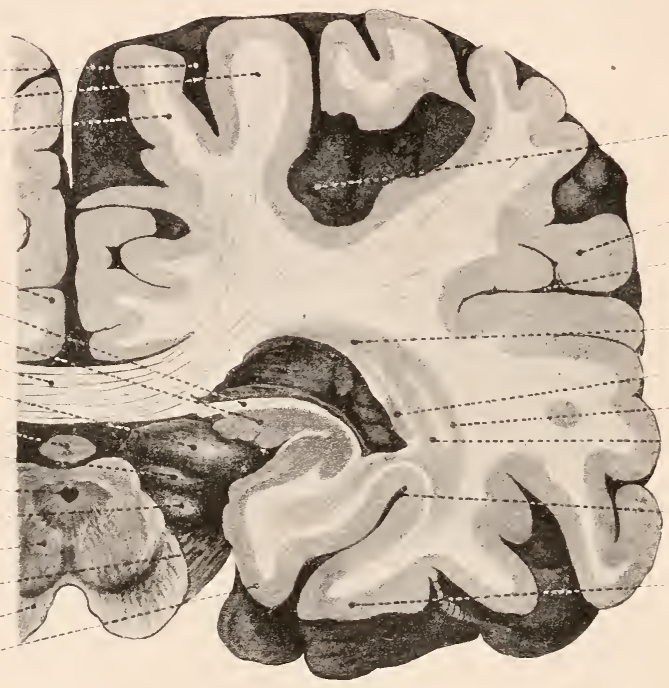

Fiss. interparietal.

Lobus pariet. inf.

Fiss. Sylvii.

Tr. occipitofrontalis.

Nucl. caudat.

Fasc. longitud. inf

IRad. occipitothalam.

Fiss. collateralis.

Gyrus fusiformis.

Fig. 186.

Hirnschenkelfuss und Haube sind nun voll entwickelt. Sie sollen erst in der nächsten Vorlesung genauer geschildert werden.

Alle 3 Kerne erhalten in dieser Ebene ihren Zuwachs aus dem Stabkranze. Die Sehstrahlung, Radiatio oceipito-thalam., und die Bahn aus dem Schläfenlappen zum Genic. mediale, die schon auf der vorigen Abtheilung als Stiel desselben bezeichnet war, sind nun deutlich sichtbar.

Das Markweiss enthält in seinem dorsalen Gebiete rorwiegend Balken- und kurze Associationsfaserung. Von langen Bahnen kann etwa der F. arcuatus hierher verfolgt werden. In seiner ventralen Hälfte besteht das Weiss vorwiegend aus der Faserung, welche dem Occipitallappen entstammt und entweder Eigenfaserung dieses oder Stabkranzfaserung zum Thalamus und lateralen Fussbündel ist. Ziemlich an der Grenze des dritten und vierten Viertels der Höhe liegt die Radiatio occipito-temporalis, oder Fasc. longit. inferior.

Die Fornixschenkel sind nun nicht mehr da, es liegt unter den Balken vielmehr die breite Platte des Psalteriums, an deren Rändern die Fimbriae liegen. 
ein atrophischer, liegt auch beim Menschen noch direct unter dem Balken. Er wird als Fasciola cinerea bezeichnet. Das Ammonshorn ist hier an seiner caudalsten Stelle, dicht vor dem Hinterhauptlappen getrofien. Der Ventrikel öfinet sich einerseits caudalwärts in das Hinterhorn andererseits ventralwärts in das Unterhorn. Deshalb erscheint er so lang und breit. Nach aussen von der Sehstrahlung liegt das Längsbündel aus dem Occipitallappen in den Schläfenlappen. Im dorsalsten Gebiete gehört das Nark noch der Strahlung aus dem obersten Stiicke der beiden Centralwindungen an, dann folgt weiter nach aussen das Gebiet der Scheitellappen und darauf das Mark des Gyrus angularis und der Schläfenwindungen.

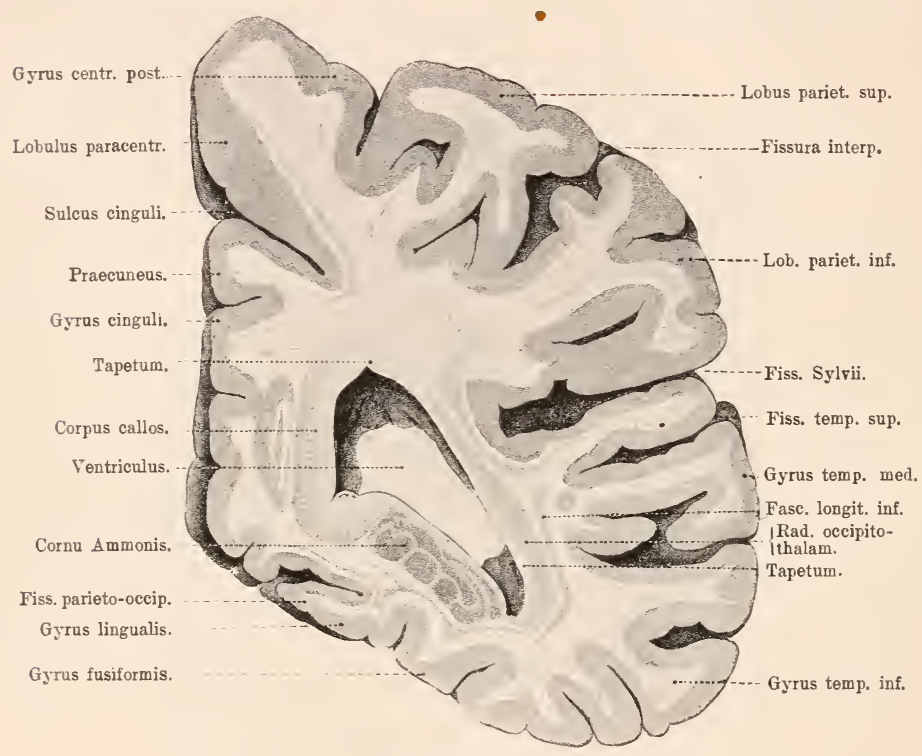

Fig. 188.

Der in Fig 18S abgebildete Schnitt liegt direct an der Basis des keilförmigen Hinterhauptlappens, also hinter dem Balkenende. Der breit eröffinete, von dem Tapetum überzogene Ventrikel führt an seinem dorsalen Ende in das Hinterhorn, an seinem ventralen aber, wo man medial die Ammonswindung noch angeschnitten findet, in das Unterhorn des Schläfenlappens. Dorsal vom Ammonshorn fällt die breite Masse der Balkenfasern auf, welche sich von den Endstätten im Occipitallappen, zum Balkenwulste begeben und hier, dicht vor dem Eintritte in das Splenium, abgeschnitten sind.

Der Radiatio occipito-thalamica begegnen wir nun, in grösserer Breite als bisher, nach aussen vom Tapetum. Sie liegt hier unter den Windungen des Schläfenlappens und diese Lage erklärt, dass manchmal Herde im Gyrus marginalis oder angularis zu Hemianopsie führen. Sie werden, wemn sie nicht gar zu oberflächlich sind, immer die Sehstrahlung treffen miissen. 
Die Basis des Gehirnes. Der Sehnerv und sein Ursprung. Die Vierhügel. 275 .

Auch der Fasciculus longitudinalis inferior, der Tractus aus dem Hinterhauptlappen zum Schläfenlappen, dessen Querschnitt Sie nach aussen von der Sehstrahlung wieder, wie auf den früheren Schnitten, finden, ist hier breiter als vorlıer, weil wir uns seinem Ursprungsgebiete nun nähern. Die eigenthïmlich abgeschrägte Form des Schnittes an der Unterseite erklärt sich daraus, dass hier die Kleinhiruhemisphären sich, nur durch das Tentorium getrennt, an das Cerebrum anlegen.

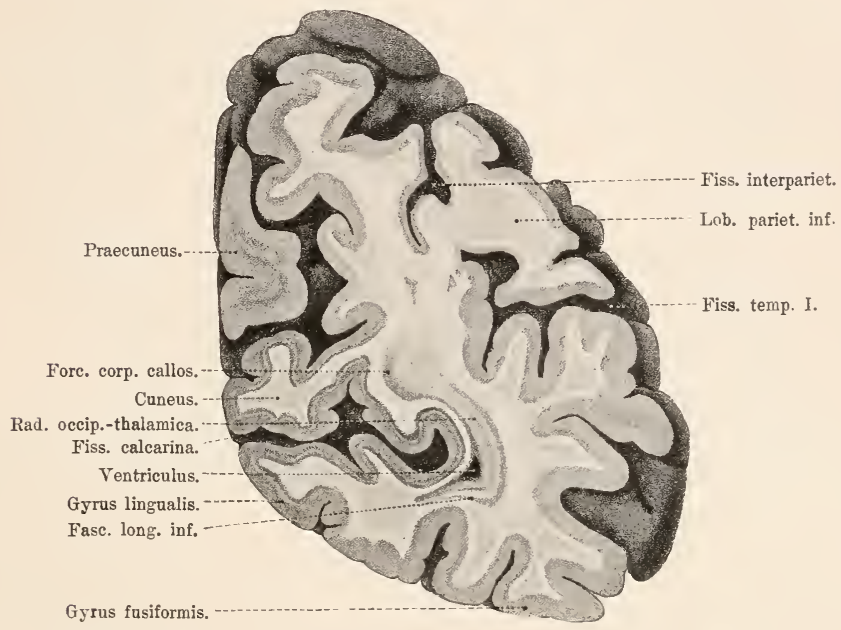

Fig. 189.

Nun sehen Sie sich zuletzt noch einen Schnitt, Fig. 189, an, welchen ich ganz nahe am caudalen Hirnpole durch den Occipitallappen gelegt habe. Das Hinterhorn des Ventrikels, das eben als kleiner Spalt noch sichtbar ist, mag Sie iiber die Lage der Gesammtfaserung wieder orientiren.

Aus der Umgebung der hier tief einsclineidenden Fissura calcarina entspringt die Sehfaserung, die wir nun von ihrem Ursprunge bis zu ihrem Ende im Thalamusgebiete und in den Vierhügeln verfolgt haben. Die letzten Ausstrahlungen der occipitalen Balkenfaserung, des Forceps, trennen sie wieder vom Ventrikelgrau. Der Fasciculns occipito-temporalis oder longitudinalis inferior liegt nun nicht melır lateral, sondern ventral von ihr.

Der grösste Theil des iibrigen auf dem Schnitte sichtbaren Markweisses gehört der Eigenfaserung des Occipitallappens, den kurzen Balnen an, welche seine einzelnen Rindengebiete unter siclı verknüpfen.

Es ist nicht unwahrscheinlich, dass auch in der Sehstrahlung Fasern zweierlei Herkunft vorhanden sind, solche aus Zellen der primären Centren zur Rinde und solche aus Rindenzellen zu diesen Centren.

Bei zerstörenden Krankheitsherden im Hinterhauptlappen und im hintersten Theil der immeren Kapsel treten ganz ähnliche Sehstörungen auf, wie wenn der Sehnerventractus der betreffenden Seite gelitten hätte. 
Es fällt die äussere Netzhauthälfte des gleichseitigen und die imnere des entgegengesetzten Auges aus.

Zum System des Opticus gehört wahrscheinlich auch ein von Gall und Spurzheim entdeckter Faserzug, der von den vorderen Vierhügeln seitlich herabzieht und den Hirnschenkelfuss an der Basis eine Strecke weit quer uiberzieht, ehe er sich in ihn nahe der Mittellinie einsenkt. Er erreicht dann ein Ganglion des ventralen Thalamusgebietes (Kölliker). Dieser Zug - Tractus peduncularis transversus - entartet nach Zerstörung eines Opticus, $(\mathrm{Gudden})$. Er ist nicht immer nachweisbar und in seiner Ausbildung variirend. Auf Fig. 141 sehen Sie ihn (nicht bezeichnet) den rechten Hirnschenkel iiberziehen. Wahrscheinlich ist das Bündel identisch mit dem, was S. 125 als Tractus thalamo - tectalis geschildert wurde.

\section{Neunzehnte Vorlesung.}

\section{Haube und Fuss des Mittelhirnes.}

M. H. Die Frontalschnitte durch das Grosshirn, mit deren Demonstration ich die letzte Torlesung abgeschlossen habe, führten uns etwas ab von der Verfolgung der Faserung. welche im Vittelhirne und weiter caudal dahinzieht.

Wir waren bei ihrer Darstellung allmählich in die Gegend gerathen, wo das caudale Ende des mittleren Ventrikels liegt. Sie sehen in Fig. 125. dass dicht hinter diesem das Mittelhirn, die Corpora quadrigemina. begimnen. Die Thalami weichen dort aus einander, der Haubenwulst schiebt sich zwischen sie ein, und der Ventrikel nimmt dadurch an Tiefe beträchtlich ab.

Wollen Sie an Fig. 190, einem Sagittalschnitt durch das Gehirn, das Auftreten des Mittelhirndaches, der vorstehenden Schilderung folgend. studiren.

Im vordersten Theile dieses Daches (s. auch Fig. 125) liegen die Fasern der Commissura posterior, dicht hinter derselben die Vierhügel. Der verengte Ventrikel, welcher jetzt unter dem Dach einherzieht, hat auf der Strecke, wo er dem Mittelhirn angehört, den Namen Aquaeductus Sylvii erhalten. Der Eingang zum Aquaeductus liegt dicht unter der Commissura posterior. Er ist überall von centralem Höhlengrau umgeben.

Im frontalsten Abschnitte, dicht hinter der Epiphyse liegt also die Commissura posterior. Bei niederen Wirbelthieren ist es leichter als bei Säugern naclizuweisen, dass ein Theil ihrer Fasern aus einem in der Tiefe des Zwischenhirnes beiderseits nahe der Mittellinie liegenden Ganglion entspringt. Aber auch für die Säuger hat Kölliker nenerdings den gleichen Ursprung gefunden. Dann gelangen sie dorsalwärts ziehend 
an die Oberfläche und wenden sich vor den Vierhïgeln zur gekreuzten Seite. Sie ziehen da aber nur eine ganz kurze Strecke horizontal dahin, tanchen vielmehr bald in die Tiefe der Mittelhirnhanbe ein. in der sie dam caudalwärts weiter streichen. Die Mehrzahl der betreffenden Fasern zieht, wie ich bei niederen Wirbelthieren besonders dentlich sehe, lateral

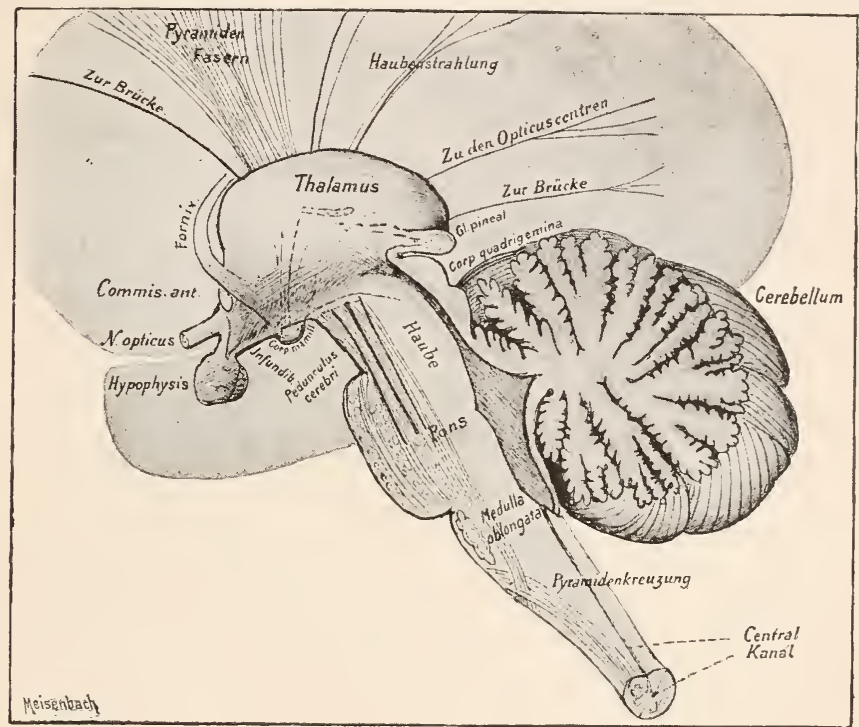

Fig. 190.

Sagittalschnitt durch das Zwischenhirn und die hinter ihm liegenden Gebilde, genau in der Mittellinie. Die Verlaufsrichtung einer Anzahl Stabkranzfasern ist durch Linien angedentet.

und ventral vom hinteren Längsbündel in die Oblongata; erst durch sie wird jenes Bündel, dass wir später kemnen lernen werden, zı einem starken. Aehnliches haben Spitzka und Darkschewitsch bei Säugern gesehen. Bei allen Wirbelthieren ist die hintere Commissur eines der ersten Bündel, die sich mit Mark umgeben.

Wir gelangen in das Bereich des Mittellirnes.

Nun wollen wir uns noch eimmal umsehen, was aus all den Faserzïgen geworden ist, denen wir in den letzten Vorlesungen begegnet sind. Wir finden nur noch wenige in den schnittebenen, die wir jetzt erreicht haben.

Der grösste Theil der Fasern, welche die weisse Markmasse des Hirnmantels bilden, ist nicht melnr in den caudalen Ebenen des Zwischenhirnes vorhanden. Er ist entweder - Associationsbahnen - in der Rinde selbst verschwunden oder - Stabkranz des Thalamus - in den Thala- 
musganglien. Ein Theil des Stabkranzes ist damn unter dem Zwischenhirn rortretend frei an die Hirnbasis gelangt, der Fuss des Hirnschenkels. Auch die Faserung aus dem Stammganglion hat sich fast völlig erschöpft. Nur noch ein Zug zur Substantia nigra Sömmeringi ist nachweisbar.

Aus dem Zwischenhirn sind in die Ebene des zuletzt betrachteten Schnittes ein Theil der Laminae medullares thalami und besonders ein lateraler Zug; die obere Schleife aus dem Thalamus, verfolgbar. Ausserdem noch einige kleinere Bündelchen, die dem Corpus mamillare und dem Ganglion habenulae entstammen.

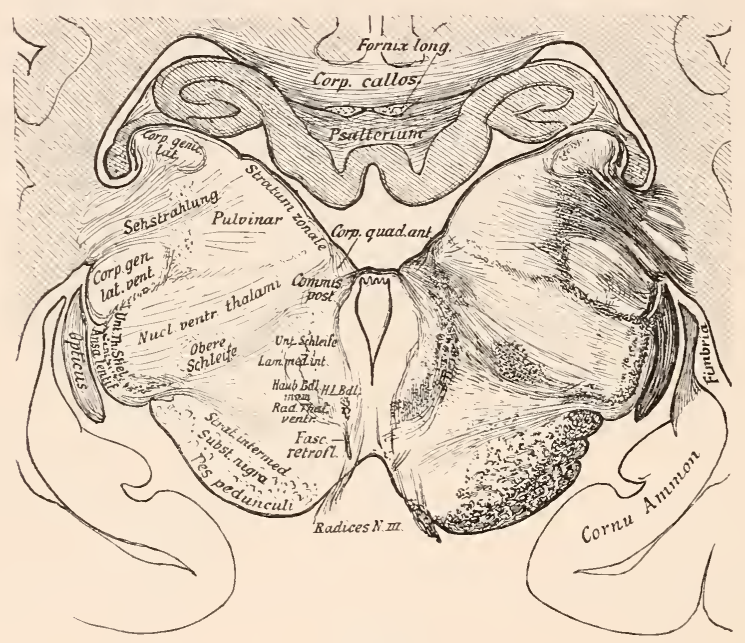

Fig. 191.

Uebergang aus dem Zwischenhirne zum Mittelhirne. (Hund). Schnitt etwa $1 \mathrm{Mm}$. caudal von dem in Fig. 177 abgebildeten. Durchquert die frontalsten Fasern der Commissura post. Stratum zonale-Fasern aus dem vorderen Vierhügel in den Opticus. Pulvinar grösser, Nucleus ventralis thalami. Obere Schleife rückt medialwärts, faserreicher als auf Fig. 177 . Aus dem Ganglion habenulae hat sich der Fasciculus retroflexus abgelöst. Frontalste Fasern der unteren Schleife, aus einem im Texte nicht erwähnten grauen Kern, der direct in das mittlere Mark der Vierhügel übergeht. Frontalste Oculomotoriusfasern. Hinteres Längsbündel, das auf dem vorhergehenden Schnitt mit wenigen Fasern aus seinem Kerne entsprang, nun stärker. Die laterale, mit Sehstrahlung bezeichnete Faserung ist der Stiel des vorderen Hügels und der Stiel des Corpus geniculatum laterale. Der grosse als Nucleus ventralis thalami bezeichnete Kern geht caudal ohne scharfe Grenze in das Corpus geniculatum mediale über. Man beachte auch die Decussation zwischen den Ammonshörnern und die Lage des Fornix longus, - Im Fusse des Hirnschenkels das Stratum intermedium aus der Einstrahlung der Stammganglionfaserung in die Regio subthalamica.

Lassen Sie ms jetzt, wo wir im Allgemeinen etwas über die Vierhügelgegend orientirt sind, einen Schnitt betrachten, der das vordere Vierhïgelpaar durchschneidet, unter ihm durch die Gebilde der Haube geht und schliesslich die Hirnschenkel durchtrennt.

Orientiren wir uns nach dem bereits Bekannten! Beiderseits aussen liegt das Pulvinar thalami. aus dem der Sehnerr zu kommen scheint. 
Das Corpus geniculatum laterale ist in seinen Verlauf wie eingeschaltet. Er bekommt einen namentlich links deutlichen Zuzug aus dem vorderen Vierhügelarme, über dem sie das rom Schnitt getroffene Corpus geuiculatum mediale erkennen.

Unter dem Pulvinar kommt der Hirnschenkelfuss aus der Tiefe.

In seiner Fasermasse sind Bahnen sehr verschiedener Herkunft enthalten. Entwicklungsgeschichtliche Studien, namentlich aber die genaue Verfolgung secundärer Degenerationen, welche von Grosshirnherden veranlasst werden, ermöglichen allein, den Ort zu bestimmen, wo die einzelnen Bahnen liegen. Es liegt bereits eine nicht geringe Anzahl gut beobachteter Fälle von partieller Fussdegeneration vor, so dass sich heute mit einiger

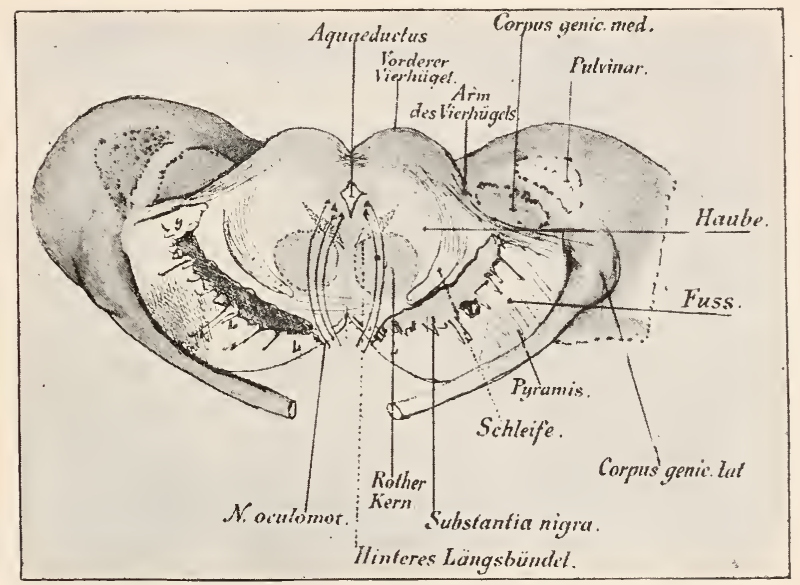

Fig. 192.

Querschnitt durch die vorderen Vierhügel (etwas schematisirt).

Sicherheit eine Eintheilung der Fussfaserung geben lässt. Nach Déjèrine's Untersuchungen, welche wohl das grösste bisher untersuchte Material umfassen, liegen im lateralsten Fünftel des Fusses Fasern, welche aus dem mittleren Theile des Schläfenlappens stammen, und im medialsten solche, die aus der Gegend der Operculum hierher herabziehen. In den mittleren 3 Fünfteln liegen dann die Fasern aus dem caudalen Abschnitte des Stirnlappens und aus der eigentlichen motorischen Zone. Alle diese Züge stammen ganz direct aus Rindenzellen und entarten, wemn sie irgendwo zwischen Rinde und Brücke unterbrochen werden. Im mittleren Drittel des Fusses etwa liegt unter ihnen natürlich auch der Tractus corticospinalis, die Pyramidenbahn, das einzige Bündel, welches von den Fussfasern weiter als bis in die Brücke gelangt.

Dorsal vom Pes pedunculi liegt das Stratum intermedium, die 
Fasern aus dem Corpus striatum, und dann folgt die Substantia nigra, eine Anhäufung von feinen Nervenfäserchen und Ganglienzellen noch ganz unbekannter Bedeutung.

In der $\mathrm{Haube}$ fallen Thnen zunächst die beiden grossen runden rothgrauen Querschnitte auf; sie gehören den rothen Kernen, Nuclei tegmenti, an; das Corpus subthalamicum, welches auf dem Fig. 179 abgebildeten Schnitt neben ihnen lag, ist in dieser Höhe verschwunden.

Der rothe Kern, in den Fasern aus dem Thalamus (und aus der Hirnrinde) gelangen, ist unter den Vierhügeln schon reich an markhaltigen Fasern. Diese ziehen ventral von den hinteren Vierhïgeln nach

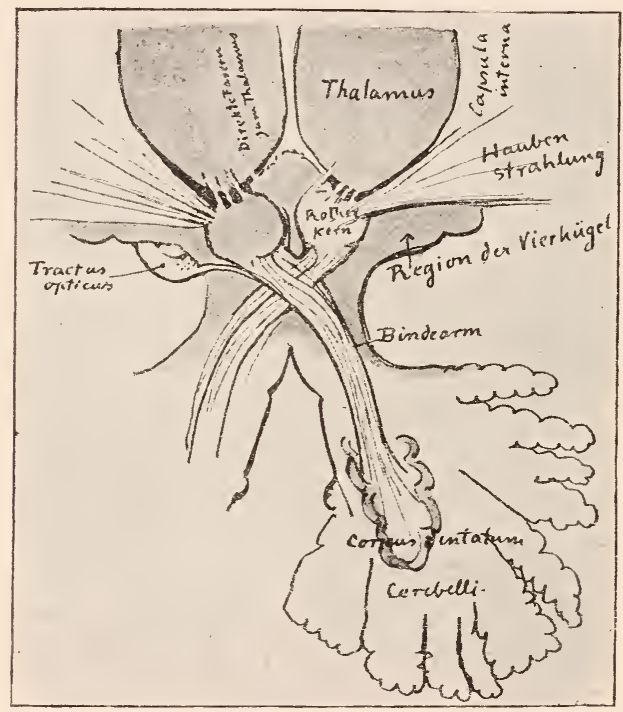

Fig. 193.

Schematisch gehaltener Horizontalschnitt durch die Bindearmkreuzung und ihre Umgebung. Der Zug zum Opticus ist fraglich.

der Nittellinie und kreuzen sich da zum grössten Theile mit denen der anderen Seite. Sie gehören dem Bindearm oder oberen Kleinhirnschenkel an; die Kreuzung heisst Bindearmkreuzung. Auf den Frontalschnitten ist sie sehr deutlich. Noch weiter hinten bilden diese Tractus tegmento-cerebellares bereits dicke, nach aussen vom rothen Kern liegende Bündel, die dann immer weiter lateralwärts rücken und schliesslich an die äussere Oberfläche gelangen. Von da ziehen sie rückwärts zum Kleinhirn. Da der Bindearm nach Kleinhirnverletzungen bis in den Haubenkern hinein entartet. so muss im Cerebellum sein Crsprung, in dem erwähnten Kern sein Ende angenommen werden. (M a ha im u. A.) 
Ein fast horizontal durch den Thalamus, die Vierhügel und das Kleinhirn gelegter Schnitt, der dem Verlauf der Bindearme folgt, würde etwa in der Weise der Fig. 193 die Beziehungen zwischen Thalamus, Nuclens ruber, Haubenstrahlung, Bindearm und Cerebellum erkemnen lassen.

Im Kleinhirn tritt der Bindearm in das corpus dentatum.

Nach anssen rom rothen Kern liegt in Fig. 192 ein dickes Bündel schräg abgeschnittener Fasern. die unter den Vierhügeln hervorzukommen scheinen. Sie ziehen nach abwärts in die Gegend dorsal von der Substantia nigra. Diese Fasern entstammen zum grossen Theil den Vierhügelganglien. Man bezeichnet sie als untere Schleife. Die obere Schleife, aus dem Thalamus, liegt in den Schnittebenen, die wir eben besprechen, etwas nach aussen und unten vom rothen Kern als geschlossenes Bündel von Querschnitten. Lateral von ihr legen sich die Fasern der unteren Schleife ihr an. So entsteht eine breite Schicht von Querschnitten direct über der Substantia nigra, die als Schleifenschicht bezeichnet wird.

Der grösste Theil der Schleifenschicht kann caudalwärts bis in die Kerne der sensiblen Nerven und diejenigen der Hinterstränge verfolgt werden. Meynert hat zuerst nachgewiesen, dass wir in ihr ein Stïck der sensiblen Bahn vor uns haben. Die Entwicklungsgeschichte und die vergleichende Anatomie bestätigen das gleichmässig. Wir werden später den weiteren Verlauf der Schleifen kennen lernen.

Die Schleifenschicht enthält also zwei Elemente, medial die obere und lateral die untere Schleife.

Die untere (besser Mittelhirn-)Schleife ent-

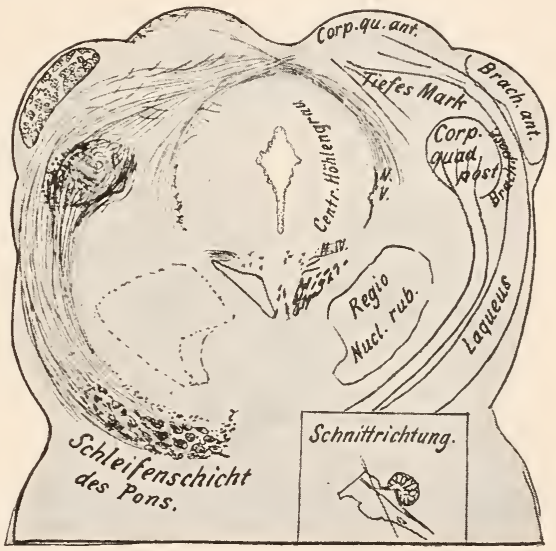

Fig. 194.

Schrăg von rorn oben nach hinten unten abfallender Frontalschnitt (Schnittrichtung in der Nebenfigur angegebon), enthält den grössten Theil des Ursprunges der Mittelhirnschleife. Färbung mit Hämatoxylinlack. Rechts oben lies statt ${ }_{n} \mathrm{Br}$. anticum“ Br. posticum.

stammt zum grössten Theile einem bisher noch nicht erwähnten Fasersystem, dem tiefen Mark des Mittelhirndaches, zum anderen Theile dem Ganglion des hinteren Vierhügels. Auf einem schräg durch beide Vierhügel abfallenden Frontalschnitte, wie ihn Fig. 194 darstellt, ist das deutlich zu erkemnen. Das erwähnte Ganglion besteht aus einem mächtigen rundlichen, von einem feinen Fasernetze erfüllten Kern, es besitzt nur diesen und zeigt deshalb nicht die abwechselnde Schichtung 
von grauer und weisser Substanz, welche den vorderen Hügel, das Opticusganglion, charakterisirt. Es steht mit dem der anderen Seite durch über dem Aquaeductus verlaufende Fasern in Verbindung.

Das tiefe Mark ist ein phylogenetisch sehr altes System. Es fehlt selbst in den einfachst gebauten Gehirnen niederer Wirbelthiere nicht und umgiebt sich bei diesen, wie auch beim Menschen, ausserordentlich frühzeitig mit Markscheiden. Seine Fasern entspringen in Schichten der Mittelhirndecke, die ventral von denjenigen liegen, welche dem Opticus

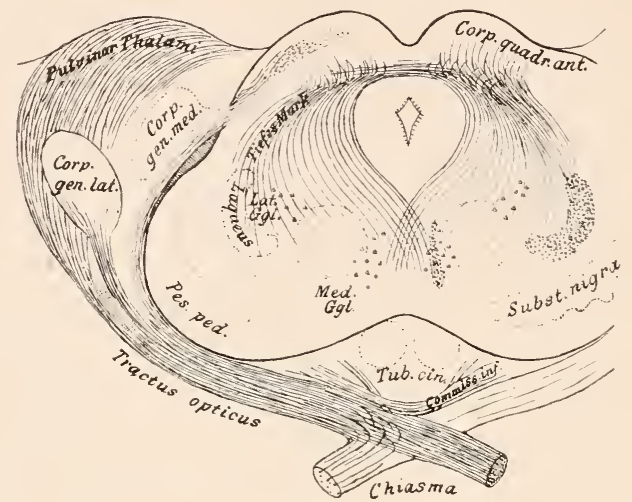

Fig. 195.

Die im Mittelhirndach entspringenden Fasern. Dorsal der Tractus opticas, ventral das tiefe Mark. Schema, das auch die anderen Opticuswurzeln enthält.

Ursprung' geben. Aus diesen ziehen sie zuerst radiär nach innen, wenden sich dann aber nahe dem centralen Höhlengrau, das den Aquaeductus umgiebt, ventralwärts. Die lateralsten dieser Fasern gelangen, vereint mit solchen, welche von der anderen Seite herstammen, in die Schleife. die medialeren aber umgürten den Aquaeductus und kreuzen sich ventral von ihm zum grossen Theil mit denen der anderen Seite: fontaineartige Haubenkreuzung, Forel (Fig. 195, 199). Bei den Fischen und den Vögeln sind gerade die Fasern des tiefen Markes so stark ausgebildet, dass ihr Verlauf leichter zu erkennen ist. Bei ihnen, aber auch bei den Amphibien und Reptilien, erkennt man, dass es sich um ein Fasersystem handelt, das, soweit es nicht in der Schleife abwärts zieht, dem Mittelhirn selbst angehört und in Zellen theils auf dessen gleicher, theils auf dessen gekreuzter Seite endet. An den entsprechenden Stellen finden sich auch beim Menschen Zellgruppen, Ganglion profundum Mesencephali laterale und mediale.

Zerstreute Zellen der Mittelhirnbasis geben wahrscheinlich einem phylogenetisch sehr interessanten Fasersysteme Ursprung. Sie erinnern zich, dass bei Knochenfischen an der Stelle, von der hier die Rede ist, ein mächtiges Ganglion, der 
Torus semicircularis, lag, und dass aus diesem ein starkes Bündel in die Seitenstränge verfolgt werden konnte. Nun ist es neuerdings Boyce gelungen, an halbseitig durchschnittenen Katzengehirnen einen Faserzug aufzufinden, der, in der Mittelhirnbasis beginnend, durch die nach der Operation eingetretene Degeneration mit Leichtigkeit weithin hinab, aus dem Mittelhirne bis in die Vorderund die Seitenstränge des Rückenmarkes verfolgt werden konnte.

Im centralen Höhlengrau unter den Vierhügeln treten die ersten Ganglienzellen auf, welche einem Hirunerven, dem Nervus oculomotorius, Ursprung gebeu. Aus ihrer Vereinigung, dem Nucleus N. oculomotorii, ziehen die Wurzelfasern des Nerven ventralwärts durch die Haube und den Fuss nach der Unterseite des Gehirnes, wo sie zu dicken Bündeln geeint austreten (s. Fig. 1\$3). Der Oculomotorius enthält die Fasern zu mehreren Muskeln in und ausser dem Auge. Es ist dadurch, dass man nucleare Lähmungen einzelner dieser Muskeln kennt, sehr wahrscheinlich geworden, dass der Kern aus einem Complex vou räumlich etwas gesonderten Einzelkeruen besteht. Beim Menschen sieht man in der That eine dentliche Sonderung in mehrere Theile. Ganz voru, z. Th. noch in der Seitenwand des Ventriculus tertius. liegt jederseits ein schmaler, kleinzelliger Keru, der Nucleus a uterior. Er sendet seine spärlichen Fasern etwas caudal gerichtet zum Hauptstamm des Nerven. Hinter ilım liegt, sich fast über die ganze Länge des Aquaeductus erstreckend, der aus grossen multipolaren Ganglienzellen bestehende Nucleus posterior, an dem man eine Anordnung der Zellen zu Gruppen erkeunt. Namentlich deutlich abgrenzbar ist eine dorsaler gelegene Zellansammlung. Während nämlich alle anderen Oculomotoriusfasern auf der Ursprungsseite austreten, ziehen, wie zuerst Gu dden nachgewiesen, die Fasern aus dieser Gruppe nach der Mittellinie, tauchen dort ventralwärts und krenzen sich dabei. Ausser der dorsalen lässt sich noch eine mediale Abtheilung wohl abgrenzen. Sie liegt genan in der Mittellinie und sendet nach rechts und

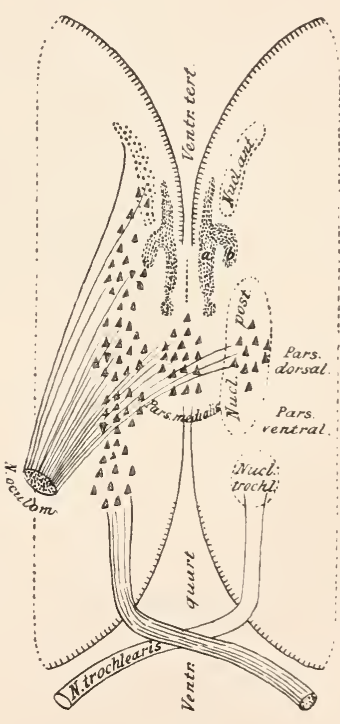

Fig. 196.

Der Boden des Aquaeductus Sylvii. Aufsicht. Die Kerne des Oculomotorius und Trochlearis. Halbschema. nach links Wurzelfaseru aus.

Fig. 196 stellt die Kerne am Boden des Aquaeductes und die Art, wie sie sich mit dem Nerven verbinden, halbschematisch dar. Sie bemerken auf ihr noch jederseits zwei kleinere Kerne $a$ und $b$, die vorn unter sich verbunden sind. Diese zuerst vor mir bei Föten gesehenen, 
dann von Westphal an Erwachsenen genauter untersuchten Keme liegen in einem dichten Netz von Nervenfasern. Es ist noch nicht sicher, ob und in welcher Weise sie mit dem Oculomotorius in Terbindung stehen. Es liegen bereits so verschiedene klinische Erfahrungen und Sectionsbefunde vor, dass man es wagen konnte, die Lage zu bestimmen, welche die einzehnen Augenmuskeln im Kerne einnehmen. Ich theile Ihmen von den mannigfachen dahin zielenden Versuchen, die durch Pick glücklich begommen wurden, den letzten, die Tabelle von Starr mit. Nach dieser liegen von vorn nach hinten die Einzelkerne so:

\section{Sphincter Iridis Musculus ciliaris \\ Levator palp. Rectus int. \\ Rectus sup. Rectus inf. \\ Obliquus inf. \\ 总}

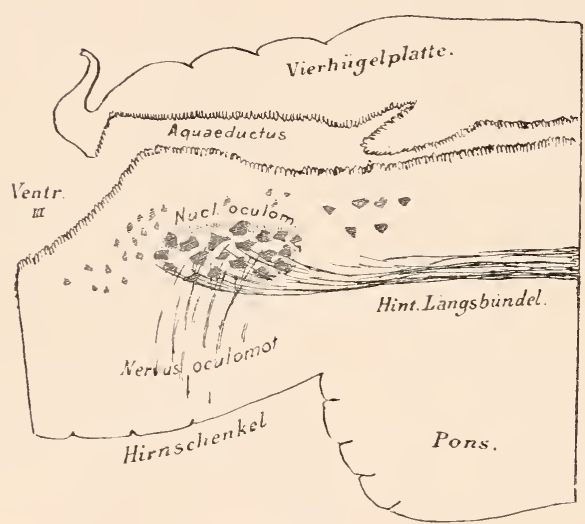

Fig. 197.

Längsschnitt durch die Vierhügelgegend eines menschlichen Fötus von 28 Wochen; nahe der Medianlinie. Die Aussenwand des Aquaeductus zum Theil getroffen. Endigung des Oculomotoriuskernantheiles des hinteren Lăngsbündels.
Die Nerven für die Innenmuskeln des Auges entspringen wahrscheinlich aus dem vorderen Kerne. Die gekreuzte Bahn, vielleicht auch der mediale Theil des hinteren Kermes, wird dem Rectus internus zuzutheilen sein. Die anatomische Grundlage für den ron der Klinik postulirten directen und gekreuzten Zusammenhang des Oculomotorius mit den Centren des Opticus ist noch nicht sicher nachgewiesen. Fasernetze und Züge, durch welche die Verbindung stattfinden

könnte, sind in dieser Gegend mehrfach vorhanden. Das beweisende Experiment oder die beweisende klinische Beobachtung mit nachträglich erhobenem Befunde steht noch aus.

Der Oculomotoriuskern liegt ventral vom Aquaeductus Sylvii, also in dessen Bodentheil. Wir werden in der Folge, wemn wir in der Betrachtung der Haubengegend allmählich abwärts schreiten, den Kernen fast aller übrigen Hirnnerven in dieser Bodenregion begegnen.

Sie haben im Anfang der heutigen Torlesung erfahren, dass aus der hinteren Commissur sich Fasern rückwärts wenden. Medial und ventral von diesen sammeln sich, aus der Tiefe des Zwischenhirnes stammend 
feine Bündelchen, ventral vom vorderen Oculomotoriuskerne. Nach hinten wird das Areal, welches sie einnehmen, immer grösser. Es treten nämlich zu ihnen noch eine Menge Fasern aus dem Kerne des Oculomotorius selbst. Dem fast dreieckigen Querschnitte des so ans rerschiedenen Bestandtheilen sich zusammensetzenden Bündels werden wir ron jetzt ab auf allen Schnitten von den Vierhügeln bis in den Anfangstheil des Rückenmarkes hinab begegnen. Die betreffenden Fasern heissen in ihrer Gesammtheit Fasciculus longitudinalis posterior, hinteres Längsbündel. Da auf der ganzen Länge des Verlaufes dieses Bündels, wie man an Embryonen aus dem 6.-7. Monat, wo nur wenige andere

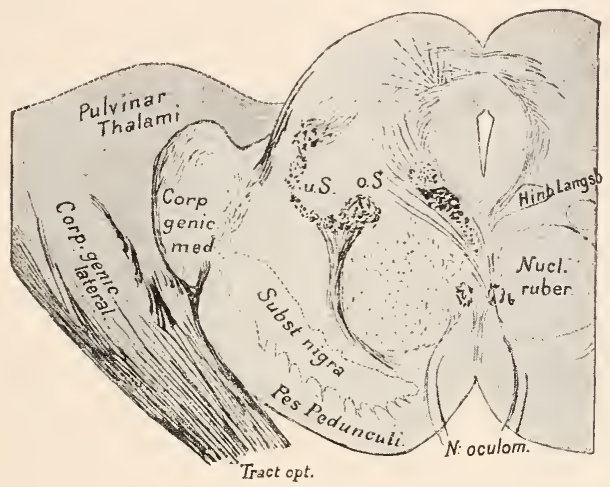

Fig. 198.

Frontalschnitt durch die vorderen Vierhügel einer Frucht aus dem neunten Monate.

Fasern markhaltig sind, gut sieht, Fasern aus ihm zu den Nervenkernen abgehen, da auch sein unteres Ende viel weiter hinab ragt, als der Abducenskern, so ist es wahrscheinlich, dass das hintere Längsbündel ausser den Verbindungen der Augenmuskelnerven unter einander auch noch Züge für andere Hirnnerven enthält.

Das hintere Längsbündel entsendet seine frontalsten Fasern viel weiter nach vorn als bis zum Oculomotorius. Man sieht, dass im centralen Höhlengrau dicht vor der Stelle, wo der Aquaeduct beginnt, eine Ansammlung grösserer Ganglienzellen liegt - Nucleus fasciculi longit. sup. Fig. 179 -, aus dem eine Anzahl solcher Fasern stammen. Bei allen Thieren ist dieser Kern nachweisbar. Er liegt in Schnittebenen bei Säugern, die ventral in die hintersten Abschnitte des Corpus mamillare fallen. Ueberall vorhanden und immer vom Zwischenhirn bis in die Gegend der Vorderstränge des Rückenmarkes nachweisbar, muss dieses Bündel ebenfalls zu den Grundbündeln des Gehirnes gerechnet werden, s. S. 79.

Die zahlreichen Fasersysteme, welche in der Vierhïgelgegend verlaufen, werden in ihren Abgrenzungen zu einander nur dann ganz klar, 
wemn man die Entwicklung ihrer Markscheidenbildung studirt. Ich möchte daher, meine Herren. diese Vorlesung nicht schliessen, ohne Ihnen ein diesbezügliches Präparat demonstrirt zu haben.

Sie sehen in Fig. 195 einen Schnitt durch die vorderen Vierhïgel, dicht an der hinteren Commissur von einem im 9. Fötalmonat geborenen Kinde. Alle zu dieser Zeit markhaltigen Fasern sind durch Hämatoxylin geschwärzt.

An den eingeschriebenen Bezeichnungen orientiren sie sich leicht. Noch nicht näher erwähnt ist das kleine Bündel im Kreis stehender Querschnitte, das zwischen beiden rothen Kernen liegt und mit $b$ bezeichnet ist. Es stammt aus dem Ganglion habenulae thalami und zieht von dort nach rückwärts zu einem kleinen, zwischen den Hirnschenkeln liegenden Ganglion, dem Ganglion interpedunculare. Dort kreuzt es sich ror seinem Eintritt in das Ganglion mit dem analogen Bündel der anderen Seite. Es heisst Tractus habenulo-peduncularis, Fasciculus retroflexus oder Meynert'sches Bündel. Sein Verlauf wird am besten aus Fig. 144 klar. In dem Ganglion habenulae endet, wie bereits früher erwähnt wurde, jener aus den lateralen Gebieten des Riechfeldes aufsteigende Faserzug. die Taenia thalami, zum grössten Theil.

Das Ganglion interpedunculare ist von Gudden entdeckt und von Forel zuerst genauer beschrieben worden. Gudden wies nach, dass nach Zerstörung eines Ganglion habenulae das gleichseitige Meynert'sche Bündel absteigend degenerirt, und dass die deg. Fasern sich bis in das gekreuzte Ganglion interped. verfolgen lassen. Ganser entdeckte noch einen aus der Haube absteigenden Zug zum Ganglion interpedunculare.

Ieine cigenen Untersuchungen an normalen Hunden und an einem solchen, dem das Gauglion habenulae zerstört war, lehren weitere Verhältnisse kennen :

Es besteht das Ganglion interpedunculare beim Hunde aus fünf verschiedenen Ganglien. Frontal liegen nebeneinander zwei birnförmige Körper, bedeckt von einer flachen Platte, die direct an die Haubenfaserung grenzt. Dieser Complex ist von den viel grösseren caudalen Gauglien von hinten her hufeisenförmig umfasst. Der hintere Umfang des Hufeisens wird von dem mächtigen, gemeinsamen Körper der caudalen Ganglien gebildet. Die vorderen dünneren Schenkel derselben nehmen die Meyuert'schen Bündel auf, die sofort nach dem Eintritt ihre Markscheiden verlieren. Bei der Eidechse erkenne ich, dass sie sich in zahllose feinste - Golgi-Methode - Endpinsel nach Kreuzung im Ganglion auflösen. Die Angabe Gudden's von der Degeneration nach Untergang eines Ganglion habenulae kann ich bestätigen. Das Deckganglion ist von einem feinen Fasernetze erfïllt. Aus diesem treten Ziige zwischen den beiden frontalen Ganglien ventralwärts. In den frontalen, birnförmigen Ganglien endet der Zuzug aus der Haube des Mittelhirnes, starke Fasern, die auch wach Zerstörung des Vorderhirnes und des Thalamus erhalten bleiben.

In der Fig. 199 lege ich Ihnen eine Abbildung vor, die, nach Präparaten aus verschiedenen Entwicklungsperioden zusammengestellt, die allermeisten Bestandtheile erkemnen lässt, welche auf einem Schnitte dicht hinter den rorderen Vierhügeln sichtbar sind. 
Sie wollen dieselben zu einer Repetition des heute Torgetragenen benutzen und die folgenden Bestandtheile aufsuchen:

1. Mittelhirndach: Corpus quadrig. anterius, aus dem dorsal der Sehnerv, ventral das tiefe Mark stammt, lie Krenzung des letzteren über dem Aquaeducte, das centrale Höhlengrau, das den Aquaeduct umgiebt. An seinem äusseren Rande liegt ein bisher noch nicht erwähnter, kleiner Kern, dessen blasige Zellen durch das ganze Mittelhirn an der gleichen Stelle

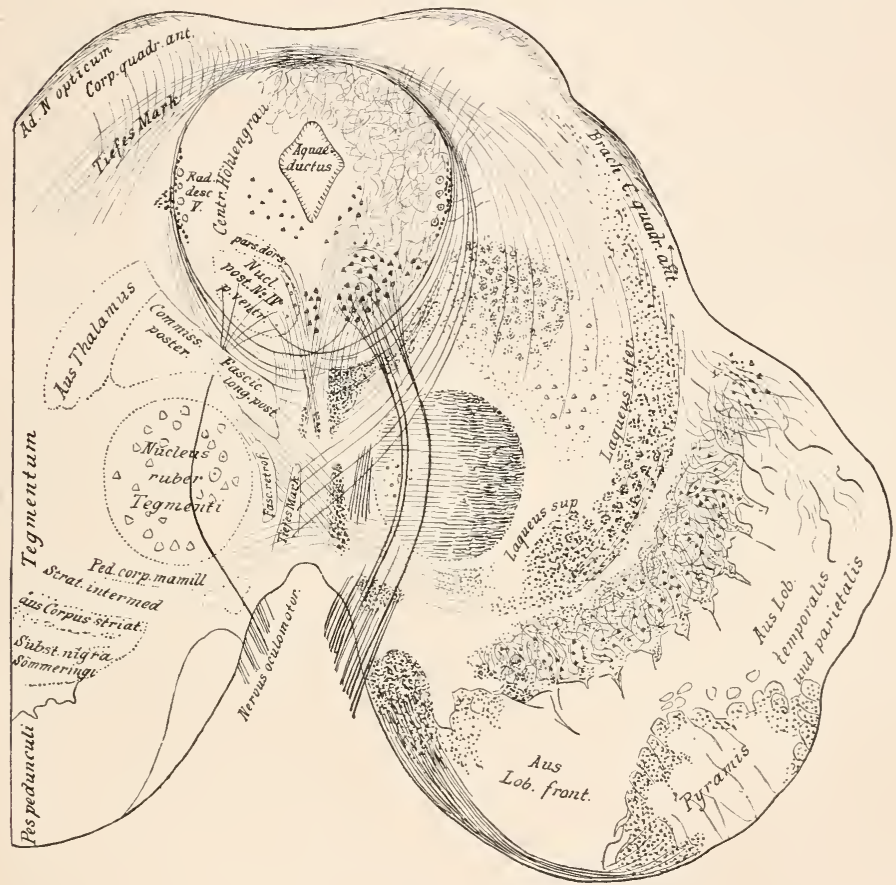

Fig. 199.

Schnitt dicht hinter don vorderen Vierhügeln, combinirt nach Präparaten aus verschiedenen Stadien der Markscheidenbildung. Hämatoxylinkupferlackmethode. - Statt: Brach. corp. quadr. a n t. lies: post.

gefunden werden. Aus ihm stammt ein dünnes Faserbündelchen, das, immelfort Zuwachs erhaltend, hinab in die Brücke zieht und dort sich zu den austretenden Fasern des Trigeminus gesellt. Es ist die Mittelhirnwurzel des Nervus trigeminus. Rad. desc. V. der Figur.

Im Mittelhirndache kann man eine etwas verwaschene Schichtung von grauen und weissen, auf einander folgenden Lagen erkennen. Der feinere gewebliche Aufbau der einzelnen ist beim Menschen noch nicht geniigend bekannt. Bei 
niederen Vertebraten sind aber die Verhältnisse hier viel klarer; zahlreiche Untersuchungen, namentlich solche, die mit der Golgi-Methode angestellt sind, liegen bereits für das Mittelhirndach der Fische, Amphibien, Reptilien und Vögel vor (s. S. 108), und es ist zu erwarten, dass in naher Zeit auch die Schichten beim Menschen richtig gedeutet werden können. Bekannt ist, dass in das Dach eintreten: Fasern aus dem Opticus, die der Retina entstammen, und Fasern aus der Sehstrahlung, also vom Occipitallappen her; dass aus Zellen im Dache Fasern entspringen, die in den Sehnerv gelangen, und solche, welche sich basalwärts zur Schleife wenden. Ausserdem ist bereits mit Sicherheit nachgewiesen, dass es im Mittelhirndache zahlreiche Ganglienzellen mit stark verzweigtem und in keine Nervenfaser übergehendem Axencylinder giebt.

Bei den Säugern unterscheidet man gewöhnlich von aussen nach innen gehend folgende Schichten im vorderen Hügel: 1. Oberflächliches Mark und Grau - die eintretenden Opticusfasern - atrophirt etwas nach Wegnahme eines Auges und ist bei dem Maulwurf mit reducirtem Sehapparate Ganser - besonders dünn. 2. Mittleres Grau, eine directe Fortsetzung des oberflächlichen Grau. Am besten studirt bei den Vögeln — Cajal, Gehuchten --, enthält es massenhafte Zellen, deren Axencylinder zum grössten Theile hinab in die Schleifenschicht gelangt, deren Dendriten sich aber um die feinen Endpinsel verästen, welche der Sehnerv in das oberflächliche Grau schickt. In und unter diesem liegt 3. das mittlere Mark. Es enthält die Züge aus der Sehstrahlung zum Opticus, muss aber noch mehr andere Züge führen, denn es degenerirt nur unvollständig nach Wegnahme der Rinde und ist auch bei Reptilien, die keinen oder nur einen sehr unbedeutenden Zuzug aus der Rinde besitzen, zum Theile nachweisbar. 4. Das tiefe Grau und das tiefe Mark. Das Grau ist nur die Fortsetzung des Vierhügelgraues überhaupt. Das tiefe Mark enthält die aus dem Vierhügel entspringenden und da einmündenden Fasern der Schleifenschicht. Sie stammen aus dem tiefen und mittleren Grau.

2. Haube: Im ventralen Theile des Höhlengraues der Nucleus posterior medialis und lateralis des Nervus oculomotorius, in ihn treten Fasern anscheinend aus dem tiefen Mark und solche aus dem Fasciculus longitudinalis posterior; lateral vom hinteren Längsbündel die Fasern der Commissura posterior, direct an es sich anschliessend. Nach aussen von diesen ein Markfeld, das aus dem Thalamus stammt, den es als Laminae medullares verlassen hat. Es enthält höchst wahrscheinlich einen Zug aus den Trigeminusendkernen zum Thalamus. Die Schleife aus den Vierhïgeln untere schleife — und die aus dem Thalamus — obere Schleife. Nach innen von der Schleife der Nucleus ruber tegmenti, aus dem massenhaft bereits Bindearmfasern entspringen. Nahe der Medianlinie liegt jene Krellzung von Fasern des tiefen Markes, die man als fontaineartige Haubenkreuzung bezeichnet. Zwischen ihr und dem Bindearm steigt ein Stück des Fasciculus retroflexus herab. Wie es an diese Stelle gerätl, zeigt Fig. 144.

3. Auf der Grenze zwischen Fuss und Haube erkennt man die Substantia nigra Sömueringi, in der massenhaft Fasern - Strat u m in termedium — verlaufen, die aus dem Linsenkern stammen.

4. Fuss des Hirnschenkels. Noch marklos; nach einem Präparate von einem 4 wöchentlichen Kinde ist die Pyramidenbahn eingezeichnet. Die 
medial von ihr liegenden Fasern stammen aus dem Lobns frontalis, die lateral liegenden aus dem Lobns parietalis mol temporalis. Fin Bündel verlässt in dieser Gegend die Pyramide, und indem es den Fuss mmzieht, gelangt es, allerdings erst in caudaler liegenden Ebenen, direct in die Lage der Schleife, deren medialste Schicht es bildet. Spitzka hat es dmrch vergleichend anatomische Gründe sehr wahrscheinlich gemacht, dass dieses Bündel die cerebralen Bahnen der Hirnnerven enthält. Nach innen von ihm sind auf der Abbildung die ITmzelfasern des Oculomotorins sichtbar. Sie durchschneiden kurz vor ihrem Anstritt den Pedunculus corporis mamillaris.

Der Faserverlauf im Bereiche des Thalamus und der Regio subthalamica ist weniger sicher bekannt, als an den meisten anderen Stellen des Gehirnes. Auf diesem schwierigen Gebiete haben II eynert, Forel, Gudden, Flechsig, Ganser, IVernicke, II onakow, Kölliker, der Verfasser u. A. gearbeitet.

Der Ursprung des Sehnerven ist wesentlich bearbeitet worden ron II eynert, J. Stilling, Tartuferi, Gudden, Bellonei, dann ron Monakow, dem wir die wesentlichsten Fortschritte verdanken, von Henschen u. A. Die genauere Kenntniss des Oculomotoriuskernes wurde durch Arbeiteu von Gudden, Perlia und von TVestplral-Siemerling, Bernheimer, Kölliker und Verfasser erzielt.

Wir haben noch das Wenige nachzutragen, was als Zeiclien der Erkrankung der Vierhïgelgegend mit einiger Sicherheit gelten kann.

Krankheitsherde in der Regio subthalamica treffen ein solches Gewirr verschiedenartiger Fasern, dass ihre Symptome die allermannigfaltigsten sein werden. Eine sichere Diagnose dürfte jetzt noch kaum zu stellen sein.

Herde im Bereiche der Hirnschenkel treffen die motorische Faserung für die gegenüberliegende Körperhälfte inclusive der gekreuzten Kopfhälfte. Auch sensorische und vasomotorische Störungen kömnen eintreten. Meist aber wird nicht nur die Extremitätenmusculatur und einer oder melırere Hirnnerven gelähmt, sondern es treten auch Störungen im Oculomotorius der erkrankten Seite auf. Wenn gleichzeitig ein Oculomotorius und die ihm gekreuzte Körperhälfte gelähmt werden, darf man an einen Herd unter den Vierhïgeln denken. Solche Kranke können die Glieder einer Seite nicht oder nur theilweise bewegen, das obere Lid hängt herab, die Pupille ist erweitert, der Augapfel durch den M. rectus externus nach aussen rotirt. Durch einen Tumor an der Hirnbasis könnten, wie ein Blick auf Fig. 237 zeigt, die gleichen Symptome einmal erzeugt werden; es ist deshalb wichtig fiir die Diagnose, wenn Augen- und Extremitätenlähmung gleichzeitig auftreten, was im letzterwähnten Falle nur durch eine ganz besondere Combination der Verhältnisse vorkommen dürfte. Wenı Anästhesie auftritt, ist sie ebenfalls nur auf der der Erkrankung entgegengesetzten Seite vorhanden. Die sensiblen Fasern verlaufen wahrscheinlich zum grössten Theile in der Schleife.

Reicht ein Krankheitsherd weiter dorsal und trifft die Corpora quadrigemina selbst, so tritt ausser der, wie ein Blick auf unsere Querschnitte zeigt, fast selbstverständlichen einseitigen oder doppelseitigen Oculomotoriusstörung bei Erkrankung des vorderen Vierhügels Sehschwäche ein; zuweilen ist ophthalmoskopisch gar nichts Abnormes dabei nachzuweisen. Bei Tumoren kann natürlich, wie bei Tumoren an anderen Stellen des Gehirnes, Stauungspapille, Sehnervenatrophie u. s. w. eintreten. Meist ist die Pupille ganz reactionslos. Welche Symptome den Erkrankungen der hinteren Vierhügel zukommen, wissen 
wir nicht. Man hat Gleichgewichts- und Coordinationsstörungen dabei eintreten sehen.

Am leichtesten wird der Verdacht auf Vierhïgelerkrankung rege, wenn beide Oculomotorii gelähmt sind, und periphere Ursachen (an der Hirnbasis) sich ausschliessen lassen, oder wenn nur ein Theil eines Oculomotorius (z. B. nur die Fasern zu dem inneren Augenmuskel) geschädigt ist. Bei Affection des peripheren Stammes ist das kaum möglich, solche Lähmungen sind fast immer nuclearer Natur.

\section{Zwanzigste Vorlesung.}

\section{Die Briicke und das Kleinhirn.}

Neine Herren! Wir haben in der letzten Torlesung gesehen, dass die Faserzïge ans dem Vorder- und Zwischenhirn sich im Bereich des Mittelhirnes in zwei verschiedene Lagen, den Fuss und die Haube, ordneten. Hinter den Vierhügeln erweitert sich der Aquaeductus bedeutend. Fuss und Haube ziehen unter ihm weiter abwärts in das Hinterhirn. Nur ein

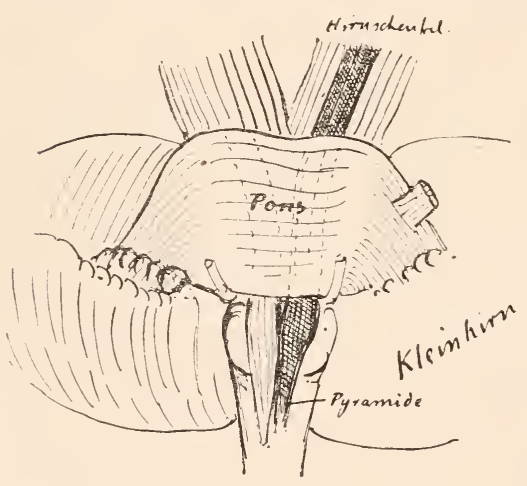

Fig. 200.

Die Hirnschenkel und die Brücke ron rorn gesehen. Die Fussbahn, welche nicht in der Brücke bleilut, ist schraffirt.
Haubenbestandtheil, der

Bindearm ans dem rothen Kern der Haube, tritt jetzt rom Boden des Mittelhirnes dorsalwärts zum Dache des Hinterhirnes. Aus diesem Dach ist beim Erwachsenen das Kleinhirn, Cereb e $11 \mathrm{~lm}$, hervorgegangen. Der darunter liegende Hohlranm. die Fortsetzung des Aquaeductes, heisst Ventriculus quartus. Im Boden und in den Seitentheilen des Hinterhirnes ist die Fortsetzung ron Fuss und Haube enthalteu.

Sehen wir zunächst zu, was aus der Faserung des Hirnschenkelfusses wird.

Nicht weit hinter den Vierhügeln legen sich dicke weisse Fasermassen ventral vor die Hirnschenkel. Aus dem Kleinhiru herabsteigend, umgreifen und bedecken sie die Fussregion in dichter Schicht. Die Gesammtheit dieser Fasern wird Brücke, Pous, genamnt.

Nur ein Theil ron ihnen bedeckt den Fuss ron aussen (Stratum superficiale pontis), die Mehrzahl dringt von beiden Seiten zwischen die Fussfaserung ein, zersprengt sie in einzelne Bündel, Stratum complexum et profundum pontis. 
Sie erimnern sich, dass vou den Fasern, welche im Fuss vom Gehirn abwärts ziehen, ein Theil nur bis zur Brücke verfolgt werden konnte. Es waren das Züge aus dem Frontal-, Parietal- und Teniporallappen. Die Pyramidenbahn aus der Gegend der Centralwindungen zieht durch die Brücke hindurch. Fast das ganze innere und das äussere Drittel des Hirnschenkelfusses bleibt in der Brücke; jenseits derselben tritt nur noch von den Fussbestandtheilen das mittlere Drittel, eben die Pyramidenbahn, aus, wie die beistehende Zeichnung. welche die Brücke von vorı gesehen mit den Hirnschenkeln und dem Kleinhirn darstellt, durch stärkere Schattirung der Pyramide schematisch andeutet.

Die Ponsfasern kommen beilerseits von oben aus den Kleinhirnhemisphären, umgreifen und durchftechten die Fussfaserung und treten in den ventraleren Gebieten - Stratum superficiale - zunieist zu Brückenganglien der gleichen, in den dorsaleren zu solchen der gekreuzten Seite, Minghazzini. Die Brïckenganglien sind graue, von einem Netze feiner Fasern erfüllte Massen, in die man einerseits die Fasern aus den Brückenarmen, andererseits die aus dem Gehirn stammenden Balınen verfolgt.

Es ist durch Untersuchungen von S. R. y Cajal ziemlich sicher geworden, dass um die grossen Zellen der Brückenganglien die mächtigen cortico-pontinen Züge aufsplittern, und dass aus den Axencylindern jener Zellen die Arme zum Kleinhirn werden. Die Degenerationsversuche zeigen, dass aber auch bei Kleinhirnentfernung ein Theil der Brïckenfasern zu Grunde geht. So müssen wir annehmen, dass, wie in vielen anderen Bündeln, so auch in den Brückenarmen Fasern doppelter Verlaufsrichtung, solche aus Zeilen des Kleinhirnes zu den Brückenganglien und solche aus den Zellen jener Ganglien hinaus zum Kleinhirne vorhanden sind.

Bei Thieren mit relativ kleinem Grosshirne ist auch die Brücke klein, beim Menschen erreicht sie die relativ grösste Ausdehnung. Man vergl. z. B. Fig. 141 mit Fig. 1S0. Hier ist beim Kalbe eine zwischen Fuss- und Haubentheil der Brïckengegend liegende Querfaserung, das Corpus trapezoides, sichtbar, das beim Menschen von Brückenfasern bedeckt wird. Es führt dem Acusticus angehörige Züge.

Bei den Säugern ist den Brückenfasern jene Bahn aus dem Kleinlime zur Haube des Nachhirnes beigemengt, welche ich Ihmen schon bei Betrachtung der niedersten Vertebratengehirme demonstriren konnte. Thre Fasern ziehen nicht in die Brïckenganglien, sondern erheben sich in der Raplie des Pons dorsalwärts kreuzend aus ihrem Verlaufe und zerstrenen siclı damn in dem Grau der Haube. Fig. $201 \mathrm{~b}$.

Ist der Fuss des Grosshirnschenkels durch die Brückenfasern zerspalten und zum Theil in das Kleinhirn abgeleitet worden, so setzt sich doch die Haube desselben nur wenig verändert durch die Pons-Region hindurcli fort.

An dem letzten Querschnitt durch die Vierhügelgegend hatten wir als wesentlich e Bestandtheile der Haube die folgenden kennen gelernt (vgl. Fig. 199): 
1. Die graue Substanz um den Aquaeductus mit den Nervenkernen. 2. Unter ihr die hinteren Längsbündel, und nach aussen von diesen 3. die Fasern der Commissura posterior.

Subst. ret. Tr. thal. bulb. Bindearm.

Lat. (untere) Schleife.

Mediale (obere) Schleife.

Bdl. v. Fuss z. Haube.

Raphe. Bindearmkreuzg. Corpus interpedunculare. Tr. mamillo-peduncular.

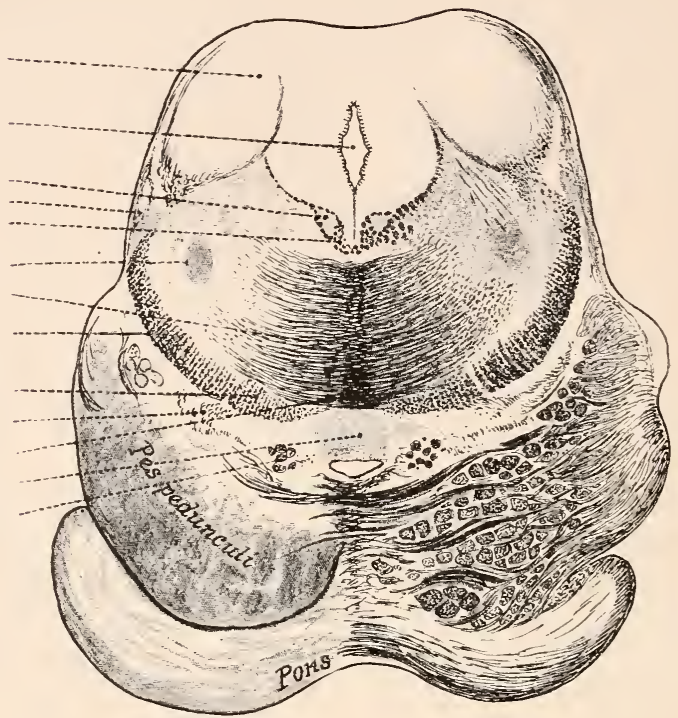

Fig. 201 a.

Velum med, ant.

Krzg. d. Trochlearis.

Rad. mesenceph. N. trig.

Nucl. laquearis.

Fasc. long. post.

Bindearm.

Bdl. aus der Hauben-1 kreuzung.

Lat. Schleife.

Bdl. aus d. Pons z. Haube.

Nediale Schleife.

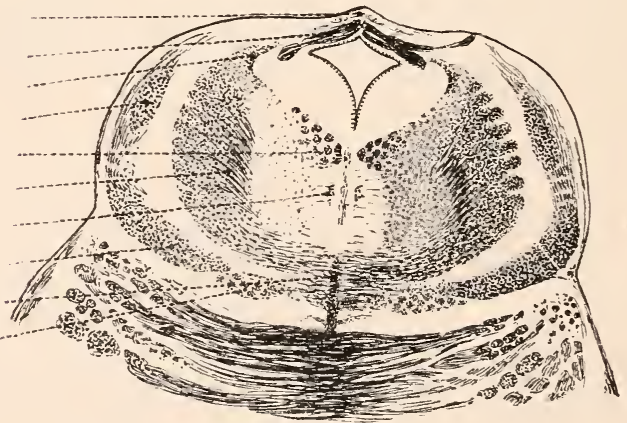

Fig. 201 b.

Zwei Schnitte durch den frontalsten Abschnitt des Ponsgebietes. Der obere enthält noch die hinteren Hügel mit den darunter liegenden Trochleariskernen und der Bindearmkreuzung. Ventral sieht man in ihm links, schemat. umrissen, noch den Hirnschenkelfuss, der rechts von den Brückenfasern zerspalten wird. An dem unteren Schnitte ist die Veränderung in der Haube, die direct hinter den Vierhügeln auftritt, gut sichtbar. Ausserdem zu beachten die Trochleariskreuzung. Es empfiehlt sich, jedes einzelne Bündel des oberen Schnittes auf dem unteren aufzusuchen. 
4. Die Fasern aus den Striae medullares thalami.

5. Die rothen Kerne im Centrum der Haube und die ans ihnen entspringenden Bindearme.

6. Die Schleifen.

7. Den Pedunculus corporis mamillaris.

s. Fasern aus dem tiefen Mark nahe der Medianlinie.

Der Aquaeductus erweitert sich, wie oben gesagt wurde, zur Rantengrube. Die ihn umgebende graue Substanz breitet sich damit auch in die Fläche mehr aus. Ein neuer Nervenkern, der Nucleus N. trochlearis, tritt unter den hinteren Vierhügeln auf. Die Trochlearisfasern steigen aber nicht wie die Oculomotorinsfasern durch die Haube nach abwärts; sie ziehen vielmehr gleich nach ihrem Ursprung ein Stiick in fast horizontaler Richtung caudalwärts, erheben sich erst dann und kreuzen sich schliesslich im Velum medullare anticum mit denjenigen der anderen Seite. So verlassen sie das Gehirn an der dorsalen Seite, dicht caudal von den hinteren Vierhügeln. Auf Fig. 201 a und $201 \mathrm{~b}$ sind Stücke des Trochlearislaufes sichtbar. Auf Fig. 196 ist der ganze Zng des Nerven nach Präparaten eingezeichnet.

Die hinteren Längsbündel und die Fasern der Commissura posterior gehen, an gleicher Stelle bleibend wie unter den Vierhügeln, hinab in die Haube des Nachhirnes. Das gleiche gilt auch von der Schleifenschicht. Dieser wachsen damn noch rom lateralen Rande der hinteren Hügel her neue Fasern zu. Sie legen sich aussen von der aus oberer und unterer Schleife gebildeten horizontalen schicht an und werden gewöhnlich als laterale Schleife von dieser, der medialen schleife, geschieden. Die laterale Schleife aus den hinteren Vierhügeln geht fast ausschliesslich zu den Endstätten des Hörnerven. In sie sind Gruppen von Ganglienzellen eingelagert - Sch l eifen k ern - die ihre Axencylinder zumeist der Schleifenfaserung ascendirend und descendirend beigesellen.

In der Fig. 202 sieht man aussen die laterale Schleife, das dorsale dreieckige Areal, zur horizontal liegenden medialen schleife herabziehen.

Die Substantia nigra und mit ihr das Stratum intermedium sind in Schnitten aus dem Bereich der Brïcke verschwunden. Ueber die Fortsetzung der striae medullares thalami wissen wir nichts Sicheres.

Noch ehe die Brïckenregion beginnt, wird der rothe Kern immer kleiner, die ihm entstammenden Bindearme rücken mehr und mehr nach aussen und präsentiren sich jetzt als zwei kräftige Faserbündel, die zwischen der Region des rothen Kernes und der Schleife liegen. In Fig. 201 a beginnt sich ihr Querschnittsbild erst anzulegen; auf Schnitten, die nur wenig weiter nach hinten fallend das Telmm schon treffen, liegen sie schon weit nach der Peripherie gerïckt (Fig. 201 b), und in dem Fig. 202 abgebildeten Schnitt durch das Telum medullare posterius bilden sie die äussere Begrenzung der Zeichnung. Bald nachher senken sie sich in das Kleinhirn ein. Fig. $210 R$. 
Das Gebiet, welches mit dem Terschwinden des rothen Kernes frei wird, nehmen die hier an Ausdehnung gewinnenden Fasern der $\mathrm{Sub}$ stantia reticularis ein, die wir später näher kennen lernen werden.

Es sind zumeist längs verlaufende Fasern, die aus den untersten Ebenen der Oblongata in allmählich abnehmender Nenge bis in das Nittelhirn hinauf und weiter bis in die rentralsten Thalamusgebiete verfolgt werden können. Sie stammen aus caudaler liegenden Zellen und aus solchen, welche in ihrem Terlaufe selbst angeordnet sind. Bei einem

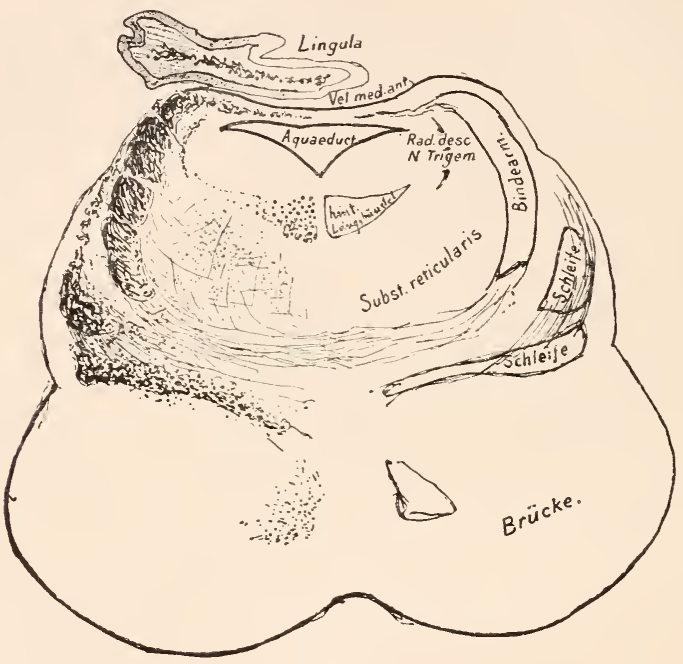

Fig. 202.

Schnitt durch die obere Brückengegend, dicht caudal von den hinteren Hügeln, von einem Fötus aus dem neunten Schwangerschaftsmonate.

Hunde mit fehlendem Thalamus waren sie erhalten. Es liandelt sich wahrscheinlich um ein System, dass verschiedene Höhen der Haube in sich rerknüpft.

Es ist nicht schwer, wenn man sich eimmal an einen guten Schnitt durch die Vierhïgelgegend die Bedeutung der einzelnen Querschnittsfelder klar gemacht hat, dieselben auch auf Schnitten durch den oberen Theil der Brücke aufzufinden und richtig zu deuten. Die Veränderungen betreffen ja im Wesentlichen nur die Lage des Bindearmes und die Gestaltung der grauen Substanz unter dem sich erweiternden Aquaeductus, wo neue Nervenkerne auftreten, dann den Zutritt der lateralen Schleife zur Schleifenschicht und die Zunahme der Systeme der Substantia reticularis.

Temn man aber weiter hinab Querschnitte anlegt, ändert sich das 
Bild doch wesentlich. Das geschieht dadurch, dass aus dem Dach des Ventrikels caudal rom Velum medullare anticum das Cerebell um wird, und dass Fasern aus der Haube und aus dem Fusse in enge Beziehung zu diesem treten.

Bindearm und Brïckenfasern verschwinden in dem Kleinhirn. Ton unten, von der Nedulla oblongata und rom Rïckenmarke her kommen Fasern, welche die Haube durchflechten und sich ebenfalls zum Cerebellum wenden.

Es ist deshalb zweckmässiger, wenn wir an dieser Stelle, also dicht linter den Vierhïgeln, die Verfolgung der Haubenbahn für einige Zeit aufgeben, wenn wir uns zunächst zum Stıdium der Theile des Centrahnervensystems wenden, aus denen sich hier Bahnen einsenken. Das Bild des Haubenquerschnittes wird Thnen zweifellos später viel leichter verständlich, wenn Sie die Faseranordnung im Cerebellum etwas übersehen, wenn Sie das Rückenmark und die Nedulla oblongata in ihrem Aufban kennen gelernt haben.

Das Kleinhirn, Cerebellum, besteht aus dem Nittelstück oder W urm (Vermis) und den beiden Hemisphären. Nit dem Zwischenhirne hängt es vorn durch die Bindearme aus dem rothen Kerne, vordere Kleinhirnschenkel, mit dem Vorderhirne ventral durch die Brückenarme, mittlere Kleinhirnschenkel, zusammen. Durch die ersteren bekommt es wesentlich Fasern aus dem Thalamus und dem Gebiete der Haubenstrahlung, durch die letzteren Züge aus der Rinde des Frontallappens, des Parietal- und des Temporallappens. Eine dritte Terbindung geht das Cerebellum durch die hinteren Kleinhirnschenkel, die Corpora restiformia, welche wir erst später betrachten können, mit der Medulla oblongata und dem Rïckenmarke ein.

Auf der folgenden Abbildung, welche das Kleinhirn von oben gesehen zeigt, wollen Sie beachten:

1. Die Lage zu den Vierhïgeln, unter denen die Bindearme zum Kleinhirne hervorkommen.

2. Die allgemeine Gestaltung, wobei in der Mitte der Wurm, beiderseits die Hemisphären zu merken sind. Wurm und Hemisphären zerfallen in einzelne grössere Lappen. Die des Wurmes sind wie die Radspeichen eines Dampfschiffes um den Markkerndes Wurmes gestellt. (Auf dem gerade durch den Wurm fallenden Schnitte Fig. 206 wird das klar.)

Der Wurm hängt rechts und links mit dem Marklager der Kleinhirnhemisphären zusammen, das an seiner Oberfläche durch tiefere Furchen in Lappen und durch flachere in Leisten getheilt ist.

Der dorsale Theil des Wurmes heisst Oberwurm. Er zerfällt in:

1. Lingula (Z üngelchen), ganz rorn zwischen den Bindearmen.

2. Lobulus centralis (Centrallappen), geht beiderseits in Alae lob. centr. ïber. 
3. Monticulus (Berg), au dem man delı vorderen Theil als Culmen, den hinteren als Declive miterscheidet.

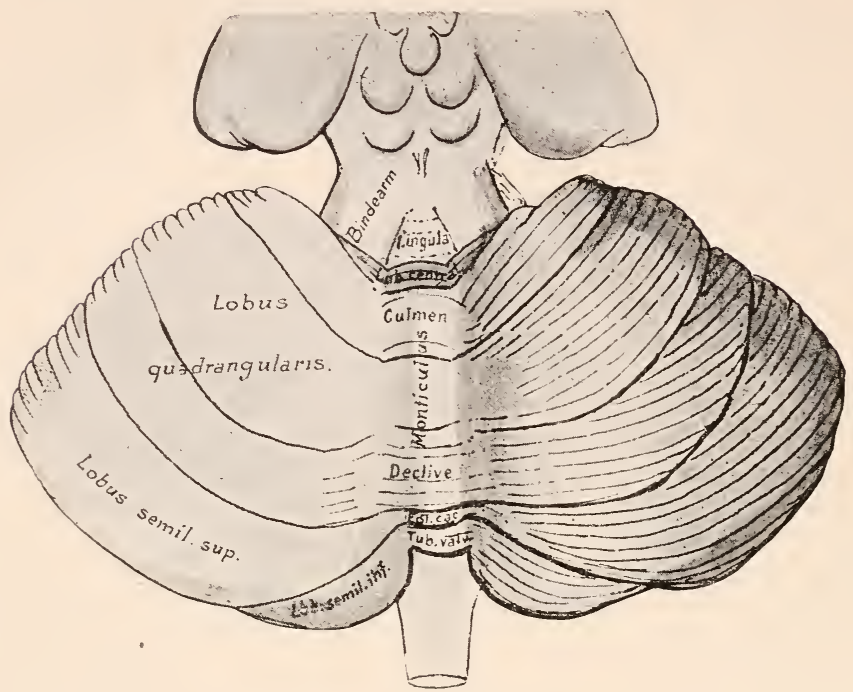

Fig. 203.

Das Cerebellum. Dorsale Seite.

4. Folium vermis (Fol. cacum. der Fig. 203), am hinteren Eude des Oberwurmes.

5. Tuber vermis (Tuber valv. d. Abbildung).

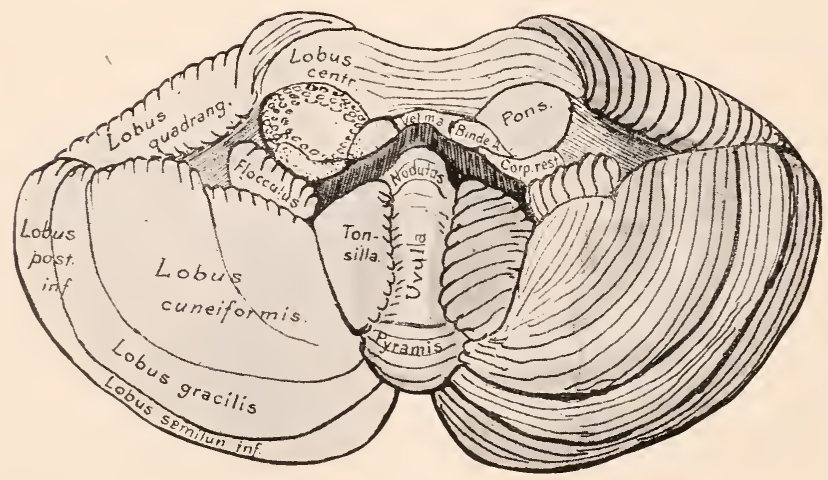

Fig. 204.

Das Cerebellum. Ventrale Seite. 
Der dorsale Theil der Hemisphären lässt unterscheiden:

1. Vorderer Oberlappen, auch Lobulus quadrangularis genannt; beiderseits vom Nonticulus.

2. Hinterer Oberlappen, Lobus semilunaris superior. Die beiden hinteren Oberlappen hängen durch das Folium vermis unter sich zusammen.

Die Lappenbildung an der Unterfläche des Kleinhirnes zeigt die folgende Zeichnung.

Sie bietet ein etwas complicirtes Bild. Um nämlich das betreffende Präparat herzustellen, muss das Kleinhirn erst von seinen Verbindungen mit dem Mittelhirne, den Bindearmen also, dann von der Brücke und von dem Corpus restiforme, der Gesammtheit der zum Rïckenmarke und verlängerten Marke gehenden Faserzüge, gelöst werden. So entstelien jederseits die 3 Querschnittsbilder der Kleinhirnschenkel. Zwischen den Bindearmen liegt eine dünne Membran, das Velum medullare anticum, auch ein Theil des Hinterhirndaches. Es ist durchtrennt auf dem Querschnitte sichtbar.

Die Lappen an der Unterseite des Wr urmes (Unterwurm), Fig. 204, heissen:

1. Nodulus (Knötchen).

2. Uvula (Zäpfchen).

3. Pyramis (Pyramide).

4. Tuber vermis vulvulae (Klappenwulst),

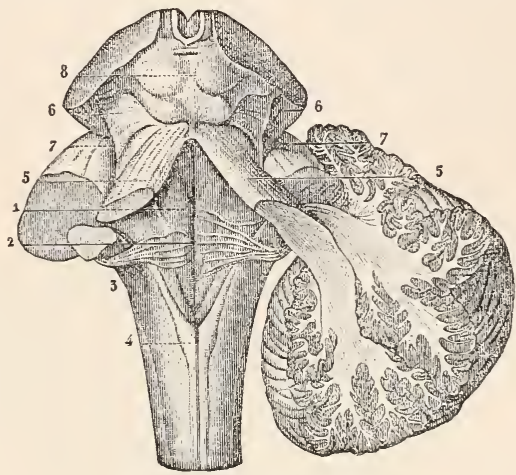

Fig. 205.

Die aus dem Mittelhirne, der Brücke und dem Rückenmarke zum Kleinhirne tretenden 3 Arme, nach Hirschfeld and Leveillé (Sappey). Man sieht unter den Vierhügeln 8 die oberen Schenkel oder Bindearme 5 hervortreten, von der ventralen Seite kommen die mittleren Schenkel oder Bräckenarme 7, und vom Rückenmarke her steigt der Strickkörper 3 als unterer Schenkel empor. Er kreuzt sich bei seinem Eintritte mit dem Bindearme. Zu bemerken sind noch auf dem Bilde die Rautengrube 1, die Striae acusticae 2, und die Clavae der Funiculi graciles 4. Bei 6 ist die Schleife zu suchen. ganz hinten, zum Theile noch auf der Dorsalseite gelegen.

In den Hemisphären liegt:

1. Beiderseits vom Nodulus die Flocke, Flocculus, an dem dünnen Pedunculus flocculi befestigt.

2. An der Uvula die Tonsilla, Mandel.

3. Aussen von ihr der Lobus cuneiformis oder Lobus biventer.

4. Hinter ihm der hintere Unterlappen, Lobus posterior inferior, an dem man die vordere Hälfte als Lobus gracilis, die hintere als Lobus semilunaris inf. bezeichnet.

Auf obenstehender Zeichnung sehen Sie die drei jederseits zum Kleinhirne ziehenden oben genannten Markfortsätze. Dieselben treten ein in den Markkern der Hemisphären, welcher sich in das Mark der 
einzelnen Lappen und ron da wieder in das der Läppchen und Markleisten fortsetzt. Diese Markleisten sind ron grauer Rinde überzogen, welche sich überall über sie hin faltet und so eine Ausdehnung gewinnt, die unverhältnissmässig grösser ist, als die äussere Form und Grösse des Kleinhirnes erwarten liessen.

In den Hemisphären ist der Markkern ziemlich mächtig. Im Wrurme ist er nur klein. Der beistehende mediane Sagittalschnitt durch das Kleinhirn geht gerade durch den Wurm. Er zeigt, wie sich dessen Mark vorn in eine dünne, nach den Vierhügeln zu ziehende Membran, das Vel u m medulla re anticum, fortsetzt. Diese dïnne, zwischen den Bindearmen ansgespannte Membran bildet das Uebergangsstiick vom Dache des Mittelhirnes zum Dache des Hinterhirnes. Auf ihr liegt das vorderste Läppchen des Oberwurmes, die Lingula.

Das eigenthümliche Längsschnittbild des Wurmes führt seit Alters den Namen Arbor vitae. Das centrale Stück, das Narklager des Wurmes,

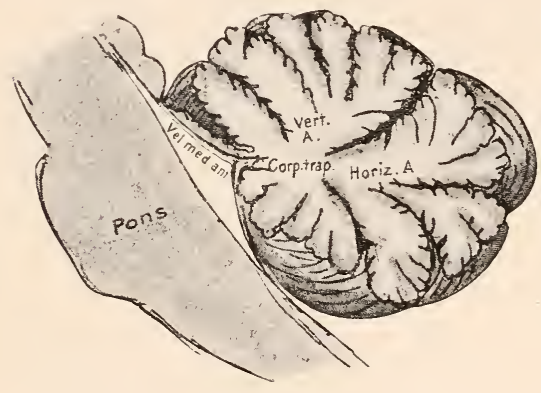

Fig. 206.

Sagittalschnitt durch die Jitte des Wurmes. heisst Corpus trapezoides. Lingula, Lobulus centralis, Uvula und Nodulus mïnden getrennt in dasselbe ein. Eine Anzahl der Lappen des Monticulus vereinen sich vor der Eimmündung zum verticalen Ast des Arbor vitae; der hintere Theil des Monticulus, das Folium cacuminis und das Tuber valvulae, also die Lappen. welche um die hintere Kante des Kleinhirnes herum liegen, treten zum

horizontalen Aste des Arbor vitae zusammen.

Hinten zieht rom Kileinhirne das Telum medullare posticum als Dach iiber die Rautengrube bis zum Ende der Hinterstränge des Riickemmarkes. Dieses Dach besteht nur in seinen lateralen Theilen ans dichterem (wesentlich Glia-) Gewebe, in der Medianlinie ist es nur durch eine Schicht cubischen Epithels repräsentirt. Aus der Pia treten an diese zahlreiche Gefässschlingen heran und stülpen sie zum Theil in den Ventrikel hinein (Plexus chorioideus - ventriculi quarti - medialis). Die lateralsten Theile bilden aber neben der Oblongata noch jederseits eine sackartige Ausbauchung, deren mediale Wand ebenfalls durch Gefässschlingen zum Plexus choroideus wird (vergl. Fig. 243. Plexus chorioideus lateralis. Sowohl in dem mittleren Plexus, als an der Ursprungsstelle des seitlichen findet man durchlöcherte stellen (Key und Retzius). Die mittelste dieser offenen Stellen im Medullarrohre heisst Foramen II agendii. Sie ist für die rasche Ausgleichung 
von Druckschwankungen der Cerebrospinalflïssigkeit von grosser Wichtigkeit.

In die oben geschilderte Masse des Kleinhirnes münden nun die drei wiederholt genannten Arme jederseits ein. Sie treten in den mächtigen Markkern und gehen da Terbindungen mit grauen Kernen ein, ausserdem senden sie Züge zur Kleinhirnrinde.

An der Rinde unterscheidet man schon bei schwacher Tergrösserung drei verschiedene Schichten. Am weitesten nach aussen liegt die Zona molecularis, am weitesten nach innen, an das Markweiss grenzend, die Zona granulosa, und zwischen beiden findet man eine Lage sehr grosser Zellen, die Purkinje'schen Zellen.

Sie erinnern sich, dass ich Ihnen in der dritten Vorlesung mit. getheilt habe, wie wir nach neueren Ansichten annehmen müssen, dass im Centralnervensysteme die Bezielıug zweier Zellen zu einander immer dadurch hergestellt werden, dass die Protoplasmafortsätze der einen umgeben werden von dem aufgezweigten Axencylinder der anderen. Da man den Complex: Zelle, Axencylinder, Aufsplitterung des letzteren als Neuron bezeichnet, kann man auch sagen: im ganzen Nerensysteme liegen unzählige einzelne Neurone; die Verbindung derselben unter einander findet immer durch Aneinanderlegen in der geschilderten Weise statt. Sie haben bisher erst im Lobus olfactorius ein Beispiel für das Gesagte kennen gelernt. Heute kann ich Ihnen in der Kleinhirnrindedas, was wir dort einmal kennen lernten, auf die mannigfachste Weise verwirklicht vorführen.

Die Purkinje'schen Zellen — 1 der Fig: 207 - senden ihren Axencylinder hinab in die Zona molecularis und in das Marklager unter dieser. Auf dem Wege dahin giebt er Collateralen ab, die zum Theil aufwärts umbiegen und sich um den Zellleib herum verästeln (s. Abbildung). Die Dendritenfortsätze sind ausserordentlich reichlich entwickelt, namentlich in der Sagittalebene, in die Transversalebene treten viel weniger ein. Will man also Bilder bekommen, wie das Fig. 207 abgebildete, so muss man senkrecht zur Kleinhirnfurchung die Schnitte anlegen.

Das ganze reiche Geäst der Dendritenausläufer wird nun umsponnen von dicken Fasern (2 der Figur), die, aus einer Zelle an unbekanntem Orte kommend, in das Kleinhirnmark eintreten, die Körnerschicht durchziehen und in der Molecularschicht sich aufzweigen. So ist jede Purkinjesche Zelle in Verbindung mit einem entfernten Orte gesetzt. Es giebt aber in der Molecularschicht auch eine Art Zellen, welche geeignet sind, eine Anzahl der Purkinje'schen Elemente unter einander in Terbindung zu bringen. Solche Zellen (3 der Fig. 207) entsenden einen langen Axencylinder ziemlich parallel der Oberfläche der Rinde, und aus diesem senkt sich von Stelle zu Stelle ein feiner Fortsatz herab. Derselbe tritt nahe an den Körper einer der grossen Purkinje'schen Zellen und splittert sich dann. diesen mit seinen Endästen umfassend, auf.

Die Körnerschicht besteht zum grössten Theile aus polygonalen kleinen Zellen (4) mit grossem Kerne. Jede derselben entsendet eine 
kleine Anzahl sich bald verzweigender Dendriten und einen Axencylinder. Der letztere dringt nach aussen in die Nolecularschicht, und dort theilt er sich in zwei transversal zur Körperaxe laufende feine Fasern. In der Figur kamn man diese Theilung nur eben durch eine kleine Querlinie angedeutet sehen, weil der abgebildete Schnitt in sagittaler Richtung, also senkrecht zum Windungsverlaufe des Kleinhirnes angelegt ist. Die zahlreichen Pünktchen in allen Höhen der Molecularschicht rechts unten

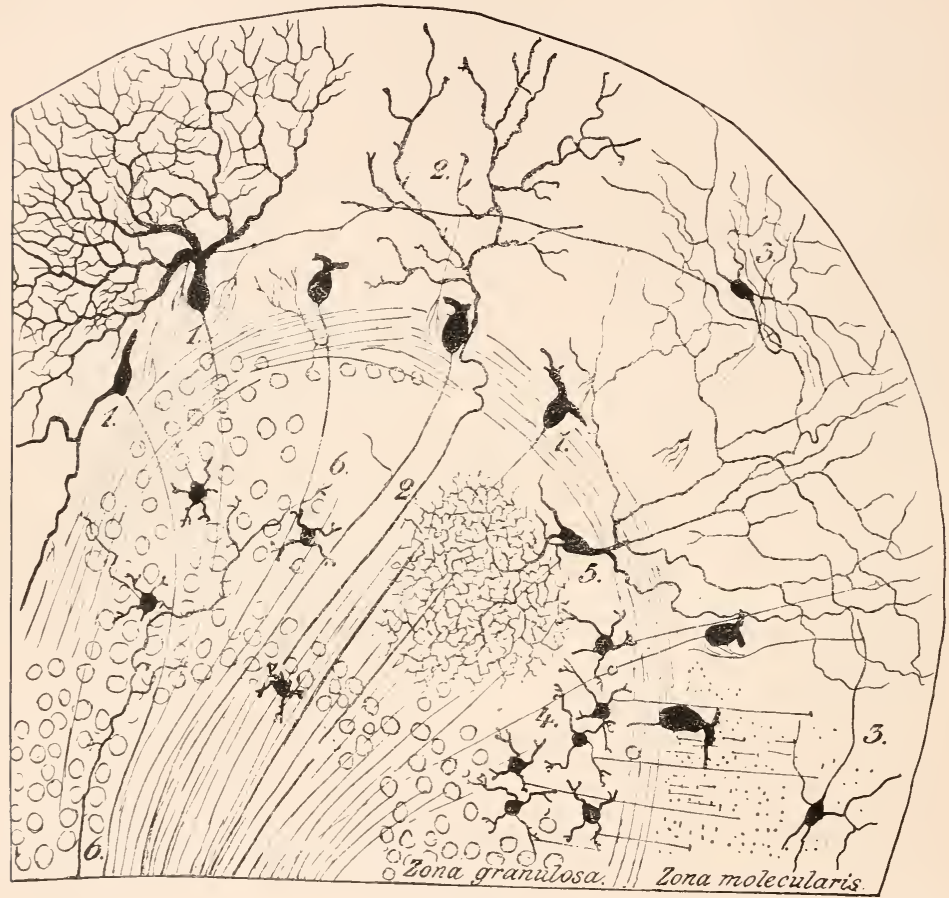

Fig. 207.

Schnitt in sagittaler Richtang durch die Rinde des Cerebellum nach Behandlung mit der Methode von Golgi. Zusammenstellung der einzelnen da beobachteten Zellen auf einem Schnitt. Nach Zeichnungen von S. R. y Cajal und v. Gehuchten.

entsprechen solchen quergetroffenen Theilästchen. Ausser den eben erwähnten Zellen kommen in der Körnerschicht noch solche vor (5), deren Axencylinder sich zwischen den Körnern ausserordentlich fein aufzweigt, während die Dendriten, nicht unähnnlich denen der P lk rkinje'schen Zellen, aber weniger reichlich, sich in der Molecularschicht vertheilen. Auch in der Körnerschicht enden Fasern (6) unbekannter Herkunft, die aus dem Marklager dahin eintreten. 
Wie Sie sehen, liegt also in der Rinde des Cerebellum ein ausserordentlich complicirter Apparat vor, ein Apparat, der wohl geeignet ist, Elemente sehr verschiedener Art und Herkunft unter einander zu verbindell.

An dem Schnitte, den ich Thnen hier in Fig. 205 vorlege, soll gezeigt werden, wie die Fasern aus dem Kleinhirnweisse in dicken, markhaltigen Zügen in die Rinde eintreten, wie von diesen Zügen im Bereiche der Körnerschicht zumeist nur gewundene Theilstïcke auf dem Schnitte sichtbar sind, und wie ein wahrer Plexus markhaltiger Nervenfasern in sagittaler Richtung unter und zwischen den Purkinje'schen Zellen einherzieht. Einzelne in gleicher Richtung ziehende dümne, markhaltige Fasern - auf der Figur nicht sichtbar - kommen auch noch ein kleines Stück über die grossen Zellen hinaus, in der Molecularschicht vor.

Die Beschreibung der Kleinhirnrinde lege ich Ihnen auch deshalb mit allem bekannten Detail vor, weil neuere Untersuchungen gezeigt haben, dass auch hier bei der progressiven Paralyse Faserschwund und andere Veränder'ungen vorkommen können. Es kann deshalb die Kenntniss der anatomi-

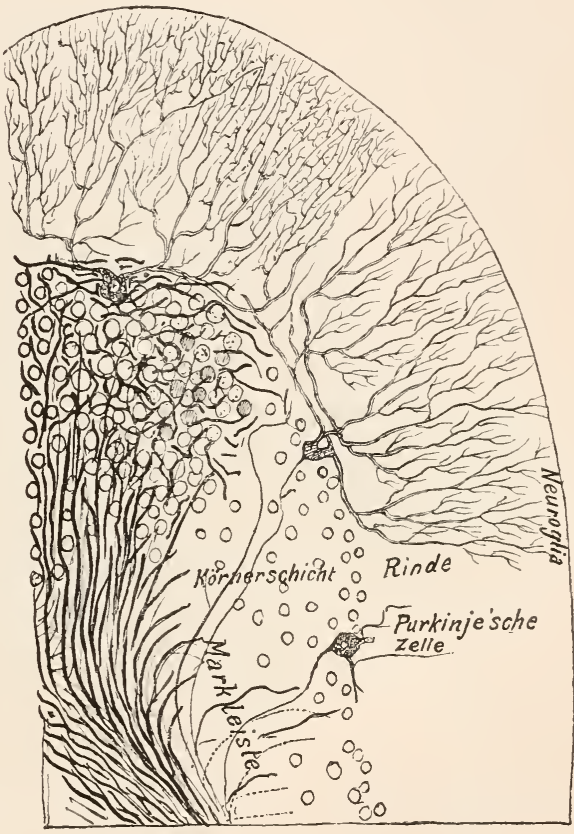

Fig. 208.

Schnitt durch die Rindenschicht des Cerebellums. Fürbang mit Hämatoxylinkupferlack. schen Verhältnisse für Untersuchungen im Bereiche der Pathologie grosse Wichtigkeit gewinnen.

Alle Rindenpartien sind durch guirlandenförmige, ihrer Contour folgende Faserzüige unter einander verknïpft.

Ausser in der Rinde bietet das Kleinhirn noch an anderen Stellen Anhäufungen grauer Substanz. Ganz lateral im Wurme liegt jederseits ein grosser, vielfach gefältelter Kern, das Corpus dentatum. Nach innen von ihm werden weitere graue Massen angetroffen; zunächst ein 
längliches Ganglion. der Pfropf. Embolus, dam der Kugelkern, Nucleus globosus, ein längliches Gebilde mit kugliger Anschwellung am hinteren Ende, schliesslich am weitesten medial im Wurme der Dachkern, Nucleus tegmenti. Am besten bringt man sich diese Kerne auf einem fast horizontal durch das Cerebellum geführten Schnitte

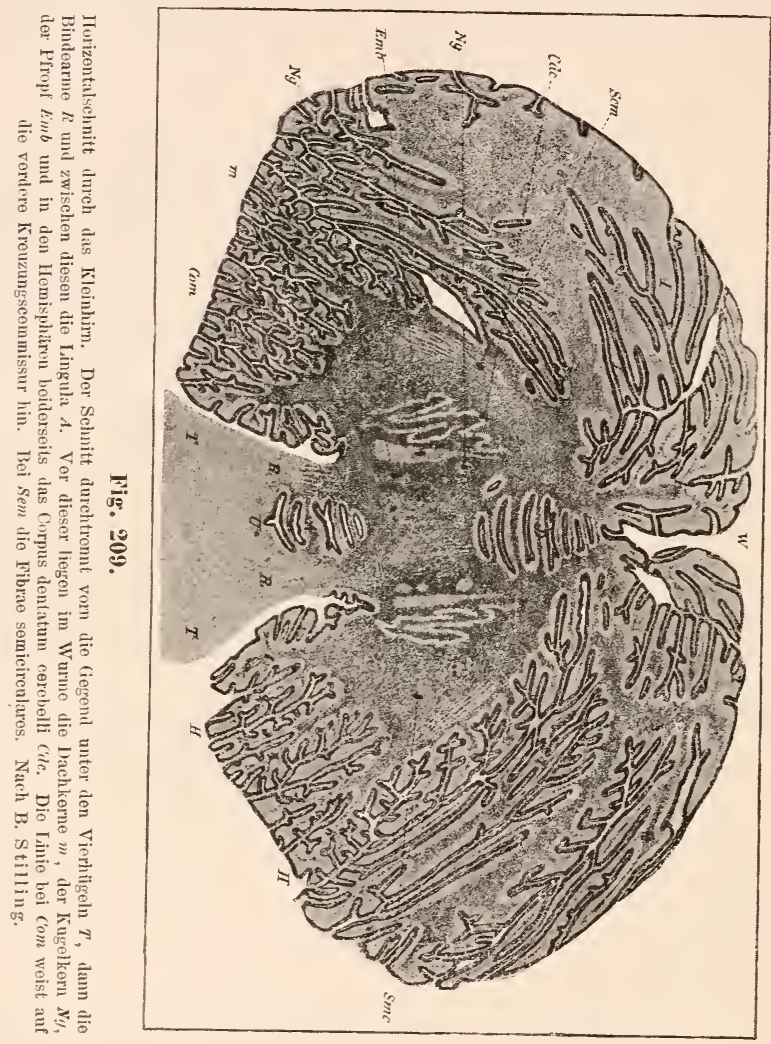

zu Gesicht, wie ihn Fig. 209 nach einer Abbildung aus B. Stilling's Atlas zeigt.

An einem solchen Schnitte erblicken sie in der Mitte den Markkern des Wurmes mit den Dachkernen, vor demselben eine Faserkreuzung, die vordere Kreuzung des Wurmes. Rechts und links schliessen sich die Marklager der Hemisphären an, in denen die Kugelkerne, der Pfropf und am weitesten anssen das gefältelte Markblatt des Nucleus dentatus 
sichtbar werden. Die tiefen Einschnitte in die Oberfläche entsprechen den Furchen zwischen den Lappen. Zwischen den Bindearmen $(R R)$ liegt, wie ich vorhin erwähnte, auf dem Velum medullare anticum die Lingula; sie ist (A) ebenfalls in der Horizontalebene durchschnitten.

Alle die Kerne in den Marklagern, welche Sie eben sehen, sind durch Züge grauer Substanz unter einander in Verbindung. Ihre Beziehungen zur Faserung des Markes sind noch fast ganz unbekannt.

Wenn man dicht hinter der Stelle, wo die Bindearme in das Kleinhirn eintreten, einen Schnitt in froutaler Richtung anlegt, so wird dorsal das Cerebellum, ventral der Pons und die von ihm ausgehende Faserung getroffen, welche sich beiderseits in den Hemisphären verliert. Zwischen Kleinhirn und Haube liegt, beiderseits von den durchschnittenen Bindearmen begrenzt, der Ventriculus quartus, die erweiterte Fortsetzung des

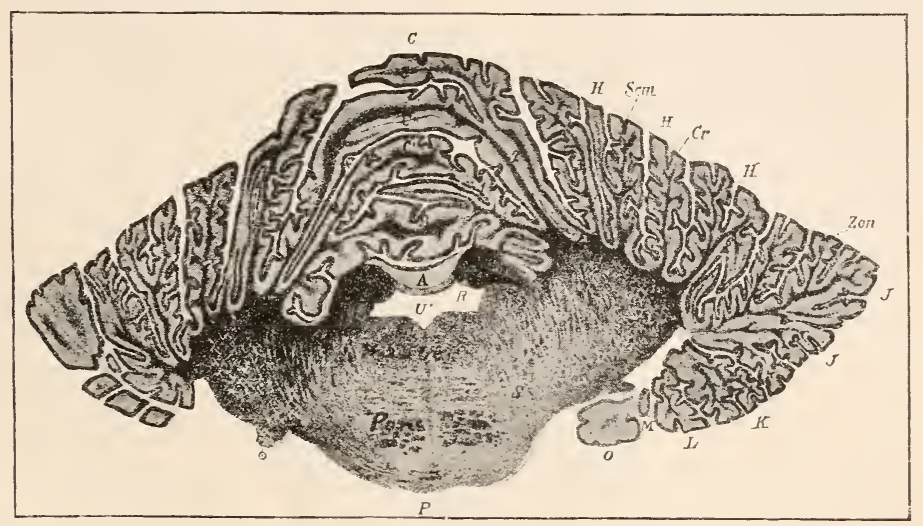

Fig. 210.

Schnitt nahe vor dem Culmen des Berges in frontaler Richtung durch das Cerebellum fallend, nach $\mathrm{B}$. Stilling. $U^{*}$ Tentriculus quartus, $R$ Bindearm, $P$ Pons. Zon Kreuzungszonen. $C r$ Züge aus dem Corpus restiforme, gehen in die halbzirkelförmigen Fasern Sem über. S Gegend des Austrittes der Trigeminuswurzeln.

Aquaeductus Sylvii. Der Markkern des Wurmes fällt an dieser Stelle nicht in die Schnittlinie. Haube und Fuss, letzterer durch die Ponsfasern zerklüftet, liegen noch ganz so angeordnet. wie wir sie zuletzt an einem Schnitte durch die Vierhügelgegend gesehen haben.

Wir haben erfahren, dass aus 3 Armen jederseits Zïge in das Cerebellum treten. Ihr Verlauf darin ist, trotzdem Benedikt stilling lange Jahre der Arbeit auf dessen Studium verwandte, nur noch sehr ungenügend bekannt.

Immerhin haben die Arbeiten der letzten Jahre, besonders solche, welche die Degenerationen verfolgten, die nach totaler oder partieller Entfernung des Cerebellums eintreten, schon eine ganze Anzahl wichtigerer 
Anhaltspunkte zur Topographie geliefert. So ist es endlich möglich, die Abstammung der einzelnen Arme klar zu legen und das alte Stillingsche Schema besserer Einsicht zu opfern.

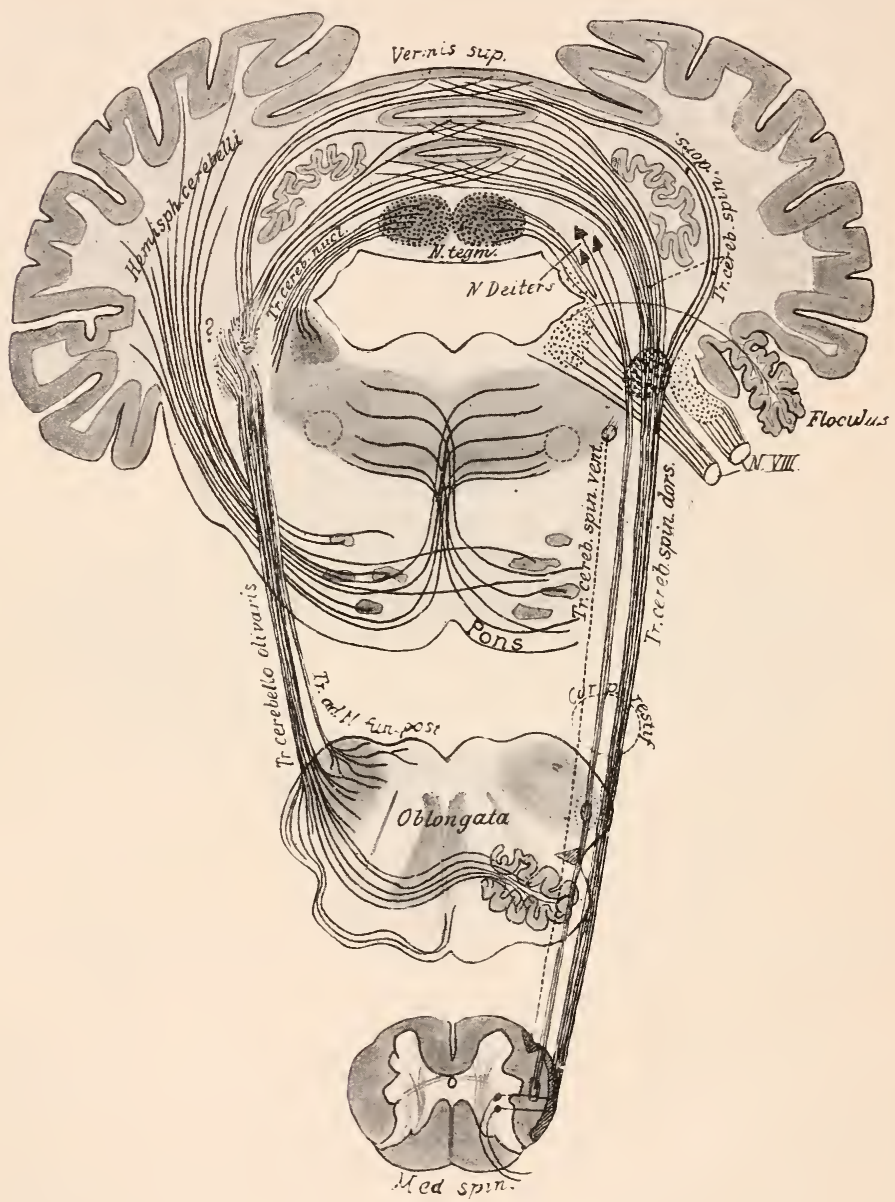

Fig. 211.

Die Arme des Kleinhirnes. Schema.

Das folgende Schema zeigt auf drei Frontalschnitten durch diejenigen Theile, welche unmittelbar mit dem Cerebellum zusammenhängen, das Wichtigste, was heute über die Kleinhirnverbindungen bekannt ist. 
Nach B. Stilling's Ansicht beziehen alle Arme aus ziemlich allen Theilen des Cerebellums Fasern, nur erhält jeder aus einem bestimmten Abschnitte deren besonder's viele.

Die vergleichende Anatomie und die Degenerationsversuche zeigen gleichmässig, dass man, sobald die Kleinhiruverbindungen untersucht werden, sclıarf zu unterscheiden hat zwischen Hemisphärenrinde und Wurmrinde, mo zwischen Rinde und Kleinhirnganglien. Das Corpus dentatum rechne ich - aus vergleichend anatomischeu Gründen - dem Mittelstiicke zu. Nicht Weniges, was in der Degenerationsliteratur iiber Entartung nach Hemisphärenverletzung gesagt ist, bezieht sich auf Verletzungen des lateralen Wurmes.

1. Zunächst kann festgestellt werden, dass die erst bei den Säugern aufgetretene Grosshirnverbindung durch den Brückenarm wohl ausschliesslich zu den Hemisphären des Kleinhirnes gelangt. Woher das innerhalb der Brïckenfaserung verlaufende, aber in der Haube endende, aufsteigende Bündel stammt, ist noch unbekannt. Die Brückenarme enthalten Fasern aus Ganglienzellen der intrapontinen Ganglien, aus denselben Zellen, an welche sich die zahlreichen Collateralen der Grosshirnbrückenbahnen anlegen. S. R. y Cajal hat das anatomisch festgestellt. Auch sehr alte Zerstörungen der Fussfaserung bringen die Brücke nicht zu völligem Schwinden. Der Umstand, dass nach Abtragung einer Kleinhirnhemisphäre ein guter Theil der Brïcke erhalten bleibt, lässt sich nur so deuten, dass die betreffenden Fasern eben aus den Brückenganglien und nicht aus dem Kleinhirne stammen. Der immerhin beträchtliche Faser'schwund nach dieser Operation (Marchi, Minghazzini, Ferrier und Turner) aber lässt vermuthen, dass wenigstens ein Theil der Brïckenfaserung aus Zellen der Hemisphäremrinde stammt.

2. Dann lässt sich auf allen Wegen nachweisen, dass die vorderen Kleinhirnarme a us dem Nucleus dentatus st ammen, vielleicht auch aus der ihm benachbarten Rinde Fasern aufaufnehmen. Sie enden zum allergrössten Theile gekreuzt im rothen Kerne der Ha ube unter den vorderen Vierhïgehn, zu kleinerem im ungekreuzten rothen Kerne und schicken - das ist aber noch nicht völlig' sicher - einige Fasern weiter vor zı den ventralen Thalamusgebieten. Da um den rothen liern eine Bahn aus dem caudalen Theile des Parietalhirnes endet, existirt hier eine indirecte Kleinhirn-Grosshirnverbindung.

3. Die caudalen Kleinhirnschenkel sind sehr viel complicirter zusammengesetzt. Wir müssen sie, wemn ilıre Betrachtung klar werden soll, eintheilen in einen ganz medial liegenden Abschnitt, der nur Beziehungen zu sensorischen Hirmnerven, ganz besonders solche zum Acusticus hat, und in das eigentliche Corpus restiforme, welches hier herauf Fasern aus den gekrenzten Oliven der Oblongata und solche aus dem Rückenmarke führt.

Alt ererbt sind der mediale Abschnitt zu den Hirnnerren und die Bahnen zum Rückeumarke. Erst bei den Säugern werden die Beziehungen zu den Oliven der Oblongata zu kräftigeren Bündeln. 
Das Corpus restiforme endet fast ausschliesslich im Mittelstïcke des Kleinhirnes, wo seine einzelnen Fasertheile sich verschiedenen Gebieten zuwenden.

Die Gegend der Dachkerne und diese Kerne selbst ist die Endstätte des nucleo-cerebellaren Apparates.

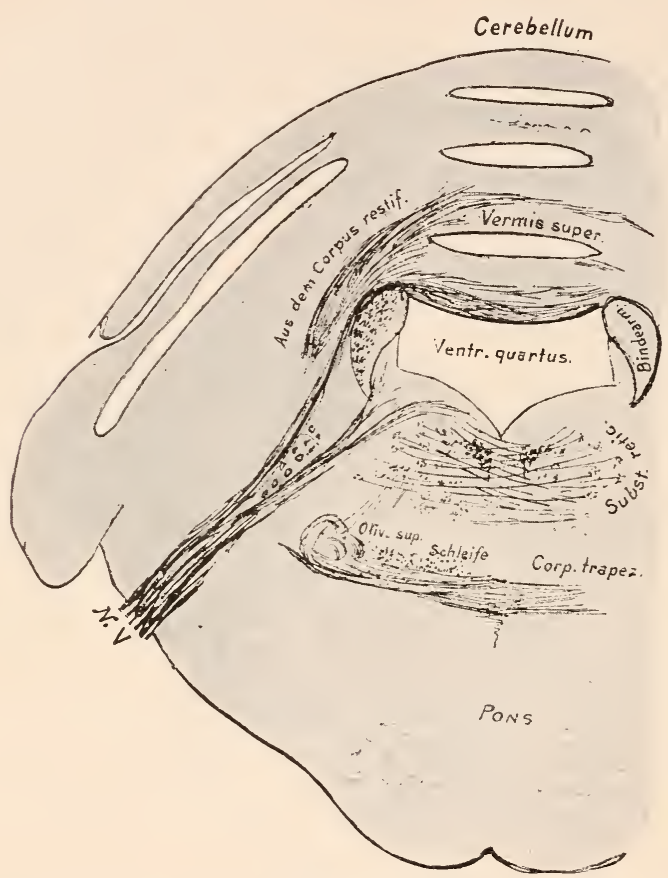

Fig. 212.

Frontalschnitt durch Cerebellum und Pons einer Frncht ron 26 Wochen. Alle markhaltigen Fasern durch Hämatoxylin gefärbt. Der Tractus Nucleo-cerebellaris N. V. sichtbar.

In der Rinde des Wurmes, ganz besonders in deren dorsalen $A b$ schnitten endet die Faserung aus dem Rückenmarke.

Die Endstätte der Olivenbahn bleibt noch zu ermitteln.

Die Bestandtheile des Corpus restiforme wollen wir nun einzeln etwas genauer betrachten.

a) Die Faserzüge aus dem Kleinhirne zu den sensorischen Nerven und ihren Kernen, welche wir früher bei den Fischen schon kennen gelernt haben, existiren auch bei den säugern noch.

Ich habe friiher geglaubt, dass es sich um directe Züge zu den Nervenstämmen handelt. Neuerdings aber sind mir Zweifel gekommen, da ich die Bahn mit voller Sicherheit doch nicht über die Kerne der 
Nerven hinaus verfolgen kamn. Vorsichtiger ist es jedenfalls, das System heute noch als Tractus nucleo-cerebellaris Acustici u.s. w. zu bezeichnen und nicht als directe sensorische Kleinhirnbahn.

Ich werde später noch Gelegenheit haben, Ihnen die Faserung in einigen Abbildungen zu zeigen, heute lege ich Thnen einen Schnitt durch die Brïcke einer Frucht aus dem 7 . Schwangerschaftsmonate vor, an dem Sie den Theil der Bahn erkemnen, welcher in den Trigeminus gelangt, Fig. 213.

b) Viel besser studirt sind die Rïckenmarksverbindungen. Es sind bis jetzt drei Tractus cerebello-spinales bekannt. Zunächst einer, der als secundäre Fortsetzung dorsaler Wurzelfasern mit vollem Rechte betrachtet wird, der Tractus cerebello-spinalis-dorsalis, die Kleinhirnseitenstrangbahn aus der Clarke'schen Säule. Dieser Faserzug macht die Hauptmasse der Rïckemmarksverbindung aus und tritt zu leichtem Bogen gekriimmt, zum Theil das Corpus dentatum umgreifend, zur Rinde des Oberwurmes. Dann kommt in Betracht der Tractus cerebello-spinalis-rentralis, das Gowers'sche Bündel. Sein dreieckiger Querschnitt ist auf allen Schnitten, die Fig. 211 bringt, abgebildet, aber seinen Eintritt in das Kileinhirn verzeichnet die Figur nicht. Er gelangt nämlich in der Haube der Brïcke weithin nach vorn und wendet sich erst in der Gegend, wo die Trochleares abtreten, dorsalwärts, umfasst innerhalb des Velum anticum den hier aus dem Kleinhirne heraustretenden Bindearm und wendet sich nun erst rïickwärts in das Cerebellum (A u erbach, Mott).

Schliesslich ist erst in den letzten Jahren durch Monakow und dann durch Ferrier und 'T urner nachgewiesen worden, dass noch eine dritte Rïckemmarksverbindung besteht. Es handelt sich um dicke Fasern aus einem grossen Kerne multipolarer Zellen, welcher gerade da liegt, wo die hinteren Arme sich in das Cerebellnm einsenken. Der Kern heisst nach seinem Entdecker der Deiter'sche Kern. Wird er zerstört, so entarten absteigend die von ihm ausgehenden Fasern bis in die Gegend der Seitenstränge, welche das Schema Fig. 211 verzeichnet.

Mit dem Corpus restiforme treten noch in das Cerebellum Fasern aus den Endstätten der Hinterstränge. Allen diesen Bestandtheilen des caudalen Kleinhirnarmes werden wir, wenn einmal die Oblongata darzustellen ist, genauere Würdigung zu Theil werden lassen mïssen.

c. Den dritten Bestandtheil des Corpus restiforme bilden die Tractus cerebello-olivares.

Ihre Fasern umgeben sich später mit Mark als die anderen des caudalen Armes. Sie entarten völlig, wemn die Hemisphären abgetragen werden. Der ganze Zug gelangt aus dem Kleinhirne herab zur Oblongata, tritt in diese ein und durchquert sie in mannigfach aufgespaltenen Bündeln, bis er in der gekreuzten Oliva inferior sein Ende findet.

Die Neuroglia des Kleinhirnes ist zunächst dem Ventrikel, wie überall, wo Hohlräume begrenzt werden, ein dichtes Geflecht; auch in der weissen Substanz ist sie mindestens gleich mächtig wie überall im Markweiss entwickelt, in der 
Körnerschicht aber fehlt sie bei gesunden Individuen so gut wie völlig, nur bei Paralytischen hat $W^{\text {e }}$ igert, von dem diese Angaben alle stammen, dort mächtige Wucherung der Glia gefunden. In der Umgebung der Purkinje'schen Zellen liegen dann bis in die innerste Schicht der Molecularschicht hinein kleine dünnere Plexus; in der Molecularschicht selbst sind bisher nur relativ spärliche, senkrecht zur Oberfläche stehende, dicke Fasern - die Bergman n-Deitersschen Fasern bekannt. Der Oberfläche des normalen Kleinhirnes fehlt das sonst ïberall am Nervensystem vorhandene hüllende Glianetz.

Bei allen Embryonen, auch bei Nichtsäugern, findet man aber als äusserste Schicht der Kleinhirninde eine oder mehrere Lagen ron rundlichen Zellen, die später verloren gehen.

Das Aenssere des Kleinhimes ist durch Malacarne, Reil und Burdach so geschildert worden, wie wir es heute kemnen. Die Erforschung des immeren Banes geschah durch F. Arnold, Reil, Kölliker, I eynert, namentlich aber durch B. Stilling. Nenere Untersuchungen über die Zusammensetzung der Arme stammen von B ech terew, II archi, Minghazzini, Ferrier und Turner und von Pellizzi. Ueber die Kleinhirnrinde existirt eine ganze Literatur, zu der namentlich Purkinje, Gerlach, Kölliker, F. E. Sclultze, Obersteiner, Bevor Beiträge lieferten. Genanere Einsicht in den Bau erhielt man aber erst durch Studien von Golgi, Ramon y Cajal, Kölliker und Gehuchten. Hier wie an so vielen anderen Stellen hat erst die Verbesserung der technischen Methoden einen Fortschritt da ermöglicht, wo die eifrigste einfache Beobachtung nur wenig zu Tage förderte.

Erkrankungen der Kleinhirnschenkel werden isolirt nur äusserst selten beobachtet. So kommt es, dass über die Symptome, welche zu erwarten sind, wenn einer derselben befallen wird, nur recht wenig bekannt ist. Langsam eintretende Zerstörung eines Briickenarmes kann, wie es scheint, ganz symptomlos bleiben. Bei Erkrankungen, welche einen Reiz ausüben, bei Blutungen, z. B. und Tumoren, kommen manchmal Zwangsbewegungen, meist Rollungen bald nach der gesunden, bald nach der kranken Seite vor. Auch Zwangshaltung des Rumpfes oder nur des Kopfes, desgleichen Zwangsstellung mit oder ohne Nystagmus sind bei reizend wirkenden Erkrankungen eines Briickenschenkels beobachtet.

Für die Feststellung der durch Erkrankungen des Kleinhirnes bedingten Symptome, sind wir im wesentlichen auf die recht häufigen Tumoren, in zweiter Linie auf die bei Ohreiterungen nicht seltenen Abscesse angewiesen. Es kommen zwar auch Blutungen. Erweichungen, arteriosklerotische und andere Schrumpfungsprocesse im Kleinhirn vor, aber diese Erkrankungen sind entweder sehr selten und beschränken sich meist nicht auf das Kleinhirn, oder aber sie führen, wie z. B. die Blutungen. gewöhnlich so rasch zum 'Tode, lass keine Zeit zur Entwicklung eines speciellen Kleinhirnsymptomencomplexes bleibt. Fiir die T'umoren und in etwas geringerem Grade auch für die Abscesse des Gehirnes besteht nur die Schwierigkeit, dass wir nicht berechtigt sind, alle bei ihnen auftretenden symptome direct auf die Läsion des vom Tumor getroffenen Gehirntheiles zurückzuführen: ausser den sogenamnten Localerscheinungen ruft die Geschwulst fast immer noch zwei andere Symptomgruppen hervor, erstens solche, welche durch die Wirkung des T'umors auf seine Nachbarschaft, zweitens solche. Welche durch Gehirndruck bedingt sind. Wir müssen diese drei Gruppen: Localsymptome. Nachbarschafts - und Allge- 
meinsymptome, stets scharf auseinander halten. Bei der Enge des Raumes unterhalb des Tentorium cerebelli sind die beiden letzteren Gruppen bei Kleinhirnerkrankungen oft besonders ausgeprägt.

$\mathrm{Zu}$ den durch die Affection des Kleinhirnes selbst hervorgerufenen Symptomen, den Localsymptomen, rechnen wir heute die folgenden: 1. die sogenannte cerebellare Ataxie; es ist wahrscheinlich, aber nicht ganz sicher, dass diese ein directes Herdsymptom nur des W urmes und speciell seiner hinteren Hälfte ist. - Tumoren können sie natürlich auch hervorrufen, wenn sie in einer Hemisphäre sitzen. Möglicher Weise beruht die Ataxie zum Theil auf einer Schwäche der Rumpfmusculatur. 2. Schwindelanfälle, echter Drehschwindel, die besonders als Frühsymptome von Wichtigkeit sind. 3. Möglicher Weise eine Art von Tremor, der die Mitte zwischen Ataxie und Intensionstumor hält, und eine ähnliche Störung der Sprache, doch sind das eventuell doch auch Nachbarschaftssymptome. Directe Beziehungen zu den motorischen Functionen im höheren Sinne scheint das Kleinhirn nicht zu haben - auch specifisch psychische Störungen bedingt seine Erkrankung nicht.

Nachbarschaftssymptome kommen bei Kleinhirnaffectionen vor allen von Seiten des Pons, der Nedulla oblongata und der Vierhïgel zu Stande.

A m verlängerten MI arke und a m Pons können zuerst die extramedullären Wurzeln oder das Mark selbst betheiligt werden; später wird beides zugleich afficirt. Besonders wichtige Symptome sind hier die alternirende Hemiplegie und eventuelle Hemianästhesie - Facialis-Abducens an der Seite des Tumors, Extremitäten gekreuzt, gelähmt - oder die Blicklähmung nach der Seite des Tumors. Die Extremitäten allein können auf der Seite des Tumors oder auf der anderen gelähmt sein, je nachdem der Tumor ober-oder unterhalb der Pyramidenkreuzung einwirkt. Auch der plötzliche Tod, der bei Kleinhirnaffectionen häufig ist, ist wohl ein Nachbarschaftssymptom von Seiten der Medulla oblongata. Das erste Symptom ron Seiten der extramedullären Nerven sind manchmal Trigeminusneuralgien.

Nachbarschaftssymptome von Seiten der Vierhügel sind doppelseitige Ophthalmoplegien, die meist die äusseren Aeste des Oculomotorius und den Trochlearis betheiligen, die inneren Augenmuskeln und den Abducens frei lassen. Sie sind bei Kleinhirntumoren ganz besonders häufig.

Deutliche Symptome von Seiten der Kleinhirnschenkel sind bei Geschwïlsten des eigentlichen Cerebellum selten - sie sind oben beschrieben.

Die Allgemeinsymptome sind dieselben wie bei anderen Hirngesclıwïlsten, sie zeichnen sich nur durch besondere Intensität aus. Es sind die Stauungspapille, die hier häufig früh zur Erblindung führt, Kopfschmerz, besonders im Hinterkopfe, manchmal mit Nackenstarre, lartnäckiges Erbrechen, Convulsionen, von denen besonders tonische mit Oposthotonus erwähnt seien. 
Die Diagnose ist, wenn die Symptome ausgeprägt sind, meist leicht. Die Nachbarschaftssymptome sind bei ihrer Prägnanz ron grösster Wichtigkeit. Natïrlich müssen, um die Diagnose Cerebellarkrankheit begriundet erscheinen zu lassen, die Localsymptome den Nachbarschaftssymptomen vorangehen. Die letzteren allein gestatten nicht selten auch die Diagnose der erkrankten Kleinhirnhälfte.

Vierhügelerkrankungen können ganz dieselben Erscheinungen wie die Kleinhimerkrankungen bedingen - hier dürfte meist die Ataxie erst auf die Ophthalmoplegie folgen, umgekehrt wie bei Kleinhirnaffectionen. Eine der cerebellaren ganz gleiche A taxie kann durch Grosshirnaffectionen bedingt werden, hier weisen die ïbrigen Symptome auf eine Erkrankung einer Grosshirnhemisphäre hin (Bruns).

\section{Einundzwanzigste Vorlesung.}

\section{Die Wurzeln der peripheren Nerven, die Spinalganglien und das Riickenmark.}

M. H.! Die peripheren Nerven führen bekanntlich motorische und sensible Fasern gemischt in ihrem Stamme. Nahe am Rückenmarke trennen sich diese aber ron einander. Das Stämmchen, welches die motorischen Fasern enthält, geht direct als vordere Trurzel in das Rückenmark hinien.

Die sensiblen Fasern senken sich in das Spinalganglion.

In den Spinalganglien liegen grosse Zellen, die zuweilen zwei, meistens aber nur einen Ausläufer haben. Ist nur einer da, so theilt er sich aber (Ranvier) bald nach seinem Abgange von der Zelle in zwei, so dass also auch hier schliesslich zwei Zellfortsätze vorhanden sind.

Diese beiden Fortsetzungen aus den Spinalganglienzellen haben Sie schon in der fünften Vorlesung kennen gelernt. Sie erimnern sich wohl noch aus dieser, dass nach den Beobachtungen von $\mathrm{His}$ die sensibeln Nerven aus den Zellen als peripheriewärts gerichtete Fortsätze auswachsen, dass aber dieselben Zellen auch zum Riickenmarke eine Faser senden, die hintere Wurzel.

Da, wie Zählungen beim Erwachsenen zeigen, die hintere Trurzel annähernd so viele Fasern zum Marke führt, als durch den Nerren in das Ganglion eingetreten sind, so möchte es scheinen, als sei einfach in den Verlauf jeder Faser eine Zelle eingeschaltet.

Es ist aber eine wichtige Frage, ob wirklich alle sensiblen Nerven aus Zellen des Spinalganglions stammen. Auf dem Wege des Experimentes, der zuerst von Waller und mit Erfolg später noch oft beschritten wurde, ist es gelungen, sie röllig befriedigend zu lösen.

Jede Nervenfaser, welche von ihrer Ursprungsstelle getrennt wird, entartet. Schneidet man nun einen sensiblen Nerven dicht vor dem Spinalganglion ab, so gehen alle seine Fasern zu Grunde, das Ganglion selbst und die 
aus ihm entspringende Wurzel bleiben fast normal. Das beweist, dass der Schnitt alle Fasern von ihren Zellen getrennt hat. Schneidet man dicht hinter dem Ganglion die sensible Wurzel durch, so entarten im sensiblen Nerven nur einige wenige Fäserchen, die Mehrzahl bleibt erhalten. Sie muss aus Fasern bestehen, welche den Spinalganglienzellen entstammen, denn mit diesen ist sie ja in Verbindung geblieben. Die untergegangenen Fasern miissen aus dem Riickellmarke selbst stammen, demn nur von diesem, nicht von dem Ganglion sind sie ja getrennt. In der That liefert nun die Untersuchung der TVurzel nach diesem Versuche den Beweis dafür. Diese ist von ihrem Ganglion getrennt, und man findet num, dass in ilhr nur ganz wenige Fasern erhalten sind, die Mehrzahl aber zu Grunde gegangen ist. Die erhaltenen Fasern müssen im Rückenmarke ihren Ursprung laben, denn nur mit diesem liängen sie noch zusammen, die untergegangenen müssen aus dem Spinalganglion kommen, denn nur ron diesem waren sie getrennt. Vgl. hierzu übrigens die ein-

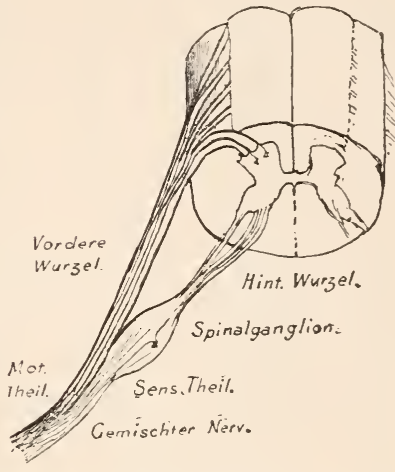

Fig. 213.

Schema der Beziehungen zwischen Rückenmark and Nervenwarzeln. schränkenden Bemerkungen S. 6. u. 7.

Die Versuche zeigen, dass aus dem Ganglion nach zwei Richtungen Zellfortsätze gehen, und dass andere, welche aus dem Rückenmarke stammen, es nur durchziehen. Wahrscheinlich kommen dazu noch Fasern aus peripheren (Sympathicus-)Zellen, die im Rückenmarke enden, s. Fig. 33. Demnach diirfte man sich die Beziehungen der sensiblen Trurzel zum Spinalganglion in der Weise denken, wie das Figur 214 abgebildete Schema sie darstellt.

Zwischen Spinalganglion und Riickenmark entfaltet sich sowohl die sensible. als die motorische Wruel in eine Nenge kleiner Faserstämmchen, „W ur z elfasern*, die auf eine lange Strecke in das Rückenmark eintreten, die sensiblen Fasern auf der Rückseite, die motorischen auf der Torderseite in einen etwas seitlich liegenden Längsspalt. Die Zahl dieser Bündelchen ist nicht gleich fiir alle Wurzeln und ist auch bei verschiedenen Individuen öfters eine verschiedene.

Nach neueren Cntersuchungen darf man für die Extremitätennerven nicht mehr an-

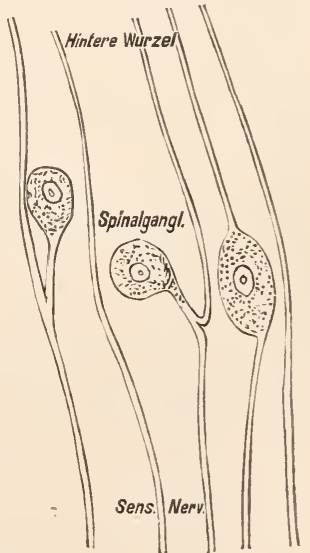

Fig. 214.

Schema der Faserung in einem Spinalganglion. nehmen, dass jede Wurzel zu einem bestimmten peripheren Nerv in Beziehung steht. Es ist nachgewiesen, dass in jeden Extremitätennerv eine 

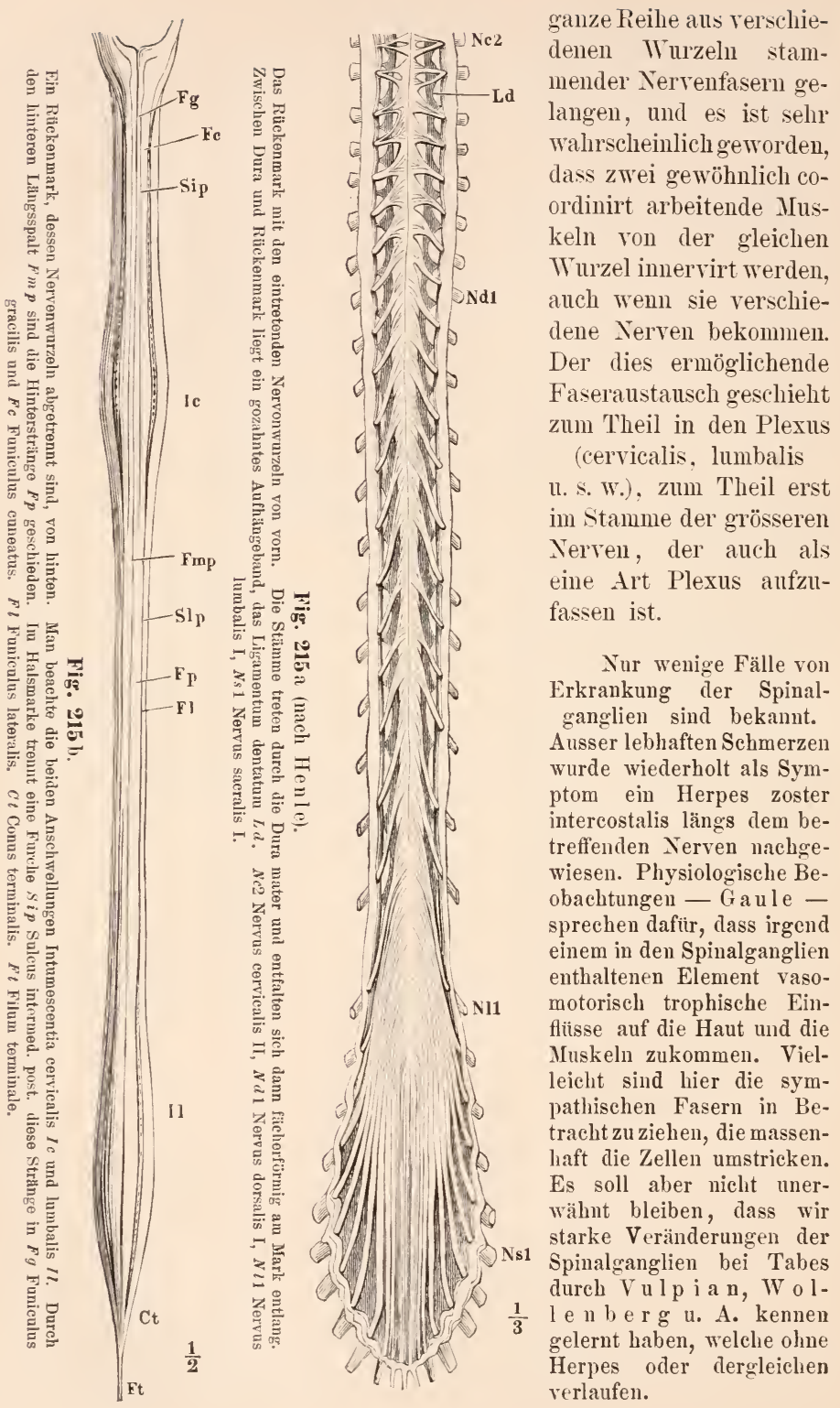
Die Wurzeln der peripheren Nerven, die Spinalganglien und das Rückenmark. 313

Die Wurzeln treten also längs des Rückemmarkes in dieses ein.

Da, wo starke Wurzeln, aus den Extremitäten kommend, herantreten, schwillt das Mark etwas an. Die Intumescentia cervicalis nimmt die Armmerven, die Intumescentia lumbalis die Beinnerven auf. Die schmalste Stelle des Rückenmarkes giebt den Intercostalnerven Ursprung. Das unterste, kegelförmig endende Stïck des Markes heisst Con us te r minalis; aus ihm entspringt ausser den Nerven ein langer, diinner Fortsatz, das Filum terminale.

Die obere Begrenzung wird durch den Anfang der Pyramidenkreuzung: (s. u.) gegeben.

Am Krankenbette tritt zuweilen die diagnostisch wichtige Frage an Sie heran, in welcher Höhe die Wurzeln entspringen, denen bestimmte gelähmte Muskeln oder anästhetische Hautpartien ilıre Innervation verdanken. Man hat sich bemiiht, diese Frage, der die reine Anatomie nie näher treten konnte, durch das Thierexperiment zu lösen. Für den Menschen ist wiederholt versucht worden, die Fälle, in denen localisirte Erkrankungen des Rückenmarkes (Quetschungen, Blutungen u. s. w.) zu bestimmten Störungen gefïhrt hatten, in dieser Hinsicht zu verwerthen. Ich lege Ihnen heute, nur wenig modificirt, die Resultate vor, zu denen Starr auf diesem Wege gekommen, als er alle ihm 1590 zugänglichen Fälle vergleichend zusammenstellte. Wahrscheinlich ist da und dort bei weiterer Erfahrung noch Berichtigung nöthig.

\section{Localisation der Function in den verschiedenen Segmenten des Rückenmarkes.}

\begin{tabular}{|c|c|c|c|}
\hline Segmente & Muskelu & Reflexe & $\begin{array}{c}\text { Gefühlsinnervation } \\
\text { der Hant }\end{array}$ \\
\hline
\end{tabular}

2.-3. Cervicalis Sterno-mastoidens

Trapezins

Scaleni und Nackenmuskeln

Diaphragma

4. Cervicalis

Diaphragma

Supra- und Infraspinatus Deltoides

Biceps u. Coraco-Brachialis

Supinator longus

Rhomboidei

5. Cervicalis

Deltoides

Biceps n. Coraco-Brachialis Smpinator longus et brevis Pectoralis, pars clavicul.

Serratus magnus

Rhomboidei

Brachialis ant.

Teres minor

6. Cervicalis
Biceps

Brachialis anticns

Pectoralis, par's clav.

Serratus magnus

Triceps

Extensoren der Hand und der Finger

Pronatoren
Inspirat. bei raschem Nacken n. Hinterkopf. Druck 11. d. Rippenbogen

Erweiterung d. Pupille anf Reizung des Nackens. 4. his 7. Cervic.

Scapular-Reflex 5. Cerv. bis 1. Dors. Sehnemreflexe $d$. entspr. Muskeln

Nacken

Obere Schnltergegend Aussenseite des Armes

Rïckseite der Schulter und des Armes

Aeussere Seite des Oberund Vorderarmes

Reflexe von den sehnen d. Extensoren d. Ober- u. Unterarmes

Handgelenksehnen 6. - 5 . Cerv.
Aeussere Seite des Vorderarmes

Rïcken der Hand, Radialisgebiet 


\begin{tabular}{|c|c|c|c|}
\hline Segmente & II uskeln & Reflexe & $\begin{array}{c}\text { Gefuihlsinnerration } \\
\text { der Haut }\end{array}$ \\
\hline
\end{tabular}

\begin{tabular}{l|l|l}
\hline 7. Cervicalis & $\begin{array}{l}\text { Caput longum Tricipitis } \\
\text { Extensoren der Hand und } \\
\text { der Finger }\end{array}$ & $\begin{array}{l}\text { Schlag auf die Vola } \\
\text { erzeugt Schliessen } \\
\text { der Finger }\end{array}$
\end{tabular}

Flexoren der Hand
Pronatoren der Hand
Pectoralis, pars costalis

Subseapularis

Latissimus dorsi

s. Cerricalis $\begin{aligned} & \text { Teres maior } \\ & \text { Flexoren der Hand und } \\ & \text { der Finger }\end{aligned}$

1. Dorsalis

Kleine Handmuskeln

Strecker des Daumens

Kleine Handmuskeln

Daumen- und KleinfingerBallen

2.-12. Dorsalis Muskeln des Rïickens und des Bauches

Erectores spinae

1. Lumbalis Ileo-Psoas

Sartorius

Bauchmuskeln

2. Lumbalis

Ileo-Psoas

Sartorius

Flexoren des Knies

(Remak?)

Quadriceps femoris

3. Lumbalis Quadriceps femoris

Einwärtsroller $d$. Schenkel

Adductores femoris

4. Lumbalis Abductores femoris

Adductores femoris

Tibialis anticus

Flexoren des Kunies

(Ferrier?)

5. Lumbalis

Auswärtsroller der Hüfte

Beuger des Knies

(Ferrier?)

Beuger des Fusses

Extensoren der Zehen

Peronei

1. u. 2. Sacralis Flexoren des Fusses u. der Zehen

Perowei

Kleine Fussmuskeln

3.-5. Sacralis Muskeln des Perineum

Glutäalreflex
$4 .-5$. Lumb.
.
Plantarreflex
Achillessehne
Blasen- und Rectal-
centren
Radialisgebiet d. Hand

Palmar-Reflex P

Pupillarreflex

Epigastr.4.-7.Dors. Haut der Brust, des Abdomen 7.-11 D.

Cremasterreflex 1. -3 . Lumb.

Patellarsehne

2. -4. Lumb.

Rückens, des Bauches und der oberen Glutäalregion

Haut der Schamgegend Vorderseite des Hodensackes

Aeussere Seite der Hüfte

Vorder- und Innenseite der Hiifte

Innere Seite der Hüfte und d. Beines bis zum Knöchel. Innenseite des Fusses

Rückseite d. Hüfte, des Oberschenkels und änsserer Theil des Fusses

Hinterseite des Oberschenkels, äussere Seite des Beines und Fusses

Haut über dem Sacrum, Anus, Perineum, Genitalien

Der Faserverlauf im Rïckenmarke. meine Herren, ist nur zu einem Theile bekannt. Zum Verständniss desselben ist es nothwendig, dass Sie sich mit dem Bilde, welches ein Schnitt quer durch das Organ bietet, voll vertraut machen.

Auf einem solchen Querschnitte erkennen Sie zunächst weisse Substanz in der Peripherie und grane Substanz in H-Form im Centrum. Die beiden Rückenmarkshälften sind getremit durch die vordere und hintere Längsfurche, verbunden durch eine Commissur weisser Substanz 
vorn, grauer Substanz hinten. Die rordere Ausdehnung der grauen Substanz nennt man die Vorderhörner oder Vordersäulen, die hintere die Hinterhörner, resp. Hintersäulen.

Die Vertheilung von weisser und grauer substanz ist nicht in allen Querschnittshöhen die gleiche. Namentlich überwiegt rom oberen Lendenmark an abwärts entschieden die graue Substanz. Fig. 217 zeigt Querschnittsbilder aus den verschiedenen Höhen des Rückenmarkes.

Ausser der verschiedenen Vertheilung der beiden Substanzen wollen Sie an derselben noch beachten, wie der lateralste Theil des Vorderhornes im unteren Hals- und oberen Brustmarke mehr und mehr selbständig wird und schliesslich (Fig. $217 D_{1}$ und $D_{3}$ ) als eigener Fortsatz, Seiten horn

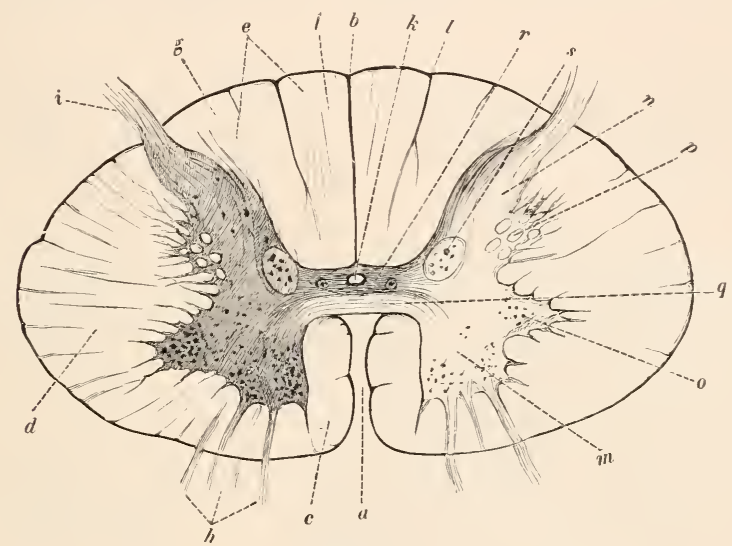

Fig. 216.

Halbschematischer Querschnitt des Rückenmarkes nach Erb.

$a$ vordere, $b$ hintere Längsfurch $\theta, c$ Vorderstrang, $d$ Seitenstrang, $e$ Hinterstrang, $f$ Funic. gracilis, $g$ Funic. cuneatus, $h$ vordere. $i$ hintere Wurzel, $k$ Centralkanal. $l$ Sulcus intermed. post., $m$ Vordersäule, $n$ Hintersäule, $o$ Tractus intermedio-lateralis, $p$ Processus reticulares, $q$ vordere Commissur ans weisser Substanz, $r$ hintere oder graue Commissur, $s$ Clarke'sche Säule oder Columna vesicularis.

oder Tractus interm edio-lateralis genannt, sich abhebt. Im unteren Brustmarke verschwindet das Seitenhor'n wieder. Auf Fig. 216 ist es bei 0 angegeben.

Im ganzen Hals - und im oberen Brustmarke ist unter dem Tractus intermedio-lateralis, im Winkel zwischen ihm und dem Torderhorne, die graue Substanz nicht scharf abgegrenzt, sie geht vielmehr in ein Netz von grauen Balken und Zügen über, das weithin in die weisse Substanz hineinragt. Dieses Netz heisst Processus reticularis.

Am Conus terminalis hat die grane Substanz nur noch einen dïmen Ueberzug weisser Fasern (Co der Fig. 217).

Ich will thnen nun zunächst beschreiben, was die einfache anatomische Untersuchung ron Schnitten durch das Riickenmark lehrt. 
Die Wurzelfasern der motorischen Nerven treten am Spinalganglion vorbei direct in das Rückenmark, durchziehen dessen weisse substanz und senken sich in die Vorderhörner ein. Alle in ihnen enthaltenen Axencylinder verbinden sich so, wie es hier auf Fig. 215 abgebildet ist, mit je einer der grossen dortliegenden Ganglienzellen. Eine Vorderhornzelle mit vielen Ausläufern ist in Fig. 4 u. Fig. $6 \mathrm{D}$ abgebildet. Nicht alle Zellen stehen in directer Verbindung mit Wurzelfasern.
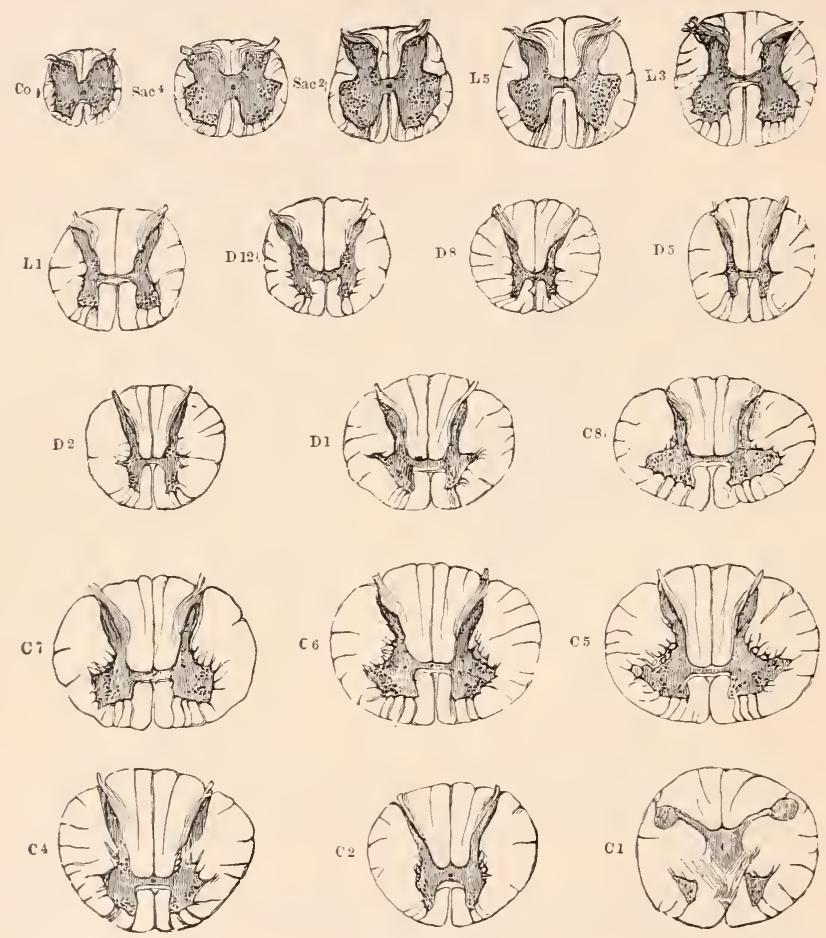

Fig. 217.

Schnitte durch das Rückenmark in verschiedenen Höhen. Die Buchstaben und Zahlen bezeichnen die Spinalnerven, deren Abgangshöhe die einzelnen Schnitte entsprechen. Nach $Q \mathrm{u} a \mathrm{in}$.

Die Vorderhornzellen sind zumeist in Gruppen angeordnet. Welche Beziehung die einzelnen Gruppen zu den Wurzelu haben, ist nur theilweise bekannt. Voraussichtlich ist ein Gewinn für unser Wissen zu erwarten, wenn in allen Fällen, wo intra vitam ein Ausfall in der Peripherie sich wohl umgrenzen liess, post mortem eine sorgfältige, speciell auf die Localisation von veränderten Ganglienzellen gerichtete Untersuchung stattfindet. Jeder von Ihnen, meine Herren, kann berufen sein, uns hier voranzuhelfen. So wird es wichtig sein, dass Sie sich mit einer Eintheilung der Zellgruppen im Rückenmarkgrau bekannt 
machen, die, auf morphologische Befunde gestützt, das rein thatsächlich einstweilen Bekannte umfasst. Eine solche Eintheilumg verdanken wir W aldeyer. Ich lege Ihnen in der Abbildung Fig. 219 (S. 31S) dieselbe vor. Die im Halsmarke sehr gut abgegrenzten und im Lendenmarke besonders zellreichen Gruppen sind im Brustmarke weniger gut ausgeprägt, entsprechend dem geringeren Volum und vielleicht auch den andersartigen Functionen der dort entspringenden Nerven.

Keine der Zellgruppen, ansser etwa der medialen linteren Gruppe, ist durch die ganze Länge des Rïckenmarkes continuirlich zu verfolgen. Manches spricht dafür, dass diese Gruppe der Imnervation der Rủckenmusculatur dient. Aus dem Cervicalmarke stammt, wie die Tabelle S. 313 zeigt, der Plexus brachialis. Für seine Einzelbestandtheile hat die Durchforschung all der Fälle, in denen vom Rückenmarke lier Ausfall der Function eingetreten war, Kayser, Collins, schon die Kerne kennen gelehrt. Es entstammen den lateralen Zellgruppen im Cervicalmarke die Nerven für die Beuger, den melır medialen diejenigen fuir die Strecker am Arme und an der Hand.

Die IIurzeln der sensiblen Nerven gelangen, nachdem sie das Spinalganglion passirt haben, zum Theil direct in das Hinterhorn, znm Theil in die weissen Hinterstränge. Der Zellencomplex des Spinalganglions ist der eigentliche Ursprungskern für die Mehrzahl dieser Fasern. Sie erimnern sich noch, dass, wie die Entwicklungsgeschichte lehrt, die Axencylinder aus den Zellen dieses Ganglions peripherwärtsinden Nerven, centralwärts in das Rïckenmark auswachsen. Der centrale Ausläufer bildet das, was wir hintere Wurzel nennen. Mit ilm aber treten auch noch Fasern ein, welche nicht aus den Zellen der Spinalganglien stammen.

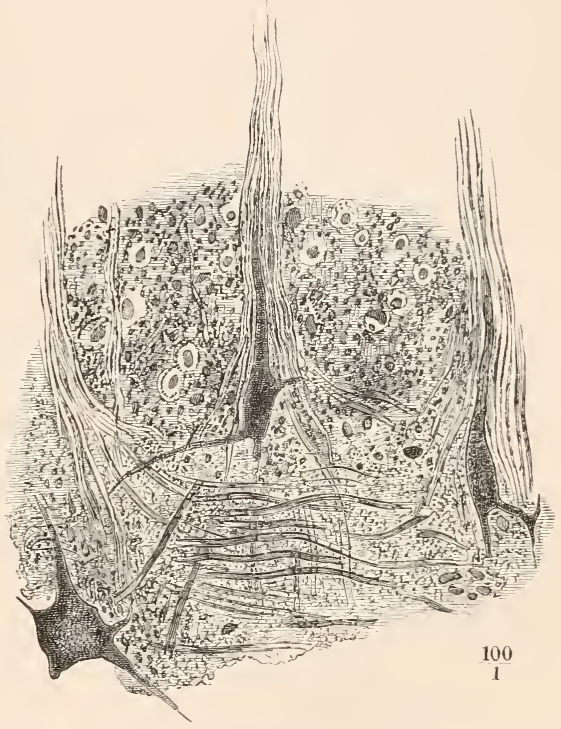

Fig. 218.

Vom vorderen Rande eines Querschnittes der grauen Tordersäule, Uebergang der Zellfortsatze in die vorderen Wurzeln. Carminpräparat ${ }^{100}{ }_{11}$. Nach $\mathrm{Henle}$.

Wie unabhängig Hinterwurzel und Rïckenmark in ilırer Entwicklung von einander sind, das lehrt ein Fall, den Leonow a beobachtete. Hier fehlte die ganze Rückenmarkanlage bei einer Missbildung, die Spinalganglien aber waren vorhanden, und aus ihnen gingen nicht nur periphere Nerven, sondern auch ganze Bündel von Hinterwurzeln hervor, die natïrlich frei in den Wirbelkanal hineingewachsen waren.

Die im Hinterhorne liegenden Ganglienzellen sind kleiner als die Torderhornzellen. Meist haben sie eine der Spindel sich nähernde Gestalt. Ihr 
Axencylinder verzweigt sich entweder schon nahe an der Zelle zu einem feinen Flechtwerke, ähnlich dem in Fig. 152 g unten links abgebildeten, oder er zieht in der Rückenmarksubstanz weiter. Nie geht er in eine periphere Nervenfaser ïber.

Zwei Gruppen treten im Hinterhorne durch ihre Form und Farbe auch schon für das nackte Auge deutlich hervor. Die Gruppe der Columna vesicularis, von stilling zuerst, damn von Clarke genauer studirt, meist Clarke'sche Säule genannt (Fig. 216 s), liegt etwa da, wo Vorderund Hinterhorn zusammenstosselı. Ausser den Zellen enthält sie noch ein feines Fasergeflecht und Bündelchen ausserordentlich feiner, in der Längsaxe des Rückenmarkes verlaufender Nervenfasern.

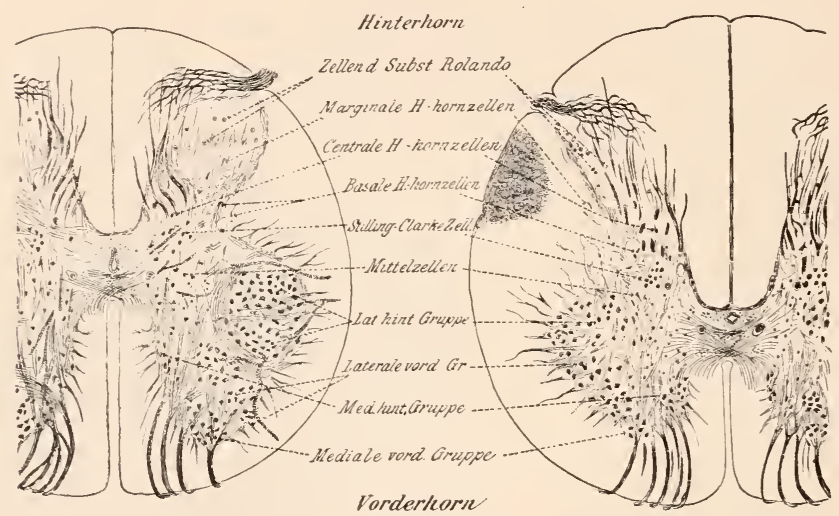

Fig. 219. Nach Waldeyer, wenig modificirt.

Schnitt durch

den caudalen Theil der Halsanschwellung.

die Lendenanschwellung.

Die Eintheilung beruht auf den Bildern, welche sich am reifen Rückenmarke mit Carmin darstellen lassen. Andere Jiethoden zeigen, dass, wenigstens am fötalen Marke, in einzelnen Gebieten sehr viel mehr Zellindividuen vorhanden sind, als hier gezeichnet wurden.

Ihr rundlicher Querschnitt ist deutlich abgegrenzt nachweisbar nur etwa vom Ende der Halsanschwellung bis zum Anfange der Lendenanschwellung. Einzelnen Zellen von ähnlichem Aussehen wie die in der Säule enthaltenen begegnet man aber in ihrer Verlängerung bis in die Oblongata hinauf.

Schärfer noch als die Stilling-Clarke'sche Säule hebt sich rom Grau des Hinterhornes die Substantia gelatinosa Rolandi ab. Sie liegt an der Spitze des Hinterhornes und wird dort von zahlreichen eintretenden Hinterwurzelfasern durchbrochen. Solange die Färbemethoden noch nicht genïgend ausgebildet waren, blieb die Bedeutung dieser eigenthümlich glasig durchscheinenden Substanz immer unklar. Erst in den 
letzten Jahren ist es gelungen, in ihr Zellen nachzuweisen, welche ähnliche Charaktere zeigen, wie die in den Hinterhörnern liegenden.

Was aus deren Axencylindern wird, schien besonders schwer, in einem Gebiete zu ermittehn, das ohnehin schon von unzähligen Axencylindern und Collateralen solcher durchzogen wird. Neuerdings konnten S. Ramon y Cajal und bes. v. Lenhosseck zeigen, dass die Axencylinder spindelförmiger Zellen (Marginale Zellen der Fig. 219), welche die Peripherie der Rolando'scheu Sub-

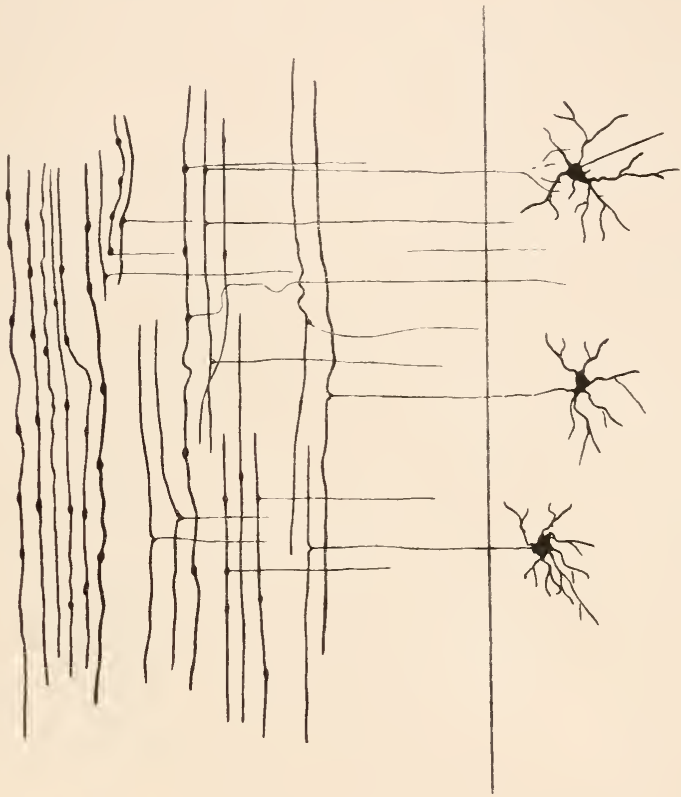

Fig. 220.

Längsschnitt durch den Seitenstrang vom neugeborenen Hunde. Die linke Hälfte der Zeichnung, nach einem Originalpräparat von $\mathrm{Ramon} y \mathrm{Cajal}$, zeigt Axencylinder, die Collateralen in die grane Substanz senden, und Axencylinder, die, aus Zellen dort kommend, sich in einen auf- und einen absteigenden Ast theilen. Die Zellverbindungen rechts sind Schema.

stanz umgeben, in den dorsalen Theil des Seitenstranges gerathen, und dass die aus den mehr sternförmigen schmalen Zellen, welche in der Substanz selbst liegen, in den benachbarten Hinterstrang und in die sogenamite Randzone des Hinterhornes eintreten. Die letzteren Zellen besitzen nicht einen, sondern mehrere Ausläufer vom histologischen Charakter eines Axencylinders.

Die weisse Substanz, welche die grane umgiebt, besteht wesentlich aus in der Längsaxe des Rückenmarkes verlaufenden Fasern, zu denen noch die schräg aufsteigenden Fasern der Nervenwurzeln und eine gewisse Anzahl von anderen Fasern kommen, welche mehr oder weniger senk- 
recht zur Längsaxe aus der grauen Substanz heraus zu den weissen Faselsträngen ziehen. Die Nervenfasern haben einen Axencylinder und eine Markscheide. Die Breite der letzteren wechselt sehr. Eine Schwannsche Scheide fehlt ihnen.

Der Axencylinder ist ein längsgestreiftes Gebilde iiberall, wo man ihn bisher untersucht hat. Wahrscheinlich besteht er aus zahlleichen einzelnen Fäserchen. Neuere Untersuchungen haben mun gezeigt, dass die Axencylinder der im Rückenmarke verlaufenden Nervenfasern nicht sich als Ganzes in die Endstätten innerhalb der grauen substanz einsenken, sondern dass es sich hier um eine Art Aufsplittern handelt. An allen langen Nervenfasern sieht man innerhalb der weissen stränge und auch innerhalb der grauen Substanz, dass in gewissen Abständen, senkrecht zur Axe, ein feines Fäserchen sich ablöst, dass dieses nach der grauen Substanz hinstrebt, und man erkemnt zuweilen, dass es dort sich in einen feinen Pinsel auflöst. Die Stelle, wo diese „Collateralen" vom Stamme abgehen, ist meist durch eine kleine Verdickung gekennzeichnet.

Das Rückenmarkweiss ist ron zahlreichen, radiär gestellten Septen durchzogen. In diesen, die von Neuroglia gebildet sind, dringen die Randgefässe des Markes in die Tiefe.

Die Nervenfasern in der weissen Substanz sind alle von einem lockeren Netz von Neurogliafasern umspomen. In der grauen Substanz findet sich die dichteste Auhäufung in der Umgebung des Centralkanales. Substantia gris ea. Sie erscheint fïr das blosse Auge bei der Weigert'schen Färbung als dunkelblauer Fleck.

Weniger dicht, aber dichter, als in der weissen Substanz ist das Gliageflecht in den Vorderhörnern. Am spärlichsten im ganzen Querschnitte des Rückenmarkes sind die Gliafasern in der Substantia gelatinosa Rolandi.

Auch die ganze Peripherie ist von einem dümnen Mantel fast reiner Gliasubstanz überzogen, der gelatinösen Rindenschicht (Fig. 219 rechts). Ebenso findet sich an der Spitze des Hinterhornes eine besonders dichte Gliawucherung. Hier erleidet die eintretende Hinterwurzel, wesentlich auf Kosten ihrer Markscheiden, eine wahre Verdünnung, so dass sie im Sclmitte wie eingeschürt erscheint. Obersteiner und Redlich.

Teber das Epithel des Centralkanales bei Föten orientirt Sie Figur 5. Auch bei jugendlichen Individuen liegen die Zellen noch in regelmässiger Reihe der Gliaschicht direct auf. Ihre Flimmern verlieren sie wahrscheinlich schon bald nach der Geburt, doch bleibt zeitlebens eine eigenthümliche Schicht kleiner regelmässig gestellter Körnchen am inneren Zellrande erhalten, die schon beim Fötus dicht unter den Flimmern nachweisbar ist. In dem Maasse, wie die Epithelzellen älter werden, scheint ilıre Resistenz sich zu schwächen. Sie weichen auseinander, lassen Gliafasern zwischen sich hindurchtreten, ja sie lösen sich von ihrer Unterlage ab und liegen als wirr oder in kleineren Kränzen zusammengeballte Haufen mitten zwischen den in die freigewordenen Räume mächtig einwuchernden Neurogliafasern. Es entsteht durch diese Verwachsung eine lumenlose Zellmasse an Stelle des urspriinglichen Centralkanales, oder man findet ein oder mehrere selır kleine Lumina im Centrum des Rinekenmarkes. Weigert.

So viel lässt sich durch die Untersuchung von Schnitten durch reife Rïckenmarke ermitteln. 
Man ist aber in der Erkemntniss des feineren Banes viel weiter gekommen.

Durch die eintretenden Turzeln und durch die Längsfurchen wird das Rückenmark. wie ein Blick auf den Querschnitt zeigt, in einzelne Stränge abgetheilt. Medial ron den Wurzeln liegen die Torder-, resp. Hinterstränge, lateral von ihnen die seitenstränge.

Das Studium der Entwicklungsgeschichte. sowie die Folgen der Faserunterbrechung, auch die Untersuchung

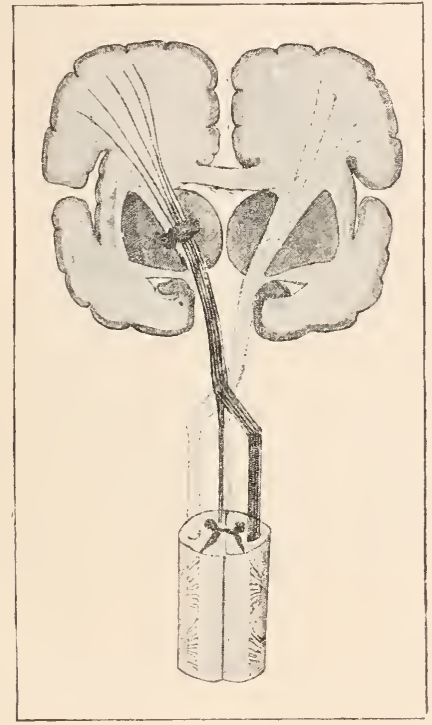

Fig. 221.

Schema der absteigenden Degeneration in dem Tractus cortico-spinalis bei einem Erknkheitsherd in der Capsula interna links. gewisser Krankheiten des Rückenmarkes haben gelehrt. dass diese Torder-, Hinter- und Seitenstränge nicht einheitliche, gleichwerthige Fasermassen sind, wie es wohl bei Betrachtung desQuerschnittes eines g'esunden Rückenmarkes rom Erwachsenen scheinen mag, dass sie sich vielmehr aus mehreren Abtheilungen zusammensetzen.

Sie erimnern sich wohl noch des Tractus corticospinalis, der Py$\mathrm{r}$ a $\mathrm{m}$ i d e $\mathrm{n}$ b a h $n$, jenes Faserzuges, den wir ron der Rinde der motorischen Region durch die Kapsel und den Hirnschenkelfuss bis in die ventralen Theile der Brücke verfolgt haben. Lassen Sie uns zunächst suchen, wohin sich diese Bahn im Rückenmarke begiebt. Es ist nicht so schwer, sie dort zu finden. Wenn sie nämlich irgendwo in ihrem langen Terlanfe durch einen Krankheitsherd zerstört wird, so schwinden allmählich ihre Nerrenfasern; sie werden durch Bindegewebe ersetzt. Diese Entartung; welche man als secundä re Degeneration bezeichnet. setzt sich nach abwärts
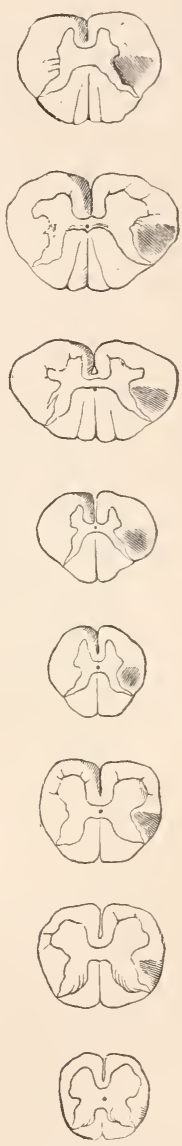

Fix. 222.

Secundäre absteigende Degeneration nach einem Erkrankungsherd in der linken Grosshirnhemisphäre. Nach Erb. 
bis in das Rïckenmark fort. Sie nimmt da zwei stellen ein: einmal den innersten Theil des Torderstranges derjenigen Seite, wo die Zerstörung im Hirne liegt, und dann ein grosses Gebiet im Seitenstrange der g e kreuzten Seite. Hoch oben, da wo die Oblongata beginnt. sieht man, dass jener gekreuzte Theil sich hinüber zum ungekreuzten begiebt, sich also mit der nicht degenerirten Pyramidenbahn kreuzt.

Die Bahn. welche also von der Degeneration in absteigender Richtung befallen wird, heisst, wie im Gehirne, so auch im Rïckenmarke, Tractus cortico-spinalis, Pyramidenbahn. Sie zerfällt in letzterem in die Pyramiden-Torderstrangbahn (innerste Partie der Vorderstränge) und in die Pyramiden-Seitenstrangbahn (in der hinteren Hälfte der Seitenstränge). Es ist Grund zur Annahme rorhanden, dass diese

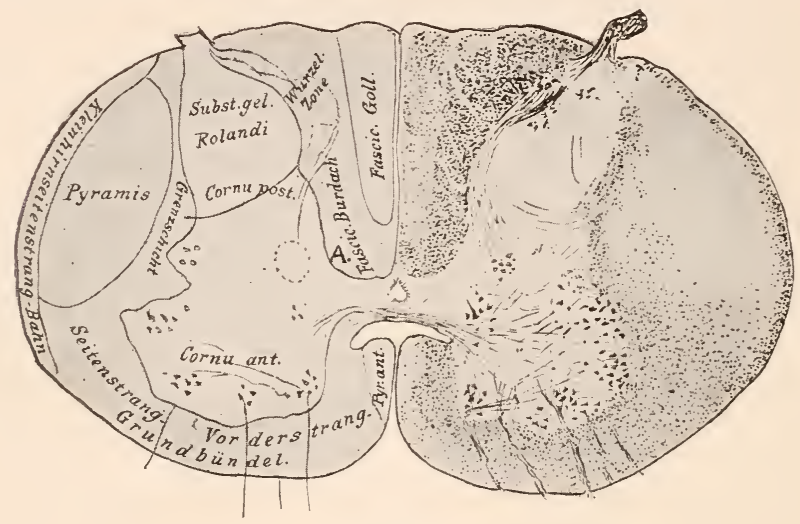

Fig. 223.

Querschnitt durch das Halsmark eines Neugeborenen. Die Pyramidenbahnen ohne markhaltige Fasern, durchscheinend hell. Die Pyramiden-Vorderstrangbahn ragt weit in die Peripherie des Vorderseitenstranges hinein.

Pyramidenbahnen die Mehrzahl der Fasern rom Gehirne zum Rückenmarke führen. welche der erïbten Bewegung dienen. Sie entarten nur absteigend, ihre Nerren schwinden regelmässig. wenn der Querschnitt der Bahn irgendwo im Gehirne oder auch im Rückenmarke zerstört wird.

In dem Areale der Seitenstränge, welches die Tractus cortico-spinales einnehmen, verlaufen noch eine Anzahl. von Fasern, die, den Associationsbündeln des Rückenmarkes angehörend, verschiedene Höhen desselben unter einander verknüpfen. Gerade die längsten Fasern dieser Kategorie liegen in dieser Gegend. So kommt es, dass bei Unterbrechung des Seitenstranges im Rückenmarke ein grösseres Areal absteigend degenerirt. als dem Pyramidenfelde in der Oblongata entspricht. Aus diesem Umstande ist der viel rerbreitete Irrthum entsprungen, dass die Pyramide noch Fasern aus dem Rïckenmarke selbst empfange. 
Zur Zeit der Geburt haben beim Menschen alle Bahnen im Rückenmarke ihre Myelinscheiden. Nur den Tractus cortico-spinales fehlen sie noch. Beim Nengeborenen erscheinen daher die Pyramidenbahnen grau im weissen Rückenmarksquerschnitte (s. Fig. 223).

Bei Thieren ist die Pyramidenbahn entsprechend der geringeren Ausdehnung der Grosshirnrinde immer dünner als beim Menschen. Auch bei diesem enthält sie wahrscheinlich nur Fasern für diejenigen Muskeln, welche vorwiegend unter Inanspruchnahme der Rinde - also iiberlegt und eingeübt - gebraucht werden. Jedenfalls nimmt sie nach Abgabe des für die Innervation der oberen Extremitäten bestimmten Theiles erheblich ab, bleibt im Brustmarke wesentlich gleich stark und verliert nach Abgabe der Fasern für die Unterextremitäten so an Volum, dass sie im unteren Lendenmarke so gut wie verschwunden ist. Untersuchungen dieser Bahn an Thieren, die sich vorwiegend der Hände bedienen - Affen, Grabthiere - und an solchen, die wesentlich mit den Hinterextremitäten arbeiten - Beutler etwa wären erwünscht. Sie müssten sich aber auf entwicklungsgeschichtliche oder degenerative Facta stiitzen, denn nur solche gestatten ein reines Ausscheiden der Pyramidenbahn.

Die Untersuchung secundär degenerirter Rückenmarke lässt uns in die Zusammensetzung der weissen Stränge aber noch ein Stück weiter eindringen. Schneiden wir ein Rückenmark, das durch Druck oder eine andere Schädigung im Brusttheile unterbrochen ist, so finden wir, wie es nach dem Ihnen eben Torgetragenen zu erwarten ist, caudal vom Herde der Erkrankung die unterbrochenen Pyramidenbahnen jederseits absteigend degenerirt. Aber auch cerebral von der Tnterbrechungsstelle zeigt sich eine Degeneration. Sie nimmt Anfangs das ganze Areal der Hinterstränge ein, beschränkt sich aber, einige Wurzelhöhen weiter, auf die mediane, der hinteren Incisur anliegende Partie derselben. Leicht können wir an solchen Präparaten die Hinterstränge trennen in äusere und in innere Stränge. Was hier aufsteigend (bis in die Oblongata) degenerirt, sind Fasern der hinteren Wurzeln, welche von ihren Ganglienzellen, in den Spinalganglien, abgetrennt sind. Führt man experimentell die Durchschneidung dieser Turzeln ganz nahe am Rückenmarke aus (Sing er), so bekommt man ganz genau das gleiche Degenerationsbild. Dicht über der Durchschneidungs-

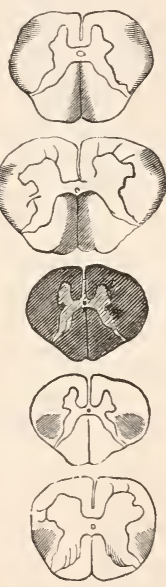

Fig. 224.

Secundäre auf - und absteigende Degeneration bei einer Querschnittsaffection im oberen Brustmarke. Nach Strüm pell. stelle sind die äusseren und die inneren Hinterstränge degenerirt, weiter oben aber, wo neue, gesunde Trurzelfasern wieder eingetreten sind, legen diese sich aussen von den kranken an, und es rücken so, je höher man kommt, die entarteten Fasern immer näher an die Medianlinie.

Was wir eben durch die Untersuchung der degenerirten Hinterstränge erfahren haben, das bestätigt das Studium der Markscheidenentwicklung. Auch es lehrt, dass dort mindestens zwei Fasergebiete enthalten sind: ein 
äusseres Gebiet. gewöhnlich als Grundbündel der Hinterstränge, auch als Keil-oder Burdach'sche stränge bezeichnet, und ein inneres. dem man den Namen der zarten Stränge oder auch der Gollschen Stränge gegeben hat. Am normalen Narke des Erwachsenen sind die beiden Hinterstrangtheile nur im Halsmarke deutlich durch Bindegewebssepten ron einander geschieden. auf caudaleren Querschnitten kamn man sie nur erkennen, wenn einer von beiden erkrankt und desshalb durch eine andere Färbung ausgezeichnet ist. Die Goll'schen Stränge nehmen von unten nach oben bis in das untere Brustmark an Stärke zu. weil sie Theile der fortwährend eintretenden hinteren Trurzeln aus den sensorischen Nerven der Beine der Medulla oblongata zuführen.

Sie werden später erfahren, dass in den Hintersträngen noch andere Unterabtheilungen gemacht werden miissen.

Die Art. wie manche Erkrankungen sich in ihnen ausbreiten, namentlich auch die Bilder, welche man gewinnt, wenn frische Rïckenmarksunterbrechungen mit der Marchi'schen Degenerationsmethode, also mit einem besonders feinen Reagens auf einzelne zerfallende Narkscheiden, untersucht werden, haben unsere Anschauungen hier sehr erweitert.

Das Gebiet ganz nahe an der granen Commissur, das in Fig. 223 links mit $A$ bezeichnet ist, muss ein eigenes Fasersystem enthalten. weil es, bei der Tabes z. B., nie mit erkrankt, wemn auch die anderen Theile der Hinterstränge degeneriren. Man kann es als ventrales Feld der Hinterstränge bezeichnen.

Die Hinterstränge bestehen fast ausschliesslich aus den eintretenden Fasern der hinteren Wurzeln. Diese Wurzeln sind so angeordnet, dass die eintretende immer am weitesten lateral, dicht an den Hinterhörnern liegt ( Truzelzone des Hinterstranges), dass aber die nach ihr; d. h. über ihr zum Rückenmarke gelangende Wurzel ihre Vorgängerin nach innen schiebt. So kommt es, dass oben im Halsmarke die Fasern aus den Unterextremitäten wesentlich in den Goll'schen Strängen zu suchen sind, während die Burdach schen Stränge noch sehr viele Fasern aus den oberen Extremitäten führen. Sie dürfen sich nun, meine Herren. nicht vorstellen, dass die genannten Hinterstrangtheile die Gesammtmasse der Fasern einer hinteren Wurzel nach oben führen. Viele Fasern gelangen rielmehr gleich nach dem Eintritte der Wurzel in die grane Substanz, andere biegen während ihres Verlaufes im Hinterstrange erst dorthin um. Desshalb liegen in den oberen Theilen des Markes nur relatir wenige von den tief unten eingetretenen Fasern im Hinterstrange. Experimentell hat man das dadurch eruirt, dass das degenerirende Querschnittsfeld einer durchschnittenen Hinterwurzel immer kleiner wurde, wenn es nach oben hin rerfolgt wurde. Gleichzeitig riickte es nach innen.

Im obersten Theile des Riickenmarkes enthalten die Keilstränge Fasern, die nicht direct aus den Hinterwurzeln stammen. Ihre Herkunft ist unsicher. 
Die Wurzeln der peripheren Nerven, die spinalganglien und das Rückemmark. 325

Ein Theil der hinteren Wurzel gelangt in die Umgebung der Zellen der Clarke'schen Säule und splittert da auf (Fig. 227). Aus der Clarkeschen Säule entspringt eine neue Rückemmarksbahn. Durchschneidet man das Riickenmark quer, so entartet das Fasergebiet, in welchem diese Bahn frontalwärts zieht. Es ist das peripher in den Seitensträngen liegende Querschnittsfeld 4 der Fig. 225. Diese Bahn kann bis hinauf in den Turm des Cerebellums verfolgt werden, Tractus cerebello-spinalis dorsalis. Es ist wesentlich Verdienst der entwicklungsgeschichtlichen Forschung (Flechsig), dass wir die Kleinhirn-Seitenstrangbaln kennen und vom übrigen Seitenstrange abgrenzen lernten. In den ersten Lebenswochen, wo die Pyramidenbahn noch marklos ist, umgiebt die Klein-

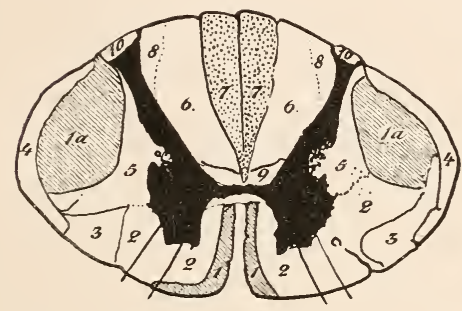

Fig. 225.

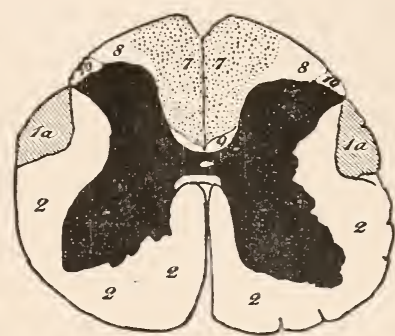

Fig. 226.

Schnitt durch das Cervical- und durch das Lumbalmark mit Einzeichnung der ungefähren Grenzen zwischen den einzelnen Abtheilungen des Markmantels. Unter Benutzung der entwicklungsgeschichtlichen Grundlagen wesentlich nach Präparaten mit secundären Degenerationen des einen oder anderen Systems. 1 a Pyramiden-Seitenstrangbahn. 1 Pyramiden-Vorderstrangbahn, 2 Grundbündel der Vorderseitenstränge. $3 \mathrm{Tr}$, cerebello-spinalis ventralis. $4 \mathrm{Tr}$. cerebello-spinalis dors. 5. Seitliche Grenzschicht der grauen Substanz. 6 Aeussere - B ur d a ch 'sche Hinterstränge. 7 Innere - Goll'sche Hinterstränge.

8 Wurzeleintrittszone. 9 Ventrales Feld der Hinterstränge.

hirnbahn als zarter weisser Saum einen grossen 'Theil der Seitenstrangperipherie (Fig. 223).

Neuere Untersuchungen (Löwenthal, Nott) haben gezeigt, dass der ventrale Abschnitt der Kleinhirn-Seitenstrangbahn, den Gowers schon als Anterolateral Tract auf Grund pathologischer Erfahrungen abgetrennt hatte, nicht aus den Zellen der Clarke'schen Säule, sondern aus anderen Zellen der grauen Substanz entspringt. Der Tractus cerebello-spinalis ventralis verläuft zwar bis in die Oblongata gemeinsam mit dem dorsalen Abschnitt, tremnt sich aber dann von ihm, um, etwas weiter frontalwärts ziehend, sich erst mit den Bindearmen in den Oberwurm des Cerebellums zu senken, s. s. 307 .

So hätten wir denn bislang an der Hand des Studiums secundärer Degenerationen und der Entwicklungsgeschichte die folgenden Unterabtheilungen - Strangsysteme ist der Name, den man ihnen gegeben - der weissen substanz kennen gelernt: In den Vordersträngen die Pyramiden-Vorderstrangbahn, in den Seitensträngen die Pyra- 
miden-seitenstrangbahn und die Kleinhirn-Seitenstrangbahn, in den Hintersträngen die Grundbündel und die zarten Stränge.

In die Umrisse der Fig. 225 u. 226 sind nun alle die Abtheilungen des Markweisses, welche Sie bisher kennen gelernt, eingezeichnet. Noch nicht erwähnt ist das vom Vorderstrange bis in den Seitenstrang reichende Gebiet 2. Dieses ron den rorderen Trurzeln durchquerte Areal heisst Torderseitenstrangrest. Der Theil, welcher in den Tordersträngen liegt, wird auch als Grundbündel der Torderstränge bezeichnet. Der Seitenstrangantheil hat den Namen vordere gemischte seitenstrangzone erhalten.

Hier wären wohl noch einige Abtheilungen zu machen, aber noch reichen die bisher bekannten Fälle secundärer Degenerationen nicht aus, sie sicher zu umgrenzen. Das wäre aber sehr erwünscht, denn es ist wohl gerade das Areal der Torderstränge, in welchem wir die letzten Enden des Fasciculus longitudinalis posterior zu suchen haben und das Areal der Vorderseitenstränge, in das bei der Katze Boyce jene Bahn aus dem tiefen Marke rerfolgte, die dem lateralen Längsbündel der niederen Tertebraten entspricht. Hier auch liegt die Fortsetzung der mächtigen Fasern aus dem Deiters'schen Kerne des Kleinhirnes, in der Lage, wie sie nach Ferrier und Turner in das Schema, Seite 304, eingezeichnet worden ist.

Die meisten Fasern in den Vorderseitenstrangresten entstammen, soweit sie nicht den vorderen Wurzeln angehören, der grauen Substanz; hier liegen ausserdem höchst wahrscheinlich die centralen Fortsetzungen ron sensorischen Bahnen. Das mit 5 bezeichnete Feld (seitliche Grenzschicht der grauen Substanz) enthält directe Fortsetzungen ron Twurzelfasern, welche nach Durchquerung des Hinterhornes (s. Fig. 223 rechts) dort aufsteigen.

\section{Zweiundzwanzigste Vorlesung.}

\section{Der Faserverlauf im Riickenmarke.}

I. H.! Lassen Sie uns jetzt, nachdem uns die allgemeinen Verhältnisse der Zusammensetzung des Rückenmarkes bekannt geworden, sehen, was aus den eintretenden Trurzelfasern wird, deren Verfolgung wir früher aufgegeben haben; lassen Sie uns untersuchen, wie weit ihr Terlauf im Centralorgane erforscht ist. Nicht Form und Gestaltung der Theile des Centralnervensystemes sind es ja, die uns hier wesentlich interessiren; auf den Zusammenhang der Theile, auf die Beziehungen. in denen die Faser zur anderen Faser und zur Zelle steht, auf diese Verhältnisse haben wir unsere Forschung im Grunde zu richten.

Sanft ansteigend treten mitten durch die Vorderseitenstränge die Züge der vorderen Trurzel. Auf eine lange Strecke des Markes ist jede einzelne ausgebreitet. An der Grenze der grauen Substanz angekommen, 
fahren die Fasern jedes Bündelchens aus einander. Der Angaben über das, was damn aus ihnen wird, besitzen wir viele und sich oft widersprechende. Die folgende Darstellung, welche sich vielfach auf eigene Untersuchung stïtzt, versucht das Wichtigste zu vereinen.

Zunächst ist als sichergestellt anzunehmen, dass Fasern der vorderen TWurzel zu Ganglienzellen der Torderhörner gelangen, resp. in deren Axencylinderfortsatz ïbergehen (s. Fig. 21s). Einige Wurzelfasern treten zu Zellen des gekreuzten Vorderhornes, indem sie die vordere Commissur überschreiten.

Gründe, welche die pathologische Beobachtung bietet, haben schon lange erschliessen lassen, dass zu den Kernen der motorischen Nerven Fasern aus der Hirnrinde durch die beiden Tractus cortico-spinales gelangen. Es ist nicht schwer, zu sehen, dass aus dem Areale der Pyramiden-Torderstrangbahn zahlreiche Fäserchen, die Commissura anterior überschreitend, in das gekreuzte Vorderhorn eintreten. Die meisten dieser Fasern sind Collateralzweige aus den längs verlaufenden Nervenfasern der Pyramidenbahn. Sie lösen sich im Vorderlorne in feine Pinselchen auf, und diese Pinsel umspinnen die Ganglienzellen. Erst in der letzten Zeit ist es geluugen, auch die postulirte Verbindung mit der Pyramiden-Seitenstrangbahn sicher zu sehen. Wieder handelt es sich in der Hauptsache um Collateralen, die sich von jener Bahn lösen und in das Torderhorn ihrer Seite direct eintreten, wo sie sich zu feinen Fasern aufsplittern.

Die Pyramidenbahn ist also die secundäre motorische Bahn. Sie tritt durch innigen Contact ihrer Axencylinder in Beziehung zu den Ursprungszellen der primären motorischen Bahn. Schematisch habe iclı Thnen das schon früher in Fig. 7 rorgelegt.

Am reifen menschlichen Rückenmarke lassen sich diese Verhältnisse nicht erkeunen. Man muss embryonale Marke, wo die Pyramiden noch marklos sind, nehmen, sie nach der schnellen Methode Golgi's mit Silber behandeln und dann Längsschnitte und Schrägschnitte aufertigen. Auf solchen gelingt es dann oft, die von den Pyramidenbahnen in rechtem Winkel abgehenden Collateralen zu sehen und in die graue Substanz zu verfolgen (vgl. Fig. 227). Diese Züge müssen später markhaltig sein; denn in Fällen von Degeneration der Pyramidenbahn findet man immer das gleichseitige Vorderhorn ärmer als normal an markhaltigen Fasern (Fürstner). Die gleichen Züge treten sehr gut hervor, wenn es gelingt, sie während ihrer Degeneration mit Osmium zu schwärzen. (Fig. 228, Schnitt 5).

Bedeutende Schwierigkeiten stellen sich der Erforschung des Verhaltens der linteren IV urzel entgegen.

Die Fasern der Hinterwurzel theilen sich gleich nách ihrem Eintritte alle oder fast alle in auf- und absteigende Aeste. Aus diesen entspringen dann zahlreiche Seitenwege, die theils in die graue Substanz, theils in die Hinterstränge eintreten. (S. Fig. 227).

Das Verhalten der einzelnen Wurzelantheile ist ein sehr verschiedenes, die Verhältnisse sind, soweit wir sie heute kemnen, recht complicirte. Ich möchte daher ausdrücklich sie bitten, das Folgende nur unter fortwäl-- 
render Benutzung der Fig. 227 zu studiren. Diese Abbildung soll wiedergeben, was augenblicklich bekannt ist. Sie lehnt sich, namentlich was die relative Fasermenge angeht, nicht an Präparate an. Ilır Zweck ist nur der, den Text zu ergänzen.

Auf einem Querschnitte durch das Riickemmark erkennt man, dass die hintere Wurzel da, wo sie eintritt, mindestens 5 Theile unterscheiden lässt.

Die am weitesten medial gelegenen Bündel (1), zumeist aus grobkalibrigen Fasern zusammengesetzt, gelangen fast alle in der Höhe ihres Eintrittes sofort in die Hinterstränge (Wurzeleintritts-

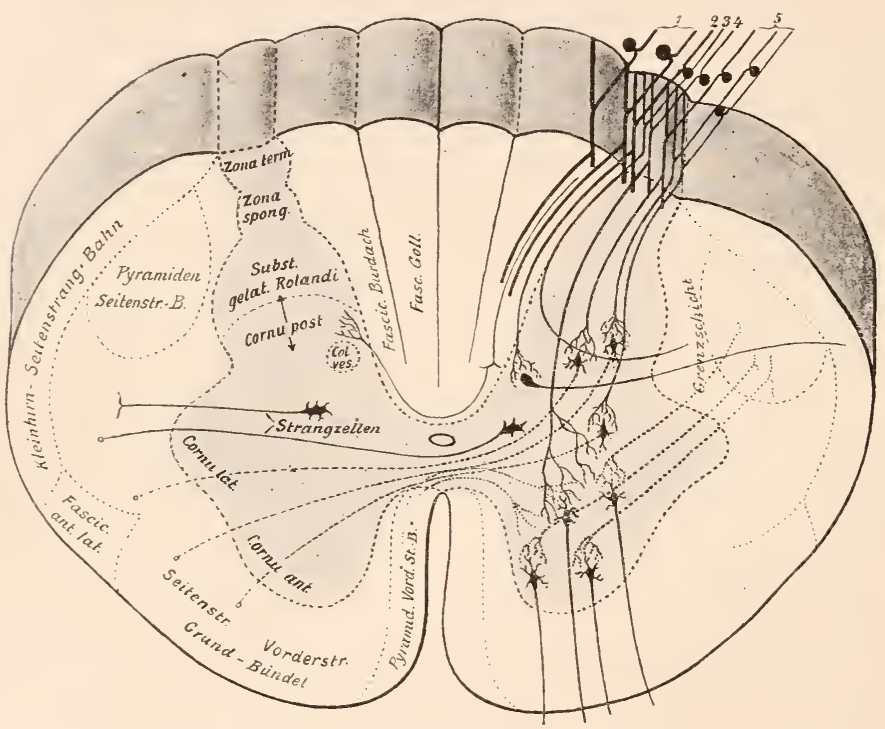

Fig. 227.

Schema eines Rückenmarksquerschnittes, in das der centrale Verlauf einiger wichtigen Züge eingezeichnet jst. Man vergleiche auch die nicht schematische Fig. 223 rechts. Die Axencylinder aus Vorderhornzellen zur hinteren Wurzel weggelassen. Bahnen erster Ordnung ausgezogen, Bahnen zweiter Ordnung panktirt.

zone). Sie haben schon erfahren, dass sie hier hirnwärts ziehen. Das Verhalten der Wurzel bei der secundären Degeneration, welche ihrer Durchschneidung folgt, hat gelehrt, dass eine in den Hinterstrang direct eingetretene Wurzel von der nächst höher eintretenden medialwärts gedrängt wird, dass so die candalen Wurzeln oben, nahe der Nittellinie, in den Goll'schen strängen liegen, und dass die Burdach'schen Stränge sich zum guten Theil aus solchen eintretenden und schräg aufwärts verlaufenden Wurzelfasern aufbauen (Fig. 25). Sie haben auch schon er- 
fahren, dass während dieses Nachimnenrïckens fortwährend Fäserchen an die graue Substanz abgegeben werden.

Gleich nach dem Eintritte sendet jede Faser, ehe sie cerebralwärts abbiegt, einen Zweig candalwärts. Sein weiteres Verhalten ist erst näher bekannt, seit frische secundäre Degenerationen mit der Marchimethode studirt wurden, Schaffer, Löwenthal u. A.

Teberhaupt gestaltet sich bei der Untersuchung mit dieser schärferen Methode das Bild der secundären Degeneration so viel complicirter, als es nach meiner Darlegung in der vorigen Vorlesung war, dass es wohl zweckmässig ist, wemn Sie dem hier abgebildeten, vou Hoche beschriebenen Falle noch kurz Thre Anfmerksamkeit schenken.

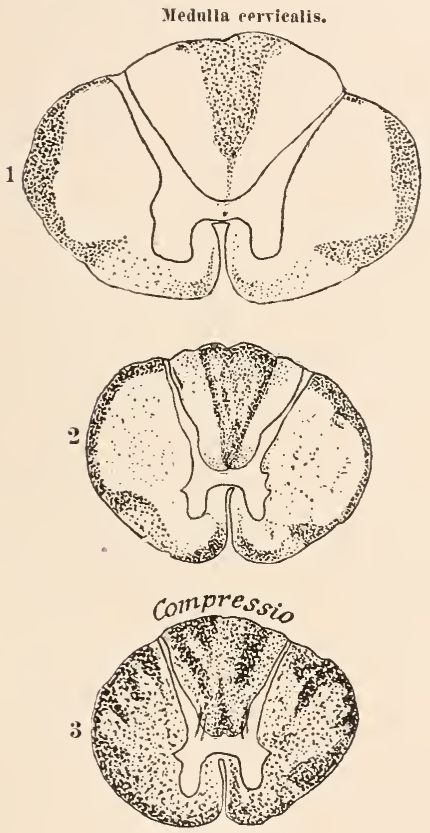

Fig. 228.
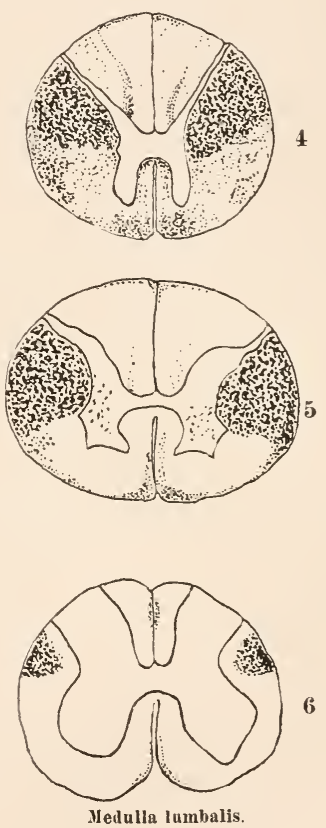

Compression des Rtickenmarkes in der Höhe des 7. Dorsalnerven. Aufsteigende Degeneration links, absteigende an den Schnitten rechts. Die Zerfallproducte durch Ueberosmiumsäure (Jarchimethode) geschwärzt. Nach Hoche.

Die Compressionsstelle liegt in der Gegend des 7. Dorsalwirbels. Hier ist die Entartung, wie sie durch die osmiumgeschwärzten Punkte sich verräth, ungleichmässig fleckig. Riickwärts, nach dem Lumbalmarke zı, zerfallen dam die Pyramiden in ihre Vorder- und Seitenstrangbahnen. In den Seitensträngen degeneriren auch noch zahlreiche Bündel längeren und kürzeren Verlaufes, die den Associationssystemen verschiedener Länge angehören. Im Allgemeinen liegen 
die Fasern kürzeren Verlaufes näher an der granen Substanz, diejenigen längeren Verlaufes weiter ab von derselben. Naturgemäss sind diese Associationsbahnen dicht über und dicht unter der Compressionsstelle am stärksten entartet, weiter von der Unterbrechung entfernt, findet man nur noch wenige, eben die längsten. In den Hintersträngen direct lateral von den Goll'schen Strängen ziehen eine längere Strecke hinab die absteigenden Bündel derjenigen Wurzelfasern dahin, die gerade von der Compression getroffen worden sind. Ihre auf dem Schnitte kommaförmige Figur - Schultze'sches Komma - liegt natürlich etwas verschieden, je nach der Wurzel, die gerade unterbrochen ist. Die Bahn, deren Zugehörigkeit zu den Hinterwurzeln übrigens noch bestritten wird, komnte, ehe sie in das Grau eintauchend verschwindet, von $\mathrm{Hoche}$ bis ïber $\mathrm{S}$ Wurzellängen verfolgt werden.

$\mathrm{Zu}$ den absteigend degenerirten Systemen gehört noch ein zarter Faserbeleg direct auf der Dorsalseite der Hinterstränge. Im Lumbalmarke wendet er sich hinein in das Septum medianum und liegt nun dicht jenem an als ,ovales Feld" - Flechsig. Er kann bis in den Conus terminalis verfolgt werden. So ist das Ende des langen Zuges wohl bekannt, nicht aber sein Anfang, da der Tractus bisher nur in die Höhe des Cervicalmarkes verfolgt ist. Vorläufig wird es zweckmässig sein, den langen $\mathrm{Zug}$ sehr dicker Fasern als Tra ctu s cervico-lumbalis dorsalis zu bezeichnen.

Ein zweiter Theil (2) der Truzel wendet sich nicht medial in die Stränge, sondern durchzieht im Bogen die weisse Substanz, um sich lateral in der Clarke'schen Säule zu verlieren, wo er um Zellen herum aufsplittert. S. Fig. 227. Einige Fasern (3) durchbrechen direct das Hinterhorn ventral ron dessen Substantia gelatinosa und ziehen damn in der dem Seitenstrang angehörigen „Grenzschicht“ weiter. Sie sind auf Fig. 223 deutlich.

Die eben geschilderten Antheile der Hinterwurzel liegen medialwärts von der Spitze des Hinterhornes. Lateral ron ihnen liegen (4) Bündelchen starker Fasern, die sich weithin durch die Substantia gelatinosa und das Hinterhorn hindurch bis zu den grossen Zellen des Torderhornes verfolgen lassen, um die herum sie aufsplittern. Diese Bahn wird gewöhnlich als kürzeste Reflexbahn aufgefasst. (Fig. 33).

Teiter lateral liegen (5) Wurzelfasern. welche nach längerem oder kürzerem Verlaufe in die graue Substanz eintreten. Diese Fasern spalten sich alle, gleich nachdem sie die Peripherie der grauen Substanz erreicht haben, oder auch erst innerhalb derselben in einen auf- und einen absteigenden Ast. Manche von ihnen, namentlich starkfaserige, durchmessen erst die Substantia gelatinosa Rolandi, ehe sie sich theilen. Aus den Theilästen treten dann zahlreiche Collateralen in das Grau, besonders des Hinterhornes, wo sie sich. kleinen dünnen Pinselchen gleich, um die Zellen verästeln. welche dort liegen. Die feineren Fasern zerfallen zumeist schon an der Peripherie des Hinterhornes in ihre Theiläste. so entsteht zwischen Hinterhornspitze und Rïckenmarkperipherie ein Feld, das von den auf- und absteigenden dünnen Fäserchen durchzogen wird (Randzone, Zona terminalis). Aus der Randzone gehen dann fortwährend feine Fäserchen in ein zwischen ihr und der gelatinösen Substanz liegendes Netzwerk - Zona spongiosa -, und erst 
aus diesem Netze entwickeln sich dann wieder feine Züge, welche die gelatinöse Substanz durchziehen und in das Fasergewirr, welches das Hinterhorn erfüllt, gelangen. Wahrscheinlich treten sie dann in gleiche Beziehung zu den Zellen, wie die stärkeren Fasern, von denen eben die Rede war.

Es darf indess nicht aus dem Auge gelassen werden, dass Vieles, was hier vom Faserverlaufe in der Hinterwurzel mitgetheilt worlen ist, beim Menschen noch nicht mit aller Sicherheit nachgewiesen werden konnte. Soweit man aber hier untersucht hat, haben sich immer gleiche Verhältnisse ergeben, wie an den Säugethieren, von denen man bei der Untersuchung ausgegangen ist.

So weit lässt sich zunächst die sensible Bahn in das Rückenmark verfolgen: Als Wichtigstes ist also festgestellt, dass ein Theil in die Hinterstränge gelangt und mit diesen hirnwärts zieht, dass ein zweiter zunächst in der Clarke'schen säule endet, und dass die Hautmasse der lateraler liegenden Fasern nach kürzerem oder längerem Verlaufe sich um Zellen der Hinter- und Torderhörner herum aufspaltet. Ausserdem sind Fasern bekannt, welche in die seitliche gemischte Zone gelangen, solche, welche aus dem Vorderhorne stammen, und solche, welche da enden.

Für die Fasern, welche in das Grau des Hinterhornes und der ventral von ihm liegenden Gebiete gelangen, liess sich mit sehr grosser Wahrscheinlichkeit nachweisen, wie sie mit höheren Centren in Verbindung treten. Aus den Ganglienzellen, um welche sich die eintretende Wurzelfaser verästelt, entspringt eine secundäre Bahn.

Ihr Axencylinder wendet sich nämlich ventralwärts und nach innen, erreicht die vordere Commissur und überschreitet sie. Dam tritt er in den Vorderstrang oder in den Seitenstrang ein, wo er centralwärts weiterzieht. Welches Gebiet des Vorderseitenstranges als das eigentlich sensorische ansusehen ist, ist noch zweifelhaft. Mir ist am wahrscheinlichsten, dass es sich um zerstreut über den ganzen Querschnitt der genannten Stränge ausgebreitete Fasern handelt. Doch spricht Manches dafür, dass speciell das Areal der Vorderseitenstrangreste viele dieser secundären sensorischen Fasern enthält.

Wir haben also jetzt zweierlei Fortsetzungen der Hinterwurzelfasern kemnen gelernt, eine directe in den Hintersträngen und eine indirecte, welche erst durch Anschluss an eine secundäre kreuzende Bahn hirnwärts gelangt. Sie werden später sehen, dass auch die ungekreuzten Fasern oben in der Oblongata durch einen Kern hindurchgehen und sich damn ebenfalls kreuzen, dass also die ganze sensible Bahn sich kreuzt.

Es wäre mir nicht möglich gewesen, dies Verhalten der hinteren Wurzelfasern zu erschliessen, wenn nicht niedere Wirbelthiere gerade hier im Rückenmarke besonders einfache, ich möchte sagen schematische Verhältnisse böten. Nachdem einmal der Nachweis an solchen geführt war, dass die Melnzahl ihrer hinteren Wurzeln in einen aus Fasern und Zellen bestehenden Apparat in centralen Grau tritt, und dass ron da 
neue Bahnen nach rorheriger Kreuzung hirnwärts ziehen, war es naheliegend, beim Menschen mnd den Säugern nach gleichen Verhältnissen zu suchen. Die Entdeckung Ramon y Cajal's, dass die Hinterwurzeln sich um die Zellen des Rückenmarkgraues herum aufsplittern, und dass aus diesen Zellen eine sich in der Commissura anterior kreuzende Bahn entspringt, gab damn der geschilderten Auffassung noch festeren Boden.

Mit dieser nen gewonnenen Kenntniss stimmen die Erfahrungen ausgezeichnet iiberein, welche das Experiment und die Beobachtung am Krankenbette liefern. Wenn nämlich ein Rückenmark halbseitig durchschnitten wird, dann geht unterhalb der Durchschneidungsstelle das Hautgefühl verloren, und zwar nicht auf der gleichen Seite, sondern auf der gekreuzten. Diese Erfahrung war bisher nicht mit dem zu vereinen, was wir iiber die gekreuzte Fortsetzung der hinteren Wurzelfasem in den Hintersträngen wussten. Sie wird aber sofort leicht verständlich, wenn wir jetzt erfahren, dass ein ansehnlicher Theil jeder Wurzel bald nach seinem Eintritte sich durch eine Bahn zweiter Ordnung auf die andere Seite begiebt.

Man muss sich nun nicht vorstellen, dass Alles dasjenige, was in den sensiblen Wurzeln an Eindrücken dem Rückenmarke zugeführtwird, identisch ist mit dem, was wirgewöhnlich "Empfinden" nennen. Damit ein Eindruck zum Bewusstsein komme, genügt es nicht, dass er dem Pückenmarke zugeleitet werde, es muss auch ron der Stelle, wo die betreffende Bahn endet, eine Verbindung zur Hirnrinde führen. Nun aber ist gar kein Zweifel, dass solcher V'erbindungen nur ganz wenige sind, dass, wenn man die Gesammtzahl der Hinterwurzelfasern etwa in Betracht zieht, die Zahi der centralen Verbindungen dagegen verschwindend klein ist. Das allein schon ermöglicht den Schluss, dass wohl zahlreiche sensorische Eindrücke dem Rückenmarke zukommen, llass aber nur von einigen wenigen wir deutliche Kenntniss bekommen. Die Organe des Körpers sind alle, wie gerade nieder neuerdings die Silbermethode zeigt, von einer ungeahnt grossen Fülle von Nerven durchzogen, und deren Anordnung und V'erlauf, ihre Beziehungen zu Gefässen und Drüsen, zu Muskelfasern und auch zu Knochen und Zahnbein macht es mehr als wahrscheinlich, dass hier ein mächtiger Apparal vorliegt, der wesentlich der Regulation von Eindrücken und der Sensomobilitüt (Exner) dient. Das wird nun fast immer vergessen, wenn die Ergebnisse von Durchschneidungsversuchen einzelner Stränge analysirt werden. so gut wie immer wurden bisher nur die allergröbsten Gefühlsqualitäten geprü/t. Desshalb sind nun, wo wir die anatomischen Verhältnisse im Piückenmarke so viel besser kennen als früher, die Ergebnisse der bisher angestellten physiologischen Versuche nur mit besonderer Vorsicht zu verwerthen; dagegen scheint mir, dass neue Untersuchungen an Menschen mit totalen oder partiellen Rü̈ckenmarkstrennungen sehr erwünscht wären, weil eben die Thiere nur auf die allergröbste Weise Eindrücken gegenüber reagiren nerden, die ihnen nicht gerade Schmerz machen. Sicher wissen wir bis heute mur, dass die Hinterstrangbahn nicht die Gefühle leitet, welche wir cortical als tactile empfinden, und sehr wahrscheinlich ist, dass diese von dem in die graue Substanz eintretenden Abschnitte, welcher bald seine secundïre Fortsetzung findet, weitergeleitet werden. Nit eben diesem Abschnitte müssen auch die centralen Bahnen verlaufen, welche uns über Temperatur- und Druckempfindungen Ausliunft geben.

In den Hintersträngen verlaufen vermuthlich Bahnen, welche einerseits durch ihre Kleinhirwerbindungen, andererseits durch eine Grosshirnverbindung 
mit den sogenannten motorischen Rindencentren irgendwie auf die sensorische Regulirung der Bewegungen und den Muskeltonus Einfluss haben.

Nun hätten wir noch jenes Antheiles der hinteren Wrurzel zu gedenken, der sich um die Zellen der ('larke schen säule aufsplittert. Er hat mit der Leitung des Hantgefühles, wie die Ergebnisse der Pathologie zeigen, wahrscheinlich nichts zu thun. Die sekundäre Bahn aus der Clarke'schen Säule geht nicht in die allgemeinen Bahnen des Gefühles weiter oben ein. Es entwickeln sich aus ihr Fasern. welche seitlich aus der grauen Substanz austreten und an die Aussenseite des Markes, zur Kleinhirn-Seitenstrangbahn gelangen. Mit dieser verlaufen sie zum Cerebellum. Diese Fasern sind wahrscheinlich ron Wichtigkeit für die Coordination unserer Bewegungen. Denn nicht nur sieht man nach Kleinhirnleiden Gang und Haltung oft uncoordinirt werden, auch bei der Tabes dorsalis, wo die hochgradigste Ataxie rorkommt. sind gerade die Fasern der Hinterstränge und die Columna resicularis degenerirt, ist also ein Theil der Bahnen zum Kleinhirne unterbrochen.

Die anatomischen Verhältnisse, welche durch den Eintritt der hinteren Turzel in das Rückenmark bedingt werden, sind also. wie Sie sehen, sehr viel complicirtere als die, welche durch die Torderwurzel geschaffen werden. Zudem sind sie uns auch erst zum Theil bekannt. Wahrscheinlich existiren noch andere, bisher nicht genannte Faserkategorien.

Die Beziehungen vieler Zellen der Torder- und der Hinterhörner zu den Wurzelfasern sind Thnen num bekannt. Es giebt aber in der grauen Substanz noch viele Zellen, welche nicht in directer Beziehung: zu Wurzelfasern stehen. Zunächst gieht es Zellen, deren Axencylinder in keine Längsbahn oder Wurzelfaser ïbergeht, sondern sich gleich nach seinem Ursprunge ausserordentlich fein verzweigt. Solche liegen überall iiber dem Querschnitte rerbreitet, sind aber in der Gegend nahe dem Hinterhorne und in diesem besonders reichlich. Dann kennt man multipolare, weit verbreitete Zellen, die einen Axencylinder in den gleichseitigen oder in den gekreuzten Vorderseitenstrang entsenden (Fig. 210 u. 227). Dort theilt er sich in einen auf- und absteigenden Ast (Fig. 220). Die Aestchen dieser "Strangzellen" verlaufen eine Strecke weit in den Vorderseitensträngen, dann geben sie Collateralen ab, welche sich frontal wieder in die graue Sustanz einsenken und dort um andere Zellen herum aufsplittern. Diese Zellen rerbinden durch ihre Ausläufer Rückenmarksgebiete, welche frontal und caudal von ihnen liegen, sind also wohl geeignet, als Substrat fiir die lange angenommenen Bahnen zu dienen, welche einzelne Höhen untereinander verknüpfen.

Irgend einem Reize, der aus der Peripherie in das Rïckenmark kommt, stehen eine grosse Menge von Verbreitungswegen offen. Es giebt zunächst eine Anzahl von Hinterwurzelfasern, welche direct voran in das Vorderhorn ziehen und um dessen Zellen aufsplittern. Diese sind wohl geeignet, jene Zellen mit den Reizmomenten zu ,laden", oder bei genügend hohen Reizen auch sofortige Entladung von motorischen Reflexen hervorzurufen. Durch rorgebildete und auf 
dem Wege der Einübung erworbene Bahnen stehen aber die motorischen Zellen. gruppen wieder unter sich in functionell associirter Verbindung, und diese Verbindung ist wohl derart beschaffen, dass ein einzelner Reiz in der Lage ist, eine ganze Functionsgruppe gleichzeitig zur Entladung zu bringen. So können Reflexe bestehen aus einzelnen Muskelbewegungen und anch aus scheinbar sehr complicirten Actionen.

Die anatomische Unterlage der Associationen bilden ausser den Dendriten namentlich jene Strangzellen mit ihren Fortsätzen. Es kat gar keine Schwierigkeit, anzunehmen, dass ein Reiz, der in das Riickenmark gelangt, auf dem Wege durch jene Zellen sich über verschiedene Höhen ausbreitet und so motorische Muskelkerne der mannigfachsten Lage zu einer gemeinsamen Action zusammenfasst. Exner u. A.

Durch alle diese Fasern und Zellausläufer entsteht im Riickenmarkgrau ein ausserordentlich complicirtes Flechtwerk. Seine Entwirrung ist nur durch Anwendung all der Methoden gelungen, deren früher gedacht wurde. Am reifen, etwa nach Weigert gefärbten Rückenmarke ist sie ganz unmöglich.

Alle Fasern, welche von der einen zur anderen seite kreuzen, passiren die vordere oder die hintere Commissur.

Sind auch die Bestandtheile dieser Commissuren jeder an seinem Orte bereits erwähnt, so ist es doch zweckmässig, sie noch einmal mehr topographisch zusammenzufassen.

Es verlaufen also in der Commissura anterior (vgl. Fig. 227):

1. Zur Vorderwurzel gehörig: Fasern aus Kernen zur gekreuzten Wurzel, Collateralen der Pyramiden-Vorderstrangbahn, zahlreiche Dendritenfortsätze aus benachbart liegenden Vorderhornzellen.

2. Aus den Zellen, um welche sich die Hinterwurzel aufspaltet, die secundäre sensorische Bahn.

3. Aus den Strangzellen: zahlreiche Axencylinderfortsätze zum gekreuzten Vorder- und Seitenstrang.

4. Eine Verbindung aus dem Seitenstrang der einen zum Vorderstrang der anderen Seite.

Dieser von Schaffer bei Wirbelthieren verschiedener Klassen gefundene Zug soll nach ihm Hinterwurzelfasern, die erst in den Seitenstrang eingetreten waren, weiter oben in den gekreuzten Vorderstrang iiberführen. Er ist auch bei Thieren, die keine markhaltigen Pyramiden besitzen, nachgewiesen (Reptilien); es kann sich also nicht um einen zu diesem Tract gehörigen Theil handeln, eine Annahme, die sonst wohl nahe läge.

Ton der hinteren Commissur wissen wir sehr viel weniger. Sicher enthält sie markhaltige Nervenfasern, und sicher enstammen diese der hinteren TTurzel und auch Gebieten, in welche Hinterwurzelfasern eintreten.

Bei Föten verschiedener Säuger sind je nach der untersuchten Thierart wechselnde Verhältnisse dieser Commissur gefunden worden. So lassen sich z. B. beim Hunde drei verschiedene Abtheilungen der Commissurfaserung unterscheiden, bei der Kuh nur zwei u. s. w.

Die anatomischen Terhältnisse des Rückenmarkes, soweit sie makroskopisch zu ermitteln waren, haben Burdach, Sömmering und J. Arnold festgestellt. Die Verbindung der grauen Substanz der Vorderhörner mit den vorderen Wurzeln hat zuerst Bellingeri, die der Hinterhörner mit Fasern der Hinterwurzeln Grainger erkannt. 
Der feinere Bau des Rückenmarkes ist aber erst durch B. Still in $\underline{g}$ erschlossen worden, dann haben Kölliker, Goll, Deiters, Gerlach, Clarke und Andere in Vieles nene Klarheit gebracht. Den Arbeiten von Türk, Flechsig, Charcot, Gowers verdanken wir den grössten Theil dessen, was wir über den Faserverlauf in der weissen Substanz bis vor Kurzem wussten. Es ist aber dann durch die Arbeiten von $\mathrm{His,Golgi}$ und S. Ramon y Cajal iCollateralen, Aufsplitterung des Axencylinders n. A.), durch Studien von Kölliker, Gehuchten, Len hosseck, deren zum Theil ja in der einleitenden Vorlesung schon Erwähnung geschehen ist, ein ganz bedeutender Fortschritt in der Kenntniss des Rückenmarkes geschaffen worden. Ausserdem haben Singer und Münzer, Löwenthal, Nott und Andere in den letzten Jahren über Vieles wichtige Aufklärung gebracht und verdanken wir Waldeyer neben manchen nenen Thatsachen eine kritische Revision unserer Kenntnisse.

Das Bild von den wichtigsten Faserbahnen im Rückenmark, das ich Ihnen heute vorlegte, könnte noch um vieles feiner ausgeführt, noch mit manchem hochinteressanten Detail verziert werden. Schon sind wir aber an so manche Stelle gerathen, wo unser Wissen unsicher wird, und getreu der Grenze, die diese Vorlesungen sich stecken mussten, will ich da abbrechen, wo die Fïlle eruirter Details und sich widersprechender Meinungen der Autoren noch nicht gestatten, dem Lernenden präcise Bilder vorzuführen.

In der Vorrede zu seinem grossen Werke ïber den Bau des Rückenmarkes sagt Stilling: „Wir dïrfen, um mit dem edlen Burdach zu reden, nicht vergessen, dass wir bei der Erforschung des Rïckenmarkbaues in ein Wunderland reisen, welches wir noch so wenig wahrhaft kennen: so mögen wir nur auf Ströme und Berge den Blick heften, um eine klare Uebersicht des Ganzen zu erlangen, und es den Nachfolgern ïberlassen, jeden Bach zu verfolgen und bei jeder Anhöhe zu verweilen."

Sechsunddreissig Jahre sind verflossen, seit mit jener Vorrede eines der inhaltsreichsten Bücher in die Welt ging. mit dem je die anatomische Wissenschaft beschenkt wurde, und noch sind wir gar weit von dem Ziele entfernt, noch lange wird es dauern, bis jene Generalstabskarte wird gezeichnet werden kömen, von der Burdach und Stilling träumten.

Im Riickenmarke liegen physiologisch weit verschiedene Fasern eng beisammen; die als Centralorgane zu betrachtenden Zellen sind dicht umgeben von peripheren Leitungen. Es wird Ihnen daher begreiflich erscheinen, dass es äusserst schwer ist die Folgen zu ermitteln, die Symptome festzustellen, welche bei Erkrankung oder Zerstörung eines dieser Componenten des Riickenmarkes auftreten.

Dennoch hat genaue Beobachtung am Krankenbette und am Sectionstische uns manches hierher gehörige gelehrt. Eine Anzahl von Rïckenmarkskrankheiten befallen immer nur bestimmte Theile des Markes, immer nur einzelne Stränge oder gewisse Gruppen von Ganglienzellen und lassen die iibrigen Theile des Querschnittes entweder für immer oder doch für lange Zeit intact. Die Beobachtung solcher Formen wird natïrlich für die uns beschäftigende Frage von grösster Wichtigkeit sein. Dann erlauben Verletzungen, Durchschneidungen, Compressionen des Markes, wie sie durch Caries der Wirbel und durch Tumoren zul Stande kommen, oft wichtige Schlüsse.

Viel weniger als durch Pathologie lässt sich durch den Versuch am Thiere ermitteln. Die nöthigen Eingriffe sind, verglichen mit den pathologischen Processen im Verhältnisse zu dem feinen Mechanismus den sie treffen, recht grober Natur. 
Es kann natürlich in diesen Torlesungen nicht unsere Aufgabe sein, die reichen Ergebnisse, welche wir zahlreichen Forschungen über die Pathologie des Rückenmarkes rerdanken, auch kurz zu resumiren. Eine Reihe vortrefflicher Bücher führen sie ja in dies Gebiet olne allzugrosse Schwierigkeit ein.

Nur einige besonders wichtige oder besonders sichergestellte Punkte seien erwähnt.

Erkrankungen der Hinterstränge machen verschiedene Symptome je nach der Stelle, wo sie die Strünge treffen. Zerstörungen der eintretenden hinteren Wurzeln müssen die ganze in diesen verlaufende Gefühlsbahn unterbrechen und nicht nur den Verlust jeder Art von Gefühl, sondern auch den der Reflexe, die ja durch die sensible Bahn vermittelt werden, nach sich ziehen. Auch die Sehnenreflexe schwinden dann. Degenerationen der Hinterstränge, welche nicht die eintretenden Wurzelfasern betreffen, oder sie doch nur in geringerem Maasse berühren, verlaufen ohne wesentliche Störungen des Hautgefühles, doch scheint immer dus Muskelgefühl zu leiden. Die motorische Kraft erleidet durch Erkrankung der Hinterstränge keine Einbusse.

Wenn die graue Substanz der Vorderhörner von einem krankhaften Processe zerstört wird, dann tritt, ganz wie bei Zerstönung peripherer Nerven, Lähmung in den Muskeln ein, welche ihre Nervenfasern aus der betreffenden Stelle beziehen. Dieser Lähmung gesellt sich ungemein rasch Atrophie der gelähmten Iuskeln zu. Auch darin ist sie der peripheren Lähmung ähnlich, dass die Duskeln auf den elektrischen Strom meistens bald so reagiren, als ob ihr zuleitender Nerv durchschnitten sei. Da der Nerv und seine Aufsplitterung im Muskel nur Ausläufer der Zelle sind, so bietet die Erklärung dieses Verhaltens keine Schwierigkeit.

Man wird aus dem geschilderten symptomencomplexe immer eine Erkrankung der motorischen Bahn erster Ordnung diagnosticiren dürfen.

Ganz andere Erscheinungen treten ein, wenn die motorische Bahn zweiter Ordnung, die Tractus cortico-spinales, unterbrochen wird.

Erkranken die Pyramidenbahnen, so werden die willkürlichen Bewegungen gestört oder unmöglich. Ausserdem gerathen die gelähmten oder auch nur geschwächten Muskeln in dauernde Spannungszunahme, neigen zur Contractur und sind auf mechanische Reize sehr viel mehr als in normalem Zustande erregbar. Immer, wenn Sie diese Symptome allein oder einem anderen Symptomencomplexe beigemischt finden, dürfen Sie mit aller Sicherheil eine Betheiligung der Pyramidenbahn an der Erkrankung annehmen. Nicht so selten hat einseitige Unterbrechung der Pyramidenbahn doppelseitige Erscheimungen von Parese und Spannungserhöhung in den Nuskeln zur Folge.

Es kommen Combinationen von Erkrankung der primüren mit solcher der secundären motorischen Bahn vor. Die bestbeobachtete ist die amyotrophische Lateralsklerose. Hier entspricht den klinischen Erscheinungen: Parese, Spasmen, Muskelatrophie, der anatomische Befund: Erkrankungen der Pyramidenbahn und der Vorderhornzellen.

An dem nachstehenden Schema (Fig. 229), welches den Zusammenhang von centraler und peripherer motorischer Bahn darstellt, können Sie sich diese Verhältnisse leicht einprägen.

Eine Erkrankung, welche sich in der Linie $x a c$, resp. in den von ihr repräsentirten Fasern localisirt, führt zur Lähmung. Wenn sie vor der Ganglienzelle die Leitung unterbricht, also bei $x$ oder a, trägt sie den Charakter 
einer centralen Lähmung ohne Atrophie und geht häufig dadurch, dass wahrscheinlich andere Bahnen für $x$ a eintreten, in Besserung, resp. Heilung über. Wird aber die Linie $x a c$ in der Ganglienzelle oder irgendwo in $c$ unterbrochen, so tritt nicht nur Lähmung, sondern auch Schwund der gelähmten Fasern und Atrophie der von ihnen versorgten Muskeln ein. Dadurch wird die Aussicht auf. Wiederherstellung der gelähmten Partien eine sehr geringe. Zuweilen tritt nach langdauernder Unterbrechung von $x$ a auch allmählich Betheiligung von $c$ auf. Das ist aber selten. Unterbrechung der Bahn a führt auch zu absteigender Degeneration von der Unterbrechungsstelle bis zur Höhe des betreffenden Vorderhornes.

Als ein Beispiel für Lähmung und Muskelschwund, wie sie nach Erkrankung der Vorderhörner auftreten, erwähne ich die "spinale Kinderlähmung". Dort tritt ganz plötzlich complete Lähmung einzelner Muskelgruppen auf, und rasch folgt ihr Schwund der Muskelsubstanz. Die Untersuchung des Rückenmarkes ergiebt dann Erkrankungsherde, welche die graue Substanz der Vorderhörner getroffen haben. Auch die Nerven, ja die Wurzeln selbst, werden allmühlich atrophisch.

Wir besitzen noch nicht genügend feine Beobachtungen, um aussagen $z u$ können, was für Symptome entstehen, wenn die graue Substanz der Hinterhörner erkrankt. Aber aus der Analyse der Fälle von Tabes dorsalis, in denen sie verschont, und derer, in denen sie betroffen war, dürfen wir schliessen,

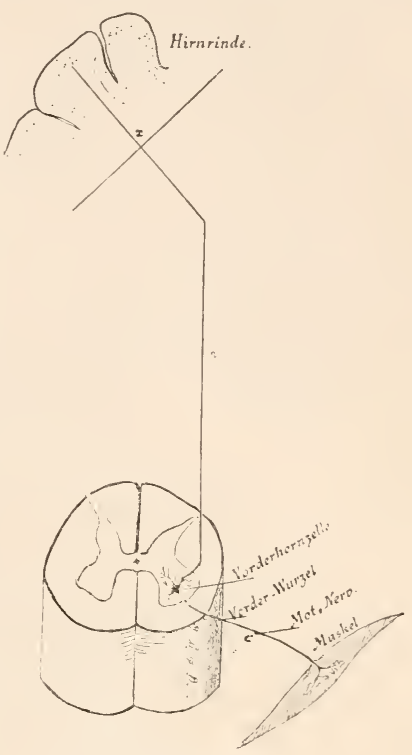

Fig. 229.

Schema der Innervation für einen Ifuskel. dass Erkrankungen, welche dort sitzen, wahrscheinlich zu Störungen der Hautsensibilität und namentlich zu trophischen Störungen der Haut führen. Bei der Syringomyelie und bei Geschwülsten, welche mitten in der grauen Substanz sitzen, treten $u$. a. Störungen des Temperatursinnes und der Schmerzempfindlichkeit auf.

\section{Dreiundzwanzigste Vorlesung.}

\section{I)as rerlingerte Iark.}

Am oberen Ende des Rückenmarkes verlagern sich die weissen Fasern, welche es zusammensetzen, in mannigfacher Weise, die Ausdehwung und Form der grauen Substanz ändert sich erheblich, neve Anhäufungen von Glia und Ganglienzellen treten auf, und rasch wird das Ihnen jetzt wohlbekannte Bild des Rückenmarksquerschnittes verwischt; namentlich wird es undeutlich, wenn dicht über dem Rückenmarksende rechts und links, 
da, wo Seitenstränge lagen, die Oliva inferior, ein granes, vielfach gefälteltes, ganglienzellenreiches Blatt sich einschiebt, wenn der Centralkanal, immer weiter nach hinten rïckend, zur R a u t en $\mathrm{g} r \mathrm{r}$ u b e sich erweitert.

Die Reihe von Querschnitten, welche ich Ihnen jetzt demonstriren werde, ist bestimmt, die Genese der Medulla oblongata aus dem Rïckenmarke zı erläutern.

Fig. 230 stellt einen Schnitt durch das Halsmark dar, etwa der Stelle entsprechend, wo der erste Cervicalnerr abgeht. Sie soll Ihnen wesentlich nur die in der vorigen Vorlesung geschilderten Formverhältnisse wieder in das Gedächtniss zurückrufen.

Drei Punkte wollen Sie aber an dieser Figur noch beachten, weil sie abweichen von dem bislang Geschilderten. Es ist eimmal die eigenthümliche Form des Hinterhornes, das nur durch einen dünnen "Hals" mit seinem dorsalsten, durch Substantia gelatinosa stark verdickten Theil, dem „Kopf des Hinterhornes“, zusammenhängt.

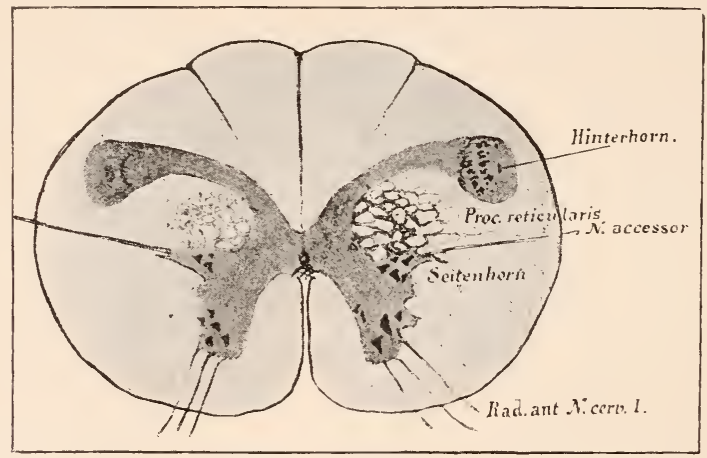

Fig. 230.

Schnitt durch den obersten Theil des Cervicalmarkes.

Die Substantia gelatinosa wird durchzogen von zahlreichen feinen Fäserchen, die zum Theile Hinterwurzelfasern sind. $\mathrm{Zu}$ einem anderen Theile aber stammen sie von weit her, nämlich aus dem Ganglion Gasseri. Die Zellen dieses Ganglions entsenden peripherwärts den Nervus Trigeminus, nach dem Centralorgan aber die Trigeminuswurzel. Von dieser wendet sich ein Theil caudalwärts. Aus ihm senken sich fortwährend feine Fäserchen in den Endkern des Trigeminus, eine Säule gelatinöser Substanz, welche von der Briicke an hinab bis in die Substantia gelatinosa des oberen Rückenmarkes nachweisbar ist. Der halbmondförmige Querschnitt des Tractus spinalis N. V. liegt im Halsmark ebenso wie in der Oblongata und Brïcke der Substantia gelatinosa dicht an. Sie werden ihm auf allen Schnitten, die ich Ihnen von heute an vorlegen werde, z. B. Figg. 232 u. 23S, begegnen. Nan hat ihn bisher als a u fsteigende Quintuswurzel bezeichnet. S. auch Fig. 251.

Dann sehen Sie, dass die Seitenhörner stark ausgebildet sind. Aus Zellen, die an ihrer Basis liegen und höher oben an den Seitenrand des Vor- 
derhornes rückell, kommt der $\mathrm{Ner}$ vus accessorius IV illisii. Seine Wurzelfasern, die bis hinab zum 6. Cervicalnerven, und anfwärts bis in den Anfangstheil der Oblongata entspringen, treten nicht in geradem Verlaufe aus, wie es nach der Abbildung Fig. 230 scheinen möchte, sondern ziehen aus den Zellen zuerst hirnwärts, um dann im Knie (Darkschewitsch) nach aussen abzubiegen. Nur der horizontale Schenkel dieses Knies ist auf dem Schnitte getroffen worden, den Fig. 230 darstellt.

Beachten Sie ausserdem, dass in dem Raume zwischen Hinter- und Vorderhorn die graue Substanz mit zahlreichen netzförmigen Zügen den Seitenstrang durchzieht, seine Bündel zerlegt; es ist dies die Formation der Processus reticulares.

Ihr Grall besteht fast ansschliesslich ans Commissurzellen, die

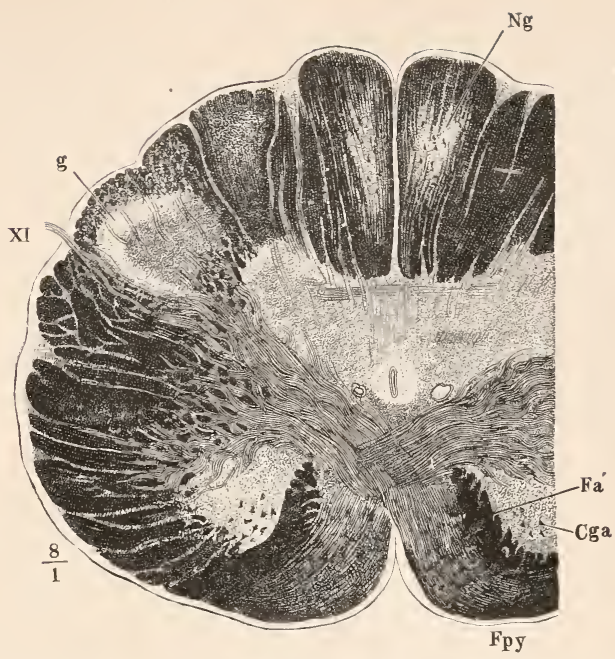

Fig. 231 (Nach Henle).

Querschnitt des verlängerten Markes durch die Pyramidenkreuzung. Fpy Pyramidenstrang, Cga Vorderhorn, $\mathrm{Fa}^{\prime}$ Vorderstrangrest, $\mathrm{Ng} \mathrm{Nucl}$, funic. gracilis, $g$ Subst. gelatinosa, $\boldsymbol{X} l \mathrm{~N}$. accessorius.

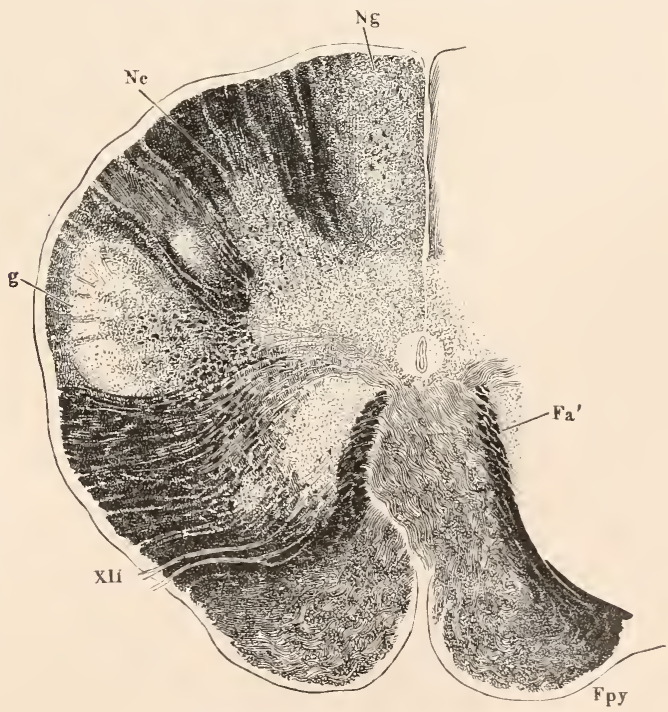

Fig. 232 (Nach Henle).

Querschnitt des verlängerten Markes in der Gegend der caudalsten Hypoglossuswurzeln. Die Pyramidenkreuzung fast vollendet. Nc Nucl. funicali cuneati, XII Nerrus hypoglossus. Alle anderen Bezeichnungen wie Fig. 231. 
rerschiedene Höhen untereinander rerknüpfen. Schon bei Betrachtung der Gehirne niederer Thiere habe ich Sie darauf aufmerksam gemacht, dass regelmässig auf der Grenze ron Oblongata und Rückenmark dies mächtige Commissursystem auftritt, resp. das rorhandene rerstärkt. Ich habe damals das ganze Feld als Associationsfeld der Oblongata bezeichnet.

Ueber der eben gezeichneten Querschnitshöhe beginnen die Umlagerungen von Fasern u.s. w., welche zur Bildung des Oblongataquerschnittes führen.

Wir haben im Rückenmarke zwei Fasciculi cortico-spinales kennen gelernt, einen, welcher, im Vorderstrange gelegen, Fasern hirnwärts führt, die ihm gekreuzt aus jeder einzelnen Wurzelregion zugeführt werden, und einen zweiten, die Pyramiden-Seitenstrangbahn, welche Fasern aus dem gleichseitigen Vorderhorne enthält.

Am oberen Ende des Rückenmarkes tritt (Fig. 231 $F_{p} y$ ) die letztere Bahn in massigen Zügen, das Vorderhorn ihrer Seite durchbrechend, in den Vorderstrang der anderen Seite. Dort trifft sie auf die PyramidenTorder strangbahn, und von nun an zieht der ungekreuzte Tractus corticospinalis vereint mit dem gekreuzten als Pyramidenstrang hirnwärts. Die Hinterhörner rücken, wenn der bislang ron der Pyramide im Seitenstrange eingenommene Platz frei wird, weiter rentral.

Wenige Millimeter höher oben ist die Pyramidenkreuzung vollendet. Es liegen jetzt Pyramiden-Torderstrangfasern und PyramidenSeitenstrangfasern vereint als mächtiges Querschnittbündel rentral am Marke. In der Figur 232 ist das deutlich sichtbar. Sie sehen an ihr auch, dass die Torderstranggrundbündel $\left(F a^{\prime}\right)$ dorsal ron den Pyramiden gerathen. Aussen vom abgetrennten Reste des Vorderhornes ist ein kleiner grauer Herd rom Schnitte getroffen worden. Er gehört der untersten Spitze der Olive an. Die Olive nimmt hirnwärts beträchtlich an Grösse zu und erfüllt einen grossen Theil des ron den Seitensträngen eingenommenen Raumes. Diese letzteren sind, seit dem Auftreten der Processus reticulares etwa, wesentlich faserreicher geworden. Das Associationsfeld entrickelt sich mehr und mehr. Doch sind die Bahnen meist nnr noch kurze Strecken verfolgbar. Viele enden in zerstreuten kleinen Ganglienzellgruppen. (Kern des Seitenstranges, Nucl. reticularis tegmenti u. s. w.).

Das Umlagern der Fasern, das Eintreten der Pyramiden-Seitenstrangbahn in den Vorderstrang der anderen Seite ist an den vorstehenden beiden Henle'schen Zeichnungen sehr gut zu sehen. Die abgetrennten Torderhörner können nach oben hin noch weiter verfolgt werden, verlieren sich aber etwa in der Höhe der Briicke.

Die Pyramidenstränge werden Sie auf allen folgenden Schnitten rorn zwischen den Oliven liegen sehen (s. die Figuren der folgenden Vorlesung). Schliesslich werden sie weiter oben ron den Querfasern der Brücke überdeckt und zerspalten. Trie sie später wieder aus der Brücke auftauchen und durch den Hirnschenkel in die innere Kapsel ziehen, wurde in fï̈heren 
Vorlesungen wiederholt gezeigt. Auch dass die secundäre Degeneration, welche nach Unterbrechung der Tractus cortico-spinalis im Gehirn von da abwärts steigt, in die Oblongata in den Hinterseitenstrang der gekreuzten Rückenmarkshälfte und in den gleichseitigen Vorderstrang gelangt, wurde bereits erwähnt.

Die Gelegenheit, den Verlauf des Pyramidenstranges zu verfolgen, wird sich Ihnen, meine Herren, nicht allzu selten bieten, wemn Sie bei der Autopsie von länger bestehenden cerebralen halbseitigen Lähmungen Querschnitte durch den Hirnschenkel, die Briicke, die Nedulla oblongata und das Rückenmark machen. Die graue Pyramide auf der erkrankten Seite wird sich meist deutlich von der weiss gebliebenen der anderen Seite abheben; im Rückenmarke wird sich im hinteren Theile des gekreuzten Seitenstranges eine grau verfärbte Stelle finden.

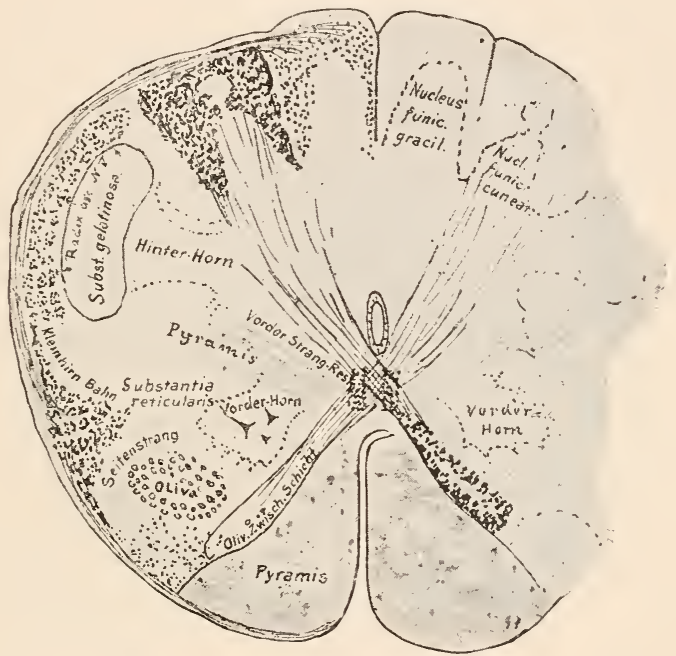

Fig. 233.

Schnitt durch den Anfangstheil der Oblongata einer menschlichen Frucht aus der 26. Schwangerschaftswoche. Jan sieht die Züge aus den Burdach'schen Străngen zur Schleifenkreuzung und die später zu schildernden Fibrae arciformes externae dorsales aus den Goll'schen Strangen. Zu beachten ist die Lage der KleinhirnSeitenstrangbahn.

Auf der Strecke, wo die Pyramidenkreuzmng stattfindet, treten auch in den Hintersträngen Veränderungen ein. Mitten in ihnen zeigen sich, zuerst im inneren, dam anch im äusseren Hinterstrang Kerne grauer, Ganglienzellen führender Massen, die Kerne des zarten Stránges und des Keilstranges. Diese Kerne verschmelzen mit der grauen Substanz, welche dadurch ihre Form sehr wesentlich ändert. (In Fig. 231 sind die ersteren, auf Fig. 232 auch die des Keilstranges schon zu sehen. Wahrscheinlich enden allmählich alle Hinterstrangfasern in diesen 
Kernen. Aus den Kernen aber dringen massenhaft Fasern durch die graue Substanz nach vorn und kreuzen sich frontal (ron der Pyramidenkreuzung) mit denjenigen der anderen Seite. Thre Fasern gelangen später in die Schleife, und desshalb hat man diese Kreuzung Schleifenkreuzung genannt.

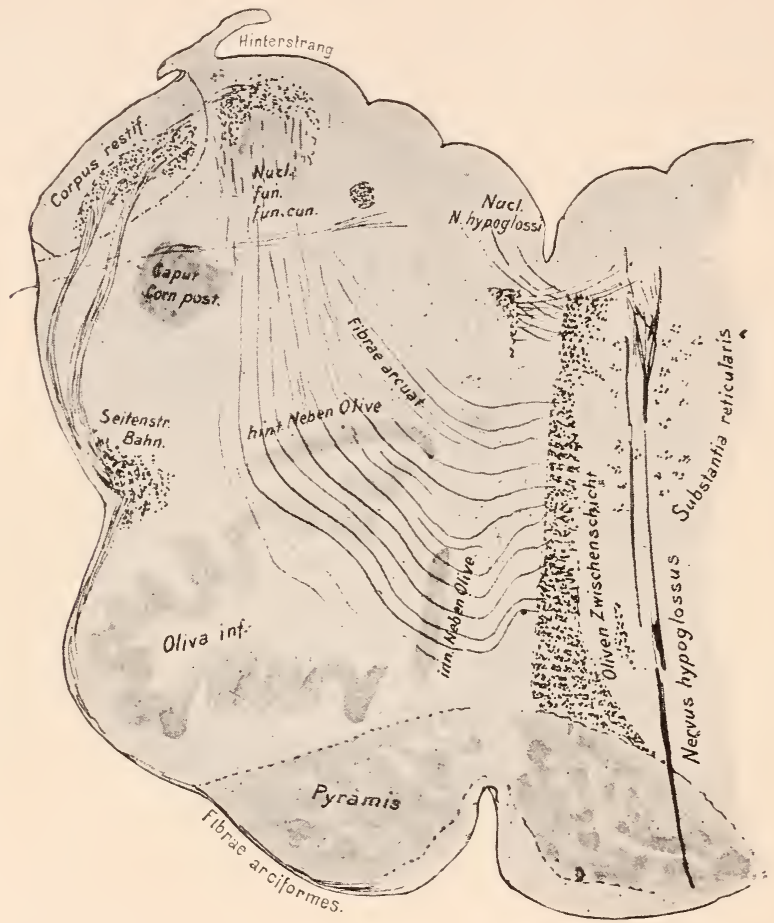

Fig. 234.

Schnitt durch die Oblongata 'einer Frucht aus der 26. Schwangerschaftswoche. Die markhaltigen Fasern durch Hämatoxylin gefärbt. Die linke Olivenzwischenschicht und der Tractus spinalis N. trigemini sind nicht eingezeichnet. Im Corpus restiforme ist nur der Rückenmarkstheil markhaltig. Fibrae arciformes $=$ Fibr. arc. ext. ant. Die Fibr. arc. ext. post. oben links aussen zwischen Corpus restiforme und Hinterstrang. Das als "Seitenstrang" bezeichnete Bündel ist der Tr. cerebello-spin. ventr. Jateralis, der an dieser Stelle bis in die vorderen Brückenebenen bleibt; der Tr. cerebellospin. dorsalis zieht, hier sichtbar, direct in das Corpus restiforme.

Es ist nicht so ganz leicht, sich am ausgebildeten Organ von der Existenz der Schleifenkreuzung mit absoluter Sicherheit zu überzeugen. Wohl aber bleibt kein Zweifel mehr, wenn man Schnitte durch die Medulla oblongata von Früchten aus dem 7. Schwangerschaftsmonate macht. Dort stören die sich kreuzenden markhaltigen Fasern der Pyramiden noch nicht die Klarheit des Bildes, dort treten die allein Markscheiden führenden Hinterstrangfasern deutlicher hervor. Zunächst sieht man wesentlich nur Fasern aus den Kernen der Burdach'schen 
Stränge austreten, im 9. Monate aber kamn man etwas höher oben auch die Kreuzung der Fasern aus den Kernen der Goll'schen Stränge erkennen.

Wollen Sie den vorstehend abgebildeten Schnitt zur Orientirung mit Figg. 231 und 232 vergleichen. Hinter dem Centralkanal liegt die sehr breit gewordene graue Substanz. In dem zarten Strang ist sein Kern aufgetreten, im Keilstrang ebenso, beide sind in Continuität mit der grauen Substanz. Nach aussen von ihnen liegt von einer dïnnen Schicht markhaltiger Fasern umgeben (Radix spinalis $\mathrm{N}$. trigemini), die Substantia gelatinosa des Hinterlornes. Der Raum nach vorn von ihr, welcher auf Fig. 232 von den dunklen Pyramidenfasern eingenommen ist, ist hell, weil jene noch ohne Mark sind. Marklıaltig sind die Torderseitenstrangreste und die Kleinhirnbahn an der Peripherie des Seitenstranges.

Nun sehen Sie aus den Hinterstrangkernen sich Fasern entwickeln, welche im Bogen ( $\mathrm{Fibrae}$ arciformes internae) durcli die graue Substanz ziehen, vor dem Centralkanal kreuzen und sich als dicke Schicht dorsal von der dort bereits gekreuzten Pyramide hinleg*en. Das Gebiet, welches sie erfüllen, ist dasjenige der Vorderseitenstränge des Rückenmarkes. Die Hauptmasse der in diesen aufsteigenden, bereits gekreuztel sensorischen Bahnen geräth dadurch nach rückwärts und auch nach aussen von diesen neuen Ankömmlingen. So füllt die uun ver einte gekreuzte sensorische Bahn zweiter Ordnung allmählich das ganze Areal aus, das zwischen den beiden in dieser Höhe der Oblongata aufgetretenen neuen grauen

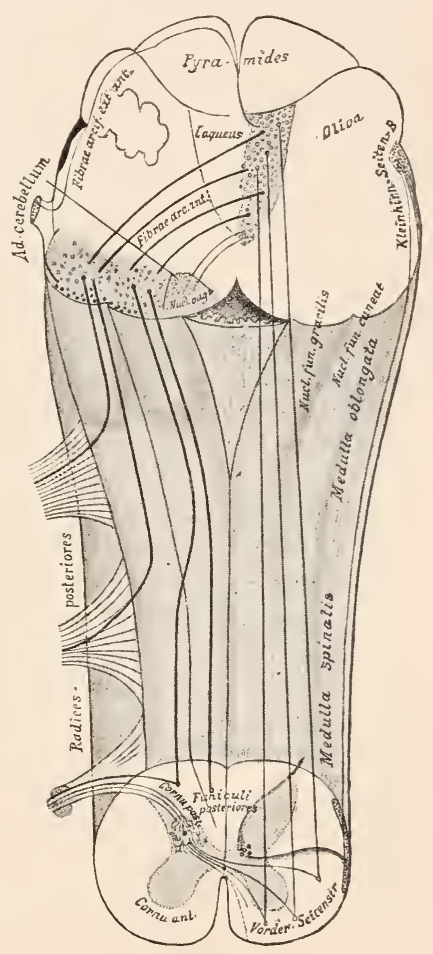

Fig. 235 .

Schema des Verlaufes der sensorischen Bahn von den Hinterwurzeln bis zum verlängerten Marke. Massen, den Oliven (Olivae in feriores), liegt. Je höher man in der Oblongata hirnwärts steigt, um so mehr verarmen die Hinterstränge an Fasern. Allmählich gelangen alle durch Fibrae arcuatae in die Schleifenkreuzung und so auf die entgegengesetzte Seite, nahe der Mittellinie, wo sie die Olivenzwischenschicht oder, wie wir sie von jetzt an nennen wollen. die Schleifenschicht 
bilden. Denn die Fasern dieser Schicht ziehen zur Schleife des Mittelhirnes empor.

In Fig. 235 lege ich Ihnen ein Schema des Verlanfes der sensorischen Fasern vor. Wollen Sie an diesem, vom Wurzeleintritte ausgehend, den Verlauf der einzelnen Züge verfolgen und schliesslich constatiren, wohin jeder einzelne in der Oblongata geräth. Wollen Sie namentlich beachten,

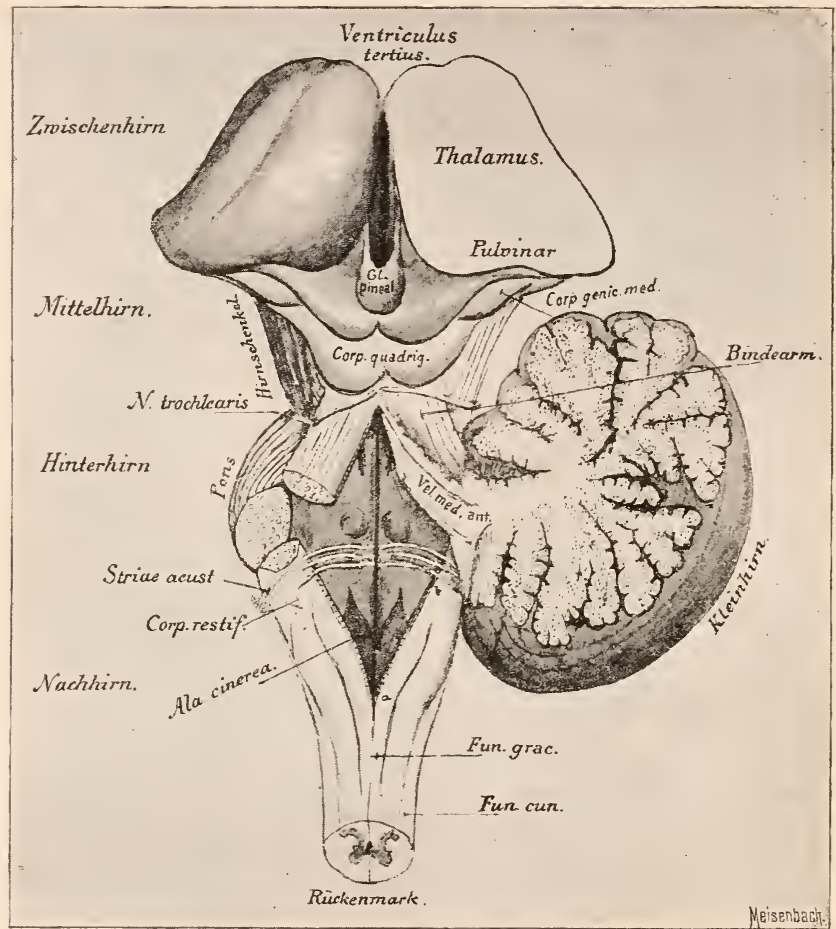

Fig. 236.

Das Hinter - und Nachhirn durch Wegnahme ihres Daches eröffnet. Velum med. ant. und Cerebellam noch sichtbar. Velum med. post. längs der gestrichelten Linie $a b$ abgetrennt.

wie in der letzteren die Bahnen, welche im Rïckenmarke schon kreuzen, und die, welche dort ungekreuzt aufsteigen, in einem Querschnittsfeld zusammenkommen.

So hätten wir jetzt zwei wichtige Kreuzungen kennen gelernt: die Pyramidenkreuzung und die Schleifenkreuzung. In der ersteren werden motorische Fasern verlagert, in der zweiten sind es Bahnen, die der Sensibilität dienen. 
Zwei grosse neue Faserareale sind entstanden, ventral das Pyramidenbündel und dorsal von diesem die Schleifenschicht. Bis hoch hinauf unter die Vierhügel werden wir beide an gleicher Stelle verfolgen können.

Das Areal der Schleifenchicht ist beim reifen Menschen viel faserreicher, als es in den eben demonstrirten Abbildungen von Föten erscheint. Bei den letzteren sind alle die Fasern auts den Vorder-Seitensträngen noch nicht markhaltig, welche zur sensorischen Bahn gehören, und nur erst die aus den Hinterstrangkernen stammenden Züge deutlich.

Durch die beiden Kreuzungen ändert sich das Querschnittsbild ganz wesentlich. Dazu kommt noch, dass die grame Substanz, wie ich gleich eingehender zeigen will, auch ihre Gestalt ändert, dass neue graue Massen in der Oblongata auftreten; drei von ihnen, die beiden Hinterstrangkerne und die Olive, haben wir ja bereits jederseits kennen gelernt. Vor Allem aber ändert sich auch die äussere Form sehr. Da allmählich die

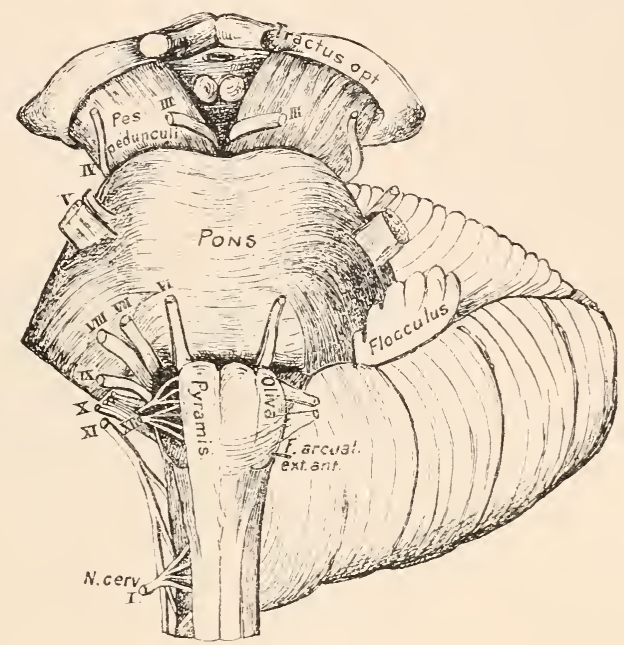

Fig. 237.

Iedulla oblongata, Pons, Cerebellum and Hirnschenkel von vorn; zar Demonstration des Crsprunges der Hirnnerven.

\section{Hinterstrangfasern}

in die Kerne treten und da enden, wird die grane substanz dieser Kerne schliesslich ganz blossgelegt, sie liegt fast frei an der Dorsalfläche des Markes. Nun weichen aber die Hinterstränge in den Höhen der Oblongata auch etwas aus einander. So kommt die hintere graue Commissur des Rückenmarkes deutlich zum Vorschein, gerade in dem Tinkel, wo die Hinterstränge auseinanderweichen. In dieser Höhe elweitert sich der Centralkanal zum Ventriculus quartus der Oblongata. Was ihn deckt, verdünnt sich weiter noch, verbreitert sich auch und ist als Velum medullare posterius bis an das Kleinhirn hin zu verfolgen. Es bildet mit diesem zusammen also das Dach des vierten Ventrikels. An dem Längsschnitt Fig. 206 sehen Sie die Zusammensetzung des Hinter-Nachhirndaches aus Velum medullare posterius, Cerebellum und Velum medullare anterius. Dicht am Beginne des Ventriculus 
quartus ist im Velum medullare posterius ein Loch, das von aussen her in den vierten Tentrikel führt. Es ist das bereits erwähnte Foramen I agendii, durch das die Flüssigkeit in den Tentrikeln mit derjenigen communicirt, welche aussen zwischen Pia und Nark, in den Spalträumen der Arachnoidea das ganze Centralnervensystem umspült.

Auf der vorstehenden Fig. 236 ist dieses ganze Dach weggenommen, so dass man ron oben frei in den Tentriculus quartus blicken kann. Sein Boden wird hinten ron den auseinander weichenden Hintersträngen, rorn ron den Bindearmen. welche nach den Vierhügeln zu convergiren, begrenzt. So erhält er die eigenthümliche Gestalt, welche ihm den Namen Rautengrube eingetragen hat.

Die in Fig. 236 abgebildete Ansicht der Oblongata von hinten lässt erkennen, dass nach oben die Hinterstränge verschwinden, dass an ihrer' Stelle der untere Kleinhirnarm, das Corpus restiforme (s. u.), auftritt. Die Anschwellung im oberen Theil der inneren Hinterstränge heisst Clava; sie wird durch die Einlagerung des Nucleus funiculi gracilis bewirkt.

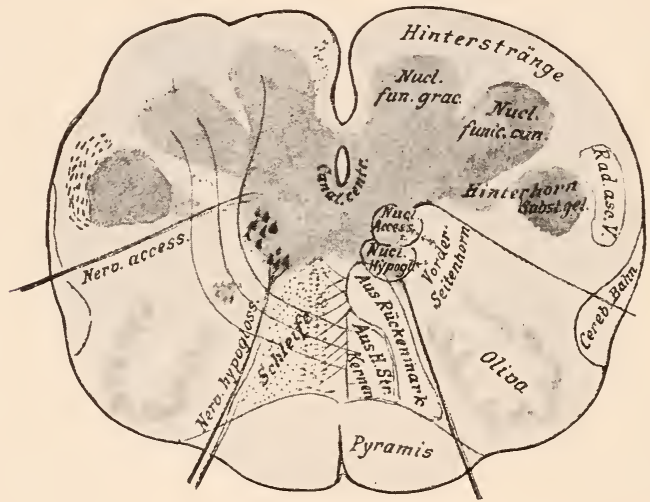

Fig. 238.

Schnitt durch die Oblongata in der Höhe der hinteren Hypoglossuswurzeln. Schema.

Eine Vorderansicht der Medulla oblongata (Fig. 237) zeigt zunächst die dicken, aus dem Rückenmarke auftauchenden Stränge der Pyramiden. Nach aussen ron ihnen befinden sich, in die Verlängerung der Seitenstränge eingebettet, die Oliven, als zwei ziemlich mächtige Anschwellungen. Nicht weit frontal ron ihmen legen sich die mächtigen Fasern des Pons quer vor die Pyramiden. In der Verlängerung des Vorderwurzelaustrittes nach oben tritt zwischen Olive und Pyramide der Nervus hypoglossus (XII) aus dem verlängerten Nark. Der Nervus accessorius Willisii (XI) entspringt rom Halsmarke bis hoch hinauf zur Oblongata seitlich, wach aussen von den Oliven, mit zahlreichen Fädchen. Ueber ihm gehen, in 
der Verlängerungslinie seines Austrittes, der Nervus ragus $(X)$ und der Glossopharyngeus $(I X)$ ab. Dicht hinter den Brückenfasern entspringen seitlich der Nervus acusticus (TIII) und der Nervus facial is (TII). Der 6. Hirnnerv, der Abducens, liegt nach innen rom Ursprungsort der beiden letztgenannten Nerven. Aus der Tiefe der Briickenfasern taucht der Trige minus ( $\mathrm{T}$ ) hervor. Ueber den Ursprung des Nervus trochlearis $(I V)$ und des Nervus oculomotorius (III) wurde früher bereits berichtet. Der erstere kommt hinter den Vierhügeln aus dem Telum medullare posterius, der zweite ventral aus den Hirnschenkeln heraus.

Wir haben rorhin die Betrachtung der Oblongataschnitte da abgebrochen, wo der Centralkanal sich zur Rautengrube erweitert. Schon vor-

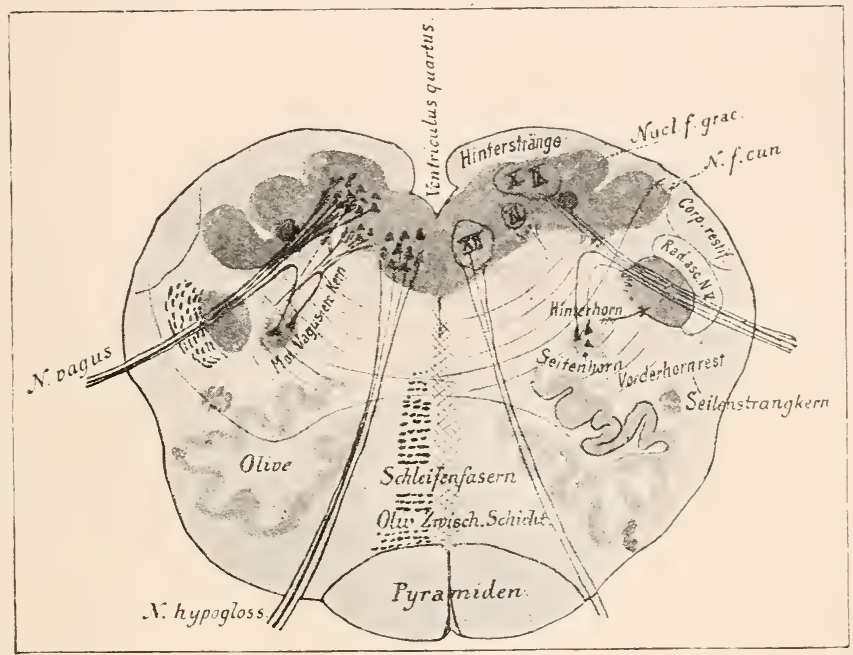

Fig. 239.

Schnitt durch die Oblongata in der Höhe des Vagusaustrittes (schematisirt).

her sind in seiner Umgebung die ersten Kerne der Hirnnerven aufgetreten. Aus Zellen des lateralen Theiles des Torderhornes kommen die Accessoriusfasern und aus einer ventral von ihnen gelegenen Stelle, die etwa der Basis des früheren Vorderhornes entspricht, Nucleus hypoglossi, entwickeln sich die Hypoglossuszüge.

In den zwei vorstehenden Figuren ist das schematisch angedeutet. Wenn Sie sich nun an der Hand dieser Zeichnungen vorstellen, wie der Centralkanal durch Auseinanderweichen der Hinterstränge sich verbreitert, zum Ventriculus quartus wird, so begreifen Sie leicht, dass von nun an alle Nervenkerne am Boden dieses Ventrikels, in der Rautengrube liegen müssen. Der Schnitt Fig. 239 lässt das denn auch deutlich erkennen. Nach aussen 
ron den Kernen liegen die sehr faserarm gewordenen Hinterstränge mit ihren Kernen. Das Hinterhorn, kemutlich an der Substantia gelatinosa seines Kopfes, ist ganz abgetrennt, aber auch der basale Theil des Seitellhornes, aus dem die Fasern des motorischen Accessorius kamen, verliert kurz über der abgebildeten Schnitthöhe den Zusammenhang mit dem compacten Theil der grauen Substanz. Er erhält sich als eine ganglienzellenreiche Säule ventral von derselben bis hoch hinauf in die Brïcke und giebt, wemn der Accessorius ganz ausgetreten ist, Fasern zum Tagus (und Glossopharyngeus?) ab, die erst dorsal steigen und dann zu dem betreffenden Nervenstamme abbiegen (motorischer Vagus- u. s. w. Kern). Höher oben werden wir ihm wieder als Facialiskeru begegnen. Sie können sich also merken, dass ausser dem Hypoglossus und den Augenmuskelnerven alle motorischen Fasern der Hirnnerven aus einer Zellsäule entspringen, welche in der Verlängerung der lateralen Vorderhornzellen liegt.

Wollen Sie noch auf Fig. 23 s bemerken, wohin der Rest des Vorderhornes gerathen ist, und wie sehr die Oliven an Umfang zugenommen haben. Wenn das Seitenlorn abgetrenut ist, tritt dort, wo früher das Hinterhorn inserirte, also in einer Gegend, in der im Rückenmarke Kerne sensibler Nerven lagen, ein neuer grosser Nervenkern auf, mit spindelförmigen Zellen, welche denen des Hinterhornes ganz ähnlich sind, der sensorische Endkern des Nervus ragus. Er liegt am Boden der Rautengrube medial von der Ala cinerea (s. Fig. 236) und reicht nach vorn bis etwa dahin, wo dort die mittlere der weissen Querlinien verläuft. In dies vordere Ende treten Fasern des Nervus glossopharyngeus ein. Die Hauptmasse dieses Nerven stammt aber aus seiner absteigenden Wurzel, s. u. Für den Vagus haben wir also jetzt zwei Kerne kennen gelernt, einen ventralen, der nach seiner Lage (in der Verlängerung eines Vorderhornabschnittes) und nach dem Aussehen seiner Zellen (multipolar mit Axencylindern direct in den Nerven) motorisch ist, und einen dorsalen, der, in der Verlängerung der grauen Substanz an der Hinterhornbasis liegend, durch seinen Bau als sensorischer Kern wohl charakterisirt ist. Der erstere dieser Kerne wird auch als Nucleus ambiguus bezeichnet. Die aus ihm entspringenden Fasern treten alle dorsalwärts und schliessen sich dann erst, im Knie abbiegend, der gestreckt austretenden, viel stärkeren sensiblen Wurzel an (s. Fig. 239). Ausser von diesen beiden Kernen erhält der Tagus auch noch Fasern aus mindestens zwei anderen Stellen. Tom oberen Halsmarke ab kann man ein feines Strängchen erkennen, das sich in die Oblongata hinauf bis dahin verfolgen lässt, wo die letzten Glossopharyngeuswurzeln abgehen. An seiner medialen Seite liegt eine Säule gelatinöser Substanz, in die spärliche Zellen eingebettet sind. Nan bezeichnet den Strang als Tractus solitarius - gemeinsame absteigende Vago-Glossopharyngeuswurzel. Er ist im Querschnitte auf Fig. 234 und Fig: 239 dorsal von den Vaguswurzeln zu sehen. Nur ein kleiner Theil der eintretenden Vaguswurzeln wendet sich in dem 
Fasciculus solitarius caudalwärts und tritt, allmählich zu Endramificationen aufgezweigt, in die graue ihn begleitende säule ein.

Diese Säule ist also der Endkern des Glossopharyngeus und eines Theiles des Vagus. S. Ramon y Cajal hat nenerdings gezeigt, dass dicht an der Stelle, wo der Centralkanal sich zur Rautengrube verbreitert die beiden Nuclei terminales NN. vagi et Glossopharygnei einander sich nähern und schliesslich gerade über jener Eröffnungsstelle des Centralkanales zu einer gemeinsamen Masse, Nucleus commissuralis, zusammenfliessen. Hier kreuzt ein beträchtlicher Theil der Fasern des Tractus solitarius zur anderen Seite.

Der Nervus glossopharyngeus tritt mit seiner Hauptmasse in den Fasciculus solitarius und endet in dessen Grau. während nur ein relativ geringer Theil direct im Bodengrau des Tentrikels sich aufzweigt. Die Existenz dieses dicht vor dem Vaguskerne gelegenen "Glossopharyngeuskernes" wird bestritten. Es ist in der That schwierig, die geringe in ihn eintauchende Nervenportion mit den gewöhnlichen Methoden zu finden. Die Anwendung der Golgimethode lehrt aber - Held -, dass die Verhältnisse so sind, wie ich sie oben darstellte. Tagus und Glossopharyngeus bekommen dann sehr wahrscheinlich noch eine absteigende Wurzel. Sie stammt aus dem Cerebellum, wo wir ihr schon als der directen sensorischen Kleinhirnbahn begegnet sind. Gerade die aus ihr zum Vagus gelangenden Fasern sind übrigens beim Menschen besonders schwer nachzuweisen. Natürlich entspringen die sensiblen Fasern der Nerven, von denen ich eben sprach, aus den Zellen der Wurzelganglia, aus welchen sie (His) ganz ebenso cerebralwärts weiter auswachsen, wie die sensiblen Rückenmarksnerven. Die erwähnten sensorischen Kerne sind ihre Endstationen. Dort verzweigen sich die Fäserchen um Zellen herım. In die ventrale Seite der Kerne sieht man viele Fasern im Bogen eintreten. Durch die Anwendung der vergleichend entwicklungsgeschichtlichen Methode ist es gelungen, nachzuweisen, dass diese gekreuzt aus der Schleifenschicht der anderen Seite stammen. So haben wir also für den sensiblen Vagus (und das Gleiche gilt vom Glossopharyngets) wieder das Schema der sensiblen Nerren: Nerv, Ursprungskern im Spinalganglion; Wurzel, Endkern (sensorischer Vaguskern), gekreuzte aufwärtsführende centrale Bahn.

Am Boden der Rautengrube liegt zwischen dem Vaguskern und der Medianlinie noch eine kleine, wulstige Erhabenheit, Clarke's Eminentia teres, in der von dem frontalen Ende des Hypoglossuskernes an bis etwa in das Gebiet des Quintusursprunges ein länglicher Kern spindelförmiger Zellen, der $\mathrm{Nucleus}$ funiculi teretis, Meynert's Nucleus medialis, nachweisbar ist. Die Bedentung ist noch ganz unbekannt.

Der Hypoglossuskern besteht aus mehreren Gruppen von Ganglienzellen, die alle unter sich durch ein feines Netzwerk verbunden sind. Aus den grossen multipolaren Zellen entwickeln sich feine Reiserchen, die, pinselartig zusammentretend, eine Anzahl von Nervenstämmchen constituiren. 
Aus dem Kerne entwickeln sich, ganz wie aus dem Vorderhorne, Fasern, Fibrae afferentes, welche über die Mittellinie hinwegtreten; sie gelangen aber nicht weit auf die andere Seite, sondern ziehen, in der Raphe gekrenzt, hirnwärts, um sich innerhalb der Brücke mit anderen (aus dem Fascialiskerne) zu vereinen. Das ganze Bündelchen gelangt dann in den Hirnschenkelfuss. Ist auch dieser Verlauf etwas abweichend

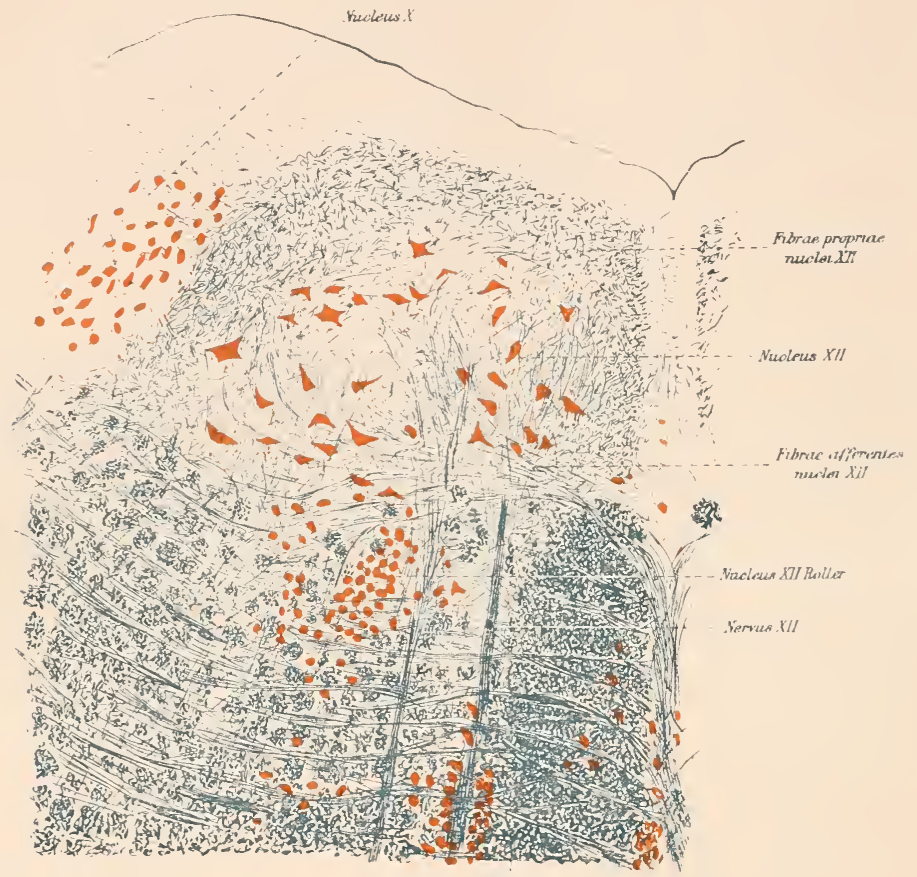

Fig. 240.

Frontalschnitt durch den Kern des Nervus hypoglossus. Nach Koch.

von dem, welchen wir an den secundären motorischen Bahnen im Rückenmarke kennen gelernt, so ist er im Wesen doch der gleiche: Wurzel, Kern, gekreuzte Bahn zum Fusse.

Ein Netz, welches den Hypoglossuskern in seinen einzelnen Theilen verbindet, ist ron besonderem Interesse; es kommt in dieser Art nur noch an einem Kerne, dem Oculomotoriuskerne, vor. Es giebt aber auch keine anderen Nerven, deren Fasern immer so gleichzeitig und ïbereinstimmend in Action treten, wie die Hypoglossusfasern beim Schluckacte, die Oculomotoriusfasern bei der Augenberregung.

Man kann jedoch in der Verlängerung des Hypoglossusnetzes hirn- 
wärts, also dicht unter dem Ventrikelepithel, jederseits ein geflechtartiges Bündel markhaltiger Nervenfasern nachweisen, aus dem Fäserchen ventralwärts (zu den Kernen der Nerren) abgehen. Dies Bündel - dorsales Längsbïndel, Schütz — liegt in der Oblongata zwischen Vaguskern und Eminentia teres. Es ist bis in die Vierhïgelgegend hinauf verfolgbar, wo es unter die Faserzüge des centralen Höhlengraues geräth.

Da ich Ihnen heute wesentlich schematisirte Abbildungen vorlegen musste, so wird es zweckmässig sein, wenn Sie zum Schluss der Torlesung noch einen Blick auf die Fig. 240, Abbildung des Hypoglossuskernes, werfen. In allem Reichthum seiner Fasern und Zellen hat ihn Koch, dem wir die Kenntniss des Netzes rerdanken, abgebildet.

Ventral rom Kerne liegen noch einige Zellanhäufungen (Roller's Hypoglossuskern), aus denen aber keine Hypoglossusfasern stammen.

Die Pyramidenkreuzung wurde bereits 1710 von Francois Petit entdeckt. Die Oliven sind zuerst von Vieussens beschrieben worden. Iakroskopisch wahrnehmbare Veränderungen beim Uebergange vom Rückenmarke zur Oblongata, namentlich die Oberflächengestaltung kennt man durch Santorini, Reil, Burdach und Rolando. Die Nuclei arciformes und die sie bedeckenden Fibrae arciformes anteriores hat Arnold zuerst genau geschildert, der sie als "Vorbrïcke" anffasste. Die Striae acusticae sind von Picolhomini entdeckt worden. "Ueber ihre Beziehungen zum Hörnerven bestand schon in der vormikroskopischen Zeit ein lebhafter Streit. Eigentliche Aufklärung über den Bau des verlängerten Markes brachten aber erst die Untersuchungen von Stilling, Kölliker, Mevnert, Schröder van der Kolk und Deiters. In nenerer Zeit ist namentlich den Tervenkernen dort eine besondere Aufmerksamkeit geschenkt worden (Gudden, Roller, Freud, Duval, Koch, Darkschewitsch, v. Kölliker, S. R. y Cajal und Andere).

\section{Vierundzwanzigste Vorlesung.}

\section{Die Medulla oblongata und die Haube der Briicke.}

I. H.! Die letzte Vorlesung hat Sie gelehrt, wie durch Verlagern mächtiger Bahnen, durch Auftreten neuer Kerne und durch das Verschwinden der Hinterstränge die Oblongata sich ausbildet. Eine Anzahl von Faserzügen aus dem Rückenmarke haben wir aber noch nicht bis in die Höhen verfolgt, welche uns eben beschäftigen. Die Hinterstränge haben indirect ihre Fortsetzung in der Schleifenschicht gefunden, und eben dorthin sind auch diejenigen sensorischen Fasern zweiter Ordnung gelangt, welche in den Vorderseitensträngen aufsteigen. Die Pyramidenbahnen aus dem Vorderund dem Seitenstrange liegen jetzt vereint ventral als dicke Pyramiden der Oblongata. Die Kleinhirn-Seitenstrangbahn behält bis hinauf in die Höhe der Olive ihre Lage ganz an der äusseren Peripherie. Dort beginnen die Fäserchen ihres dorsalen Theiles sich leicht ansteigend dorsalwärts dem Cerebellum zuzuwenden. Sie bilden dann bald den Kern eines mächtigen Bündels, das in dieser Höhe nel auftritt, des hinteren Kleinhirnarmes, Corpus restiforme. Der ventrale Theil bleibt bis hinauf 
in die Brücke an der alten Stelle liegen. Dann erst wendet er sich rückwärts zum Oberwurm hinauf.

Das Corpus restiforme entsteht lateral ron dem oberen Ende der Hinterstränge zunächst dadurch, dass die Kleinhirn-Seitenstrangbahn dort, wie erwähnt, hinauf zum Kleinhirne zieht. Zu ihr nun treten als Verstärkung Fasern aus den Hintersträngen, welche, wie Sie an Fig. 233 und auch an Fig. 234 (links oben) sehen. ihr um die hintere äussere Peripherie der Oblongata herum zuwachsen, Fibrae arcuatae externae posteriores. Auch von rorn her gelangen Fasern dorthin. Diese, die F. arc. ext. anteriores, stammen wahrscheinlich aus der Schleifenschicht zwischen den Oliven, also aus den gekreuzten Hintersträngen. treten nahe der Mittellinie rorn an die Oberfläche und ziehen theils rentral, theils dorsal ron den Pyramiden, zum Theil auch sie durchschneidend, nach hinten aussen zum Corpus restiforme. Die letzteren Fasern hat man auch als Fibrae arciformes der Pyramiden bezeichnet (Fig. 237 ron rorn). In sie ist ein Kern von wechselnder Grösse, der Nucleus arcuatus (Fig. 241), eingelagert. So wachsen dem Corpus restiforme aus dem Rückenmarke zu: 1) die Kleinhirn-Seitenstrangbahn, 2) Fasern der gleichseitigen Hinterstränge, 3) Fasern wahrscheinlich aus den gekreuzten Hintersträngen. $\left.{ }^{1}\right)$

In dem Fig. 234 abgebildeten Entwicklungsstadium sind nur die Rückenmarksfasern markhaltig. Sie können sich daher an diesem Schuitt gut iiber Lage und Ausdehnung dieses Theiles des unteren Kleinhirnarmes orientiren. Die rerschiedenen Arten der Fibrae arcuatae s. auch Fig. 241.

Im Corpus restiforme ist aber ausser den Rückenmarksfasern noch ein zweites, viel mächtigeres System enthalten, das, weil es sich viel später als das erste mit Markscheiden umkleidet, ron diesem getremnt werden muss. Es sind Fasern zur Olive der gekreuzten Seite. Da sie aus dem Kleinhirne kommen und nicht weiter als in die Oliven verfolgt werden können, wollen wir sie einstweilen Tractus cerebelloolivares des Corpus restiforme nennen. Erst durch sie wird der untere Kleinhirnschenkel zu einem mächtigen Gebilde.

Die Olive, Nucleus olivaris inferior, ist ein Hohlkörper ron der Form eines beiderseits zugespitzten Eies, dessen Oberfläche ausserordentlich stark gefaltet ist. Medialwärts hat sie einen langen, breiten Spalt - Hilus nuclei oliv. Den vielgefalteten Querschnitten sind Sie bereits auf manchen Schnitten begegnet, die ich Ihnen rorgelegt habe. Die Olive hat frisch eine graue, durchsichtige Färbung, weil sie wesentlich aus dichter Gliamasse besteht, in die vielverästelte Ganglienzellen eingelagert sind. Diese Zellen senden einen langen Stammfortsatz aus (Tincenci), um sie herum rerzweigen sich die Endpinsel eines anderen Fasersystems aus den Purkinje'schen Zellen (Kölliker).

1) Die sub 3 genamnten Fasern bekommen Monate vor den Prramiden und den Oliven, wahrscheinlich gleichzeitig mit den Hintersträngen, ihr Mark. 
Wohin die Axencylinder der Olivenzellen gehen, ist noch unbekannt. Kölliker denkt an Beziehungen zu den Seitensträngen des Rückemmarkes.

Die Tractus cerebello-olivares sind eine mächtige Fasermasse, die aus dem ventralen Rande des Corpus restiforme heranstritt, sich weiter in schön gekrümmten Bogenfasern herab zur Olive begiebt und damn von der Aussenseite, den Nuclens olivaris durchbrechend, in das Innere des Olivenkörpers gelangt. Von da treten die Fasern, sich nun zu geschlossenerem Bündel wieder sammelnd, aus dem Hilus heraus über die Mittellinie um in der gekreuzten Olive zu enden. Sie haben im allgemeinen den gleichen Terlauf wie die Fibrae arcuatae aus der Schleife und sind von diesen nur degenerativ zu sondern. S. Fig. 242. Wemn eine Kleinhirnhälfte verloren geht, atrophiren sie mit der gekreuzten Olive. Dorsal von

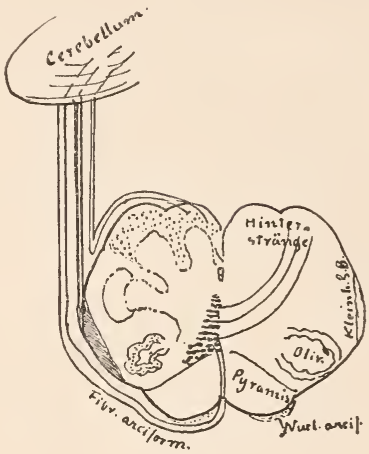

Fig. 241.

Ursprung des Rückenmarktheiles des Corpus rostiformo. Die Fasern endon zumeist oder alle im Wurme.

der Olive ziehen im Bereiche der Substantia reticularis eine Anzahl Faserbündel, die mit Fasern aus dem das Ganglion umgebenden Geflecht im

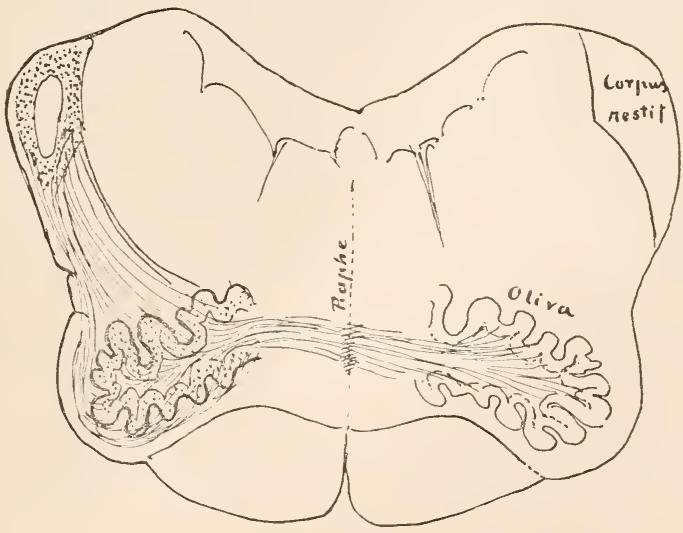

Fix. 242.

Der Kleinhirn-Olivenantheil des Corpus rostiforme. Das weiss gelassene Feld im linken Corpus restiforme giebt die Lage des Rückenınarkantheiles an.

Zusammenhang stehen, in der Haube aufwärts (Bechterew's centrale Haubenbahn, Stilling's Seitenstrangrest). 
Die Kleinhirn-Olivenbahn des Corpus restiforme kommt wesentlich ron der Aussenseite des Tliesses. Dieses ist wiederum durch den Nucleus dentatus Cerebelli, den es umgiebt, mit dem Bindearm im Zusammenhang. So kömnen wir uns vorstellen, dass die Olive, das gekreuzte Corpus restiforme, das Vliess, der Bindearm und der rothe Haubenkern wieder der gekreuzten Seite ein Leitungssystem bilden. Manches, namentlich Experimente an Thieren. spricht dafür, dass diese Bahn für die Erhaltung des Körpergleichgewichtes und des Mnskeltonus ron Wichtigkeit ist. Nur die Säuger haben grosse dentliche Oliven, s. s. 92.

In der Höhe der Oblongata, wo der Taguskern liegt, sind die meisten Rückenmarksfasern in das Corpus restiforme getreten. Ebenso entlält dasselbe dort schon einen Theil der Olivenbahn. Als dickes Bündel liegt nun der untere Kleinhirnarm lateral von den letzten Resten der Hinterstränge.

Es ist jetzt dasjenige Querschnittsbild entstanden, welches für die Oblongata typisch ist. Lassen Sie uns, nachdem sie die Mehrzahl der dort rorhandenen Bildungen einzeln kennen gelernt haben, nun einmal dieses Bild in seiner Gesammtheit durchmustern. Manches noch nicht Erwähnte wird sich damn auch leicht einfügen. Fig. 243.

Tentral liegen die Pyramiden. Das lange dreieckige Feld querdurchschnittener Nervenfasern dicht hinter ihnen ist die Oliv en z w is chenschicht, die gekreuzte Fortsetzung der hinteren Wurzelfasern. Die Kerne der Hinterstränge liegen, nur noch ron wenig Nervenfasern überzogen, dorsal aussen. Zahlreiche Fibrae arciformes internae entspringen dort und dringen, die Region zwischen Hinterhorn und Olivenzwischenschicht durchsetzend, in die Raphe und ron da auf die andere Seite.

Ganz den gleichen Verlauf haben eine strecke weit die Olivenkleinhirnfasern. Auf der Zeichnung sind sie allerdings punktirt, factisch aber sind beim Erwachsenen die beiden Arten von Fibrae arciformes internae nicht zu unterscheiden. Erst die Untersuchung der Markscheidenbildung hat ja ihre Tremung ermöglicht.

In der Mittellinie müssen sich natürlich alle diese Züge mit den von der anderen Seite kommenden krenzen. Diese Linie mit ihren vielen Kreuzungen heisst Raphe.

Die Olivenzwischenschicht oder Schleife enthält in dieser Höhe ausser den in den Torderseitensträngen aufgestiegenen Bahnen schon den grössten Theil der aus den Hinterstrangkernen stammenden. Diese letzteren gelangen weiter vorn wesentlich in die obere Schleife.

Beachten Sie auf dem Schnitte auch die aus der Schleifenschicht zum Taguskern der gekreuzten Seite tretenden Fäserchen; sie sind das Analogon der Kreuzungsfasern aus dem Torderseitenstrang zum Hinterhorn, die secmndäre Tagmsbahn.

Dorsal ron der schleifenschicht begegnen uns zum ersten Male wieder die Ihnen schon von der 7 . Torlesmng her bekannten hinteren Längsbündel. schon im Bereich des ersten Cervicalnerven hätten wir ihre Fasern in der Tiefe des Torderstranges treffen können. 
Beiderseits aussen ron den Pyramiden liegen die unteren Oliven. Sie sind von den Fibrae arciformes durchbrochen, die, wie Sie jetzt wissen, zum Theil in ihnen enden, soweit sie ans dem C'erebellum stammen, zum Theil, soweit sie aus den Hinterstrangkernen kommen, sie nur durchziehen.

Lateral sowohl als dorsal ron der Olive liegen die innere und hintere Nebenolive, Kerne, die ähnlich gebaut sind, wie die Oliven,

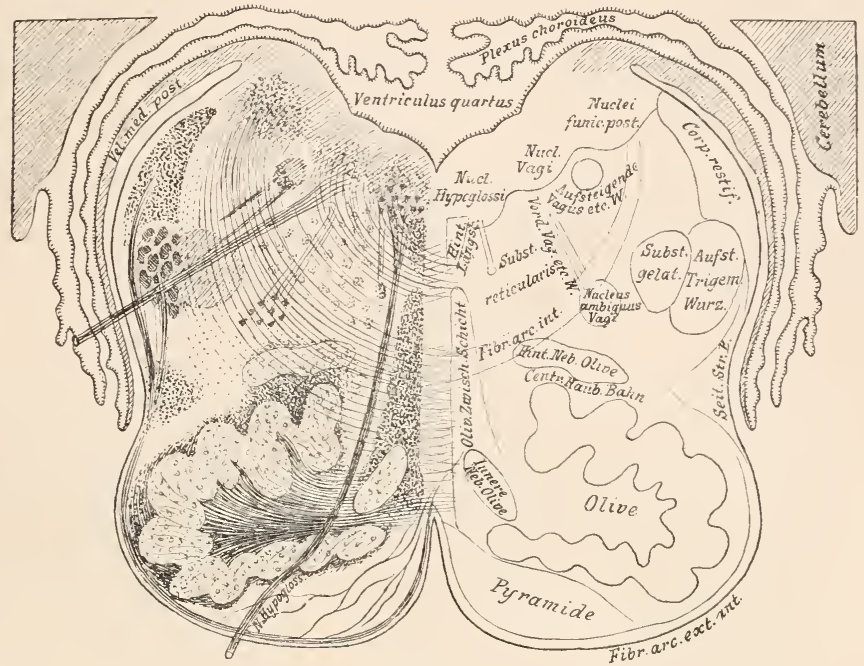

Fig. 243.

Schnitt durch die Medulla oblongata.

und wie diese ron den Fibrae arcuatae durchbrochen werden. Durch die erstere, die innere, treten namentlich die Fasern aus der einen zur anderen Olive, die hintere wird wesentlich von den Hinterstrangfasern durchschnitten, wie das in der Zeichnung angedeutet ist.

Dorsal von der Olive liegt in Bereich der hinteren Nebenolive ein Markfeld, das von nun an mitten in der Haube immer sichtbar bleibt und bis über den Ursprung des Trigeminus hinauf mit Sicherheit verfolgt werden kann. Die Gesammtheit seiner Fasern - centrale Haubenbahn - verbindet wahrscheinlich die Olive mit dem Mittelhirn (Bechterew).

Die hintere Periplerie des Schnittes wird eingenommen von den Nervenkernen. Zu innerst liegt der Kern des Nervus hypoglossus, dessen Fasern, die Olivengegend durchbrechend, ventralwärts dringen (vgl. Fig. 240). Aus der Raphe ziehen zahlleiche Fasern in ihn. Nach aussen folgt dann der Endkern des Vagus. Ein Rest der lateralen Vorderhorn- 
zellen liegt als ventraler oder motorischer Vaguskern dicht ror dem Hinterhorne. Die ihm entspringenden Fasern machen ror ihrem Austritt ein Knie, um sich der Wurzel aus dem sensorischen Kerne zuzugesellen.

Das dümne Bündel querdurchschnittener Nerrenfasern, welches nach aussen von dem vorhin genannten sensorischen Kerne liegt, ist die gemeinsame Vago-Glossopharyngeuswurel mit dem ihr anliegenden Endkerne.

Nach aussen rom gemeinschaftlichen Kerne der zwei Nerven liegen, nur noch ron wenigen Nervenfasern bedeckt, die Kerne der Hinterstränge, nach rorn ron ihnen finden Sie die Substantia gelatinosa rom Kopfe des Rückenmark-Hinterhornes. Sie ist aussen umschlossen von einem dicken, vielfach zerklüfteten Bündel markhaltiger Nervenfasern, das sie schon rom obersten Halsmarke an begleitet, nach oben aber etwas stärker wird. Dies Bündel kann bis hoch hinauf in die Brücke verfolgt werden. Dort gesellt es sich zu den austretenden Fasern des Trigeminus. Ueber diese Radix spinalis Trigemini vergl. die Notiz S. 33 `.

Das Gebiet zwischen den Oliven und den Kernen der Hinterstränge, welches nach aussen von der Kleinhirn-Seitenstrangbahn und der aufsteigenden Quintuswurzel, nach innen ron der Schleife begrenzt wird, enthält ausser den zahlreichen Fibrae arciformes internae noch eine Anzahl von Fasern kurzen Verlaufes und ausserdem, zwischen diese gelagert, multipolare, zerstreut liegende Nerrenzellen.

Das auf Querschnitten der Oblongata netzförmige Aussehen der Faserbündel rechtfertigt die Bezeichnung als substantia reticularis. Die Summe der Ganglienzellengruppen hat Bechterew als Nucleus reticularis tegmenti bezeichnet und bis hinauf, nahe an die Vierhügel verfolgt. Die Zellen und die Fasern sind, soweit wir heute wissen, ganz rom gleichen Charakter wie die Strangzellen im Rückenmarke; sie verbinden mit ihren häufig getheilten Axencylindern verschiedene Höhen der Oblongata unter einander. Nur nimmt das ganze System, dem wir ja schon in den Seitensträngen des Rückenmarkes begegnet sind, hier in der Oblongata an Ausdehnung enorm zu. Es ist desshalb zweckmässig; dieses für das verlängerte Mark sehr charakteristische Areal als Associationsfeld der Oblongata zu bezeichnen. Es ist früher (S. 76) schon mitgetheilt worden, dass dieser reichen Associationsfaserung wahrscheinlich die Oblongata die Fähigkeit zu der genauen Zusammenordnung der Functionen dankt, denen sie dient.

Wenn man uun weiter Schnitte durch das verlängerte Mark macht, so ändert sich für ca. 2 IIm. das Querschnittsbild wenig. Man sieht, dass der sensorische Vaguskern, weit hinaufragend, fortwährend an seinem ventralen Rande Wurzelbïndel ron der Peripherie empfängt. Aus dem Fasciculus solitarius wenden sich nahe der frontalen Spitze des Taguskernes die Fasern des Glossopharyngeus in einzelnen Bündelchen nach aussen. Nur 
das Corpus restiforme nimmt jetzt an Umfang enorm zu. Treten doch hier zu ilm aus dem Cerebellum die Olivenfasern herab.

Die letzten Schnitte vor der Brücke (Fig. 244) zeigen, dass die Hinterstrangkerne verschwunden sind, dass an ihrer Stelle die enorme Fasermasse des Corpus restiforme liegt. Ihr ist innen ein neues Feld von Querschnitten angelagert, die directe sensorische Kleinhirnbahn. Wo sie begann, ist schwer zu sagen, vielleicht war sie schon innerhalb der Hinterstrangkerne vorhanden. Ausserdem liegt in diesem Felde noch eine vom Acusticus herabziehende Wurzel. Aus dem Corpus restiforme ziehen Fasern zu der in diesen Ebenen schon stark verkleinerten unteren Olive. Die Schleife liegt noch, wie sie auf dem letzten demonstrirten Schnitte lag, ebenso die centrale Haubenbahn. Neu aufgetreten

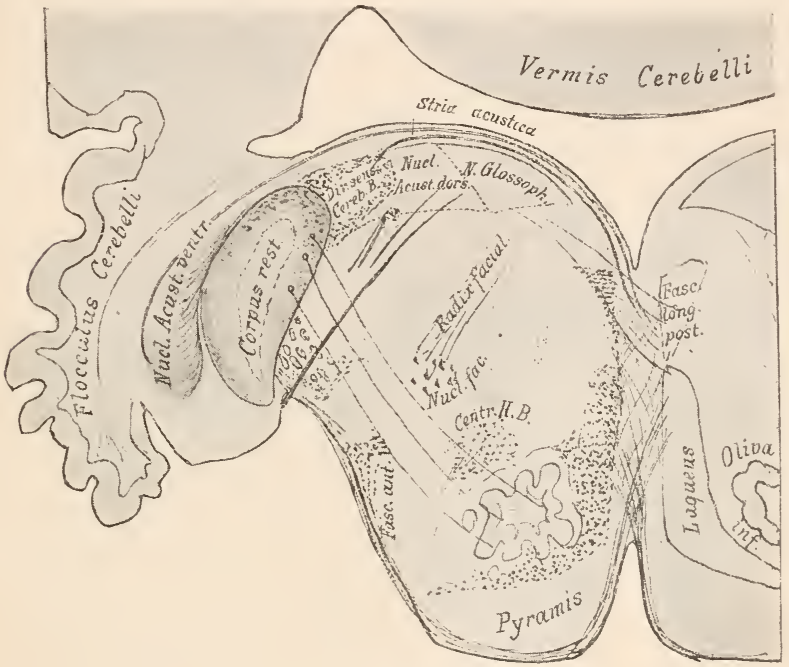

Fig. 244.

Die Zusammensetzung der Oblongata am caudalen Brückenrande.

sind drei Kerne. Einer, an der Stelle gelegen, von der weiter candal die motorischen Tagusfasern entsprangen (Fig. 243), sendet seine Fäserchen alle dorsalwärts und nach innen, wo sie sich bald nahe der Mittellinie zu einem Bündel sammeln werden, das ist der Facialiskern. Der zweite Kern liegt nach aussen vom Corpus restiforme. Einstweilen sehen wir in ihn nur Fasern eintreten, welche von dorsalwärts aus der Gegend des eben in dieser Höhe sichtbar werdenden d or's a len A cus s i c uske rn es stammen, ii den nächsten Schnitten aber werden Sie erkennen, dass hier ein sehr mächtiges Gebilde vorhanden ist, der ventrale - frülıer vordere - K e rn des Acusticus. Beobachten Sie schon hier, wie er zwischen das Klein- 
hirn und das Corpus restiforme eingelagert ist. Eine Hervorragung lateral von ihm, an der Aussenseite der Oblongata, heisst Tuberculum acusticum.

Aufwärts schreitend sind wir jetzt an der Stelle angekommen, wo sich die ersten Brückenfasem aus dem Cerebellum über die Pyramiden an der ventralen Seite der Schnitte hinlegen.

Alle von nun ab zu demonstrirenden Schnitte werden deshalb im ventralen Abschnitte den viel durchflochtenen Fusstheil des Pons zeigen. Er wechselt relatir weng bis hinauf zu den Ebenen. die Sie schon in der 20. Vorlesung kennen gelernt haben.

Sehr viel complicirter als der Fussabschnitt ist aber der Haubentheil der Brücke gebaut. Denn hier begimnt ein Hirngebiet, in dem auf rerhältnissmässig sehr engem Raum sich wichtige Formverhältnisse zusammen-

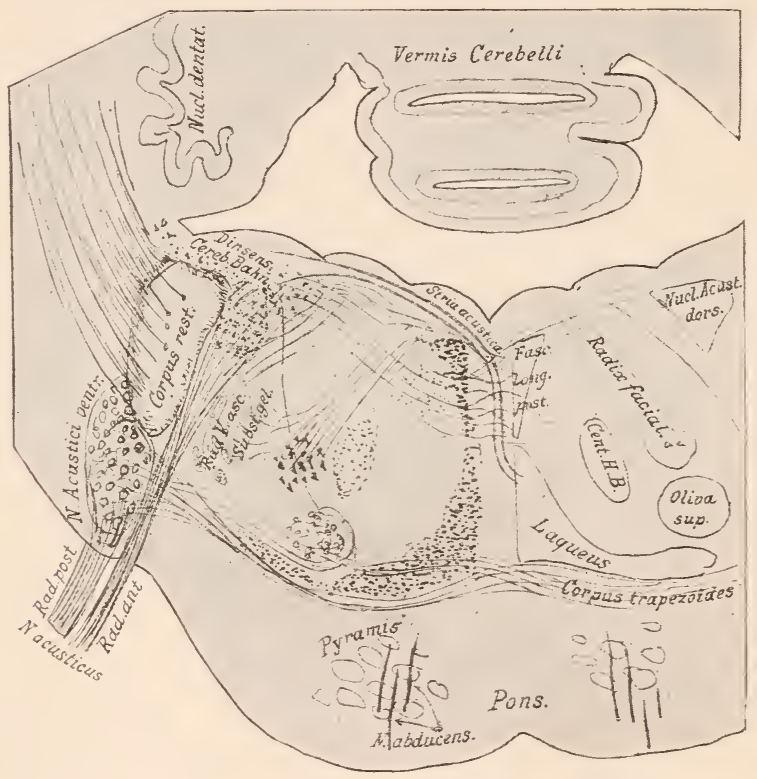

Fig. 245.

Die wichtigsten Elemente, welche ein Schnitt in der Gegend des Acusticusursprunges aufweist.

gedrängt finden, die Gegend, in die der Acusticus eindringt, und aus welcher der Facialis und der Abducens entspringen.

Der achte Hirnnerv besteht aus zwei Nerven, für die bekanntlich verschiedene Function nachgewiesen ist. Es ist deshalb der Vorschlag gemacht worden, die beiden Bündel — Nervus cochleae und Nervus vestibuli - 
ganz zu trennen und den ersteren allein als Hörnerven, den anderen als Tonusnerven (Ewald) zu bezeichnen.

Der Nervus cochleae entspringt aus den Zellen des Ganglion spiraleder Schnecke. Diese Zellen senden peripher einen feinen Ast aus, der sich rasch zwischen den Hörzellen aufzweigt, Fig. 16 b, während centralwärts, analog der hintereu Wurzel aus den spinalganglienzellen zum Rückenmark, die Hörnervenwurzel, eben der Nervus cochlea e, abgeht.

Auf dem Fig. 245 dargestellten Schnitt sehen Sie, wie dieser früher als "Radix posterior" " bezeichnete Zug mit zarten Fasern in den oben schon erwähnten ventralen Acusticuskern eintritt. Er zweigt sich um die mächtigen Zellen dieses Kernes zu feinen Endbäumchen auf.

Zum kleineren Theile begiebt er sich in ein beim Menschen relativ dümnes, bei Thieren aber oft ganz mächtiges Ganglion, das zwischen Kleinhirn und Brïcke dorso-lateral vom Cochleariskerne gelagert ist. Das ist das Tuberculum acusticum. Auch dieser Theil zweigt um Zellen herum auf. So hat das primäre Neuron des Cochlearis an diesen zwei Stätten sein Ende gefunden.

Aus beiden primären Endstätten entspringt ein neuer Faserzug, der in secundärer und tertiärer Verlängerung schliesslich in die laterale schleife führt oder, besser gesagt, diese Schleife erst bildet.

1. Die Zellen des Nucleus ventralis senden ihre Axencylinder medialwärts, wo man sie als starken Zug geschlossen aus dem Kerne austreten sieht. Dieser Zug heisst Corpus trapezoid eum. Er liegt direct dorsal von der Brïckenfaserung und wird bei den Thieren, weil ihre Brücke kürzer als die des Menschen ist, frei an der Hirnbasis sichtbar. Siehe Fig. 246.

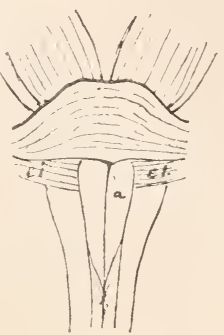

Fig. 246.

Medulla oblongata und Pons eines Affen, zur Demonstration des Corpus trapezoideum $c t$. a Pyramidon.

Mitten in den Trapezkörper sind überall grosse Zellen, Nucleus trapezoideus, Kölliker, eingelagert, die ihre Axencylinder in gleicher Richtung wie die dicken Trapezfasern aus dem Cochleariskerne senden. Die ganze, nicht unbeträchtliche Fasermasse zieht zu einer kleinen Gruppe von Ganglien, dem Nucleus olivaris superior, und zwar sowohl auf der gleichen Seite, als auch nach Ueberschreiten der Mittellinie zu denjenigen der gekreuzten Seite. Fig. 245. Hier scheint das zweite Neuron der Hörnervenbahn zu enden. In die obere Olive tauchen mit massenhaften Endverzweigungen die Fasern der lateralen Schleife. Durch diese ist eine Terbindung des Acusticus mit den hinteren und wahrscheinlich auch den vorderen Vierhügeln hergestellt.

Degenerationsbilder — Bu m m, Bagins $\mathrm{k}$ — lassen es als wahrscheinlich erscheinen, dass nicht nur die hier herabsteigenden Schleifenfasern nassenhaft Collaterale um den oberen Olivenkern abgeben. sonder'n dass 
auch aus diesem selbst, aus dem Trapezkörper und aus den später noch zu schildernden Striae acusticae zahlreiche Züge hier in die Schleife eintreten und mit ihr hinauf bis zu den hinteren Hügeln ziehen. Dazu wïrden sich noch Fasern gesellen, die in den Kernen entspringen, welche in die laterale Schleife dicht hinter den Vierhügeln (s. Fig. 206 b, aussen)

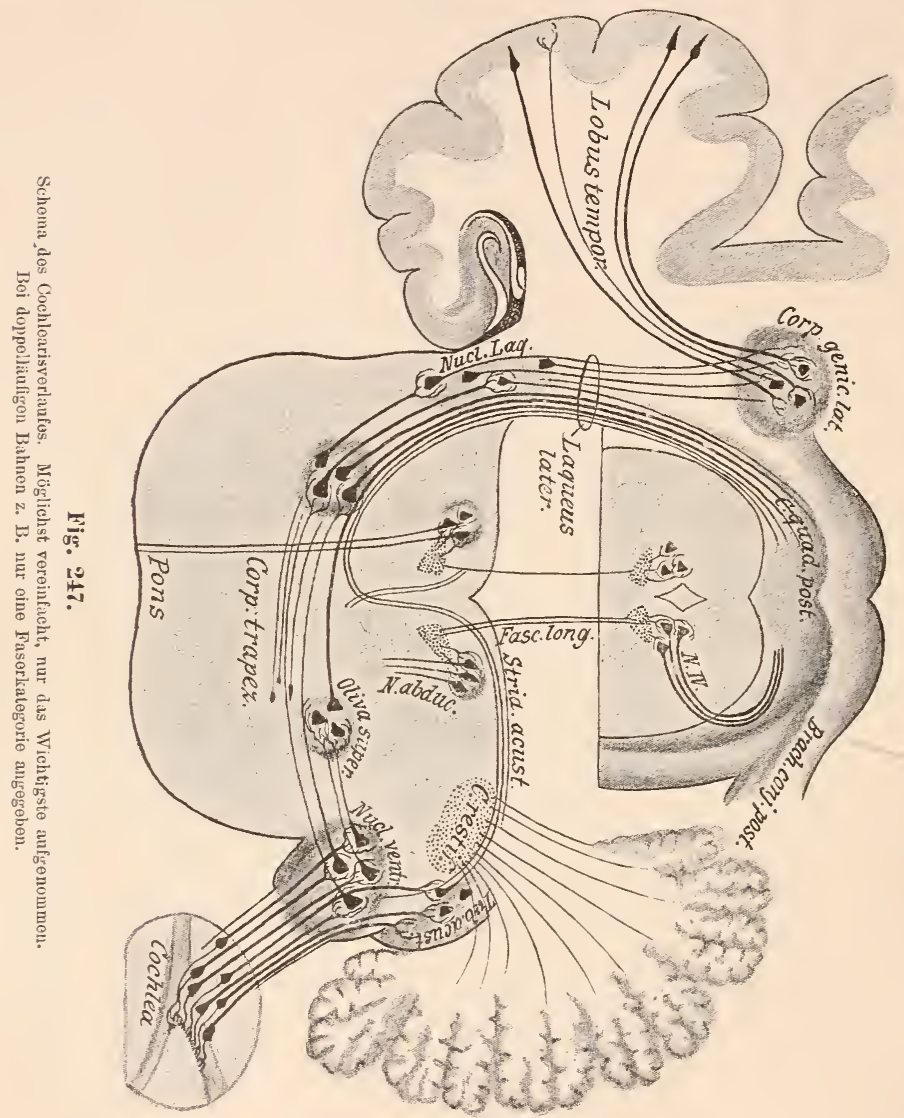

eingelagert sind. Die laterale sclileife enthielte dementsprechend im Tesentlichen zahlreiche Neurone aus den, wohl tertiären, Acusticusendstätten.

2. Wenn Sie einen Blick vou oben her auf die Rautengrube werfen, so fallen Ihnen regelmässig einige dicke Faserzüge auf, welche aus der Raphe auftanchend lateralwärts ziehen und sich dicht am Cerebellum in 
das Gewebe einsenken. Sie entspringen nicht alle dicht neben einander, es kommt vielmehr nicht so selten vor, dass eines oder das andere dieser Bündel riel weiter vorn an Rantengrubenboden auftancht und in relativ langem Zuge erst nach hinten streicht, ehe es sich den ïbrigen Bündeln in Acusticushöhe zugesellt. Diese ganze Faserung wird als Striae acusticae bezeichnet; dem langen, gelegentlich nach vorn aberrirenden Bündel hat Bergmann den Namen Klangstab gegeben.

Wenn die erste Abtheilung des Cochlearis erst durch Vermittelung des Corpus trapezoideum und der oberen Oliven mit der Schleife in Terbindung getreten ist, so ist das für die im Tuberculum endende Bahn ander's. Diese sendet ihre Züge ganz direct in die secundäre Acusticushahn hinein, in die gekreuzte Schleife, und diese Fasern sind eben die Striae acusticae. Verfolgen wir den Verlauf noch eimmal etwas genauer topographisch.

Die Striae entspringen aus dem Tuberculum acusticum, das zwischen Brïcke und Kleinhirn liegt, zu kleinerem Theile übrigens auch aus dem grossen Cochleariskerne - Nucleus ventralis unserer Abbildungen - und ziehen dam, indem sie das Corpus restiforme lateral umgreifen, dicht unter dem Ependym des Ventrikels medialwärts. Nahe der Raphe senken sie sich in die Tiefe, und indem sie sich innerhalb der Raphe selbst etwas frontalwärts wenden und diese schliesslich überschreiten, gelangen sie auf die gekreuzte Seite. wo sie sich der lateralen schleife anschliessen, deren Volum beträchtlich vermehrend.

Monakow sah die Striae atrophiren, als er hoch oben an den Vierhügeln die gekreuzte laterale Schleife zerstörte. Bum m mo Baginsky sahen sie nach Zerstörung der Schnecke aufsteigend ebendahin entarten, also vierhiigelwärts. Die laterale Schleife muss also Bahnen von zweierlei Verlaufsrichtung enthalten.

Sie erkennen als das Wichtigste an diesen etwas complicirten Verhältnissen, dass der Nervus cochlearis, nachdem er einmal im Cochleariskerne und im Tuberculumacusticum geendet hat, weiter seine höheren Bahnen zu den hinteren Hügeln sendet. Sie verlanfen auf deụ Wege der lateralen Schleifenfaserung. Doch geht nur ein Theil direct via Striae in die schleife, ein zweiter, recht beträchtlicher, endet zunächst in den oberen Oliven, die er durch das Corpus trapezoideum erreicht, underst ron da entspringt die Schleifenbahn, die sich dann mit derjenigen aus den Striae acusticae vereint.

Die oberen Oliven, welche so in die centrale Hörnervenfaserung eingeschaltet sind, miissen wichtige Centren darstellen. Thre Constanz durch die ganze Sängerreihe, ihre oft mächtige Entwicklung und vor allem die zahlreichen Fasern, welche zu ihnen in Beziehung treten, sprechen dafür. Es sind darunter Züge aus dem Cerebellum. die noch wenig bekannt sind, und ein mächtiger, auf Fig. 24 s gut sichtbarer Zug zu dem Kerne des Nervus abducens. Da in ebendiesem Ferne aber Fasern enden, welche durch das hintere Längsbündel zu den anderen Augenunskelkernen und 
in den Thalamus gelangen, so besteht lier offenbar ein zusammengehöriger. wohl organisirter Apparat, der wohl eimmal experimentelle Durcharbeitung verdiente.

Viel weniger gut als der Nerrus cochlearis ist der andere Zweig des Nervus octavus, der Nervus vestibularis bekannt.

Er stammt aus Ganglienzellen, welche im Labyrinth und anch noch innerhalb des Nervenverlaufes liegen. Diese senden einen Zweig hinein zum Epithel der Simnesapparate in den Ampullen, wo er sich ausserordentlich fein um die Epithelzellenbasis herum anfzweigt. und einen zweiten hinaus in den Nerven.

Ton den beiden zum Acusticus zusammentretenden Bündeln ist der Vestibularis das frontalere. Er tritt, medial vom Corpus restiforme und

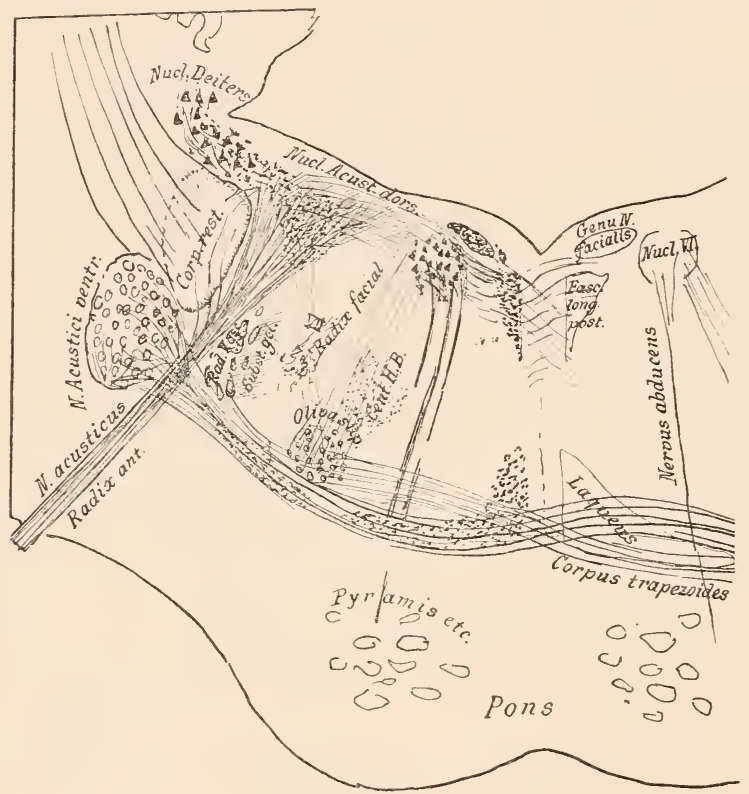

Fig. 245.

Schnitt in der Gogend des Abduconsursprunges. Ursprung des N. restibularis.

der aufsteigenden Quintuswurzel, durch die Oblongata dorsalwärts, dem Bodengrau zu. Ein Theil seiner Fasern endet da in dem dor'salen Kerne mit Endaufzweigungen. Diese Fasern aber senden, ganz wie die in die Hinterstränge eintretenden Wurzeln der sensiblen Yerven. ehe sie im Gran sich aufsplittern, Fasern in caudaler Richtung, absteigende Acusticuswureln (Roller). Ein Theil der Fasern des Nerrus ves- 
tibularis endet übrigens nicht im dorsilen Kerne, sondern begiebt sich zu noch nicht genügend gekannten Kernen zwischen Kleinhirnwurm und Oblongata.

Der Nucleus dorsalis - Nucleus $\mathrm{N}$. vestibularis - ist ein langgestreckter Körper von etwa prismatischem Querschnitte, der schon in den Ebenen caudal auftritt, wo die vorderen Vagnswurzeln abgehen. S. Fig. 244.

Von anderen Endstätten ist bisher wohl als die sicherste der Bechterew'sche Kern anzusehen, welcher medial von den zum Cerebellum aufsteigenden Fasern des Corpus restiforme in der Seitenwand des Ventrikels liegt und sich mit zerstreuten grauen Ansammlungen aufwärts bis sehr nahe an das Kleinhirn hinzieht.

Der Nervus vestibularis hat ebenfalls eine grosse Menge von anatomischen Beziehungen zu anderen Hirngebieten.

Der Nucleus dorsalis ist durch eine Bahn mit der oberen Olive und durch lateral von ihm abgehende Zïge mit dem Cerebellum verbunden. Ueber die cerebellaren Beziehungen der' Testibularis-Fasern, welche weiter hinauf als bis zu diesem Kern ziehen, wissen wir noch nichts Sicheres.

Die Ursprungsverhältnisse des Acusticus, die lange dunkel waren, sind in den letzten Jahren durch verschiedene Forscher untersucht worden, die nicht alle zu den gleichen Resultaten gelangten, wie sie hier wesentlich auf Grund eigener Tntersuchungen vorgetragen werden. Der Verfasser uud Freud, welche an menschlichen Früchten untersuchten, kamen zu wesentlich gleichen Resultaten; Bechterew und Flechsig bestreiten, dass die vordere Wurzel ans dem dorsalen Kerue stamme, lassen sie vielmehr von Zellen in der Nachbarschaft des Deiters'schen Kernes heruntersteigen. Der Crsprung der hinteren Wurzel aus dem ventralen Kerne wird von allen Seiten zugegeben. Dieser Kern wird auch nach Ausreissung des Hörnerven atrophisch (Forel, Onufrowics, Baginsky). Eine sehr genaue Durcharbeitnng des ganzen Apparates verdanken wir Kölliker.

Die für unsere Auffassung des Acusticus so wichtige Endverzweigung im Ohre, die Beziehungen der dort liegenden Ganglienzellen sind von Re tzi us und Gehuchten studirt worden. Fïr das feinere Detail der Aufsplitterung in den einzelnen Kernen bin ich wesentlich den Angaben ron Held gefolgt, dessen auf die früheren Untersuchungen gestiitzte, wesentlich mit der Golgimethode ausgeführte Arbeit, neuerdings durch eine experimentelle Studie von $\mathrm{B} \mathrm{umm}$ viel fach bestätigt wird.

Lateral rom Nucleus N. acustici dorsalis liegt das Feld der directen sensorischen Kleinhirnbahn. Aus ihm treten wahrscheinlich auch in den Acusticus Fasern ab. Die Bahn wendet sich in dieser Höhe als innere Abtheilung des Corpus restiforme kleinhirnwärts. Hier liegt in sie eingebettet ein Kern von noch unbekannter Bedeutung, der früher als äusserer Acusticuskern bezeichnet wurde. Er atrophirt, wemn der Halstheil des Rückenmarkes auf der gleichen Seite durchschnitten wird (Monakow). Eine Verbindung mit dem Hörnerven ist noch nicht sicher erwiesen. So ist es besser, ihn einstweilen mit dem Namen seines Entdeckers, des um die Anatomie der Oblongata hochrerdienten Deiters, als Deiters'schen Kern zu bezeichnen. 
In den Schnittebenen, welche den rentralen Acusticuskern enthielten, ist auch der Kern des Nervus facialis bereits sichtbar (Fig. 245). $\mathrm{Er}$ besteht aus einer langen Reihe von zu Gruppen angeordneten Zellen. Aus derselben entströmen fortwährend Fasern dorsalwärts. Sie sammeln sich allmählich zu einem kräftigen Bündel, das, unter dem Boden des Ventrikels angelangt, plötzlich eine scharfe Wendung in frontaler Richtung macht, um danm ebenso scharf abbiegend sich rentralwärts nach der Aussenseite der Oblongata zu wenden. Die Facialiswurzel macht also ein doppeltes Knie. S. Figg. 245, 24S, 219, 250. In dieses Knie ist der Kern des A bducens eingelagert.

Dem Stamme der Facialiswurzel schliessen sich Fäserchen aus der aufsteigenden Trigeminuswurzel an. Das ist vielleicht wichtig, weil wir wissen, dass aus diesem Theile des Trigeminus gerade die sensiblen Fasern für das Cesicht stammen.

Gerade da, wo der Facialis aus dem Gehirn austritt, senkt sich ein dünnes Nervenstämmchen, das bisher den peripheren Facialisverlauf begleitet hat, ein. Es ist die Portio intermedia Wrisbergi.

Duval hat zuerst entdeckt, dass sie dem oberen Ende des Glossopharyugeuskernes, - nach Köllik e r dem Kerne des solitären Bündels - entstamme, und dieser Ursprung ist durch die Entdeckung von P. Martin und His gestützt, welche beim Embryo nachweisen konnten, dass aus dem Ganglion geniculi N. facialis Fäserchen in das Hirn einwachsen.

Das Ganglion geniculi - im Wesentlichen übrigens (Lenhossék) ein Sympathicusganglion - wäre also der Trsprungskern der Portio intermedia, der Fasciculus solitarius am frontalen Ende ihr Endkern.

Die Trureln des Abducens ge-

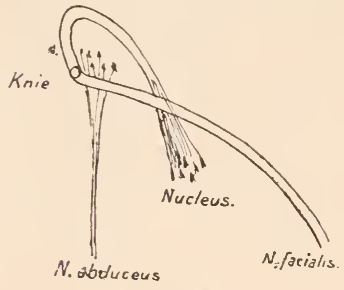

Fig. 249.

Schema des centralen Verlaufes des

$\mathrm{N}$. facialis und des $\mathrm{N}$. abducens. langen in mehreren Bündelchen gestreckten Verlaufes, welche die Haube und die Brücke durchsetzen, an der Brückenbasis nach aussen. Der Kern steht medial durch Fasern mit dem hinteren Längsbündel in Terbindung. Es wird behauptet, erscheint mir aber noch nicht genügend bewiesen, dass diese Fasern oben in den gekreuzten Oculomotorius eintreten. Ganz sichergestellt aber ist eine merkwürdige Terbindung des Abducenskernes mit der oberen Olive. Dieser Zug, den sie auf der Fig. 24s parallel der Facialiswurzel dahinziehen selen, muss den Acusticus in Terbindung mit den Augenbewegungsnerven setzen und ist vielleicht wichtig für die Aufrechterhaltung unserer Orientirung im Raume.

Wollen Sie, ehe wir weiter schreiten, noch einmal die übrigen. im Texte nicht mehr besonders genannten Haubengebilde aufsuchen, um ihre Lage und Gestalt in diesen Höhen kennen zu lernen. Eines, der Nucleus reticularis tegmenti, welcher gleichmässig mit den Fasern der Substantia reticularis über die Gegend zwischen der Raphe und der Facialis- 
wurzel zerstreut liegt, ist in den Abbildungen, um deren Klarheit nicht zu beeinträchtigen, nicht eingezeichnet. Er wäre in allen Höhen, die wir auf Schnitten kennen lernten, zu sehen gewesen.

Die beistehende Abbildung (Fig. 250) schliesst sich direct der vorhergehenden an und soll nur zeigen, wie der Facialis sich nach kurzem Verlaufe ventralwärts wendet, und wie die directe sensorische Kleinhirnbahn jetzt aufwärts in das Cerebellum tritt. In dem letzteren sind in dieser Höhe schon die von vorn kommenden Bindearme zu sehen.

Wenn eimmal der Acusticus, der Facialis und der Abducens die Haube verlassen haben, wird das Bild, welches ilır Querschnitt bietet, natürlich wesentlich einfacher.

Wir betreten das Eintrittsgebiet des Ner vus trigeminus. Zuuächst tritt in der Fortsetzung des Facialiskernes, doch etwas dorsaler, der motorische Trigeminuskern auf. Aus ihm kommt, wieder in leichtem Knie, die motorische Wurzel, die Portio minor, welche die

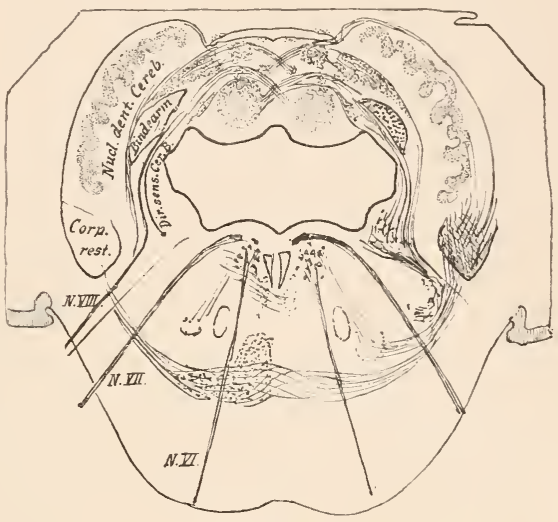

Fig. 250.

Schnitt an der Stelle, wo die innere Abtheilung des Corpus restiforme in das Cerebellum tritt.

Kaumuskeln versorgt. Wahrscheinlich gelangen mit ilı auch Fasern heraus, welche aus dem gekieuzten motorischen Kerne stammen und durch die Raphe herübergelangen.

Es treten aber mit dem mot. Trigeminus auch Fasern aus der Brücke, welche nicht im motorischen Kerne, sondern hoch oben in der Vierhügelgegend entspringen, wo spärliche Ganglienzellen, seitlich vom Aquaeductus Sylvii (in Fig. 199 links oben) der Radix mesencephalica Nervi trigemin i Ursprung geben.

Diese Zellen setzen sich candalwärts, immer in der Seitenwand liegend, fort, und man kann eine grössere Ansammlung von ilnnen durch das dünne Tentrikelependym als dunkle Gruppe vorn, jederseits am Anfang des Ventriculus quartus, durchschimmeru sehen. Sie heisst dort L ocus c o eru leus.

Der Kern des Kaumuskelnerven ist im Wesentlichen gebaut wie die anderen motorischen Kerne im Riickenmarke. Neuerdings aber hat S. R a mon y Cajal an ihm ein eigenthümliches Verhalten aufgedeckt. Die Mittelhirnwurzel aus den grossen blasigen Zellen um den Aquäduct sendet nämlich in den grossen motorischen Hauptkern eine ungeheure Menge der allerfeinsten Collateralen. 
Jede der Zellen ist ron einem ganz dichten Netze solcher Fäden umsponnen. Der Entdecker dieses merkwiirdigen Apparates ist der Ansicht, dass durch diese Collateralen es ermöglicht werde, dass ein relativ schwacher Reiz, von dem frontaleren Kern ausgesendet, sich im Hauptkerne zu einer mächtig wirksamen Erregung umsetze. Es würden die grossen motorischen Zellen gewissermaassen geladen und könnten sich zeitlich einheitlich entladen, so die Kraft und das Zusammenspiel des Kauactes erzeugend.

Der Ha u theil des Nervus trigeminus, der sensible, entstammt zweifellos den Zellen des Ganglion Gasseri, deren peripher gerichteter Fortsatz ganz wie bei den Spinalganglienzellen zum Nerven wird, während ein central verlaufender als dicke.. Turzel" in die Brïckenfaserung eintritt. Diese durchbohrt er und senkt sich zu einem geringen Theil in den dort liegenden Endkern (sensibler Trigeminuskern) ein.

Da. wo die Fasern eintreten, theilt sich ihre Mehrzahl in einen feinen aufsteigenden und in einen absteigenden Ast. Der cerebralwärts ziehende endet bald in demjenigen Theile des Kernes, der frontal von der Eintrittsstelle liegt, anfgesplittert in kleinen Pinselchen, der spinalwärts ziehende endet auch unter Abgabe massenhafter Collateralen allmählich; aber der Kern, in dem das geschieht, die caudale Fortsetzung des schon genannten Endkernes, ist ungemein lang und reicht als $\mathrm{N} u$ cleus terminalis $\mathrm{N}$. trigemini hinab bis in das Halsmark. Auf diesem ganzen Trege wird er von der natiirlich immer dünner werdenden Hauptmasse der Trigeminusfasern begleitet. Sein langes, im Querschnitt halbmondförmiges Bündel ist uns auf allen Schnitten rom Halsmarke an schon begegnet. Es liegt dieser Tractus bulbo-spinalis Nerri Trigemini der langen glasig aussehenden Säule des Endkernes überall dicht an. bis hinab in das Hinterhorn des Halsmarkes, wo er damn sich endlich elschöpft.

In dem Schema der Fig. 251 lege ich den Gesammtrerlauf der einzelnen Trigeminuswurzeln Ihnen vor. Tiele Details sind nach Präparaten von S. Ramon y Cajal eingezeiclnet.

Aus dem langen Endkerne des sensiblen Trigeminustheiles entspringt die secund äre Trigeminusbahn. schon vor Jahren ist mir auf Grund von vergleichend anatomischen Tntersuchungen der Nachweis gelungen, dass es eine gekreuzte Bahn aus dem 'Trigeminusendkerne giebt, die hirnwärts zieht. Diese aus dem Endkerne ibberall austretenden und die Mittellinie überschreitenden Züge sind seitdem oft gesehen worden, aber es ist erst ganz ror kurzem TVallenberg ihre Durchschneidung und damit der Nachweis gelungen, wo das centrale Stïck der Trigeminusbahn im Gehirne liegt und wo es endet. Seine Tersuche sind an Kaninchen angestellt. Hier liess sich erkennen, dass der nach Abtrennung des Endganglions auftretende Degenerationsstreifen sich im unteren Oblongataabschnitte innerhalb des grossen Associationsfeldes, dicht unter den Нypoglossuskernen, gekreuzt von der Terletzungsstelle befindet und mit dieser durch lange Bogenfasern verbunden ist. Teiter hirnwärts findet man ihn immer lateral und etwas ventral vom Fasciculus longitudinalis posterior. Beim Menschen findet man an gleicher stelle wie beim Kaninchen eine 
grosse Anzahl von Faserquerschnitten, s. Fig. 201 a. Doch ist für diese noch nicht durch Degeneration der Nachweis erbracht, dass sie dem Trigeminus angehören. Tergl. auch Fig. 199 das Feld, das „aus Thala-

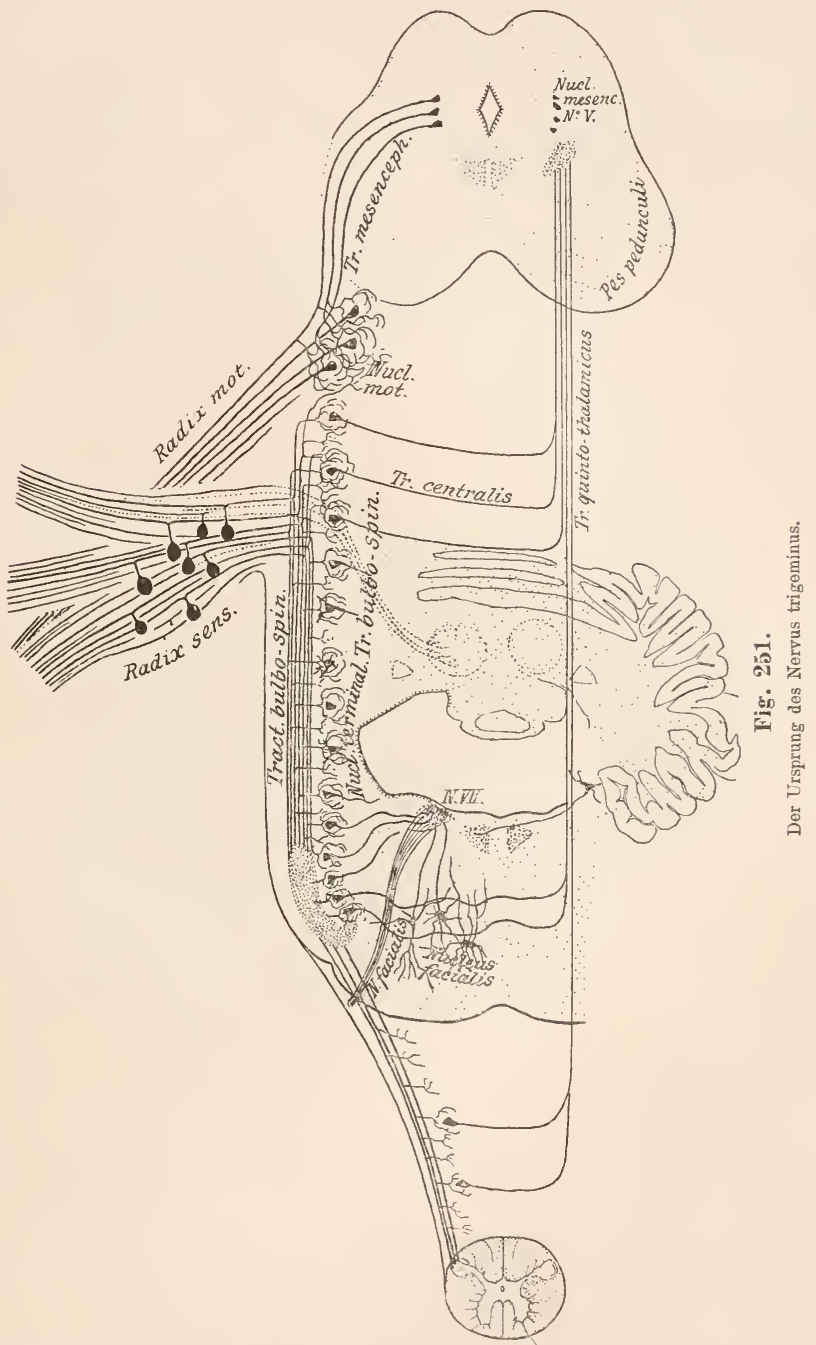

mus" bezeichnet ist. Im Mittelhirne findet man die centrale Trigeminusbahn lateral von den absteigenden Fasern der Commissura posterior, und 
schliesslich kann man sie nach Wallenberg bis in den ventralen Thalamuskern verfolgen, wo sie sich dann der oberen Schleife, resp. deren Endstätten, anreiht.

S. Ramon y Cajal hat die gleiche Bahn unabhängig von Wallen berg, wenigstens in ihren Ursprungsgebieten, entdeckt und uns eine sehr genaue Beschreibung des Baues jenes Endkernes gegeben, aus dem sie entspringt. Dieser enthält eine grosse Nenge recht ansehnlicher multipolarer Zellen. Um dieselben splittert peripher die Trigeminuswurzel auf. und aus den Zellen entspringen die Axencylinder der centralen Bahn.

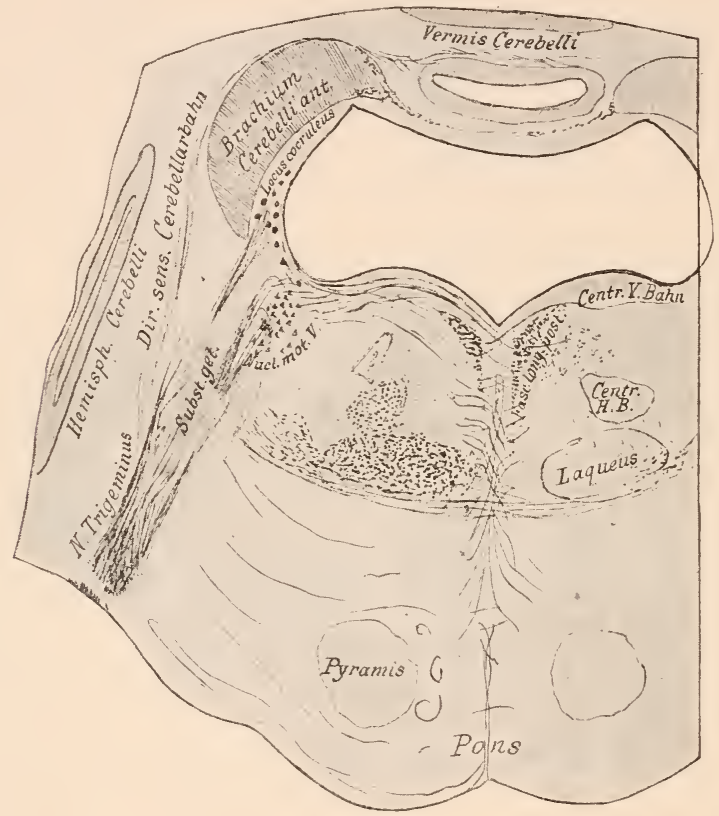

Fig. 252.

Schnitt an der Stelle, wo die aufsteigende Trigeminuswurzel nach aussen abbiegt. 'Trigeminuswurzeln.

Die Mehrzahl begiebt sich, ganz wie das oben angegeben wurde, hinüber auf die andere seite und zieht da als dorsalste Lage der Substantia reticularis hirnwärts, eine Ninderzahl aber soll nach R. y Cajal auf der gleichen Seite bleiben. Hier besteht noch ein Widerspruch mit den Ergebnissen, welche das Degenerationsexperiment geliefert hat.

Aus dieser centralen Trigeminusbahn gehen zahlreiche Collateralen in den Facialiskern, so den sensomotorischen Reflexbogen für das Antlitz herstellend. Durchschneidnngen des Trigeminus sind wegen der damm 
wegfallenden sensiblen Controle von nicht unbeträchtlichen Bewegungsstörungen im Gesichte begleitet.

Der Hauptstamm des Quintus heisst da, wo er nahe dem motorischen Kern in die Brücke eintritt, Portio major. In diese Portio major Trigemini gelangen auch die aus dem Cerebellum herabsteigenden Züge der directen sensorischen Bahn.

Vom Abgange des Quintus bis hinauf zum Abgange des Trochlearis bietet die Haube der Brïcke einen relativ einfacheren Ball, als wir ihn bisher all ihr erkannt haben.

Schon auf dem Schnitte, den ich Thmen zuletzt demonstrirte, sahen Sie, dass von der grossen Masse des Cerebellum sich die Bindearme loszulösen begannen. Sie treten nun ganz heraus und legen sich zunächst lateral beiderseits an die Haube, so deren äusserste Begränzung im dorsaleren Gebiete bildend.

Die laterale Begränzung weiter ventral, also direct über der Brückenfaserung, bildet die Schleifenschicht und zwar speciell derjenige Theil der Schleife, welcher aus den Endkernen der sensiblen Nerven stammend als laterale oder untere Schleife von dem mehr medial liegenden Theile, der zumeist den Hinterstrangkernen entstammt, getrennt wird. Wie in eine Hohlrinne ist der frontale Haubentheil in die Schleifenfaserung eingebettet (Fig. 253). Der horizontal liegende Theil dieser Rinne gehört zum grösseren 'Theile der medialen Schleife an. Er trennt in breiter' Lage die Faserung der Haube von der im Ponsgebiete schon recht reichen Fussfaserung. So ist auch hier wieder das Bild zu Stande gekommen, das Sie ron der Vierhügelgegend her schon kennen und in der That bleibt es nun bis hinauf in jene so erhalten.

Die mediale Schleife zieht zunächst in der Schleifenschicht einfach hirnwärts und gelangt schliesslich, wie das frïher' schon geschildert worden ist, frontal von den Vierhügeln in die Gegend ventral vom Thalamus, wo sie in dessen ventralem Kerne ihr Ende findet.

Die laterale Schleife, welche ausser den Acusticusfasern alle Züge aus den tiefen Endkernen der sensiblen Nerven zum Mittelhirndache enthält, wendet sich in den Höhen, die hirnwärts vom Trigeminusaustritte liegen, aus der Schleifenschicht dorsal und zieht an der äusseren Seite der Brückenhaube schräg hinauf zu den Vierhügeln, unter denen sie verschwindet. Thr gut ausgeprägtes Band ist seitlich am unverletzten Hirnstamme immer wohl erkennbar. Da, wo sich die Schleife dorsalwärts wendet, sind ihr Ganglienzellen eingelagert (lateraler Schleifenkern, Obersteiner). Diese Gruppe lässt sich vorwärts bis in den am äusseren Rande der Substantia nigra gelegenen oberen schleifenkern verfolgen.

Dass die mediale Schleife in den Kernen der Hintersträng'e endet, haben Flechsig und Hösel bewiesen. Diese leiten übrigens das ganze Bündel direct vom Grosshirn als $\mathrm{R}$ indenschleife ab. Es ist schon früher (S. 257) dargelegt worden, dass die Grosshirnbahn, um die es sich hier handelt, zunächst im rentralen 
Thalamuskern endet, und dass dort erst die mediale oder obere Schleife entspringt.

Wir haben nun Schleifenfasern zu allen sensiblen Endkernen kennen gelernt. Die Schleife enthält eben die secundären sensorischen Bahnen und führtsie hinauf zu dem Mittelhirn und zum Thalamus. Monakow ist es gelungen, zu derselben Zeit den experimentellen Beweis für diese Auffassung zu erbringen, wo ich aus vergleichend anatomischen Grïnden sie aufgestellt habe. Auf dem Wege derexperimentellen Herstellung von Degenerationen lässt sich sogar der Schleifenantheil für einzelne Nerven, Trigeminus, Acusticus u.s. w. absondern.

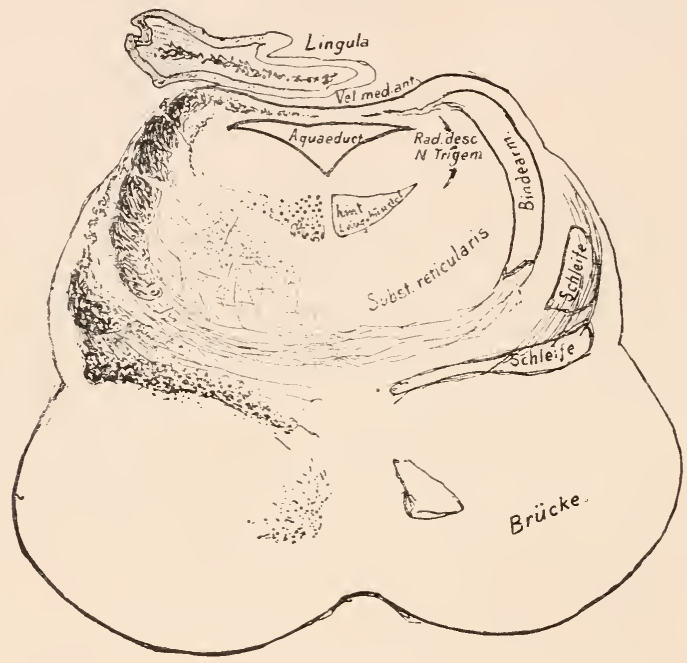

Fig. 253.

Schnitt durch die obere Brückengegend von einem Fötus aus dem neunten Schwangerschaftsmonate.

In gleicher Horizontalebene mit der Schleife, dorsal von der Brückenfaserung. trifft man, ganz medial, noch ein Bündel dicker Fasern. Dasselbe stammt aus der Pyramidengegend des Fusses. Es wurde früher gezeigt, wie es sich dort loslöst und, den ganzen Fuss des Hirnschenkels nach innen umgreifend, an die mediale Seite der Schleife gelangt. Spitzka hat es aus vergleichend anatomischen Gründen sehr wahrscheinlich gemacht, dass dieses Bündelchen die centralen Bahnen für die motorischen Hirnnerven enthält. In der That kann man sich überzeugen, dass aus ihm fortwährend Fasern in die Raphe aufsteigen, und sieht am dorsalen Ende der Raphe Fasern über die Mittellinie hinweg nach den Kernen, des Hypoglossus mindestens, treten. 
Wir kommen jetzt allmählich in die Gegend der Brücke, wo das Dach des Hinterhirns nicht mehr vom Kleinhirn, sondern vom Velum medullare anticum gebildet wird. Dort beginnt der Ventriculus quartus sich zum Aquaeductus Sylvii zu verengern.

Die einzelnen Bestandtheile, welche in dieser Höhe die Haube zusammensetzen, treten sehr dentlich hervor an dem vorstehenden, nicht schematisirten Querschnitt durch den obersten Theil der Brücke einer neun Monate alten Frucht. Im Fuss ist zu dieser Zeit nur ein kleines Bündel markhaltig. In der Haube aber sind die Schleifenschicht, dann die Bindearme, das hintere Längsbündel und viele Fasern der Substantia reticularis vollkommen ausgebildet. Die Bindearme gehen oben in das Velum medullare anticum über, auf dem das vordere Ende der Lingula ruht. Unten, über der Schleifenschicht, sind schon die hintersten Fasern der Bindearmkreuzung zu sehen.

Die absteigende Trigeminuswurzel liegt zu beiden Seiten des Aquaeductus als dünnes Faserbündelchen. Nach innen von ihr, unter dem Boden des Aquaeductus oder dem vorderen Ende der Rautengrube, haben Sie sich die Zellen des Locus coeruleus zu denken, die an dem gezeichneten Präparate nicht ganz dentlich waren. Die Substantia reticularis besteht hier wesentlich ans Längsfasern, welche nicht höher als bis zum Niveau der vorderen Vierhügel zu verfolgen sind. Nahe der Mittellinie liegt beiderseits das hintere Längsbündel.

Von jetzt an ändert sich das Querschnittsbild der Haube bis in die Vierhügelgegend nicht mehr wesentlich. Die Schleife zieht auf der Aussenseite dorsalwärts. Die Bindearme rücken sich einander näher und kreuzen sich schliesslich weiter oben.

Die Faserung des Fusses und die sie durchflechtenden Ziige der Brücke haben Sie bereits früher kennen gelernt. Es erübrigt noch, zu sagen, dass in den vorderen Ebenen des Pons sich ein Fasersystem findet, das kurz vor der Geburt markhaltig wird, aus der Brückenfaserung durch die Raphe aufsteigt und dann seine Züge nach rechts und links in die Substantia reticularis der Haube sendet. Nach Bechterew sollen sie in dem vordersten Theile des Nucleus reticularis enden.

Ganglien, ähnlich gebaut wie die Brückenganglien, sind dann zu beiden Seiten der Raphe und in dieser selbst bis in die Haube hinein zerstreut.

\section{Fünfundzwanzigste Vorlesung.}

\section{Schlussiibersicht.}

So hätten wir denn, meine Herren, in der letzten Vorlesung den Anschluss an jenen Theil der Haube erreicht, der Ihnen noch von der 8. Vorlesung her bekannt ist.

Wenige Millimeter nach vorn von dem zuletzt geschilderten Querschnitte treten die Fussfasern aus der Brücke hervor, um als Pes pedun- 
culi frei zum Gehirn zu ziehen. Wir hatten in der Oblongata nur die Pyramiden als einzige Bestandtheile des Fusses kennen gelernt, aus den Ganglien der Brïcke aber haben sich nun die mächtigen Züge entwickelt, welche in der medialen und der lateralen Abtheilung des Fusses hinauf zur Rinde des Stirn- und Scheitellappens und zum Temporallappen gelangen.

Nun tritt im Hirnschenkel auch zwischen Fuss und Haube, beide trennend, die Substantia nigra auf.

Die Bindearme der Haube verlieren sich im rothen Kerne. An der Stelle des Telum medullare anticum zeigen sich im Dache die Tierhïgel.

Einige schematische Abbildungen mögen die Art des Ueberganges. aus der Brïcke in die Vierhïgelgegend klarer stellen.

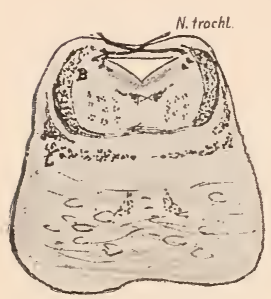

Fig. 254.

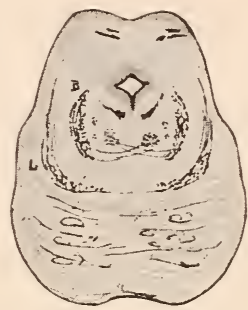

Fig. 25 อ̆.

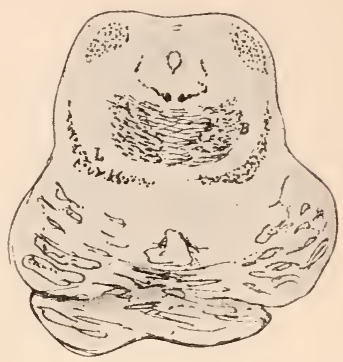

Fig. 256.

Drei Schnitte durch die Brücke und die Vierhügelgegend vom Neugeborenen, zur Demonstration des Verlaufes der Bindearme und der Schleifenschicht. Die letztere liegt dicht über den Ponsfasern; die Bindearme $B$ (Fig. "254) treten in Fig. $25 \overline{5}$ weiter nach innen, ihre Kreuzung beginnt, die Fig. 250 auf der Höhe ist. Hämatoxylinfärbung.

Die Symptome, welche bei Erkrankungen des Pons und der Oblongata auftreten, sind in ihrer Gruppirung ein guter Prüfstein auf die Richtigkeit der Thnen vorgelegten anatomischen Verhältnisse.

Auf kleinem Raume sind dort die wichtigsten Bahnen für die Bewegungen der Körpermuskulatur, für die Empfindung, die Sprechmuskulatur, den Schluckact u. s. w. vereint. Fin Herd braucht da nicht gross zu sein, um gar mancherlei Symptome hervorzurufen.

Die motorischen und sensorischen centralen Bahnen, welche aus der Rinde, aus dem Zwischen- und dem Mittelhirne stammen, durchziehen die Brücke und die Oblongata und geben dort nur die für die Ursprungs- und Endkerne der Hirnnerven bestimmten Fasern ab.

Da eine Unterbrechung dieser langen Bahnen die gleichen Symptome machen wird, einerlei ob sie schon im Vorderhirne oder Mittelhirne oder erst im Nachhirne erfolgt, nämlich Anästhesie, resp. Lähmung auf der gekreuzten Seite, so ist es wichtig, zu merken, dass man nur dann eine Störung der Gefühls - oder Bewegungsbahn in Pons-Oblongata vermuthen darf, wenn gleichzeitig Symptome vorliegen, welche anzeigen, dass ein einzelner oder mehrere Hirnnerrenkerne befallen sind.

Die Atrophie der Muskulatur, welche bei Affectionen der Kerne selbst auf- 
tritt, wird genau studiert werden müssen, wenn es gilt, den Ort und die Ausdehnung einer solchen Affection festzustellen. Fig. 257, welche die Lage der Nervenkerne auf den Längsschnitt einer Oblongata projicirt darstellt, wird Ihnen diese Aufgabe wohl etwas leichter machen, als die früher demonstrirten Bilder von Querschnitten der Nervenursprünge es vermögen.

Sprech-, Athem-, Schluckbeschwerden werden wahrscheinlich durch einen Herd in der Oblongata, Kaulähmung (motorische Portion des N. trigeminus), Facialislähmung, Abducensaffection durch einen Brückenherd bedingt sein.

Da jedoch die centralen Fasern zu den Nervenkernen der Oblongata die Brücke passiren, so können auch Schluckstörungen u. s. w. gelegentlich durch dort sitzende Erkrankungen erzeugt werden.

Die motorischen Bahnen für die Extremitäten liegen vorn ventral in den Pyramiden, sie treten erst selır viel weiter hinten, gerade vor dem Rückenmarke, auf die andere Seite. Die motorischen Fasern für die Hirnnerven aber liegen nahe der Medianlinie, steigen in der Raphe der Haube auf und kreuzen ganz nahe an den Nervenkernen selbst zu diesen hinïber.

Ein Erkrankungsherd in der Brücke wird desshalb in den meisten Fällen

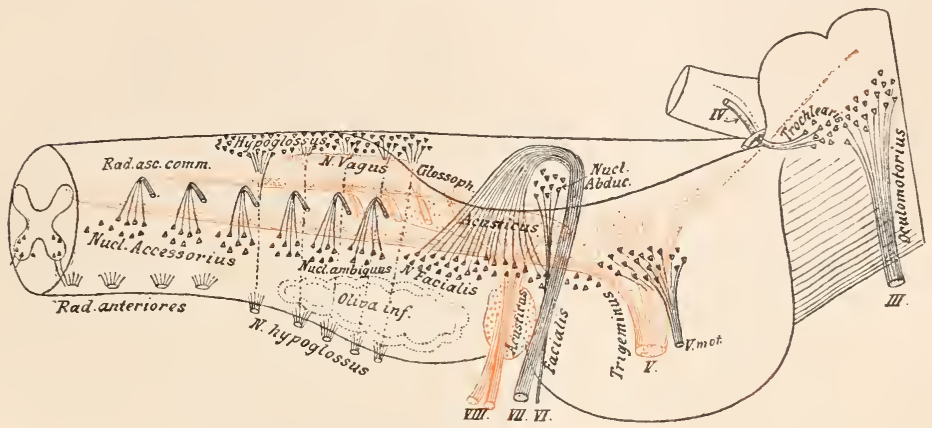

Fig. 257.

Die Lage der Hirnnervenkerne. Die Oblongata und der Pons durchsichtig gedacht. Die Ursprungskerne (mot.) schwarz, die Endkerne (sens.) roth.

zwar die Extremitäten auf der gekreuzten Seite, den Facialis, Abducens oder Trigeminus aber auf der gleichen Seite treffen, wo er selbst sitzt. Das Schema Fig. 258 versucht, dieses wichtigste Symptom vieler Pons- und Medullaaffectionen, die gekreuzte Lähmung, Ihrem Gedächtnisse fester einzuprägen, als es das geschriebene Wort vermag. Es stellt die Bahn der motorischen Innervation für den Antlitznerven und fiur die Extremitätennerven dar. Sie sehen an der Zeichnung, dass ein Herd bei $A$ im Grosshirn oder in den Hirnschenkeln rechts den linken Facialis und die linksseitigen Extremitäten lähmen wird, dass aber eine Erkrankung bei $B$ im Bereich der Brücke rechts die Extremitäten wohl links, den Facialis aber rechts treffen kann, dass ein solcher Herd die Mittellinie überschreitend eventuell beide Faciales und die Extremitäten einer Seite ausser Gebrauch zu setzen vermag. Sie sehen auch an dem Schema, dass Krankheitsherde in der Brücke (bei $C$ ) so sitzen können, dass sie halbseitige, nicht alternirende Hemiplegie erzeugen, dass sie also dieselben Symptome machen, wie wenn sie im Grosshirne sässen. Alternirende Lähmungen können, wenn sie nicht durch verschiedene Herde erzengt werden, überhaupt nur durch 
Ponsaffectionen oder durch Geschwillste u. dergl. hervorgerufen werden, die ventral vom Pons sitzend die Hirnnerven im peripheren Verlauf und die Pyramidenbahnen zerstören. Da ausser dem Facialis noch der Abducenskern und der

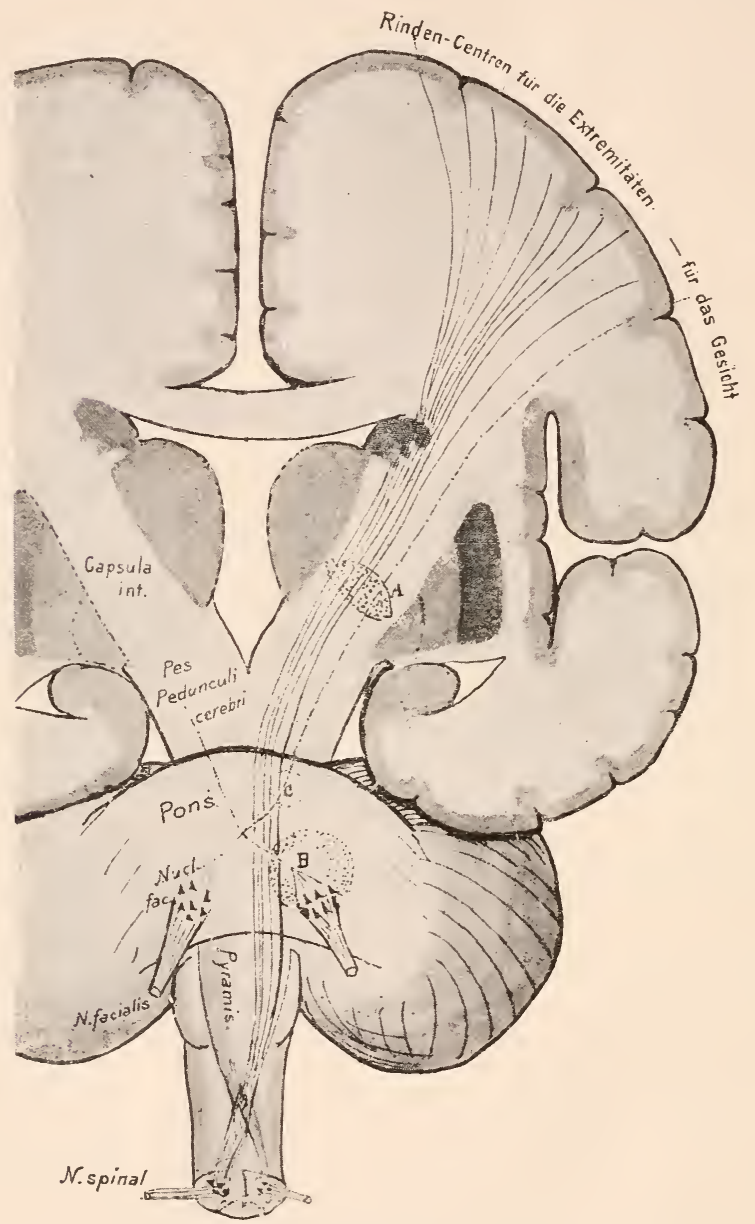

Fig. 258.

Schema der motorischen Innervationsbahn für den Facialis und die Extremitätennerven. Frontalschnitt durch Grosshirn, Hirnschenkel, Brücke, verlängertes Mark und Rückenmark.

Quintuskern in der Brücke liegen, so können natürlich auch diese an den mannigfachen Modificationen sich betheiligen, die bei Brückenerkrankungen im Bilde 
der wechselständigen Lähmung eintreten können. Wie sich der Acusticus verhält, ist noch unsicher.

Durch die Brücke verlaufen auch die Fasern zu den Nervenkernen der Oblongata, welche die Muskeln innerviren, die der Rede dienen. Desshalb kommen bei Pons- und bei Oblongataerkrankungen oft trotz vollkommen intacten Sprach vermögens Sprechstörungen vor. Man bezeichnet sie, je naclı dem Grade, als Dysarthrie oder als Anarthrie.

Erkrankungen in der Haube rer Brücke und der Oblongata können auch zu Störungen der Sensibilität führen. Wir haben Grund, anzunelımen, dass in der Schleife die centralen Gefühlbahnen liegen, und dass namentlich die mediale Schleife die Bahnen enthält, welche der so wichtigen statischen Sensibilität dienen. Desshalb werden nach Unterbrechung der Olivenzwischenschicht in der Oblongata leicht Muskelsinnstörungen beobachtet. Aber es hat die neuere klinische Forschung es durchaus wahrscheinlich erscheinen lassen, dass, in der Oblongata wenigstens, die Bahnen für den Tastsiun der Haut nicht in der Medianebene liegen, sondern den Längsbahnen angehören, welche lateral von der Olivenzwischenschicht angetroffen werden. In der Brücke können jedenfalls auch lateral gelegene Erkrankungen gekreuzte Gefühlsstörung hervorrufen. Liegt aber ein Herd irgendwo in der Haube der Oblongata oder Brücke, so trifft er nicht nur jene centralen Bahnen, die immer zum Kerne gekreuzt verlaufen, sondern auch das periphere Stück vieler sensiblen Nerven. Es kann z. B. ein Herd seitlich in der Oblongata rechts den spinalen Quintuszug und die gekreuzten sensiblen Bahnen treffen, also rechtsseitige Gesichts - und linksseitige Rumpfanästhesie erzeugen.

Gewöhnlich zerstört eine einzelne Erkrankung nicht alle sensiblen centralen und peripheren Bahnen, erzeugt also nicht wie die vom Grosshirnmarke ausgehende Erkrankung complete Hemianästhesie. Der eine oder der andere Nerv bleibt zumeist frei. Namentlich gilt dies von den Geschmacksbahnen und den Hörbahnen, von denen nur selteu completc intrapontine Leitungsunterbrechung: bekannt wurde.

Sitzt ein relativ breiter Herd irgendwo median, so kann natürlich doppelseitige Hemianästhesie entstelıen, jedenfalls ein ungewöhnlich seltenes Vorkommniss.

Kaustörungen, Schluckstörungen kommen natürlich ebenfalls zur Beobachtung, da ja die Kerne des motorischen Trigeminus, des Glossopharyngeus, des Hypoglossus leicht mitgetroffen werden können.

Ob eine Erkrankung in dem verlängerten Mark oder in der Brücke ihren Sitz hat, ist oft schwer zu entscheiden. Durch die Lage des motorischen Vagus-, Accessorius-, Glossopharyngeuskernes wird es bedingt, dass Heiserkeit, Stimmlosigkeit, dann Respirationsstörungen wesentlich nur bei Herden in der Oblongata beobachtet werden. Sprechstörungen, Dysarthrie, Anarthrie (Nucleus N. hypoglossi), Circulationsstörungen kommen ebenfalls häufiger durch Oblongataaffection zu Stande.

Fast alle diese Symptome können in seltenen Fällen auch durch Grosshirnaffectionen bedingt sein, da ja Zerstörung des centralen Verlaufes der Hirnnervenfasern ganz wie die des Kernes oder des peripheren Nerven zu Lähmung führt. Lähmung verschiedener von Oblongatanerven versorgter Muskelı ist nur dann mit Sicherheit auf einen Herd im verlängerten Mark zu beziehen, wenn gleichzeitig Muskelatrophie besteht, und eine Zerstörung des eigentlichen Nervenstammes nach seinem Abgang vom Centralorgan auszuschliessen ist.

Begegnet Ihnen einmal ein Fall der durch die Combination seiner Symptome, Betheiligung ausgebreiteter Leitungszüge und nur einzelner Hirnnerven, wechselständige Gefühls- oder motorische Ausfallerscheinungen, den Gedanken aufdrängt, 
dass in der Oblongata oder Brücke die Unterbrechungsstelle liegen müsse, so wird es immer am einfachsten sein, wenn Sie an einer der früher gegebenen Abbildungen studiren, ob sie eine Stelle enthält, durch deren Zerstörung alle Unterbrechungen entstanden sein könnten. So wird es in vielen Fällen gelingen, ziemlich genau Ausdehnung und Lage des Herdes zu ermitteln. Versäumen Sie aber nie, gleichzeitig, Fig. 180, die Abbildung der basalen Ansicht des Gelirnes zu studiren, weil auch durch Erkrankungen an der Hirnbasis sowohl Druck auf längere Bahnen als Zerstörung einzelner Nervenäste bedingt werden kann.

Meine Herren! Unsere Aufgabe ist im Wesentlichen erledigt. Eine grosse Anzahl wichtiger Fasersysteme wurde in ihren Lagerungsverhältnissen zu den grauen centralen Massen studirt und in ihrem Verlaufe vom Vorderhirn bis gegen das Ende des Nittelhirns hinab, oder vom Rückenmark bis zur gleichen Höhe aufwärts verfolgt. Doch erscheint es zweckmässig, einzelne von ihnen nochmals kurz im Zusammenhang zu betrachten; entweder weil sie von besonderer Dignität in physiologischer und pathologischer Beziehung sind, oder auch weil Ihnen die Uebersicht über deren Gesammtverlauf durch die nach der 20. Vorlesung in didaktischem Interesse eingetretene Unterbrechung der continuirlichen Verfolgung erschwert wird.

Lassen Sie sich diese nochmalige kurze Darstellung auch als Führer zu einer Art Repetition dienen, die Sie an der Hand der Abbildungen leicht vornehmen können.

1. Die motorischen Nerven sind die verlängerten Axencylinder der grossen Ganglienzellen in den motorischen Kernen des Rückenmarkes und des Gehirns. Um diese Ganglienzellen verzweigen sich die Endausläufer der centralen motorischen Bahn. Diese verläuft, zum guten Theil wenigstens, in der Pyramidenbahn.

2. Die Pyramidenbahn, die wichtigste Bahn des motorischen Innervationsweges, zieht aus den oberen $2 / 3$ der Centralwindungen und des Paracentrallappens hinab zu einer Stelle, die hinter dem Knie der Capsula interna liegt. Von da gelangt sie in den Hirnschenkelfuss, dessen mittleres Drittel etwa sie einnimmt. Im Pons werden ihre Fasern nur wenig durch Querfasern zerspalten. Wemn sie aus der Brücke auftaucht, liegen ihre Zïge als zwei mächtige Bündel der Oblongata ventral an. So zieht sie hinab zum Rückenmark. Dort tritt der grösste Theil ihrer Fasern hinüber in den Seitenstrang, ein kleinerer (Pyramidenvorderstrang) bleibt auf der gleichen Seite. Beide Faserantheile treten durch abgehende Collateralzweige in Beziehung zu den Vorderhornzellen derjenigen Seite, welche dem Pyramidenursprung in der Rinde gegenüber liegt. Aus diesen Zellen entspringen die motorischen Wurzeln.

3. Die centrale Bahn der motorischen Hirnnerven ist nur näher bekannt für den Facialis und für den Hypoglossus.

Die Facialisbahn entspringt im Bereich des unteren Drittels der Centralwindungen, wahrscheinlich nur für die unteren Aeste, der Crsprung 
des Stirnantheiles ist unbekannt (Gyrus angularis?), zieht dann einwärts über den Nucleus lentiformis quer hinweg und liegt schliesslich in der inneren Kapsel der Pyramidenbahn sicher sehr nahe. Jedenfalls lässt sie sich im Hirnschenkelfuss von jener nicht (klinisch) trennen. Ihre Züge verlassen dann wahrscheinlich mit dem mehrfach genannten „Bündel vom Fuss zur Haube:" den allgemeinen motorischen Innervationsweg. Sicher sind sie in der Brïcke von jenem getrennt (s. Schema Fig. 25s). Wie sie an den Kern herantreten, ist noch unbekannt. Jedenfalls aber gelangen sie in den gekreuzten Facialiskern, der im caudalen Theil des Pons liegt. Aus diesem entspringt der Nerv.

In dem ventralsten Theile der vorderen Centralwindung liegt wahrscheinlich das Rindengebiet des Hypoglossus. Jedenfalls zieht aus dieser Gegend ein Bündel ventral rom Facialisbündel herab, dessen Unterbrechung zuweilen doppelseitige Hypoglossusstörungen erzeugt. Auf seinem Wege von der Rinde zur Capsula interna zieht es über die obere Kante des Linsenkernes hinweg und muss dicht nach aussen rom Anfang des Nucleus caudatus-Schwanzes der Sprachbahn sehr nahe kommen. In einem von mir beobachteten Falle unterbrach ein Herd, der kaum die Grösse und Dicke eines Fünfpfemnigstïckes hatte, an dieser Stelle beide Balınen In der Capsula liegt die Hypoglossusbahn wahrscheinlich zwischen der des Facialis und der Extremitäten. Innerhalb der Brücke mïssen ihre Fasern bereits von der Pyramide gesondert sein, sie ziehen wahrscheinlich aus dem vorhin erwähnten Bündel medial von der Schleife in der Raphe rïckwärts und aufwärts. Erst in der Oblongata treten sie zum gekreuzten (und gleichseitigen?) Kerne. Aus diesem entspringt der Nerv.

4. Die motorische sprachbahn. Wir kennen von dieser mit aller Sicherheit erst wenige Punkte: den Ausgangspunkt in der unteren Stirnwindung, den Endpunkt in den Kernen des Facialis und Hypoglossus und zwischen beiden einen Punkt, der nach aussen von Schwanz des Nucleus caudatus liegt. Wahrscheinlich (Wernicke) zieht die Bahn ron der Brocaschen Windung - untere Stirnwindung - etwas medianwärts und bedeckt von der Insel in fast horizontalem Verlauf dorsal von der Capsula externa dahin. Ihre Fasern gelangen damn in den caudal von dem motorischen Gebiete liegenden Theil der inneren Kapsel und von da jedenfalls in den Hirnschenkelfuss. Innerhalb der Brïcke müssen sie sich allmählich aus der Fussfaserung zur Haube hinauf erheben. Von allen den eben erwähnten Punkten aus sind bei Erkrankungen Sprachstörungen beobachtet worden.

Jeder motorische Nerv entspringt also im Centralorgane in einem Kerne. Nerv nnd Kern bilden das erste Glied der Bahn; zu dem Kerne gelangt aus der Rinde des Vorderhirnes der Stabkranzzug der Pyramide als das zweite Glied der Kette: Nerv, Kern - Stabkranz, Rinde.

Solange das erste Glied intact ist, können die betreffenden Muskeln noch durch elektrische, mechanische, reflectorische Reize, bei Thieren auch bis zu einem gewissen Grade durch Willensimpulse zur Bewegung gebracht werden; wird Nerv oder Kern zerstört, so ist absolute Lähmung da. Zur vollen Möglichkeit 
des bewussten Wollens aber bedarf es der Intactheit des zweiten Gliedes; ja bei dem hochausgebildeten Gehirne des Menschen ist ïberhaupt, wenn das zweite Glied unterbrochen ist, kein Bewegen durch den Willen mehr möglich. Wenn Jemand durch Schlagfluss eine Zerreissung der Capsula interna bekommt, so sind die Muskeln der gekreuzten Körperhälfte nicht eigentlich gelähmt; sie können nur nicht mehr durch den Willen, wohl aber durch andere Reize zur Contraction gebracht werden. Anders ist es, wenn, bei der spinalen Kinderlälımung z. B., ein Nervenkern selbst zu Grunde gelit; dann haben wir eine echte Lähmung, welche, meist irreparabel, zu Atrophie führt, und bei der reflectorische und andere Reize wenig vermögen. Es ist ein grosser Unterschied in Bezug anf die Aussicht auf Wiederherstellung der Function, ob die Grosshirnbahn oder eine tiefere Stelle des Innervationsweges unterbrochen ist.

5. Die Stabkranzfasern zur Brïcke entspringen aus der Rinde des Torderhirns, besonder's aus dem Schläfen-Hinterhauptslappen, vielleicht auch aus dem Stimlappen. Sie ziehen durch die Capsula interna in den Fuss des Hirnschenkels und von da in die Brïcke. Die an secundären Degenerationen gemachten Erfahrungen zeigen, dass sie nicht weiter als bis zu den Ganglienzellgruppen dort gelangen. $\mathrm{Zu}$ den gleichen Gruppen kann man aber Faserzïge verfolgen, welche aus der gekreuzten Kleinhirnhälfte stammen (Brïckenarme).

6. Die sensiblen Nerven entspringen aus den Zellen der Spinalganglien. Tenigstens ist bei Tirbelthieren bisher noch kein anderer $\mathrm{Ur}_{1}$ sprung nachgewiesen. Da wir aber wissen, dass der Opticus und der Olfactorius Fasern enthalten, welche, aus simmesepithelien entspringend. centralwärts gehen, da ferner auch bei Wirbellosen Fasern nachgewiesen sind, welche aus Sinnesepithelien der Epidermis stammen, so wäre es nicht unmöglich, dass auch in den sensiblen Nerven Fasern verlaufen, welche aus der Peripherie stammen. Der Verlauf der secundären Degeneration nach Durchschneidung sensorischer Nerven spricht gegen diese Vermuthung.

Aus den Zellen der Spinalganglien entspringt noch eine Bahn, die Wruel, welche in das Centralorgan eintritt. Ein Theil der Wurzel splittert sich in den Hinterhörnern, resp. in den Kernen der sensorischen Hirmnerven um Zellen herum auf (Endkerne dersensiblen Ner ren).

Ein anderer Theil zieht, ehe er in Endkernen endet, erst eine Strecke weit im Centralorgan dahin, entweder hirnwärts, wie die in den Hintersträngen enthaltenen Fasern der spinalen Nerven, oder auch caudalwärts, so manche Wurzehn von sensorischen Hirnnerven.

Aus den Zellen der Endkerne entspringt die centrale sensible Bahn oder die sensible Bahn zweiter Ordnung. Sie gelangt entweder schon auf der Höhe etwa des Wurzeleintrittes, oder in höheren Zonen immer in das Gebiet der gekreuzten Schleifenfaserung. Mit der Schleife aber zieht sie hirnwärts.

7. Ton den sensiblen Bahnen zweiter und höherer Ordnung kemnen wir noch nicht ibberall die Ausgangszellen oder die Endaufzweigung.

Sensible Bahmen höherer ordnung liegen in der medialen Schleife a us dem 'Thalamus und in der lateralen oder Vierhügelschleife. 
Die Fasern, welche in den Hinterstrangkernen entspringen, wahrscheinlich auch diejenigen, welche aus den Endkernen im Rückenmarke stammen, ziehen medial innerhalb der Schleifenschicht hinauf und enden in den ventralen Abschnitten des Thalamus opticus. Den gleichen Endpunkt haben die Fasern aus dem Endkerne des Trigeminus, sie ziehen aber nicht innerhalb des Schleifenareales zum Thalamus, sondern weiter dorsal und medial. In den Thalamusregionen, wo die mediale Schleife endet, endet auch die Haubenstrahlung aus dem Parietalhirne. Durch sie ist also die sensible Faserung zu gutem Theile mit der Rinde verbunden. Sie stellt eine tertiäre sensible Bahn dar.

Die Haubenfaserung entspringt im Parietallappen, möglicher Teise in denselben Windungen wie die Pyramidenfaserung und gelangt ron da in das hintere Drittel der Capsula interna. In dieser Gegend kommen ihr die Sehstrahlung aus dem Occipitallappen und die centrale Acusticusbahn sehr nahe. Ein Theil der Haubenbahn zieht in und durch den Linsenkern, ein anderer gelangt in den Thalamus.

Die centralen Fasern aus den Endkernen der Hirnnerven, vielleicht auch solche aus Kernen der spinalen Nerven ziehen in der unteren oder lateralen Schleife hirnwärts. Diese endet zu gutem Theile in dem Ganglion der Tierhügel und zu einem anderen im Corpus geniculatum mediale, hier wohl vorwiegend die Acusticusbahnen höherer Ordnung:

$\mathrm{Zu}$ diesen Endstätten zieht, wesentlich aus dem Marke des Schläfenlappens, aber auch aus weiter frontal liegenden Rindengegenden, ein Faserzug, die Rindenbahn des Acusticus etc.

So verbinden sich also sämmtliche Fasern der Schleifenschicht mit Kernen, welche auf der Seite liegen, welche zur Schleife gekreuzt ist. Nur findet für einen Theil die Kreuzung schon in der Oblongata, für einen anderen erst im Rïckenmarke statt. In den Kernen enden immer die Fasern der Hinterwurzeln oder der sensorischen Hirnnerven.

s. Ein Theil der sensiblen Nerven endet in der Umgebung der Zellen der Clarke'schen Säule. Aus diesen entspringt die Kleinhirnseitenstrangbahn, welche in der Peripherie des Rückenmarkseitenstranges zum Cerebellum hinauf zieht.

9. Einige sensible Hirnnerven erhalten einen Zuwachs ron Fasern, der aus dem Cerebellum stammt (directe sensorische Kleinhirnbahn).

10. Das Rindenfeld und der centrale Verlauf des sensiblen Theiles des Nervus trigeminus von der Rinde bis zu der Kapsel ist noch unbekannt. In der Kapsel mïssen, den pathologischen Erfahrungen zufolge, seine Zïge im hinteren Drittel liegen. Die Rindenbahn des Trigeminus endet, wenigstens beim Kaninchen, im ventralen Thalamusgebiete. Dorthin zieht aus dem gekreuzt liegenden Endkerne ein mächtiger Zug herauf. Im Endkerne aber lösen sich die Ausläufer der Zellen des Ganglion Gasseri auf.

Der Trigeninus stammt ïbrigens auch zum Theil aus Kernen, welche 
im Centralorgan selbst liegen. Bis jetzt kennen wir zwei: einen, welcher in der Seitenwand des Aquäductes unter den Vierhïgeln, und einen zweiten, den sog. motorischen Kern, welcher in der Brücke liegt.

Die aufsteigende Wurzel enthält, wie die Pathologie zeigt, die Gefühlsnerven für das Gesicht.

11. Den Nervus acusticus zerlegt man zweckmässig in Nervus cochlearis und Nervus vestibularis.

Der Rindenursprung des eigentlichen Hörnerven, des Cochlearis, muss im Bereich der Schläfenlappenwindungen gesucht werden. Klinische Beobachtungen lassen erschliessen, dass von da eine Bahn in den candalen Theil der inneren Kapsel und wahrscheinlich durch den Arm des hinteren Hügels in dessen Grau führt. Von da geht die laterale Schleife in das Gebiet der oberen Oliven in der Oblongata herab, und in diesem endet die Faserung aus dem Nucleus acustici ventralis, das Corpus trapezoides. In dem Nucleus ventralis aber splittern sich die Endbäumchen ans den Ganglienzellen des Ganglion spirale cochleae auf, die Hörnervenwurzeln.

Ueber den centralen Verlauf des Nervus vestibuli ist wenig bekannt. Seine aus den Zellen der Macula und Crista acustica stammenden Fasern enden zum Theil im Nucleus dorsalis, zum anderen ziehen sie dem Kleinhirne zu. Ausserdem enthält dieser Nerv noch Fasern aus weiter caudalen Ebenen der Oblongata und Zuzüge aus der Schleife als Striae acust. Siehe hierfür die genauere Beschreibung vorn.

Die obere Olive, mit welcher sowohl der Cochlearis als der Vestibularis zusammenhängen, ist innig mit den Kernen der Augenbewegungsnerven und auch mit dem Kleinhirn verbunden. Ausserdem wahrscheinlich auch mit den Vierhügeln. Es ist wahrscheinlich, dass sie zum Gleichgewichtsapparat des Körpers gehört.

Der Trigeminus sowohl, als der Acusticus bekommen einen Faserzuwachs aus dem Cerebellum.

12. Ueber den centralen Verlauf des Vagus im Vorderhirn ist nichts bekannt. Wenn die mehrerwähnte Stelle im hinteren Theile der Kapsel zerstört wird, treten nicht Vagussymptome auf; Geschmacksstörungen (Glossopharyngeus) kommen vor. Des Verlaufes der schleifenfasern zu den gekrenzten Kernen des Vagus und Glossopharyngeus wurde gedacht. Auch diese beiden Nerven bekommen wahrscheinlich einen Zug aus dem Cerebellum.

13. Der centrale Verlauf des Opticus wurde schon früher im Zusammenhange dargestellt.

Ich erinnere Sie nochmals daran, dass dieser Nerr aus dem Pulvinar thalami, dem Corpus geniculatum laterale, dem Tuber cinereum und aus den Vierhügehn entspringt, dass er aber auch Fasern enthält, welche, aus der Retina stammend, in den genannten Hirntheilen enden. $\mathrm{Zu}$ allen diesen „primären optischen Centren“ gelangen Fasern ans der im Occipitallappen beginnenden sehstrahlung. Diese verläuft an der lateralen 
Seite des Hinterhornes, zieht also auf ihrem Wege von dem Rindenursprung zu den primären Opticuscentren unter dem unteren Scheitelläppchen dahin. Daher kommt es, dass bei Erkrankungen dieses Läppchens oder bei experimenteller Zerstörung der entsprechenden Stelle bei Thieren Sehstörungen beobachtet werden, die ganz den Charakter von corticalen haben.

Die Fasern des Tractus opticus verlaufen zum Chiasma. Dort tritt ein grösserer Theil auf die andere Seite hinïber, ein kleinerer, der aber bisher nicht zum Bündel gesondert lag, bleibt auf der gleichen Seite. Der Streit, welcher lange um das Chiasma gepflogen wurde, ist in letzter Zeit durch Singer und Münzer endgiltig und überzeugend in dem eben vorgetragenen Simne entschieden worden. Das gleichseitige Bündel ist bei einigen Thieren sehr unbedeutend, fehlt sogar bei bestimmten Arten ganz. Im letzteren Falle besteht also Totalkreuzung:

Der Sehtractus muss noch die aus dem Oculomotorius stammenden Pupillarfasern mit sich führen. Es ist noch nicht überzeugend nachgewiesen, wie diese in ihn gelangen.

Der centrale Verlauf des Olfactorius ist in der 13. Torlesung im Zusammenhang geschildert worden. Vergl, namentlich die Abbildung Fig. 144, welche alles hierher Gehörige zusammenstellt. 


\section{REGISTER.}

Die nicht in Klammern gesetzten Zahlen beziehen sich auf allgemeine und vergleichend anatomische Verhältnisse, die in Klammern gesetzten enthalten das Register des dritten Theiles, der nur vom Säugergehirne handelt.

Abducens 69. (347). (364).

Accessorius 62. 90. (339).

Acusticus 66. S\&. (357). (380).

Acusticusfeld $5 \%$.

Acusticuskern $\varsigma_{6} 6$.

Ala cinerea (345).

Alveus (226).

Ammonshorn 166. (211). (224).

Ammonshorn, Riechbündel (209).

Ansa lentiformis s. Linsenkermschlinge.

Ansa peduncularis s. Substantia innominata.

Aquaeductus Srlvii 107. (276).

Arbor vitae (298).

Area olfactoria 141.

Area parolfactoria 160 .

Arme der Vierhïgel (266).

Associationsbündel 173. (229).

Associationsbündel des Nucleus caudatus (245).

Associationsfeld der Oblongata 76. (35t).

Associationszellen 2ऽ.

Axencylinderfortsatz 15. 20.

Baillarger'scher Streif (223).

Balken s Corpus callosum.

Bechterew's centrale Haubenbahn (353).

Bechterew'scher Streif (223).

Bergmann-Deiters'sche Fasern (30s).

Bewegungscombination 32.

Bindearm 101. 115. 130.

Bindearmkreuzung (2与0).

Bogenbündel (229).

Brachinm conjunctivum ant. et post. (266).

Brïcke 103. (290). (305). (371).

Brïckenbahn (235). (37s).

Bulbus olfactorius 142. (204). (207).

Burdach'sche Stränge (32S). (341).

Calcar avis (193).

Capsula exterma (1). (85). (239).

Capsula interna 139. 153. 175. (155). (237). (240). (241).

Cellulae commissurales 76 .

Centrum semiovale (1ऽo).

Centralkanal (320).

Cerebellum 47. 95. (290).

Chiasma 134. 137. (265). (351).

Cingulum (212). (229).

Clarkesche Säule (307). (31ธ). (325). (379).
Claustrum 166. (155). (239).

Clava $(346)$.

Collateralen 21.

Columna vesicularis s. Clarke'sche Säule.

Columnae fornicis (152).

Commissura ansulata 109.

Commissura anterior 145. (153). (156). (20s). (231). (334).

Commissura grisea thalami 126.

Commissura habenularis 119. 120. 122. (154). (260).

Commissura inferior (267).

Commissura media (153). (239). (247).

Commissura mollis s. Commissura media.

Commissura postchiasmatica 134.

Commissura posterior 10S. 115. (154). (276). (334).

Conus terminalis (313).

Coruu Ammonis s. Ammonshorn.

Corpora quadrigemina (276).

Corpus callosum 165. 169. (150). (192). (231).

Corpus dentatum (251). (301).

Corpus ectomammillare 112. 132.

Corpus trapezoideum SS. (291). (296). (359).

Corpus candicans s. Corpus mammillare.

Corpus fornicis (152). (212).

Corpus geniculatum laterale 126. (184). (279). (246). (266). (268).

Corp. genic. mediale 126. (268). (279).

Corpus habenulae s. Ganglion habenulae.

Corpus interpedunculare 123. (285).

Corpns mammillare 132. (259). (265).

Corpus pineale (183).

Corpus quadrigeminum posterius 107 .

Corpus restiforme 93. 102. (351).

Corpus striatum 149. (155.) (237).

Corpus subthalamieum 116. (257).

Crura fornicis (181).

Cuneus (193).

Dachkern des Mittelhirnes 92. 113.

Dachkern des Kleinhirnes (302).

Dachkreuzung des Mittelhirnes 111.

Decussatio cerebelli ventralis 104 .

Decussation hypothalamica posterior 137.

Decussatio supra-infundibularis 135. 137.

Decussatio transversa 11\%. 134.

Decussatio tuberis 135 .

Decussatio veli 101 . 
Deiters'scher Kern ss. 102. (307). (326). (363). Deiters'sche Zellen 16.

Dendriten 20.

Directe sensorische Kleinhirnbahn $\varsigma_{7}$. (306). (357). (369).

Dorsalstrang s. Hinterstrang.

Dorsalzellen 6 s.

Embolus (302).

Eminentia teres (349).

Endplatte 23.

Ependym 109.

Epiphysis 120. (260).

Epistriatum 144.

Epithalamus 119. 122.

Espace quadrilatère Broca (204).

Facialis 74. 90. (357). (377).

Facialiskern 90. (357).

Fascia dentata (225).

Faseiculus longitudinalis dorsalis s. posterior 66. 79. 94. 176. (2S5). (326).

Fasciculus retroflexus 123. (255).

Fasciculus fronto-occipitalis (230).

Fasciola cinerea (274).

Feld, ovales $(330)$.

Fibrae acustico-sacrales 65 .

Fibrae acustico-spinales 79 .

Fibrae arcuatae externae 93. 102. (352).

Fibrae arcuatae int. Med. obl. 75. (343).

Fila olfactoria 141. (204).

Filum terminale (313).

Fimbria 167. (211). (152).

Fissura areuata (197). (213).

Fissura calcarina (193).

Fissura chorioidea 161. (197).

Fissura coronalis (213).

Fissura Hippocampi (194).

Fissura limbica (195). (205). (205).

Fissura parieto-occipitalis (193).

Fissura perpendicularis ext. (193). (195).

Fissura retrocentralis (190).

Fissura sagittalis (213).

Floceulus (297).

Folium vermis (296).

Foramen Magendii (295).

Foramen Monroi (1S3).

Forceps (231).

Formatio bulbaris 142.

Formatio reticularis 72. (356).

Fornix 133. 167. (1s1). (211).

Fornixsäule 167.

Fossa Sylvii (187).

Fovea limbica 159.

Fovea collateralis 160 .

Fritsch'sche Commissur 136.

Ganglienknoten 25 .

Ganglienentwicklung $56 \mathrm{ff}$.

Ganglienleiste 56 .

Ganglienzelle 15, 15, 24.

Gangl. ectomammillare 133.

Ganglion Gasseri 75. (366).

Ganglion habenulae 119. 122. (184). (246). (260).

Ganglion interpedunculare 123. (255).

Ganglion Isthmi 94.
Fanglion laterale Mesencephali 110.

Gangl. profundum Mesencephali (252).

Gangl. tegmenti ventrale 116.

Gemnari'scher Streif (221).

Geschmackapparate 40.

Glandula pinealis s. Epiphyse.

Gleichgewicht 86 .

Globus pallidus 153. (155). (243).

Glomerulus olfactorius 142. (205).

Glossopharyngeus \$4. (347). (348). (356).

frolls sche Stränge (324). (341).

Gowers'sches Bündel (30i).

Gratiolet's Bündel \&. Radiatio thalamooccipitalis.

Gudden'sche Commissur s. Decussatio transversa.

Gyri centrales (159).

Gyrus angularis (190).

Gyrus callosus (195).

Gyrus cinguli (197).

Gyrus dentatus 167. (205).

Gyrus fornicatus (192). (20) .

Gyrus fusiformis (196).

Gyrus Hippocampi (193).

Gyrus lingualis (193).

Gyrus marginalis (190).

Gyrus rectus (195).

Gyrus subcallosus (195). (266).

IIakenbiindel (229).

Haube (242). (280).

Haubenbahn (257).

Haubenfaserung 117.

Haubenkreuzung (2ऽ2).

Hambenstrahlung (234).

Hautsinnesapparate 15.

Hinterhirn 45 .

Hinterhorn (315).

Hinterstrang 65. (324). (32ऽ).

Hinterstränge, Kerne der 76 . (341).

Hirnbasis (263).

Hirnmantel s. Pallium.

Hirnnervenkerne (373).

Hirnrinde 164. (21s).

Hirnsand (260).

Hirnschenkelfuss (279).

Höhlengrau, centrales 125.

Hypophysis 120. (264).

Hypothalamus 119. 130. (256).

Hypoglossus 74. 75. s1. (346). (347). (349). $(377)$.

Infundibulum (153). (264).

Innervation, sensible 43.

Insula Reili (157). (237).

Intumescentia cervicalis (313).

Intumescentia lumbalis (313).

Keimblatt, äusseres 15.

Keimzelle 15.

Kernkappe 24.

Klangstab (361).

Kleinhirn s. Cerebellum.

Kleinhirnbahn, directe sensorische 57 . (306). (357). (369).

Kleinhirnseitenstrangbahn $(307)$. 
Körnerschicht 95.

Kungelkern (302).

Längsbiindel, dorsales (351).

Lamina commissuralis Mesencephali 111.

Lamina medullaris circumvoluta (226.)

Lamina medullaris externa thalami (249).

Lamina medullaris interna thalami (249).

Lamina mednllaris nuclei tegmenti (255).

Lamina supraneuroporica 119.

Lamina terminalis 45.119 .156 . (266).

Lancisischer Streif (205).

Laqueus s. Schleife.

Lateralstrang s. Seitenstrang.

Lingula (295).

Linsenkern (237). (244).

Linsenkernschlinge 153. (243). 250).

Lobulus centralis (295).

Lobulus acusticus 103.

Lobulus quadrangularis (29i).

Lobus cerebellaris Acustici 100.

Lobus cerebellaris Trigemini 100 .

Lobus cornu ammonis 147 .

Lobus cuneiformis (297).

Lobus frontalis (15s).

Lobus gracilis (297).

Lobus Hippocampi (205).

Lobus limbicus (205).

Lobus lingualis (193).

Lobus nervi vagi $y 2$.

Lobus olfactorius (265).

Lobus pyramidalis 147 .

Lobus pyriformis (204).

Lobus semilumaris sup. (297).

Lobus temporalis (155).

Lobus Trigemini 90.

Locus coeruleus (365).

Lỵra Daridis (152).

Iandelkern 145. (156),

Mantelbiundel 135.

Mark, Kurze Bahnen 65.

Mark, tiefes 106. 109. (290).

Markkern (299).

Marklager 164.

Marklager subcorticales 163.

Markmantel, weisser is.

Markplatte 15.

Markstrahlen (221).

Mauthmer'sche Fasern 65. ง9.

Mesostriatum 152.

Metathalamus 129, (256).

Methylenblaureaction 21.

Mernert'sche Commissur (24i).

Mittelhirubasis 47 .

Mittelhirndach $4 \overline{7}$.

Mittelhirnganglien 47 .

Mittelhirnkern, tiefer 111 .

Mittelhirnmark, tiefes 66 .

Molecularsehicht 97.

Montieulus (296).

Nebenoliven (35̃. ).

Nerven, elektrische 5.5.

Nerven, periphere 35 .

Nerren, s. die einzelnen.

Nervenfasern 1 s.
Nerrengewebe 15.

Nervenkerne $; 2$.

Nerrenknoten, zerstreute 15.

Netz, tangentiales 163.

Neurit 20.

Neuroblasten 16.

Neuroglia 16.

Neuron 22.

Nodulus (2979.

Nuclei laterales Termis 100.

Nuclei thalami 125. (235).

Nucleus amygdalae 145. (156).

Nucleus ant. tuberis cinerei 132.

Nucleus ambignus (345).

Nucleus arcuatus (352).

Nucleus caudatus 152. (153). (235). (239). (243).

Nucleus commiss. post. 130.

Nucleus commissuralis (349).

Nucleus dentatus cerebelli 100. (302).

Nucleus entopeduncularis 127 .

Nucleus funiculi teretis (349).

Nucleus globosus cerebelli 100. (302).

Nucleus lentiformis 153. (243).

Nucleus magno-cellularis Strati grisei 126.

Nucleus der Medianlinie 126.

Nucleus praetectalis 105. 129. 133.

Nucleus lateral. mesencephali 114.

Nucleus reticularis tegmenti (356).

Nucleus rotundus thalami 125. 131.

Nucleus ruber tegmenti 130. (250).

Nucleus Thaeniae 146. 150.

Nucleus tegmenti 115. (257). (250). (301).

Nucleus trapezoides (359).

Oblongata (33; ff.).

Oculomotorius 114. (2ऽ3).

Olfactorius 47. 141. (297).

Oliva cerebelli 100.

Oliva inferior 92. (335). (343). (352).

Oliva superior ş. (359).

Olivenbahn (306).

Olivenzwischenschicht (354).

Operculum (1ss).

Opticus 106. 111. 137. (265 ff.). (350.)

Pallium 4s. 140. 154.

Paracentrallappen (193).

Paraphysis 120.

Peduneuli cerebelli (303).

Pedunculus cerebri (1ऽ4).

Pedunculus conarii (1つ4). (260).

Pes Hippocampi 166. (194).

Pes peduneuli (242).

Plexus chorioideus 52. 119.

Polus occipitalis pallii 155 .

Polus temporalis 159.

Pons s. Brïcke.

Portio intermedia Trishergi (364).

Praecuneus (192).

Processus reticularis (315). (339).

Proencephalon 4s.

Protoplasmafortsatz 20.

Psalterium (209). (211).

Pulvinar (1>4), (246), (2-5).

Purkinje sche Zellen 97. (299.)

Putamen 152. (235). (243.) 
Pyramidenbahn 79. 240. (340). (353). (376).

Pyramidenkreuzung (313). (340).

Pyramidenzellen d. Rinde 164. (218).

Radiatio strio-thalamica (245).

Radiatio thalamo-occipitalis

Radiatio thalami ventralis (249).

(270).

Radix bulbo-spinalis Glossopharyngei 84.

Radix bulbo-spinalis Vagi 84. 90.

Radix mesencephalica Trigemini 91.

Randfurche, innere 161.

Randwindung (193).

Raphe 76. (354).

Rautengrube (33s).

Recessus infundibularis 120.

Recessus mammillaris 121 .

Recessus postopticus 121.

Recessus praeopticus 121.

Reflex 30 .

Regio subthalamica (245). (256).

Retina 40.

Rhinencephalon (20s).

Rhombencephalon 45 .

Riechapparat 140. (204).

Riechrinde 161.

Riechfeld (156).

Riechschleimhaut 39.

Rindenplatten 165.

Rindenschleife (25i).

Rother Kern der Haube 130. (250).

Rückemmark (310).

Saccus vasculosus 121.

Schleife 67. 7\%. (251). (293). (369). (S. auch

Tractus tecto-bulbares et spinales.)

Schleifenbahn corticale (234). (369).

Schleifenfaserung 109.

Schleifenkern 94. (293). (369).

Schleifenkreuzıug (342).

Schleifenschicht 77. 93. (2S1). (344). (369).

Schlussplatte, embryonale 45. (266).

Schultze'sches Komma (330).

Schwann'sche Scheide 29.

Sehstrahlung 169. (270). (379).

Seitenhorn (315).

Seitenhornzone $\mathbf{5 1 .}$

Seitenstrang 65.

Seitenstrangzone, vordere gemischte (326).

Sensomobilität 42.

Septum pellucidum 160. (182).

Sinus rhomboidalis 69 .

Spatium olfactorium (204).

Spinalganglien 36. (310).

Spongioblasten 16.

Sprachbahn, motorische (377).

Stabkranz 169. (233). (242). (378).

Stabkranz, des Thalamus 129. (246).

Stammfortsatz 20.

Stammganglien s. Corpus striatum.

Stammlappen 140.

Stilus corp. geniculati 126.

Strangzellen (333).

Stratum complexum pontis (290).

Stratum intermedium pedunculi (242). (257). (279).

Stratum lucidum (226).

Stratum moleculare corticis 164 .

Edinger, Nervöse Centralorgane. 5. Auflage.
Stratum profundum pontis (290).

Stratum superficiale pontis (290).

Stratum zonale Thalami (246).

Streifenhügelrinde 151.

Stria longitudinalis medialis (212).

Stria terminalis (153).

Striae acusticae (361).

Subiculum cornu Ammonis (225).

Substantia gelatinosa Rolandi 75. (318).

Substantia innominata (250).

Substantia nigra Soemmeringi (25i). (2is).

Substantia perforata ant. (265).

Substantia perforata post. (263).

Substantia reticularis (294).

Sulcus calloso-marginalis (192).

Sulcus centralis (15s).

Sulcus centralis insulae (165).

Sulcus interparietalis (190).

Sulcus occipitalis (190).

Sulci olfactorii (195).

Sympathicus 36 .

Taenia thalami 123. 140. (212). (154).

Taenia semicircularis (153).

Tangentialfasern (21s).

Tapetum (231).

Tectum mesencephali 107.

Tectum opticum 66.

Tela chorioidea posterior 71 .

Tela chorioidea 119. 140.

Thalamus opticus 119. (246).

Thalamusschleife 129.

Tonsilla (297).

Torus semicircularis 114 .

Tractus acustico-spinalis 59 .

Tractus acustico-tectalis ss.

Tractus breves Oblongatae 76 .

Tractus bulbo-corticalis 146 .

Tractus bulbo-epistriaticus 146 .

Tractus cerebello-olivaris 102. (307). (352).

Tractus cerebello-spinalis 66. 76. 93, 102. $(307)$.

Tractus cerebello-spinalis dorsalis (325).

Tractus cerebello-spinalis ventralis $(307)$.

Tractus cerebello-tegmentalis 103 .

Tractus cortico-epistriaticus 146 .

Tractus cortico-habenularis 103. 167.

Tractus cortico-mammillaris 167 .

Tractus cortico-spinalis s. auch Pyramidenbahn 67. 79. 94. (321).

Tractus cortico-tegmentalis (257).

Tractus cortico-thalamicus 125. 172. (234).

Tractus diencephalo-cerebellaris 101.

Tractus habenulo-peduncularis s. auch Fasciculus retroflexus 123. (261). (286).

Tractus intermedio-lateralis 315 .

Tractus lobo-cerebellaris frontalis et caudalis 131 .

Tractus mammillo-peduncularis 133.

Tractus nucleo-cerebellaris (307).

Tractus occipito-mesencephalicus 170 .

Tractus olfactorius 142 .

Tractus olfacto-habenularis 123. 146.

Tractus olfactorius septi 161 .

Tractus olfactorius lateralis 145 .

Tractus opticus (246).

Tractus peduncularis transversus $(276)$. 
Tractus strio-lobaris 125. 131. 150.

Tractus septo-mesencephalicus 161 .

Tractus solitarius (34s).

Tractus tecto-bulbaris 67. 109. 110.

Tractus tecto- et thalamo-spinalis 76 .

Tractus tecto-nuclearis 92.

Tractus tecto-spinalis 67. 92. 109. 110.

Tractus tecto-thalamicus 112 .

Tractus tegmento-cerebellaris 115 .

Tractus thalamo-bulbaris et spinalis $6 \pi .12 \pi$. (257).

Tractus thalamo-mammillaris 126. (260).

Tractus thalamo-tectalis 125 .

Tractus vago-cerebellaris $\$ 3$.

Trigeminus 75. 90. (286). (338). (343). (365). (379).

Trochlearis 103. 105. 114. (293).

Tuber cinereum 120. (153). (155). (263).

Tuber rermis (296).

Tuber valvulae (297).

Tuberculum anterius thalami (1১3).

Uebergangsganglion 94.

Uneus (193).

Unterhorn 159.

Uvula (297).

Vagus 74. 53. (34i). (380).

Valrula cerebelli 100.
Velum medullare anticum 95, 105.

Velum medullare posticum (345).

Ventralstrang s. Vorderstrang.

Ventriculus quartus 71 . (345).

Ventriculus septi pellucidi (1S2).

Ventriculus Terga (152).

Verzweigungskegel 24.

Vicq.-d'Azyr'sches Bündel 126. S. auch Tractus thalamo-mammillaris.

Vicq.-d'Azyr'scher Streif (223).

Vierhügelarm 138.

Vorderhirnbündel, basales 125 (244).

Vorderhorn (315).

Vorderhornzone 81.

Vorderstrang 65.

Vorderstrangfasern 75 .

Vorderstrangrest (326).

Windungen des Grosshirues (1ऽb).

Trurzeleintrittszone (32s).

Zirbel s. Epiphysis.

Zona granulosa cort. cerebelli (299).

Zona molecularis cort. cerebelli (299).

Zona spongiosa (330).

Zona terminalis (330).

Zwischenhirn 115 (246). 
Verlag von F.C.W.VOGEL in Leipzig.

\section{Die Mikroorganismen.}

Mit besonderer Berücksichtigung der

Aetiologie der Infectionskrankheiten.

Dritte völlig umgearbeitete Auflage

bearbeitet von

Dr. P. Frosch in Berlin, Dr. E. Gotschlich in Breslau, Dr. W. Kolle in Berlin, Dr. W. Kruse in Bonn, Prof. R. Pfeiffer in Berlin.

herausgegeben von

Dr. C. Fliigge

о. ö. Professor u. Direktor des Hygienischen Instituts zu Breslau,

Mit 210 Abbildungen im Text. 2 Theile. gr. 8o. 1896. Preis 36 M. geb. 40 II.

\section{HANDBUCH \\ der \\ NEURAS'T H E N I E.}

Bearbeitet von

Dr. R. v. HÖSLIN - Nen wittelsbach, Dr. G. HÜNERFAUTH - Homburg, Dr. J. WILHEII -Wien, Dr. K. LAHUSEN - München, Dr. F. EGGER - Arosa, Dr. C. SCHÜTZE-Kösen, Dr. E. KOCH-Hagdeburg, Dr. F. C. MÜLLER-Alexandersbad and Dr. A. Frhr. von SCHENCK-NOTZING-München.

Herausgegeben von

Dr. Carl Franz Miiller,

Dir. der Wasserheilanstalt und des Stahlbades Alexandersbad i. F.

gr. 8. 1893. Preis $12 \mathrm{M}$., geb. $14 \mathrm{M}$.

\section{DEUTSCHE ZEI'TSCHRIFT}

fiir

\section{NERVEN H E I L K U N E.}

Heramsgegeben ron

Prof. WILH. ERB,

Director der medicin. Klinik in Heidelberg.

Prof. FR. SCHULTZE,

Director der medicin Klinik in Bonn.

\section{Prof. L. LICHTIELI,} Director der medicin. Klinik in Königsberg. Prof. AD. v. STRÜMPELL. Director der medicin. Klinik in Erlangen.

\section{ERSTER - ZEHNTER BAND.}

gr. \. Preis pro Band von fi Heften: 16 M. 
Verlag von F.C.W.VOGEL in Leipzig.

Zehnte, verbesserte Auflage.

Prof. Dr. Adolph Strümpell's

LEHRBUCH

der

SPECIELLEN PATHOLOGIE UND THERAPIE.

3 Bănde. gr. 8. 1896.

Preis geh. 36 M., geb. $42 \mathrm{M}$.

\section{SPECIELLE DIAGNOSE}

\section{IN N E R E N R A N K H I T EN.}

Ein Handbuch für Aerzte und Studierende

von Prof. Dr. WILHELI v. LEUBE.

Vierte umgearbeitete Auflage.

2 Bănde. Mit 67 Abbildungen. Lex. S. 1895 . Preis 22 M., geb. 24 M. 50 Pf.

\section{DIAGNOSTIK \\ der \\ INNEREN KRANKHEI'TEN}

auf Grund der hentigen Untersuchungsmethoden.

Ein Lehrbuch für Aerzte und Studirende

Prof. Dr. D. Vienondt in Heidelberg.

Vierte verbesserte und vermehrte Auflage.

Mit 180 Abbildungen. gr. 8. 1894. Preis 10 M. geb. $12 \mathrm{M}$.

\section{DIAGNOSTIK \\ der \\ NER VENKR R A NK HEITEN}

Paul Julius IIöbius.

Zweite veränderte und vermehrte Auflage.

Mit 104 Abbildungen im Text.

gr. 8. 1894. 8 M., geb. 9 M. 25 Pf.

\section{HANDBUCH der \\ ÄR'ZTLICHEN TECHNIK \\ von}

DR. HERMLAN RIEDER,

Privatdocent und Assistent der medicinischen Klinik zu München.

Mit 423 Abbildungen im Text.

gr. 8. 1595 . Preis $10 \mathrm{M}$., geb. $11 \mathrm{M} .25 \mathrm{Pf}$. 







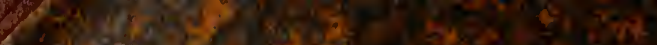

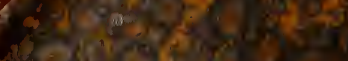

$39=2010$

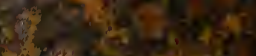

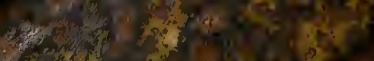

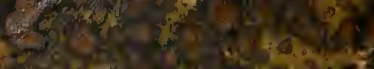

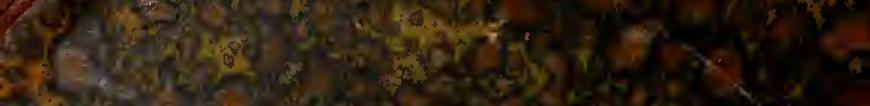

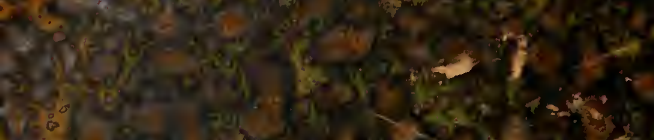

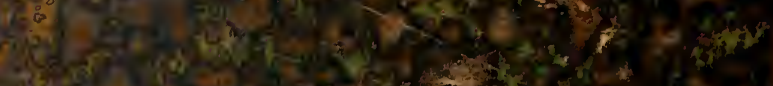

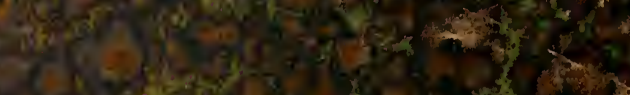

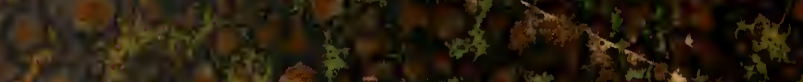

3.7.

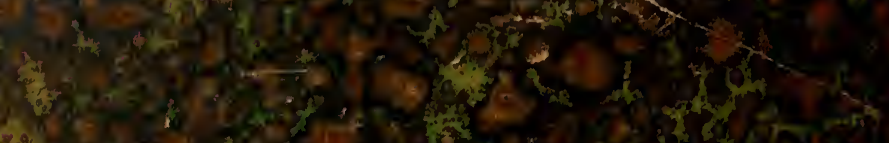

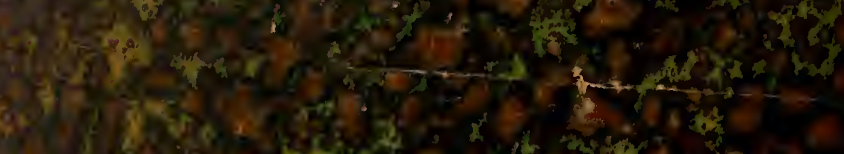

19.0.

-4.

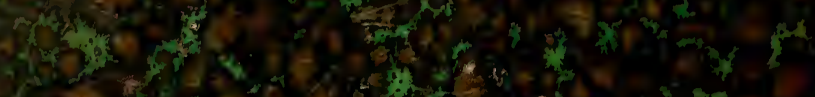

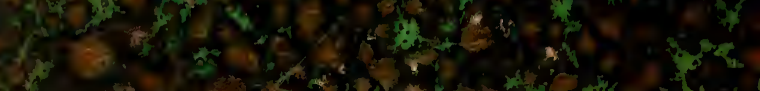

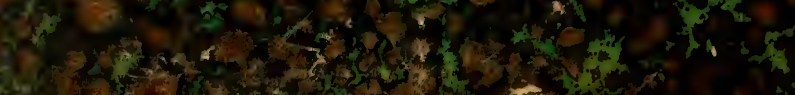

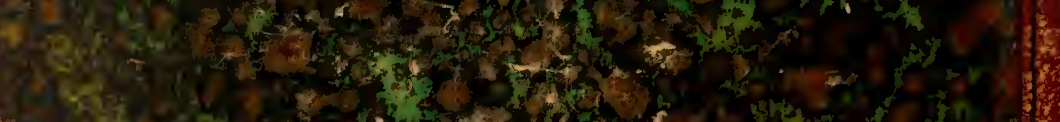

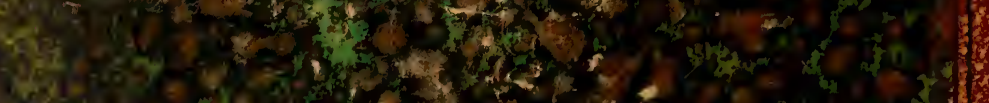

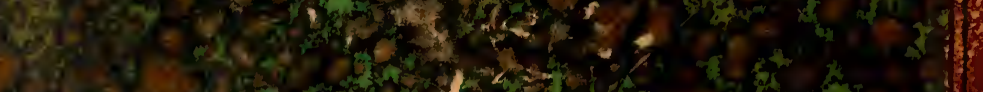
4.

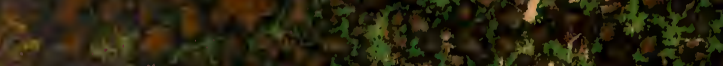

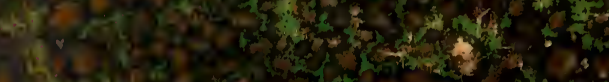

W.

A.

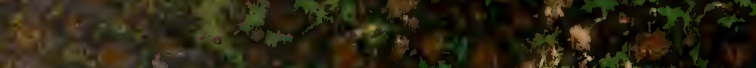

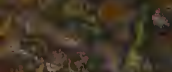

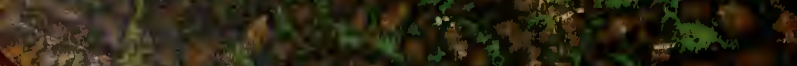

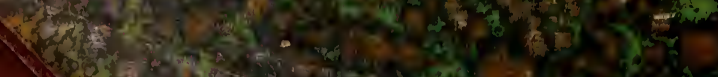

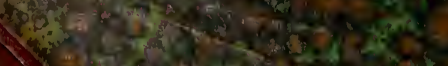

(2507)

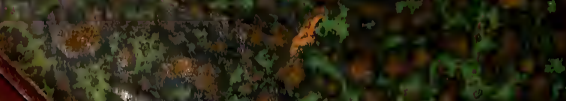

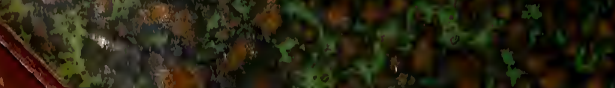

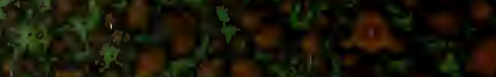

